DOC.20041111.0002

QA: QA

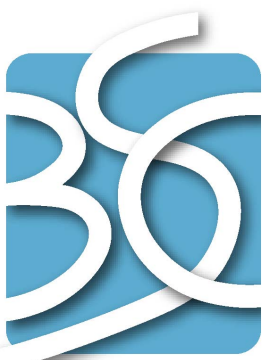

BECHTEL

SAIC COMPANYLC

ANL-EBS-MD-000045 REV 02

November 2004

\title{
In-Drift Precipitates/Salts Model
}

Prepared for:

U.S. Department of Energy

Office of Civilian Radioactive Waste Management

Office of Repository Development

1551 Hillshire Drive

Las Vegas, Nevada 89134-6321

Prepared by:

Bechtel SAIC Company, LLC

1180 Town Center Drive

Las Vegas, Nevada 89144

Under Contract Number

DE-AC28-01RW12101 


\section{DISCLAIMER}

This report was prepared as an account of work sponsored by an agency of the United States Government. Neither the United States Government nor any agency thereof, nor any of their employees, nor any of their contractors, subcontractors or their employees, makes any warranty, express or implied, or assumes any legal liability or responsibility for the accuracy, completeness, or any third party's use or the results of such use of any information, apparatus, product, or process disclosed, or represents that its use would not infringe privately owned rights. Reference herein to any specific commercial product, process, or service by trade name, trademark, manufacturer, or otherwise, does not necessarily constitute or imply its endorsement, recommendation, or favoring by the United States Government or any agency thereof or its contractors or subcontractors. The views and opinions of authors expressed herein do not necessarily state or reflect those of the United States Government or any agency thereof. 
QA: QA

In-Drift Precipitates/Salts Model

ANL-EBS-MD-000045 REV 02

November 2004 


\begin{tabular}{|l|l|l|}
\hline \multirow{2}{*}{ OCRWM } & Model Signature Page/Change History & Page iii \\
\cline { 3 - 3 } & 1. Total Pages: 318 \\
\hline
\end{tabular}

\begin{abstract}
2. Type of Mathematical Model
$\triangle$ Process Model

Abstraction Model

System Model

Describe Intended Use of Model

The intended use of this model is to estimate, within an appropriate level of confidence, the effects of evaporation and deliquescence on the chemical evolution of water and precipitated minerals within the repository during the post-closure period.
\end{abstract}

\title{
3. Title
}

In-Drift Precipitates/Salts Model

4. DI (including Rev. No., if applicable):

ANL-EBS-MD-000045 REV 02

\begin{tabular}{|l|l|}
\hline $\begin{array}{l}\text { 5. Total Appendices } \\
\text { Three (3) }\end{array}$ & $\begin{array}{l}\text { 6. No. of Pages in Each Appendix } \\
\text { I-94, II-8, III-6 }\end{array}$ \\
\hline
\end{tabular}

\begin{tabular}{|c|c|c|c|c|}
\hline & & Printed Name & Signature & Date \\
\hline 7. & Originator & Paul Mariner & $\hat{n}$ & $11 / 9 / 04$ \\
\hline 8. & $\begin{array}{l}\text { Independent Technical } \\
\text { Reviewer }\end{array}$ & Robert Andrews & & $11-9.04$ \\
\hline & Checker & David Shields & & \begin{tabular}{l|l|l|}
$11 / 9$ & 04 \\
\end{tabular} \\
\hline & QER & Jerry Heaney & & 1119104 \\
\hline 11. & Responsible Manager/Lead & Charles Bryan W.T.DUEFY & & $11 / 9 / 04$ \\
\hline 12. & Responsible Manager & Ernest Hardin & & $11 / 9 / 04$ \\
\hline
\end{tabular}

13. Remarks

Change History

\begin{tabular}{|l|l|}
\hline \multicolumn{2}{|c|}{ Change History } \\
\hline 14. Revision No. & \multicolumn{1}{c|}{ 15. Description of Change } \\
\hline 00 & Initial Issue. \\
\hline $00 / 01$ & $\begin{array}{l}\text { ICN to incorporate discussion affirming the application of this AMR and its calculations to backfill } \\
\text { and no backfill scenarios. This ICN includes modifications resulting from changes in AP-3.10Q } \\
\text { procedures and data qualification status. }\end{array}$ \\
\hline
\end{tabular}




\begin{tabular}{|l|l|}
\hline $00 / 02$ & ICN to qualify previously unqualified technical products. \\
\hline $00 / 03$ & $\begin{array}{l}\text { ICN to improve transparency, incorporate model enhancements, document newly discovered model } \\
\text { limitations, and qualify model enhancements used in calculations performed for the SSPA. This } \\
\text { ICN affects Sections 1 through 8. Affected pages (except those for table of contents, table of } \\
\text { figures, and table of tables) are identified by vertical change bars in the margin indicating the } \\
\text { locations of the changes. Changes can be found on pages 1-15, 19-23, 25-27, 29, 31-38, 41, 42, 44, } \\
45,47-50,52,54,56,58,62,66,69,70,72-74,82,93-100, \text { and 102-106. }\end{array}$ \\
\hline 01 & $\begin{array}{l}\text { Revision to qualify and document major improvements to the In-Drift Precipitates/Salts model. } \\
\text { These improvements include the use of a new software version of EQ3/6 (version 8.0) and a new } \\
\text { Pitzer database, which together are designed to predict aqueous chemical reactions in highly } \\
\text { concentrated brines. These changes are extensive and required a full revision of the document. }\end{array}$ \\
\hline $01 / 01$ & $\begin{array}{l}\text { ICN to extend validation range to higher temperature and ionic strength. Changes bars in the } \\
\text { margins mark changes from REV 01. Attachment II in REV 01, "MINTEQA2 Mineral Occurrence } \\
\text { Database," was removed because it is reference material that can be found in the TIC. For the } \\
\text { remaining three attachments, there are no changes from REV 01 (except for headers, footers, and } \\
\text { renumbering due to removal of the mineral database attachment). }\end{array}$ \\
\hline 02 & $\begin{array}{l}\text { Minor rewriting and clarifications to address transparency and data traceability comments resulting } \\
\text { from Regulatory Integration Team Phase I evaluation and to address CR 2049. }\end{array}$ \\
\hline
\end{tabular}




\section{ACKNOWLEDGMENTS}

Several key contributions to this document must be acknowledged. One is the Pitzer thermodynamic database developed and documented in Appendix I. Carlos Jove-Colon with the assistance of Tom Wolery, Joseph Rard, Ananda Wijesinghe, and Russell Jarek developed the Pitzer database and provided the documentation included in Section 4.1.1 and Appendix I. Another key contribution is the mineral suppression methodology presented in Section 6.6.2.6. This methodology was developed by Darren Jolley with the assistance of Richard Metcalf. In addition, Tom Wolery contributed the theoretical validation for predicting $\mathrm{pH}$ at high temperature and high ionic strength in Section 7.5.1. Tom Wolery, with the assistance of Joseph Rard, Ananda Wijesinghe, and Carlos Jove-Colon, also produced DTN: LL031106231032.007, a compilation and reduction of salt solubilities and vapor pressures in binary and ternary systems.

The work presented in this document was supported by the Office of Repository Design as part of the Civilian Radioactive Waste Management Program, managed by the U.S. Department of Energy. 


\section{INTENTIONALLY LEFT BLANK}




\section{CONTENTS}

Page

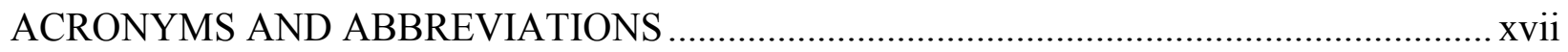

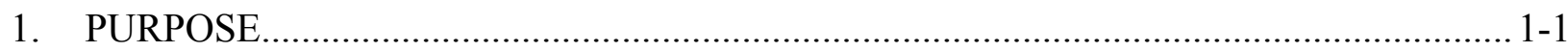

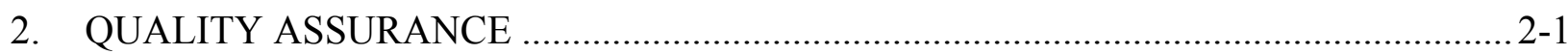

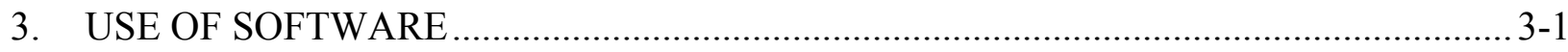

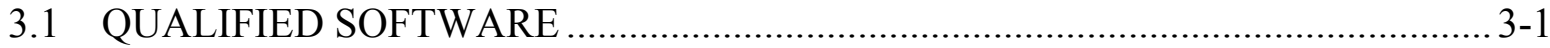

3.1.1 EQ3/6 Version 8.0 ..............................................................................

3.1.2 GetEQData Version 1.0.1 .................................................................... 3-1

3.1.3 SUPCRT92 Version 1.0 .................................................................... 3-1

3.2 EXEMPT SOFTWARE ……………………..............................................

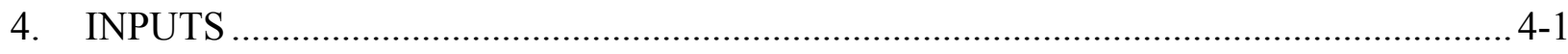

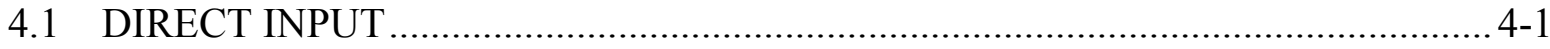

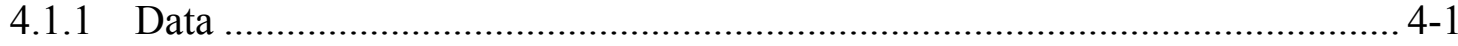

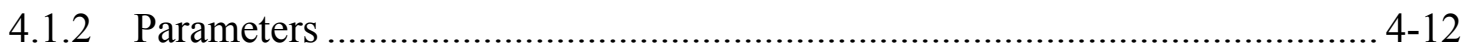

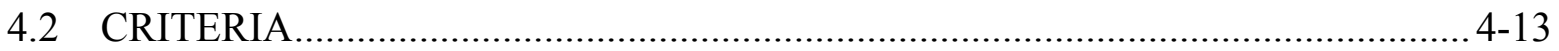

4.2.1 Acceptance Criterion 1 - System Description and Model Integration Are Adequate.............................................................................................. 4-14

4.2.2 Acceptance Criterion 2 - Data Are Sufficient for Model Justification ......... 4-15

4.2.3 Acceptance Criterion 3 - Data Uncertainty Is Characterized and Propagated Through the Model Abstraction ……………………………..... 4-16

4.2.4 Acceptance Criterion 4 - Model Uncertainty Is Characterized and Propagated Through the Model Abstraction …………….............................. 4-17

4.2.5 Acceptance Criterion 5 - Model Abstraction Output Is Supported by Objective Comparisons ............................................................................. 4-17

4.3 CODES, STANDARDS, AND REGULATIONS ………................................. 4-18

4.4 VALIDATION AND DEMONSTRATION DATA …........................................... 4-18

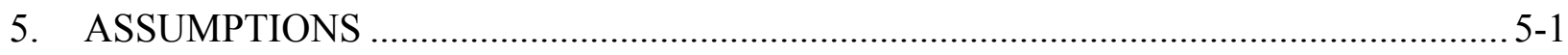

5.1 STANDARD STATE OF LIQUID PHASE …….............................................. 5-1

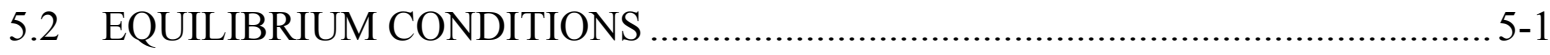

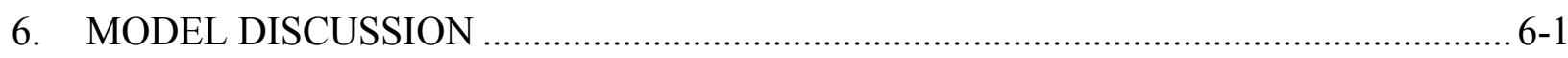

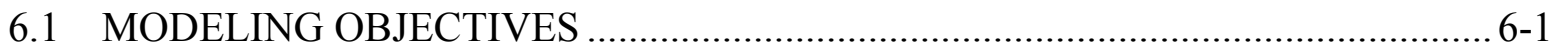

6.2 FEATURES, EVENTS, AND PROCESSES INCLUDED IN MODEL ................... 6-1

6.3 SALTS/PRECIPITATES PROCESSES …………......................................... 6-3

6.3.1 Evaporation, Relative Humidity, and Salt Precipitation ................................. 6-3

6.3.2 Formation and Chemistry of Brines and Salt Precipitates .............................. 6-4

6.3.3 Potential Brines and Salt Precipitates at Yucca Mountain ............................... 6-7

6.3.4 Simplified Binary Salts Model ................................................................ 6-9

6.4 BASE CASE CONCEPTUAL MODEL ………............................................... 6-11

6.5 CONSIDERATION OF ALTERNATIVE CONCEPTUAL MODELS................... 6-13 


\section{CONTENTS (Continued)}

Page

6.6 MODEL FORMULATION FOR BASE CASE MODEL ..................................... 6-14

6.6.1 Mathematical Description of Base Case Model ........................................ 6-15

6.6.2 Base Case Model Inputs and Boundary Conditions ................................... 6-18

6.6.3 Summary of Computational Model ......................................................... 6-28

6.7 DEMONSTRATION OF BASE CASE MODEL ................................................ 6-32

6.7.1 Evaporation of Average In Situ J-13 Well Water ...................................... 6-32

6.7.2 Dilution of Average In Situ J-13 Well Water......................................... 6-37

6.7.3 Resulting Model Lookup Tables ................................................................... 6-39

6.8 MODEL SENSITIVITY TO CORRECTED ZEOLITE DATA............................. 6-40

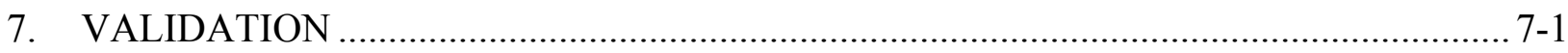

7.1 VALIDATION USING EVAPORATION DATA …................................... $7-5$

7.1.1 Evaporation of Average $\mathrm{J}-13 \mathrm{Well}$ Water at $85^{\circ} \mathrm{C}$........................................ 7-5

7.1.2 Evaporation of 100x Average J-13 Well Water at $90^{\circ} \mathrm{C}$ and 85 Percent Relative Humidity ............................................................................... 7-11

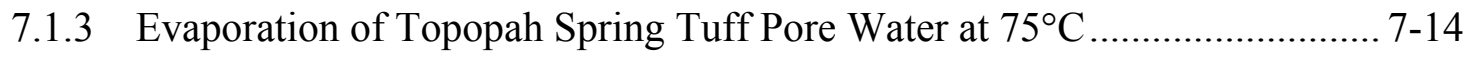

7.1.4 Seawater Evaporation ............................................................................. 7-18

7.2 EVAPORATION OF SIMPLE SALT SOLUTIONS ..................................... $7-23$

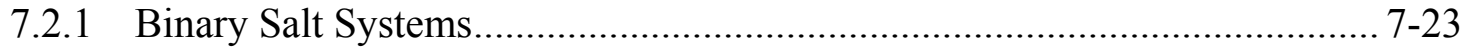

7.2.2 Ternary Salt Systems ............................................................................ 7-41

7.3 COMPARISON OF PITZER AND YMP.R2 DATABASE PREDICTIONS ......... 7-57

7.4 VALIDATION FOR MINERAL OUTPUTS ….................................................. 7-60

7.5 VALIDATION SUMMARY AND ESTIMATED UNCERTAINTIES................. 7-61

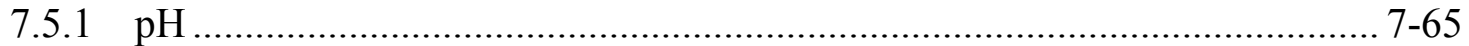

7.5.2 Ionic Strength .................................................................................. $7-70$

7.5.3 Deliquescence Relative Humidity .......................................................... 7-71

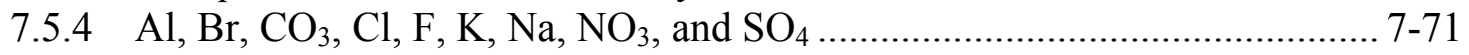

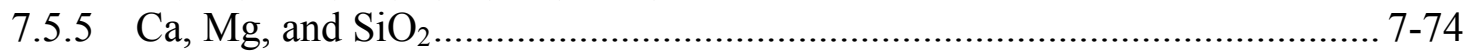

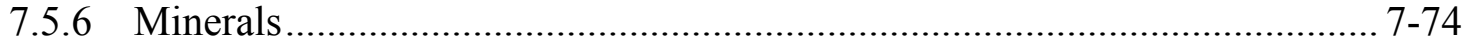

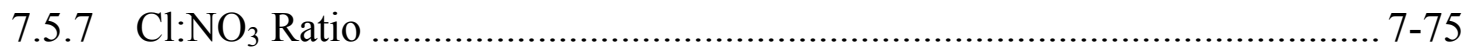

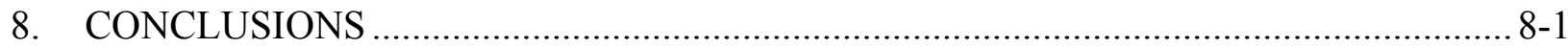

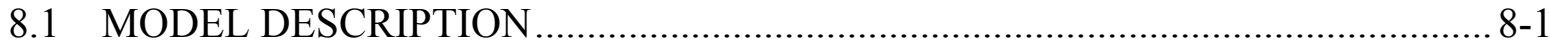

8.2 DEVELOPED OUTPUTS .......................................................................... $8-1$

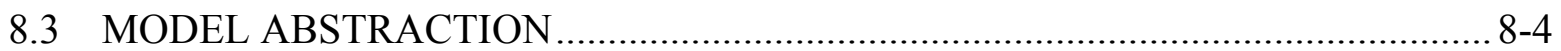

8.4 UNCERTAINTY AND LIMITATIONS .................................................... $8-4$

8.5 YUCCA MOUNTAIN REVIEW PLAN CRITERIA ASSESSMENT ................... 8-6

8.5.1 Acceptance Criterion 1 - System Description and Model Integration Are Adequate......................................................................................... 8-6

8.5.2 Acceptance Criterion 2 - Data Are Sufficient for Model Justification ........... 8-9

8.5.3 Acceptance Criterion 3 - Data Uncertainty Is Characterized and Propagated Through the Model Abstraction $8-10$ 


\section{CONTENTS (Continued)}

Page

8.5.4 Acceptance Criterion 4 - Model Uncertainty Is Characterized and Propagated Through the Model Abstraction ……………………................. 8-12

8.5.5 Acceptance Criterion 5 - Model Abstraction Output Is Supported by Objective Comparisons .............................................................................. 8-13

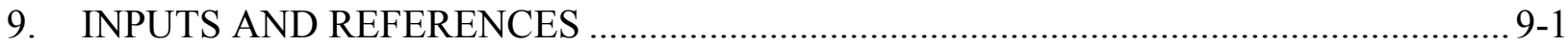

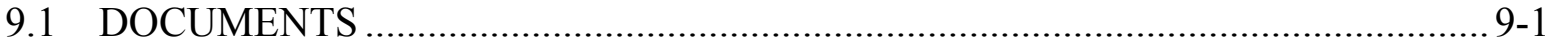

9.2 CODES, STANDARDS, REGULATIONS, AND PROCEDURES ……………..... 9-17

9.3 SOURCE DATA, LISTED BY TRACKING NUMBER ………............................ 9-18

9.4 OUTPUT DATA, LISTED BY DATA TRACKING NUMBER ………….............9-18

9.5 SOFTWARE CODES ………………………............................................ 9-20 


\section{INTENTIONALLY LEFT BLANK}




\section{FIGURES}

Page

6-1. Processes Simulated by the In-Drift Precipitates/Salts Model .................................... 6-12

6-2. General Process Required to Give a Valid Technical Basis for Mineral

Suppression or Inclusion in Geochemical Equilibrium Modeling.

6-3. Representation of Steady-State Flow-Through for the In-Drift Precipitates/Salts

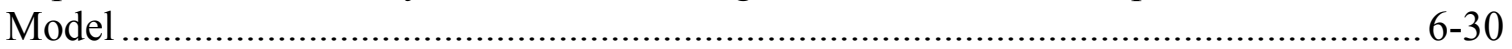

6-4. Example Aqueous Composition Evaporation Predictions vs. $R H$............................... 6-34

6-5. Example Aqueous Composition Evaporation Predictions vs. $C F$................................ 6-34

6-6. Example Acid-Neutralizing Capacity Species Concentration Evaporation Predictions vs. $R H$. 6-35

6-7. Example Acid-Neutralizing Capacity Species Concentration Evaporation

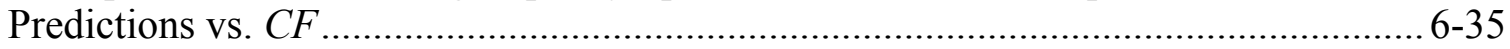

6-8. Example Mineral Precipitation Evaporation Predictions vs. $R H$.................................. 6-36

6-9. Example Mineral Precipitation Evaporation Predictions vs. $C F$.................................. 6-36

6-10. Example Aqueous Composition Condensation Predictions vs. $R H$.............................. 6-37

6-11. Example Aqueous Composition Condensation Predictions vs. $D F$............................. 6-38

6-12. Example Acid-Neutralizing Capacity Species Concentration Condensation

Predictions vs. RH......................................................................................... 6-38

6-13. Example Acid-Neutralizing Capacity Species Concentration Condensation

Predictions vs. $D F$.

7-1. Predicted Aqueous Evolution of Synthetic J-13 Water for Evaporation

Experiments of Rosenberg et al. (1999 [DIRS 125338])............................................. 7-9

7-2. Predicted Mineral Evolution of Synthetic J-13 Water for Evaporation

Experiments of Rosenberg et al. (1999 [DIRS 125338])............................................ 7-9

7-3. Predicted vs. Measured Concentrations for Synthetic J-13 Water Evaporation

Experiments of Rosenberg et al. (1999 [DIRS 125338]) ............................................ 7-10

7-4. Predicted vs. Measured pH Values for Synthetic J-13 Water Evaporation

Experiments of Rosenberg et al. (1999 [DIRS 125338]) ........................................... 7-10

7-5. Predicted Aqueous Evolution of 100x Synthetic J-13 Water for Evaporation

Experiments (BSC 2001 [DIRS 155640]) …………….......................................... 7-13

7-6. Predicted Mineral Evolution of 100x Synthetic J-13 Water for Evaporation

Experiments (BSC 2001 [DIRS 155640]) …………………………….................... 7-13

7-7. Predicted vs. Measured Concentrations for 100x Synthetic J-13 Water

Evaporation Experiments (BSC 2001 [DIRS 155640])...

7-8. Predicted Aqueous Evolution of Synthetic Topopah Spring Tuff Pore Water for

Evaporation Experiments of Rosenberg et al. (1999 [DIRS 125339]) ......................... 7-16

7-9. $\quad$ Predicted Mineral Evolution of Synthetic Topopah Spring Tuff Pore Water for Evaporation Experiments of Rosenberg et al. (1999 [DIRS 125339]) ……................. 7-17

7-10. Predicted vs. Measured Concentrations for Synthetic Topopah Spring Tuff Pore Water from Evaporation Experiments of Rosenberg et al. (1999 [DIRS 125339]).......7-17

7-11. Predicted vs. Measured pH Values for Synthetic Topopah Spring Tuff Pore Water from Evaporation Experiments of Rosenberg et al. (1999 [DIRS 125339]).......7-18

7-12. Predicted vs. Measured $\mathrm{Ca}, \mathrm{K}, \mathrm{Mg}$, and $\mathrm{Na}$ Concentrations from Evaporation of Inagua Seawater 


\section{FIGURES (Continued)}

Page

7-13. Predicted vs. Measured $\mathrm{Br}, \mathrm{Cl}$, and $\mathrm{SO}_{4}$ Concentrations from Evaporation of Inagua Seawater....

7-14. Predicted vs. Measured pH and Ionic Strength from Evaporation of Inagua Seawater $7-22$

7-15. Predicted Mineral Precipitation from Evaporation of Inagua Seawater ........................ 7-22

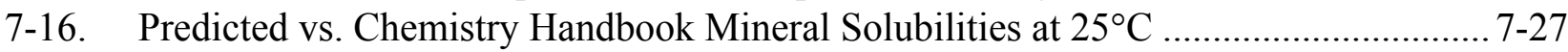

7-17. Predicted vs. Chemistry Handbook Mineral Solubilities at $100^{\circ} \mathrm{C}$............................. 7-27

7-18. Solubility and Deliquescence $R H$ Predictions vs. Data for $\mathrm{NaCl}$............................... 7-30

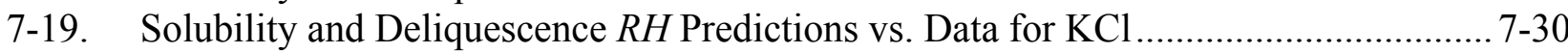

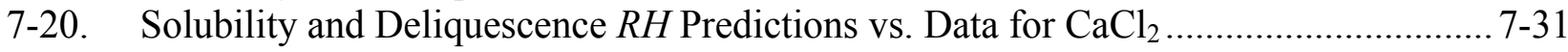

7-21. Solubility and Deliquescence $R H$ Predictions vs. Data for $\mathrm{MgCl}_{2} \ldots \ldots \ldots \ldots \ldots \ldots \ldots \ldots \ldots \ldots . . . . .1-31$

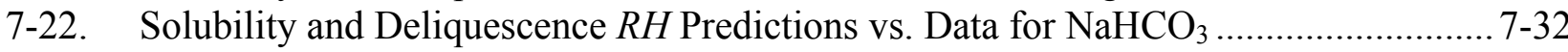

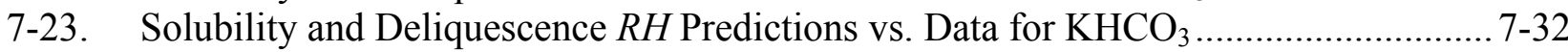

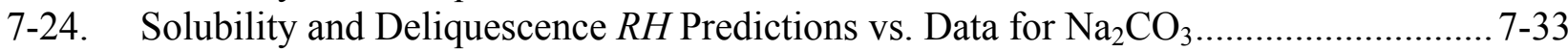

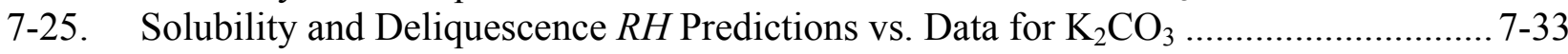

7-26. Solubility and Deliquescence $R H$ Predictions vs. Data for NaF.................................. 7-34

7-27. Solubility and Deliquescence $R H$ Predictions vs. Data for KF ................................... 7-34

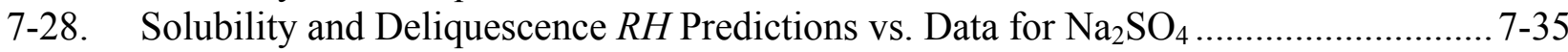

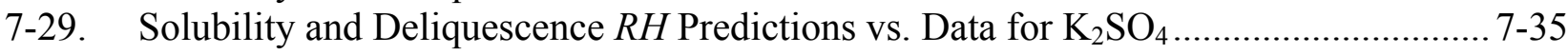

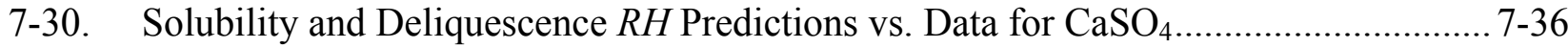

7-31. Solubility and Deliquescence $R H$ Predictions vs. Data for $\mathrm{MgSO}_{4} \ldots \ldots \ldots \ldots \ldots \ldots \ldots \ldots \ldots \ldots . . . .7-36$

7-32. Solubility and Deliquescence $R H$ Predictions vs. Data for $\mathrm{NaBr}$................................ 7-37

7-33. Solubility and Deliquescence $R H$ Predictions vs. Data for $\mathrm{KBr}$.................................... 7-37

7-34. Solubility and Deliquescence $R H$ Predictions vs. Data for $\mathrm{CaBr}_{2} \ldots \ldots \ldots \ldots \ldots \ldots \ldots \ldots \ldots \ldots \ldots . . . . .7-38$

7-35. Solubility and Deliquescence $R H$ Predictions vs. Data for $\mathrm{MgBr}_{2} \ldots \ldots \ldots \ldots \ldots \ldots \ldots \ldots \ldots \ldots \ldots . . . . .7-38$

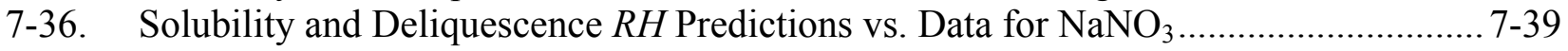

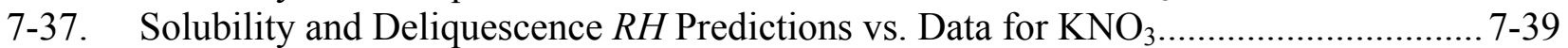

7-38. Solubility and Deliquescence $R H$ Predictions vs. Data for $\mathrm{Ca}\left(\mathrm{NO}_{3}\right)_{2} \ldots \ldots \ldots \ldots \ldots \ldots \ldots \ldots \ldots . . . . . . .7-40$

7-39. Solubility and Deliquescence $R H$ Predictions vs. Data for $\mathrm{Mg}\left(\mathrm{NO}_{3}\right)_{2} \ldots \ldots \ldots \ldots \ldots \ldots \ldots \ldots . . . . . . . .7-40$

7-40. Model Predictions vs. Data for Na-K-Cl Eutectic System ......................................... 7-43

7-41. Model Predictions vs. Data for Na-K-NO $\mathrm{NO}_{3}$ Eutectic System ....................................... 7-43

7-42. Model Predictions vs. Data for Na-Cl-NO $\mathrm{N}_{3}$ Eutectic System ...................................... 7-44

7-43. $\quad \mathrm{Cl}: \mathrm{NO}_{3}$ Mole Ratio Predictions vs. Data for Na-Cl-NO${ }_{3}$ Eutectic System..................... 7-44

7-44. $\mathrm{NaCl}$ Solubility Predictions vs. Data as a Function of $\mathrm{NaNO}_{3}$ Concentration at

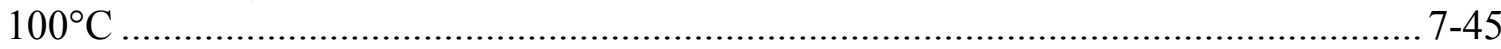

7-45. Cl: $\mathrm{NO}_{3}$ Mole Ratio Predictions at $\mathrm{NaCl}$ Saturation vs. Data as a Function of

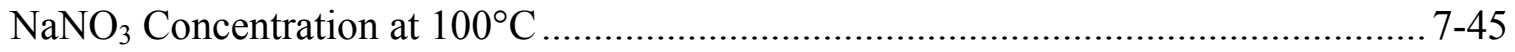

7-46. Model Predictions vs. Data for $\mathrm{Na}_{-10} \mathrm{NO}_{3}-\mathrm{SO}_{4}$ Eutectic System.................................... 7-46

7-47. Model Predictions vs. Data for Na-Cl-SO ${ }_{4}$ Eutectic System....................................... 7-46

7-48. Model Predictions vs. Data for K-Cl-NO $\mathrm{N}_{3}$ Eutectic System ....................................... 7-47

7-49. $\mathrm{Cl}: \mathrm{NO}_{3}$ Mole Ratio Predictions vs. Data for Na-Cl-NO 3 Eutectic System..................... 7-47

7-50. KCl Solubility Predictions vs. Data as a Function of $\mathrm{KNO}_{3}$ Concentration at

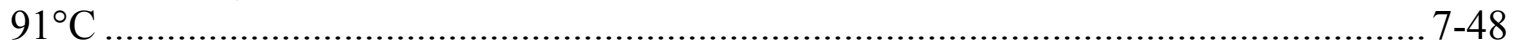




\section{FIGURES (Continued)}

Page

7-51. $\mathrm{Cl}: \mathrm{NO}_{3}$ Mole Ratio Predictions at $\mathrm{KCl}$ Saturation vs. Data as a Function of

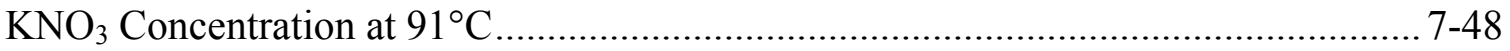

7-52. $\mathrm{KCl}$ Solubility Predictions vs. Data as a Function of $\mathrm{KNO}_{3}$ Concentration at $150^{\circ} \mathrm{C}$

7-53. $\mathrm{Cl}: \mathrm{NO}_{3}$ Mole Ratio Predictions at $\mathrm{KCl}$ Saturation vs. Data as a Function of $\mathrm{KNO}_{3}$ Concentration at $150^{\circ} \mathrm{C}$

7-54. Model Predictions vs. Data for Na-Cl- $\mathrm{CO}_{3}$ Eutectic System ..................................... 7-50

7-55. Model Predictions vs. Data for $\mathrm{Na}-\mathrm{Ca}-\mathrm{NO}_{3}$ Eutectic System...................................... 7-50

7-56. Model Predictions vs. Data for $\mathrm{K}_{-1} \mathrm{CO}_{3}-\mathrm{SO}_{4}$ Eutectic System..................................... 7-51

7-57. Model Predictions vs. Data for Na-Mg-Cl Eutectic System......................................... 7-51

7-58. $\mathrm{NaCl}$ Solubility Predictions vs. Data in the Presence of $1.05 \mathrm{Molal}^{\mathrm{MgCl}} \mathrm{Cl}_{2} \ldots \ldots \ldots \ldots \ldots \ldots . . . .7-52$

7-59. Model Predictions vs. Data for K-Mg-Cl Eutectic System......................................... 7-52

7-60. $\mathrm{KCl}$ Solubility Predictions vs. Data as a Function of $\mathrm{MgCl}_{2}$ Concentration at $150^{\circ} \mathrm{C}$ $7-53$

7-61. Model Predictions vs. Data for $\mathrm{Ca}-\mathrm{Cl}-\mathrm{NO}_{3}$ Eutectic System ..................................... 7-53

7-62. Cl: $\mathrm{NO}_{3}$ Mole Ratio Predictions vs. Data for Ca-Cl-NO ${ }_{3}$ Eutectic System..................... 7-54

7-63. $\mathrm{Ca}\left(\mathrm{NO}_{3}\right)_{2}$ Solubility Predictions vs. Data as a Function of $\mathrm{CaCl}_{2}$ Concentration at

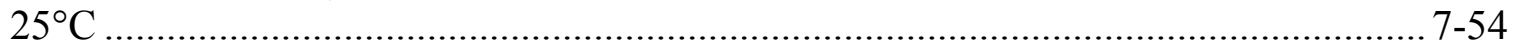

7-64. $\mathrm{Cl}: \mathrm{NO}_{3}$ Mole Ratio Predictions at $\mathrm{Ca}\left(\mathrm{NO}_{3}\right)_{2}$ Saturation vs. Data as a Function of

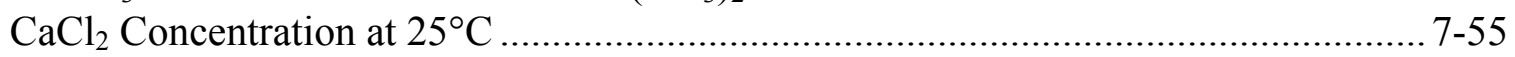

7-65. $\mathrm{CaCl}_{2}$ Solubility Predictions vs. Data as a Function of $\mathrm{Ca}\left(\mathrm{NO}_{3}\right)_{2}$ Concentration at

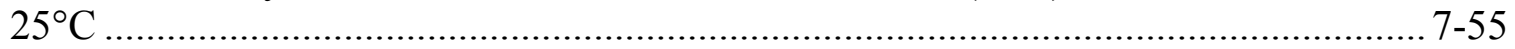

7-66. $\mathrm{Cl}: \mathrm{NO}_{3}$ Mole Ratio Predictions at $\mathrm{CaCl}_{2}$ Saturation vs. Data as a Function of

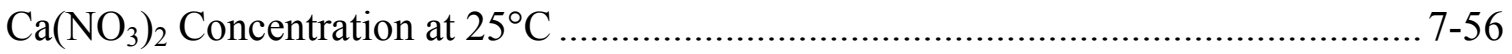

7-67. Model Predictions vs. Data for $\mathrm{Mg}-\mathrm{Cl}-\mathrm{NO}_{3}$ Eutectic System ...................................... 7-56

7-68. Cl: $\mathrm{NO}_{3}$ Mole Ratio Predictions vs. Data for Mg-Cl-NO ${ }_{3}$ Eutectic System................... 7-57

7-69. Pitzer vs. Set 1 data0.ymp.R2 (YMP.R2) Aqueous Predictions for Average In Situ J-13 Well Water at $70^{\circ} \mathrm{C}$ and $\mathrm{CO}_{2}(\mathrm{~g})$ Fugacity of $10^{-3}$ Bars............................... 7-58

7-70. Pitzer vs. Set 1 data0.ymp.R2 (YMP.R2) pH and Ionic Strength Predictions for Average In Situ J-13 Well Water at $70^{\circ} \mathrm{C}$ and $\mathrm{CO}_{2}(\mathrm{~g})$ Fugacity of $10^{-3}$ Bars.............. 7-59

7-71. Pitzer vs. Set 2 data0.ymp.R2 (YMP.R2) Aqueous Predictions for Average In Situ J-13 Well Water at $70^{\circ} \mathrm{C}$ and $\mathrm{CO}_{2}(\mathrm{~g})$ Fugacity of $10^{-3}$ Bars.

7-72. Pitzer vs. Set 2 data0.ymp.R2 (YMP.R2) pH and Ionic Strength Predictions for Average In Situ J-13 Well Water at $70^{\circ} \mathrm{C}$ and $\mathrm{CO}_{2}(\mathrm{~g})$ Fugacity of $10^{-3}$ Bars. $7-60$

7-73. Differences Between Measurements and Model Predictions of Salt Solubilities for Ternary Systems Involving Both $\mathrm{Cl}$ and $\mathrm{NO}_{3}$ $7-64$ 


\section{INTENTIONALLY LEFT BLANK}




\section{TABLES}

Page

3-1. Comparison of $\log \mathrm{K}$ Values for the Dissolution Reactions of $\mathrm{CaCl}_{2}, \mathrm{NaNO}_{3}$, and $\mathrm{Na}_{2} \mathrm{CO}_{3}: \mathrm{H}_{2} \mathrm{O}$ Obtained Using SUPCRT92 (Version 1.0) on Windows NT and Windows 2000 Operating Systems

4-1. Input Sources for Pitzer Database ...................................................................... 4-4

4-2. Binary Pitzer Ion Interaction Coefficients .............................................................. 4-6

4-3. Ternary Pitzer Ion Interaction Coefficients ............................................................ 4-7

4-4. Corrections to Log K Values for Seven Zeolites .......................................................... 4-12

4-5. In-Drift Precipitates/Salts Model Input Parameters .................................................... 4-13

4-6. Data Used for Model Validation, Model Demonstration, and Estimation of Model Uncertainties................................................................................................ 4-19

4-7. Water Chemistry Data from Experimental J-13 Well Water Evaporation of Rosenberg et al. (1999 [DIRS 125338]) ............................................................... 4-19

4-8. $\quad \mathrm{pH}$ Data from Experimental J-13 Well Water Evaporation of Rosenberg et al. (1999 [DIRS 125338])

4-9. Water Chemistry Data from Experimental 100x J-13 Well Water (BSC 2001 [DIRS 155640])

4-10. Water Chemistry Data from Topopah Spring Tuff Pore Water Evaporation Experiment of Rosenberg et al. (1999 [DIRS 125339]) ............................................ 4-21

4-11. Sample Data for Evaporated Seawater .................................................................... 4-22

4-12. Aqueous Solubilities of $\mathrm{Na}, \mathrm{K}, \mathrm{Ca}$, and $\mathrm{Mg}$ Salts................................................... 4-23

4-13. Equilibrium Relative Humidity for Saturated Aqueous Solutions in Contact with an Excess of Solid-Phase Salts

4-14. Sources of Additional Aqueous Solubility Data for $\mathrm{Na}, \mathrm{K}, \mathrm{Ca}$, and Mg Salts as a Function of Temperature.

4-15. Sources of Additional Vapor Pressure Data for Several Salt Solutions as a Function of Temperature.

4-16. Equilibrium $R H$ of Saturated Aqueous Solutions of Selected Pure Salts as a Function of Temperature.

4-17. Selected Vapor Pressure Data for Saturated Aqueous $\mathrm{NaNO}_{3}$ Solutions and Pure Water as a Function of Temperature......................................................................... 4-26

4-18. Sources of Salt Solubilities in Ternary Systems as a Function of Temperature ............. 4-27

4-19. Average Composition of Water from Well J-13 ...................................................... 4-27

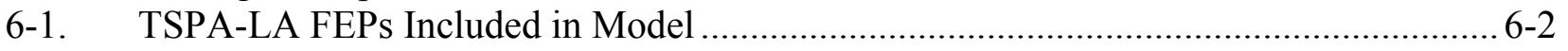

6-2. Alternative Conceptual Models Considered ........................................................ 6-13

6-3. Mineral Suppressions Included in the IDPS Model................................................. 6-25

6-4. Minerals Allowed to Precipitate in the IDPS Model ................................................. 6-26

6-5. Corrections to Log K Values for Seven Zeolites ........................................................ 6-40

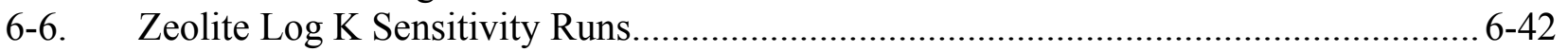

7-1. Model Validation Criteria .........................................................................................

7-2. Calculation of "Measured" Ionic Strength in Average J-13 Well Water Evaporation Experiment ....................................................................................... 7-8

7-3. Calculation of "Measured" Ionic Strength in Topopah Spring Tuff Pore Water Evaporation Experiment …………………......................................................... 7-16 


\section{TABLES (Continued)}

Page

7-4. Unit Conversion of Chemistry Handbook Aqueous Solubilities of $\mathrm{Na}, \mathrm{K}, \mathrm{Ca}$, and

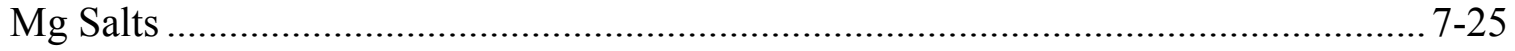

7-5. Comparison of Model Predictions to Chemistry Handbook Aqueous Solubilities ....... 7-26

7-6. Model Predictions of Equilibrium Relative Humidity for Saturated Aqueous Solutions in Contact with an Excess of Solid-Phase Salts........................................... 7-28

7-7. Maximum Differences Between Predictions and Measurements for $\mathrm{pH}$, Ionic Strength, $\mathrm{Cl}, \mathrm{NO}_{3}$, and the $\mathrm{Cl}: \mathrm{NO}_{3}$ Ratio.............................................................. 7-62

7-8. Estimated IDPS Model Uncertainties for Temperatures Between $25^{\circ} \mathrm{C}$ and $140^{\circ} \mathrm{C} \ldots \ldots . .7-65$

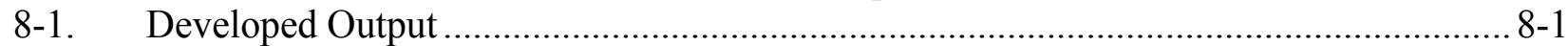




\section{ACRONYMS AND ABBREVIATIONS}

$100 \mathrm{x}$ concentration factor of 100

$C_{i} \quad$ concentration of component $i$

$C F \quad$ concentration factor

$D F \quad$ dilution factor

DTN data tracking number

EBS Engineered Barrier System

$f_{\mathrm{CO} 2} \quad$ carbon dioxide fugacity

$f_{\mathrm{O} 2} \quad$ oxygen fugacity

FEPs features, events, and processes

gm gram

IS ionic strength

IDPS in-drift precipitates/salts

kg kilogram

L liter

mg milligram

$\mathrm{mL} \quad$ milliliter

molal moles per kilogram of water

NBS National Bureau of Standards

$Q^{d} \quad$ discharge rate (rate of flow out of cell)

$Q^{e} \quad$ net evaporation rate (net of evaporation [positive] and condensation [negative])

$Q^{s} \quad$ incoming seepage rate

$R^{e s} \quad$ relative evaporation rate $\left(Q^{e} / Q^{s}\right)$

RH relative humidity

$R H_{d} \quad$ deliquescence point or deliquescence relative humidity of a solution or mineral assemblage in $R H$ units

$S_{m} \quad$ Suppression flag for mineral $m$

$T \quad$ temperature

TSPA total system performance assessment

TSPA-LA Total System Performance Assessment for the License Application

TSPA-SR Total System Performance Assessment for the Site Recommendation

TWP technical work plan

YMP Yucca Mountain Project 


\section{INTENTIONALLY LEFT BLANK}




\section{PURPOSE}

This report documents the development and validation of the in-drift precipitates/salts (IDPS) model. The IDPS model is a geochemical model designed to predict the postclosure effects of evaporation and deliquescence on the chemical composition of water within the Engineered Barrier System (EBS) in support of the Total System Performance Assessment for the License Application (TSPA-LA). Application of the model in support of TSPA-LA is documented in Engineered Barrier System: Physical and Chemical Environment Model (BSC 2004 [DIRS 169860]).

Technical Work Plan for: Near-Field Environment and Transport In-Drift Geochemistry Model Report Integration (BSC 2004 [DIRS 171156]) is the technical work plan (TWP) for this report. It called for a revision of the previous version of the report (BSC 2004 [DIRS 167734]) to achieve greater transparency, readability, data traceability, and report integration.

The intended use of the IDPS model is to estimate and tabulate, within an appropriate level of confidence, the effects of evaporation, deliquescence, and potential environmental conditions on the $\mathrm{pH}$, ionic strength, and chemical compositions of water and minerals on the drip shield or other location within the drift during the postclosure period. Specifically, the intended use is as follows:

- To estimate, within an appropriate level of confidence, the effects of evaporation and deliquescence on the presence and composition of water occurring within the repository during the postclosure period (i.e., effects on $\mathrm{pH}$, ionic strength, deliquescence relative humidity, total concentrations of dissolved components in the system Na-K-H-Mg-Ca$\mathrm{Al}-\mathrm{Cl}-\mathrm{F}-\mathrm{NO}_{3}-\mathrm{SO}_{4}-\mathrm{Br}-\mathrm{CO}_{3}-\mathrm{SiO}_{2}-\mathrm{CO}_{2}-\mathrm{O}_{2}-\mathrm{H}_{2} \mathrm{O}$, and concentrations of the following aqueous species that potentially affect acid neutralizing capacity: $\mathrm{HCO}_{3}^{-}, \mathrm{CO}_{3}{ }^{2-}, \mathrm{OH}^{-}$, $\mathrm{H}^{+}, \mathrm{HSO}_{4}{ }^{-}, \mathrm{Ca}^{2+}, \mathrm{Mg}^{2+}, \mathrm{CaHCO}_{3}{ }^{+}, \mathrm{MgHCO}_{3}{ }^{+}, \mathrm{HSiO}_{3}{ }^{-}$, and $\mathrm{MgOH}^{+}$)

- To estimate, within an appropriate level of confidence, mineral precipitation resulting from the evaporation of water occurring within the repository during the postclosure period (specifically, minerals of the system Na-K-H-Mg-Ca-Al-Cl-F-NO ${ }_{3}-\mathrm{SO}_{4}-\mathrm{Br}-\mathrm{CO}_{3}-$ $\left.\mathrm{SiO}_{2}-\mathrm{CO}_{2}-\mathrm{O}_{2}-\mathrm{H}_{2} \mathrm{O}\right)$

- To provide a means for abstracting these effects into a set of lookup tables that provide input to downstream models used for performance assessment.

The presence and composition of liquid water in the drift depend upon relative humidity, temperature, incoming water composition, in-drift gas composition, and relative rates of evaporation and seepage. In downstream applications of this model, intended input values for these parameters are abstracted results from thermal-hydrological-chemical models, water sample measurements, dust leachate samples, and values used in sensitivity and uncertainty analyses that encompass the expected ranges of these parameters.

The IDPS model is a quasi-equilibrium model. All reactions proceed to equilibrium except for several suppressed minerals in the thermodynamic database not expected to form under 
repository conditions within the modeling timeframe. These minerals are listed in Table 6-3, which contains references that document why these minerals are not expected to form. The EQ3/6 code (Version 8.0) and Pitzer thermodynamic database developed in this report allow equilibrium and reaction-path modeling of evaporation to highly concentrated brines for potential water compositions of the system $\mathrm{Na}-\mathrm{K}-\mathrm{H}-\mathrm{Mg}-\mathrm{Ca}-\mathrm{Al}-\mathrm{Cl}-\mathrm{F}-\mathrm{NO}_{3}-\mathrm{SO}_{4}-\mathrm{Br}_{-} \mathrm{CO}_{3}-\mathrm{SiO}_{2}-$ $\mathrm{CO}_{2}-\mathrm{O}_{2}-\mathrm{H}_{2} \mathrm{O}$ at temperatures in the range of $0^{\circ} \mathrm{C}$ to $140^{\circ} \mathrm{C}$, pressures in the atmospheric range, and relative humidity in the range of 0 to 100 percent. This system applies to oxidizing conditions only, and therefore limits the model to applications involving oxidizing conditions.

A number of thermodynamic parameters in the Pitzer database have values that have not been determined or verified for the entire temperature range. In these cases, the known values are used to approximate the values for the rest of the temperature range. Although such treatment contributes to uncertainty in model outputs, the model validation test cases indicate that the model, with its associated uncertainty, is valid for its intended use. 


\section{QUALITY ASSURANCE}

The Quality Assurance program has been determined to apply to the development of this document, as discussed in Technical Work Plan for: Near-Field Environment and Transport InDrift Geochemistry Model Report Integration (BSC 2004 [DIRS 171156]), because it involves activities that provide data used to assess the potential dispersion of radioactive materials from the facility. This model provides bases for predicting performance of engineered barriers that are important to the demonstration of compliance with the postclosure performance objective prescribed in 10 CFR 63.113 [DIRS 156605]. Thus, it is classified as "Safety Category (SC)" with regard to importance to waste isolation as defined in AP-2.22Q, Classification Criteria and Maintenance of the Monitored Geologic Repository Q-List. This document was developed as directed in Section 1.2.1 of the TWP. The TWP was prepared in accordance with AP-2.27Q, Planning for Science Activities. The methods used to control the electronic management of data as required by AP-SV.1Q, Control of the Electronic Management of Information, are identified in the TWP. As directed in the TWP, this document was prepared in accordance with AP-SIII.10Q, Models, and reviewed in accordance with AP-2.14Q, Document Review. 


\section{INTENTIONALLY LEFT BLANK}




\section{USE OF SOFTWARE}

\subsection{QUALIFIED SOFTWARE}

All qualified software discussed in this document was obtained from Software Configuration Management in accordance with LP-SI.11Q-BSC, Software Management. This software was used in the operating environments for which they were baselined. One of the software, SUPCRT92 Version 1.0, was also used in a nonbaselined operating environment, as explained in Section 3.1.3.

\subsubsection{EQ3/6 Version 8.0}

EQ3/6 Version 8.0 (EQ3/6 V8.0, STN: 10813-8.0-00 [DIRS 162228]) was installed and used on IBM-compatible computers using the Microsoft Windows 2000 operating system. This software was selected because it was the best software available for implementing the model developed in this report. There are no limitations of the software within the range of application of the model as established in Section 8.4. This software is appropriate for the application and was used only within the range of model validation in accordance with LP-SI.11Q-BSC. No macros or software routines were developed for, or used by, this software.

\subsubsection{GetEQData Version 1.0.1}

GetEQData Version 1.0.1 (GetEQData V1.0.1, STN: 10809-1.0.1-00 [DIRS 161900]) was installed and used on IBM-compatible computers using the Microsoft Windows 2000 operating system. This software was selected because it was the only available software for extracting data from EQ3/6 output files. There are no relevant limitations of the software. This software is appropriate for the application and was used only within the range of validation in accordance with LP-SI.11Q-BSC. No other macros or software routines were developed for, or used by, this software. GetEQData is itself a macro for Microsoft Excel.

\subsubsection{SUPCRT92 Version 1.0}

SUPCRT92 Version 1.0 (SUPCRT92 V1.0, STN: 10058-1.0-00 [DIRS 153218]) was first installed and used on an IBM-compatible computer using the Microsoft Windows 2000 operating system. This software was selected because it was the best available software for generating the thermodynamic data needed. There are no relevant limitations of the software. Because the software was not qualified for this operating system, it was later installed and used on an IBM-compatible computer using the Microsoft Windows NT operating system to verify and justify use of the original calculations. Microsoft Windows NT is a qualified operating system for this code. All of the calculations performed on the Microsoft Windows 2000 operating system were rerun on the Microsoft Windows NT system. The results on the two platforms are identical, and both sets of calculations are documented in DTN: SN0306T0510102.007. These results are summarized below in Table 3-1 and also in the spreadsheet file 'comparison_SUPCRT92_salts_Carlos_Yueting.xls' in DTN: SN0306T0510102.007. Details on how these calculations were used in this report are provided in Sections I-5, I-5.1, I-5.2, and I-5.3 of Appendix I. This software is appropriate for the Windows NT application and was used 
only within the range of validation in accordance with LP-SI.11Q-BSC. No macros or software routines were developed for, or used by, this software.

Table 3-1. Comparison of log $\mathrm{K}$ Values for the Dissolution Reactions of $\mathrm{CaCl}_{2}, \mathrm{NaNO}_{3}$, and $\mathrm{Na}_{2} \mathrm{CO}_{3}: \mathrm{H}_{2} \mathrm{O}$ Obtained Using SUPCRT92 (Version 1.0) on Windows NT and Windows 2000 Operating Systems

\begin{tabular}{|l|l|l|l|}
\hline $\begin{array}{c}\text { Temperature } \\
\left({ }^{\circ} \mathrm{C} \text { ) }\right.\end{array}$ & $\begin{array}{c}\text { Log K Calculated } \\
\text { with SUPCRT92 } \\
\text { (Windows NT) }\end{array}$ & $\begin{array}{c}\text { Log K Calculated } \\
\text { with SUPCRT92 } \\
\text { (Windows 2000) }\end{array}$ & \multicolumn{1}{|c|}{ Salt Phase } \\
\hline 0.1 & 13.177 & 13.177 & $\mathrm{CaCl}_{2}$ \\
\hline 25 & 11.942 & 11.942 & $\mathrm{CaCl}_{2}$ \\
\hline 60 & 10.325 & 10.325 & $\mathrm{CaCl}_{2}$ \\
\hline 100 & 8.649 & 8.649 & $\mathrm{CaCl}_{2}$ \\
\hline 150 & 6.738 & 6.738 & $\mathrm{CaCl}_{2}$ \\
\hline 200 & 4.935 & 4.935 & $\mathrm{CaCl}_{2}$ \\
\hline 250 & 3.124 & 3.124 & $\mathrm{CaCl}_{2}$ \\
\hline 300 & 1.126 & 1.126 & $\mathrm{CaCl}_{2}$ \\
\hline 0.1 & 0.679 & 0.679 & $\mathrm{NaNO}_{3}$ \\
\hline 25 & 1.039 & 1.039 & $\mathrm{NaNO}_{3}$ \\
\hline 60 & 1.386 & 1.386 & $\mathrm{NaNO}_{3}$ \\
\hline 100 & 1.644 & 1.644 & $\mathrm{NaNO}_{3}$ \\
\hline 150 & 1.819 & 1.819 & $\mathrm{NaNO}_{3}$ \\
\hline 200 & 1.861 & 1.861 & $\mathrm{NaNO}_{3}$ \\
\hline 250 & 1.769 & 1.769 & $\mathrm{NaNO}_{3}$ \\
\hline 300 & 1.496 & 1.496 & $\mathrm{NaNO}_{3}$ \\
\hline 0.1 & 11.404 & 11.404 & $\mathrm{Na}_{2} \mathrm{CO}_{3}: \mathrm{H}_{2} \mathrm{O}$ \\
\hline 25 & 10.974 & 10.974 & $\mathrm{Na}_{2} \mathrm{CO}_{3}: \mathrm{H}_{2} \mathrm{O}$ \\
\hline 60 & 10.46 & 10.46 & $\mathrm{Na}_{2} \mathrm{CO}_{3}: \mathrm{H}_{2} \mathrm{O}$ \\
\hline 100 & 9.985 & 9.985 & $\mathrm{Na}_{2} \mathrm{CO}_{3}: \mathrm{H}_{2} \mathrm{O}$ \\
\hline 150 & 9.499 & 9.499 & $\mathrm{Na}_{2} \mathrm{CO}_{3}: \mathrm{H}_{2} \mathrm{O}$ \\
\hline 0404 & & \\
\hline
\end{tabular}

Output DTN: SN0306T0510102.007.

\subsection{EXEMPT SOFTWARE}

Microsoft Excel 2000, a commercially available spreadsheet software package, was installed and used on IBM-compatible computers using the Microsoft Windows 2000 operating system. This software was used to tabulate results, visually display results, and perform the algebraic equations documented in Section 6.6.3.5, Appendix I, and elsewhere. This software was selected because it is the standard Yucca Mountain Project (YMP) software used for performing these tasks. There are no limitations of the software relevant to these tasks. Hand calculations and visual inspection of these tabulations, charts, and equations confirm that the spreadsheet applications provided correct results. Except for GetEQData listed above (which is an Excel macro), no macros or software routines were developed for, or used by, this software, and 
consequently it is an exempt software application in accordance with Section 2.1 of LP-SI.11Q-BSC.

Output data tracking numbers (DTNs) containing Excel spreadsheets include:

- DTN: LL031106231032.007

- DTN: MO0303MWDINJ13.000

- DTN: MO0303MWDJ13GD.000

- DTN: MO0303MWDJ13RB.000

- DTN: MO0303MWDSEDSS.000

- DTN: MO0303MWDTSWRB.000

- DTN: MO0304SPAJ13IS.001

- DTN: MO0307MWDSEAEV.000

- DTN: MO0307MWDUNEVP.000

- DTN: MO0311MWDMVBTS.000

- DTN: MO0312SPAESMUN.002

- DTN: MO0308SPAUCIMV.000

- DTN: MO0410MWDIDPSM.000

- DTN: SN0306T0510102.007. 


\section{INTENTIONALLY LEFT BLANK}




\section{INPUTS}

\subsection{DIRECT INPUT}

This report is a revision of a previously developed and validated in-drift precipitates/salts model (BSC 2004 [DIRS 167734]). This revision replaces no DTNs documented in the previous report. Thus, the DTNs associated with the previous version are unchanged.

Data inputs used to develop the IDPS model and associated Pitzer thermodynamic database are presented in Sections 4.1.1 and 4.1.2. After reviewing a wide range of data, these data were found to be the most reliable and appropriate sources of information and data available for developing the model. Section 4.1.1 focuses on data constants in the Pitzer database, and Section 4.1.2 focuses on variable model parameters and values for these parameters used in model validation. The Data Input Reference System (DIRS) is used to track the quality of these data.

Independent data used to validate and demonstrate the IDPS model are presented in Section 4.4. A subset of the independent data in Section 4.4 is also used in Section 7.5 to estimate uncertainties. While it is preferable to have an additional independent set to estimate uncertainties (independent of the data used to validate the model), such data were not available. Per AP-SIII.10Q, Attachment 2, these data do not belong in Section 4.1 because they were not used to develop the model.

\subsubsection{Data}

A Pitzer thermodynamic database is developed in this report for use in the IDPS model. The IDPS model is designed to predict the evolution of water in the drift caused by changing environmental conditions. To predict salt precipitation, deliquescence, and aqueous concentrations in brines, a Pitzer database is needed. This database is developed for the system $\mathrm{Na}-\mathrm{K}-\mathrm{H}-\mathrm{Mg}-\mathrm{Ca}-\mathrm{Al}-\mathrm{Cl}-\mathrm{F}-\mathrm{NO}_{3}-\mathrm{SO}_{4}-\mathrm{Br}-\mathrm{CO}_{3}-\mathrm{SiO}_{2}-\mathrm{CO}_{2}-\mathrm{O}_{2}-\mathrm{H}_{2} \mathrm{O}$, which generally encompasses the most abundant ions in natural ground waters. It is designed for temperatures ranging from $0^{\circ} \mathrm{C}$ to $200^{\circ} \mathrm{C}$, a broader range than that of the IDPS model $\left(0^{\circ} \mathrm{C}\right.$ to $\left.140^{\circ} \mathrm{C}\right)$. The smaller range for the IDPS model is due to the smaller temperature range of the independent set of model validation data.

Qualification of data for use in the present report is achieved within this report under the provisions of AP-SIII.10Q, Models. A principal technical product of this report is an EQ3/6 Pitzer data file that is qualified for use elsewhere, particularly for use in Engineered Barrier System: Physical and Chemical Environment Model (BSC 2004 [DIRS 169860]) and Environment on the Surfaces of the Drip Shield and Waste Package Outer Barrier (BSC 2004 [DIRS 161237].

The development of the Pitzer database is discussed in detail in Appendix I. The sources of direct input data used in the development of the Pitzer database are listed in Table 4-1. Uncertainty associated with these data is also addressed in Appendix I. In general, the input data (in the form of all the numerical values used to develop the present model) are far too numerous to list in Section 4.1.1 of this report or even in Appendix I. In order to perform a thorough 
checking against the cited sources, it is necessary to refer to the direct input numerical values as contained in the many spreadsheets that are part of the technical product output of this report.

Binary and ternary Pitzer temperature-dependent interaction coefficients are presented in Table 4-2 and Table 4-3. Each interaction coefficient is generally treated as a temperature function, which has its own coefficients (see Appendix I for details). These temperature coefficients comprise the actual set of data. They are too numerous to reproduce in Table 4-2 and Table 4-3. Uncertainty in the values of the coefficients (the interaction coefficients or the temperature coefficients used to calculate them) is difficult to assess given the multiple sources of data and the series of refitting and conversions conducted in the retrieval of coefficient data. For practical purposes, the retrieved coefficients were tested upon refitting/conversion for the prediction of parameters such as osmotic coefficients from their sources. When alternative data were available for the system in question, a simple check comparison between coefficient values was also made. The error analyses and comparisons of these predictions are reported in the spreadsheets referenced in Appendix I and pertain only to the original sources where the fitted coefficients were derived.

The Debye-Hückel $\mathrm{A}_{\varphi}$ parameter is also an intrinsic part of any Pitzer model. This is also treated by the use of a temperature function. The representation used in the IDPS model is based on that given by Greenberg and Møller (1989 [DIRS 152684]). However, the data were refitted to a different temperature function, the same one used in the IDPS model for the Pitzer interaction coefficients. This refitting of $\mathrm{A}_{\varphi}$ was repeated in each of the refittings for each set of binary interaction parameters, not because it needed to be repeated, but because this functionality was built into the spreadsheet template for binary coefficient refitting. The model of Greenberg and Møller (1989) was in fact used as the "core" of the database developed in the present report, and for the sake of thermodynamic consistency, it was appropriate to use their data for the $\mathrm{A}_{\varphi}$ parameter as a direct input for the expanded model.

Table 4-1 summarizes the input sources used in constructing the Pitzer database and lists selected factors used to justify qualification of the data. These sources are demonstrated in this section and/or in Appendix I to be suitable for the specific application per AP-SIII.10Q Section 5.2.1(k). In all cases, the extent to which the data demonstrate the properties of interest is in their entirety. Reliability of data source, qualifications of personnel or organizations generating the data, prior uses of the data, and/or availability of corroborating data are described in this section and/or Appendix I to justify qualification of the data for the intended use.

The data taken from these sources is in general not provided on a source by source basis, but rather on a data subset by data subset basis. For example, Table 4-2 summarizes the binary Pitzer parameter groupings, each of which is identified by a pair of aqueous species, usually ions (e.g., " $\mathrm{Na}^{+}-\mathrm{Cl}^{-}$"). Appendix I discusses the binary Pitzer parameter groupings in Section I-4.4, presenting the case for each grouping in a subsection named after the species pair (e.g., "Ions: " $\left.\mathrm{Na}^{+}-\mathrm{Cl}^{-, "}\right)$. These discussions are presented in a pseudo-alphabetic ordering. Thus, the discussions for " $\mathrm{Na}^{+}-\mathrm{Cl}^{-}$" and " $\mathrm{K}^{+}-\mathrm{Cl}^{-}$", for both of which the input data are taken from Greenberg and Møller (1989 [DIRS 152684]), do not appear in a common grouping within Section I-4.4. Furthermore, the ternary Pitzer parameter groupings are similarly identified by similar species pairs (e.g., " $\mathrm{K}^{+}-\mathrm{Na}^{+}$") and triplets (e.g., " $\mathrm{Na}^{+}-\mathrm{K}^{+}-\mathrm{Cl}^{-}$") listed in Table 4-3, and the corresponding justifications for the individual groupings of this type are given in 
Section I-4.5 in subsections labeled accordingly (e.g., "Ions: $\mathrm{K}^{+}-\mathrm{Na}^{+}$" and "Ions: " $\mathrm{Na}^{+}-\mathrm{K}^{+}-$ $\mathrm{Cl}^{-}$"). The input data for these particular examples are also taken from Greenberg and Møller (1989 [DIRS 152684]). Additional Pitzer data used "as-is" (not requiring conversion to the Pitzer parameter temperature function used in the present model) are described in detail in Section I-4.6 and their usage is justified therein.

Table 4-1 also summarizes the input sources for single-phase mineral thermodynamic data, solubility data, and solubility product constant data (including related data necessary to compute equilibrium constants, such as standard state thermodynamic data for water and aqueous species). Note that Greenberg and Møller (1989 [DIRS 152684]) is also a source of such data. The detailed justifications of these input data are presented in Section I-5.

In addition, Table 4-1 summarizes the sources of the various equations and mathematical relationships employed in the developed Pitzer model. The use of these mathematical elements does not require specific justification under the procedures governing the development of the present model. However, it is noted that the cited sources include Pitzer 1973 [DIRS 152738] and Pitzer 1991 [DIRS 152709], works by the late Professor Kenneth S. Pitzer, who promulgated the model that bears his name. These works, which contain equations and data used widely throughout the scientific community, have proven to be reliable, and therefore are suitable for the intended use in this report.

The sources listed in Table 4-1 include several major works on the subject of Pitzer's equations. Pitzer 1973 [DIRS 152738] is a journal article that is a classic in the field of physical chemistry and the original paper describing the basic Pitzer model. Harvie et al. 1984 [DIRS 118163] is another classic paper containing the first extensive application of the Pitzer model to aqueous geochemical systems at $25^{\circ} \mathrm{C}$. Pabalan and Pitzer 1987 [DIRS 162147], Pabalan and Pitzer 1987 [DIRS 162096], and Greenberg and Møller 1989 [DIRS 152684] are three notable papers describing application to systems of geochemical interest extending to high temperature. A number of the other sources are books that are de facto handbooks in the field of aqueous geochemistry or related disciplines, including Barin and Platzki 1995 [DIRS 157865] (a two-volume compendium of thermodynamic data based on calorimetry), Linke 1965 [DIRS 166191] (the second volume in a two-volume set of solubility data, of which Linke 1958 [DIRS 166192] is the first volume), and Robie and Hemingway 1995 [DIRS 153683] (a compendium of mineral thermodynamic data published by the U.S. Geological Survey). Data from the Linke volumes were primarily used for validation (see Table 4-6 in Section 4.4). Only the data for thermonatrite on p. 915 of the second volume was used in the actual development of the present model. Some non-Pitzer thermodynamic data were taken from the data0.ymp.R2, a YMP non-Pitzer database (DTN: MO0302SPATHDYN.000 [DIRS 161756], and DTN: MO0302SPATHDYN.001 [DIRS 161886]) developed for other applications within the Project. The remaining input sources, which are generally not as widely used in the construction of the Pitzer database, are addressed in Appendix I.

Errors in source DTN: MO0302SPATHDYN.000 [DIRS 161756] were discovered after the calculations in this report were completed. These errors are documented in Qualification of Thermodynamic Data for Geochemical Modeling of Mineral-Water Interactions in Dilute Systems (BSC 2004 [DIRS 171916]). The errors that affect the Pitzer database developed in the current report are the equilibrium constants (log K values) of seven zeolites. These zeolites and 
the corrected $\log \mathrm{K}$ values are presented in Table 4-4. To evaluate the impacts of these errors, an updated Pitzer database was created and used in a set of EQ3/6 simulations. The resulting sensitivity analysis is documented in Section 6.8.

Table 4-1. Input Sources for Pitzer Database

\begin{tabular}{|c|c|c|}
\hline Type of Input & Source & Qualifications \\
\hline \multirow{18}{*}{$\begin{array}{l}\text { Pitzer ion } \\
\text { interaction } \\
\text { coefficients } \\
\text { and/or osmotic } \\
\text { coefficient data; } \\
\text { Debye-Hückel } \\
\mathrm{A}_{\varphi} \text { parameter }\end{array}$} & Archer 2000 [DIRS 162065] & $\begin{array}{l}\text { Reliable source; Prior uses of the data } \\
\text { (Section I-2) }\end{array}$ \\
\hline & Clegg and Brimblecombe 1990 [DIRS 162067] & $\begin{array}{l}\text { Reliable source; Prior uses of the data } \\
\text { (Section I-4.4.7) }\end{array}$ \\
\hline & Clegg and Brimblecombe 1990 [DIRS 162089] & $\begin{array}{l}\text { Reliable source; Availability of corroborating } \\
\text { data (Section I-4.5.16) }\end{array}$ \\
\hline & Clegg et al. 1996 [DIRS 162068] & $\begin{array}{l}\text { Reliable source; Prior uses of the data } \\
\text { (Section I-4.4.21) }\end{array}$ \\
\hline & Felmy et al. 1994 [DIRS 162111] & $\begin{array}{l}\text { Reliable source; Availability of corroborating } \\
\text { data (Sections } 1-4.4 .7, \mathrm{I}-4.5 .16)\end{array}$ \\
\hline & Felmy et al. 1994 [DIRS 162112] & $\begin{array}{l}\text { Reliable source; Availability of corroborating } \\
\text { data (Section I-4.4.26) }\end{array}$ \\
\hline & Greenberg and Møller 1989 [DIRS 152684] & $\begin{array}{l}\text { Reliable source; Prior uses of the data } \\
\text { (Section 4.1.1) }\end{array}$ \\
\hline & He and Morse 1993 [DIRS 162090] & $\begin{array}{l}\text { Reliable source; Prior uses of the data } \\
\text { (Section I-2) }\end{array}$ \\
\hline & Holmes and Mesmer 1983 [DIRS 162073] & $\begin{array}{l}\text { Reliable source; Prior uses of the data } \\
\text { (Section I-4.4.3) }\end{array}$ \\
\hline & Holmes and Mesmer 1994 [DIRS 162078] & $\begin{array}{l}\text { Reliable source; Prior uses of the data } \\
\text { (Section I-2) }\end{array}$ \\
\hline & Holmes and Mesmer 1998 [DIRS 162083] & $\begin{array}{l}\text { Reliable source; Availability of corroborating } \\
\text { data (Sections I-4.4.8, I-4.4.11, I-4.4.12, I- } \\
4.4 .16 \text { ) }\end{array}$ \\
\hline & Holmes et al. 1987 [DIRS 162075] & $\begin{array}{l}\text { Reliable source; Prior uses of the data } \\
\text { (Section I-4.4.4); Availability of corroborating } \\
\text { data (Section I-4.4.4) }\end{array}$ \\
\hline & Oakes et al. 2000 [DIRS 162102] & $\begin{array}{l}\text { Reliable source; Prior uses of the data } \\
\text { (Section I-2) }\end{array}$ \\
\hline & Pabalan and Pitzer 1987 [DIRS 162096] & $\begin{array}{l}\text { Reliable source; Prior uses of the data } \\
\text { (Section I-2) }\end{array}$ \\
\hline & Pabalan and Pitzer 1987 [DIRS 162147] & $\begin{array}{l}\text { Reliable source; Prior uses of the data } \\
\text { (Section I-2) }\end{array}$ \\
\hline & Pitzer 1991 [DIRS 152709] & $\begin{array}{l}\text { Reliable source; Prior uses of the data } \\
\text { (Section 4.1.1) }\end{array}$ \\
\hline & Sterner et al. 1998 [DIRS 162116] & $\begin{array}{l}\text { Reliable source; Availability of corroborating } \\
\text { data (Section I-4.4.1) }\end{array}$ \\
\hline & Thiessen and Simonson 1990 [DIRS 162108] & $\begin{array}{l}\text { Reliable source; Availability of corroborating } \\
\text { data (Section I-4.4.22) }\end{array}$ \\
\hline
\end{tabular}


Table 4-1. Input Sources for Pitzer Database (Continued)

\begin{tabular}{|c|c|c|}
\hline Type of Input & Source & Qualifications \\
\hline \multirow{11}{*}{$\begin{array}{l}\text { Single-phase } \\
\text { mineral } \\
\text { thermodynamic } \\
\text { data, mineral } \\
\text { solubility data, } \\
\text { and solubility } \\
\text { product constants }\end{array}$} & Barin and Platzki 1995 [DIRS 157865] & $\begin{array}{l}\text { Reliable source; Prior uses of the data } \\
\text { (Section 4.1.1) }\end{array}$ \\
\hline & Greenberg and Møller 1989 [DIRS 152684] & $\begin{array}{l}\text { Reliable source; Prior uses of the data } \\
\text { (Section 4.1.1) }\end{array}$ \\
\hline & Harvie et al. 1984 [DIRS 118163] & $\begin{array}{l}\text { Reliable source; Prior uses of the data } \\
\text { (Section 4.1.1) }\end{array}$ \\
\hline & Linke 1965 [DIRS 166191], p. 915 & $\begin{array}{l}\text { Reliable source; Prior uses of the data } \\
\text { (Section 4.1.1) }\end{array}$ \\
\hline & Meisingset and Grønvold 1986 [DIRS 162094] & $\begin{array}{l}\text { Reliable source; Availability of corroborating } \\
\text { data (Section I-5.1) }\end{array}$ \\
\hline & Pabalan and Pitzer 1987 [DIRS 162096] & $\begin{array}{l}\text { Reliable source; Prior uses of the data } \\
\text { (Section I-2) }\end{array}$ \\
\hline & Pitzer and Oakes 1994 [DIRS 163583] & $\begin{array}{l}\text { Reliable source; Availability of corroborating } \\
\text { data (Section I-5.1) }\end{array}$ \\
\hline & Pitzer and Shi 1993 [DIRS 163582] & $\begin{array}{l}\text { Reliable source; Availability of corroborating } \\
\text { data (Section I-5.1) }\end{array}$ \\
\hline & $\begin{array}{l}\text { Robie and Hemingway } 1995 \text { [DIRS 153683], } \\
\text { pp. } 23,27,53 \text {, and } 55\end{array}$ & $\begin{array}{l}\text { Reliable source; Prior uses of the data } \\
\text { (Section 4.1.1) }\end{array}$ \\
\hline & $\begin{array}{l}\text { DTN: MO0302SPATHDYN.000 [DIRS } \\
\text { 161756] }\end{array}$ & Product output, as defined in AP-3.15Q \\
\hline & $\begin{array}{l}\text { DTN: MO0302SPATHDYN.001 [DIRS } \\
\text { 161886] }\end{array}$ & Product output, as defined in AP- $3.15 \mathrm{Q}$ \\
\hline \multirow{5}{*}{$\begin{array}{l}\text { Equations and } \\
\text { theoretical } \\
\text { relations }\end{array}$} & Garrels and Christ 1990 [DIRS 144877] & Reliable source; Prior use (Section I-3.2.1) \\
\hline & Møller 1988 [DIRS 152695] & Reliable source; Prior use (Section I-2) \\
\hline & Pitzer 1991 [DIRS 152709] & $\begin{array}{l}\text { Reliable source; Prior uses of the data } \\
\text { (Section 4.1.1) }\end{array}$ \\
\hline & Pitzer 1973 [DIRS 152738] & $\begin{array}{l}\text { Reliable source; Prior uses of the data } \\
\text { (Section 4.1.1) }\end{array}$ \\
\hline & Rard and Wijesinghe 2003 [DIRS 162327] & Reliable source; Prior use (Section I-2) \\
\hline
\end{tabular}

NOTE: Additional input sources used to estimate model uncertainties are noted in Table 4-6 (Section 4.4). 
Table 4-2. Binary Pitzer Ion Interaction Coefficients

\begin{tabular}{|c|c|c|c|c|c|c|}
\hline lons & $\begin{array}{l}\text { Coefficient } \\
\text { Name }\end{array}$ & $\begin{array}{l}\text { Coefficient } \\
\text { Type }\end{array}$ & $\begin{array}{l}\text { Coefficient } \\
\text { Units }\end{array}$ & $\begin{array}{l}\text { Coefficient } \\
\text { Source }\end{array}$ & $\begin{array}{c}\text { Coefficient } \\
\text { Source's } \\
\text { DIRS \# }\end{array}$ & $\begin{array}{c}\text { Coefficient } \\
\text { Use in this } \\
\text { Report }\end{array}$ \\
\hline $\mathrm{Na}^{+}-\mathrm{Cl}^{-}$ & $\beta^{(0)}, \beta^{(1)}$, and $C^{(\phi)}$ & Binary & $\begin{array}{l}\mathrm{kg} / \mathrm{mol}, \mathrm{kg} / \mathrm{mol} \text {, and } \\
(\mathrm{kg} / \mathrm{mol})^{2} \text { respectively }\end{array}$ & Greenberg and Møller 1989 & 152684 & Appendix I \\
\hline $\mathrm{Na}^{+}-\mathrm{SO}_{4}^{2-}$ & $\beta^{(0)}, \beta^{(1)}$, and $C^{(\phi)}$ & Binary & $\begin{array}{l}\mathrm{kg} / \mathrm{mol}, \mathrm{kg} / \mathrm{mol} \text {, and } \\
(\mathrm{kg} / \mathrm{mol})^{2} \text { respectively }\end{array}$ & Greenberg and Møller 1989 & 152684 & Appendix I \\
\hline $\mathrm{Na}^{+}-\mathrm{HSO}_{4}^{-}$ & $\beta^{(0)}, \beta^{(1)}$, and $C^{(\phi)}$ & Binary & $\begin{array}{l}\mathrm{kg} / \mathrm{mol}, \mathrm{kg} / \mathrm{mol} \text {, and } \\
(\mathrm{kg} / \mathrm{mol})^{2} \text { respectively }\end{array}$ & Holmes and Mesmer 1994 & 162078 & Appendix I \\
\hline $\mathrm{Na}^{+}-\mathrm{OH}^{-}$ & $\beta^{(0)}, \beta^{(1)}$, and $C^{(\phi)}$ & Binary & $\begin{array}{l}\mathrm{kg} / \mathrm{mol}, \mathrm{kg} / \mathrm{mol} \text {, and } \\
(\mathrm{kg} / \mathrm{mol})^{2} \text { respectively }\end{array}$ & Pabalan and Pitzer 1987 & 162147 & Appendix I \\
\hline $\mathrm{Na}^{+}-\mathrm{NO}_{3}^{-}$ & $\beta^{(0)}, \beta^{(1)}$, and $C^{(\phi)}$ & Binary & $\begin{array}{l}\mathrm{kg} / \mathrm{mol}, \mathrm{kg} / \mathrm{mol} \text {, and } \\
(\mathrm{kg} / \mathrm{mol})^{2} \text { respectively }\end{array}$ & Archer 2000 & 162065 & Appendix I \\
\hline $\mathrm{Na}^{+}-\mathrm{CO}_{3}^{-}$ & $\beta^{(0)}, \beta^{(1)}$, and $C^{(\phi)}$ & Binary & $\begin{array}{l}\mathrm{kg} / \mathrm{mol}, \mathrm{kg} / \mathrm{mol} \text {, and } \\
(\mathrm{kg} / \mathrm{mol})^{2} \text { respectively }\end{array}$ & He and Morse 1993 & 162090 & Appendix I \\
\hline $\mathrm{Na}^{+}-\mathrm{HCO}_{3}^{-}$ & $\beta^{(0)}, \beta^{(1)}$, and $C^{(\phi)}$ & Binary & $\begin{array}{l}\mathrm{kg} / \mathrm{mol}, \mathrm{kg} / \mathrm{mol} \text {, and } \\
(\mathrm{kg} / \mathrm{mol})^{2} \text { respectively }\end{array}$ & He and Morse 1993 & 162090 & Appendix I \\
\hline $\mathrm{Na}^{+}-\mathrm{Br}^{-}$ & $\beta^{(0)}, \beta^{(1)}$, and $C^{(\phi)}$ & Binary & $\begin{array}{l}\mathrm{kg} / \mathrm{mol}, \mathrm{kg} / \mathrm{mol} \text {, and } \\
(\mathrm{kg} / \mathrm{mol})^{2} \text { respectively }\end{array}$ & Holmes and Mesmer 1998 & 162083 & Appendix I \\
\hline $\mathrm{Na}^{+}-\mathrm{AlO}_{2}^{-}$ & $\beta^{(0)}, \beta^{(1)}$, and $C^{(\phi)}$ & Binary & $\begin{array}{l}\mathrm{kg} / \mathrm{mol}, \mathrm{kg} / \mathrm{mol} \text {, and } \\
(\mathrm{kg} / \mathrm{mol})^{2} \text { respectively }\end{array}$ & Felmy et al. 1994 & 162112 & Appendix I \\
\hline $\mathrm{H}^{+}-\mathrm{Cl}^{-}$ & $\beta^{(0)}, \beta^{(1)}$, and $C^{(\phi)}$ & Binary & $\begin{array}{l}\mathrm{kg} / \mathrm{mol}, \mathrm{kg} / \mathrm{mol} \text {, and } \\
(\mathrm{kg} / \mathrm{mol})^{2} \text { respectively }\end{array}$ & Holmes et al. 1987 & 162075 & Appendix I \\
\hline $\mathrm{H}^{+}-\mathrm{NO}_{3}^{-}$ & $\beta^{(0)}, \beta^{(1)}$, and $C^{(\phi)}$ & Binary & $\begin{array}{l}\mathrm{kg} / \mathrm{mol}, \mathrm{kg} / \mathrm{mol} \text {, and } \\
(\mathrm{kg} / \mathrm{mol})^{2} \text { respectively }\end{array}$ & $\begin{array}{l}\text { Felmy et al. 1994; Clegg and } \\
\text { Brimblecombe } 1990\end{array}$ & $\begin{array}{l}162111 \\
162067 \\
\end{array}$ & Appendix I \\
\hline $\mathrm{H}^{+}-\mathrm{SO}_{4}{ }^{2-}$ & $\beta^{(0)}, \beta^{(1)}$, and $C^{(\phi)}$ & Binary & $\begin{array}{l}\mathrm{kg} / \mathrm{mol}, \mathrm{kg} / \mathrm{mol} \text {, and } \\
(\mathrm{kg} / \mathrm{mol})^{2} \text { respectively }\end{array}$ & Holmes and Mesmer 1992 & 162076 & Appendix I \\
\hline $\mathrm{H}^{+}-\mathrm{HSO}_{4}^{-}$ & $\beta^{(0)}, \beta^{(1)}$, and $C^{(\phi)}$ & Binary & $\begin{array}{l}\mathrm{kg} / \mathrm{mol}, \mathrm{kg} / \mathrm{mol} \text {, and } \\
(\mathrm{kg} / \mathrm{mol})^{2} \text { respectively }\end{array}$ & Holmes and Mesmer 1992 & 162076 & Appendix I \\
\hline $\mathrm{K}^{+}-\mathrm{Cl}^{-}$ & $\beta^{(0)}, \beta^{(1)}$, and $C^{(\phi)}$ & Binary & $\begin{array}{l}\mathrm{kg} / \mathrm{mol}, \mathrm{kg} / \mathrm{mol} \text {, and } \\
(\mathrm{kg} / \mathrm{mol})^{2} \text { respectively }\end{array}$ & Greenberg and Møller 1989 & 152684 & Appendix I \\
\hline $\mathrm{K}^{+}-\mathrm{SO}_{4}{ }^{2-}$ & $\beta^{(0)}, \beta^{(1)}$, and $C^{(\phi)}$ & Binary & $\begin{array}{l}\mathrm{kg} / \mathrm{mol}, \mathrm{kg} / \mathrm{mol} \text {, and } \\
(\mathrm{kg} / \mathrm{mol})^{2} \text { respectively }\end{array}$ & Greenberg and Møller 1989 & 152684 & Appendix I \\
\hline
\end{tabular}


Table 4-3. Ternary Pitzer Ion Interaction Coefficients

\begin{tabular}{|c|c|c|c|c|c|c|}
\hline Ions & $\begin{array}{l}\text { Coefficient } \\
\text { Name }\end{array}$ & $\begin{array}{l}\text { Coefficient } \\
\text { Type }\end{array}$ & $\begin{array}{l}\text { Coefficient } \\
\text { Units }\end{array}$ & $\begin{array}{l}\text { Coefficient } \\
\text { Source }\end{array}$ & $\begin{array}{c}\text { Coefficient } \\
\text { Source's } \\
\text { DIRS \# }\end{array}$ & $\begin{array}{c}\text { Coefficien } \\
\text { Use in this } \\
\text { Report }\end{array}$ \\
\hline $\mathrm{K}^{+}-\mathrm{Br}^{-}$ & $\beta^{(0)}, \beta^{(1)}$, and $C^{(\phi)}$ & Binary & $\begin{array}{l}\mathrm{kg} / \mathrm{mol}, \mathrm{kg} / \mathrm{mol} \text {, and }(\mathrm{kg} / \mathrm{mol})^{2} \\
\text { respectively }\end{array}$ & Holmes and Mesmer 1998 & 162083 & Appendix I \\
\hline $\mathrm{Ca}^{++}-\mathrm{Cl}^{-}$ & $\beta^{(0)}, \beta^{(1)}$, and $C^{(\phi)}$ & Binary & $\begin{array}{l}\mathrm{kg} / \mathrm{mol}, \mathrm{kg} / \mathrm{mol} \text {, and }(\mathrm{kg} / \mathrm{mol})^{2} \\
\text { respectively }\end{array}$ & Sterner et al. 1998 & 162116 & Appendix I \\
\hline $\mathrm{Ca}^{++}-\mathrm{SO}_{4}{ }^{2-}$ & $\beta^{(0)}, \beta^{(1)}$, and $C^{(\phi)}$ & Binary & $\begin{array}{l}\mathrm{kg} / \mathrm{mol}, \mathrm{kg} / \mathrm{mol} \text {, and }(\mathrm{kg} / \mathrm{mol})^{2} \\
\text { respectively }\end{array}$ & Greenberg and Møller 1989 & 152684 & Appendix I \\
\hline $\mathrm{Ca}^{++}-\mathrm{NO}_{3}^{-}$ & $\beta^{(0)}, \beta^{(1)}$, and $C^{(\phi)}$ & Binary & $\begin{array}{l}\mathrm{kg} / \mathrm{mol}, \mathrm{kg} / \mathrm{mol} \text {, and }(\mathrm{kg} / \mathrm{mol})^{2} \\
\text { respectively }\end{array}$ & Oakes et al. 2000 & 162102 & Appendix I \\
\hline $\mathrm{Li}^{+}-\mathrm{Cl}^{-}$ & $\beta^{(0)}, \beta^{(1)}$, and $C^{(\phi)}$ & Binary & $\begin{array}{l}\mathrm{kg} / \mathrm{mol}, \mathrm{kg} / \mathrm{mol} \text {, and }(\mathrm{kg} / \mathrm{mol})^{2} \\
\text { respectively }\end{array}$ & Holmes and Mesmer 1983 & 162073 & Appendix I \\
\hline $\mathrm{Li}^{+}-\mathrm{Br}^{-}$ & $\beta^{(0)}, \beta^{(1)}$, and $C^{(\phi)}$ & Binary & $\begin{array}{l}\mathrm{kg} / \mathrm{mol}, \mathrm{kg} / \mathrm{mol} \text {, and }(\mathrm{kg} / \mathrm{mol})^{2} \\
\text { respectively }\end{array}$ & Holmes and Mesmer 1998 & 162083 & Appendix I \\
\hline $\mathrm{Mg}^{++}-\mathrm{SO}_{4}{ }^{2-}$ & $\beta^{(0)}, \beta^{(1)}$, and $C^{(\phi)}$ & Binary & $\begin{array}{l}\mathrm{kg} / \mathrm{mol}, \mathrm{kg} / \mathrm{mol} \text {, and }(\mathrm{kg} / \mathrm{mol})^{2} \\
\text { respectively }\end{array}$ & Pabalan and Pitzer 1987 & 162096 & Appendix I \\
\hline $\mathrm{Mg}^{++}-\mathrm{Cl}^{-}$ & $\beta^{(0)}, \beta^{(1)}$, and $C^{(\phi)}$ & Binary & $\begin{array}{l}\mathrm{kg} / \mathrm{mol}, \mathrm{kg} / \mathrm{mol} \text {, and }(\mathrm{kg} / \mathrm{mol})^{2} \\
\text { respectively }\end{array}$ & Pabalan and Pitzer 1987 & 162096 & Appendix I \\
\hline $\mathrm{Cs}^{+}-\mathrm{Br}^{-}$ & $\beta^{(0)}, \beta^{(1)}$, and $C^{(\phi)}$ & Binary & $\begin{array}{l}\mathrm{kg} / \mathrm{mol}, \mathrm{kg} / \mathrm{mol} \text {, and }(\mathrm{kg} / \mathrm{mol})^{2} \\
\text { respectively }\end{array}$ & Holmes and Mesmer 1998 & 162083 & Appendix I \\
\hline $\mathrm{Cs}^{+}-\mathrm{Cl}^{-}$ & $\beta^{(0)}, \beta^{(1)}$, and $C^{(\phi)}$ & Binary & $\begin{array}{l}\mathrm{kg} / \mathrm{mol}, \mathrm{kg} / \mathrm{mol} \text {, and }(\mathrm{kg} / \mathrm{mol})^{2} \\
\text { respectively }\end{array}$ & Holmes and Mesmer 1983 & 162073 & Appendix I \\
\hline $\mathrm{NH}_{4}{ }^{+}-\mathrm{SO}_{4}{ }^{2-}$ & $\beta^{(0)}, \beta^{(1)}$, and $C^{(\phi)}$ & Binary & $\begin{array}{l}\mathrm{kg} / \mathrm{mol}, \mathrm{kg} / \mathrm{mol} \text {, and }(\mathrm{kg} / \mathrm{mol})^{2} \\
\text { respectively }\end{array}$ & Clegg et al. 1996 & 162068 & Appendix I \\
\hline $\mathrm{NH}_{4}^{+}-\mathrm{Cl}^{-}$ & $\beta^{(0)}, \beta^{(1)}$, and $C^{(\phi)}$ & Binary & $\begin{array}{l}\mathrm{kg} / \mathrm{mol}, \mathrm{kg} / \mathrm{mol} \text {, and }(\mathrm{kg} / \mathrm{mol})^{2} \\
\text { respectively }\end{array}$ & $\begin{array}{l}\text { Thiessen and Simonson } \\
1990\end{array}$ & 162108 & Appendix I \\
\hline
\end{tabular}


Table 4-3. Ternary Pitzer Ion Interaction Coefficients (Continued)

\begin{tabular}{|c|c|c|c|c|c|c|}
\hline lons & $\begin{array}{l}\text { Coefficient } \\
\text { Name }\end{array}$ & $\begin{array}{c}\text { Coefficient } \\
\text { Type }\end{array}$ & $\begin{array}{l}\text { Coefficient } \\
\text { Units }\end{array}$ & Coefficient Source & $\begin{array}{c}\text { Coefficient } \\
\text { Source's } \\
\text { DIRS \# }\end{array}$ & $\begin{array}{c}\text { Coefficient } \\
\text { Use in this Report }\end{array}$ \\
\hline $\mathrm{Na}^{+}-\mathrm{K}^{+}$ & $\theta$ & Ternary & $\mathrm{kg} / \mathrm{mol}$ & Greenberg and Møller 1989 & 152684 & Appendix I \\
\hline $\mathrm{Na}^{+}-\mathrm{Ca}^{++}$ & $\theta$ & Ternary & $\mathrm{kg} / \mathrm{mol}$ & Greenberg and Møller 1989 & 152684 & Appendix I \\
\hline $\mathrm{K}^{+}-\mathrm{Ca}^{++}$ & $\theta$ & Ternary & $\mathrm{kg} / \mathrm{mol}$ & Greenberg and Møller 1989 & 152684 & Appendix I \\
\hline $\mathrm{Na}^{+}-\mathrm{Mg}^{++}$ & $\theta$ & Ternary & $\mathrm{kg} / \mathrm{mol}$ & Pabalan and Pitzer 1987 & 162096 & Appendix I \\
\hline $\mathrm{K}^{+}-\mathrm{Mg}^{++}$ & $\theta$ & Ternary & $\mathrm{kg} / \mathrm{mol}$ & Pabalan and Pitzer 1987 & 162096 & Appendix I \\
\hline $\mathrm{NO}_{3}^{-}-\mathrm{AlO}_{2}^{-}$ & $\theta$ & Ternary & $\mathrm{kg} / \mathrm{mol}$ & Felmy et al. 1994 & 162112 & Appendix I \\
\hline $\mathrm{OH}^{-}-\mathrm{AlO}_{2}^{-}$ & $\theta$ & Ternary & $\mathrm{kg} / \mathrm{mol}$ & Felmy et al. 1994 & 162112 & Appendix I \\
\hline $\mathrm{Cl}^{-}-\mathrm{OH}^{-}$ & $\theta$ & Ternary & $\mathrm{kg} / \mathrm{mol}$ & Pabalan and Pitzer 1987 & 162096 & Appendix I \\
\hline $\mathrm{Cl}^{-}-\mathrm{SO}_{4}{ }^{2-}$ & $\theta$ & Ternary & $\mathrm{kg} / \mathrm{mol}$ & Greenberg and Møller 1989 & 152684 & Appendix I \\
\hline $\mathrm{HSO}_{4}{ }^{-}-\mathrm{SO}_{4}{ }^{2-}$ & $\theta$ & Ternary & $\mathrm{kg} / \mathrm{mol}$ & Holmes and Mesmer 1992 & 162076 & Appendix I \\
\hline $\mathrm{SO}_{4}{ }^{2-}-\mathrm{OH}^{-}$ & $\theta$ & Ternary & $\mathrm{kg} / \mathrm{mol}$ & Pabalan and Pitzer 1987 & 162096 & Appendix I \\
\hline $\mathrm{Ca}^{++}-\mathrm{Mg}^{++}$ & $\theta$ & Ternary & $\mathrm{kg} / \mathrm{mol}$ & Pitzer 1991 & 152709 & Appendix I \\
\hline $\mathrm{Cs}^{+}-\mathrm{H}^{+}$ & $\theta$ & Ternary & $\mathrm{kg} / \mathrm{mol}$ & Pitzer 1991 & 152709 & Appendix I \\
\hline $\mathrm{Cs}^{+}-\mathrm{K}^{+}$ & $\theta$ & Ternary & $\mathrm{kg} / \mathrm{mol}$ & Pitzer 1991 & 152709 & Appendix I \\
\hline $\mathrm{Cs}^{+}-\mathrm{Li}^{+}$ & $\theta$ & Ternary & $\mathrm{kg} / \mathrm{mol}$ & Pitzer 1991 & 152709 & Appendix I \\
\hline $\mathrm{Cs}^{+}-\mathrm{Na}^{+}$ & $\theta$ & Ternary & $\mathrm{kg} / \mathrm{mol}$ & Pitzer 1991 & 152709 & Appendix I \\
\hline $\mathrm{H}^{+}-\mathrm{K}^{+}$ & $\theta$ & Ternary & $\mathrm{kg} / \mathrm{mol}$ & Pitzer 1991 & 152709 & Appendix I \\
\hline $\mathrm{H}^{+}-\mathrm{Li}^{+}$ & $\theta$ & Ternary & $\mathrm{kg} / \mathrm{mol}$ & Pitzer 1991 & 152709 & Appendix I \\
\hline $\mathrm{H}^{+}-\mathrm{Mg}^{++}$ & $\theta$ & Ternary & $\mathrm{kg} / \mathrm{mol}$ & Pitzer 1991 & 152709 & Appendix I \\
\hline $\mathrm{H}^{+}-\mathrm{Na}^{+}$ & $\theta$ & Ternary & $\mathrm{kg} / \mathrm{mol}$ & Pitzer 1991 & 152709 & Appendix I \\
\hline $\mathrm{H}^{+}-\mathrm{NH}_{4}^{+}$ & $\theta$ & Ternary & $\mathrm{kg} / \mathrm{mol}$ & Pitzer 1991 & 152709 & Appendix I \\
\hline $\mathrm{H}^{+}-\mathrm{Sr}^{++}$ & $\theta$ & Ternary & $\mathrm{kg} / \mathrm{mol}$ & Pitzer 1991 & 152709 & Appendix I \\
\hline $\mathrm{K}^{+}-\mathrm{Li}^{+}$ & $\theta$ & Ternary & $\mathrm{kg} / \mathrm{mol}$ & Pitzer 1991 & 152709 & Appendix I \\
\hline $\mathrm{K}^{+}-\mathrm{Mg}^{++}$ & $\theta$ & Ternary & $\mathrm{kg} / \mathrm{mol}$ & Pitzer 1991 & 152709 & Appendix I \\
\hline $\mathrm{K}^{+}-\mathrm{Li}^{+}$ & $\theta$ & Ternary & $\mathrm{kg} / \mathrm{mol}$ & Pitzer 1991 & 152709 & Appendix I \\
\hline
\end{tabular}


Table 4-3. Ternary Pitzer Ion Interaction Coefficients (Continued)

\begin{tabular}{|c|c|c|c|c|c|c|}
\hline Ions & $\begin{array}{c}\text { Coefficient } \\
\text { Name }\end{array}$ & $\begin{array}{c}\text { Coefficient } \\
\text { Type }\end{array}$ & $\begin{array}{c}\text { Coefficient } \\
\text { Units }\end{array}$ & Coefficient Source & $\begin{array}{c}\text { Coefficient } \\
\text { Source's } \\
\text { DIRS \# }\end{array}$ & $\begin{array}{c}\text { Coefficient } \\
\text { Use in this Report } \\
\end{array}$ \\
\hline $\mathrm{Li}^{+}-\mathrm{Na}^{+}$ & $\theta$ & Ternary & $\mathrm{kg} / \mathrm{mol}$ & Pitzer 1991 & 152709 & Appendix I \\
\hline $\mathrm{SiO}_{2}-\mathrm{NO}_{3}^{-}$ & $\lambda$ & Ternary & $\mathrm{kg} / \mathrm{mol}$ & Felmy et al. 1994 & 162111 & Appendix I \\
\hline $\mathrm{SiO}_{2}-\mathrm{Na}^{+}$ & $\lambda$ & Ternary & $\mathrm{kg} / \mathrm{mol}$ & Felmy et al. 1994 & 162111 & Appendix I \\
\hline $\mathrm{SiO}_{2}-\mathrm{Cl}^{-}$ & $\lambda$ & Ternary & $\mathrm{kg} / \mathrm{mol}$ & Felmy et al. 1994 & 162111 & Appendix I \\
\hline $\mathrm{SiO}_{2}-\mathrm{SO}_{4}{ }^{2-}$ & $\lambda$ & Ternary & $\mathrm{kg} / \mathrm{mol}$ & Felmy et al. 1994 & 162111 & Appendix I \\
\hline $\mathrm{SiO}_{2}-\mathrm{Mg}^{++}$ & $\lambda$ & Ternary & $\mathrm{kg} / \mathrm{mol}$ & Felmy et al. 1994 & 162111 & Appendix I \\
\hline $\mathrm{O}_{2}(\mathrm{aq})-\mathrm{Na}^{+}$ & $\lambda$ & Ternary & $\mathrm{kg} / \mathrm{mol}$ & Clegg and Brimblecombe 1990 & 162089 & Appendix I \\
\hline $\mathrm{O}_{2}(\mathrm{aq})-\mathrm{K}^{+}$ & $\lambda$ & Ternary & $\mathrm{kg} / \mathrm{mol}$ & Clegg and Brimblecombe 1990 & 162089 & Appendix I \\
\hline $\mathrm{O}_{2}(\mathrm{aq})-\mathrm{Mg}^{++}$ & $\lambda$ & Ternary & $\mathrm{kg} / \mathrm{mol}$ & Clegg and Brimblecombe 1990 & 162089 & Appendix I \\
\hline $\mathrm{O}_{2}(\mathrm{aq})-\mathrm{Ca}^{++}$ & $\lambda$ & Ternary & $\mathrm{kg} / \mathrm{mol}$ & Clegg and Brimblecombe 1990 & 162089 & Appendix I \\
\hline $\mathrm{O}_{2}(\mathrm{aq})-\mathrm{Al}^{+++}$ & $\lambda$ & Ternary & $\mathrm{kg} / \mathrm{mol}$ & Clegg and Brimblecombe 1990 & 162089 & Appendix I \\
\hline $\mathrm{O}_{2}(\mathrm{aq})-\mathrm{Cl}^{-}$ & $\lambda$ & Ternary & $\mathrm{kg} / \mathrm{mol}$ & Clegg and Brimblecombe 1990 & 162089 & Appendix I \\
\hline $\mathrm{O}_{2}(\mathrm{aq})-\mathrm{Br}^{-}$ & $\lambda$ & Ternary & $\mathrm{kg} / \mathrm{mol}$ & Clegg and Brimblecombe 1990 & 162089 & Appendix I \\
\hline $\mathrm{O}_{2}(\mathrm{aq})-\mathrm{OH}^{-}$ & $\lambda$ & Ternary & $\mathrm{kg} / \mathrm{mol}$ & Clegg and Brimblecombe 1990 & 162089 & Appendix I \\
\hline $\mathrm{O}_{2}(\mathrm{aq})-\mathrm{SO}_{4}{ }^{2-}$ & $\lambda$ & Ternary & $\mathrm{kg} / \mathrm{mol}$ & Clegg and Brimblecombe 1990 & 162089 & Appendix I \\
\hline $\mathrm{O}_{2}(\mathrm{aq})-\mathrm{H}^{+}$ & $\lambda$ & Ternary & $\mathrm{kg} / \mathrm{mol}$ & Clegg and Brimblecombe 1990 & 162089 & Appendix I \\
\hline $\mathrm{O}_{2}(\mathrm{aq})-\mathrm{Li}^{+}$ & $\lambda$ & Ternary & $\mathrm{kg} / \mathrm{mol}$ & Clegg and Brimblecombe 1990 & 162089 & Appendix I \\
\hline $\mathrm{O}_{2}(\mathrm{aq})-\mathrm{NH}_{4}{ }^{+}$ & $\lambda$ & Ternary & $\mathrm{kg} / \mathrm{mol}$ & Clegg and Brimblecombe 1990 & 162089 & Appendix I \\
\hline $\mathrm{O}_{2}(\mathrm{aq})-\mathrm{Ba}^{++}$ & $\lambda$ & Ternary & $\mathrm{kg} / \mathrm{mol}$ & Clegg and Brimblecombe 1990 & 162089 & Appendix I \\
\hline $\mathrm{O}_{2}(\mathrm{aq})-\mathrm{I}^{-}$ & $\lambda$ & Ternary & $\mathrm{kg} / \mathrm{mol}$ & Clegg and Brimblecombe 1990 & 162089 & Appendix I \\
\hline $\mathrm{O}_{2}(\mathrm{aq})-\mathrm{HCO}_{3}^{-}$ & $\lambda$ & Ternary & $\mathrm{kg} / \mathrm{mol}$ & Clegg and Brimblecombe 1990 & 162089 & Appendix I \\
\hline $\mathrm{O}_{2}(\mathrm{aq})-\mathrm{CO}_{3}^{2-}$ & $\lambda$ & Ternary & $\mathrm{kg} / \mathrm{mol}$ & Clegg and Brimblecombe 1990 & 162089 & Appendix I \\
\hline $\mathrm{CO}_{2}(\mathrm{aq})-\mathrm{Ca}^{++}$ & $\lambda$ & Ternary & $\mathrm{kg} / \mathrm{mol}$ & He and Morse 1993 & 162090 & Appendix I \\
\hline $\mathrm{CO}_{2}(\mathrm{aq})-\mathrm{K}+$ & $\lambda$ & Ternary & $\mathrm{kg} / \mathrm{mol}$ & He and Morse 1993 & 162090 & Appendix I \\
\hline $\mathrm{CO}_{2}(\mathrm{aq})-\mathrm{Mg}^{++}$ & $\lambda$ & Ternary & $\mathrm{kg} / \mathrm{mol}$ & He and Morse 1993 & 162090 & Appendix I \\
\hline
\end{tabular}


Table 4-3. Ternary Pitzer Ion Interaction Coefficients (Continued)

\begin{tabular}{|c|c|c|c|c|c|c|}
\hline lons & $\begin{array}{c}\text { Coefficient } \\
\text { Name }\end{array}$ & $\begin{array}{c}\text { Coefficient } \\
\text { Type }\end{array}$ & $\begin{array}{c}\text { Coefficient } \\
\text { Units }\end{array}$ & Coefficient Source & $\begin{array}{c}\text { Coefficient } \\
\text { Source's } \\
\text { DIRS \# }\end{array}$ & $\begin{array}{c}\text { Coefficient } \\
\text { Use in this Report }\end{array}$ \\
\hline $\mathrm{CO}_{2}(\mathrm{aq})-\mathrm{Na}^{+}$ & $\lambda$ & Ternary & $\mathrm{kg} / \mathrm{mol}$ & He and Morse 1993 & 162090 & Appendix I \\
\hline $\mathrm{CO}_{2}(\mathrm{aq})-\mathrm{H}^{+}$ & $\lambda$ & Ternary & $\mathrm{kg} / \mathrm{mol}$ & He and Morse 1993 & 162090 & Appendix I \\
\hline $\mathrm{CO}_{2}(\mathrm{aq})-\mathrm{Cl}^{-}$ & $\lambda$ & Ternary & $\mathrm{kg} / \mathrm{mol}$ & He and Morse 1993 & 162090 & Appendix I \\
\hline $\mathrm{CO}_{2}(\mathrm{aq})-\mathrm{HSO}_{4}^{-}$ & $\lambda$ & Ternary & $\mathrm{kg} / \mathrm{mol}$ & He and Morse 1993 & 162090 & Appendix I \\
\hline $\mathrm{CO}_{2}(\mathrm{aq})-\mathrm{SO}_{4}{ }^{2-}$ & $\lambda$ & Ternary & $\mathrm{kg} / \mathrm{mol}$ & He and Morse 1993 & 162090 & Appendix I \\
\hline $\mathrm{CO}_{2}(\mathrm{aq})-\mathrm{H}^{+}-\mathrm{Cl}^{-}$ & $\zeta$ & Ternary & $\mathrm{kg} / \mathrm{mol}$ & He and Morse 1993 & 162090 & Appendix I \\
\hline $\mathrm{CO}_{2}(\mathrm{aq})-\mathrm{Na}^{+}-\mathrm{Cl}^{-}$ & $\zeta$ & Ternary & $\mathrm{kg} / \mathrm{mol}$ & He and Morse 1993 & 162090 & Appendix I \\
\hline $\mathrm{CO}_{2}(\mathrm{aq})-\mathrm{K}^{+}-\mathrm{Cl}^{-}$ & $\zeta$ & Ternary & $\mathrm{kg} / \mathrm{mol}$ & He and Morse 1993 & 162090 & Appendix I \\
\hline $\mathrm{CO}_{2}(\mathrm{aq})-\mathrm{Ca}^{++}-\mathrm{Cl}^{-}$ & $\zeta$ & Ternary & $\mathrm{kg} / \mathrm{mol}$ & He and Morse 1993 & 162090 & Appendix I \\
\hline $\mathrm{CO}_{2}(\mathrm{aq})-\mathrm{Mg}^{++}-\mathrm{Cl}^{-}$ & $\zeta$ & Ternary & $\mathrm{kg} / \mathrm{mol}$ & He and Morse 1993 & 162090 & Appendix I \\
\hline $\mathrm{CO}_{2}(\mathrm{aq})-\mathrm{H}^{+}-\mathrm{SO}_{4}{ }^{2-}$ & $\zeta$ & Ternary & $\mathrm{kg} / \mathrm{mol}$ & He and Morse 1993 & 162090 & Appendix I \\
\hline $\mathrm{CO}_{2}(\mathrm{aq})-\mathrm{Na}^{+}-\mathrm{SO}_{4}{ }^{2-}$ & $\zeta$ & Ternary & $\mathrm{kg} / \mathrm{mol}$ & He and Morse 1993 & 162090 & Appendix I \\
\hline $\mathrm{CO}_{2}(\mathrm{aq})-\mathrm{K}^{+}-\mathrm{SO}_{4}{ }^{2-}$ & $\zeta$ & Ternary & $\mathrm{kg} / \mathrm{mol}$ & He and Morse 1993 & 162090 & Appendix I \\
\hline $\mathrm{CO}_{2}(\mathrm{aq})-\mathrm{Mg}^{++}-\mathrm{SO}_{4}{ }^{2-}$ & $\zeta$ & Ternary & $\mathrm{kg} / \mathrm{mol}$ & He and Morse 1993 & 162090 & Appendix I \\
\hline $\mathrm{SiO}_{2}-\mathrm{H}^{+}-\mathrm{NO}_{3}^{-}$ & $\zeta$ & Ternary & $\mathrm{kg} / \mathrm{mol}$ & Felmy et al. 1994 & 162111 & Appendix I \\
\hline $\mathrm{SiO}_{2}-\mathrm{Na}^{+}-\mathrm{Cl}^{-}$ & $\zeta$ & Ternary & $\mathrm{kg} / \mathrm{mol}$ & Felmy et al. 1994 & 162111 & Appendix I \\
\hline $\mathrm{SiO}_{2}-\mathrm{Mg}^{++}-\mathrm{Cl}^{-}$ & $\zeta$ & Ternary & $\mathrm{kg} / \mathrm{mol}$ & Felmy et al. 1994 & 162111 & Appendix I \\
\hline $\mathrm{O}_{2}(\mathrm{aq})-\mathrm{Na}^{+}-\mathrm{Cl}^{-}$ & $\zeta$ & Ternary & $\mathrm{kg} / \mathrm{mol}$ & Clegg and Brimblecombe 1990 & 162089 & Appendix I \\
\hline $\mathrm{O}_{2}(\mathrm{aq})-\mathrm{Na}^{+}-\mathrm{Br}^{-}$ & $\zeta$ & Ternary & $\mathrm{kg} / \mathrm{mol}$ & Clegg and Brimblecombe 1990 & 162089 & Appendix I \\
\hline $\mathrm{O}_{2}(\mathrm{aq})-\mathrm{Na}^{+}-\mathrm{OH}^{-}$ & $\zeta$ & Ternary & $\mathrm{kg} / \mathrm{mol}$ & Clegg and Brimblecombe 1990 & 162089 & Appendix I \\
\hline $\mathrm{O}_{2}(\mathrm{aq})-\mathrm{Na}^{+}-\mathrm{NO}_{3}^{-}$ & $\zeta$ & Ternary & $\mathrm{kg} / \mathrm{mol}$ & Clegg and Brimblecombe 1990 & 162089 & Appendix I \\
\hline $\mathrm{O}_{2}(\mathrm{aq})-\mathrm{Na}^{+}-\mathrm{SO}_{4}{ }^{2-}$ & $\zeta$ & Ternary & $\mathrm{kg} / \mathrm{mol}$ & Clegg and Brimblecombe 1990 & 162089 & Appendix I \\
\hline $\mathrm{O}_{2}(\mathrm{aq})-\mathrm{K}^{+}-\mathrm{Cl}^{-}$ & $\zeta$ & Ternary & $\mathrm{kg} / \mathrm{mol}$ & Clegg and Brimblecombe 1990 & 162089 & Appendix I \\
\hline $\mathrm{O}_{2}(\mathrm{aq})-\mathrm{K}^{+}-\mathrm{Br}^{-}$ & $\zeta$ & Ternary & $\mathrm{kg} / \mathrm{mol}$ & Clegg and Brimblecombe 1990 & 162089 & Appendix I \\
\hline $\mathrm{O}_{2}(\mathrm{aq})-\mathrm{K}^{+}-\mathrm{OH}^{-}$ & $\zeta$ & Ternary & $\mathrm{kg} / \mathrm{mol}$ & Clegg and Brimblecombe 1990 & 162089 & Appendix I \\
\hline
\end{tabular}


Table 4-3. Ternary Pitzer Ion Interaction Coefficients (Continued)

\begin{tabular}{|c|c|c|c|c|c|c|}
\hline Ions & $\begin{array}{c}\text { Coefficient } \\
\text { Name }\end{array}$ & $\begin{array}{c}\text { Coefficient } \\
\text { Type }\end{array}$ & $\begin{array}{c}\text { Coefficient } \\
\text { Units }\end{array}$ & Coefficient Source & $\begin{array}{c}\text { Coefficient } \\
\text { Source's } \\
\text { DIRS \# }\end{array}$ & $\begin{array}{c}\text { Coefficient } \\
\text { Use in this Report } \\
\end{array}$ \\
\hline $\mathrm{O}_{2}(\mathrm{aq})-\mathrm{K}^{+}-\mathrm{NO}_{3}^{-}$ & $\zeta$ & Ternary & $\mathrm{kg} / \mathrm{mol}$ & Clegg and Brimblecombe 1990 & 162089 & Appendix I \\
\hline $\mathrm{O}_{2}(\mathrm{aq})-\mathrm{K}^{+}-\mathrm{SO}_{4}{ }^{2-}$ & $\zeta$ & Ternary & $\mathrm{kg} / \mathrm{mol}$ & Clegg and Brimblecombe 1990 & 162089 & Appendix I \\
\hline $\mathrm{O}_{2}(\mathrm{aq})-\mathrm{H}^{+}-\mathrm{Cl}^{-}$ & $\zeta$ & Ternary & $\mathrm{kg} / \mathrm{mol}$ & Clegg and Brimblecombe 1990 & 162089 & Appendix I \\
\hline $\mathrm{O}_{2}(\mathrm{aq})-\mathrm{Li}^{+}-\mathrm{Cl}^{-}$ & $\zeta$ & Ternary & $\mathrm{kg} / \mathrm{mol}$ & Clegg and Brimblecombe 1990 & 162089 & Appendix I \\
\hline $\mathrm{O}_{2}(\mathrm{aq})-\mathrm{Ca}^{++}-\mathrm{Cl}^{-}$ & $\zeta$ & Ternary & $\mathrm{kg} / \mathrm{mol}$ & Clegg and Brimblecombe 1990 & 162089 & Appendix I \\
\hline $\mathrm{O}_{2}(\mathrm{aq})-\mathrm{Ca}^{++}-\mathrm{NO}_{3}^{-}$ & $\zeta$ & Ternary & $\mathrm{kg} / \mathrm{mol}$ & Clegg and Brimblecombe 1990 & 162089 & Appendix I \\
\hline $\mathrm{O}_{2}(\mathrm{aq})-\mathrm{Na}^{+}-\mathrm{HCO}_{3}^{-}$ & $\zeta$ & Ternary & $\mathrm{kg} / \mathrm{mol}$ & Clegg and Brimblecombe 1990 & 162089 & Appendix I \\
\hline $\mathrm{O}_{2}(\mathrm{aq})-\mathrm{Na}^{+}-\mathrm{CO}_{3}^{2-}$ & $\zeta$ & Ternary & $\mathrm{kg} / \mathrm{mol}$ & Clegg and Brimblecombe 1990 & 162089 & Appendix I \\
\hline $\mathrm{Na}^{+}-\mathrm{K}^{+}-\mathrm{Cl}^{-}$ & $\psi$ & Ternary & $\mathrm{kg} / \mathrm{mol}$ & Greenberg and Møller 1989 & 152684 & Appendix I \\
\hline $\mathrm{Na}^{+}-\mathrm{K}^{+}-\mathrm{SO}_{4}{ }^{2-}$ & $\psi$ & Ternary & $\mathrm{kg} / \mathrm{mol}$ & Greenberg and Møller 1989 & 152684 & Appendix I \\
\hline $\mathrm{Na}^{+}-\mathrm{Ca}^{++}-\mathrm{Cl}^{-}$ & $\psi$ & Ternary & $\mathrm{kg} / \mathrm{mol}$ & Greenberg and Møller 1989 & 152684 & Appendix I \\
\hline $\mathrm{Na}^{+}-\mathrm{Ca}^{++}-\mathrm{SO}_{4}{ }^{2-}$ & $\psi$ & Ternary & $\mathrm{kg} / \mathrm{mol}$ & Greenberg and Møller 1989 & 152684 & Appendix I \\
\hline $\mathrm{Na}^{+}-\mathrm{Mg}^{++}-\mathrm{Cl}^{-}$ & $\psi$ & Ternary & $\mathrm{kg} / \mathrm{mol}$ & Pabalan and Pitzer 1987 & 162096 & Appendix I \\
\hline $\mathrm{Na}^{+}-\mathrm{Cl}^{-}-\mathrm{OH}^{-}$ & $\psi$ & Ternary & $\mathrm{kg} / \mathrm{mol}$ & Pabalan and Pitzer 1987 & 162096 & Appendix I \\
\hline $\mathrm{Na}^{+}-\mathrm{Cl}^{-}-\mathrm{SO}_{4}{ }^{2}$ & $\psi$ & Ternary & $\mathrm{kg} / \mathrm{mol}$ & Greenberg and Møller 1989 & 152684 & Appendix I \\
\hline $\mathrm{Na}^{+}-\mathrm{NO}_{3}{ }^{-}-\mathrm{AlO}_{2}^{-}$ & $\psi$ & Ternary & $\mathrm{kg} / \mathrm{mol}$ & Felmy et al. 1994 & 162112 & Appendix I \\
\hline $\mathrm{Na}^{+}-\mathrm{OH}^{-}-\mathrm{SO}_{4}{ }^{2-}$ & $\psi$ & Ternary & $\mathrm{kg} / \mathrm{mol}$ & Pabalan and Pitzer 1987 & 162096 & Appendix I \\
\hline $\mathrm{Na}^{+}-\mathrm{OH}^{-}-\mathrm{AlO}_{2}^{-}$ & $\psi$ & Ternary & $\mathrm{kg} / \mathrm{mol}$ & Pabalan and Pitzer 1987 & 162096 & Appendix I \\
\hline $\mathrm{K}^{+}-\mathrm{Ca}^{++}-\mathrm{Cl}^{-}$ & $\psi$ & Ternary & $\mathrm{kg} / \mathrm{mol}$ & Greenberg and Møller (1989) & 152684 & Appendix I \\
\hline $\mathrm{K}^{+}-\mathrm{Mg}^{++}-\mathrm{Cl}^{-}$ & $\psi$ & Ternary & $\mathrm{kg} / \mathrm{mol}$ & Pabalan and Pitzer 1987 & 162096 & Appendix I \\
\hline $\mathrm{K}^{+}-\mathrm{Cl}^{-}-\mathrm{SO}_{4}{ }^{2-}$ & $\psi$ & Ternary & $\mathrm{kg} / \mathrm{mol}$ & Greenberg and Møller 1989 & 152684 & Appendix I \\
\hline $\mathrm{Ca}^{++}-\mathrm{Cl}^{-}-\mathrm{SO}_{4}{ }^{2-}$ & $\psi$ & Ternary & $\mathrm{kg} / \mathrm{mol}$ & Greenberg and Møller 1989 & 152684 & Appendix I \\
\hline $\mathrm{Mg}^{++}-\mathrm{Cl}^{-}-\mathrm{SO}_{4}{ }^{2-}$ & $\psi$ & Ternary & $\mathrm{kg} / \mathrm{mol}$ & Pabalan and Pitzer 1987 & 162096 & Appendix I \\
\hline
\end{tabular}


Table 4-4. Corrections to Log K Values for Seven Zeolites

\begin{tabular}{|l|c|c|c|c|c|c|c|c|}
\hline \multicolumn{1}{|c|}{ Zeolite } & $\begin{array}{c}\log \mathbf{K} \text { at } \\
\mathbf{0}^{\circ} \mathbf{C}\end{array}$ & $\begin{array}{c}\log \mathbf{K} \text { at } \\
\mathbf{2 5} 5^{\circ} \mathbf{C}\end{array}$ & $\begin{array}{c}\log \mathbf{K} \text { at } \\
\mathbf{6 0 ^ { \circ } \mathbf { C }}\end{array}$ & $\begin{array}{c}\log \mathbf{K} \text { at } \\
\mathbf{1 0 0} \mathbf{C}\end{array}$ & $\begin{array}{c}\log \mathbf{K} \text { at } \\
\mathbf{1 5 0 ^ { \circ } \mathbf { C }}\end{array}$ & $\begin{array}{c}\log \mathbf{K} \text { at } \\
\mathbf{2 0 0} \mathbf{C}\end{array}$ & $\begin{array}{c}\log \mathbf{K} \text { at } \\
\mathbf{2 5 0 ^ { \circ } \mathbf { C }}\end{array}$ & $\begin{array}{c}\log \mathbf{K} \text { at } \\
\mathbf{3 0 0 ^ { \circ } \mathbf { C }}\end{array}$ \\
\hline Analcime & 7.3411 & 6.0057 & 4.3207 & 2.7687 & 1.2666 & 0.0739 & -0.9734 & -2.0317 \\
\hline Erionite & -2.4264 & -4.8296 & -8.5254 & -11.9726 & -15.1353 & -17.5303 & -19.7298 & -22.3994 \\
\hline Phillipsite & -4.7708 & -6.7617 & -9.8737 & -12.7688 & -15.3984 & -17.3689 & -19.1824 & -21.4273 \\
\hline Stellerite & -6.1718 & -8.7844 & -12.7407 & -16.4486 & -19.8970 & -22.5474 & -24.9839 & -27.8839 \\
\hline Chabazite & 14.9395 & 10.3714 & 4.5581 & -0.7982 & -5.9745 & -10.0955 & -13.7420 & -17.4773 \\
\hline Laumontite & 19.4704 & 14.2657 & 7.6939 & 1.6028 & -4.3587 & -9.1673 & -13.4421 & -17.7733 \\
\hline Clinoptilolite-Na & -4.6593 & -5.7696 & -8.5612 & -11.9362 & -16.0971 & -20.4363 & -25.3442 & -31.3726 \\
\hline
\end{tabular}

Source: BSC 2004 [DIRS 171916] Section 6.3.2.

\subsubsection{Parameters}

The variable input parameters important to the IDPS model are summarized in Table 4-5. The modeled incoming seepage includes the following components: $\mathrm{Na}, \mathrm{K}, \mathrm{Ca}, \mathrm{Mg}, \mathrm{Cl}, \mathrm{F}, \mathrm{CO}_{3}, \mathrm{SO}_{4}$, $\mathrm{NO}_{3}, \mathrm{SiO}_{2}, \mathrm{Al}, \mathrm{H}, \mathrm{H}_{2} \mathrm{O}$, and potentially $\mathrm{Br}$. The input for hydrogen $(\mathrm{H})$ is the $\mathrm{pH}$ of the incoming water. $\mathrm{pH}$ is the negative logarithm of the activity of the hydrogen ion. Input values for the aqueous component concentrations are acquired directly from water sample analyses or are qualified technical product output from geochemical model simulations. Values for $T, R H$, $f_{\mathrm{CO} 2}$, and $f_{\mathrm{O} 2}$ are selected by the user of the IDPS model to cover the expected ranges of these parameters for the systems being modeled (Section 6.6.2.4). The approximate atmospheric value for $f_{O 2}\left(10^{-0.7}\right.$ bars $)$ limits the model to oxidizing conditions and inhibits the components from reducing to lower oxidation states. The actual value of $f_{\mathrm{O} 2}$ has little effect on the model results when it is above $10^{-9.0}$ bars, as can be demonstrated by running the model at a $f_{O 2}$ value of $10^{-9.0}$ bars. Though $f_{O 2}$ in the drift could decrease markedly during the thermal period, oxidizing conditions will prevail for nearly the entire regulatory period (BSC 2004 [DIRS 169860] Section 6.7). Consequently, the IDPS model is used in TSPA only for oxidizing conditions, achieved by setting $f_{O 2}$ at approximately atmospheric for all runs.

Use of the IDPS model is demonstrated in an example in Section 6.7. This example demonstrates how the IDPS model is used to produce technical product output. The input data for this example are introduced in Section 4.4. They are not introduced here because the example inputs are not used to develop the IDPS model and the results from this example are not directly used in performance assessment. Model calculations used in support of TSPA-LA are documented elsewhere, such as in Engineered Barrier System: Physical and Chemical Environment Model (BSC 2004 [DIRS 169860]). 
Table 4-5. In-Drift Precipitates/Salts Model Input Parameters

\begin{tabular}{|c|c|c|c|c|}
\hline $\begin{array}{l}\text { Parameter } \\
\text { Name }\end{array}$ & $\begin{array}{l}\text { Parameter } \\
\text { Description }\end{array}$ & Parameter Units & Parameter Source Range & $\begin{array}{c}\text { Parameter Use in } \\
\text { this Report }\end{array}$ \\
\hline$C_{i}^{s}$ & $\begin{array}{l}\text { Concentration or } \\
\text { activity of each } \\
\text { modeled } \\
\text { component } i \text { in the } \\
\text { incoming seepage } \\
\end{array}$ & $\begin{array}{l}\text { mass/volume, } \\
\text { moles/mass, or } \\
\text { moles/volume (or } \\
\mathrm{pH} \text { for the hydrogen } \\
\text { ion activity) }\end{array}$ & 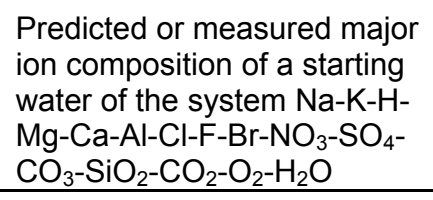 & $\begin{array}{l}\text { Section } 4.4, \\
\text { Section } 6.6 .2 .1 \\
\text { Section } 6.7 \\
\text { Sections } 7.1 \text { to } 7.3\end{array}$ \\
\hline$T$ & Temperature & degrees Celsius & 0 to 140 & $\begin{array}{l}\text { Section } 4.4, \\
\text { Section } 6.6 .2 .4, \\
\text { Section } 6.7 \text {, } \\
\text { Sections } 7.1 \text { to } 7.3 \\
\end{array}$ \\
\hline$R H$ & Relative humidity & $\begin{array}{l}\text { non-dimensional or } \\
\text { percentage }\end{array}$ & $0 \%$ to $100 \%$ & $\begin{array}{l}\text { Section } 4.4, \\
\text { Section } 6.6 .2 .4 \\
\text { Section } 6.7 \text {, } \\
\text { Sections } 7.1 \text { to } 7.3 \\
\end{array}$ \\
\hline$f_{\mathrm{CO} 2}$ & $\begin{array}{l}\text { Fugacity of } \\
\text { carbon dioxide }\end{array}$ & bars & 0 to 1 & $\begin{array}{l}\text { Section } 4.4, \\
\text { Section } 6.6 .2 .4 \\
\text { Section } 6.7 \\
\text { Sections } 7.1 \text { to } 7.3 \\
\end{array}$ \\
\hline$f_{\mathrm{O} 2}$ & $\begin{array}{l}\text { Fugacity of } \\
\text { oxygen }\end{array}$ & bars & $\begin{array}{l}10^{-0.7} \text { (This value is chosen to } \\
\text { represent a range of oxidizing } \\
\text { conditions from } 10^{-9.0} \text { to } \\
10^{-0.0} \text {, as explained in } \\
\text { Section } 4.1 .2 \text {.) }\end{array}$ & $\begin{array}{l}\text { Section } 4.4, \\
\text { Section } 6.6 .2 .4 \\
\text { Section } 6.7 \text {, } \\
\text { Sections } 7.1 \text { to } 7.3\end{array}$ \\
\hline $\begin{array}{l}R^{e s} \\
\left(\text { or } Q^{e} / Q^{s}\right)\end{array}$ & $\begin{array}{l}\text { Relative } \\
\text { evaporation rate }\end{array}$ & non-dimensional & -99 to 1 & $\begin{array}{l}\text { Section } 6.6 .2 .5 \text {, } \\
\text { Section } 6.7 \text {, } \\
\text { Sections } 7.1 \text { to } 7.3\end{array}$ \\
\hline$S_{m}$ & $\begin{array}{l}\text { Suppression flag } \\
\text { for mineral } m\end{array}$ & Boolean & True or False & $\begin{array}{l}\text { Section } 6.6 .2 .6 \\
\text { Section } 6.7 \\
\text { Sections } 7.1 \text { to } 7.3\end{array}$ \\
\hline
\end{tabular}

\subsection{CRITERIA}

Project Requirements Document (Canori and Leitner 2003 [DIRS 166275]) contains one criterion that is relevant to the work documented in this report: PRD-002/T-015 Requirements for Performance Assessment. See $10 \mathrm{CFR} 63.114$ for complete requirement text. Work described in this report supports PRD-002/T-015, but more specific criteria exist in Yucca Mountain Review Plan, Final Report (NRC 2003 [DIRS 163274]). Selected Yucca Mountain Review Plan acceptance criteria are presented in order to supplement or clarify the Project Requirements Document citation.

Yucca Mountain Review Plan, Final Report (NRC 2003 [DIRS 163274]) acceptance criteria applicable to this report are identified in Section 3.2 of the TWP (BSC 2004 [DIRS 171156]). The criteria are those established for the quantity and chemistry of water contacting engineered barriers and waste forms as presented in Section 2.2.1.3.3.3 of NRC (2003 [DIRS 163274]) and 10 CFR 63.114(a)-(c) and (e)-(g). These criteria are presented in the following subsections, and an assessment of how these criteria are addressed is provided in Sections 8.5.1-8.5.5. 


\subsubsection{Acceptance Criterion 1 - System Description and Model Integration Are Adequate}

(1) Total system performance assessment adequately incorporates important design features, physical phenomena, and couplings, and uses consistent and appropriate assumptions throughout the quantity and chemistry of water contacting engineered barriers and waste forms abstraction process.

(2) The abstraction of the quantity and chemistry of water contacting engineered barriers and waste forms uses assumptions, technical bases, data, and models, that are appropriate and consistent with other related U.S. Department of Energy abstractions. For example, the assumptions used for the quantity and chemistry of water contacting engineered barriers and waste forms are consistent with the abstractions of "Degradation of Engineered Barriers" (Section 2.2.1.3.1); "Mechanical Disruption of Waste Packages" (Section 2.2.1.3.2); "Radionuclide Release Rates and Solubility Limits" (Section 2.2.1.3.4); "Climate and Infiltration" (Section 2.2.1.3.5); and "Flow Paths in the Unsaturated Zone" (Section 2.2.1.3.6). The descriptions and technical bases provide transparent and traceable support for the abstraction of quantity and chemistry of water contacting engineered barriers and waste forms.

(3) Important design features, such as waste package design and material selection, drip shield, ground support, thermal loading strategy, and degradation processes, are adequate to determine the initial and boundary conditions for calculations of the quantity and chemistry of water contacting engineered barriers and waste forms.

(4) Spatial and temporal abstractions appropriately address physical couplings (thermal-hydrologic-mechanical-chemical). For example, the U.S. Department of Energy evaluates the potential for focusing of water flow into drifts, caused by coupled thermal-hydrologic-mechanical-chemical processes.

(5) Sufficient technical bases and justification are provided for total system performance assessment assumptions and approximations for modeling coupled thermal-hydrologic-mechanical-chemical effects on seepage and flow, the waste package chemical environment, and the chemical environment for radionuclide release. The effects of distribution of flow on the amount of water contacting the engineered barriers and waste forms are consistently addressed, in all relevant abstractions.

(6) The expected ranges of environmental conditions within the waste package emplacement drifts, inside of breached waste packages, and contacting the waste forms and their evolution with time are identified. These ranges may be developed to include: (i) the effects of the drip shield on the quantity and chemistry of water (e.g., the potential for condensate formation and dripping from the underside of the shield); (ii) conditions that promote corrosion of engineered barriers and degradation of waste forms; (iii) irregular wet and dry cycles; (iv) 
gamma-radiolysis; and (v) size and distribution of penetrations of engineered barriers.

(7) The model abstraction for quantity and chemistry of water contacting engineered barriers and waste forms is consistent with the detailed information on waste package design and other engineered features. For example, consistency is demonstrated for: (i) dimensionality of the abstractions; (ii) various design features and site characteristics; and (iii) alternative conceptual approaches. Analyses are adequate to demonstrate that no deleterious effects are caused by design or site features that the U.S. Department of Energy does not take into account in this abstraction.

(8) Adequate technical bases are provided, including activities such as independent modeling, laboratory or field data, or sensitivity studies, for inclusion of any thermal-hydrologic-mechanical-chemical couplings and features, events, and processes.

(9) Performance-affecting processes that have been observed in thermal-hydrologic tests and experiments are included into the performance assessment. For example, the U.S. Department of Energy either demonstrates that liquid water will not reflux into the underground facility or incorporates refluxing water into the performance assessment calculation, and bounds the potential adverse effects of alteration of the hydraulic pathway that result from refluxing water.

(10) Likely modes for container corrosion (Section 2.2.1.3.1 of the Yucca Mountain Review Plan) are identified and considered in determining the quantity and chemistry of water entering the engineered barriers and contacting waste forms. For example, the model abstractions consistently address the role of parameters, such as $\mathrm{pH}$, carbonate concentration, and the effect of corrosion on the quantity and chemistry of water contacting engineered barriers and waste forms.

(11) Not applicable, as this report does not address criticality.

(12) Guidance in NUREG-1297 (Altman et al. 1988 [DIRS 103597]) and NUREG1298 (Altman et al. 1988 [DIRS 103750]), or other acceptable approaches, is followed.

\subsubsection{Acceptance Criterion 2 - Data Are Sufficient for Model Justification}

(1) Geological, hydrological, and geochemical values used in the license application are adequately justified. Adequate description of how the data were used, interpreted, and appropriately synthesized into the parameters is provided.

(2) Sufficient data were collected on the characteristics of the natural system and engineered materials to establish initial and boundary conditions for conceptual models of thermal-hydrologic-mechanical-chemical coupled processes, that affect seepage and flow and the waste package chemical environment. 
(3) Not applicable, as the model developed in this report is a thermal-chemical model.

(4) Sufficient information to formulate the conceptual approach(es) for analyzing water contact with the drip shield, engineered barriers, and waste forms is provided.

(5) Not applicable, as this report does not address microbial activity.

\subsubsection{Acceptance Criterion 3 - Data Uncertainty Is Characterized and Propagated Through the Model Abstraction}

(1) Models use parameter values, assumed ranges, probability distributions, and bounding assumptions that are technically defensible, reasonably account for uncertainties and variabilities, and do not result in an under-representation of the risk estimate.

(2) Parameter values, assumed ranges, probability distributions, and bounding assumptions used in the total system performance assessment calculations of quantity and chemistry of water contacting engineered barriers and waste forms are technically defensible and reasonable, based on data from the Yucca Mountain region (e.g., results from large block and drift-scale heater and niche tests), and a combination of techniques that may include laboratory experiments, field measurements, natural analog research, and process-level modeling studies.

(3) Input values used in the total system performance assessment calculations of quantity and chemistry of water contacting engineered barriers (e.g., drip shield and waste package) are consistent with the initial and boundary conditions and the assumptions of the conceptual models and design concepts for the Yucca Mountain site. Correlations between input values are appropriately established in the U.S. Department of Energy total system performance assessment. Parameters used to define initial conditions, boundary conditions, and computational domain in sensitivity analyses involving coupled thermal-hydrologic-mechanicalchemical effects on seepage and flow, the waste package chemical environment, and the chemical environment for radionuclide release, are consistent with available data. Reasonable or conservative ranges of parameters or functional relations are established.

(4) Adequate representation of uncertainties in the characteristics of the natural system and engineered materials is provided in parameter development for conceptual models, process-level models, and alternative conceptual models. The U.S. Department of Energy may constrain these uncertainties using sensitivity analyses or conservative limits. For example, the U.S. Department of Energy demonstrates how parameters used to describe flow through the engineered barrier system bound the effects of excavation-induced changes.

(5) Not applicable, as this report does not address criticality. 
(6) Not applicable, as there are not instances where sufficient data do not exist. Expert elicitation is not used in the development of this report.

\subsubsection{Acceptance Criterion 4 - Model Uncertainty Is Characterized and Propagated Through the Model Abstraction}

(1) Alternative modeling approaches of features, events, and processes are considered and are consistent with available data and current scientific understanding, and the results and limitations are appropriately considered in the abstraction.

(2) Alternative modeling approaches are considered and the selected modeling approach is consistent with available data and current scientific understanding. A description that includes a discussion of alternative modeling approaches not considered in the final analysis and the limitations and uncertainties of the chosen model is provided.

(3) Consideration of conceptual model uncertainty is consistent with available site characterization data, laboratory experiments, field measurements, natural analog information and process-level modeling studies; and the treatment of conceptual model uncertainty does not result in an under-representation of the risk estimate.

(4) Adequate consideration is given to effects of thermal-hydrologic-mechanicalchemical coupled processes in the assessment of alternative conceptual models. These effects may include: (i) thermal-hydrologic effects on gas, water, and mineral chemistry; (ii) effects of microbial processes on the waste package chemical environment and the chemical environment for radionuclide release; (iii) changes in water chemistry that may result from the release of corrosion products from the waste package and interactions between engineered materials and ground water; and (iv) changes in boundary conditions (e.g., drift shape and size) and hydrologic properties, relating to the response of the geomechanical system to thermal loading.

(5) Not applicable, as an equivalent continuum model is not used.

\subsubsection{Acceptance Criterion 5 - Model Abstraction Output Is Supported by Objective Comparisons}

(1) Not applicable, as a total system performance assessment abstraction is not performed in this report.

(2) Not applicable, as a total system performance assessment abstraction is not performed in this report.

(3) Accepted and well-documented procedures are used to construct and test the numerical models that simulate coupled thermal-hydrologic-mechanical-chemical effects on seepage and flow, waste package chemical environment, and the chemical environment for radionuclide release. Analytical and numerical models 
are appropriately supported. Abstracted model results are compared with different mathematical models, to judge robustness of results.

\subsection{CODES, STANDARDS, AND REGULATIONS}

10 CFR 63 [DIRS 156605]. Energy: Disposal of High-Level Radioactive Wastes in a Geologic Repository at Yucca Mountain, Nevada.

\subsection{VALIDATION AND DEMONSTRATION DATA}

Data used to validate the IDPS model, demonstrate its use, and estimate model uncertainties are presented in this section. These data are independent of IDPS model development and therefore are not presented in Sections 4.1.1 or 4.1.2.

Table 4-6 lists the sources of these independent data, the specific tables where the data are presented (or identified in further detail), and how and where the data are used in this report. Data used to validate a model are considered "indirect inputs." Data used to estimate model uncertainty are "direct inputs" because estimated model uncertainties (Table 7-8) are used in support of TSPA-LA. These data are not "directly used to develop the model," so in accordance with AP-SIII.10Q, Models, they are not introduced in Section 4.1. Data used solely for validation or demonstration are not direct inputs because outputs having these data as sources are not used directly or indirectly in TSPA-LA calculations. Some data listed in Table 4-6 (from McCaffrey et al. 1987 [DIRS 164481], for seawater evaporation; and from Linke 1965 [DIRS 166191], pp. 127 to 128, 482 to 483, and 976 to 978; and Linke 1958 [DIRS 166192], p. 573, for mutual solubilities of salt minerals), are treated as both indirect inputs (for validation use) and as direct inputs (for the purpose of estimating uncertainties to use in TSPA-LA).

Qualification of the data in the Linke sources is justified per AP-SIII.10Q Section 5.2.1(k) for use within the report based on reliability of the data source, extent to which the data demonstrate the properties of interest, and prior uses of the data. As explained in Section 4.1.1, the Linke volumes are essentially de facto handbooks in the field of aqueous geochemistry. These volumes are identified in Section 4.1.1 in support of a specific data set from Linke (1965 [DIRS 166191], p. 915) used only for model development. Qualification of the McCaffrey et al. (1987 [DIRS 164481]) data is justified per AP-SIII.10Q Section 5.2.1(k) for use within the report based on the extent to which the data demonstrate the properties of interest. The reliability of this source is supported by the fact that the paper was published in a refereed scientific journal. This paper is highly relevant to the validation of the IDPS model and estimates of model uncertainty because it is the only source of $\mathrm{pH}$ and ionic strength measurements found in the literature for a naturally evaporating brine. Results from McCaffrey et al. (1987 [DIRS 164481]) and the Linke volumes used in estimating uncertainty are summarized in Tables 7-7 and 7-8. 
Table 4-6. Data Used for Model Validation, Model Demonstration, and Estimation of Model Uncertainties

\begin{tabular}{|c|c|c|c|}
\hline Data & Tables & Use in Report & $\begin{array}{l}\text { Sections Where Data } \\
\text { in Tables Are Used }\end{array}$ \\
\hline $\begin{array}{l}\text { Laboratory evaporation data for synthetic average J-13 well } \\
\text { water (Rosenberg et al. } 1999 \text { [DIRS 125338]; DTN: } \\
\text { LL991008104241.042 [DIRS 120489]) }\end{array}$ & $\begin{array}{l}\text { Table 4-7 } \\
\text { Table 4-8 }\end{array}$ & Validation & $7.1 .1,7.5$ \\
\hline $\begin{array}{l}\text { Laboratory evaporation data for synthetic } 100 x \mathrm{~J}-13 \text { well } \\
\text { water (BSC } 2001 \text { [DIRS 155640]; DTN: } \\
\text { LL000202905924.117 [DIRS 144913]) }\end{array}$ & Table 4-9 & Validation & $7.1 .2,7.5$ \\
\hline $\begin{array}{l}\text { Laboratory evaporation data for synthetic Topopah Spring } \\
\text { Tuff pore water (Rosenberg et al. } 1999 \text { [DIRS 125339]; } \\
\text { DTN: LL991008004241.041 [DIRS 120487]) }\end{array}$ & Table 4-10 & Validation & $7.1 .3,7.5$ \\
\hline $\begin{array}{l}\text { Seawater evaporation data (McCaffrey et al. } 1987 \text { [DIRS } \\
\text { 164481]) (This source is suitable for use in estimating IDPS } \\
\text { model uncertainty because it provides data that } \\
\text { demonstrate the properties of interest and it is a reliable } \\
\text { source of data.) }\end{array}$ & Table 4-11 & $\begin{array}{l}\text { Validation and } \\
\text { Uncertainty } \\
\text { Estimation }\end{array}$ & $7.1 .4,7.5$ \\
\hline $\begin{array}{l}\text { Chemistry handbook data for binary salt systems (Lide } \\
2000 \text { [DIRS 162229]; Dean 1992 [DIRS 100722]; Weast } \\
\text { and Astle 1981 [DIRS 100833]) }\end{array}$ & $\begin{array}{l}\text { Table } 4-12 \\
\text { Table } 4-13 \\
\text { Table } 4-17 \\
\end{array}$ & Validation & 7.2.1.1, 7.5 \\
\hline $\begin{array}{l}\text { Non-handbook data for binary salt systems (Linke } 1965 \\
\text { [DIRS 166191]; Linke } 1958 \text { [DIRS 166192]; Dutrizac } 2002 \\
\text { [DIRS 166148]; Moore et al. } 1997 \text { [DIRS 166150]; Kracek } \\
1928 \text { [DIRS 122125]; Greenspan } 1977 \text { [DIRS 104945]; } \\
\text { Dingemans and Dijkgraaf } 1948 \text { [DIRS 166149]); Grønvold } \\
\text { and Meisingset (1983); Robie and Hemingway (1995) }\end{array}$ & $\begin{array}{l}\text { Table } 4-14 \\
\text { Table 4-15 } \\
\text { Table 4-16 } \\
\text { Table 4-17 }\end{array}$ & Validation & $7.2 .1 .2,7.5$ \\
\hline $\begin{array}{l}\text { Salt solubilities in ternary systems (Linke } 1965 \text { [DIRS } \\
\text { 166191]; de Lima \& Pitzer } 1983 \text { [DIRS 162110]; Linke } 1958 \\
\text { [DIRS 166192]) }\end{array}$ & Table 4-18 & Validation & $7.2 .2,7.5$ \\
\hline $\begin{array}{l}\text { Salt solubilities in ternary systems involving both } \mathrm{Cl} \text { and } \\
\mathrm{NO}_{3} \text { (Linke 1965 [DIRS } 166191 \text { ] pp. } 127 \text { to } 128,482 \text { to } \\
483,976 \text { to } 978 \text { ); Linke } 1958 \text { [DIRS } 166192 \text { ] p. } 573 \text { ) (This } \\
\text { source is suitable for use in estimating IDPS model } \\
\text { uncertainty because it provides data that demonstrate the } \\
\text { properties of interest and it is a reliable source of data } \\
\text { (Section 4.1.1).) }\end{array}$ & Table 4-18 & $\begin{array}{l}\text { Validation and } \\
\text { Uncertainty } \\
\text { Estimation }\end{array}$ & $7.2 .2,7.5$ \\
\hline $\begin{array}{l}\text { Average in situ composition of water from well J-13 } \\
\text { (Harrar et al. } 1990 \text { [DIRS } 100814 \text { ]; } \\
\text { DTN: MO0006J13WTRCM.000 [DIRS 151029]) }\end{array}$ & Table 4-19 & Demonstration & 6.7 \\
\hline
\end{tabular}

Table 4-7. Water Chemistry Data from Experimental J-13 Well Water Evaporation of Rosenberg et al. (1999 [DIRS 125338])

\begin{tabular}{|l|l|l|l|l|l|}
\hline & & $\begin{array}{c}\text { Synthetic } \\
\text { J-13 Well } \\
\text { Water } \\
\text { for evap1 }\end{array}$ & $\begin{array}{c}\text { Evaporated } \\
\text { Synthetic J-13 Well } \\
\text { Water for evap1 } \\
\text { (Concentration } \\
\text { Factor: 956) }\end{array}$ & $\begin{array}{c}\text { Synthetic J-13 } \\
\text { Well Water } \\
\text { for evap4 }\end{array}$ & $\begin{array}{c}\text { Evaporated Synthetic } \\
\text { J-13 Well Water for } \\
\text { evap4 (Concentration } \\
\text { Factor: 157) }\end{array}$ \\
\hline $\mathrm{Ca}$ & $\mathrm{mg} / \mathrm{kg}$ & 6.4 & 29.86 & 5.3 & 1.2 \\
\hline $\mathrm{Mg}$ & $\mathrm{mg} / \mathrm{kg}$ & 2.2 & 0.14 & 2.1 & 0.05 \\
\hline $\mathrm{Na}$ & $\mathrm{mg} / \mathrm{kg}$ & 46 & 44082 & 45.4 & 5298 \\
\hline $\mathrm{K}$ & $\mathrm{mg} / \mathrm{kg}$ & 5.3 & 4792 & 4.9 & 560 \\
\hline $\mathrm{SiO}_{2}$ & $\mathrm{mg} / \mathrm{kg}$ & 11.3 & 18008 & 10 & 999 \\
\hline
\end{tabular}


Table 4-7. Water Chemistry Data from Experimental J-13 Well Water Evaporation of Rosenberg et al. (1999 [DIRS 125338]) (Continued)

\begin{tabular}{|l|l|l|l|l|l|}
\hline Constituent & Units & $\begin{array}{c}\text { Synthetic } \\
\text { J-13 Well } \\
\text { Water } \\
\text { for evap1 }\end{array}$ & $\begin{array}{c}\text { Evaporated } \\
\text { Synthetic J-13 Well } \\
\text { Water for evap1 } \\
\text { (Concentration } \\
\text { Factor: 956) }\end{array}$ & $\begin{array}{c}\text { Synthetic J-13 } \\
\text { Well Water } \\
\text { for evap4 }\end{array}$ & $\begin{array}{c}\text { Evaporated Synthetic } \\
\text { J-13 Well Water for } \\
\text { evap4 (Concentration } \\
\text { Factor: 157) }\end{array}$ \\
\hline $\mathrm{NO}_{3}$ & $\mathrm{mg} / \mathrm{kg}$ & 8.0 & 5532 & 8.0 & 1050 \\
\hline $\mathrm{HCO}_{3}$ & $\mathrm{mg} / \mathrm{kg}$ & 108 & 24878 & 103 & 4295 \\
\hline $\mathrm{Cl}$ & $\mathrm{mg} / \mathrm{kg}$ & 6.9 & 4835 & 7.5 & 849 \\
\hline $\mathrm{F}$ & $\mathrm{mg} / \mathrm{kg}$ & 2.2 & 1550 & 2.4 & 247 \\
\hline $\mathrm{SO}_{4}$ & $\mathrm{mg} / \mathrm{kg}$ & 18.1 & 12926 & 19 & 2162 \\
\hline $\mathrm{pH}$ & $\mathrm{pH}$ & 7.84 & $\mathrm{nr}$ & 8.33 & 10.18 \\
\hline
\end{tabular}

Source: DTN: LL991008104241.042 [DIRS 120489], Tables S00004_001 ["evap1"] and S00004_004 ["evap4"].

NOTE: "evap1" and "evap4" refer to the two evaporation cases for which data are shown in this table.

$\mathrm{nr}=$ not reported.

Table 4-8. pH Data from Experimental J-13 Well Water Evaporation of Rosenberg et al. (1999 [DIRS 125338])

\begin{tabular}{|l|l|}
\hline \multicolumn{1}{|c|}{ Concentration Factor } & \multicolumn{1}{c|}{ pH } \\
\hline 1 & 8.46 \\
\hline 1 & 8.65 \\
\hline 1.05 & 9.04 \\
\hline 1.29 & 9.43 \\
\hline 1.6 & 9.58 \\
\hline 2.41 & 9.67 \\
\hline 6.08 & 9.67 \\
\hline 6.37 & 9.77 \\
\hline 7.59 & 9.79 \\
\hline 11.6 & 9.95 \\
\hline 12.6 & 10 \\
\hline 15.3 & 10.03 \\
\hline 20.9 & 10.08 \\
\hline 25.2 & 10.09 \\
\hline 34.4 & 10.12 \\
\hline 52.1 & 10.18 \\
\hline 104 & 10.18 \\
\hline 157 & 10.18 \\
\hline
\end{tabular}

Source: DTN: LL991008104241.042 [DIRS 120489], Table S00004_003. 
Table 4-9. Water Chemistry Data from Experimental 100x J-13 Well Water (BSC 2001 [DIRS 155640])

\begin{tabular}{|l|l|l|l|}
\hline \multicolumn{1}{|c|}{ Constituent } & \multicolumn{1}{c|}{ Units } & \multicolumn{1}{c|}{$\begin{array}{c}\text { Synthetic 100x J-13 } \\
\text { Well Water }\end{array}$} & \multicolumn{1}{|c|}{$\begin{array}{c}\text { Evaporated Synthetic } \\
\text { 100x J-13 Well Water }\end{array}$} \\
\hline $\mathrm{Ca}$ & $\mathrm{mg} / \mathrm{L}$ & 5 & 36 \\
\hline $\mathrm{Mg}$ & $\mathrm{mg} / \mathrm{L}$ & 2 & 0 \\
\hline $\mathrm{Na}$ & $\mathrm{mg} / \mathrm{L}$ & 4032 & 76314 \\
\hline $\mathrm{K}$ & $\mathrm{mg} / \mathrm{L}$ & 513 & 10832 \\
\hline $\mathrm{NO}_{3}$ & $\mathrm{mg} / \mathrm{L}$ & 732 & 14085 \\
\hline $\mathrm{CO}_{3}\left(\mathrm{as} \mathrm{HCO}_{3}\right)$ & $\mathrm{mg} / \mathrm{L}$ & 4142 & 54614 \\
\hline $\mathrm{Cl}$ & $\mathrm{mg} / \mathrm{L}$ & 730 & 14419 \\
\hline $\mathrm{F}$ & $\mathrm{mg} / \mathrm{L}$ & 208 & 3630 \\
\hline $\mathrm{SO}_{4}$ & $\mathrm{mg} / \mathrm{L}$ & 1632 & 29783 \\
\hline $\mathrm{pH}$ & $\mathrm{pH}$ & $\mathrm{nr}$ & $\mathrm{nr}$ \\
\hline
\end{tabular}

Source: DTN: LL000202905924.117 [DIRS 144913], Table S00134_002.

NOTE: "100x" J-13 Well Water is an approximate synthetic equivalent of J-13 Well Water concentrated by a factor of 100 . It is subject to mineral precipitation relative to the unconcentrated water. Also, in general, even in the absence of such precipitation, it is difficult to prepare "concentrated" synthetic waters that exactly match the specified concentration factor for all dissolved components. Therefore, deviations are to be expected.

$\mathrm{nr}=$ not reported.

Table 4-10. Water Chemistry Data from Topopah Spring Tuff Pore Water Evaporation Experiment of Rosenberg et al. (1999 [DIRS 125339])

\begin{tabular}{|l|l|l|l|}
\hline Constituent & Units & $\begin{array}{c}\text { Synthetic Pore } \\
\text { Water }\end{array}$ & $\begin{array}{c}\text { Evaporated Synthetic Pore Water } \\
\text { (Concentration Factor: 1243x) }\end{array}$ \\
\hline $\mathrm{Ca}$ & $\mathrm{mg} / \mathrm{kg}$ & 57.2 & 15629 \\
\hline $\mathrm{Mg}$ & $\mathrm{mg} / \mathrm{kg}$ & 11.7 & 5478 \\
\hline $\mathrm{Na}$ & $\mathrm{mg} / \mathrm{kg}$ & 8.2 & 5961 \\
\hline $\mathrm{K}$ & $\mathrm{mg} / \mathrm{kg}$ & 4.2 & 2779 \\
\hline $\mathrm{SiO}_{2}$ & $\mathrm{mg} / \mathrm{kg}$ & 9.8 & 513 \\
\hline $\mathrm{NO}_{3}$ & $\mathrm{mg} / \mathrm{kg}$ & 11.0 & $\mathrm{~nm}^{\mathrm{a}}$ \\
\hline $\mathrm{HCO}_{3}$ & $\mathrm{mg} / \mathrm{kg}$ & 16.2 & $<35$ \\
\hline $\mathrm{Cl}$ & $\mathrm{mg} / \mathrm{kg}$ & 78.0 & 53084 \\
\hline $\mathrm{F}$ & $\mathrm{mg} / \mathrm{kg}$ & 2.3 & $<577$ \\
\hline $\mathrm{SO}$ & $\mathrm{mg} / \mathrm{kg}$ & 81.7 & 2077 \\
\hline $\mathrm{pH}$ & $\mathrm{pH}$ & 7.68 & $6-6.5^{\mathrm{b}}$ \\
\hline
\end{tabular}

Source: DTN: LL991008004241.041 [DIRS 120487], Table S00002_002.

${ }^{\text {a }}$ Not measured

${ }^{\mathrm{b}}$ Estimation from $\mathrm{pH}$ paper. 
Table 4-11. Sample Data for Evaporated Seawater

\begin{tabular}{|c|c|c|c|c|c|c|c|c|c|c|c|c|}
\hline \multirow[b]{2}{*}{ Brine } & \multirow{2}{*}{$\begin{array}{c}T \\
\left({ }^{\circ} \mathrm{C}\right) \\
\end{array}$} & \multirow{2}{*}{$\begin{array}{l}\text { Den. }{ }^{\mathrm{a}} \\
\left(\mathrm{mg}^{3} /\right. \\
\left.\mathrm{cm}^{3}\right)\end{array}$} & \multirow[b]{2}{*}{ pH } & \multirow[b]{2}{*}{ IS } & \multirow{2}{*}{$\begin{array}{c}\text { Deg. } \\
\text { of } \\
\text { Ev. }^{b}\end{array}$} & \multicolumn{7}{|c|}{ Total Concentration (molal) } \\
\hline & & & & & & $\mathrm{Cl}$ & $\mathrm{Br}$ & $\mathrm{SO}_{4}$ & $\mathbf{M g}$ & $\mathrm{Ca}$ & $\mathbf{K}$ & $\mathrm{Na}$ \\
\hline w63 & 28.4 & 1024 & 8.19 & 0.72 & 0.95 & 0.579 & 0.000883 & 0.0294 & 0.0520 & 0.00987 & 0.0107 & 0.497 \\
\hline w64 & - & 1024 & & 0.73 & 0.98 & 0.585 & 0.000917 & 0.0303 & 0.0541 & 0.00985 & 0.0111 & 0.497 \\
\hline w49 & 28.6 & 1028 & 8.12 & 0.75 & 1.10 & 0.594 & 0.000931 & 0.0305 & 0.0604 & 0.0108 & 0.0120 & 0.506 \\
\hline w53 & 29.9 & 1028 & 8.15 & 0.83 & 1.17 & 0.649 & 0.00099 & 0.0339 & 0.0642 & 0.0118 & 0.0132 & 0.582 \\
\hline w57 & 30.0 & 1040 & 8.33 & 1.21 & 1.75 & 0.947 & 0.00149 & 0.0518 & 0.0965 & 0.0192 & 0.0179 & 0.839 \\
\hline w54 & 32.6 & 1050 & 8.43 & 1.5 & 2.26 & 1.21 & 0.00177 & 0.0615 & 0.124 & 0.0210 & 0.0219 & 1.01 \\
\hline w55 & 29.6 & 1060 & 8.53 & 1.79 & 2.68 & 1.44 & 0.00224 & 0.0781 & 0.147 & 0.0247 & 0.0266 & 1.22 \\
\hline w52 & 30.4 & 1075 & 8.35 & 2.23 & 3.16 & 1.79 & 0.00285 & 0.0956 & 0.174 & 0.0316 & 0.0348 & 1.60 \\
\hline w56 & 31.4 & 1088 & 8.11 & 2.48 & 3.53 & 2.03 & 0.00305 & 0.110 & 0.194 & 0.0401 & 0.0392 & 1.71 \\
\hline w51 & 30.2 & 1103 & 8.14 & 2.98 & 4.36 & 2.49 & 0.00375 & 0.123 & 0.240 & 0.0325 & 0.0468 & 2.16 \\
\hline w50 & 29.8 & 1141 & 7.85 & 3.95 & 6.07 & 3.50 & 0.00536 & 0.138 & 0.334 & 0.0171 & 0.0623 & 2.93 \\
\hline w58 & 32.3 & 1151 & 7.70 & 4.41 & 6.91 & 3.87 & 0.00584 & 0.156 & 0.381 & 0.0185 & 0.0723 & 3.36 \\
\hline w48 & 28.8 & 1181 & 7.60 & 5.37 & 8.45 & 4.90 & 0.00733 & 0.184 & 0.466 & 0.0123 & 0.0905 & 4.17 \\
\hline w59 & 32.6 & 1181 & 7.56 & 5.39 & 8.62 & 4.90 & 0.00722 & 0.175 & 0.475 & 0.0121 & 0.0877 & 4.21 \\
\hline w61 & 32.1 & 1187 & 7.53 & 5.46 & 9.03 & 4.90 & 0.00757 & 0.190 & 0.498 & 0.0107 & 0.0914 & 4.22 \\
\hline w46 & 33.2 & 1215 & 7.42 & 6.25 & 10.5 & 5.67 & 0.00880 & 0.205 & 0.579 & 0.00610 & 0.112 & 5.00 \\
\hline w62 & 34.1 & 1215 & 7.43 & 6.34 & 11.0 & 5.88 & 0.00938 & 0.232 & 0.604 & 0.00581 & 0.109 & 4.83 \\
\hline w37 & 29.5 & 1220 & 7.41 & 6.49 & 12.6 & 5.91 & 0.0108 & 0.254 & 0.691 & 0.00433 & 0.115 & 4.70 \\
\hline w43 & 32.5 & 1220 & 7.45 & 6.68 & 13.2 & 5.75 & 0.0119 & 0.274 & 0.728 & 0.00352 & 0.152 & 5.02 \\
\hline w35 & 28.9 & 1224 & 7.44 & 6.88 & 15.1 & 6.04 & 0.0127 & 0.287 & 0.830 & & 0.157 & 4.74 \\
\hline w42 & 32.8 & 1224 & 7.34 & 6.94 & 16.4 & 5.82 & 0.0138 & 0.314 & 0.904 & & 0.180 & 4.67 \\
\hline w44 & 31.9 & 1225 & 7.40 & 6.96 & 17.6 & 5.72 & 0.0146 & 0.328 & 0.968 & & 0.190 & 4.48 \\
\hline w34 & 31.8 & 1231 & 7.25 & 7.27 & 20.1 & 5.98 & 0.0167 & 0.381 & 1.11 & & 0.208 & 4.14 \\
\hline w32 & 32.0 & 1231 & 7.28 & 7.34 & 20.4 & 6.01 & 0.0174 & 0.399 & 1.13 & & 0.212 & 4.13 \\
\hline w33 & 30.7 & 1236 & 7.22 & 7.75 & 23.4 & 6.08 & 0.0195 & 0.446 & 1.29 & & 0.249 & 4.11 \\
\hline w30 & 31.4 & 1239 & 7.28 & 7.61 & 23.6 & 5.98 & 0.0208 & 0.417 & 1.30 & & 0.242 & 3.96 \\
\hline w28 & 32.4 & 1239 & 7.13 & 7.87 & 25.4 & 6.08 & 0.0195 & 0.478 & 1.40 & & 0.253 & 3.81 \\
\hline w41 & 32.7 & 1242 & 7.22 & 7.84 & 26.8 & 5.85 & 0.0230 & 0.450 & 1.48 & & 0.278 & 3.72 \\
\hline w45 & 35.1 & 1249 & 7.06 & 8.42 & 31.4 & 5.92 & 0.0264 & 0.600 & 1.73 & & 0.33 & 3.32 \\
\hline w38 & 29.6 & 1254 & 7.12 & 8.65 & 32.8 & 5.96 & 0.02 & 0.678 & 1.81 & & 0.339 & 3.17 \\
\hline w36 & 29.9 & 1254 & 7.03 & 8.64 & 34.0 & 5.83 & 0.0282 & 0.632 & 1.87 & & 0.342 & 3.19 \\
\hline w40 & 32.1 & 1260 & 7.00 & 9.01 & 36.8 & 5.89 & 0.0299 & 0.694 & 2.03 & & 0.379 & 3.06 \\
\hline w39 & 32.6 & 1260 & 6.99 & 9.33 & 39.4 & 5.93 & 0.0331 & 0.776 & 2.17 & & 0.402 & 2.83 \\
\hline $36 \# 1$ & & & & 9.29 & 40.4 & 5.86 & 0.0343 & 0.753 & 2.23 & & 0.417 & 2.63 \\
\hline $40 \# 1$ & & & & 9.47 & 43.5 & 5.74 & & 0.796 & 2.39 & & 0.443 & 2.31 \\
\hline $36 \# 2$ & & & & 9.81 & 44.8 & 6.03 & 0.0384 & 0.849 & 2.47 & & 0.449 & 2.27 \\
\hline 40\#2 & & & & 10.1 & 48.9 & 5.80 & 0.0401 & 0.895 & 2.70 & & 0.495 & 1.96 \\
\hline $36 \# 3$ & & & & 11.3 & 58.1 & 6.10 & 0.0482 & 1.11 & 3.20 & & 0.591 & 1.37 \\
\hline 40\#3 & & & & 11.4 & 58.6 & 6.26 & 0.0481 & 1.09 & 3.23 & & 0.588 & 1.50 \\
\hline $40 \# 4$ & & & & 11.9 & 63.6 & 6.23 & 0.0518 & 1.19 & 3.50 & & 0.637 & 1.16 \\
\hline 39\#1 & & & & 12.7 & 66.2 & 6.62 & 0.0590 & 1.21 & 3.91 & & 0.632 & 0.842 \\
\hline $36 \# 4$ & & & & 13.0 & 69.2 & 6.47 & 0.0598 & 1.35 & 3.99 & & 0.754 & 0.712 \\
\hline $40 \# 5$ & & & & 12.3 & 72.9 & 7.13 & 0.0661 & 0.966 & 3.76 & & 0.782 & 0.825 \\
\hline 40\#6 & & & & 12.3 & 78.8 & 7.38 & 0.0716 & 0.763 & 3.98 & & 0.712 & 0.545 \\
\hline 39\#6 & & & & 12.2 & 87.9 & 7.50 & 0.0777 & 0.679 & 4.03 & & 0.565 & 0.413 \\
\hline 39\#2 & & & & 11.8 & 87.9 & 6.89 & 0.0748 & 0.703 & 3.96 & & 0.348 & 0.553 \\
\hline 39\#3 & & & & 12.4 & 93.3 & 7.50 & 0.0773 & 0.664 & 4.20 & & 0.311 & 0.500 \\
\hline 36\#5 & & & & 12.8 & 97.1 & 7.80 & 0.0828 & 0.713 & 4.27 & & 0.597 & 0.428 \\
\hline $39 \# 4$ & & & & 9.53 & 98.1 & 5.99 & 0.0774 & 0.366 & 3.35 & & 0.125 & 0.169 \\
\hline
\end{tabular}

Source: McCaffrey et al. 1987 [DIRS 164481] Tables 1 through 3.

${ }^{a}$ Density of sample.

${ }^{b}$ Degree of evaporation (equivalent to concentration factor, relative to seawater). 
Table 4-12. Aqueous Solubilities of $\mathrm{Na}, \mathrm{K}, \mathrm{Ca}$, and Mg Salts

\begin{tabular}{|c|c|c|}
\hline Salt & $\begin{array}{c}\text { Aqueous Solubility at } 25^{\circ} \mathrm{C} \\
\text { (mass percent of solute) }\end{array}$ & $\begin{array}{c}\text { Aqueous Solubility at } 100^{\circ} \mathrm{C} \\
\text { (mass percent of solute) }\end{array}$ \\
\hline $\mathrm{NaCl}$ & $26.45 \%$ & $28.05 \%$ \\
\hline $\mathrm{KCl}$ & $26.22 \%$ & $36.05 \%$ \\
\hline $\mathrm{CaCl}_{2}$ & $44.83 \%$ & $59.94 \%$ \\
\hline $\mathrm{MgCl}_{2}$ & $35.90 \%$ & $42.15 \%$ \\
\hline $\mathrm{NaHCO}_{3}$ & $9.32 \%$ & $19.10 \%$ \\
\hline $\mathrm{KHCO}_{3}$ & $26.6 \%$ & $40.45 \%$ at $70^{\circ} \mathrm{C}$ \\
\hline $\mathrm{Na}_{2} \mathrm{CO}_{3}$ & $23.5 \%$ & $30.09 \%$ \\
\hline $\mathrm{K}_{2} \mathrm{CO}_{3}$ & $52.7 \%$ & $61.0 \%$ \\
\hline $\mathrm{NaF}$ & $3.97 \%$ & $4.82 \%$ \\
\hline KF & $50.4 \%$ & $60.0 \%$ at $80^{\circ} \mathrm{C}$ \\
\hline $\mathrm{CaF}_{2}$ & $0.0016 \%$ & not reported above $25^{\circ} \mathrm{C}$ \\
\hline $\mathrm{MgF}_{2}$ & $0.013 \%$ & not reported above $25^{\circ} \mathrm{C}$ \\
\hline $\mathrm{Na}_{2} \mathrm{SO}_{4}$ & $21.94 \%$ & $29.67 \%$ \\
\hline $\mathrm{K}_{2} \mathrm{SO}_{4}$ & $10.7 \%$ & $19.3 \%$ \\
\hline $\mathrm{CaSO}_{4}$ & $0.205 \%$ & $0.163 \%$ \\
\hline $\mathrm{MgSO}_{4}$ & $26.3 \%$ & $33.3 \%$ \\
\hline $\mathrm{NaBr}$ & $48.6 \%$ & $54.9 \%$ \\
\hline $\mathrm{KBr}$ & $40.4 \%$ & $50.8 \%$ \\
\hline $\mathrm{CaBr}_{2}$ & $61.0 \%$ & $73.0 \%$ at $60^{\circ} \mathrm{C}$ \\
\hline $\mathrm{MgBr}_{2}$ & $50.6 \%$ & $55.7 \%$ \\
\hline $\mathrm{NaNO}_{3}$ & $47.7 \%$ & $63.8 \%$ \\
\hline $\mathrm{KNO}_{3}$ & $27.7 \%$ & $70.8 \%$ \\
\hline $\mathrm{Ca}\left(\mathrm{NO}_{3}\right)_{2}$ & $59.0 \%$ & $78.5 \%$ \\
\hline $\mathrm{Mg}\left(\mathrm{NO}_{3}\right)_{2}$ & $41.6 \%$ & $72.0 \%$ \\
\hline
\end{tabular}

Source: Lide 2000 [DIRS 162229], pp. 8-102 to 8-110.

Table 4-13. Equilibrium Relative Humidity for Saturated Aqueous Solutions in Contact with an Excess of Solid-Phase Salts

\begin{tabular}{|l|l|l|}
\hline \multicolumn{1}{|c|}{ Salt } & $\begin{array}{c}\text { Equilibrium Relative } \\
\text { Humidity (\%) }\end{array}$ & $\begin{array}{c}\text { Temperature of } \\
\text { Measurement }\left(^{\circ} \mathrm{C} \text { ) }\right.\end{array}$ \\
\hline $\mathrm{NaCl}$ & 76.4 & 80 \\
\hline $\mathrm{KCl}$ & 79.5 & 80 \\
\hline $\mathrm{MgCl}_{2} \cdot 6 \mathrm{H}_{2} \mathrm{O}$ & 33.0 & 25 \\
\hline $\mathrm{Na}_{2} \mathrm{CO}_{3} \cdot 10 \mathrm{H}_{2} \mathrm{O}$ & $87^{\mathrm{a}}$ & 24.5 \\
\hline $\mathrm{K}_{2} \mathrm{CO}_{3} \cdot 2 \mathrm{H}_{2} \mathrm{O}$ & 42 & 40 \\
\hline $\mathrm{NaF}$ & $96.6^{\mathrm{a}}$ & 100 \\
\hline $\mathrm{KF}$ & $22.9^{\mathrm{a}}$ & 100 \\
\hline $\mathrm{Na} \mathrm{SO}_{4} \cdot 10 \mathrm{H}_{2} \mathrm{O}$ & $93^{\mathrm{a}}$ & 20 \\
\hline $\mathrm{K}_{2} \mathrm{SO}_{4}$ & 96 & 60 \\
\hline & &
\end{tabular}


Table 4-13. Equilibrium Relative Humidity for Saturated Aqueous Solutions in Contact with an Excess of Solid-Phase Salts (Continued)

\begin{tabular}{|l|l|l|}
\hline \multicolumn{1}{|c|}{ Salt } & $\begin{array}{c}\text { Equilibrium Relative } \\
\text { Humidity (\%) }\end{array}$ & \multicolumn{1}{|c|}{$\begin{array}{c}\text { Temperature of } \\
\text { Measurement }\left({ }^{\circ} \mathrm{C}\right)\end{array}$} \\
\hline $\mathrm{NaNO}_{3}$ & 65.5 & 80 \\
\hline $\mathrm{KNO}_{3}$ & 82 & 60 \\
\hline $\mathrm{KNO}_{3}, \mathrm{NaNO}_{3}$, and $\mathrm{NaCl}$ & $30.49^{\mathrm{a}}$ & 16.39 \\
\hline
\end{tabular}

Source: Dean 1992 [DIRS 100722] p. 11.6.

${ }^{a}$ Weast and Astle 1981 [DIRS 100833] p. E-44.

Table 4-14. Sources of Additional Aqueous Solubility Data for $\mathrm{Na}, \mathrm{K}, \mathrm{Ca}$, and $\mathrm{Mg}$ Salts as a Function of Temperature

\begin{tabular}{|c|c|}
\hline Salt $^{a}$ & Source \\
\hline $\mathrm{NaCl}$ & Linke 1965 [DIRS 166191] p. 959 \\
\hline $\mathrm{KCl}$ & Linke 1965 [DIRS 166191] p. 114 \\
\hline $\mathrm{CaCl}_{2}$ & Linke 1958 [DIRS 166192] p. 565 \\
\hline $\mathrm{MgCl}_{2}$ & Linke 1965 [DIRS 166191] p. 480 \\
\hline $\mathrm{NaBr}$ & Linke 1965 [DIRS 166191] p. 831 \\
\hline $\mathrm{KBr}$ & Linke 1965 [DIRS 166191] p. 12 \\
\hline $\mathrm{CaBr}_{2}$ & Linke 1958 [DIRS 166192] p. 503 \\
\hline $\mathrm{MgBr}_{2}$ & Linke 1965 [DIRS 166191] p. 444 \\
\hline $\mathrm{NaF}$ & Linke 1965 [DIRS 166191] p. 102 \\
\hline KF & Linke 1965 [DIRS 166191] p. 202 \\
\hline $\mathrm{NaNO}_{3}$ & Linke 1965 [DIRS 166191] p. 1069 \\
\hline $\mathrm{KNO}_{3}$ & Linke 1965 [DIRS 166191] p. 250 \\
\hline $\mathrm{Ca}\left(\mathrm{NO}_{3}\right)_{2}$ & Linke 1958 [DIRS 166192] p. 616 \\
\hline $\mathrm{Mg}\left(\mathrm{NO}_{3}\right)_{2}$ & Linke 1965 [DIRS 166191] p. 511 \\
\hline $\mathrm{Na}_{2} \mathrm{SO}_{4}$ & Linke 1965 [DIRS 166191] p. 1122 \\
\hline $\mathrm{K}_{2} \mathrm{SO}_{4}$ & Linke 1965 [DIRS 166191] p. 296 \\
\hline $\mathrm{CaSO}_{4}$ & $\begin{array}{l}\text { Linke } 1958 \text { [DIRS 166192] pp. } 660 \text { to } 662 ; \\
\text { Dutrizac } 2002 \text { [DIRS 166148] }\end{array}$ \\
\hline $\mathrm{Na}_{2} \mathrm{CO}_{3}$ & $\begin{array}{l}\text { Grønvold and Meisingset (1983); Robie } \\
\text { and Hemingway (1995 pp. } 26 \text { and 55) }\end{array}$ \\
\hline $\mathrm{K}_{2} \mathrm{CO}_{3}$ & $\begin{array}{l}\text { Linke } 1965 \text { [DIRS 166191] p. 81; } \\
\text { Moore et al. } 1997 \text { [DIRS 166150] }\end{array}$ \\
\hline $\mathrm{NaHCO}_{3}$ & Linke 1965 [DIRS 166191] p. 947 \\
\hline $\mathrm{KHCO}_{3}$ & Linke 1965 [DIRS 166191] p. 102 \\
\hline
\end{tabular}

${ }^{a}$ Potential hydration states not shown. 
Table 4-15. Sources of Additional Vapor Pressure Data for Several Salt Solutions as a Function of Temperature

\begin{tabular}{|l|l|}
\hline \multicolumn{1}{|c|}{ Salt ${ }^{\text {a }}$} & \multicolumn{1}{c|}{ Source } \\
\hline $\mathrm{NaCl}$ & Kracek 1928 [DIRS 122125] p. 369 \\
\hline $\mathrm{KCl}$ & Kracek 1928 [DIRS 122125] p. 373 \\
\hline $\mathrm{CaCl}$ & Kracek 1928 [DIRS 122125] p. 368 \\
\hline $\mathrm{MgCl}_{2}$ & Kracek 1928 [DIRS 122125] pp. 367 to 368 \\
\hline $\mathrm{KNO}_{3}$ & Kracek 1928 [DIRS 122125] p. 373 \\
\hline $\mathrm{Ca}\left(\mathrm{NO}_{3}\right)_{2}$ & Kracek 1928 [DIRS 122125] p. 368 \\
\hline $\mathrm{Na}_{2} \mathrm{SO}_{4}$ & Kracek 1928 [DIRS 122125] pp. 371 to 372 \\
\hline a Potential hydration states not shown.
\end{tabular}

Table 4-16. Equilibrium $R H$ of Saturated Aqueous Solutions of Selected Pure Salts as a Function of Temperature

\begin{tabular}{|c|c|c|c|c|c|c|c|c|c|}
\hline $\begin{array}{c}\text { Temperature } \\
\left({ }^{\circ} \mathrm{C}\right)\end{array}$ & KF & $\mathrm{MgCl}_{2}$ & $\mathrm{~K}_{2} \mathrm{CO}_{3}$ & $\mathrm{Mg}\left(\mathrm{NO}_{3}\right)_{2}$ & $\mathrm{NaNO}_{3}$ & $\mathrm{NaCl}$ & $\mathrm{KCl}$ & $\mathrm{KNO}_{3}$ & $\mathrm{~K}_{2} \mathrm{SO}_{4}$ \\
\hline 0 & $\mathrm{nr}$ & $33.66 \%$ & $43.13 \%$ & $60.35 \%$ & $\mathrm{nr}$ & $75.51 \%$ & $88.61 \%$ & $96.33 \%$ & $98.77 \%$ \\
\hline 5 & $\mathrm{nr}$ & $33.60 \%$ & $43.13 \%$ & $58.86 \%$ & $78.57 \%$ & $75.65 \%$ & $87.67 \%$ & $96.27 \%$ & $98.48 \%$ \\
\hline 10 & $\mathrm{nr}$ & $33.47 \%$ & $43.14 \%$ & $57.36 \%$ & $77.53 \%$ & $75.67 \%$ & $86.77 \%$ & $95.96 \%$ & $98.18 \%$ \\
\hline 15 & $\mathrm{nr}$ & $33.30 \%$ & $43.15 \%$ & $55.87 \%$ & $76.46 \%$ & $75.61 \%$ & $85.92 \%$ & $95.41 \%$ & $97.89 \%$ \\
\hline 20 & $\mathrm{nr}$ & $33.07 \%$ & $43.16 \%$ & $54.38 \%$ & $75.36 \%$ & $75.47 \%$ & $85.11 \%$ & $94.62 \%$ & $97.59 \%$ \\
\hline 25 & $30.85 \%$ & $32.78 \%$ & $43.16 \%$ & $52.89 \%$ & $74.25 \%$ & $75.29 \%$ & $84.34 \%$ & $93.58 \%$ & $97.30 \%$ \\
\hline 30 & $27.27 \%$ & $32.44 \%$ & $43.17 \%$ & $51.40 \%$ & $73.14 \%$ & $75.09 \%$ & $83.62 \%$ & $92.31 \%$ & $97.00 \%$ \\
\hline 35 & $24.59 \%$ & $32.05 \%$ & $\mathrm{nr}$ & $49.91 \%$ & $72.06 \%$ & $74.87 \%$ & $82.95 \%$ & $90.79 \%$ & $96.71 \%$ \\
\hline 40 & $22.68 \%$ & $31.60 \%$ & $\mathrm{nr}$ & $48.42 \%$ & $71.00 \%$ & $74.68 \%$ & $82.32 \%$ & $89.03 \%$ & $96.41 \%$ \\
\hline 45 & $21.46 \%$ & $31.10 \%$ & $\mathrm{nr}$ & $46.93 \%$ & $69.99 \%$ & $74.52 \%$ & $81.74 \%$ & $87.03 \%$ & $96.12 \%$ \\
\hline 50 & $20.80 \%$ & $30.54 \%$ & $\mathrm{nr}$ & $45.44 \%$ & $69.04 \%$ & $74.43 \%$ & $81.20 \%$ & $84.78 \%$ & $95.82 \%$ \\
\hline 55 & $20.60 \%$ & $29.93 \%$ & $\mathrm{nr}$ & $\mathrm{nr}$ & $68.15 \%$ & $74.41 \%$ & $80.70 \%$ & $\mathrm{nr}$ & $\mathrm{nr}$ \\
\hline 60 & $20.77 \%$ & $29.26 \%$ & $\mathrm{nr}$ & $\mathrm{nr}$ & $67.35 \%$ & $74.50 \%$ & $80.25 \%$ & $\mathrm{nr}$ & $\mathrm{nr}$ \\
\hline 65 & $21.18 \%$ & $28.54 \%$ & $\mathrm{nr}$ & $\mathrm{nr}$ & $66.64 \%$ & $74.71 \%$ & $79.85 \%$ & $\mathrm{nr}$ & $\mathrm{nr}$ \\
\hline 70 & $21.74 \%$ & $27.77 \%$ & $\mathrm{nr}$ & $\mathrm{nr}$ & $66.04 \%$ & $75.06 \%$ & $79.49 \%$ & $\mathrm{nr}$ & $\mathrm{nr}$ \\
\hline 75 & $22.33 \%$ & $26.94 \%$ & $\mathrm{nr}$ & $\mathrm{nr}$ & $65.56 \%$ & $75.58 \%$ & $79.17 \%$ & $\mathrm{nr}$ & $\mathrm{nr}$ \\
\hline 80 & $22.85 \%$ & $26.05 \%$ & $\mathrm{nr}$ & $\mathrm{nr}$ & $65.22 \%$ & $76.29 \%$ & $78.90 \%$ & $\mathrm{nr}$ & $\mathrm{nr}$ \\
\hline 85 & $23.20 \%$ & $25.11 \%$ & $\mathrm{nr}$ & $\mathrm{nr}$ & $65.03 \%$ & $\mathrm{nr}$ & $78.68 \%$ & $\mathrm{nr}$ & $\mathrm{nr}$ \\
\hline 90 & $23.27 \%$ & $24.12 \%$ & $\mathrm{nr}$ & $\mathrm{nr}$ & $65.00 \%$ & $\mathrm{nr}$ & $78.50 \%$ & $\mathrm{nr}$ & $\mathrm{nr}$ \\
\hline 95 & $\mathrm{nr}$ & $23.07 \%$ & $\mathrm{nr}$ & $\mathrm{nr}$ & $\mathrm{nr}$ & $\mathrm{nr}$ & $\mathrm{nr}$ & $\mathrm{nr}$ & $\mathrm{nr}$ \\
\hline 100 & $\mathrm{nr}$ & $21.97 \%$ & $\mathrm{nr}$ & $\mathrm{nr}$ & $\mathrm{nr}$ & $\mathrm{nr}$ & $\mathrm{nr}$ & $\mathrm{nr}$ & $\mathrm{nr}$ \\
\hline
\end{tabular}

Source: Greenspan 1977 [DIRS 104945].

$\mathrm{nr}=$ not reported. 
Table 4-17. Selected Vapor Pressure Data for Saturated Aqueous $\mathrm{NaNO}_{3}$ Solutions and Pure Water as a Function of Temperature

\begin{tabular}{|c|c|c|c|c|c|}
\hline $\begin{array}{c}\text { Temperature } \\
\left({ }^{\circ} \mathrm{C}\right)\end{array}$ & $\begin{array}{c}\mathrm{NaNO}_{3} \\
\text { Solution Vapor } \\
\text { Pressure } \\
\text { (bar) }\end{array}$ & $\begin{array}{l}\text { Vapor } \\
\text { Pressure of } \\
\text { Pure Water } \\
(\mathrm{mm} \mathrm{Hg})^{a}\end{array}$ & $\begin{array}{c}\text { Temperature } \\
\left({ }^{\circ} \mathrm{C}\right)\end{array}$ & $\begin{array}{l}\mathrm{NaNO}_{3} \\
\text { Solution Vapor } \\
\text { Pressure } \\
\text { (bar) }\end{array}$ & $\begin{array}{c}\text { Vapor } \\
\text { Pressure of } \\
\text { Pure Water } \\
(\mathrm{mm} \mathrm{Hg})^{\mathrm{a}}\end{array}$ \\
\hline 10.0 & 0.0095 & 9.209 & 80.0 & 0.2852 & 355.1 \\
\hline 15.0 & 0.0128 & 12.788 & 85.0 & 0.3412 & 433.6 \\
\hline 20.0 & 0.0173 & 17.535 & 90.0 & 0.4052 & 525.76 \\
\hline 25.0 & 0.0232 & 23.756 & 95.0 & 0.4781 & 633.9 \\
\hline 30.0 & 0.0305 & 31.824 & 100.0 & 0.5606 & 760.00 \\
\hline 35.0 & 0.0399 & 42.175 & 105.0 & 0.6534 & 906.07 \\
\hline 40.0 & 0.0515 & 55.324 & 110.0 & 0.7570 & 1074.56 \\
\hline 45.0 & 0.0656 & 71.88 & 115.0 & 0.8719 & 1267.98 \\
\hline 50.0 & 0.0831 & 92.51 & 120.0 & 0.9989 & 1489.14 \\
\hline 55.0 & 0.1043 & 118.04 & 125.0 & 1.1386 & 1740.93 \\
\hline 60.0 & 0.1296 & 149.38 & 130.0 & 1.2906 & 2026.16 \\
\hline 65.0 & 0.1596 & 187.54 & 140.0 & 1.6332 & 2710.92 \\
\hline 70.0 & 0.1952 & 233.7 & 145.0 & 1.8239 & 3116.76 \\
\hline 75.0 & 0.2368 & 289.1 & 150.0 & 2.0265 & 3570.48 \\
\hline
\end{tabular}

Source: Dingemans and Dijkgraaf 1948 [DIRS 166149].

NOTE: $1 \mathrm{bar}=750.062 \mathrm{~mm} \mathrm{Hg}$ (Weast and Astle 1981 [DIRS 100833] p. F-283).

${ }^{a}$ Weast and Astle 1981 [DIRS 100833] pp. D-168 to D-169. 
Table 4-18. Sources of Salt Solubilities in Ternary Systems as a Function of Temperature

\begin{tabular}{|c|c|}
\hline Salts $^{a}$ & Source \\
\hline $\mathrm{NaCl}-\mathrm{KCl}$ & Linke 1965 [DIRS 166191] pp. 146 to 148 \\
\hline $\mathrm{NaCl}-\mathrm{NaNO}_{3}$ & Linke 1965 [DIRS 166191] pp. 976 to 978 \\
\hline $\mathrm{NaCl}-\mathrm{Na}_{2} \mathrm{SO}_{4}$ & de Lima \& Pitzer 1983 [DIRS 162110] \\
\hline $\mathrm{NaCl}-\mathrm{MgCl}_{2}$ & $\begin{array}{l}\text { Linke } 1965 \text { [DIRS 166191] p. 489; de Lima \& Pitzer } 1983 \\
\text { [DIRS 162110] }\end{array}$ \\
\hline $\mathrm{NaCl}-\mathrm{Na}_{2} \mathrm{CO}_{3}$ & Linke 1965 [DIRS 166191] pp. 931 to 932 \\
\hline $\mathrm{NaNO}_{3}-\mathrm{KNO}_{3}$ & Linke 1965 [DIRS 166191] pp. 262 to 263 \\
\hline $\mathrm{NaNO}_{3}-\mathrm{Ca}\left(\mathrm{NO}_{3}\right)_{2}$ & Linke 1958 [DIRS 166192] p. 621 \\
\hline $\mathrm{NaNO}_{3}-\mathrm{Na}_{2} \mathrm{SO}_{4}$ & Linke 1965 [DIRS 166191] p. 1076 \\
\hline $\mathrm{Na}_{2} \mathrm{CO}_{3}-\mathrm{NaHCO}_{3}$ & Linke 1965 [DIRS 166191] pp. 926 to 927 \\
\hline $\mathrm{KCl}-\mathrm{KNO}_{3}$ & Linke 1965 [DIRS 166191] pp. 127 to 128 \\
\hline $\mathrm{KCl}-\mathrm{MgCl}_{2}$ & Linke 1965 [DIRS 166191] pp. 141 to 143 \\
\hline $\mathrm{K}_{2} \mathrm{CO}_{3}-\mathrm{K}_{2} \mathrm{SO}_{4}$ & Linke 1965 [DIRS 166191] p. 89 \\
\hline $\mathrm{CaCl}_{2}-\mathrm{Ca}\left(\mathrm{NO}_{3}\right)_{2}$ & Linke 1958 [DIRS 166192] p. 573 \\
\hline $\mathrm{CaSO}_{4}-\mathrm{Na}_{2} \mathrm{SO}_{4}$ & Linke 1958 [DIRS 166192] pp. 676 to 677 \\
\hline $\mathrm{CaSO}_{4}-\mathrm{K}_{2} \mathrm{SO}_{4}$ & Linke 1958 [DIRS 166192] pp. 671 to 672 \\
\hline $\mathrm{MgCl}_{2}-\mathrm{Mg}\left(\mathrm{NO}_{3}\right)_{2}$ & Linke 1965 [DIRS 166191] pp. 482 to 483 \\
\hline
\end{tabular}

a Potential hydration states not shown.

Table 4-19. Average Composition of Water from Well J-13

\begin{tabular}{|c|c|c|}
\hline Constituent & Units & $\begin{array}{c}\text { Average J-13 Well Water } \\
\text { Concentration }\end{array}$ \\
\hline $\mathrm{Al}$ & $\mathrm{mg} / \mathrm{L}$ & $0.028^{a}$ \\
\hline $\mathrm{Ca}$ & $\mathrm{mg} / \mathrm{L}$ & 13.0 \\
\hline $\mathrm{Mg}$ & $\mathrm{mg} / \mathrm{L}$ & 2.01 \\
\hline $\mathrm{Na}$ & $\mathrm{mg} / \mathrm{L}$ & 45.8 \\
\hline $\mathrm{K}$ & $\mathrm{mg} / \mathrm{L}$ & 5.04 \\
\hline $\mathrm{Si}$ & $\mathrm{mg} / \mathrm{L}$ & 28.5 \\
\hline $\mathrm{NO}_{3}$ & $\mathrm{mg} / \mathrm{L}$ & 8.78 \\
\hline Alkalinity (as $\mathrm{HCO}_{3}$ ) & $\mathrm{mg} / \mathrm{L}$ & 128.9 \\
\hline $\mathrm{Cl}$ & $\mathrm{mg} / \mathrm{L}$ & 7.14 \\
\hline $\mathrm{F}$ & $\mathrm{mg} / \mathrm{L}$ & 2.18 \\
\hline $\mathrm{SO}_{4}$ & $\mathrm{mg} / \mathrm{L}$ & 18.4 \\
\hline Lab pH & standard units & 7.41 \\
\hline Field $\mathrm{pH}$ & standard units & 6.9 and $7.1^{b}$ \\
\hline Temperature & Celsius & $31^{b}$ \\
\hline $\mathrm{O}_{2}(\mathrm{aq})$ & $\mathrm{mg} / \mathrm{L}$ & 5.5 to $5.7^{b}$ \\
\hline
\end{tabular}

Source: DTN: MO0006J13WTRCM.000 [DIRS 151029].

${ }^{a}$ Mean detected value in Table 4.2 (Harrar et al. 1990 [DIRS 100814], p 4.3).

${ }^{b}$ Harrar et al. 1990 [DIRS 100814] p 4.9. 


\section{INTENTIONALLY LEFT BLANK}




\section{ASSUMPTIONS}

This section addresses the assumptions built into the IDPS model. There are no upstream assumptions relevant to the IDPS model.

\subsection{STANDARD STATE OF LIQUID PHASE}

Assumption: Liquid phase is at standard state.

Basis: As discussed in Section 6.3.1, an aqueous solution at standard state has an equilibrium relative humidity that is equivalent to the activity of water in the aqueous solution. Standard state in this sense implies that the water-air interface is flat (i.e., that the boundary between water and air is a plane) and that the behavior of the water molecule $\left(\mathrm{H}_{2} \mathrm{O}\right)$ is not influenced by solid surfaces in contact with the water. Adsorption and air-water interface curvature, such as the curvature of menisci caused by capillary forces, create non-standard state conditions with respect to vapor pressure and equilibrium relative humidity near the air-water interface (Walton 1994 [DIRS 127454]; Koorevaar et al. 1983 [DIRS 125329] pp. 67 to 68).

For the IDPS model, nonstandard state aqueous solutions are not considered. Only dissolved salts and temperature are considered to affect liquid-vapor equilibrium. Water held by the surface tension effects of capillary binding are more mobile than water in double layers or adsorbed to solids; however, even capillary forces under dry conditions (in the range of negative 500 meters water pressure head) have a limited effect on $\mathrm{H}_{2} \mathrm{O}$ activity in solution (Walton 1994 [DIRS 127454] pp. 3,480 to 3,481). Because of this limited effect, the assumption that the liquid phase in the IDPS model is at standard state is negligible compared to the more sizable uncertainties in the IDPS model and model inputs (Section 8.4).

Confirmation Status: No further confirmation is required.

Use in the Model: This assumption is used throughout.

\subsection{EQUILIBRIUM CONDITIONS}

Assumption: The system is in a state of local metastable equilibrium. All aqueous and gas constituents in the model achieve and maintain local equilibrium, and most mineral phases achieve and maintain local equilibrium upon saturation. Several slow-forming and unlikely minerals identified in Section 6.6.2.6 will not precipitate upon saturation or supersaturation. The model can be used, however, to make steady-state non-equilibrium predictions with respect to relative humidity, provided the appropriate inputs are used (Section 6.6.3.3).

Basis: Most chemical reactions included in the model occur rapidly compared to the modeling timeframe. Redox reactions, which generally are not rapid, are not included in the model. Similarly, certain mineral precipitation reactions are not expected to be rapid enough to occur to a considerable degree for the anticipated applications of the model. Mineral precipitation reactions that fall into this category are suppressed, as explained in Section 6.6.2.6, permitting the formation of metastable mineral phases in the model. 
Confirmation Status: No further confirmation is required.

Use in the Model: This assumption is used throughout. 


\section{MODEL DISCUSSION}

\subsection{MODELING OBJECTIVES}

The objective of the IDPS model is to predict the effects of evaporation and deliquescence on the chemical evolution of potential aqueous solutions and mineral deposition within the repository. Specific details of these objectives are described in Section 1. The data used to develop the model are identified in Section 4.1. Data used to demonstrate the model (Section 6.7) are presented in Table 4-19 of Section 4.4. Data used in validation are addressed in Section 7.

\subsection{FEATURES, EVENTS, AND PROCESSES INCLUDED IN MODEL}

The comprehensive list of features, events, and processes (FEPs) potentially relevant to postclosure performance of the potential Yucca Mountain repository are summarized in DTN: MO0407SEPFEPLA.000 [DIRS 170760]. The approach for developing an initial list of FEPs, in support of Total System Performance Assessment for the Site Recommendation (TSPA-SR) (CRWMS M\&O 2000 [DIRS 153246]), was documented in The Development of Information Catalogued in REV00 of the YMP FEP Database (Freeze et al. 2001 [DIRS 154365]). The initial FEP list contained 328 FEPs, of which 176 were included in TSPA-SR models (CRWMS M\&O 2000 [DIRS 153246], Tables B-9 through B-17). To support TSPA-LA, the FEP list was re-evaluated in accordance with the Enhanced FEP Plan (BSC 2002 [DIRS 158966] Section 3.2). Table 6-1 provides a list of FEPs that are included in TSPA-LA models described in this model document. For each of these FEPs, the implementation in TSPA-LA is described in this model document. Details of the implementations are summarized here in the table, including specific references to sections within this document.

To be consistent with Technical Work Plan for: Regulatory Integration Team Revision of Features, Events, and Processes (FEPs) Analysis Reports Integration (BSC 2004 [DIRS 170408]), Table 6-1 includes updates to FEP numbers and FEP subjects for two FEPs identified in the TWP for the IDPS model report (BSC 2004 [DIRS 171156], Table 1). FEP 2.1.09.06.0A (Reduction-oxidation potential in EBS) in the IDPS model report TWP became 2.1.09.06.0B, and FEP 2.1.09.07.0A (Reaction kinetics in EBS) became 2.1.09.07.0B. These deviations from the IDPS model report TWP are justified because they improve integration with FEPs documents. These updates have no impact on the model developed in this report. 
Table 6-1. TSPA-LA FEPs Included in Model

\begin{tabular}{|c|c|c|}
\hline FEP Number & FEPs Subject & Section Where Discussed \\
\hline \multirow[t]{2}{*}{ 2.1.09.01.0A } & \multirow[t]{2}{*}{$\begin{array}{l}\text { Chemical characteristics of } \\
\text { water in drifts }\end{array}$} & $\begin{array}{l}\text { This model document provides a partial treatment of this FEP in Section } \\
\text { 6.6.3.5. The relevant parameters and ranges for this model are listed in } \\
\text { Table 4-5. The IDPS model is designed to perform in-drift water } \\
\text { chemistry calculations that provide detail required for predicting } \\
\text { interactions of water chemistry with in-drift materials. Further disposition } \\
\text { of this FEP is addressed in Engineered Barrier System: Physical and } \\
\text { Chemical Environment Model (BSC } 2004 \text { [DIRS 169860]). }\end{array}$ \\
\hline & & $\begin{array}{l}\text { The IDPS model lookup table output includes boundary values, } \\
\text { abstraction output, and supplemental calculations, as defined in Section } \\
6.6 .3 .5 \text {. Boundary values include temperature, the fugacities of carbon } \\
\text { dioxide and oxygen, and the reaction progress. Abstraction output } \\
\text { includes pH, activity of water, ionic strength, mass of solvent water } \\
\text { remaining, total concentrations of each element, concentrations of select } \\
\text { aqueous species that potentially contribute to acid-neutralizing capacity, } \\
\text { and amounts of solids precipitating in a given EQ6 run. Supplemental } \\
\text { calculations include relative humidity, concentration factor, relative } \\
\text { evaporation rate, and dilution factor. }\end{array}$ \\
\hline \multirow[t]{2}{*}{$\begin{array}{l}2.1 .09 .28 .0 \mathrm{~A} \\
2.1 .09 .28 .0 \mathrm{~B}\end{array}$} & \multirow[t]{2}{*}{$\begin{array}{l}\text { Deliquescence on waste } \\
\text { package outer surface and } \\
\text { deliquescence on drip } \\
\text { shield outer surface }\end{array}$} & $\begin{array}{l}\text { This model document provides a partial treatment of these FEPs in } \\
\text { Section 6.4. The IDPS model is used in Engineered Barrier System: } \\
\text { Physical and Chemical Environment Model (BSC } 2004 \text { [DIRS 169860]) to } \\
\text { predict the composition of water on the waste package and/or drip shield } \\
\text { resulting from the deliquescence of salts and dust deposited on these } \\
\text { surfaces. }\end{array}$ \\
\hline & & $\begin{array}{l}\text { The IDPS model lookup table output includes boundary values, } \\
\text { abstraction output, and supplemental calculations, as defined in Section } \\
6.6 .3 .5 \text {. Boundary values include temperature, the fugacities of carbon } \\
\text { dioxide and oxygen, and the reaction progress. Abstraction output } \\
\text { includes pH, activity of water, ionic strength, mass of solvent water } \\
\text { remaining, total concentrations of each element, concentrations of select } \\
\text { aqueous species that potentially contribute to acid-neutralizing capacity, } \\
\text { and amounts of solids precipitating in a given EQ6 run. Supplemental } \\
\text { calculations include relative humidity, concentration factor, relative } \\
\text { evaporation rate, and dilution factor. }\end{array}$ \\
\hline \multirow[t]{2}{*}{ 2.1.09.06.0B } & \multirow[t]{2}{*}{$\begin{array}{l}\text { Reduction-oxidation } \\
\text { potential in drifts }\end{array}$} & $\begin{array}{l}\text { This model document provides a partial treatment of this FEP in Section } \\
\text { 4.1.2. The IDPS model is only validated for oxidizing conditions. } \\
\text { Oxidizing conditions prevail as long as the equilibrium fugacity of oxygen } \\
\text { does not fall far below } 10^{-9} \text { bars. Above } 10^{-9} \text { bars, the model is } \\
\text { insensitive to the value of the fugacity of oxygen; thus, the fugacity in the } \\
\text { model is typically set at the approximate atmospheric value of } 10^{-0.7} \text { bars. }\end{array}$ \\
\hline & & $\begin{array}{l}\text { The IDPS model lookup table output includes boundary values, } \\
\text { abstraction output, and supplemental calculations, as defined in Section } \\
\text { 6.6.3.5. Boundary values include temperature, the fugacities of carbon } \\
\text { dioxide and oxygen, and the reaction progress. Abstraction output } \\
\text { includes pH, activity of water, ionic strength, mass of solvent water } \\
\text { remaining, total concentrations of each element, concentrations of select } \\
\text { aqueous species that potentially contribute to acid-neutralizing capacity, } \\
\text { and amounts of solids precipitating in a given EQ6 run. Supplemental } \\
\text { calculations include relative humidity, concentration factor, relative } \\
\text { evaporation rate, and dilution factor. }\end{array}$ \\
\hline
\end{tabular}


Table 6-1. TSPA-LA FEPs Included in Model (Continued)

\begin{tabular}{|l|l|l|}
\hline FEP Number & \multicolumn{1}{|c|}{ FEPs Subject } & \multicolumn{1}{|c|}{ Section Where Discussed } \\
\hline 2.1.09.07.0B & Reaction kinetics in drifts & $\begin{array}{l}\text { This model document provides a partial treatment of this FEP in Section } \\
5.2 \text {. In the IDPS model, all aqueous and gas constituents achieve and } \\
\text { maintain local equilibrium, and most mineral phases achieve and } \\
\text { maintain local equilibrium upon saturation. Most chemical reactions } \\
\text { included in the model occur rapidly compared to the modeling timeframe. } \\
\text { Redox reactions, which generally are not rapid, are not included in the } \\
\text { model. Similarly, certain mineral precipitation reactions are not expected } \\
\text { to be rapid enough to occur to a considerable degree for the anticipated } \\
\text { applications of the model. Mineral precipitation reactions that fall into this } \\
\text { category are suppressed, as explained in Section 6.6.2.6, permitting the } \\
\text { formation of metastable mineral phases in the model. Reaction rates } \\
\text { themselves are not included in the model because the model is used to } \\
\text { develop lookup tables that provide water compositions that are } \\
\text { independent of time, i.e., at metastable equilibrium. }\end{array}$ \\
\hline 2.1.11.08.0A & $\begin{array}{l}\text { Thermal effects on } \\
\text { chemistry and microbial } \\
\text { activity in the EBS }\end{array}$ & $\begin{array}{l}\text { This model document provides a partial treatment of this FEP in Section } \\
\text { 6.6.3.5. The IDPS model performs in-drift water chemistry calculations } \\
\text { that provide detail required for predicting thermal effects on water } \\
\text { chemistry. This model is not used to predict the thermal effects on } \\
\text { microbial activity. } \\
\text { The IDPS model lookup table output includes boundary values, } \\
\text { abstraction output, and supplemental calculations, as defined in Section } \\
\text { 6.6.3.5. Boundary values include temperature, the fugacities of carbon } \\
\text { dioxide and oxygen, and the reaction progress. Abstraction output } \\
\text { includes pH, activity of water, ionic strength, mass of solvent water } \\
\text { remaining, total concentrations of each element, concentrations of select } \\
\text { aqueous species that potentially contribute to acid-neutralizing capacity, } \\
\text { and amounts of solids precipitating in a given EQ6 run. Supplemental } \\
\text { calculations include relative humidity, concentration factor, relative } \\
\text { evaporation rate, and dilution factor. }\end{array}$ \\
\hline
\end{tabular}

\subsection{SALTS/PRECIPITATES PROCESSES}

\subsubsection{Evaporation, Relative Humidity, and Salt Precipitation}

Within a drift environment, water exists in two phases, liquid and vapor. Because these two phases are in contact with one another throughout time (except in the event that all liquid water vaporizes), Brownian motion causes water molecules to exchange constantly between the two phases. According to the Maxwell-Boltzmann law, a fraction of the molecules in one phase has the energy required to make the transformation to the other phase, and vice versa, for as long as both phases exist (Mahan 1975 [DIRS 125331], pp. 131 to 139).

Under equilibrium conditions, there is no net movement of water molecules from one phase to the other, i.e., the non-zero evaporation rate equals the non-zero condensation rate. For liquid water to be in equilibrium with the vapor phase, the partial pressure of water vapor must equal the saturation vapor pressure of the liquid water.

$R H$, is the ratio, expressed in percent, of the measured water vapor pressure and the saturated water vapor pressure at the same temperature and total pressure. This definition applies to water 
in its standard state. In porous media or on solid surfaces, there are other mechanisms that decrease the saturation water vapor pressure of the liquid, such as capillary binding of water by surface tension, osmotic binding of water in double layers, and direct adhesion of water molecules to solid surfaces by London-van der Waals forces (Koorevaar et al. 1983 [DIRS 125329], p. 63). For the IDPS model, these effects are assumed to be negligible (Assumption 5.1).

Dissolved salts in water also decrease the saturation water vapor pressure because they reduce the chemical activity of water in the solution. The chemical activity of the water molecule, $a(w)$, is a function of the mole fraction of water in the aqueous solution and is equivalent to the equilibrium relative humidity of the solution (Kinsman 1976 [DIRS 100769], p. 274). As a result, brines reach liquid-vapor equilibrium, and thus stability, at relative humidity values below 100 percent. This effect on brine stability is included in the IDPS model.

Based on relative humidity measurements from the single heater test (Tsang 1999 [DIRS 124334], Section 2.2.2), the relative humidity within the potential drift is expected to fall below 99 percent for many years during the pre- and postclosure periods. As a result, dilute ground water in the unsaturated zone, having an activity of water greater than 0.99 , is not expected to be at liquid-vapor equilibrium within the drift during this time. For any dilute ground water that resides or flows into the drift during this period, there is a net transfer of liquid water to the vapor phase that results in increasing concentrations of dissolved salts in the remaining liquid water. If the vaporization rate is rapid compared to the flux of liquid water flowing into the drift, brines will develop within the drift. In addition, if the relative humidity is sufficiently low, dissolved salts will precipitate until either a more stable brine develops or all free liquid water evaporates, adsorbs, and/or is incorporated in hydrated salts.

\subsubsection{Formation and Chemistry of Brines and Salt Precipitates}

As water evaporates from solution, dissolved solids concentrate until they become supersaturated with respect to a solid phase whereupon, assuming conditions are favorable and precipitation is sufficiently rapid, the solid phase will precipitate. If the solid phase is a binary salt and the normalities of the two reactants are not equal, the reactant having the lower normality will become depleted in solution while the reactant with higher normality will continue to concentrate (Eugster and Hardie 1978 [DIRS 100743], pp. 243 to 247; Eugster and Jones 1979 [DIRS 123175], pp. 614 to 629). This mechanism is known as a chemical divide (Drever 1988 [DIRS 118564], pp. 235 to 236). A chemical divide determines which reactant concentrations are predominantly controlled by the solubility of a precipitating phase (i.e., those that become depleted in solution) and which reactant concentrations are only partially controlled by a precipitating phase (i.e., those that continue to concentrate in solution despite partial precipitation). It should be noted that the resulting evaporative evolution depends on how close the normalities of the reactants are. If they are close, both reactants will maintain fairly constant concentrations as evaporation and precipitation continue. Eventually, however, the normalities of the reactants will begin to diverge rapidly, with the predominant reactant concentrating and the lesser reactant depleting.

The chemical divide during evaporative precipitation is demonstrated by thermodynamic calculations and studies of saline lakes and sabkhas (hardpan salt playas). Garrels and 
Mackenzie (1967 [DIRS 123636]) thermodynamically simulated the evaporative evolution of Sierra Nevada spring water into a strongly alkaline sodium carbonate brine observed in natural saline lakes in the western United States. In these calculations, calcite precipitates first, depleting the aqueous calcium concentration. Calcite precipitation is an important evolutionary step because the chemical divide for calcium and carbonate determines whether the evaporating water becomes carbonate poor or carbonate rich (Eugster and Hardie 1978 [DIRS 100743], p. 244). In this case, the water becomes carbonate rich. Next in the calculations, precipitation of sepiolite depletes the magnesium concentration. Continued evaporation results in a sodium carbonate brine with a pH near 10 (Garrels and Mackenzie 1967 [DIRS 123636], p. 239).

Studies of saline lakes in the western United States show that alkaline sodium carbonate brines, such as the brine derived by Garrels and Mackenzie (1967 [DIRS 123636]), are common (Eugster and Hardie 1978 [DIRS 100743], p. 240). Many of these same alkaline brines occur in volcanic terrain and have high silica content (Jones et al. 1967 [DIRS 123170]). These waters are also enriched in chloride, sulfate, and to some extent potassium. Studies of naturally occurring brines indicate that potassium is largely removed during evaporative precipitation. The likely mechanisms for this removal are ion exchange reactions on clay minerals, silicate gels, and volcanic glass (Eugster and Hardie 1978 [DIRS 100743], p. 246).

In the late stage of evaporation, the highly soluble components precipitate. In carbonate-rich brines, these salts include, but are not limited to, salts of $\mathrm{Na}, \mathrm{Cl}, \mathrm{SO}_{4}, \mathrm{CO}_{3}$, and $\mathrm{SiO}_{2}$ (Eugster and Hardie 1978 [DIRS 100743], p. 244). The predominant dissolved components in carbonate-poor brines, such as brines resulting from the evaporation of seawater, are $\mathrm{Na}, \mathrm{Ca}, \mathrm{Mg}, \mathrm{Cl}$, and $\mathrm{SO}_{4}$ (Eugster and Hardie 1978 [DIRS 100743], p. 244). Other dissolved components observed to become enriched in some brines include $\mathrm{K}, \mathrm{F}, \mathrm{Br}, \mathrm{Sr}, \mathrm{PO}_{4}$, and $\mathrm{B}$ (Eugster and Hardie 1978 [DIRS 100743], pp. 239 to 241). $\mathrm{NO}_{3}$, although it is highly soluble, is not mentioned (and perhaps not investigated) in these studies.

The sequence of salt precipitation by evaporation depends on the chemistry of the solution and the environment. The relative and total activities of the dissolved salt species and the solubilities of the solid salt phases determine when a dissolved species becomes supersaturated, when it begins to precipitate, which other species precipitate with it, and which species continue to concentrate in the remaining solution.

The aqueous solubilities of various combinations of binary $\mathrm{Na}, \mathrm{K}, \mathrm{Ca}$, and $\mathrm{Mg}$ salts at $25^{\circ} \mathrm{C}$ and $100^{\circ} \mathrm{C}$ (or temperatures near $100^{\circ} \mathrm{C}$ ) are presented in Table 4-12 (Section 7.2). Each value represents the maximum amount of the specified salt that can be dissolved into pure water at the given temperature. These handbook values are useful in assessing semi-quantitatively the relative solubilities of different salts in an aqueous solution containing many different dissolved solids. For example, Table 4-12 indicates that sulfate salts and sodium fluoride are some of the least soluble of these salts.

In naturally occurring brines, high sulfate concentrations are attributed to the dissolution of gypsum in geologic strata or the oxidation of sulfides such as pyrite, which is widespread in the western United States (Eugster and Hardie 1978 [DIRS 100743], p. 243). In a carbonate-poor (calcium-rich) brine, such as a brine derived from the evaporation of seawater, sulfate precipitates as gypsum or anhydrite before halite precipitates (Kinsman 1976 [DIRS 100769], 
p. 275). In carbonate-rich alkaline brines, sulfate precipitates as a sodium salt (Eugster and Hardie 1978 [DIRS 100743], p. 246). Based on the data in Table 4-12, sulfate salts would be expected to precipitate due to evaporation prior to halite or other more soluble salts, given approximately equal molar concentrations of sulfate and chloride in the solution.

Another indication of the likely sequence of salt precipitation is evident in the comparison of hygroscopic properties, i.e., the abilities of different brines or salts to absorb water from the air. Deliquescence is the process of dissolution of a solid by absorbing moisture from the air. This process is the reverse of evaporation to dryness and can be modeled as such. Table 4-13 lists literature values of the equilibrium relative humidity of aqueous solutions saturated with a given salt. Lower values in this table imply lower chemical activities of $\mathrm{H}_{2} \mathrm{O}$ (see previous section) and therefore higher salt solubilities. This relationship is apparent when comparing the values in Table 4-12 and Table 4-13.

For evaporating seawater, when the chemical activity of $\mathrm{H}_{2} \mathrm{O}$ falls below 0.93 due to net evaporation of water into air having a relative humidity less than 93 percent, sodium sulfate precipitates (Kinsman 1976 [DIRS 100769], p. 273). In this same water, when the chemical activity of $\mathrm{H}_{2} \mathrm{O}$ falls below 0.77 due to net evaporation of water into air having a relative humidity less than about 77 percent, halite precipitates (Kinsman 1976 [DIRS 100769], pp. 274 to 275). Thus, as water evaporates, the chemical activity of water in the brine decreases, forcing less hygroscopic, less soluble salts to precipitate before more hygroscopic, more soluble salts. Based on the values in Table 4-12 and Table 4-13, it follows that the sequence of precipitation in a calcium-poor (carbonate-rich) brine is likely sodium sulfate followed by halite.

The sequence of precipitation reactions in an evaporating water can often be reliably predicted using a quantitative evaporation simulation that assumes control by thermodynamic equilibrium or metastable equilibrium. Such a simulation can be performed using a code like EQ3/6. An evaporation simulation is a series of incremental steps in which a small amount of water is removed (or evaporated) at the beginning of a step and the remaining solution is re-equilibrated at the end of the step. If the ion activity product of a salt exceeds the solubility equilibrium constant of the precipitation reaction at the beginning of the step, the salt will begin to precipitate, assuming the rate of the reaction is sufficiently rapid (Stumm and Morgan 1996 [DIRS 125332], pp. 351 to 359). Insensibly slow reactions on the time scale of interest can be dealt with by instructing the modeling code to suppress the formation of associated minerals, in which case other (metastable) minerals are typically precipitated instead. For example, amorphous silica may form if quartz is suppressed. In a batch evaporation simulation, an early precipitated mineral may later redissolve as a more lately precipitated phase competes with it for common chemical components. An evaporation simulation often achieves a final (eutectic) state in which the composition of the last remaining aqueous solution is fixed by a combination of mineral and gas equilibria.

Evaporative precipitation generally results in the precipitation of dissolved components from solution. One exception is carbonate because it can both precipitate and degas. Degassing of carbon dioxide in alkaline brines is represented by the reaction:

$$
2 \mathrm{HCO}_{3}^{-}=\mathrm{CO}_{3}{ }^{2-}+\mathrm{CO}_{2}+\mathrm{H}_{2} \mathrm{O}
$$


This reaction causes the $\mathrm{pH}$ to rise (Drever 1988 [DIRS 118564], p. 244). The $\mathrm{pH}$ rise is enhanced by the decrease in carbon dioxide solubility as salinity increases (Eugster and Jones 1979 [DIRS 123175], p. 614). Carbonate precipitation includes calcite during the early stages of evaporation and various sodium carbonate salts at later stages (Jones et al. 1977 [DIRS 123192], p. 64; Eugster and Hardie 1978 [DIRS 100743], pp. 244 to 246).

For silica, wetting and drying cycles can be responsible for the silica precipitation observed in alkaline brines. At Lake Magadi in Kenya, complete evaporation causes the formation of silica crusts that do not easily dissolve during the following wetting cycle because of slow kinetics. As a result, only the most soluble salts; e.g., salts of $\mathrm{Na}, \mathrm{K}, \mathrm{Cl}$, and $\mathrm{SO}_{4}$, dissolve into the recharged interstitial waters (Eugster and Hardie 1978 [DIRS 100743], pp. 245 to 246).

\subsubsection{Potential Brines and Salt Precipitates at Yucca Mountain}

A number of simulations and experimental studies have been performed to directly assess evaporative precipitation effects within and near the repository in Yucca Mountain. In these studies, water entering the drift is predicted to have variable composition as a function of time as a result of the boiling/condensation and reaction of both heated and condensed waters with minerals and gases in the fractures of the host rocks (Arthur and Murphy 1989 [DIRS 100699]; Glassley 1994 [DIRS 100741]; Murphy 1993 [DIRS 100804]; Wilder 1996 [DIRS 100792]; Lichtner and Seth 1996 [DIRS 100771]; Glassley 1997 [DIRS 100742]; Hardin 1998 [DIRS 100123] Section 6.2.2). These reacted, or thermally perturbed, fluid compositions could flow down fracture pathways and enter potential emplacement drifts where they could undergo reaction with introduced materials or evaporate, depositing salts (Glassley 1994 [DIRS 100741]; Murphy and Pabalan 1994 [DIRS 100805]; Wilder 1996 [DIRS 100792]; Lichtner and Seth 1996 [DIRS 100771]). The salts deposited and brines that occur within the drifts would depend on the volume, composition, and extent of evaporation of water seeping into the drift over time from the unsaturated zone.

As temperature increases, a number of changes could affect the geochemical behavior of the near-field environment. Mineral stabilities and phase equilibria are temperature dependent, and the rates at which reactions occur generally increase at higher temperatures. Both continuous reactions (such as the gradual dehydration or shift in cation composition of a solid phase) and discontinuous reactions (such as the disappearance of a phase outside of its stability range) occur as temperature increases (Glassley 1994 [DIRS 100741]; Murphy 1993 [DIRS 100804]; Hardin 1998 [DIRS 100123], Sections 5 and 6).

The increased temperatures are predicted to vaporize much of the water in the near-field as an above-boiling zone forms within the drift and in the near-field (Glassley 1994 [DIRS 100741]). This transition would increase the capacity of the system to transport moisture as volatiles and would result in precipitation of dissolved solids from boiling fluids in the near-field. Condensation of water in cooler regions in three dimensions above the repository horizon could dissolve new material, which could be transported through fractures back down into the boiling zone with subsequent boiling and phase precipitation.

Mineral precipitates including salts will form in the drift and near-field due to boiling and evaporation of water. Water undergoing boiling or evaporation or reacting with precipitated salts 
is predicted to become concentrated in a number of dissolved constituents either in close proximity to, or within, potential emplacement drifts (Hardin 1998 [DIRS 100123], Section 6.2.2). The evolving compositions of these fluids can be predicted by geochemical mass-transfer calculations for simplified systems designed to simulate the vaporization that would occur within a thermally perturbed repository environment. Results from two such calculations (Murphy and Pabalan 1994 [DIRS 100805]; Wilder 1996 [DIRS 100792]; Hardin 1998 [DIRS 100123], Section 6.2.2) are discussed here.

In one calculation (Wilder 1996 [DIRS 100792]; Hardin 1998 [DIRS 100123], Section 6.2.2), $\mathrm{J}-13$ water is predicted to evaporate/boil along a temperature rise from ambient to $95^{\circ} \mathrm{C}$ at equilibrium with atmospheric gases. This calculation represents 95 percent evaporation. The second set of calculations (Murphy and Pabalan 1994 [DIRS 100805]) starts with a synthetic $\mathrm{J}-13$ water evaporatively evolved at $75^{\circ} \mathrm{C}$ (heated $\mathrm{J}-13$ water that has reacted with tuff) and heats it instantaneously to $100^{\circ} \mathrm{C}$ in equilibrium with atmospheric oxygen and the calculated $\mathrm{CO}_{2}$ fugacity (this latter parameter value is higher than atmospheric values and was derived from a coupled reactive transport calculation in which both gas and fluid flow were calculated). The compositions resulting from this second set are reported to about 99.6 percent evaporation. Even though the results of these two calculations are not directly comparable because they represent different compositional systems and different controls on the gas phase, they appear to be roughly consistent. Relative to ambient compositions, these fluids, in general, have high ionic strength values (greater than 1 molal stoichiometric ionic strength for the 99.6 percent evaporated case); high concentrations of alkalis, chloride, sulfate, and other ligands ( $\mathrm{F}^{-}$, and $\mathrm{HCO}_{3}{ }^{-}$); and have high $\mathrm{pH}$ (around 9.5).

Because mineral precipitation occurs throughout these calculations (calcite, silica polymorphs, etc.), these compositions do not represent simply concentrated ambient values, but are selectively concentrated. In both sets of calculations, the dissolved Ca content is low $(<50 \mathrm{mg} / \mathrm{kg})$ because calcite precipitation removes $\mathrm{Ca}$ from the fluid. However, concentrations of elements that do not precipitate in the calculations are orders of magnitude higher than at ambient conditions. For example, at the 99 and 99.6 percent evaporation points, chloride concentrations are about 100 times and about 250 times higher, respectively, than the average value for J-13 water (Murphy and Pabalan 1994 [DIRS 100805]).

Modeling results of water evaporation indicate that resultant composition may be profoundly affected by the gas phase assumed to be in equilibrium with the evaporating water and by whether the system behaves as open to the atmosphere or in a closed manner (Wilder 1996 [DIRS 100792]; Hardin 1998 [DIRS 100123], Section 6.2.2). In an open system with a fixed partial pressure of carbon dioxide, J-13 well water evolves to $\mathrm{pH}$ above 9.5 at high degrees of evaporation. Alternatively, in a closed system, the $\mathrm{pH}$ falls below 6.8 after a similar extent of evaporation. The results are sensitive to the constraints on $\mathrm{CO}_{2}$ fugacity (Murphy and Pabalan 1994 [DIRS 100805]), with different solid phases precipitating for lower $\mathrm{CO}_{2}$ fugacities. When refluxed water is nearly completely evaporated, more calcite precipitates in an open system compared to a closed system (Murphy and Pabalan 1994 [DIRS 100805]). These results emphasize the need to have a model that incorporates consistently the evolution of near-field gas composition, and the need to have such constraints defined for each scenario. 
In another modeling study, Lichtner and Seth (1996 [DIRS 100771]) used a multiphase, multicomponent, non-isothermal reactive transport code to simulate the evolution, vaporization, and condensation of groundwater through the vertical centerline of the repository during the boiling period. This type of code does not fix local gas fugacities within the grid block, but evaluates them based on multiphase reactions. Their results predict that in the vicinity of the repository, the $\mathrm{pH}$ will rise to about 10 and chloride concentration will increase to approximately $100 \mathrm{mg} / \mathrm{L}$ in the vicinity of the drift. This predicted $\mathrm{pH}$ rise suggests that the repository will behave more like an open system than a closed system with respect to carbon dioxide. Lichtner and Seth (1996 [DIRS 100771]) indicate that a 10-fold increase in J-13 fluid concentrations (for elements that do not precipitate in this range) could be a reasonable water composition entering the drift through fractures during the boiling period. Quartz and calcite were predicted to dissolve where water was predicted to condense and to precipitate where water was predicted to evaporate (Lichtner and Seth 1996 [DIRS 100771]).

\subsubsection{Simplified Binary Salts Model}

The conceptual IDPS model (Section 6.4) evolved from the simplified binary salts model (CRWMS M\&O 1998 [DIRS 100358]). The simplified binary salts model 1) defined the general processes that lead to salts accumulation, brine formation, and dry conditions in the repository, 2) approximated the total accumulations of salts that might occur, and 3) predicted the effects of deliquescence and dissolution of precipitated salts as the relative humidity slowly increases during the cooling period. The results indicated that response surfaces, generated as a function of relative humidity or relative evaporation rate (instead of time), could be used to estimate water composition for the overall performance assessment model. The results of this model are presented below.

\subsubsection{Salt Precipitation Results}

The purpose of the simplified binary salts model was to derive a set of bounding analyses for the timing, accumulation, and total amount of salts that accumulate and dissolve in the drift and the effects of these salts and evaporative processes on the chemical composition of the water. The model considered the elements $\mathrm{Al}, \mathrm{C}, \mathrm{Ca}, \mathrm{Cl}, \mathrm{F}, \mathrm{Fe}, \mathrm{H}, \mathrm{K}, \mathrm{Mg}, \mathrm{N}, \mathrm{Na}, \mathrm{S}$, and $\mathrm{Si}$. The incoming seepage water for these calculations was average $\mathrm{J}-13$ well water.

To initialize the simplified binary salts model, separate EQ3/6 evaporation calculations using a non-Pitzer database were performed. These simulations predicted that $\mathrm{Na}, \mathrm{Si}, \mathrm{S}, \mathrm{Cl}, \mathrm{K}, \mathrm{N}$, and F, would increase in concentration in proportion to the amount of vaporization as the ionic strength increased to 1 molal. Changes in carbonate concentrations were similar, but some deviation from direct proportionality occurred. The fugacity of carbon dioxide for the periods modeled ranged from $10^{-10}$ to $10^{-4}$ bars. As the water became more saline and approached an ionic strength of 1 molal, the $\mathrm{pH}$ increased to values between 10.3 and 11.7 (CRWMS M\&O 1998 [DIRS 100358], Section 4.6.2.2.3.1).

Precipitation reactions in the thermodynamic database caused concentrations of $\mathrm{Ca}, \mathrm{Al}, \mathrm{Mg}$, and $\mathrm{Fe}$ to decrease or remain essentially unchanged as water vaporized in the EQ3/6 calculations. As a result, approximately 98 percent or more of these dissolved components were precipitated as 
the seepage water became 98 percent vaporized. Ca concentrations were controlled primarily by calcite.

After evaporation of the average J-13 well water to 1 molal ionic strength using EQ3/6, Na and $\mathrm{K}$ accounted for more than 99.9 percent of the remaining positive charge. As a result, $\mathrm{Na}$ and $\mathrm{K}$ salts were responsible for the overwhelming majority of all salt precipitation in the late stage evaporation calculations of the simplified binary salts model, and the elements $\mathrm{Si}, \mathrm{Cl}, \mathrm{S}, \mathrm{C}, \mathrm{F}$, and $\mathrm{N}$ and their stable hydrolyzed species were the primary sources of negative charge.

A spreadsheet was used to implement the simplified binary salts model for the late stage evaporation calculations. Normative binary salts were chosen to precipitate based on handbook solubilities, relative ion activity products, and conservation of mass and charge. All Ca precipitated as calcite due to its low solubility and an excess of carbonate. Next, sodium sulfate precipitated. The high concentration of sodium relative to sulfate caused the complete depletion of sulfate while depleting the sodium concentration by approximately 20 percent.

The simplified binary salts model was not capable of predicting the changes in $\mathrm{pH}$. Because silica salt solubility is a function of $\mathrm{pH}$ at high $\mathrm{pH}$, it was difficult to determine which salt would be the last to precipitate. Based on J-13 well water evaporation experiments, it was determined that nitrate would precipitate last along with potassium due to its high solubility (BSC 2001 [DIRS 155640], Section 6.4.2). Because there was slightly more nitrate than potassium in the reflux water, some nitrate was precipitated as sodium nitrate. Consistent with mass balance and charge balance constraints, the rest of the components, $\mathrm{Na}, \mathrm{Cl}, \mathrm{C}, \mathrm{F}$, and $\mathrm{Si}$, precipitated as $\mathrm{NaCl}$, $\mathrm{Na}_{2} \mathrm{CO}_{3}, \mathrm{NaHCO}_{3}, \mathrm{NaF}, \mathrm{Na}_{2} \mathrm{Si}_{2} \mathrm{O}_{5}$, and $\mathrm{Na}_{2} \mathrm{SiO}_{3}$. The total accumulation of these normative salts on the waste package was directly proportional to the seepage rate.

\subsubsection{Salt Dissolution Results}

During the boiling period in the repository, the simplified binary salts model analysis predicted that the high temperature and low relative humidity would cause all normative salts to precipitate and all seepage water to vaporize (CRWMS M\&O 1998 [DIRS 100358]). The dissolution (deliquescence) of salt phases was essentially instantaneous once the relative humidity exceeded the maximum allowed for a stable solid phase. Such rapid dissolution is consistent with the observation that puddles of dissolved salt (primarily $\mathrm{NaCl}$ brine) occur overnight on salt flats of the Persian Gulf when the relative humidity rises above the maximum equilibrium relative humidity for solid-phase $\mathrm{NaCl}$ but remains far below the dew point (Kinsman 1976 [DIRS 100769]). These same puddles then dry up during the day as soon as the relative humidity falls below the critical relative humidity.

In the simplified binary salts model analysis, the first critical value of relative humidity encountered as the potential drift cooled was determined to correspond to the nitrate phases. In this previous model, at about 160 years, the relative humidity was predicted to rise above 50 percent and the temperature to fall to about $117^{\circ} \mathrm{C}$ (CRWMS M\&O 1998 [DIRS 100358]). This was taken to be the approximate relative humidity value that would cause $\mathrm{NaNO}_{3}$ to dissolve. Also, the temperature at this time was below the boiling point of a concentrated solution of $\mathrm{NaNO}_{3}$, which is approximately $120^{\circ} \mathrm{C}$ (Saxton et al. 1928 [DIRS 127320], V. 3, p. 326). Thus, all solid-phase $\mathrm{NaNO}_{3}$, condensing water vapor from the in-drift air, deliquesced 
to a sodium nitrate brine. At the same time, $\mathrm{KNO}_{3}$, which has hygroscopic properties similar to $\mathrm{NaNO}_{3}$, was allowed to dissolve completely into the brine.

The next threshold in this earlier model was encountered at approximately 80 percent relative humidity around $105^{\circ} \mathrm{C}$, which corresponded to approximately 800 years (CRWMS M\&O 1998 [DIRS 100358]). $\mathrm{NaCl}, \mathrm{NaF}, \mathrm{Na}_{2} \mathrm{CO}_{3}, \mathrm{NaHCO}_{3}, \mathrm{Na}_{2} \mathrm{Si}_{2} \mathrm{O}_{5}$, and $\mathrm{Na}_{2} \mathrm{SiO}_{3}$ dissolved at this point based on their solubilities. The maximum relative humidity for $\mathrm{NaCl}$ is 76.4 percent at $80^{\circ} \mathrm{C}$ in a pure $\mathrm{NaCl}$ aqueous solution (Table 4-13).

The final threshold in this earlier model was crossed at 1,250 years when the relative humidity exceeded approximately 90 percent and the temperature was around $100{ }^{\circ} \mathrm{C}$ (CRWMS M\&O 1998 [DIRS 100358]). $\mathrm{Na}_{2} \mathrm{SO}_{4}$ was no longer stable and was determined to dissolve completely, representing the last of the highly soluble salts precipitated throughout the boiling period. This left $\mathrm{CaCO}_{3}$ as the only normative salt remaining and accumulating beyond 1,250 years.

\subsection{BASE CASE CONCEPTUAL MODEL}

The conceptual model for the IDPS model incorporates a set of processes that affect the chemical aqueous composition of water in the repository. These processes, illustrated in Figure 6-1, include evaporation, condensation, deliquescence, exchange of gases with the atmosphere, and precipitation and dissolution of salts.

The conceptual model asserts that the controlling variables in the chemical evolution of water within the drift are the drift conditions (specifically, relative humidity, temperature, and gas fugacities) and the starting composition of the incoming seepage or dust. Though interaction of seepage water or deliquesced water with other solid materials within the drift could also control the chemical evolution of the water, such interaction is not included in the base case IDPS model. The base case conceptual model also does not consider steady-state flow-through conditions. However, a steady-state flow-through model is discussed in Section 6.6.3.3 and included in the IDPS model output as an alternative conceptual model (Section 6.6.3.5, Table 6-2).

The IDPS conceptual model is based on processes expected to occur within the repository over its lifetime. In the early years, high temperatures and low values of relative humidity are expected to generate dry conditions as water boils away or evaporates completely. Seepage water that enters the drift during this period is expected to vaporize quickly, depositing its dissolved, nonvolatile constituents as salts and minerals.

In addition to these potential salt deposits, dust produced by excavation and construction activities is expected to settle onto the drip shield and waste package surface. Deliquescent salts in the dust can absorb water, resulting in the formation of brines that may be corrosive to these surfaces.

Over time, temperature will fall and relative humidity will rise. At some point, the relative humidity will rise to a point at which the brine of a salt is more stable than the solid phase. For sodium nitrate at $100^{\circ} \mathrm{C}$, the critical relative humidity that defines the cutoff between liquid and solid is around 65 percent for a pure aqueous solution of sodium nitrate (Table 4-13). Thus, if 
sodium nitrate is the most soluble and hygroscopic salt deposited from the evaporation of incoming seepage water, wet conditions will persist whenever the relative humidity exceeds about 65 percent. The critical relative humidity will vary depending on the concentrations of other ions in the mixed salts system. If a calcium chloride salt is the most soluble and hygroscopic salt deposited, the critical relative humidity would be around 22 percent (BSC 2001 [DIRS 155640], p. 29) or lower depending on the abundance of additional soluble components.

As the relative humidity continues to rise with time, the activity of water rises and precipitated salts either dissolve completely or to saturation. For example, halite will dissolve into an initial sodium nitrate brine to maintain saturation with respect to halite. Because the sodium concentration is already high in the sodium nitrate brine, little halite will dissolve before halite saturation is reached. As the mole fraction of water rises due to increasing relative humidity, the sodium concentration effectively becomes more dilute, allowing for additional halite dissolution. Eventually, this effective dilution process exhausts the halite in the system at a relative humidity near the critical relative humidity for halite, approximately 76 percent at $80^{\circ} \mathrm{C}$ (Table 4-13).

In the conceptual model, the effects of relative humidity and temperature on the evaporation and dilution processes are reversible. Because the conceptual model is an equilibrium model in which the relative humidity controls the extent of evaporation or dilution, the complete evaporative evolution of the aqueous solution to a final mineral assemblage describes in reverse the deliquescence and sequential dissolution of the mineral assemblage that produces the original incoming water composition. Thus, given the incoming seepage water composition, temperature, and the fugacities of $\mathrm{O}_{2}$ (always set at atmospheric, as explained in Section 4.1.2) and $\mathrm{CO}_{2}$, the conceptual model allows a single evaporation calculation to provide predictions of aqueous and mineral compositions for the full range of relative humidity potentially encountered under the specified conditions, regardless of whether relative humidity is rising or falling.

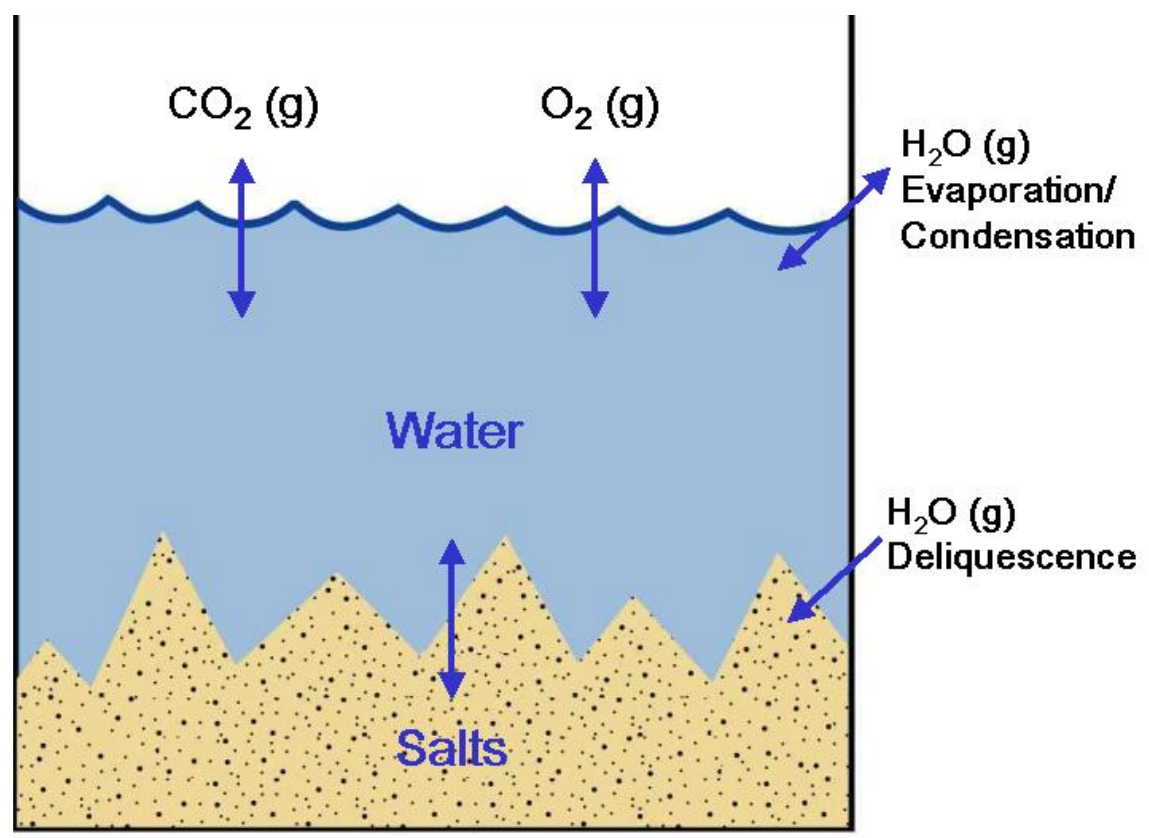

Figure 6-1. Processes Simulated by the In-Drift Precipitates/Salts Model 


\subsection{CONSIDERATION OF ALTERNATIVE CONCEPTUAL MODELS}

Uncertainties in the conceptual model arise from an incomplete understanding of processes implemented in the model. This type of uncertainty is addressed in part by identifying, developing, and evaluating alternative conceptual models.

Table 6-2 lists six alternative conceptual models for the IDPS model, each of which are defined by a unique set of equations. Five of the six are not utilized because they either are not as realistic as the IDPS model, do not provide the types of outputs requested of the IDPS model, or do not cover the necessary ranges of applicability. The one that is utilized, the steady-state alternative conceptual model, is incorporated directly into the IDPS model lookup table output files. Details of the key assumptions of these alternative conceptual models and the associated screening assessments are presented in Table 6-2.

Table 6-2. Alternative Conceptual Models Considered

\begin{tabular}{|c|c|c|}
\hline $\begin{array}{c}\text { Alternative } \\
\text { Conceptual } \\
\text { Model }\end{array}$ & Key Assumptions & Screening Assessment and Basis \\
\hline $\begin{array}{l}\text { Ion } \\
\text { Association } \\
\text { Model }\end{array}$ & $\begin{array}{l}\text { Non-ideal ion interaction can be } \\
\text { adequately modeled using an ion } \\
\text { association approach, such as } \\
\text { the Davies equation or B-dot } \\
\text { equation. }\end{array}$ & $\begin{array}{l}\text { This model was not utilized because it cannot be used at the } \\
\text { high ionic strengths of extensively evaporated natural waters. } \\
\text { The IDPS model utilizes a Pitzer ion interaction model, which can } \\
\text { be used at high ionic strength and low ionic strength. At low } \\
\text { ionic strength, ion association and ion interaction models provide } \\
\text { nearly identical results, as illustrated in Section 7.3. }\end{array}$ \\
\hline $\begin{array}{l}\text { Steady-State } \\
\text { Model }\end{array}$ & $\begin{array}{l}\text { The flow-through of incoming } \\
\text { seepage water is too rapid to } \\
\text { allow local equilibrium with } \\
\text { respect to } R H \text { (Section 6.6.3.3, } \\
\text { Figure 6-3). }\end{array}$ & $\begin{array}{l}\text { This model is included in the current IDPS model (Section } \\
6.6 .3 .3) \text { and cross-referenced in the model lookup tables } \\
\text { (Section 6.6.3.5). It can be implemented if two parameter values } \\
\text { are determined prior to use: } 1 \text { ) the relative evaporation rate }\left(R^{e s}\right) \\
\text { at the location being modeled, and } 2 \text { ) the precise composition of } \\
\text { the incoming water (or the approximate concentration factor of } \\
\text { an abstracted incoming water). }\end{array}$ \\
\hline $\begin{array}{l}\text { Simplified } \\
\text { Binary Salt } \\
\text { Model }\end{array}$ & $\begin{array}{l}\text { Evaporative evolution of a } \\
\text { potential incoming ground water } \\
\text { can be approximated by } \\
\text { completely precipitating } \\
\text { components of lowest normality } \\
\text { upon chemical saturation with } \\
\text { respect to binary salts as } \\
\text { evaporation occurs. }\end{array}$ & $\begin{array}{l}\text { This model is a predecessor to the IDPS model (Section 6.3.4). } \\
\text { Unlike the IDPS model, it does not account for } \mathrm{CO}_{2} \text { dissolution or } \\
\text { degassing or the effects of } \mathrm{pH} \text {, ionic strength, and incomplete } \\
\text { depletion of dissolved solids. Also, the simplified binary salt } \\
\text { model cannot be used to predict all of the IDPS model outputs, } \\
\text { such as pH and concentrations of aqueous species that } \\
\text { potentially contribute to acid-neutralizing capacity. }\end{array}$ \\
\hline $\begin{array}{l}\text { SNORM } \\
\text { (Bodine and } \\
\text { Jones } 1986 \\
\text { [DIRS } \\
\text { 162352]) }\end{array}$ & $\begin{array}{l}\text { An equilibrium normative salt } \\
\text { assemblage at complete } \\
\text { evaporation can be predicted } \\
\text { from an aqueous solution } \\
\text { composition without predicting } \\
\text { the evaporative evolution of the } \\
\text { aqueous solution. }\end{array}$ & $\begin{array}{l}\text { This model was not utilized because predicting the evaporative } \\
\text { evolution of the aqueous solution is the primary modeling } \\
\text { objective. SNORM cannot predict the evaporative evolution of } \\
\text { the aqueous solution. SNORM also is not capable of making } \\
\text { predictions at temperatures other than } 25^{\circ} \mathrm{C} \text { or making } \\
\text { predictions involving silica or aluminum. The IDPS model can } \\
\text { make these predictions. }\end{array}$ \\
\hline $\begin{array}{l}\text { Kinetic } \\
\text { Model }\end{array}$ & $\begin{array}{l}\text { Slow reactions are to be } \\
\text { modeled using kinetic rate } \\
\text { equations. }\end{array}$ & $\begin{array}{l}\text { Kinetic rate equations are not utilized in the IDPS model because } \\
\text { the IDPS model is designed to produce model abstractions that } \\
\text { are necessarily independent of time. Slow redox reactions are } \\
\text { excluded from the IDPS model and sufficiently slow mineral } \\
\text { precipitation reactions are prevented by suppression (Section } \\
6.6 .2 .6 \text { ). Thus, the IDPS model is a quasi-equilibrium model. }\end{array}$ \\
\hline
\end{tabular}


Table 6-2. Alternative Conceptual Models Considered (Continued)

\begin{tabular}{|l|l|l|}
\hline $\begin{array}{l}\text { Alternative } \\
\text { Conceptual } \\
\text { Model }\end{array}$ & \multicolumn{1}{|c|}{ Key Assumptions } & \multicolumn{1}{c|}{ Screening Assessment and Basis } \\
\hline $\begin{array}{l}\text { Closed } \\
\text { System } \\
\text { Model with } \\
\text { respect to } \\
\mathrm{CO}_{2}\end{array}$ & $\begin{array}{l}\text { Carbonate exchange with the } \\
\text { gas phase via } \mathrm{CO}_{2} \text { degassing or } \\
\text { dissolution results in a } \\
\text { corresponding increase or } \\
\text { decrease of } \mathrm{CO}_{2} \text { in the gas } \\
\text { phase. }\end{array}$ & $\begin{array}{l}\text { A closed system with respect to } \mathrm{CO}_{2} \text { is not implemented in the } \\
\text { IDPS model because the expected volume ratio of air to water in } \\
\text { the drift is so large that } \mathrm{CO}_{2} \text { degassing from, or dissolution into, } \\
\text { seepage water in the drift would negligibly affect the } \mathrm{CO}_{2} \text { fugacity } \\
\text { compared to the uncertainty in the input value for } \mathrm{CO}_{2} \text { fugacity. } \\
\text { To address this issue further, the IDPS model is used to quantify } \\
\text { the output uncertainty resulting from the uncertainty in } \mathrm{CO}_{2} \\
\text { fugacity in Engineered Barrier System: Physical and Chemical } \\
\text { Environment Model (BSC 2004 [DIRS 169860]). }\end{array}$ \\
\hline
\end{tabular}

\subsection{MODEL FORMULATION FOR BASE CASE MODEL}

The mathematical IDPS model is designed to simulate the conceptual model. As detailed in Section 1, the intended use of this model is to estimate and tabulate, within an appropriate level of confidence (as defined in Section 7), the effects of evaporative processes and potential environmental conditions on the $\mathrm{pH}$, ionic strength, deliquescence relative humidity, and chemical compositions of water and minerals on the drip shield or other location within the drift during the postclosure period. Per Section 2.2.1.1 of the TWP (BSC 2004 [DIRS 171156]), the IDPS model has a moderate impact on dose estimates and therefore warrants a validation level of II.

The current IDPS model covers two predominant regimes. The first regime occurs at low relative humidity $(R H<98$ percent) where the solubilities of "soluble" salts begin to control the water chemistry. In this regime, incoming seepage water either evaporates completely (e.g., during the boiling period), thereby precipitating all dissolved solids of the seepage water, or it evaporates to a stable brine (e.g., during the early cool-down period). This regime also includes the realm of deliquescence, which occurs when $R H$ rises to a level at which a hygroscopic salt is no longer stable in solid form. This first regime generally requires the use of Pitzer equations because the ionic strength of water in equilibrium with the relative humidity $(R H<98$ percent) is generally around 1 molal or higher. This model regime is simulated using the geochemical code EQ3/6 Version 8.0 and the Pitzer database developed in Appendix I.

In the second regime, $R H$ is 98 percent or higher. In this regime, the steady-state water composition can be more precisely controlled by the ratio of the rates of evaporation and seepage $\left(Q^{e} / Q^{s}\right)$. This ratio is always less than one in this regime. If it were not, steady-state conditions would either be dry (if $R H$ were sufficiently low) or consist of a steady-state brine, either of which is simulated in the first regime. This regime is also simulated using the geochemical code EQ3/6 Version 8.0. However, the thermodynamic database for this regime can either be the Pitzer database developed in Appendix I or the data0.ymp.R2 thermodynamic database (DTN: MO0302SPATHDYN.000 [DIRS 161756]). While the Pitzer equations are generally not required for this regime, they are accurate at low ionic strengths for major ion chemistry, as shown in Section 7.3. 


\subsubsection{Mathematical Description of Base Case Model}

The IDPS model uses the code EQ3/6 Version 8.0 to execute the mathematical formulation of the conceptual model. A general description of the IDPS mathematical model is presented below. A full discussion of the relevant equations is presented in the appendices of the EQ3/6 user's manual (SNL 2003 [DIRS 162494]).

EQ3/6 consists of two primary codes, EQ3NR and EQ6. EQ3NR is a speciation-solubility code designed to predict equilibrium aqueous species concentrations and to compute the degree of disequilibrium with respect to mineral phases, oxidation-reduction reactions, and various other phases and reactions. EQ6 is a companion code that takes the results of executed EQ3NR runs and performs reaction path calculations, such as evaporation, mineral precipitation, and mineral dissolution.

The governing equations consist primarily of mass balance and mass action equations. Mass balance equations ensure that the total mass of each chemical component (e.g., $\mathrm{Na}, \mathrm{K}, \mathrm{Ca}, \mathrm{Mg}$, $\mathrm{Cl}, \mathrm{SO}_{4}$, etc.) is conserved, and mass action equations ensure that each chemical reaction involving these components achieves equilibrium, if equilibrium is desired.

The total mass of each component in solution is distributed among all aqueous species involving the component. The aqueous mass balance equation for each component is the cumulative mass of the component among all aqueous species involving the component multiplied by the appropriate stoichiometric coefficients. For example, the aqueous mass balance equation for $\mathrm{F}$ would be:

$$
m_{T, F}=m_{F^{-}}+m_{H F(a q)}+2 m_{H F_{2}^{-}}+\ldots
$$

where $m_{T, F}$ is the total molality of $\mathrm{F}$ and $m_{i}$ is the individual molality of each aqueous species $i$ in the model. The set of species for a given component includes one basis species and a number of other species, equal to the number of reactions in the database involving the component. For F, the basis species is $\mathrm{F}^{-}$. All other species involving $\mathrm{F}$ are determined from reactions involving the basis species $\mathrm{F}^{-}$.

The reactions of the basis species are represented by mass action equations. For the chemical reaction:

$$
\mathrm{HF}_{2}^{-}=2 \mathrm{~F}^{-}+\mathrm{H}^{+}
$$

where " $="$ denotes a reversible reaction, the mass action equation is:

$$
K_{H F_{2}^{-}}=\frac{a_{F^{-}}^{2} a_{H^{+}}}{a_{H F_{2}^{-}}}
$$

where $K_{i}$ is the equilibrium constant of species $i$ and $a_{i}$ is the thermodynamic activity. The equilibrium constant for each species is provided by the thermodynamic database. At 
equilibrium, the value of the term on the right-hand side of this equation equals the equilibrium constant.

The thermodynamic activity $a_{i}$ is related to the molal concentration $m_{i}$ by the equation:

$$
a_{i}=m_{i} \gamma_{i}
$$

where $\gamma_{i}$ is the activity coefficient. The activity coefficient is used to correct for non-ideal behavior that occurs when the aqueous solution is not highly dilute. Calculation of the activity coefficient depends on the model chosen. For the Pitzer ion interaction model, Pitzer equations are used, as described in Appendix I.

Substituting Equation 6.6.1-4 into Equation 6.6.1-3 gives:

$$
K_{H F_{2}^{-}}=\frac{m_{F^{-}}^{2} \gamma_{F^{-}}^{2} m_{H^{+}} \gamma_{H^{+}}}{m_{H F_{2}^{-}} \gamma_{H F_{2}^{-}}}
$$

which shows how the molalities of the reactants and products relate to the reaction equilibrium constant and the mass action equation.

Each mass action equation can be solved for the molality of the non-basis species (e.g., $\mathrm{HF}_{2}{ }^{-}$). The resulting functions can then be substituted into the mass balance equations to generate equations in which the only unknowns are the molalities of the basis species. Doing this for each component generates a set of $n$ equations and $n$ unknowns, which is solved in EQ3/6 using variations of the Newton-Raphson iteration method (SNL 2003 [DIRS 162494]). The solution to these equations provides basis species concentrations that are then used to calculate the concentrations of each non-basis species via the mass action equations. By solving this set of equations simultaneously, the code can calculate equilibrium concentrations for each included chemical reaction while also maintaining mass balance for each component.

In some cases, the total component concentration is not an input. For example, the total hydrogen concentration is not a convenient measurement or bound for an aqueous model. Instead, another parameter, such as $\mathrm{pH}$, is often used as the input value. The activity of the basis species $\mathrm{H}^{+}$can be directly computed from the $\mathrm{pH}$ using the equation:

$$
a_{H^{+}}=10^{-\mathrm{pH}}
$$

This value can then be converted to molality using the relation given in Equation 6.6.1-4. Thus, the molality of the basis species $\mathrm{H}^{+}$becomes a known value, and the total hydrogen mass balance equation is no longer needed to constrain the system.

In the case of a fixed fugacity of carbon dioxide, the activity of the carbonate basis species $\mathrm{HCO}_{3}{ }^{-}$can be determined explicitly from the $\mathrm{pH}$ and the equilibrium constant relating $\mathrm{HCO}_{3}{ }^{-}$to carbon dioxide. The relevant chemical reaction in the Pitzer database developed in Appendix I (DTN: SN0302T0510102.002) is: 


$$
\mathrm{CO}_{2}(\mathrm{~g})+\mathrm{H}_{2} \mathrm{O}=\mathrm{HCO}_{3}^{-}+\mathrm{H}^{+}
$$

which has an associated equilibrium constant $K_{\mathrm{CO}_{2}(g)}$. The mass action equation for this reaction is:

$$
K_{\mathrm{CO}_{2}(g)}=\frac{a_{\mathrm{HCO}_{3}^{-}} a_{\mathrm{H}^{+}}}{a_{\mathrm{CO}_{2}(g)} a_{\mathrm{H}_{2} \mathrm{O}}}
$$

When the $\mathrm{pH}$ is known, the activity of the hydrogen ion is determined directly from Equation 6.6.1-6. The activity of carbon dioxide is equivalent to the known fixed fugacity. Thus, the only two unknowns in Equation 6.6.1-8 are the activities of $\mathrm{HCO}_{3}{ }^{-}$and $\mathrm{H}_{2} \mathrm{O}$.

In dilute solutions (e.g., ionic strength less than 0.1 molal), the activity of $\mathrm{H}_{2} \mathrm{O}$ is approximately one, and Equation 6.6.1-8 can be solved directly for the activity of $\mathrm{HCO}_{3}{ }^{-}$. Another way to solve for the activity of $\mathrm{HCO}_{3}{ }^{-}$is to allow equilibrium with a fixed relative humidity because at equilibrium the activity of $\mathrm{H}_{2} \mathrm{O}$ is equivalent to the relative humidity. However, because relative humidity is an output of the titration and not an input, the activity of $\mathrm{H}_{2} \mathrm{O}$ must be determined based on the molalities of all other aqueous species in solution. For EQ3/6, the equation used to calculate the activity of $\mathrm{H}_{2} \mathrm{O}$ and its derivation can be found in the EQ3/6 user's manual (SNL 2003 [DIRS 162494], pp. B-28 to B-29). After estimating the activity of $\mathrm{H}_{2} \mathrm{O}$, solving Equation 6.6.1-8 for the activity of $\mathrm{HCO}_{3}{ }^{-}$, and converting the $\mathrm{HCO}_{3}{ }^{-}$activity to molality using Equation 6.6.1-4, the molality of the carbonate basis species $\mathrm{HCO}_{3}{ }^{-}$is no longer an unknown. As a result, the total dissolved carbonate molality mass balance equation is no longer a constraint on the system, and the total molality of dissolved carbonate becomes an output of the model instead of an input.

In the IDPS model, the fugacity of carbon dioxide is fixed in the EQ6 input file. Because EQ6 is a reaction path code and the solution is previously equilibrated using EQ3NR, EQ6 effectively adds or subtracts dissolved carbon dioxide to bring the solution into equilibrium with the fixed fugacity. When $\mathrm{CO}_{2}(\mathrm{aq})$ is added to the solution, it acts like an acid according to the reaction in Equation 6.6.1-7. In accordance with Le Chatelier's principle, the increase in reactants results in an increase in products such that the overall effect on the system is minimized. Thus, addition of $\mathrm{CO}_{2}$ (aq) results in an increase in $\mathrm{HCO}_{3}{ }^{-}$and $\mathrm{H}^{+}$, implying a decrease in $\mathrm{pH}$. Subtraction of $\mathrm{CO}_{2}$ (aq) has the opposite effect. In effect, EQ6 titrates (or "de-titrates") the solution with dissolved carbon dioxide until the fixed fugacity of carbon dioxide is achieved.

Evaporation of water is also a process that is simulated using EQ6. For evaporation, $\mathrm{H}_{2} \mathrm{O}$ is incrementally removed from solution. Each incremental removal of $\mathrm{H}_{2} \mathrm{O}$ causes the total molalities of the aqueous components to change. As a result, the IDPS model system must be re-equilibrated after each incremental removal of $\mathrm{H}_{2} \mathrm{O}$ (i.e., the set of $n$ equations and $n$ unknowns must be solved again using revised total molalities of components). In this way, the evolution of the solution can be predicted as evaporation occurs.

Mineral precipitation also affects the total molalities of aqueous components. Mineral precipitation occurs in EQ6 when the solution becomes supersaturated with respect to a mineral phase. As an example, the anhydrite mineral reaction is presented: 


$$
\mathrm{CaSO}_{4}(\mathrm{~s})=\mathrm{Ca}^{2+}+\mathrm{SO}_{4}^{2-}
$$

The corresponding mass action equation is:

$$
K_{\mathrm{CaSO}_{4}(s)}=\frac{a_{\mathrm{Ca}^{2+}} a_{\mathrm{SO}_{4}^{2-}}}{a_{\mathrm{CaSO}_{4}(s)}}
$$

The mass action equation for a mineral phase does not constrain the model unless the ion activity product (IAP) equals or potentially exceeds the equilibrium constant. The IAP is the term on the right-hand side of the mass action equation as presented in Equation 6.6.1-10. By convention, the activity of a pure solid phase is always one; thus, only the activities of aqueous basis species are important to the IAP.

If the solution to the set of $n$ equations and $n$ unknowns indicates that the IAP of a mineral exceeds the mineral's equilibrium constant, then either the solution will be supersaturated with respect to the mineral or the code will precipitate the mineral. In the IDPS model, suppressed minerals are allowed to be supersaturated while unsuppressed minerals are required to precipitate to saturation. Thus, only unsuppressed mineral phases can constrain the IDPS model system.

Precipitation of a mineral phase moves a portion of the masses of the mineral components from the aqueous phase to the solid phase. This process requires adjustments to the total dissolved concentrations of the precipitating aqueous components and their corresponding mass balance equations. The exact amount of precipitation is determined by iteration. At equilibrium, the IAP for the precipitating mineral equals the mineral equilibrium constant, and the total masses of the mineral's components are conserved between the aqueous and solid phases.

\subsubsection{Base Case Model Inputs and Boundary Conditions}

\subsubsection{Seepage Water Composition}

The elements in the model include $\mathrm{Na}, \mathrm{K}, \mathrm{Ca}, \mathrm{Mg}, \mathrm{Cl}, \mathrm{F}, \mathrm{C}, \mathrm{S}, \mathrm{N}, \mathrm{Br}, \mathrm{Si}, \mathrm{Al}, \mathrm{H}$, and O. Except for $\mathrm{H}$ and $\mathrm{O}$, the incoming seepage water composition $\left(C_{i}^{s}\right)$ for each element is defined by the total aqueous concentration of the corresponding basis species. For the Pitzer database, the corresponding basis species are $\mathrm{Na}^{+}, \mathrm{K}^{+}, \mathrm{Ca}^{2+}, \mathrm{Mg}^{2+}, \mathrm{Cl}^{-}, \mathrm{F}^{-}, \mathrm{HCO}_{3}{ }^{-}, \mathrm{SO}_{4}{ }^{2-}, \mathrm{NO}_{3}{ }^{-}, \mathrm{Br}^{-}, \mathrm{SiO} 2(\mathrm{aq})$, and $\mathrm{Al}^{3+}$. $\mathrm{O}$ and $\mathrm{H}$ are found in several of these basis species, but their elemental totals are almost entirely accounted for in the $1 \mathrm{~kg}$ of water solvent used to initialize each EQ3/6 run. Defining the mass of solvent is necessary for calculating the corresponding masses of the other components from their input concentrations. In addition, the negative log of the activity of the hydrogen ion is defined by entering the $\mathrm{pH}$ of the incoming seepage water.

\subsubsection{Time Period Modeled}

To capture the effects of time in the repository, time is divided into discrete periods in which the incoming seepage water composition is fairly constant. Thus, for each time period, the incoming seepage water composition is constant while the relative humidity, temperature, and gas 
fugacities are varied over their potential ranges. Because chemical equilibrium conditions are assumed for each time period, time itself is not an input to the model.

\subsubsection{Locations Modeled}

The IDPS model can be used to describe evaporative processes at any location where evaporative or condensation processes occur. Possible locations are on the drip shield and on the waste package surface.

\subsubsection{Temperature, Gas Composition, and Relative Humidity}

Temperature, gas composition, and relative humidity in the drift environment will change over time. The thermodynamic database is designed for a temperature range from 0 to $200^{\circ} \mathrm{C}$ (though only validated to $140^{\circ} \mathrm{C}$ here). Discrete values are chosen for temperature and the fugacities of oxygen and carbon dioxide. The fugacity of oxygen is set at atmospheric for all applications. Relative humidity, however, is varied over the entire range from 100 percent to the critical relative humidity below which no water solvent remains. Because relative humidity is not an identified input or output parameter in EQ3/6, the activity of water is the actual parameter that is allowed to vary over this range. The activity of water is equivalent to the relative humidity at equilibrium (Section 6.3.1). To evaporate a given water to the lowest relative humidity possible, an input value of 0 is entered for the final activity of water.

\subsubsection{Relative Evaporation Rate}

Relative evaporation rate can potentially become important under steady-state flow-through conditions. The relative evaporation rate $\left(R^{e s}\right)$ [units: nondimensional] is defined by the equation:

$$
R^{e s}=\frac{Q^{e}}{Q^{s}}
$$

where $Q^{e}$ is the steady-state net evaporation rate [units: volume/time] and $Q^{s}$ is the incoming seepage rate [units: volume/time]. As explained in Section 6.6.3.3, seepage rates that exceed net evaporation rates can create flow-through conditions that generate a steady-state sustained disequilibrium between the relative humidity and the activity of water in the solution.

The model is designed for a range of $R^{e s}$ from -99 to 1 . Negative values indicate condensation of water vapor. At steady state, the net evaporation rate cannot exceed the seepage rate (i.e., $R^{e s}$ cannot exceed 1) without achieving dry conditions.

$R^{e s}$ can be directly related to the concentration factor $(C F)$ [units: nondimensional] of a conservative ion in the starting water. A conservative ion is an ion that does not precipitate and therefore concentrates in proportion to the concentration factor of the water. For example, if $R^{e s}$ is 0.9 , then at steady state, the incoming water will evolve to a steady state in which the concentration of a conservative ion is 10 times the incoming concentration, i.e., a $C F$ of 10 . This relationship is described by the following equation: 


$$
C F=\frac{1}{1-R^{e s}}
$$

Alternatively, a value of -99 for $R^{e s}$ is equivalent to $C F$ of 0.01 . Concentration factors less than one indicate condensation of water vapor. Defining a dilution factor $(D F)$ [units: nondimensional] as the inverse of $C F$ :

$$
D F=\frac{1}{C F}
$$

it would follow that the $D F$ would be 100 for a $R^{e s}$ value of -99 , implying that the original starting water is diluted 100 -fold by the condensation of pure water vapor.

Version 8.0 of EQ3/6 does not provide for a solid-centered flow-through mode, which would be needed to directly simulate the relative rates of evaporation and seepage. However, because $R^{e s}$ is related to $C F$ by Equation 6.6.2.5-2, all that is required in the calculations is that a sufficient amount of pure water be subtracted or added to the starting water to achieve the $C F$ corresponding to the $R^{e s}$ desired. One additional equation is needed for this because $C F$ must be calculated from the EQ3/6 output, and there are no conservative ions that stay conservative for the entire range of concentration factors. Therefore, the best estimate of $C F$ is provided by the relative amount of solvent water remaining (or accumulating) at each stage of evaporation (or condensation).

Each EQ3/6 run is designed to begin with $1 \mathrm{~kg}$ of water solvent. Dividing the original amount of water solvent $(1 \mathrm{~kg})$ by the amount of water solvent in the system at any point during evaporation or condensation defines the $C F$ for the IDPS model. That is:

$$
C F=\frac{M_{H 2 O}^{o}}{M_{H 2 O}}
$$

where $M_{H_{2} O}^{o}$ is the original mass of water solvent in the system $(1 \mathrm{~kg})$ and $M_{H_{2} O}$ is the mass of water solvent after evaporation or condensation.

\subsubsection{Mineral Suppressions}

To understand the technical basis for why minerals are included in, or excluded from, applications of the IDPS model, such as applications documented in Engineered Barrier System: Physical and Chemical Environment Model (BSC 2004 [DIRS 169860]), it is important to establish a framework for the selection of suppressed minerals. This framework is established in the subsections below for the anticipated geochemical boundary conditions at Yucca Mountain.

\subsection{Geochemical Modeling Methodology}

Generally, a reaction path geochemical equilibrium model is constructed using the steps outlined in Figure 6-2. First, a conceptual model is defined where the chemical system and state are defined. Constructing a first-order model tests this system and state. A first-order model generally simulates complete thermodynamic equilibrium. Results of the first-order model are 
compared with independent experimental, natural analogue, or other modeling data to ensure that the model is reasonable for the system. If mineral phases are predicted to occur that are not appropriate for the system or timeframe being analyzed, then the precipitation/dissolution reactions involving these minerals should be suppressed.

Below is a brief summary of the importance of kinetics in determining whether a mineral phase should be suppressed. Detailed discussions of various aspects of this modeling methodology are documented elsewhere (Bethke 1996 [DIRS 162270]; Smith and Missen 1991 [DIRS 161602]; Van Zeggeren and Storey 1970 [DIRS 161603]).

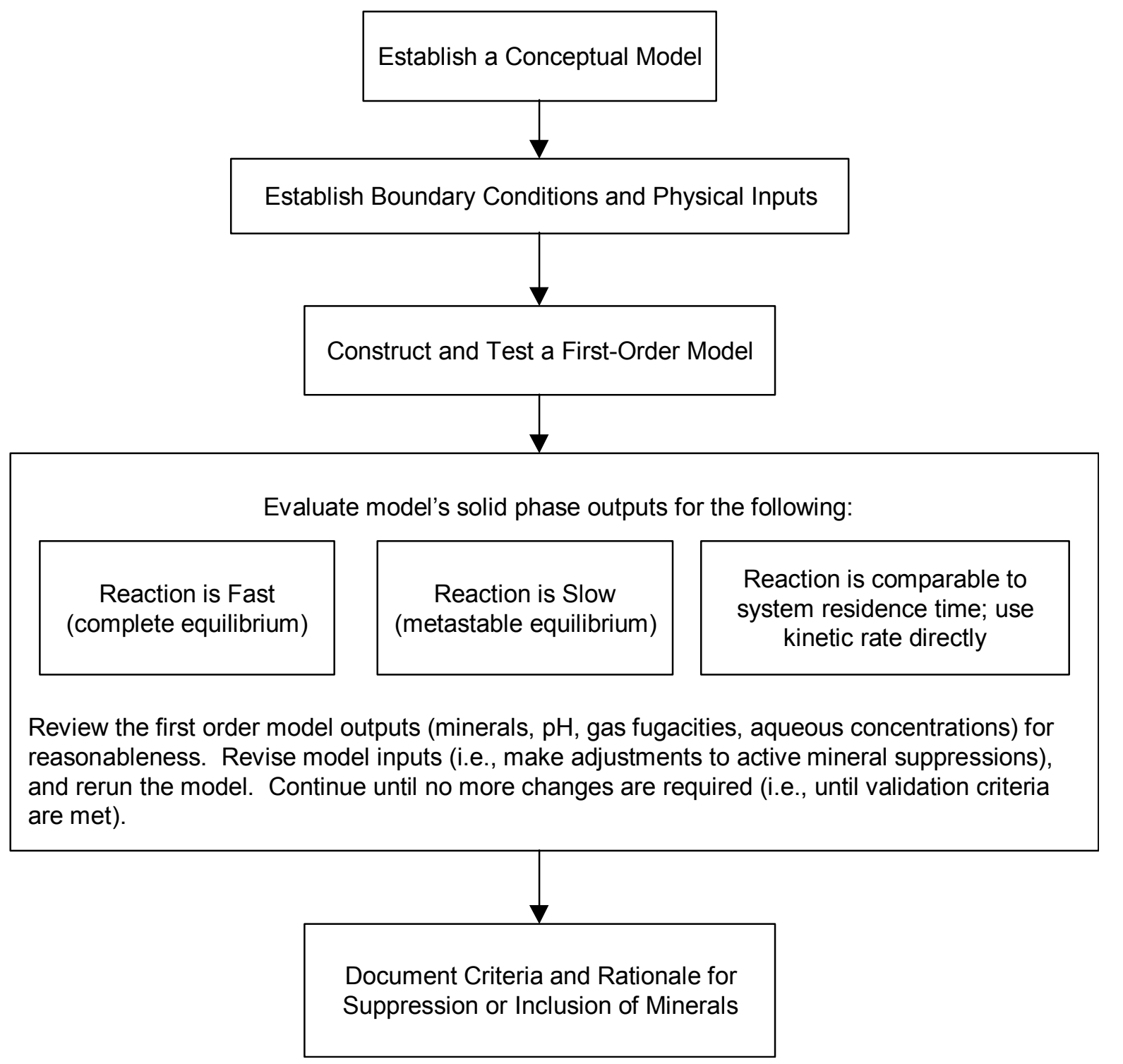

Figure 6-2. General Process Required to Give a Valid Technical Basis for Mineral Suppression or Inclusion in Geochemical Equilibrium Modeling 


\subsection{Metastable Equilibrium}

The IDPS model is designed to predict long-term chemical processes occurring within the repository drift. "Long-term" for this model can vary from weeks to millennia, consistent with the abstracted time periods that the model is designed to simulate. While relatively short-term occurrences, such as a drop of water falling onto the drip shield, can cause sporadic divergence from equilibrium for a short period of time, a metastable local equilibrium approach is adopted for this model (Assumption 5.2). This approach generally represents the long-term processes that the model is designed to simulate.

An equilibrium reaction path model relies upon a thermodynamic database that contains the standard state and equation-of-state thermo-chemical properties of the different chemical species in a system to determine the chemical reaction equilibria as functions of the changing conditions. In addition to the homogeneous reactions that occur within each phase (e.g., water, gas, solid), there are heterogeneous reactions that involve more than one phase, such as mineral precipitation and degassing of volatile constituents from the aqueous phase.

Most of the reactions in the IDPS model are rapid relative to the timeframe of the modeling period; therefore, most reactions are allowed to reach local equilibrium. However, there are several minerals in the thermodynamic database that are not expected to form under the expected conditions of the repository. These minerals typically require high pressures or high temperatures (i.e., greater than $200^{\circ} \mathrm{C}$ ) in order to achieve the kinetic rates of formation that would produce a considerable mass within the modeling timeframe. In this case, the system can be described by metastable equilibrium. Metastable equilibrium occurs when one or more chemical reactions proceed toward equilibrium at a rate that is so small on the time scale of interest that the system cannot produce a considerable quantity of the product (Bethke 1996 [DIRS 162270], Chapter 2). The rates of nucleation or growth of some minerals frequently fall into this category. This state of metastable equilibrium can be simulated in the IDPS model by suppressing slow reactions.

The pressure in the repository will remain near atmospheric, and the temperature at the drift wall will not likely rise above $200^{\circ} \mathrm{C}$ (BSC 2004 [DIRS 169856]). These conditions would prevent many minerals in the database from forming at a rate that would produce a considerable mass. By suppressing a mineral that falls into this category, the IDPS model does not allow the mineral to precipitate, allowing for potential supersaturation of that phase. The ability to suppress minerals, therefore, is necessary for equilibrium models that simulate systems in which metastable phases are more likely to occur. By suppressing unlikely minerals, slow kinetic processes can be qualitatively accounted for without knowing the precise kinetic rates of the dissolution or precipitation reactions.

\subsection{Mineral Suppression Criteria}

The Pitzer thermodynamic database developed in Appendix I contains more than 250 minerals, but only a small number of these are expected to require suppression. It is unnecessary to identify a priori every one of the 250-plus minerals that should be suppressed for the IDPS model. The limited range of chemical compositions of the waters likely to occur within the drift dictates that a large number of these minerals will never achieve a chemical potential favoring 
precipitation. Preliminary IDPS model runs for more than 40 different observed and predicted water compositions at Yucca Mountain have been evaporated to dryness, yet fewer than 40 minerals have become saturated or supersaturated with respect to the aqueous composition. Of these, 12 are identified for suppression in the IDPS model (Section 6.6.2.6.4).

A methodology was developed to identify mineral phases to suppress in the IDPS model. Five criteria were developed to assist in determining the justification for suppression in the model in order to account for the kinetic or metastable equilibrium arguments stated above. An affirmative answer to any one of these criteria can be used to justify suppression of the mineral. This methodology used to categorize the minerals in Table 6-3 and Table 6-4 is recommended for categorizing additional minerals when they are initially predicted to precipitate in IDPS model applications. These five criteria, which are not mutually exclusive, are presented below.

Criterion 1. Is the mineral of interest unreasonable for the defined chemical system of the model?

If the mineral lies outside or beyond the defined chemical system of the model, then there is no reason to allow the mineral to precipitate. For example, if the reactions between rainwater and a soil derived from the weathering of mafic minerals were being modeled, a clay mineral that is known to form exclusively from authigenic minerals that are felsic in composition would not be expected. For another example, minerals known only to form at high temperature or pressure would not be expected to form in a low temperature, low pressure system.

These determinations can be made using reference sources such as Klein and Hurlbut's Manual of Mineralogy (1999 [DIRS 124293]), Kerr's Optical Mineralogy (1977 [DIRS 161606]) or another appropriate reference source that discusses the petrology or mineralogy of a given system or analogue system. One source that could be of use is a resource for the MINTEQA2 software code (Wadley and Buckley 1997 [DIRS 162329]). This source discusses the mineral forms at ambient temperature and pressure and gives comments on their occurrence or formation.

Criterion 2. Is the mineral precipitation or dissolution reaction so slow for the given system that the reaction hardly progresses at all during the timeframe of interest?

When a reaction is much slower than the residence time (for example, 100 times slower than the residence time), the reaction hardly progresses within the modeling timeframe. In this case, suppressing the mineral reaction provides results that would be nearly identical to the results of a kinetic model of the same system.

One of the most commonly suppressed minerals in EBS geochemical modeling is quartz. When precipitation initiates, amorphous phases will tend to form first, and then a process of mineral recrystallization will take place (Langmuir 1997 [DIRS 100051], p. 55). Because precipitation of quartz and other crystalline silica phases is kinetically limited at low temperature and pressure, amorphous silica is generally the metastable phase allowed to precipitate in EBS models. If instead the conceptual model were to account for a longer system residence time or higher temperatures, then the modeler would allow quartz or one of its polymorphs to precipitate.

Criterion 3. Is analytical or natural analogue information available that warrants additional mineral suppressions? 
A geochemical modeler can often find information or data from the relevant literature used to develop the conceptual model. This information often comes from analytical data or natural analog information and could warrant the suppression or inclusion of minerals that might otherwise be dispositioned differently based on an analysis using Criteria 1 and 2 . In these instances, the analytical or analogue data justify their use. This criterion allows for additional mineral suppressions that permit the formation of metastable phases observed to occur in the laboratory or natural analogue.

Criterion 4. Do minerals need to be suppressed to test overall model uncertainty or sensitivity due to reported uncertainty in the supporting literature, database, or conceptual model?

For minerals whose potential occurrence is uncertain, runs can be performed with and without suppressing the minerals to evaluate the sensitivity of the output to these minerals.

Criterion 5. Does the suppression of a mineral whose occurrence is highly uncertain drive the resulting chemical output to a more or less conservative modeling result?

A sensitivity analysis could reveal whether suppression of an uncertain potential mineral results in a more conservative output than inclusion of the mineral, or vice versa. If so, the more conservative choice could potentially be justified.

\subsection{Mineral Suppressions for the IDPS Model}

Relevant natural analogues for mineral assemblages in the IDPS and physical and chemical environment conceptual models are the evaporative mineral assemblages observed by Eugster and Hardie (1978 [DIRS 100743]) and Papke (1976 [DIRS 162274]) in the saline lakes and playa deposits of the western United States. The minerals from these types of evaporitic environments reflect the mineral assemblages that could form in a low-temperature, low-pressure, in-drift environment where the activity of water is below 0.99 and the solution compositions are comparable.

Table 6-3 provides a listing of the minerals that are suppressed in the IDPS and Physical and Chemical Environment models for the TSPA-LA. This list of minerals is documented in DTN: MO0303SPAMNSUP.000. Table 6-4 provides a listing of the minerals that have been allowed to precipitate. 
Table 6-3. Mineral Suppressions Included in the IDPS Model

\begin{tabular}{|c|c|c|c|c|}
\hline Mineral & Formula & $\begin{array}{l}\text { Criterion } \\
\text { Selected }\end{array}$ & Rationale & References \\
\hline $\begin{array}{l}\text { Cristobalite } \\
\text { (alpha) }\end{array}$ & $\mathrm{SiO}_{2}$ & Criterion 2 & $\begin{array}{l}\text { Cristobalite forms at temperatures } \\
\text { greater than } 1470^{\circ} \mathrm{C} \text {. At standard } \\
\text { temperatures and pressures } \\
\text { cristobalite will slowly convert to } \\
\text { quartz. }\end{array}$ & $\begin{array}{l}\text { Krauskopf } \\
1979 \text { [DIRS } \\
105909], \\
\text { Figure 14-1 }\end{array}$ \\
\hline Dolomite & $\mathrm{CaMg}\left(\mathrm{CO}_{3}\right)_{2}$ & Criterion 2 & $\begin{array}{l}\text { Although dolomite is a common } \\
\text { mineral in evaporite deposits from } \\
\text { springs derived from carbonate and } \\
\text { tuffaceous waters in southern Nevada } \\
\text { at Yucca Mountain, its growth } \\
\text { mechanism is slow when compared to } \\
\text { the precipitation of calcite and Mg- } \\
\text { bearing minerals. }\end{array}$ & $\begin{array}{l}\text { Vaniman et al. } \\
1992 \text { [DIRS } \\
107066 \text { ] }\end{array}$ \\
\hline Glaserite & $\mathrm{NaK}_{3}\left(\mathrm{SO}_{4}\right)_{2}$ & Criterion 4 & $\begin{array}{l}\text { Although glaserite is a mineral that is } \\
\text { expected to form in evaporitic type } \\
\text { deposits, the thermodynamic data in } \\
\text { the Pitzer database are questionable. }\end{array}$ & $\begin{array}{l}\text { Suppressed, } \\
\text { subject to } \\
\text { sensitivity } \\
\text { analysis. }\end{array}$ \\
\hline Magnesite & $\mathrm{MgCO}_{3}$ & Criterion 4 & $\begin{array}{l}\text { Magnesite is commonly associated } \\
\text { with metamorphic mineral } \\
\text { assemblages such as schist. There } \\
\text { are instances where magnesite is } \\
\text { associated with salt deposits, yet it is } \\
\text { uncertain that it can form under } \\
\text { standard temperatures and pressures } \\
\text { as magnesite could be associated } \\
\text { with the diagenesis of buried salt } \\
\text { deposits. }\end{array}$ & $\begin{array}{l}\text { Klein and } \\
\text { Hurlbut 1999 } \\
\text { [DIRS 124293], } \\
\text { p. 408; } \\
\text { Langmuir 1997 } \\
\text { [DIRS 100051], } \\
\text { p. 195; } \\
\text { Eugster and } \\
\text { Hardie 1978 } \\
\text { [DIRS 100743]; } \\
\text { Suppressed, } \\
\text { subject to } \\
\text { sensitivity } \\
\text { analysis. }\end{array}$ \\
\hline $\begin{array}{l}\text { Maximum } \\
\text { Microcline }\end{array}$ & $\mathrm{KAISi}_{3} \mathrm{O}_{8}$ & Criterion 1 & $\begin{array}{l}\text { Microcline is generally associated with } \\
\text { the formation of granite, syenite and } \\
\text { gneiss at high temperature and } \\
\text { pressure. Although it is often found } \\
\text { as a common mineral in sandstone or } \\
\text { arkose, the occurrence in these } \\
\text { instances is detrital and not } \\
\text { authigenic. }\end{array}$ & $\begin{array}{l}\text { Kerr } 1977 \\
\text { [DIRS 161606], } \\
\text { p. } 306\end{array}$ \\
\hline Quartz & $\mathrm{SiO}_{2}$ & Criterion 2 & $\begin{array}{l}\text { Amorphous silica is at metastable } \\
\text { equilibrium with respect to quartz at } \\
\text { low temperatures and pressures. } \\
\text { This is also evidenced by the } \\
\text { precipitation of opal-CT (an } \\
\text { amorphous silica phase) as opposed } \\
\text { to quartz in evaporated carbonate and } \\
\text { tuffaceous waters of southern } \\
\text { Nevada. }\end{array}$ & $\begin{array}{l}\text { Langmuir 1997 } \\
\text { [DIRS 100051]; } \\
\text { Vaniman et al. } \\
1992 \text { [DIRS } \\
\text { 107066] }\end{array}$ \\
\hline
\end{tabular}


Table 6-3. Mineral Suppressions Included in the IDPS Model (Continued)

\begin{tabular}{|c|c|c|c|c|}
\hline Mineral & Formula & $\begin{array}{l}\text { Criterion } \\
\text { Selected }\end{array}$ & Rationale & References \\
\hline Talc & $\mathrm{Mg}_{3} \mathrm{Si}_{4} \mathrm{O}_{10}(\mathrm{OH})_{2}$ & Criterion 1 & $\begin{array}{l}\text { Talc is characteristically associated } \\
\text { with low-grade metamorphic rock and } \\
\text { hydrothermal alteration of ultramafic } \\
\text { rocks. }\end{array}$ & $\begin{array}{l}\text { Klein and } \\
\text { Hurlbut } 1999 \\
\text { [DIRS } \\
124293] \\
\text { p. 514 }\end{array}$ \\
\hline $\begin{array}{l}\text { Ca-saponite } \\
\text { Mg-saponite } \\
\text { Na-saponite } \\
\text { H-saponite } \\
\text { K-saponite }\end{array}$ & $\begin{array}{l}\mathrm{Ca}_{0.165} \mathrm{Mg}_{3} \mathrm{Al}_{0.33} \mathrm{Si}_{3 \cdot 67} \mathrm{O}_{10}(\mathrm{OH})_{2} \\
\mathrm{Mg}_{3 \cdot 165} \mathrm{Al}_{0.33} \mathrm{Si}_{3 \cdot 67} \mathrm{O}_{10}(\mathrm{OH})_{2} \\
\mathrm{Na}_{0.33} \mathrm{Mg}_{3} \mathrm{Al}_{0.33} \mathrm{Si}_{3.67} \mathrm{O}_{10}(\mathrm{OH})_{2} \\
\mathrm{H}_{0.33} \mathrm{Mg}_{3} \mathrm{Al}_{0.33} \mathrm{Si}_{3.67} \mathrm{O}_{10}(\mathrm{OH})_{2} \\
\mathrm{~K}_{0.33} \mathrm{Mg}_{3} \mathrm{Al}_{0.33} \mathrm{Si}_{3.67} \mathrm{O}_{10}(\mathrm{OH})_{2}\end{array}$ & Criterion 1 & $\begin{array}{l}\text { Saponite is a smectite clay. Smectite } \\
\text { clays are commonly associated with } \\
\text { fracture linings at Yucca Mountain. } \\
\text { However, saponitic clays are } \\
\text { associated with the weathering of } \\
\text { basalt and not rhyolitic tuffs. Saponite } \\
\text { also does not generally form } \\
\text { independently from its associated } \\
\text { parent material. }\end{array}$ & $\begin{array}{l}\text { Krauskopf } \\
1979 \text { [DIRS } \\
105909] ; \\
\text { Carlos et al. } \\
1995 \text { [DIRS } \\
105213 \text { ]; Deer } \\
\text { et al 1966 } \\
\text { [DIRS } \\
\text { 102773]; } \\
\text { Borchardt } \\
\text { 1995 [DIRS } \\
\text { 156639] }\end{array}$ \\
\hline
\end{tabular}

Table 6-4. Minerals Allowed to Precipitate in the IDPS Model

\begin{tabular}{|c|c|c|c|}
\hline Mineral & Formula & Rationale for Inclusion & References \\
\hline Anhydrite & $\mathrm{CaSO}_{4}$ & $\begin{array}{l}\text { Anhydrite is associated with evaporite deposits in } \\
\text { Nevada playas. }\end{array}$ & $\begin{array}{l}\text { Papke } 1976 \text { [DIRS } \\
\text { 162274], Table 1; Kerr } \\
1977 \text { [DIRS 161606], } \\
\text { p. } 221\end{array}$ \\
\hline Arcanite & $\mathrm{K}_{2} \mathrm{SO}_{4}$ & $\begin{array}{l}\text { Arcanite is a highly soluble mineral belonging to the } \\
\text { Mascagnite group and can be precipitated in the } \\
\text { laboratory from the slow evaporation of water } \\
\text { solutions. This mineral is related to thenardite and } \\
\text { should have similar properties. }\end{array}$ & $\begin{array}{l}\text { Palache et al. } 1951 \\
\text { [DIRS 162280], pp. } 398 \\
\text { to } 400\end{array}$ \\
\hline Burkeite & $\mathrm{Na}_{6} \mathrm{CO}_{3}\left(\mathrm{SO}_{4}\right)_{2}$ & $\begin{array}{l}\text { Burkeite is a saline mineral associated with } \mathrm{Na}- \\
\mathrm{CO}_{3}-\mathrm{SO}_{4}-\mathrm{Cl} \text { brines. }\end{array}$ & $\begin{array}{l}\text { Eugster and Hardie } \\
1978 \text { [DIRS 100743], } \\
\text { Table } 3\end{array}$ \\
\hline Calcite & $\mathrm{CaCO}_{3}$ & $\begin{array}{l}\text { Calcite is a common evaporite mineral formed from } \\
\text { evaporated waters of southern Nevada. }\end{array}$ & $\begin{array}{l}\text { Vaniman et al. } 1992 \\
\text { [DIRS 107066] }\end{array}$ \\
\hline Carnallite & $\mathrm{KMgCl}_{3}: 6 \mathrm{H}_{2} \mathrm{O}$ & $\begin{array}{l}\text { Carnallite is associated with evaporite deposits in } \\
\text { Nevada playas. }\end{array}$ & $\begin{array}{l}\text { Papke 1976 [DIRS } \\
\text { 162274], Table 1; Kerr } \\
1977 \text { [DIRS 161606], } \\
\text { p. } 221\end{array}$ \\
\hline Celadonite & $\mathrm{KMgAISi}_{4} \mathrm{O}_{10}(\mathrm{OH})_{2}$ & $\begin{array}{l}\text { Although its occurrence is generally associated } \\
\text { with hydrothermally altered mafic volcanic rocks } \\
\text { and with illite-chlorite minerals, celadonite is also } \\
\text { found as an authigenic silicate mineral in saline, } \\
\text { alkaline, nonmarine environments such as playa } \\
\text { deposits. }\end{array}$ & $\begin{array}{l}\text { Li et al. } 1997 \\
\text { [DIRS 159034]; } \\
\text { Hay } 1966 \\
\text { [DIRS 105965] }\end{array}$ \\
\hline Fluorite & $\mathrm{CaF}_{2}$ & $\begin{array}{l}\text { Fluorite is associated with evaporite deposits in } \\
\text { Nevada playas. }\end{array}$ & $\begin{array}{l}\text { Papke } 1976 \text { [DIRS } \\
\text { 162274], Table } 1\end{array}$ \\
\hline Glauberite & $\mathrm{Na}_{2} \mathrm{Ca}\left(\mathrm{SO}_{4}\right)_{2}$ & $\begin{array}{l}\text { Glauberite is associated with evaporite deposits in } \\
\text { Nevada playas. }\end{array}$ & $\begin{array}{l}\text { Papke 1976 [DIRS } \\
\text { 162274], Table } 1\end{array}$ \\
\hline
\end{tabular}


Table 6-4. Minerals Allowed to Precipitate in the IDPS Model (Continued)

\begin{tabular}{|c|c|c|c|}
\hline Mineral & Formula & Rationale for Inclusion & References \\
\hline Gypsum & $\mathrm{CaSO}_{4}: 2 \mathrm{H}_{2} \mathrm{O}$ & $\begin{array}{l}\text { Gypsum is associated with evaporite deposits in } \\
\text { Nevada playas. }\end{array}$ & $\begin{array}{l}\text { Papke 1976 [DIRS } \\
\text { 162274], Table 1; Kerr } \\
1977 \text { [DIRS 161606], } \\
\text { p. } 221\end{array}$ \\
\hline Halite & $\mathrm{NaCl}$ & $\begin{array}{l}\text { Halite is associated with evaporite deposits in } \\
\text { Nevada playas. }\end{array}$ & $\begin{array}{l}\text { Papke 1976 [DIRS } \\
\text { 162274], Table 1; Kerr } \\
1977 \text { [DIRS 161606], } \\
\text { p. } 221\end{array}$ \\
\hline Huntite & $\mathrm{CaMg}_{3}\left(\mathrm{CO}_{3}\right)_{4}$ & $\begin{array}{l}\text { Huntite is a Mg carbonate mineral associated with } \\
\text { cave and evaporite deposits as well as with } \\
\text { meteoric (low-temperature) dissolution, and } \\
\text { reprecipitation of calcite, dolomite or magnesite. } \\
\text { Huntite will precipitate instead of calcite when } \mathrm{Mg}^{2+} \\
\text { is concentrated in solutions with respect to } \mathrm{Ca}^{2+} \text {. }\end{array}$ & $\begin{array}{l}\text { Faust } 1953 \text { [DIRS } \\
162282] ; \text { Walling et al. } \\
1995 \text { [DIRS 162283], } \\
\text { p. } 360\end{array}$ \\
\hline Kieserite & $\mathrm{MgSO}_{4}: \mathrm{H}_{2} \mathrm{O}$ & $\begin{array}{l}\text { Kieserite is an evaporite mineral commonly found } \\
\text { in salt deposits. Often it is associated with halite or } \\
\text { carnallite. }\end{array}$ & $\begin{array}{l}\text { Palache et al. } 1951 \\
\text { [DIRS 162280], pp. } 477 \\
\text { to } 479\end{array}$ \\
\hline Nahcolite & $\mathrm{NaHCO}_{3}$ & $\begin{array}{l}\mathrm{Nahcolite} \text { is a saline mineral associated with } \mathrm{Na}- \\
\mathrm{CO}_{3}-\mathrm{Cl} \text { brines. }\end{array}$ & $\begin{array}{l}\text { Eugster and Hardie } \\
1978 \text { [DIRS 100743], } \\
\text { Table } 3\end{array}$ \\
\hline Natrite & $\mathrm{Na}_{2} \mathrm{CO}_{3}$ & $\begin{array}{l}\text { Natrite is a highly soluble carbonate mineral } \\
\text { associated with shortite, pirssonite, and gaylussite. } \\
\text { These three minerals are also associated with the } \\
\text { precipitation of trona, calcite and montmorillonite } \\
\text { and are found in clay beds that have deposited in } \\
\text { borax lakes. }\end{array}$ & $\begin{array}{l}\text { Fleischer and Pabst } \\
1983 \text { [DIRS 162284]; } \\
\text { Palache et al. 1951 } \\
\text { [DIRS 162280] }\end{array}$ \\
\hline Niter & $\mathrm{KNO}_{3}$ & $\begin{array}{l}\text { Niter is associated with evaporite deposits in } \\
\text { Nevada playas. }\end{array}$ & $\begin{array}{l}\text { Papke 1976 [DIRS } \\
\text { 162274], Table } 1\end{array}$ \\
\hline $\begin{array}{l}\text { Pentasalt } \\
\text { (Gorgeyite) }\end{array}$ & $\mathrm{K}_{2} \mathrm{Ca}_{5}\left(\mathrm{SO}_{4}\right)_{6}: \mathrm{H}_{2} \mathrm{O}$ & $\begin{array}{l}\text { Gorgeyite occurs in association with glauberite, } \\
\text { halite, and polyhalite in salt deposits. }\end{array}$ & $\begin{array}{l}\text { Fleischer and Efremov } \\
1954 \text { [DIRS 162312] }\end{array}$ \\
\hline Phillipsite & $\begin{array}{l}\mathrm{K}_{0.7} \mathrm{Na}_{0.7} \mathrm{Ca}_{1.1} \mathrm{Al}_{3.6^{-}} \\
\mathrm{Si}_{12.4} \mathrm{O}_{32}: 12.6 \mathrm{H}_{2} \mathrm{O}\end{array}$ & $\begin{array}{l}\text { Phillipsite is a zeolite mineral commonly associated } \\
\text { with evaporite deposits. }\end{array}$ & $\begin{array}{l}\text { Hay } 1966 \text { [DIRS } \\
\text { 105965] }\end{array}$ \\
\hline Sellaite & $\mathrm{MgF}_{2}$ & $\begin{array}{l}\text { Sellaite is the } \mathrm{Mg} \text { analogue to fluorite that forms in } \\
\text { evaporite deposits. }\end{array}$ & $\begin{array}{l}\text { Palache et al. } 1951 \\
\text { [DIRS 162280], pp. } 37 \\
\text { to } 39\end{array}$ \\
\hline Sepiolite & $\begin{array}{l}\mathrm{Mg}_{4} \mathrm{Si}_{6} \mathrm{O}_{15}(\mathrm{OH})_{2}: \\
6 \mathrm{H}_{2} \mathrm{O}\end{array}$ & $\begin{array}{l}\text { Precipitation of sepiolite is common in conjunction } \\
\text { with calcite precipitation in calcrete deposits. } \\
\text { Sepiolite is a common fracture-lining mineral above } \\
\text { the basal vitrophyre of the Topopah Spring } \\
\text { Member at Yucca Mountain. Sepiolite is also } \\
\text { known to commonly form on evaporation of either } \\
\text { carbonate-source or tuff-source waters in southern } \\
\text { Nevada. Poorly crystallized sepiolite precipitates } \\
\text { readily at low temperature }\left(\sim 25^{\circ} \mathrm{C}\right) \text { in alkaline } \\
\text { solutions. }\end{array}$ & $\begin{array}{l}\text { Hay and Wiggens } 1980 \\
\text { [DIRS 162281]; Carlos } \\
\text { et al. 1995 [DIRS } \\
105213 \text { ]; Vaniman et al. } \\
1992 \text { [DIRS 107066]; } \\
\text { Jones 1983 [DIRS } \\
\text { 162331]; Wollast et al. } \\
\text { 1968 [DIRS 162340]; } \\
\text { Kent and Kastner 1985 } \\
\text { [DIRS 162345] }\end{array}$ \\
\hline $\mathrm{SiO}_{2}(\mathrm{am})$ & $\mathrm{SiO}_{2}$ & $\begin{array}{l}\text { Literature evidence suggests that amorphous silica } \\
\text { is at metastable equilibrium with respect to quartz } \\
\text { at low temperatures and pressures. This is also } \\
\text { evidenced by precipitation of opal-CT as opposed } \\
\text { to quartz in evaporated carbonate and tuffaceous } \\
\text { waters of southern Nevada. }\end{array}$ & $\begin{array}{l}\text { Langmuir } 1997 \text { [DIRS } \\
100051] \text {; Vaniman et al. } \\
1992 \text { [DIRS 107066] }\end{array}$ \\
\hline
\end{tabular}


Table 6-4. Minerals Allowed to Precipitate in the IDPS Model (Continued)

\begin{tabular}{|l|l|l|l|}
\hline \multicolumn{1}{|c|}{ Mineral } & \multicolumn{1}{|c|}{ Formula } & \multicolumn{1}{c|}{ Rationale for Inclusion } & \multicolumn{1}{c|}{ References } \\
\hline Soda Niter & $\mathrm{NaNO}_{3}$ & $\begin{array}{l}\text { Soda Niter is associated with evaporite deposits in } \\
\text { Nevada playas. }\end{array}$ & $\begin{array}{l}\text { Papke 1976 [DIRS } \\
\text { 162274], Table 1 }\end{array}$ \\
\hline Stellerite & $\mathrm{Ca}_{2} \mathrm{Al}_{4} \mathrm{Si}_{14} \mathrm{O}_{36}: 14 \mathrm{H}_{2} \mathrm{O}$ & $\begin{array}{l}\text { Stellerite is a zeolite mineral commonly associated } \\
\text { with fracture linings at Yucca Mountain. }\end{array}$ & $\begin{array}{l}\text { Carlos et al. 1995 } \\
\text { [DIRS 105213] }\end{array}$ \\
\hline Sylvite & $\mathrm{KCl}$ & $\begin{array}{l}\text { Sylvite is associated with evaporite deposits in } \\
\text { Nevada playas. }\end{array}$ & $\begin{array}{l}\text { Papke 1976 [DIRS } \\
\text { 162274], Table 1; Kerr } \\
1977 \text { [DIRS 161606], } \\
\text { p. 221 }\end{array}$ \\
\hline Syngenite & $\mathrm{K}_{2} \mathrm{Ca}\left(\mathrm{SO}_{4}\right)_{2}: \mathrm{H}_{2} \mathrm{O}$ & $\begin{array}{l}\text { Syngenite is associated with salt deposits } \\
\text { (especially halite) and is known to be precipitated } \\
\text { in cavities created by volcanic action. It } \\
\text { precipitates at room temperatures from solutions } \\
\text { that contain K2SO }\end{array}$ & $\begin{array}{l}\text { Palache et al. 1951 } \\
\text { [DIRS 162280], pp. 442 } \\
\text { to 444 }\end{array}$ \\
\hline Thenardite & $\mathrm{Na}_{2} \mathrm{SO}_{4}$ & $\begin{array}{l}\text { Thenardite is associated with evaporite deposits in } \\
\text { Nevada playas. }\end{array}$ & $\begin{array}{l}\text { Papke 1976 } \\
\text { [DIRS 162274], Table 1 }\end{array}$ \\
\hline Trona & $\mathrm{Na}_{3} \mathrm{H}_{(}\left(\mathrm{CO}_{3}\right)_{2}: 2 \mathrm{H}_{2} \mathrm{O}$ & $\begin{array}{l}\text { Trona is associated with evaporite deposits in } \\
\text { Nevada playas. }\end{array}$ & $\begin{array}{l}\text { Papke 1976 } \\
\text { [DIRS 162274], Table 1 }\end{array}$ \\
\hline
\end{tabular}

\subsubsection{Summary of Computational Model}

\subsubsection{Preparation of Starting Water}

The IDPS model starting water is the incoming seepage water or other aqueous solution subjected to evaporation by the IDPS model. For TSPA-LA, Drift-Scale THC Seepage Model (BSC 2004 [DIRS 169856]) will be the primary provider of data on this water and its composition. For validation or other analyses, starting waters can include synthesized starting waters used in laboratory evaporation experiments, hypothetical dilute binary solutions of soluble salts, and compositions of water samples collected from the site.

To prepare these starting waters for evaporation, it is important to charge balance them. The reason for this is that evaporation will result in precipitation of minerals and/or degassing of carbon dioxide. Because the precipitating minerals and carbon dioxide are neutrally charged, each of these processes removes an equivalent amount of positive and negative charge from the solution. Thus, if the starting water is not charge balanced prior to evaporation, the charge imbalance can increase to unacceptable levels after much of the dissolved solids have precipitated or degassed.

Although outputs from upstream models may be charge balanced in the upstream model, they are not necessarily charge balanced for the IDPS model. Small differences in the thermodynamic databases of models can generate small but considerable differences in charge balance calculations. Therefore, to ensure that the starting waters provided by upstream models are charge balanced for the IDPS model calculations, the EQ3NR is instructed to charge balance the starting waters. 
Charge balance is achieved in the IDPS model by manually identifying the dissolved component in each starting water that has the largest normality and selecting the option to add or subtract this component to achieve charge balance. This method results in the smallest percentage adjustment of a starting component concentration.

For starting waters in which information is missing or measurements are known to be highly uncertain or below detection limits, other approaches can be justified for charge balancing. These approaches might include fixing the fugacity of carbon dioxide to atmospheric values, or preventing supersaturation of readily precipitated minerals, or other methods. Whatever the approach, it must be documented in the analysis.

\subsubsection{Simple Evaporation}

Evaporative concentration of dissolved solids in solution can be performed using EQ3/6. Water, the designated reactant, is incrementally removed from the solution while the remaining solution is maintained at equilibrium. Depending on mineral saturation indices and interaction with the gas phase, removal of water causes the dissolved ions to concentrate, precipitate, and/or degas.

A simple evaporation mode is used in the IDPS model to predict the evolution of a given water composition at a given temperature and carbon dioxide fugacity as it evaporates. For this mode, there is no solution flowing into the cell and no solution flowing out, as depicted in the conceptual model illustrated in Figure 6-1 (Section 6.4). The run begins with a given starting water composition, the solution is equilibrated with the fixed gas fugacities, all supersaturated unsuppressed minerals are allowed to precipitate, and water is incrementally removed from the system. In EQ3/6 Version 8.0, "H2O" is declared the aqueous species reactant, and the rate constant (rk1) is set at -1.0 . The concentration factor of the evolving solution is calculated from Equation 6.6.2.5-4.

These reactions can be simulated to an ionic strength of about 1 molal using traditional ion activity correction equations such as the B-dot equation (SNL 2003 [DIRS 162494], p. B-32 of user's manual). However, with EQ3/6 Version 8.0 and the Pitzer database in Appendix I, evaporation for the system Na-K-H-Mg-Ca-Al-Cl-F-NO${ }_{3}-\mathrm{SO}_{4}-\mathrm{Br}_{-}-\mathrm{CO}_{3}-\mathrm{SiO}_{2}-\mathrm{CO}_{2}-\mathrm{O}_{2}-\mathrm{H}_{2} \mathrm{O}$ can proceed until there is essentially no free water remaining.

In the simple evaporation mode, the activity of water decreases as water evaporates. Because this mode assumes equilibrium conditions at all times (Assumption 5.2), the resulting activity of water after each incremental decrease in solvent determines the equilibrium relative humidity. As evaporation proceeds to its extreme, the model produces a complete sweep of equilibrium results down to the relative humidity of the dry out point of the solution. In the opposite direction, the model predicts equilibrium results for condensation of water into an initial seepage water. Condensation predictions can be obtained for dilution factors of 100 or more. Together, the evaporation and condensation results can then be tabulated in a set of lookup tables so that the equilibrium composition can be identified or interpolated for any given equilibrium relative humidity (Section 6.6.3.5). 


\subsubsection{Representation of Steady-State Evaporation with Flow-Through}

The IDPS model abstraction for TSPA-LA simulates discrete time intervals in which the seepage rate of water flowing into the drift can be modeled as a constant. If the seepage rate exceeds the evaporation rate, then a steady-state condition can develop such that some of the water will evaporate from the assigned control volume (e.g., a pool) and some will flow out of it. Such a steady-state condition is represented in Figure 6-3. EQ3/6 Version 8.0 cannot directly model a flow-through system like this, but there is a way to represent this system using the simple evaporation mode presented in the previous section.

In the simple evaporation mode, the total volume (or mass) of water within the cell (or control volume) decreases with evaporation. This is not the case for the steady-state flow-through mode. In the steady-state flow-through mode, the total volume (or mass) of water in the cell is maintained. At steady state, the flux of water seeping into the cell $\left(Q^{s}\right)$ is equivalent to the sum of the evaporation flux $\left(Q^{e}\right)$ and the flux of water flowing out of the cell $\left(Q^{d}\right)$ (Figure 6-3). As a result, the water composition within the cell will reach a steady-state concentration factor that depends only on the incoming water composition and the relative evaporation rate, $R^{e s}$, as described by Equation 6.6.2.5-2.

For example, from Equation 6.6.2.5-2, a CF of 10 implies a $R^{e s}$ value of 0.9. This implies that if $R^{e s}$ equals 0.9 , a conservative constituent in the incoming seepage water will reach a steady-state concentration in the cell that is a factor of 10 higher than the incoming seepage concentration. Thus, whether the incoming seepage undergoes simple evaporation to achieve the concentration factor or steady-state flow-through evaporation, a unique and identical resulting water composition can be determined from the incoming seepage composition and the CF.

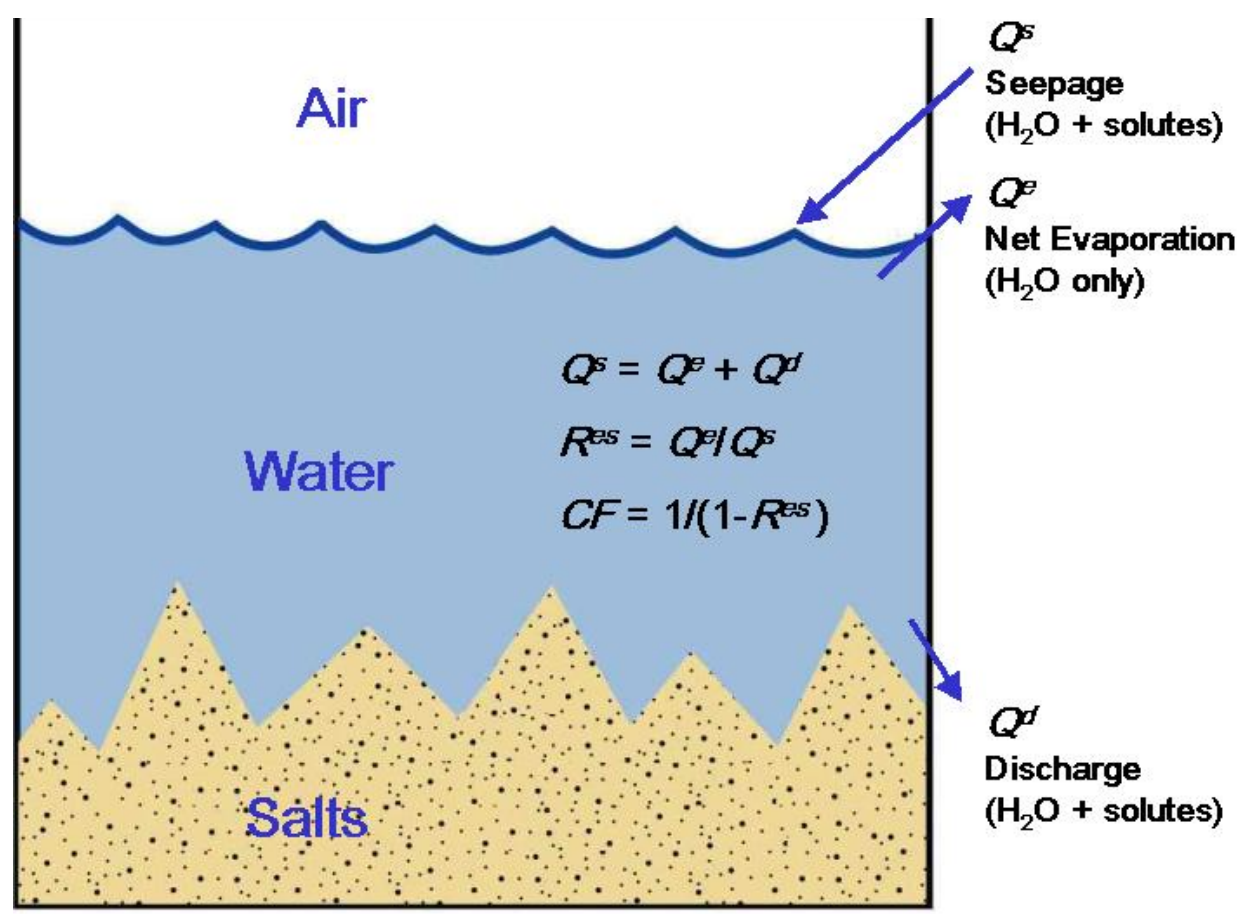

Figure 6-3. Representation of Steady-State Flow-Through for the In-Drift Precipitates/Salts Model 
In the IDPS model abstractions for TSPA-LA, the time required to reach equilibrium or steady state is negligible compared to the abstraction timeframes to which a given incoming seepage is applied. For simple evaporation, water evaporates quickly when the relative humidity is considerably below 100 percent. For flow-through conditions, steady-state compositions are nearly achieved after as few as 10 cell flushes (i.e., after the total volume of incoming seepage exceeds 10 cell volumes). Because abstraction timeframes are long compared to the time required for equilibrium evaporation of static water or 10 cell flushes under flow-through conditions, equilibrium or steady-state assumptions provide reasonable evaporation predictions.

It is possible for steady-state conditions to develop such that equilibrium with respect to relative humidity will not occur. For example, if the evaporation rate is one half of the seepage rate (i.e., $R^{e s}$ equals 0.5), Equation 6.6.2.5-2 dictates that conservative ions will reach a steady-state concentration that is twice the incoming concentration ( $C F$ equals 2$)$. The importance of this is that if the incoming seepage water is dilute, the steady-state activity of water could be around 0.999 or higher. If this is the case and the relative humidity in the drift is much lower than 99.9 percent, then equilibrium with respect to $R H$ would not be achieved at steady state.

\subsubsection{Model Input Files}

Three EQ3/6 input files are required to represent the IDPS model. The first is the EQ3NR input file used to define the starting water, as described in Section 6.6.3. The other two are the EQ6 input files used to either evaporate the starting water or dilute the starting water with condensed water vapor. The EQ3NR pickup files, produced by EQ3NR, must be appended to the corresponding EQ6 input files to initialize the EQ6 runs. The general formats of these input files are documented in DTN: MO0303SPAMEQ36.000.

\subsubsection{Model Output}

Application of the IDPS model generates EQ3/6 output files that describe the boundary conditions, equilibrium calculations, and effects of evaporation, condensation, and dust deliquescence on water composition and precipitation of solids. These output files contain much more information than is used in downstream modeling. Lookup tables are generated to summarize the outputs important to the TSPA-LA.

Three types of model output are tabulated in the lookup tables: boundary values, abstraction output, and supplemental calculations. The first two types of output are directly provided in the EQ6 output files. The third type, supplemental calculations, consists of simple algebraic manipulations of the EQ6 output.

Boundary values include temperature, the fugacities of carbon dioxide and oxygen, and the reaction progress. These values are, for all practical purposes, input values. The reaction progress is a measure of the extent of evaporation or condensation that has occurred for a set of equilibrium output values.

Abstraction output includes all EQ6 calculations for the aqueous output variables of direct or indirect interest in the TSPA-LA. It includes the $\mathrm{pH}$, activity of water, ionic strength, mass of solvent water remaining, total concentrations of each element, concentrations of select aqueous species that potentially contribute to acid-neutralizing capacity, and amounts of solids 
precipitating in a given EQ6 run. Although some of this information is not directly used in support of TSPA-LA, this information is useful in understanding how a starting water chemically evolves for a given set of boundary conditions. Direct outputs in support of TSPA-LA are $\mathrm{pH}$, ionic strength, concentrations of $\mathrm{Cl}$ and $\mathrm{NO}_{3}$, the $\mathrm{Cl}: \mathrm{NO}_{3}$ mole ratio, and the deliquescence relative humidity. There is only one value for the deliquescence relative humidity in each table. It is the lowest relative humidity in the table, located in the last row.

Supplemental calculations include lookup table calculations for relative humidity $(R H)$, concentration factor $(C F)$, relative evaporation rate $\left(R^{e s}\right.$ or $\left.Q^{e} / Q^{s}\right)$, and dilution factor $(D F$ or $1-$ $Q^{e} / Q^{s}$ ). These calculations support the base case equilibrium model (Figure 6-1) and steady-state alternative conceptual model (Figure 6-3). $R H$ is calculated by multiplying the activity of water by 100 percent. $C F$ is calculated using Equation 6.6.2.5-2 above. $R^{e s}$ (or $Q^{e} / Q^{s}$ ) is calculated from an algebraic manipulation of Equation 6.6.2.5-2. Solving Equation 6.6.2.5-2 for $R^{e s}$ gives:

$$
R^{e s}=1-\frac{1}{C F}
$$

Finally, the dilution factor $\left(D F\right.$ or $\left.1-Q^{e} / Q^{s}\right)$ is calculated by subtracting $Q^{e} / Q^{s}$ from one. The value of $\left(1-Q^{e} / Q^{s}\right)$ is equivalent to the dilution factor $(D F)$ defined in Equation 6.6.2.5-3. This calculation is useful for plotting and visually comparing the results of various EQ6 runs. In addition, plotting evaporative evolution as a function of $\left(1-Q^{e} / Q^{s}\right)$ generally linearizes the results. This is useful when interpolations must be made because linear interpolation of linearized data can increase the accuracy of interpolations. An example lookup table is presented in Section 6.7.3.

\subsection{DEMONSTRATION OF BASE CASE MODEL}

An example application of the IDPS model is presented in this section to demonstrate how the model is used to produce lookup tables for the TSPA-LA. For this demonstration, an average in situ J-13 well water is used as the incoming seepage composition.

The composition of in situ J-13 well water used in the demonstration is summarized in Table 4-19. This composition originates from a report by Harrar et al. (1990 [DIRS 100814]), in which sample data for individual dissolved components in well J-13 water were compiled and averaged. These averages are documented in DTN: MO0006J13WTRCM.000 [DIRS 151029]. For this example, $\mathrm{pH}$ is set at 7.0, which is the average of the two field-measured $\mathrm{pH}$ values (6.9 and 7.1) reported in Harrar et al. (1990 [DIRS 100814], p. 4.9). Similarly, for this example, dissolved oxygen is set at $5.6 \mathrm{mg} / \mathrm{L}$, which is in the middle of the 5.5 to $5.7 \mathrm{mg} / \mathrm{L}$ range reported in Harrar et al. (1990 [DIRS 100814], p. 4.9). The initial temperature is set at $31{ }^{\circ} \mathrm{C}$, corresponding to the approximate down-hole temperature reported in Harrar et al. (1990 [DIRS 100814], p. 4.9). This demonstration is not directly used in performance assessment.

\subsubsection{Evaporation of Average In Situ J-13 Well Water}

Average in situ J-13 water (summarized in Table 4-19 and described in Section 6.7 above) was evaporated using the IDPS model. For this simulation, EQ3/6 Version 8.0 and the Pitzer thermodynamic database (DTN: SN0306T0510102.007, developed in Appendix I) were the 
code and database used to run the IDPS model. Because EQ3/6 uses $\mathrm{SiO}_{2}$ (aq) as the basis species, the input value for $\mathrm{Si}(28.5 \mathrm{mg} / \mathrm{L})$ was converted to an equivalent amount of $\mathrm{SiO}_{2}(\mathrm{aq})$ $(61.0 \mathrm{mg} / \mathrm{L})$. This conversion required multiplying the input value for Si by the ratio of the molecular weight of $\mathrm{SiO}_{2}$ (aq) $(60.0843 \mathrm{gm} / \mathrm{mole})$ to the atomic weight of $\mathrm{Si}(28.0855 \mathrm{gm} / \mathrm{mole})$. The molecular weight of $\mathrm{SiO}_{2}(\mathrm{aq})$ is the sum of the atomic weights of one mole of $\mathrm{Si}$ (28.0855 $\mathrm{gm} / \mathrm{mole})$ and two moles of atomic oxygen $(15.9994 \mathrm{gm} / \mathrm{mole})$. These atomic weights are those provided in the "elements" section of the Pitzer database (DTN: SN0306T0510102.007). The temperature for the evaporation was reset at $70^{\circ} \mathrm{C}$ and the carbon dioxide fugacity was fixed at $10^{-3}$ bars. The results are documented in DTNs: MO0303MWDIOJ13.000 and MO0304SPAJ13IS.001.

Figure 6-4 and Figure 6-5 show the predicted evolution of $\mathrm{pH}$, ionic strength (IS), and total concentrations of aqueous constituents as a function of equilibrium $R H$ and concentration factor $(C F)$. In the model, $R H$ reflects the equilibrium activity of water, and $C F$ reflects the ratio of the original and remaining masses of $\mathrm{H}_{2} \mathrm{O}$ in solution (Equation 6.6.2.5-4). These results show that more than 99 percent of the $\mathrm{H}_{2} \mathrm{O}$ is evaporated before the equilibrium $R H$ falls below 99 percent.

As shown in Figure 6-5, in the early stages of evaporation, Cl, F, K, Na, N, and $\mathrm{S}$ concentrate in a linear manner such that the concentration at a given $C F$ equals the starting equilibrium concentration multiplied by $C F$. This linear relationship implies conservative behavior (i.e., the total masses of these components are conserved within the evaporating solution). Departures from conservative behavior are caused by heterogeneous reactions such as precipitation or degassing. At a $C F$ around 1,200, which corresponds to an equilibrium $R H$ of about 94 percent, $\mathrm{F}$ begins to depart from the linear trend. Beyond this point, $\mathrm{Cl}, \mathrm{K}$, and $\mathrm{N}$ continue to concentrate in a conservative manner until $\mathrm{Cl}$ departs from this trend at a $C F$ around $22,000 . \mathrm{K}$ and $\mathrm{N}$ continue to concentrate linearly until the run is complete at a $C F$ around 82,400 ( $R H$ around 56 percent).

Aqueous species that potentially contribute to acid-neutralizing capacity are plotted in Figure 6-6 and Figure 6-7.

Figure 6-8 and Figure 6-9 show the predicted accumulations of precipitating minerals. At the start, calcite, sepiolite, and stellerite are predicted to precipitate. As the solution evaporatively concentrates by a factor of about 1,000 , stellerite is replaced by celadonite and amorphous silica begins to precipitate. At a $C F$ of about 1,200, fluorite begins to precipitate, which corresponds to the point at which $\mathrm{F}$ departs from the linear trend (Figure 6-5). Further evaporation results in precipitation of natrite, thenardite, and eventually halite. 


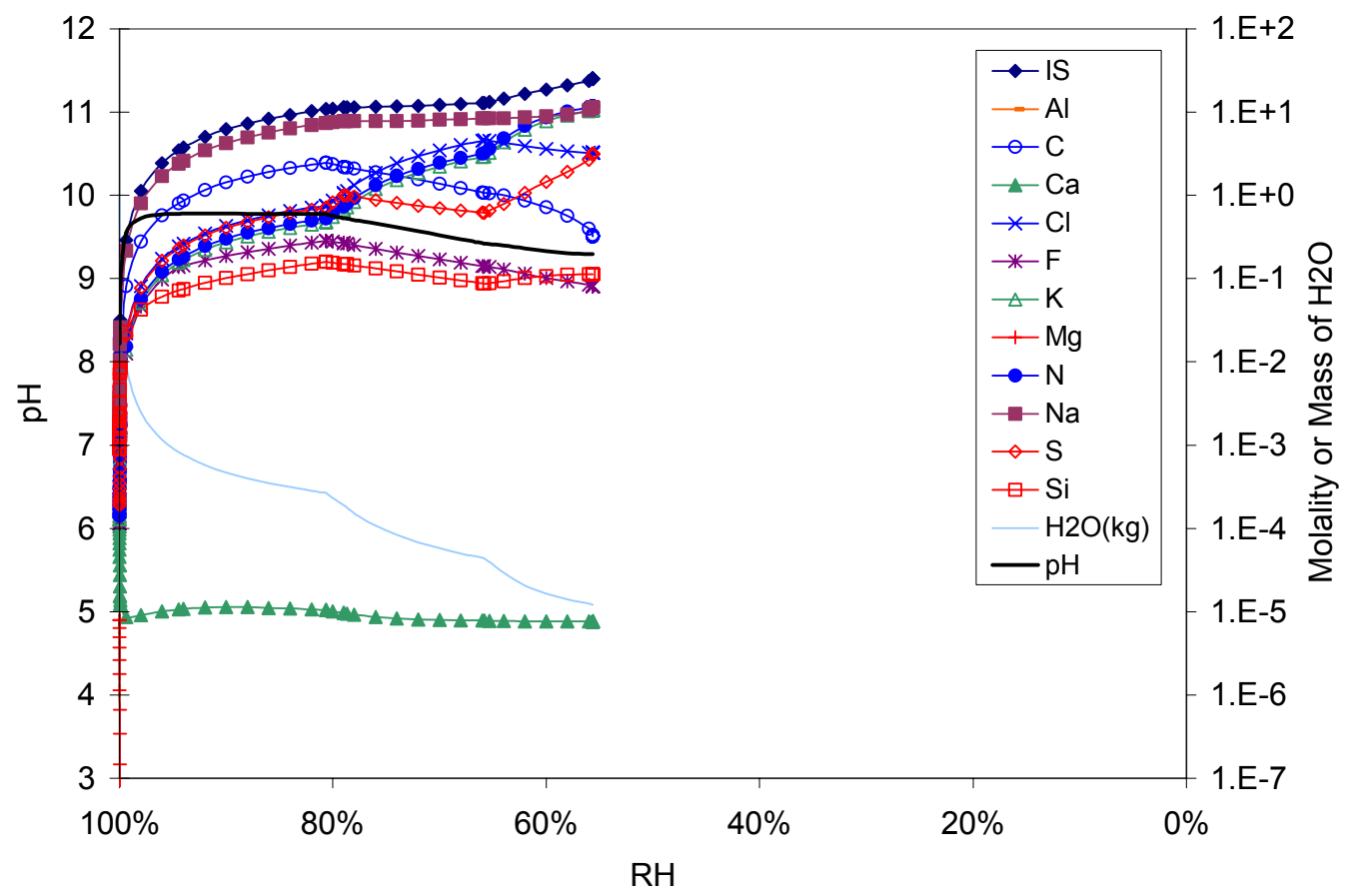

Output DTN: MO0304SPAJ13IS.001.

Figure 6-4. Example Aqueous Composition Evaporation Predictions vs. $R H$

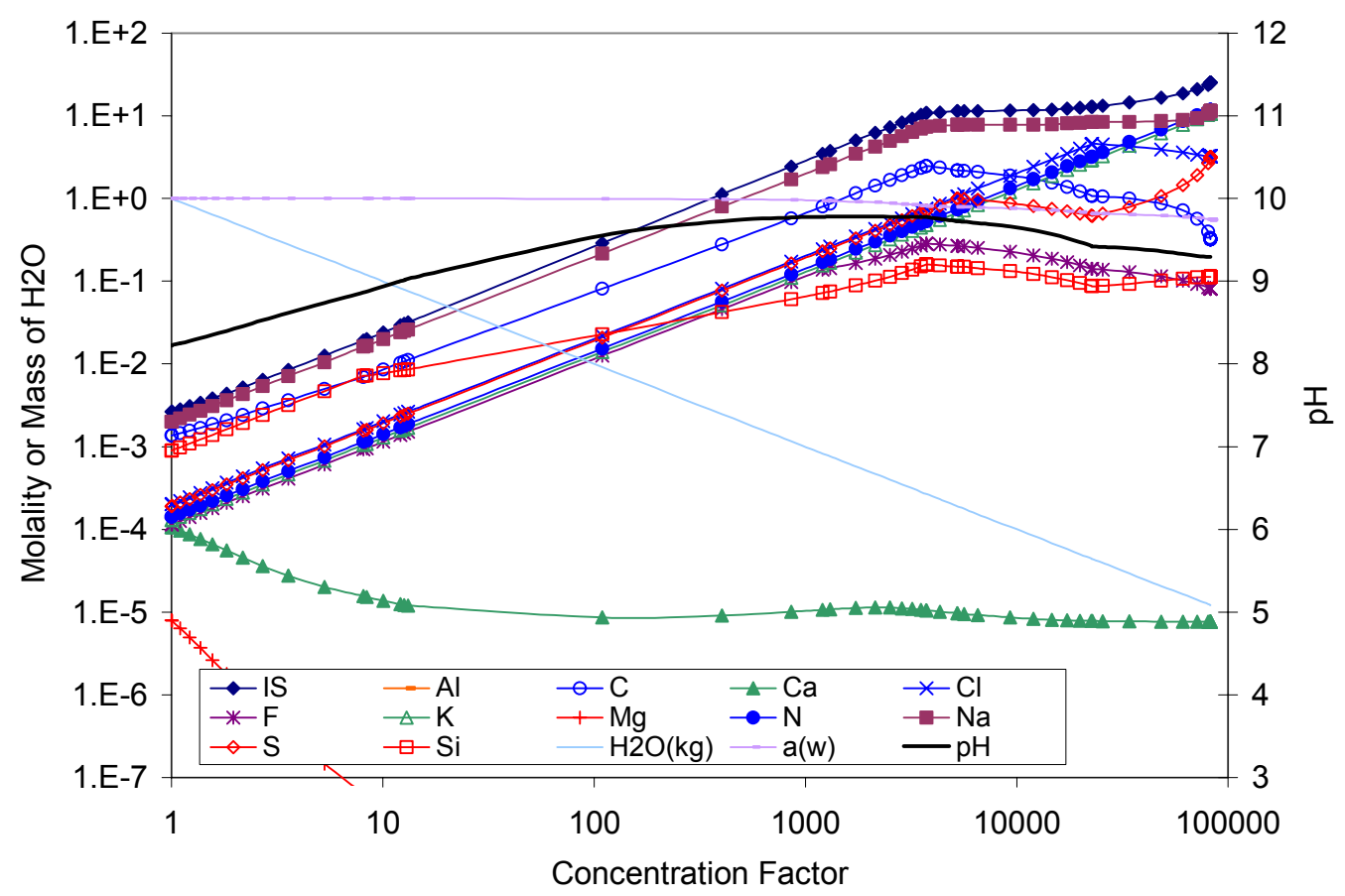

Output DTN: MO0304SPAJ13IS.001.

Figure 6-5. Example Aqueous Composition Evaporation Predictions vs. CF 


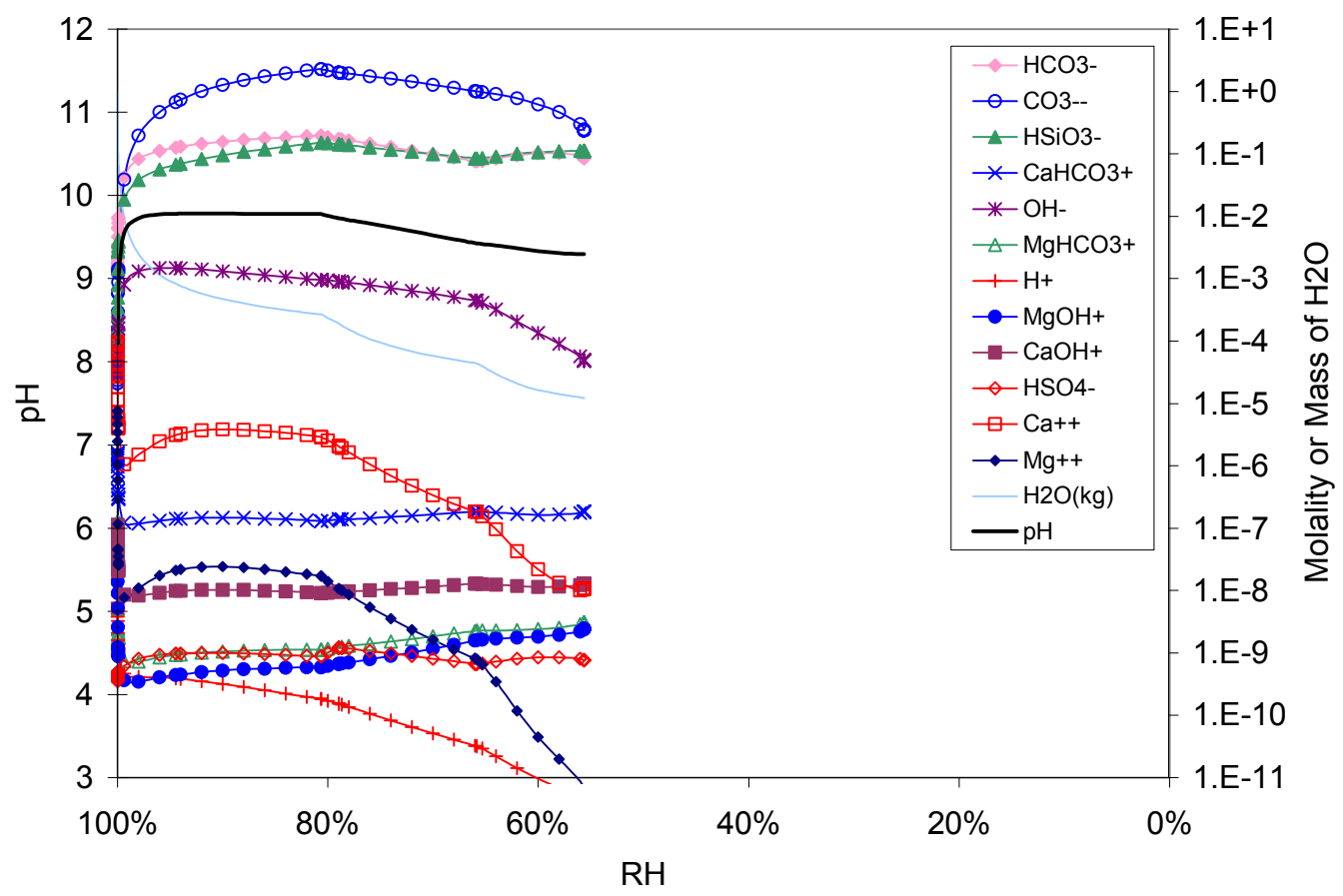

Output DTN: MO0304SPAJ13IS.001.

Figure 6-6. Example Acid-Neutralizing Capacity Species Concentration Evaporation Predictions vs. RH

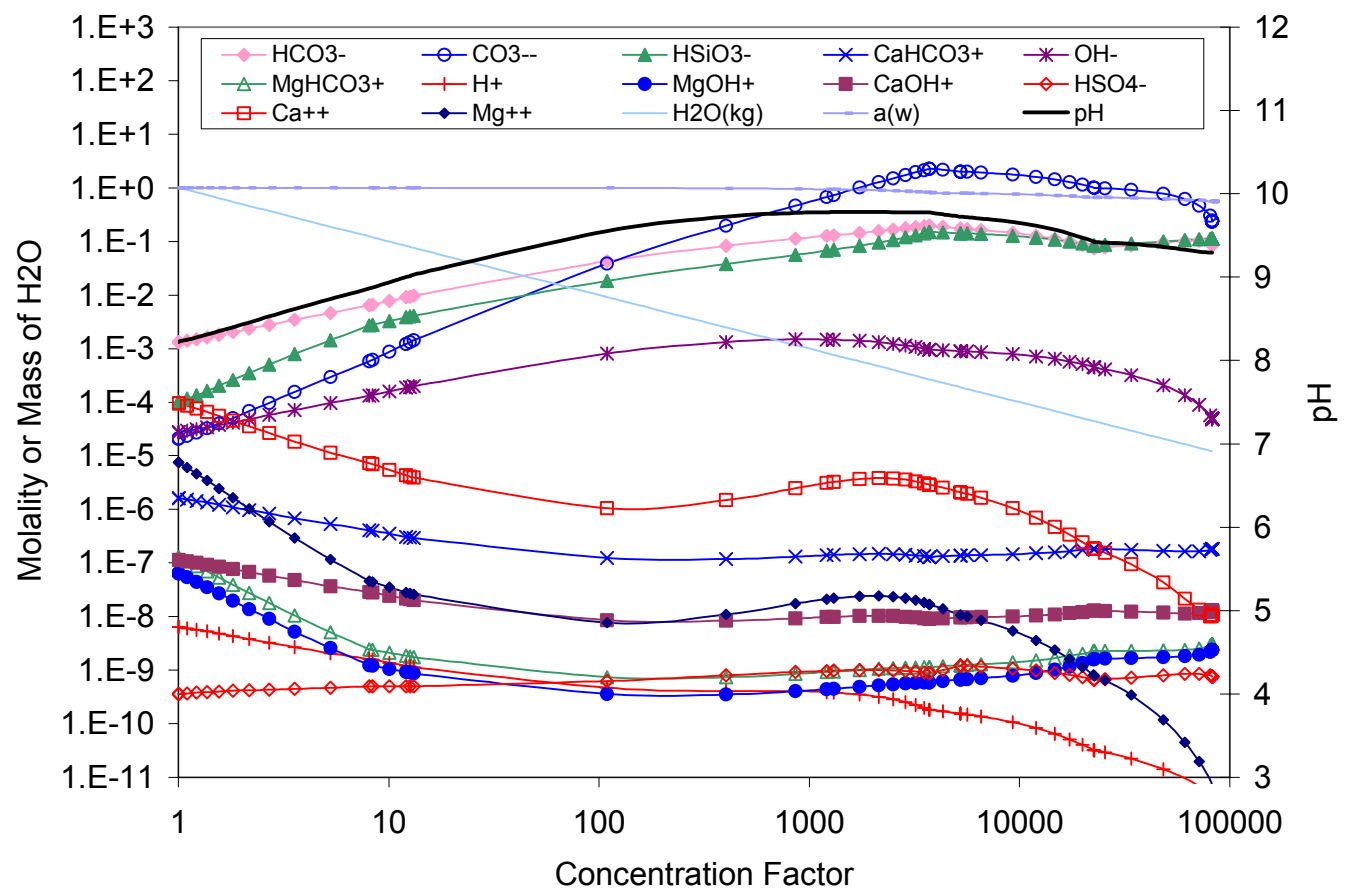

Output DTN: MO0304SPAJ13IS.001.

Figure 6-7. Example Acid-Neutralizing Capacity Species Concentration Evaporation Predictions vs. CF 


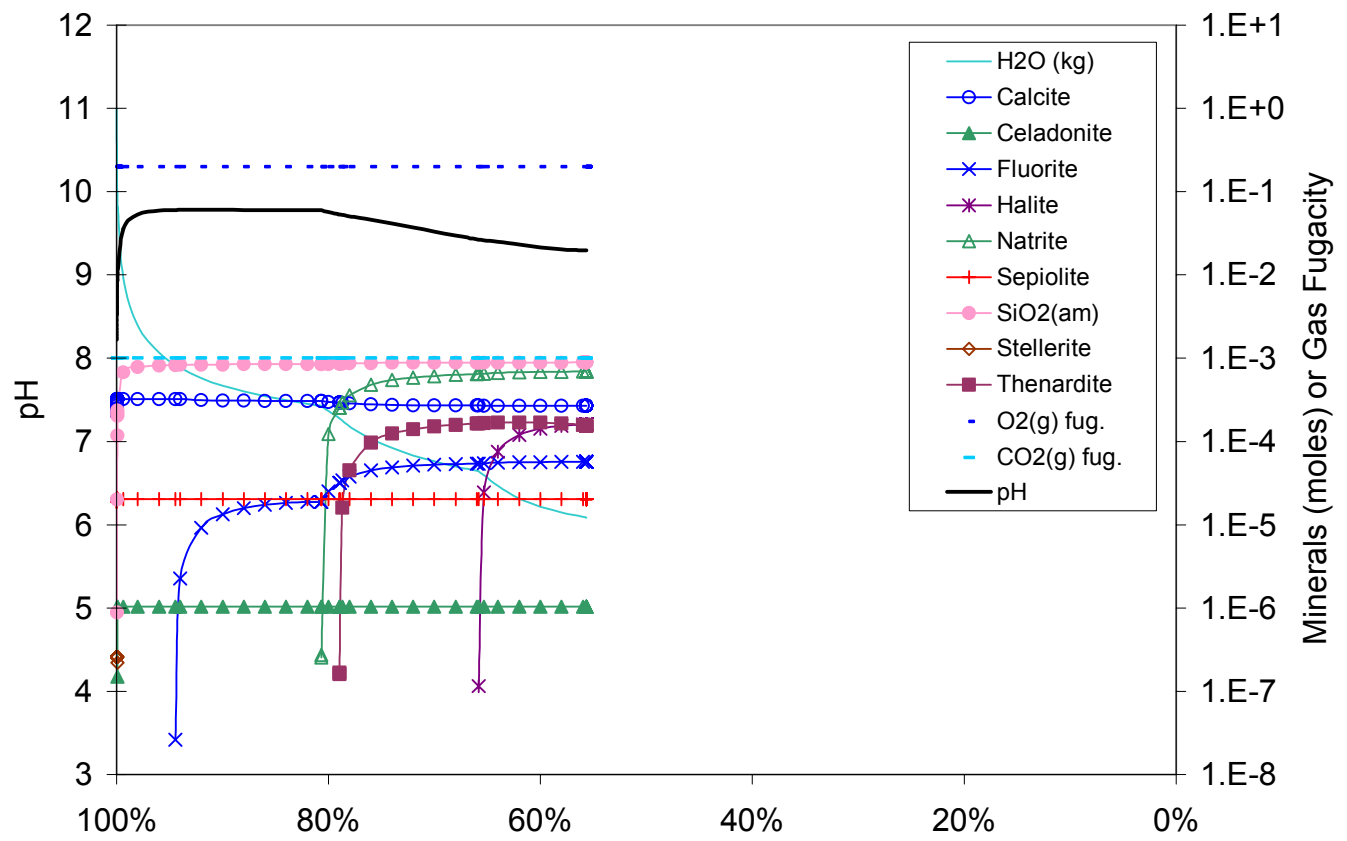

Relative Humidity

Output DTN: MO0304SPAJ13IS.001.

Figure 6-8. Example Mineral Precipitation Evaporation Predictions vs. $R H$

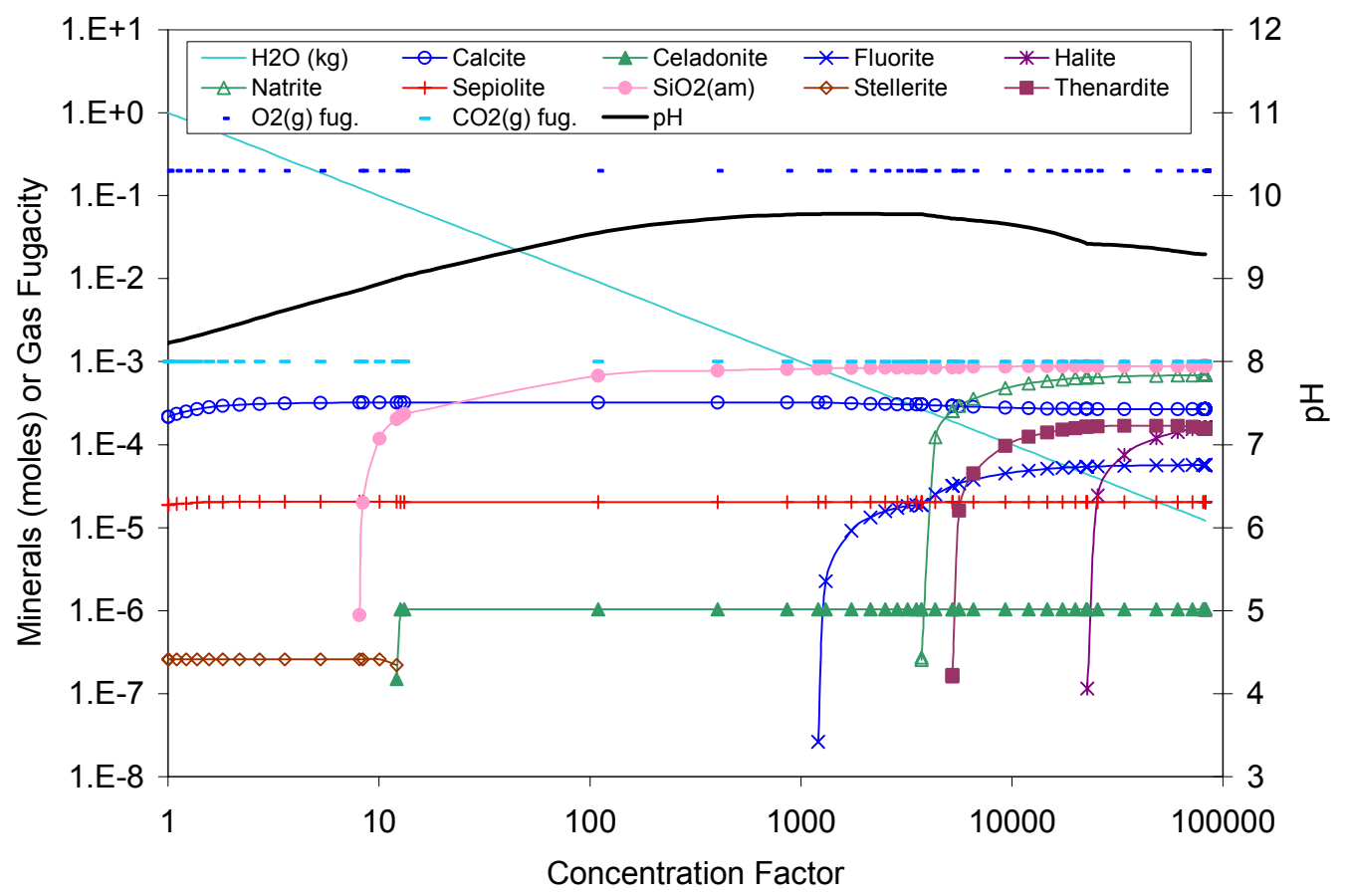

Output DTN: MO0304SPAJ13IS.001.

Figure 6-9. Example Mineral Precipitation Evaporation Predictions vs. CF 


\subsubsection{Dilution of Average In Situ J-13 Well Water}

Dilution of incoming seepage water could also occur in the repository due to condensation. An incoming seepage water will absorb water vapor from the air if the $R H$ in the drift exceeds the activity of water of the incoming seepage.

To ensure that the lookup tables provide outputs for potential dilution of incoming seepage for each TSPA-LA realization, each identified incoming seepage water must be diluted as needed using the IDPS model. For the example here, the starting average in situ J-13 well water is diluted by a factor of 100 . This is done by incrementally adding water until the final mass of water equals the original mass multiplied by the dilution factor. The results for this example are documented in DTNs: MO0303MWDIOJ13.000 and MO0304SPAJ13IS.001.

Figure 6-10 and Figure 6-11 show the results of diluting the example water by a factor of 100 . In general, the aqueous concentrations behave conservatively, decreasing in proportion to the dilution factor. There are departures, however, resulting from heterogeneous reactions such as exchange of carbonate with the atmosphere and dissolution of minerals that precipitated upon initial equilibration of the starting composition. Aqueous species that potentially contribute to acid neutralizing capacity are plotted in Figure 6-12 and Figure 6-13.

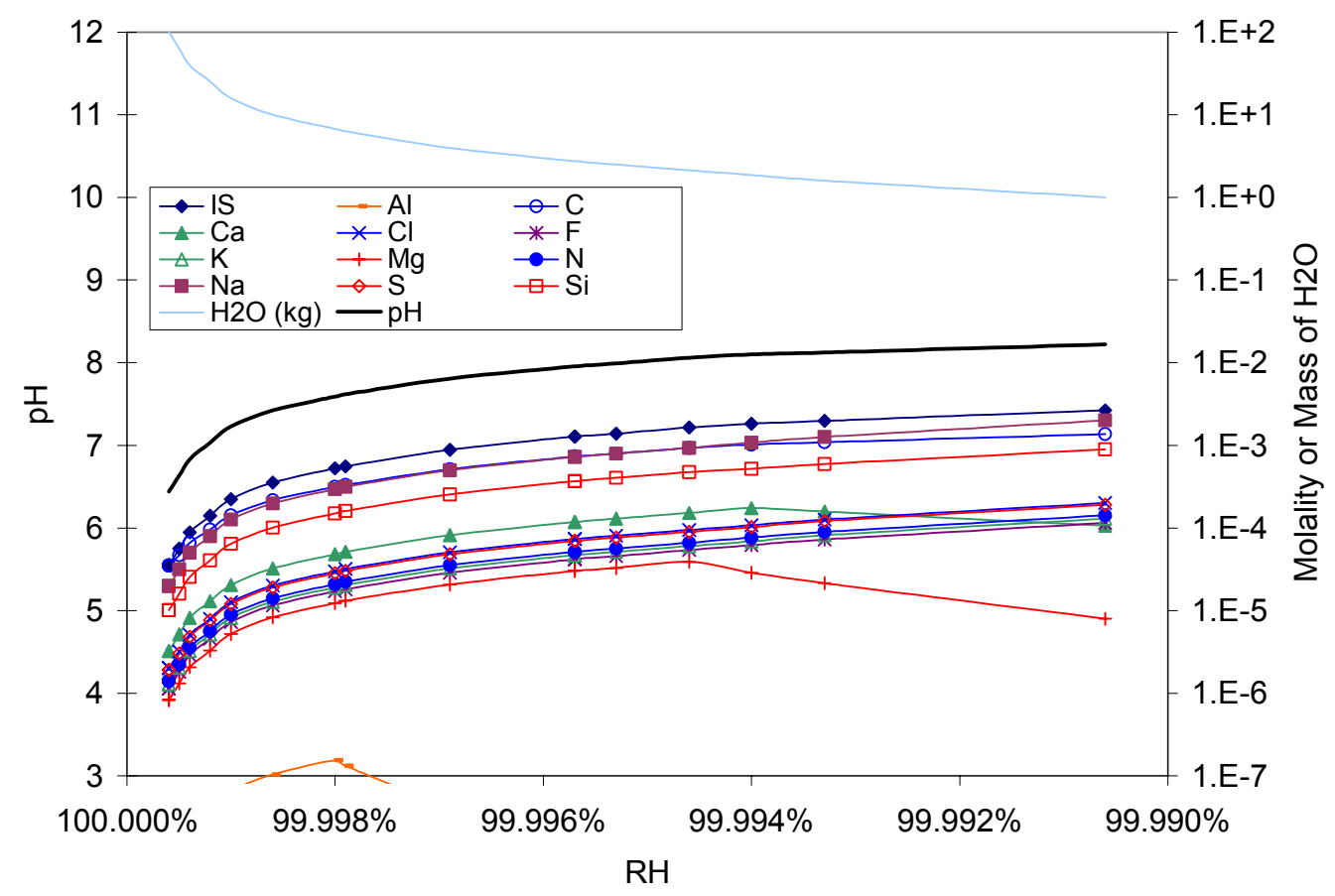

Output DTN: MO0304SPAJ13IS.001.

Figure 6-10. Example Aqueous Composition Condensation Predictions vs. RH 


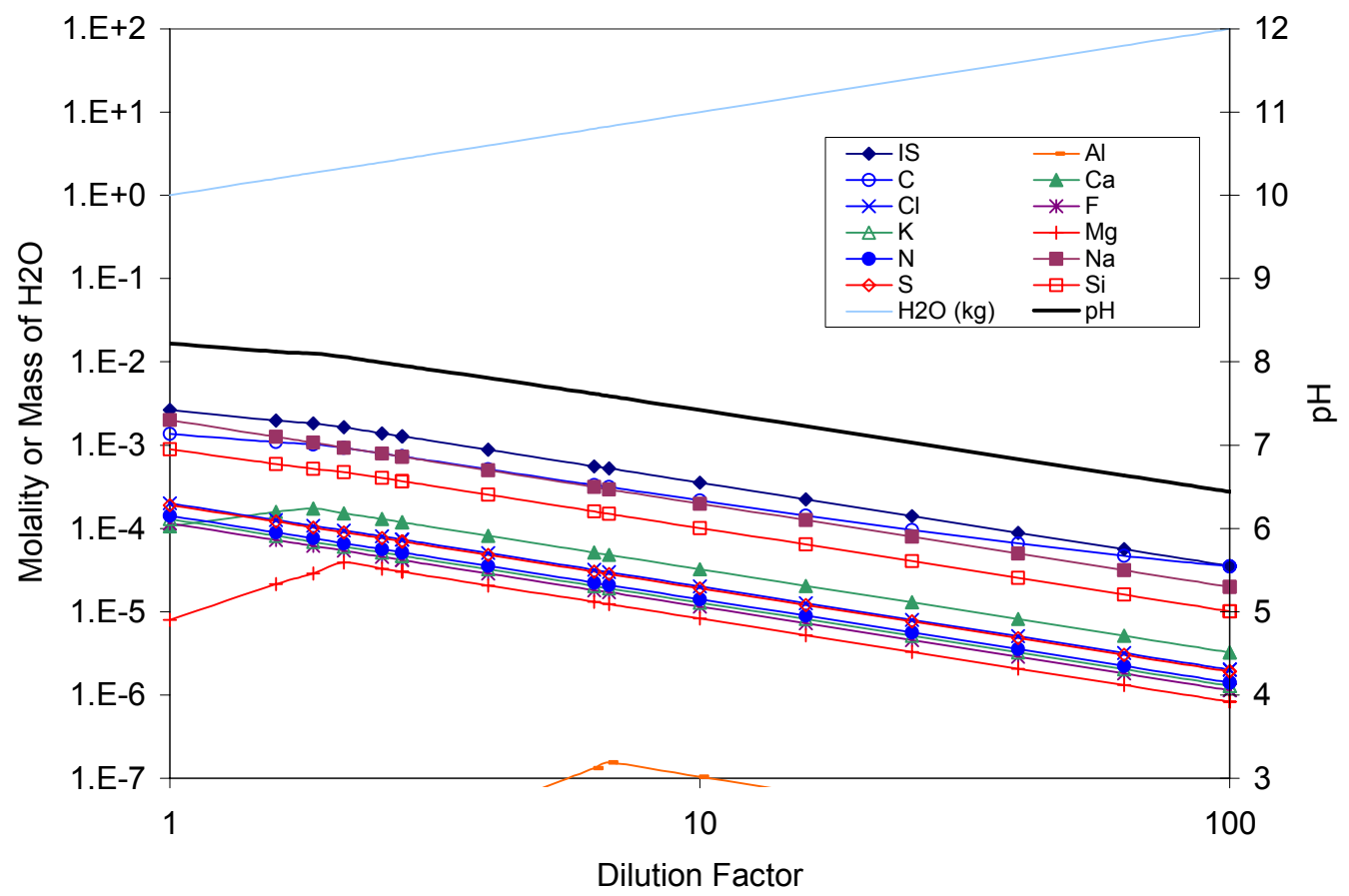

Output DTN: MO0304SPAJ13IS.001.

Figure 6-11. Example Aqueous Composition Condensation Predictions vs. DF

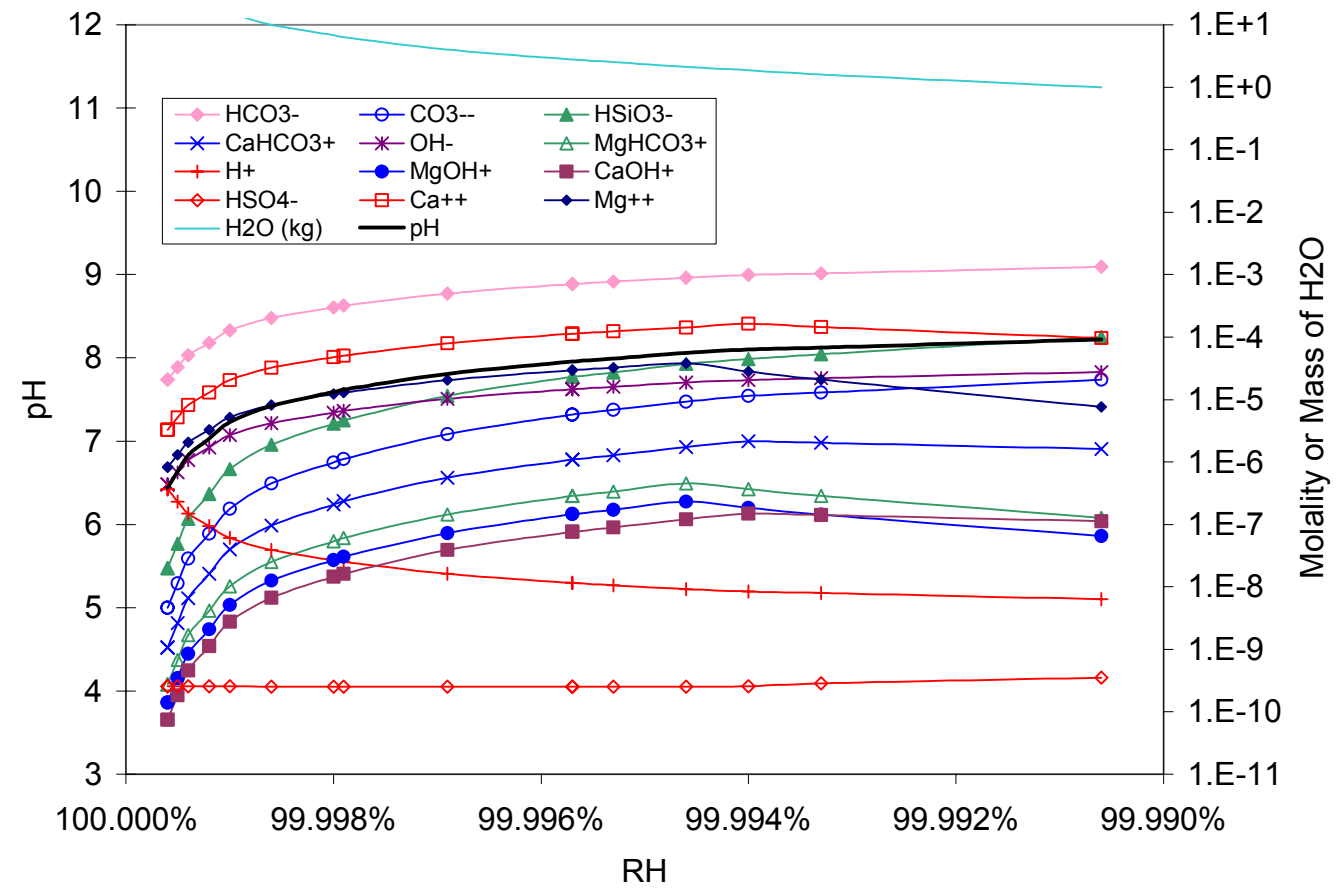

Output DTN: MO0304SPAJ13IS.001.

Figure 6-12. Example Acid-Neutralizing Capacity Species Concentration Condensation Predictions vs. $\mathrm{RH}$ 


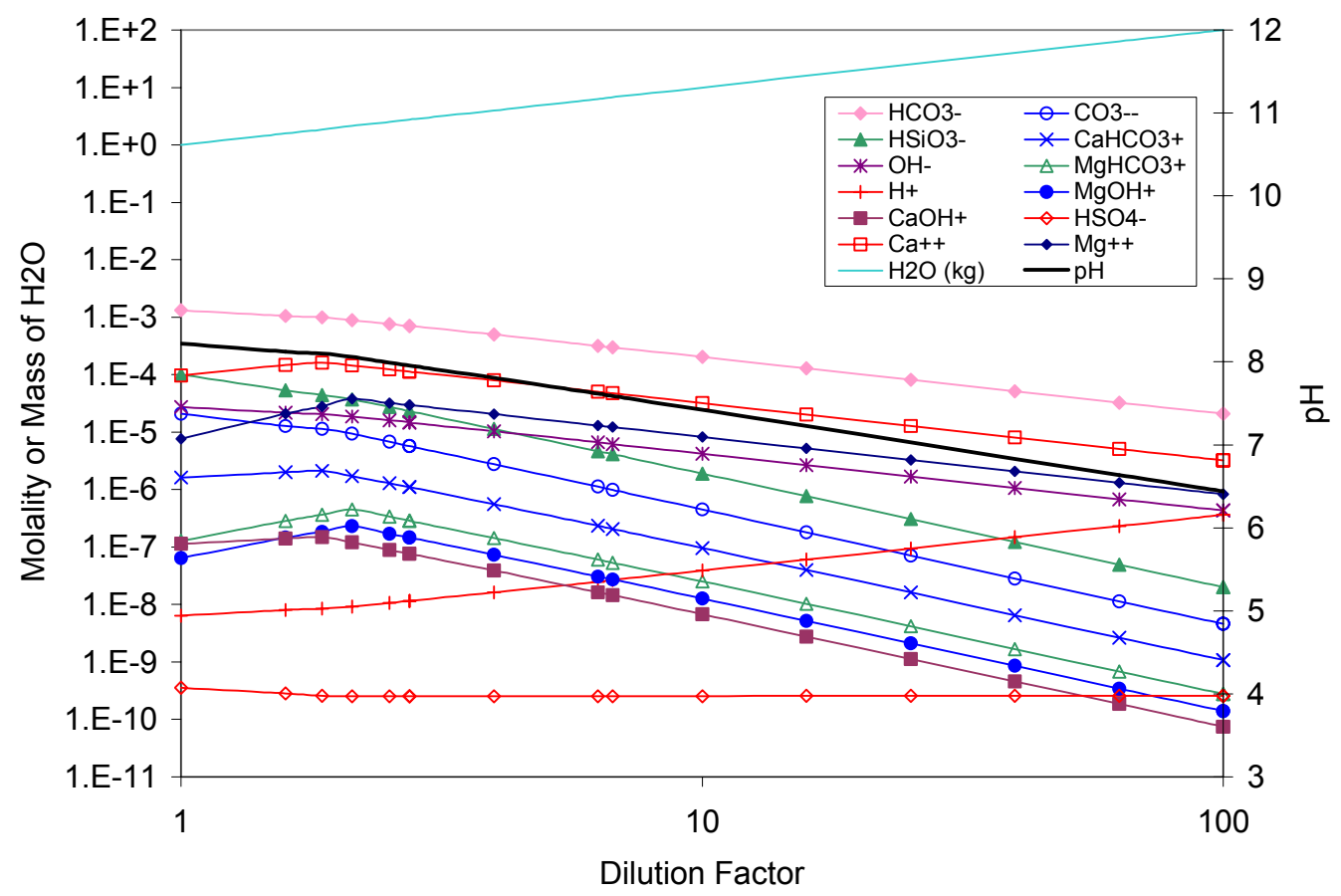

Output DTN: MO0304SPAJ13IS.001.

Figure 6-13. Example Acid-Neutralizing Capacity Species Concentration Condensation Predictions vs. $D F$

\subsubsection{Resulting Model Lookup Tables}

As described in Section 6.6.3.5, the IDPS model outputs that are important to the TSPA-LA include boundary conditions, abstraction output, and supplemental calculations. Each evaporation or condensation lookup table is specific to a defined set of boundary conditions. These tables provide snapshots of the output parameter values as the water incrementally evolves due to evaporation or condensation given the defined boundary conditions. Each snapshot is defined by a unique equilibrium $R H, C F$ (and/or $D F$ ), and $Q^{e} / Q^{S}$.

An example set of lookup tables is provided in Appendices II and III. Appendix II is the lookup table associated with the evaporative concentration of the average in situ J-13 well water presented in Section 6.7.1. Appendix III is the corresponding lookup table for dilution of the same starting water due to condensation (Section 6.7.2). These lookup tables are documented in DTN: MO0304SPAJ13IS.001.

The evaporation lookup tables are divided into sections by column. The first three columns are supplemental spreadsheet calculations for concentration factor $(C F)$, relative evaporation rate $\left(Q^{e} / Q^{S}\right)$, and dilution factor $(D F)$. These calculations are described in Section 6.6.3.5. The next column is the equilibrium $R H$, calculated by multiplying the activity of water (in column 11) by 100 percent. The rest of the columns are filled using GetEQData Version 1.0.1. Columns 5 through 8 show reaction progress and the boundary conditions for the starting water, i.e., the temperature and the fugacities of oxygen and carbon dioxide. Columns 9 through 24 show reaction progress, $\mathrm{pH}$, activity of water, ionic strength, mass of $\mathrm{H}_{2} \mathrm{O}$ in the reactor, and the total concentrations of the aqueous components. Columns 25 through 38 present reaction progress, 
mass of $\mathrm{H}_{2} \mathrm{O}$ in the reactor, and the concentrations of potential acid-neutralizing species. Finally, columns 39 through 56 are reserved to show the amounts of minerals accumulated in the reactor. This last section is not included in the condensation lookup tables because mineral outputs from the IDPS model are only needed from evaporation runs. The top three rows in these spreadsheets provide a visual check that the correct type of information was entered into each column. The values in the lookup tables may be used to define response surfaces so that interpolations or extrapolations may be obtained for precise input values not provided in the tables.

\subsection{MODEL SENSITIVITY TO CORRECTED ZEOLITE DATA}

Errors in equilibrium constants (log $\mathrm{K}$ values) for seven zeolites in the Pitzer database were discovered during the qualification of the data0.ymp.R2 thermodynamic database (Table 4-4). These errors, which were discovered after the original calculations in this report had been completed, are documented in Qualification of Thermodynamic Data for Geochemical Modeling of Mineral-Water Interactions in Dilute Systems (BSC 2004 [DIRS 171916]). The seven zeolites are analcime, erionite, phillipsite, stellerite, chabazite, laumontite, and clinoptilolite-Na.

To evaluate the impacts of these errors, a sensitivity analysis was performed. A revised Pitzer database, called data0.yp1, was created in which the original $\log \mathrm{K}$ values were replaced with the corrected values. Next, selected EQ3/6 simulations were run with the revised database. The results were then compared to the original results to assess the importance of the errors.

Table 6-5 provides a comparison of the original and corrected $\log \mathrm{K}$ values. The comparison shows that the $\log \mathrm{K}$ values did not change at $25^{\circ} \mathrm{C}$ and that analcime is the only zeolite whose $\log \mathrm{K}$ values decreased at the other temperatures. A decrease in $\log \mathrm{K}$ implies a reduction in solubility. Thus, the zeolites that increased in solubility at temperatures other than $25^{\circ} \mathrm{C}$ are erionite, phillipsite, stellerite, chabazite, laumontite, and clinoptilolite-Na.

Table 6-5. Corrections to Log K Values for Seven Zeolites

\begin{tabular}{|c|c|c|c|c|c|c|c|c|}
\hline Zeolite & $\begin{array}{c}\log K \text { at } \\
0^{\circ} \mathrm{C}\end{array}$ & $\begin{array}{c}\log K \text { at } \\
25^{\circ} \mathrm{C}\end{array}$ & $\begin{array}{c}\log K \text { at } \\
60^{\circ} \mathrm{C}\end{array}$ & $\begin{array}{c}\log K \text { at } \\
100^{\circ} \mathrm{C}\end{array}$ & $\begin{array}{c}\log K \text { at } \\
150^{\circ} \mathrm{C}\end{array}$ & $\begin{array}{c}\log K \text { at } \\
200^{\circ} \mathrm{C}\end{array}$ & $\begin{array}{c}\log K \text { at } \\
250^{\circ} \mathrm{C}\end{array}$ & $\begin{array}{c}\log K \text { at } \\
300^{\circ} \mathrm{C}\end{array}$ \\
\hline \multirow[t]{3}{*}{ Analcime } & 7.3411 & 6.0057 & 4.3207 & 2.7687 & 1.2666 & 0.0739 & -0.9734 & -2.0317 \\
\hline & 7.5960 & 6.0057 & 4.7307 & 4.4496 & 5.3841 & 7.2915 & 9.8175 & 12.6819 \\
\hline & -0.2549 & 0.0000 & -0.4100 & -1.6809 & -4.1175 & -7.2176 & -10.7909 & -14.7136 \\
\hline \multirow[t]{3}{*}{ Erionite } & -2.4264 & -4.8296 & -8.5254 & -11.9726 & -15.1353 & -17.5303 & -19.7298 & -22.3994 \\
\hline & -2.7178 & -4.8296 & -8.9463 & -13.5913 & -18.8201 & -23.5713 & -28.2226 & -33.3381 \\
\hline & 0.2914 & 0.0000 & 0.4209 & 1.6187 & 3.6848 & 6.0410 & 8.4928 & 10.9387 \\
\hline \multirow[t]{3}{*}{ Phillipsite } & -4.7708 & -6.7617 & -9.8737 & -12.7688 & -15.3984 & -17.3689 & -19.1824 & -21.4273 \\
\hline & -5.0381 & -6.7617 & -10.2599 & -14.2541 & -18.7801 & -22.9139 & -26.9789 & -31.4706 \\
\hline & 0.2673 & 0.0000 & 0.3862 & 1.4853 & 3.3817 & 5.5450 & 7.7965 & 10.0433 \\
\hline \multirow[t]{3}{*}{ Stellerite } & -6.1718 & -8.7844 & -12.7407 & -16.4486 & -19.8970 & -22.5474 & -24.9839 & -27.8839 \\
\hline & -6.4688 & -8.7844 & -13.1698 & -18.0986 & -23.6535 & -28.7068 & -33.6443 & -39.0401 \\
\hline & 0.2970 & 0.0000 & 0.4291 & 1.6500 & 3.7565 & 6.1594 & 8.6604 & 11.1562 \\
\hline
\end{tabular}


Table 6-5. Corrections to Log K Values for Seven Zeolites (Continued)

\begin{tabular}{|c|c|c|c|c|c|c|c|c|}
\hline Zeolite & $\begin{array}{c}\log K \text { at } \\
0^{\circ} \mathrm{C}\end{array}$ & $\begin{array}{c}\log K \text { at } \\
25^{\circ} \mathrm{C}\end{array}$ & $\begin{array}{c}\log K \text { at } \\
60^{\circ} \mathrm{C}\end{array}$ & $\begin{array}{c}\log K \text { at } \\
100^{\circ} \mathrm{C}\end{array}$ & $\begin{array}{c}\log K \text { at } \\
150^{\circ} \mathrm{C} \\
\end{array}$ & $\begin{array}{c}\log K \text { at } \\
200^{\circ} \mathrm{C}\end{array}$ & $\begin{array}{c}\log K \text { at } \\
250^{\circ} \mathrm{C}\end{array}$ & $\begin{array}{c}\log K \text { at } \\
300^{\circ} \mathrm{C}\end{array}$ \\
\hline \multirow[t]{3}{*}{ Chabazite } & 14.9395 & 10.3714 & 4.5581 & -0.7982 & -5.9745 & -10.0955 & -13.7420 & -17.4773 \\
\hline & 14.7333 & 10.3714 & 4.2602 & -1.9440 & -8.5835 & -14.3739 & -19.7583 & -25.2283 \\
\hline & 0.2062 & 0.0000 & 0.2979 & 1.1458 & 2.6090 & 4.2784 & 6.0163 & 7.7510 \\
\hline \multirow[t]{3}{*}{ Laumontite } & 19.4704 & 14.2657 & 7.6939 & 1.6028 & -4.3587 & -9.1673 & -13.4421 & -17.7733 \\
\hline & 19.2830 & 14.2657 & 7.4233 & 0.5631 & -6.7243 & -13.0442 & -18.8908 & -24.7894 \\
\hline & 0.1874 & 0.0000 & 0.2706 & 1.0397 & 2.3656 & 3.8769 & 5.4487 & 7.0161 \\
\hline \multirow[t]{3}{*}{ Clinoptilolite-Na } & -4.6593 & -5.7696 & -8.5612 & -11.9362 & -16.0971 & -20.4363 & -25.3442 & -31.3726 \\
\hline & -4.6606 & -5.7696 & -8.5627 & -11.9415 & -16.1074 & -20.4506 & -25.3610 & -31.3903 \\
\hline & 0.0013 & 0.0000 & 0.0015 & 0.0053 & 0.0103 & 0.0143 & 0.0168 & 0.0177 \\
\hline
\end{tabular}

NOTE: $\quad$ The first row for each zeolite contains the revised log $\mathrm{K}$ values as documented in Table 4-4. The second row is from DTN: MO0302SPATHDYN.000 [DIRS 161756]. The third row (italicized) is the change in the log $\mathrm{K}$ value.

A revised Pitzer database called data0.yp1 was created from the original data0.ypf.R1 (DTN: SN0302T0510102.002) by replacing the original $\log \mathrm{K}$ values for the seven zeolites with the corrected $\log \mathrm{K}$ values. The revised database is documented in DTN: MO0410SPAPITZR.000.

Two water types were used in the sensitivity analysis. One was the average J-13 well water modeled in Section 6.7. The other was the synthesized Topopah Spring tuff pore water modeled in Section 7.1.3. Because zeolites are Al-silicates and the synthesized Topopah Spring tuff pore water in Section 7.1.3 did not include Al, Al was added at a concentration of $1 \mathrm{mg} / \mathrm{kg}$ to the Topopah Spring tuff pore water. This concentration of Al supersaturates the pore water with respect to $\mathrm{Al}$, which results in immediate precipitation of the most stable Al phase in each of the simulations.

The various sensitivity runs and associated spreadsheets are summarized in Table 6-6 and documented in DTN: MO0410MWDIDPSM.000. In addition to the sensitivity runs at the temperatures of the original simulations, runs were repeated at $100^{\circ} \mathrm{C}$ for both the original Pitzer database and the revised data0.yp1 database.

For each of the Topopah Spring tuff pore water sensitivity runs, the seven zeolites remained below saturation. Thus, the predicted evolution of the evaporating waters was not affected by the $\log \mathrm{K}$ corrections. Even for the $100^{\circ} \mathrm{C}$ runs, where the $\log \mathrm{K}$ corrections are larger, the Topopah Spring tuff pore water remained undersaturated with respect to the seven zeolites for the entire evaporations. The phase that controls the Al concentrations in each of these simulations is amesite-14A. 
Table 6-6. Zeolite Log K Sensitivity Runs

\begin{tabular}{|c|c|c|c|c|}
\hline $\begin{array}{l}\text { Source } \\
\text { Section }\end{array}$ & Description & $\begin{array}{c}\text { EQ6 Output } \\
\text { Filenames }\end{array}$ & $\begin{array}{l}\text { Database } \\
\text { Used }\end{array}$ & Spreadsheets \\
\hline \multirow[t]{3}{*}{6.7} & $\begin{array}{l}\text { Evaporation and dilution of average } \\
\mathrm{J}-13 \text { well water at } 70^{\circ} \mathrm{C}\end{array}$ & $\begin{array}{l}\text { j13c3t7e.6o, } \\
\text { j13c3t7c.6o }\end{array}$ & data0.yp1 & $\begin{array}{l}\text { j13c3t7e yp1.xls, } \\
\text { j13c3t7c yp1.xls }\end{array}$ \\
\hline & \multirow{2}{*}{$\begin{array}{l}\text { Evaporation of average } \mathrm{J}-13 \text { well } \\
\text { water at } 100^{\circ} \mathrm{C}\end{array}$} & j13c3t1r.6o & data0.ypf.R1 & j13c3 100C.xls \\
\hline & & j13c3t1e.6o & data0.yp1 & j13c3 100C yp1.xls \\
\hline \multirow[t]{3}{*}{7.1 .3} & $\begin{array}{l}\text { Evaporation of synthesized Topopah } \\
\text { Spring tuff pore water at } 75^{\circ} \mathrm{C} \text { with } \\
1 \mathrm{mg} / \mathrm{kg} \mathrm{Al} \text { added }\end{array}$ & $\begin{array}{l}\text { tspw1243.6o, } \\
\text { tspw3sep.6o }\end{array}$ & data0.yp1 & tspw3 sep yp1.xls \\
\hline & \multirow{2}{*}{$\begin{array}{l}\text { Evaporation of synthesized Topopah } \\
\text { Spring tuff pore water at } 100^{\circ} \mathrm{C} \text { with } \\
1 \mathrm{mg} / \mathrm{kg} \mathrm{Al} \text { added }\end{array}$} & tspw3t1r.6o & data0.ypf.R1 & tspw3 100C.xls \\
\hline & & tspw3t1e.6o & data0.yp1 & tspw3 100C yp1.xls \\
\hline
\end{tabular}

Output DTN: MO0410MWDIDPSM.000.

For the average $\mathrm{J}-13$ well water simulations, the results show a slight difference in the timing and presence of three zeolites. For example, in the $70^{\circ} \mathrm{C}$ runs, instead of stellerite being replaced by celadonite at a concentration factor of around 10 (Figure 6-9), it is replaced at a concentration factor around 12 (DTN: MO0410MWDIDPSM.000, file: “j13c3t7e yp1.xls”). This shift occurs because the corrected stellerite $\log \mathrm{K}$ is higher than the original $\log \mathrm{K}$ at the temperature of the simulation. This shift, however, has no impact on the primary outputs of the IDPS model. No differences in the predicted values of $\mathrm{pH}$, ionic strength, concentrations of chloride and nitrate, and deliquescence relative humidity are evident. For the $100^{\circ} \mathrm{C} \mathrm{J}-13$ evaporations, stellerite precipitation occurs in the concentration factor range of 1.3 to 3.8. Below 1.3, laumontite is the precipitating zeolite, and above 3.8 celadonite is the precipitating phase (file: " $\mathrm{j} 13 \mathrm{c} 3 \mathrm{100 \textrm {C }}$ yp1.xls"). Without the $\log \mathrm{K}$ corrections, laumontite remains undersaturated at all concentration factors and stellerite is replaced by celadonite at a concentration factor of 11 (file: " $\mathrm{j} 13 \mathrm{c} 3$ 100C.xls"). However, as in the case of the $70^{\circ} \mathrm{C}$ runs, the $\log \mathrm{K}$ corrections have no impact on the primary IDPS model outputs: $\mathrm{pH}$, ionic strength, concentrations of chloride and nitrate, and deliquescence relative humidity.

As demonstrated above, precipitation and dissolution of zeolites are expected to have negligible impacts on the primary IDPS outputs. The amount of precipitation or dissolution of zeolites in a given water is limited by the low solubility of zeolites and the low solubility and concentration of Al relative to other components in water. Thus, while precipitation and dissolution of zeolites may control the concentration of relatively minor dissolved components such as Al, they do not control the ionic strength, concentrations of more predominant ions such as $\mathrm{Cl}$ and $\mathrm{NO}_{3}$, deliquescence relative humidity, or $\mathrm{pH}$ of the evaporating solution. As a result, use of the original Pitzer database is justified for the intended use despite the errors discovered in the zeolite $\log \mathrm{K}$ values. 


\section{VALIDATION}

This section documents the validation of the IDPS model. As stated in AP-SIII.10Q, Models, model validation is a process used to establish confidence that a mathematical model and its underlying conceptual model adequately represent with sufficient accuracy the system, process, or phenomenon in question. Validation is used to generate confidence that the model is appropriate and adequate for the intended use. The intended use is defined in Section 1. All data used in the validation are identified in Section 4.4. According to AP-2.27Q, Attachment 3, this model must be validated to a validation level of II, as determined in Section 2.2.1.1 of the TWP (BSC 2004 [DIRS 171156]).

Two general approaches to confidence building are identified in AP-SIII.10Q, Models: 1) confidence building during model development to establish scientific basis and accuracy for intended use, and 2) confidence building after model development to support the scientific basis of the model. These approaches and how they were used in the development of the IDPS model are explained below.

Confidence Building During Model Development. AP-SIII.10Q, Section 5.3.2(b), specifies several methods for confidence building during model development. The development of the IDPS model has been conducted according to these criteria, as follows:

1. Selection of input parameters and/or input data, and a discussion of how the selection process builds confidence in the model [AP-SIII.10 Q Section 5.3.2(b) (1)].

The inputs to the IDPS model are described in Section 4.1.1 and Appendix I, including discussion about selection of input and design parameters. The selection process was specifically designed to build confidence in the ability of the model to predict the effects of large ranges of temperature and relative humidity on the chemical evolution of water in the repository. This process included determining which data would be used to develop the model (dependent) and which data would be used to validate the model (independent) after model development. The dependent data included the relevant Pitzer thermodynamic data available in the literature that could be qualified in accordance with AP-SIII.10Q. When multiple sources were available, the data were either combined to derive fitted values or comparisons were made to assess and document differences. The independent data include: 1) data derived from independent laboratory experiments specifically designed to investigate the effects of evaporation on the chemical evolution of water compositions and environmental conditions relevant to the repository, 2) data from the evaporation of seawater, and 3) compilations of salt solubility measurements (Section 4.4). Unlike the Pitzer thermodynamic data, these independent data provided excellent tests of the model's ability to predict the combined effects of temperature and relative humidity on water compositions and the effects of complex multi-component systems. Detailed discussion about model concepts can be found in Section 6.3. Thus, this requirement can be considered satisfied. 
2. Description of calibration activities, and/or initial boundary condition runs, and/or run convergences, and a discussion of how the activity or activities build confidence in the model. Inclusion of a discussion of impacts of any non-convergence runs [(AP-SIII.10Q Section 5.3.2(b)(2)].

Detailed discussion of initial and boundary conditions for the model can be found in Sections 4.1.2, 6.4, and 6.6.2. Discussion about non-convergence runs is not relevant for this report. Thus, this requirement can also be considered satisfied.

3. Discussion of the impacts of uncertainties to the model results [(AP-SIII.10 Q Section 5.3.2(b)(3)].

Discussion of model uncertainties analyses is provided in Section 7.5. A summary discussion on uncertainties and their impact is given in Section 8.4. Thus, this requirement can be considered satisfied.

Confidence Building After Model Development to Support the Scientific Basis of the Model. For confidence building after model development, AP.SIII.10Q, Section 5.3.2(c), requires that at least one of seven different listed methods be used for model validation. The postdevelopment methods used to validate the IDPS model are:

1. AP-SIII.10Q, Section 5.3.2(c), Method 1: Corroboration of model results with experimental data not used to develop or calibrate the model.

For model validation, independent experimental data, showing the combined effects of temperature and relative humidity on water compositions and the effects of complex multi-component systems, as well as independent salt solubility data, were compared to model predictions. These comparisons, presented in Sections 7.1, 7.2, and 7.4, build a high degree of confidence in the model and support its scientific basis.

2. AP-SIII.10Q, Section 5.3.2(c), Method 2: Corroboration of results with alternative mathematical models.

Additional confidence in the model was attained by comparing model results at low ionic strengths (below 1 molal) to results using the qualified data0.ymp.R2 database. This comparison is presented in Section 7.3.

As stated in Section 2.2.1 of the TWP (BSC 2004 [DIRS 171156]), validation is to be accomplished by comparing model results with results from evaporation experiments and with data published in handbooks and refereed journals. Sections 7.1 through 7.3 present model validation simulations to compare with the results of multi-component evaporation experiments, sample data for evaporated seawater, handbook aqueous solubilities and deliquescence relative humidity values of simple salts, and predictions using an independent database. These sections focus primarily on validating the aqueous outputs of the IDPS model. Section 7.4 draws upon these model validation simulations to document how the IDPS model is validated for mineral outputs. Section 7.5 summarizes the results of the simulations and their implications. 
The experimental data used as validation cases may not be fully representative of possible in-drift conditions. Variations may occur in regard to water compositions, temperatures, and other environmental variables such as the partial pressure of $\mathrm{CO}_{2}$. Because of this, the validation was conducted using a suite of test data collected under a variety of laboratory conditions involving aqueous solutions of various chemistries. The validation cases chosen include cases representative of or similar to potential repository conditions, such as evaporation test data for Yucca Mountain groundwater compositions. However, the cases used here also include others to provide tests of the general modeling capability that do not represent and may not be similar to potential conditions in the repository. These cases include data for the solubility of single salt minerals as a function of temperature and data for the evaporation of seawater under normal earth surface conditions. These cases build confidence that the model is free of conceptual or numerical errors, and add confidence to the use of the model when a set of validation data spanning the complete range of potential conditions for the application of interest is unavailable.

Quantitative validation criteria for the IDPS model and their justification are provided in Section 2.2.1 of the TWP (BSC 2004 [DIRS 171156]). These criteria are summarized in Table 7-1. Because the IDPS model is designed to evaluate changes in the composition of natural waters upon high degrees of evaporation and concentration, some species concentrations (e.g., nitrate and chloride) can change by six orders of magnitude or more. In addition, uncertainties related to the thermodynamic database are system-dependent and difficult to quantify for any given system. For these reasons, the validation criterion for predicting experimental results to within one (or two) order(s) of magnitude (or one unit for $\mathrm{pH}$, a log-transformed parameter) is justified. The IDPS model is also used to predict deliquescence relative humidity $\left(R H_{d}\right)$. The TWP sets a validation criterion of \pm 15 percent ( $R H$ units). In this report, this criterion is lowered to \pm 10 percent ( $R H$ units), which is equivalent to \pm 0.1 in units of activity of water. This criterion is justified because differences larger than this generally indicate a lack of reliable data to validate or constrain the model.

The IDPS model is, in much of its range of application, considerably more accurate than required. This is the case, for example, for the solubility of sodium chloride $(\mathrm{NaCl})$ in water over a temperature range of 25 to $200^{\circ} \mathrm{C}$. The data required to develop the model for sodium chloride are abundant and accurate (to within a few percent or better), the uncertainty in the sodium chloride data set used for validation is generally accurate and available, and also the assumption of rapid chemical equilibrium is valid. On the other hand, the broad range of criteria in Table 7-1 is appropriate in the validation of the IDPS model for several reasons. The data available to develop some parts of the model may be more limited or less accurate than for other parts. This may also be the case for the validation data set, particularly data sets associated with complex, more difficult tests or with more complex chemistries. Also, the assumption of rapid chemical equilibrium is not always applicable, particularly when certain chemical components, species, or minerals are involved.

The equilibrium assumption works best for strongly ionic components, species, and minerals (i.e., usually salt minerals). The equilibrium assumption breaks down when covalent bonding is involved because kinetic limitations are more likely to become evident. A good example is the precipitation of quartz $\left(\mathrm{SiO}_{2}\right)$. In an experimental system, evaporation of a silica-containing water is likely to result in the formation of metastable amorphous silica instead of quartz. In some cases, suppressing the precipitation of a mineral with known kinetic difficulties and 
allowing a metastable mineral to form may produce a more accurate model. However, in other cases the kinetics may be such that neither assumption of stable equilibrium nor simple metastable equilibrium improves the model.

Because of the factors discussed above, the validation criteria used here do not necessarily imply large uncertainties in the model outputs. Uncertainties must be individually assessed for the specific applications of the model. In addition, large differences between model predictions and experimental results may not be due to model uncertainty but rather to errors or uncertainty in experimental data or how the data are reported. Such experimental uncertainties complicate assessments of model validation and model uncertainty. For example, the published concentration factors for the evaporation experiments simulated in Sections 7.1.1 and 7.1.3 are shown to be in error. Further analysis shows that these errors account for most of the differences between model predictions (based on the erroneous concentration factors) and the experimental data. Often, experimental errors and uncertainties are not quantifiable from published reports. Considerable uncertainties are inherent in methods used to measure or control $\mathrm{pH}$ and relative humidity in equilibrium with concentrated salt solutions, especially at high temperature (e.g., Section 7.5.1). As a result, model uncertainties, such as those estimated in Section 7.5, cannot be separated from experimental uncertainty with a high degree of confidence. Thus, the model uncertainties estimated in this report account for both model uncertainties and experimental uncertainties.

Of all the IDPS model output parameters developed and validated in this report, the specific output parameters developed in support of the TSPA-LA are $\mathrm{pH}$, ionic strength, concentrations of $\mathrm{Cl}$ and $\mathrm{NO}_{3}$, the $\mathrm{Cl}: \mathrm{NO}_{3}$ ratio, and deliquescence relative humidity $\left(R H_{d}\right)$. The ionic strength predicted by the IDPS model is used in downstream modeling to predict colloid stability. The other output parameters are principally used in downstream modeling to predict corrosion rates. High $\mathrm{Cl}$ concentrations increase corrosion rates while high $\mathrm{NO}_{3}$ concentrations decrease them. As a result, the $\mathrm{Cl}: \mathrm{NO}_{3}$ ratio is important in corrosion modeling because a high ratio combined with a high $\mathrm{Cl}$ concentration increases corrosion rates. The role of $\mathrm{pH}$ is not as straightforward, but it is nevertheless important in predicting corrosion rates in downstream modeling. The remaining output parameter, $R H_{d}$, defines the $R H$ below which liquid water cannot persist for the given conditions and therefore corrosion cannot occur.

Model uncertainties associated with these parameters are evaluated and determined in Section 7.5 for propagation into the TSPA-LA. Although this report provides the model uncertainties for these parameters, it does not determine the nominal predicted values. The nominal predictions for TSPA-LA are instead provided in Engineered Barrier System: Physical and Chemical Environment Model (BSC 2004 [DIRS 169860]) where the IDPS model is applied. 
Table 7-1. Model Validation Criteria

\begin{tabular}{|c|c|c|c|c|c|}
\hline $\begin{array}{l}\text { Category of } \\
\text { Model Output }\end{array}$ & $\begin{array}{c}\text { Related } \\
\text { Components }\end{array}$ & $\begin{array}{l}\text { Related } \\
\text { ANC } \\
\text { Species } \\
\end{array}$ & Related Minerals & $\begin{array}{c}\text { Experimental } \\
\text { Agreement for } \\
\text { Aqueous } \\
\text { Components and } \\
\text { ANC Species } \\
\end{array}$ & $\begin{array}{l}\text { Experimental } \\
\text { Agreement for } \\
\text { Minerals }\end{array}$ \\
\hline $\mathrm{pH}$ & $\mathrm{H}$ & $\mathrm{H}^{+}, \mathrm{OH}^{-}$ & not applicable & $\begin{array}{l}\mathrm{pH} \text { within } 1 \mathrm{pH} \\
\text { unit; Concentration } \\
\text { within } 1 \text { order of } \\
\text { magnitude (factor } \\
\text { of } 10 \text { ) }\end{array}$ & not applicable \\
\hline Ionic Strength & $\begin{array}{l}\mathrm{Al}, \mathrm{Br}, \mathrm{Ca}, \mathrm{CO}_{3} \\
\mathrm{Cl}, \mathrm{F}, \mathrm{K}, \mathrm{Mg} \\
\mathrm{Na}, \mathrm{NO}_{3}, \mathrm{SiO}_{2} \\
\mathrm{SO}_{4}\end{array}$ & $\begin{array}{l}\text { not } \\
\text { applicable }\end{array}$ & not applicable & $\begin{array}{l}\text { Concentration } \\
\text { within } 1 \text { order of } \\
\text { magnitude (factor } \\
\text { of 10) }\end{array}$ & not applicable \\
\hline $\begin{array}{l}\text { Deliquescence } \\
\text { Relative Humidity } \\
\left(R H_{d}\right)\end{array}$ & $\mathrm{H}_{2} \mathrm{O}$ & $\begin{array}{l}\text { not } \\
\text { applicable }\end{array}$ & $\begin{array}{l}\text { Highly soluble minerals in } \\
\text { the system } \mathrm{Al}-\mathrm{Br}-\mathrm{Ca}-\mathrm{CO}_{3-}^{-} \\
\mathrm{Cl}-\mathrm{F}-\mathrm{K}-\mathrm{Mg}-\mathrm{Na}-\mathrm{NO}_{3}-\mathrm{SO}_{4-} \\
\mathrm{SiO}_{2}-\mathrm{H}-\mathrm{H}_{2} \mathrm{O} \text { at potential } \\
\text { repository temperatures } \\
\text { and pressures }\end{array}$ & $\begin{array}{l}\text { Activity of water } \\
\text { within } 0.1 \text { of } \\
\text { deliquescence } \\
\text { relative humidity } \\
\left(R H_{d}\right)\end{array}$ & $\begin{array}{l}\text { Solubility within } \\
1 \text { order of } \\
\text { magnitude } \\
\text { (factor of } 10)\end{array}$ \\
\hline $\begin{array}{l}\text { Rapidly } \\
\text { equilibrated } \\
\text { components and } \\
\text { their associated } \\
\text { ANC species and } \\
\text { minerals }\end{array}$ & $\begin{array}{l}\mathrm{Al}, \mathrm{Br}, \mathrm{CO}_{3}, \mathrm{Cl} \\
\mathrm{F}, \mathrm{K}, \mathrm{Na}, \mathrm{NO}_{3} \\
\mathrm{SO}_{4}\end{array}$ & $\begin{array}{l}\mathrm{HCO}_{3}{ }^{-} \\
\mathrm{CO}_{3}{ }^{--} \\
\mathrm{HSO}_{4}{ }^{-}\end{array}$ & 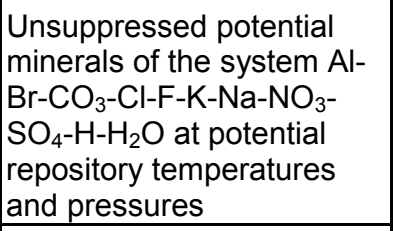 & $\begin{array}{l}\text { Concentration } \\
\text { within } 1 \text { order of } \\
\text { magnitude (factor } \\
\text { of } 10 \text { ) }\end{array}$ & $\begin{array}{l}\text { Solubility within } \\
1 \text { order of } \\
\text { magnitude } \\
\text { (factor of } 10 \text { ) }\end{array}$ \\
\hline $\begin{array}{l}\text { Less rapidly } \\
\text { equilibrated } \\
\text { components and } \\
\text { their associated } \\
\text { ANC species and } \\
\text { minerals }\end{array}$ & $\mathrm{Ca}, \mathrm{Mg}, \mathrm{SiO}_{2}$ & $\begin{array}{l}\mathrm{Ca}^{2+}, \mathrm{Mg}^{2+} \\
\mathrm{CaHCO}_{3}^{+} \\
\mathrm{MgHCO}_{3}^{+} \\
\mathrm{MgOH}^{+} \\
\mathrm{HSiO}_{3}^{-}\end{array}$ & $\begin{array}{l}\text { Unsuppressed potential } \\
\mathrm{Ca} \text {, Mg, and } \mathrm{SiO}_{2} \text { minerals } \\
\text { of the system } \mathrm{Al}-\mathrm{Br}-\mathrm{Ca}- \\
\mathrm{CO}_{3}-\mathrm{Cl}-\mathrm{F}-\mathrm{K}-\mathrm{Mg}-\mathrm{Na}-\mathrm{NO}_{3}- \\
\mathrm{SO}_{4}-\mathrm{SiO}_{2}-\mathrm{H}-\mathrm{H}_{2} \mathrm{O} \text { at } \\
\text { potential repository } \\
\text { temperatures and } \\
\text { pressures }\end{array}$ & $\begin{array}{l}\text { Concentration } \\
\text { within } 2 \text { orders of } \\
\text { magnitude (factor } \\
\text { of } 100 \text { ) }\end{array}$ & $\begin{array}{l}\text { Equilibrium } \\
\text { solubility within } \\
1 \text { order of } \\
\text { magnitude } \\
\text { (factor of } 10)\end{array}$ \\
\hline
\end{tabular}

NOTE: $\quad$ ANC $=$ acid-neutralizing capability.

\subsection{VALIDATION USING EVAPORATION DATA}

Several sources of evaporation data are relevant to the validation of the model. They include Rosenberg et al. (1999 [DIRS 125338]), Rosenberg et al. (1999 [DIRS 125339]), Environment on the Surfaces of the Drip Shield and Waste Package Outer Barrier (BSC 2001 [DIRS 155640]), and McCaffrey et al. (1987 [DIRS 164481]). These data are presented in Table 4-7 through Table 4-11 in Section 4.4.

\subsubsection{Evaporation of Average J-13 Well Water at $85^{\circ} \mathrm{C}$}

Rosenberg et al. (1999 [DIRS 125338]) evaporated synthetic J-13 well water in a beaker that was open to the atmosphere and maintained at a constant elevated temperature of $85^{\circ} \mathrm{C}$. In the experiment named evap1, synthetic average J-13 well water was evaporated without contact with tuff or other non-precipitated rock material. The experiment began with 30 liters of synthetic average $\mathrm{J}-13$ well water with a measured composition as shown in Table 4-7. A peristaltic pump was used to pump this water into a 1-liter Pyrex beaker at a constant rate while a hot plate was 
used to maintain a water temperature of $85^{\circ} \mathrm{C}$ to evaporate the water. Water samples were collected after the 30 liters had been evaporated to approximately $30 \mathrm{~mL}$. Results of this experiment are also included in Table 4-7. The solids that had accumulated at this stage were identified by x-ray diffraction to be amorphous silica, aragonite, and calcite. Analysis of solids after complete evaporation indicated the additional presence of halite, niter, thermonatrite, and possibly gypsum, anhydrite, and hectorite.

In a similar synthetic J-13 well water evaporation experiment (named evap4), the $\mathrm{pH}$ of the evaporating water was monitored (Rosenberg et al. 1999 [DIRS 125338]). The experiment used approximately the same $\mathrm{J}-13$ starting solution as evap1 (Table 4-7). The $\mathrm{pH}$ measurements are presented in Table 4-8 as a function of concentration factor. There is some uncertainty associated with the $\mathrm{pH}$ measurements. Details of the $\mathrm{pH}$ measurement procedure are not reported. Measuring $\mathrm{pH}$ at high temperature and/or in saline conditions requires special methods (Section 7.5.1), which may or may not have been adopted. The concentration factor was measured as the ratio of the initial water mass divided by the measured water mass at the time of analysis.

The results of these evaporation experiments were modeled using the IDPS model and Pitzer database. Total aqueous concentrations, $\mathrm{pH}$, ionic strength (IS), and mineral precipitation predictions are plotted in Figure 7-1 and Figure 7-2. Comparisons of measurements and predictions are plotted in Figure 7-3 and Figure 7-4. Modeling results are documented in DTN: MO0303MWDJ13RB.000.

One adjustment to the model was to augment the Pitzer database sepiolite $\left(\mathrm{Mg}_{4} \mathrm{Si}_{6} \mathrm{O}_{15}(\mathrm{OH})_{2}: 6 \mathrm{H}_{2} \mathrm{O}\right) \log \mathrm{K}$ by $6 \log \mathrm{K}$ units. This was done to represent an amorphous sepiolite because a crystalline sepiolite, like the sepiolite in the Pitzer database, requires up to 10 years to form at $25^{\circ} \mathrm{C}$ (Jones and Galan 1988 [DIRS 162347], Chapter 16). Formation of an amorphous sepiolite in short timeframes like the evaporation experiment is more likely described by $\log \mathrm{K}$ values closer to those provided by Wollast et al. (1968 [DIRS 162340]). Augmenting the Pitzer database $\log \mathrm{K}$ for sepiolite by $6 \log \mathrm{K}$ units is approximately equivalent (after stoichiometric normalization) to the difference between the amorphous phase $\log \mathrm{K}$ value of Wollast et al. (1968 [DIRS 162340]) and the crystalline phase log K value of Stoessell (1988 [DIRS 127964]) (Jones and Galan 1988 [DIRS 162347], Chapter 16, Table 6).

As shown in Figure 7-3, the modeled evaporation results approximate the $\mathrm{Na}, \mathrm{F}, \mathrm{HCO}_{3}, \mathrm{Cl}, \mathrm{K}$, $\mathrm{Mg}, \mathrm{NO}_{3}, \mathrm{SO}_{4}$, and $\mathrm{SiO}_{2}$ concentrations within a factor of 10 or better when compared to the laboratory measurements. Ca predictions are within a factor of 100 of the measurements. The differences in the predicted and measured aqueous concentrations are within the acceptable range of the model validation criteria listed in Table 7-1.

Figure 7-4 shows general agreement between the laboratory measured $\mathrm{pH}$ and modeled $\mathrm{pH}$ in evap4. The predicted $\mathrm{pH}$ is largely controlled by the fugacity of carbon dioxide, which is fixed at $10^{-3.4}$ bars to approximate the laboratory condition of a beaker open to the atmosphere. Water in evap4 was concentrated to 157 times the original solution.

The discrepancies between the predicted and measured $\mathrm{Si}, \mathrm{Ca}$, and $\mathrm{Mg}$ concentrations and $\mathrm{pH}$ may be due to errors or uncertainty in the Pitzer thermodynamic database, kinetic limitations of 
precipitation reactions, and/or analytical errors such as incomplete removal of small particles of minerals containing these elements from the aqueous samples. If errors and uncertainty in the database and analytical measurements can be ruled out, the relatively short laboratory experiments could have produced sustained supersaturated conditions for calcite and sepiolite. Calcite, the more rapidly precipitated of the two minerals, is perpetually supersaturated in surface seawater where evaporation is an ongoing process (Drever 1988 [DIRS 118564], pp. 71 to 72) and has been shown to be supersaturated in laboratory evaporation experiments (Krauskopf and Bird 1995 [DIRS 101702], p. 72). Precipitation of calcite when the $\mathrm{pH}$ is below 10 results in the release of a proton from the bicarbonate ion:

$$
\mathrm{Ca}^{2+}+\mathrm{HCO}_{3}^{-}=\mathrm{CaCO}_{3}(\mathrm{~s})+\mathrm{H}^{+}
$$

Thus, slow precipitation of calcite could also explain why the model predicts lower $\mathrm{pH}$ than observed. These minerals precipitate in the model at a concentration factor of 157 as shown in Figure 7-2.

The fixed carbon dioxide fugacity is another possible explanation for the observed discrepancies in $\mathrm{pH}$. In a solution that is boiling or evaporating from a beaker, it is possible that the atmospheric partial pressure of carbon dioxide is below atmospheric values because of an increased partial pressure of water vapor and a net flux of vapor flowing out of the beaker. If this was the case, the actual carbon dioxide fugacity would have been lower and $\mathrm{pH}$ predictions would have been higher.

At a concentration factor of 956 ( $C F$ 956) in evap1, precipitation of amorphous silica $\left(\mathrm{SiO}_{2}\right.$ (am)), aragonite $\left(\mathrm{CaCO}_{3}\right)$, and calcite $\left(\mathrm{CaCO}_{3}\right)$ was identified in the experiment. These minerals cannot account for the loss of $\mathrm{Mg}$, whose concentration decreases by more than a factor of 10 rather than increases by a factor of 956. At this stage the model predicts precipitation of calcite and sepiolite. Actual precipitation of amorphous sepiolite $\left(\mathrm{Mg}_{4} \mathrm{Si}_{6} \mathrm{O}_{15}(\mathrm{OH})_{2}: 6 \mathrm{H}_{2} \mathrm{O}\right)$ would be consistent with the reported precipitation of amorphous silica, if the loss of $\mathrm{Mg}$ was accounted for in the observed mineral assemblage at $C F 956$.

Upon complete evaporation, the following minerals were observed: amorphous silica, aragonite, calcite, halite, niter, thermonatrite, gypsum, anhydrite, and hectorite. The last three minerals were not positive matches. These minerals do not account for the precipitation of $\mathrm{Mg}$ or $\mathrm{F}$ (except for the possible occurrence of hectorite). In comparison, the following minerals were predicted by the IDPS model to precipitate: calcite, fluorite, halite, natrite, sepiolite, amorphous silica, and thenardite. Although the predicted phases may not perfectly match the actual phases that precipitate in the experiment, their predicted precipitation accurately accounts for mass balance and produces a scenario that is consistent with the observed evaporative evolution of the solution to $C F 956$.

Ionic strength was not directly measured in these experiments. However, a "measured" ionic strength was estimated from the reported evaporated water compositions using EQ3NR. This was done by entering the reported water compositions and instructing the code to maintain any charge imbalances while it equilibrated the solutions. These EQ3NR calculations did not permit precipitation of potentially supersaturated minerals and did not equilibrate the solution with fixed partial pressures. Such heterogeneous reactions would alter the water compositions from the 
measured concentrations. Thus, the results provided estimated "measured" values of ionic strength, as the data0.ypf database would calculate them. These calculations are documented in DTN: MO0307MWDUNEVP.000 and are summarized in Table 7-2. "Measured" ionic strength was not estimated at a concentration factor of 956 because $\mathrm{pH}$ was not measured at this concentration factor. Ionic strength can be highly sensitive to $\mathrm{pH}$.

It should be noted that the concentration factors reported in LL991008104241.042 [DIRS 120489] are overestimated. $\mathrm{Cl}$ and $\mathrm{NO}_{3}$ should have concentrated conservatively in this experiment. These components should not have precipitated at the concentration factors reported because the concentration factors were not nearly high enough for them to become saturated with respect to any minerals. In fact, no $\mathrm{Cl}$ and $\mathrm{NO}_{3}$ minerals were identified by x-ray diffraction at these concentration factors. The overestimates in the reported concentration factors are substantiated by the measured concentrations of $\mathrm{SO}_{4}$ and $\mathrm{K}$, which also should not precipitate in this concentration factor range, as predicted in Figure 7-2. If the concentration of $\mathrm{NO}_{3}$ or $\mathrm{Cl}$ had been used to determine the concentration factor in the experiment (instead of indirectly estimating the concentration factor from measurements of amounts of water evaporated), then the measured concentration factors would have been approximately 16 to 33 percent lower and the simulated EQ6 evaporations would have been stopped much earlier. This would have considerably lowered the predicted concentrations and reduced the differences between predictions and measurements of $\mathrm{Cl}, \mathrm{NO}_{3}, \mathrm{SO}_{4}$, and $\mathrm{K}$. Thus, the majority of the differences observed in Figure 7-3 between the predicted and measured values for these components are due to errors in the reported concentration factors. These errors also explain the considerable difference between the predicted and "measured" ionic strength values in the concentrated sample in Table 7-2. Had the model been used to concentrate the starting solution to the correct concentration factor, the predicted ionic strength would have been much closer to the "measured" ionic strength.

Table 7-2. Calculation of "Measured" lonic Strength in Average J-13 Well Water Evaporation Experiment

\begin{tabular}{|l|l|l|l|}
\hline $\begin{array}{c}\text { Concentration } \\
\text { Factor }\end{array}$ & \multicolumn{1}{|c|}{$\begin{array}{c}\text { EQ3NR Input/Output } \\
\text { Filenames }\end{array}$} & $\begin{array}{c}\text { "Measured" lonic } \\
\text { Strength } \\
\text { (molal) }\end{array}$ & $\begin{array}{c}\text { Predicted lonic } \\
\text { Strength } \\
\text { (molal) }\end{array}$ \\
\hline 1 & j13n1is.3i, j13n1is.3o & $2.97 \mathrm{E}-03$ & $2.84 \mathrm{E}-03$ \\
\hline 157 & j13n157i.3i, j13n157i.3o & $3.27 \mathrm{E}-01$ & $4.79 \mathrm{E}-01$ \\
\hline
\end{tabular}

Output DTN: MO0307MWDUNEVP.000, File: "Experimental Uncert.xls." 


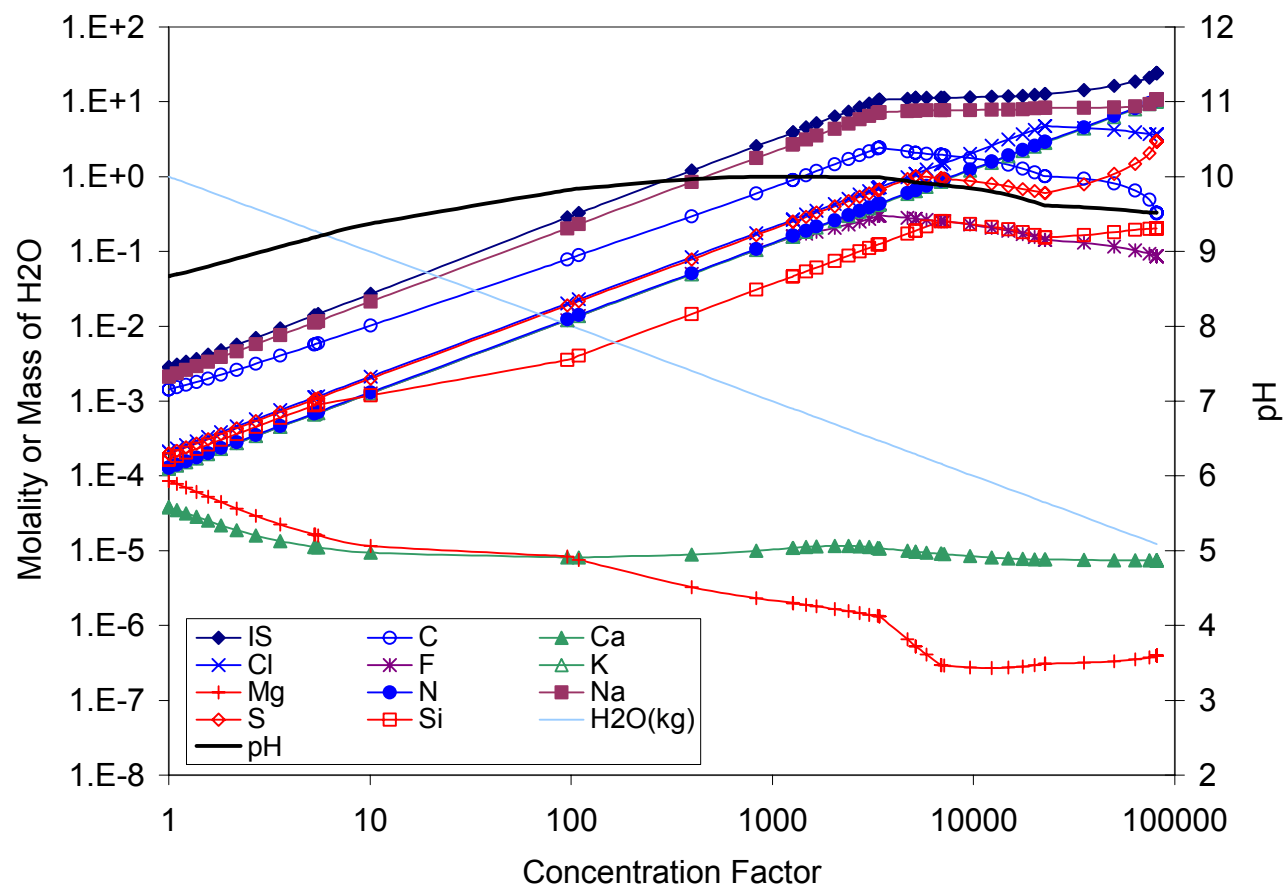

Output DTN: MO0303MWDJ13RB.000.

Figure 7-1. Predicted Aqueous Evolution of Synthetic J-13 Water for Evaporation Experiments of Rosenberg et al. (1999 [DIRS 125338])

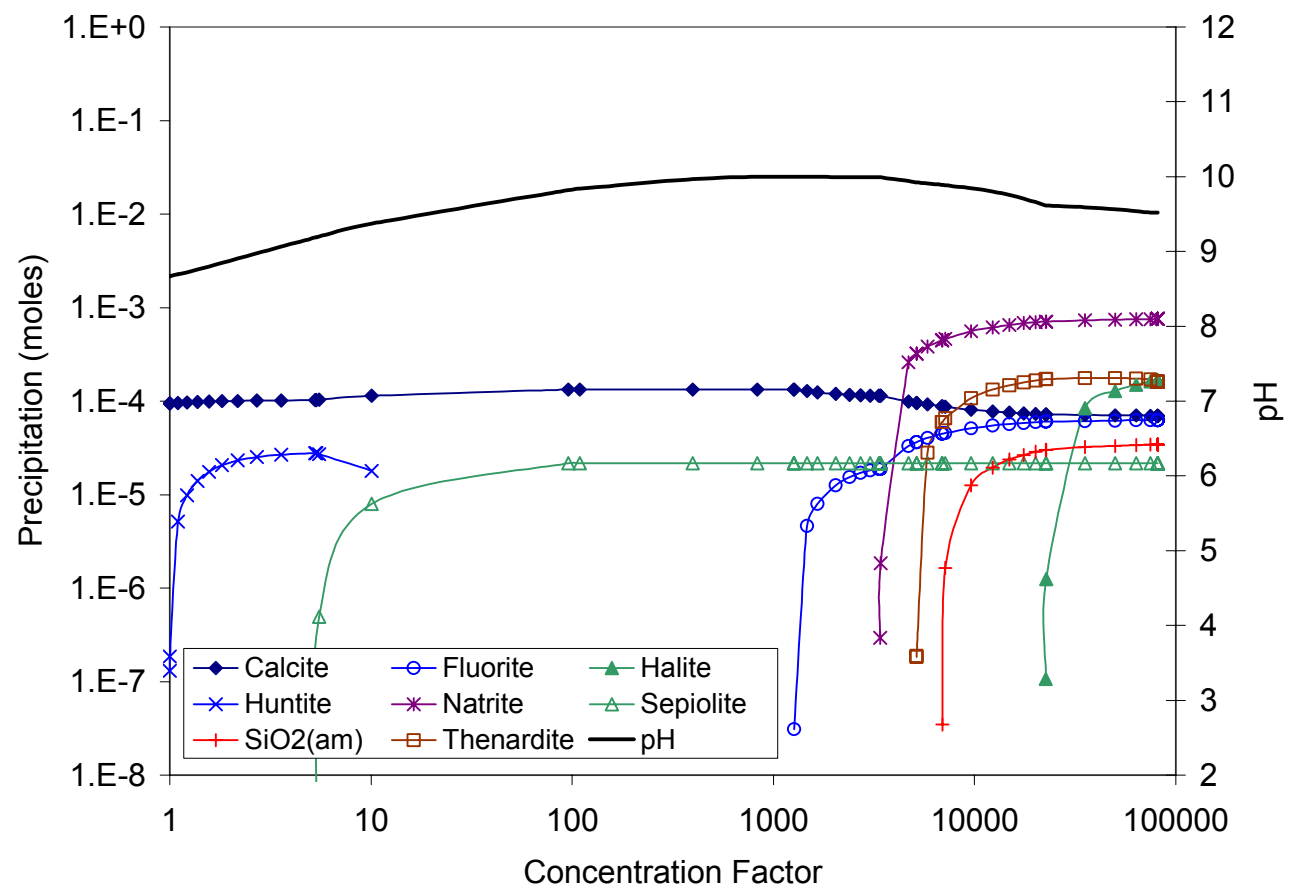

Output DTN: MO0303MWDJ13RB.000.

Figure 7-2. Predicted Mineral Evolution of Synthetic J-13 Water for Evaporation Experiments of Rosenberg et al. (1999 [DIRS 125338]) 


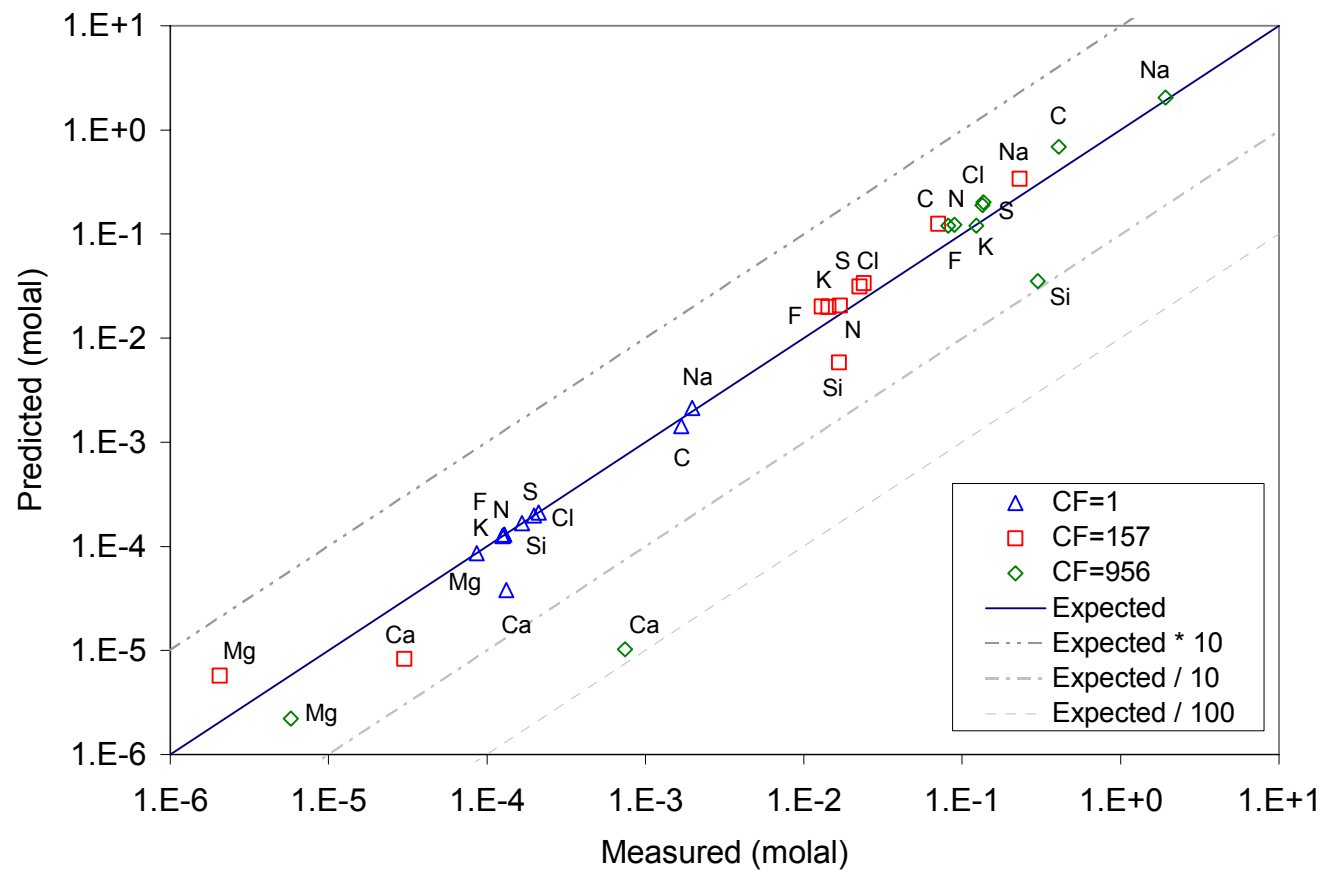

Output DTN: MO0303MWDJ13RB.000.

Figure 7-3. Predicted vs. Measured Concentrations for Synthetic J-13 Water Evaporation Experiments of Rosenberg et al. (1999 [DIRS 125338])

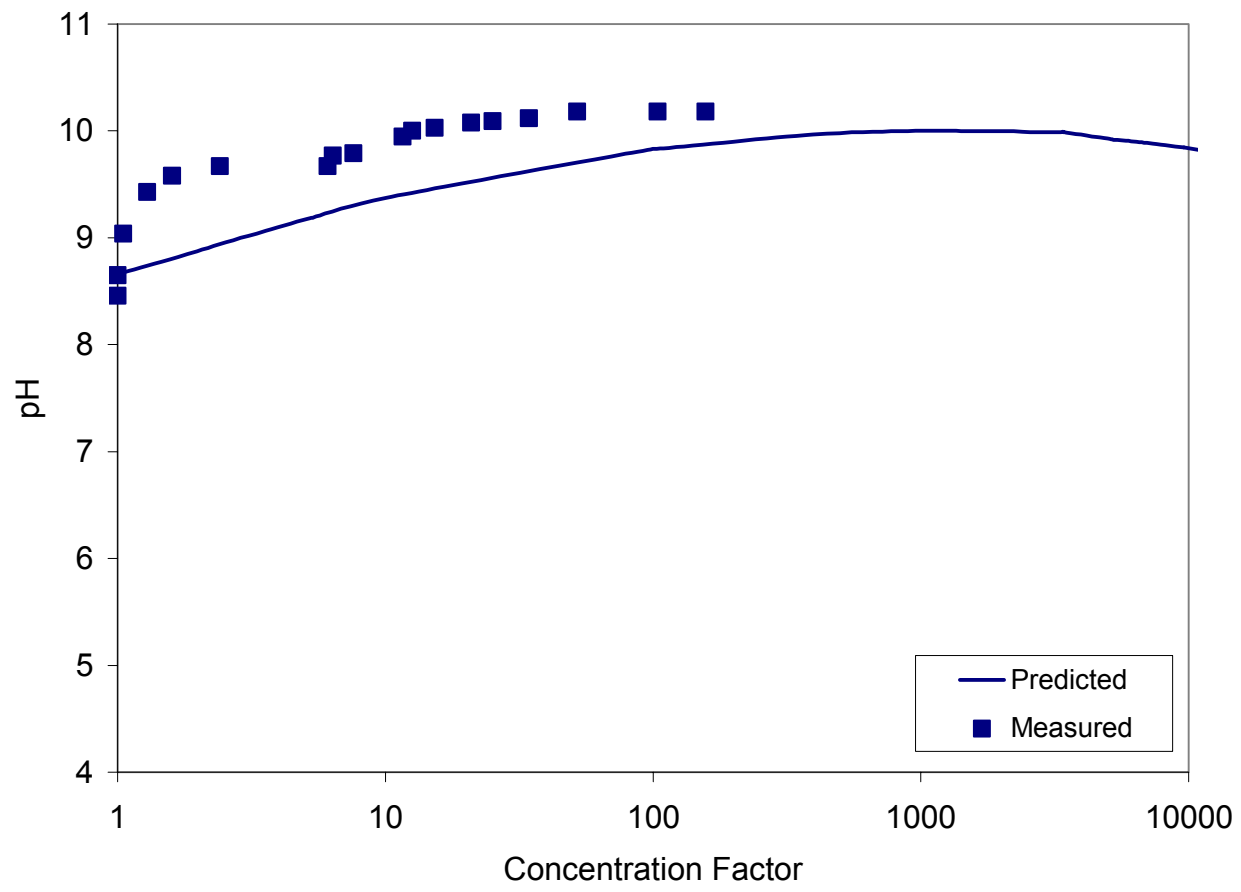

Output DTN: MO0303MWDJ13RB.000.

Figure 7-4. Predicted vs. Measured pH Values for Synthetic J-13 Water Evaporation Experiments of Rosenberg et al. (1999 [DIRS 125338]) 


\subsubsection{Evaporation of $100 x$ Average $\mathrm{J}-13$ Well Water at $90^{\circ} \mathrm{C}$ and 85 Percent Relative Humidity}

In another synthetic J-13 well water evaporation experiment, a synthetic 100 -times concentrated (100x) average J-13 well water was dripped through a column of heated tuff into a Teflon beaker (BSC 2001 [DIRS 155640], pp. 6 to 16). In this experiment (called Batch 1), the beaker was open to the atmosphere and maintained at a constant temperature of $90^{\circ} \mathrm{C}$ and relative humidity of 85 percent. The solution was then allowed to evaporate to a volume of approximately five percent of the original volume, based on the concentration factors reported (the actual volume or mass decrease in the solution was not reported). The starting and final solution compositions are displayed in Table 4-9. The recipe for the synthetic 100x J-13 well water did not include Si, Al, or Fe, likely because these components have limited solubility or are minor constituents (Al and $\mathrm{Fe}$ ). A 100x concentration of these components cannot be prepared without making adjustments, such as raising the $\mathrm{pH}$ to an unrealistic value. A true $100 \mathrm{x} \mathrm{J}-13$ water can only be realistically derived by evaporating unconcentrated $\mathrm{J}-13$ in a container open to a fixed fugacity of carbon dioxide and allowing supersaturated minerals to precipitate from solution during the process (as was done in Rosenberg et al. 1999 [DIRS 125338]).

The results of these evaporation experiments were modeled using the IDPS model and the Pitzer database. Predictions of total aqueous concentrations, $\mathrm{pH}$, ionic strength, and mineral precipitation upon evaporation are documented in DTN: MO0303MWDJ13GD.000 and plotted in Figure 7-5 and Figure 7-6. Measurements and predictions are compared in Figure 7-7. No pH measurements were reported. In this simulation, the sepiolite $\log \mathrm{K}$ was not augmented as was done when modeling the evaporation experiment in Section 7.1.1 because there was no Si in the synthetic 100x J-13 well water. Dissolved Si was not measured after this solution was passed through the column of heated tuff or after subsequent evaporation. Thus, Si was not included in the EQ6 evaporation simulation. Sepiolite cannot precipitate in the absence of Si.

Figure 7-7 shows that the predictions closely approximate the $\mathrm{Na}, \mathrm{F}, \mathrm{Cl}, \mathrm{K}, \mathrm{NO}_{3}, \mathrm{HCO}_{3}$, and $\mathrm{SO}_{4}$ concentrations when compared to the laboratory measurements. To compare the results to the data, the reported nitrate concentration factor of 20.7 is used to represent the concentration factor of the solution. However, because the original concentration factor of the synthesized 100x J-13 water is defined as 100, the final concentration factor is represented here as $2070(100 \times 20.7)$. As shown in the figures, the agreement between the $\mathrm{Na}, \mathrm{F}, \mathrm{Cl}, \mathrm{K}, \mathrm{HCO}_{3}$, and $\mathrm{SO}_{4}$ measurements and predictions indicate that the concentration factor of the solution is well represented by the nitrate concentration factor.

The model underestimates $\mathrm{Ca}$ and $\mathrm{Mg}$ by about 1 to 2 orders of magnitude when compared to the laboratory measurements. Two of several possible explanations for these underestimates are errors or uncertainties in the Pitzer database and/or analytical measurements. The concentration factor of 100 represents the starting water prior to the water flowing through the column of crushed tuff. According to the EQ3/6 calculations, this starting water is supersaturated with respect to calcite and huntite. No $\mathrm{pH}$ measurements were reported, so $\mathrm{pH}$ was predicted by EQ3/6 based on heterogeneous equilibrium with respect to an atmospheric carbon dioxide fugacity of $10^{-3.4}$ bars. Thus, other potential explanations for the underestimates of $\mathrm{Ca}$ and $\mathrm{Mg}$ are that predictions of $\mathrm{pH}$ might be higher than actual, the actual carbon dioxide fugacity might be considerably lower than atmospheric, and/or the precipitation of calcite and huntite is not 
rapid enough to achieve equilibrium in the laboratory experiment. At a concentration factor of around 2070, the model predicts additional precipitation of $\mathrm{Ca}$ and $\mathrm{Mg}$ minerals fluorite and sellaite, as shown in Figure 7-6. Precipitation of these minerals could also be kinetically limited in the experiment. Laboratory analysis of the precipitates was not performed.

In a solution that is boiling or evaporating from a beaker, it is possible that the atmospheric partial pressure of carbon dioxide is below atmospheric values because of an increased partial pressure of water vapor and a net flux of vapor flowing out of the beaker. If this were the case, the actual carbon dioxide fugacity would have been lower and the $\mathrm{pH}$ predictions would have been higher.

Calcite can be supersaturated by as much as a factor of two when calcium and carbonate concentrations are slowly increased in laboratory experiments (Krauskopf and Bird 1995 [DIRS 101702], p. 72). This phenomenon may partly explain why measured Ca concentrations in this evaporation experiment (and the one in the previous section) are larger than the predicted values. Because the model assumes equilibrium for calcite due to the long periods of time that the model is designed to simulate for TSPA-LA, it is understandable that the model might underpredict the $\mathrm{Ca}$ concentration in a short-term laboratory evaporation experiment. Regardless, the model cannot be invalidated for its intended use simply because the prediction of $\mathrm{Ca}$ in a short-term experiment falls slightly outside the validation criteria approximated in Table 7-1. If calcite were allowed to be supersaturated in the simulation due to the slow kinetics of calcite precipitation and the short-term experiment, $\mathrm{Ca}$ predictions would have fallen within the approximated validation criteria. Alternatively, if the evaporation experiment had been conducted over a longer period of time, on the scale of the time periods that the IDPS model is designed to simulate for TSPA-LA, calcite precipitation would have had time to progress towards equilibrium, resulting in a $\mathrm{Ca}$ concentration closer to the value predicted by the IDPS model.

Ionic strength was not directly measured in these experiments and cannot be accurately estimated without $\mathrm{pH}$ measurements. Thus, "measured" ionic strength was not estimated for this experiment using EQ3NR, as was done for the data in Sections 7.1.1 and 7.1.3. 


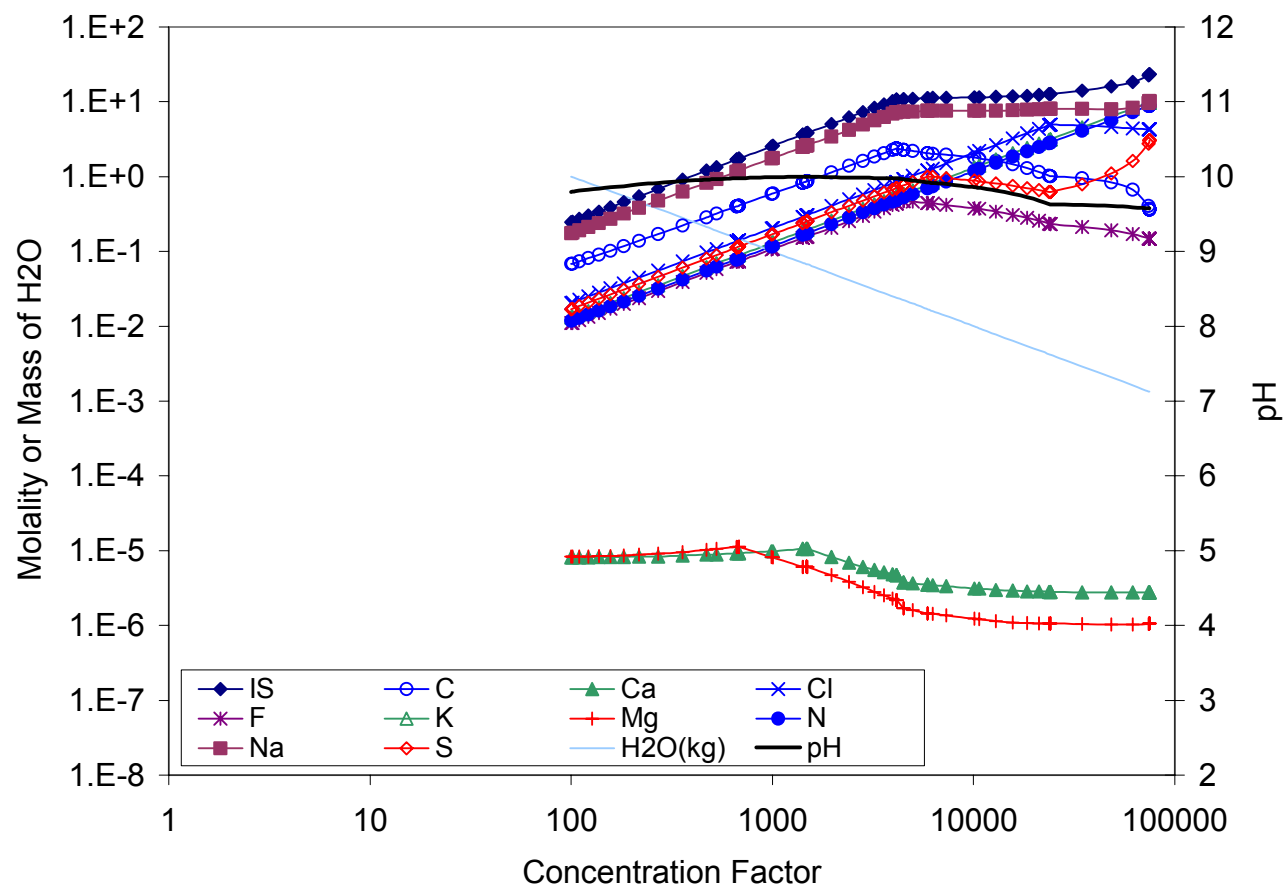

Output DTN: MO0303MWDJ13GD.000.

Figure 7-5. Predicted Aqueous Evolution of 100x Synthetic J-13 Water for Evaporation Experiments (BSC 2001 [DIRS 155640])

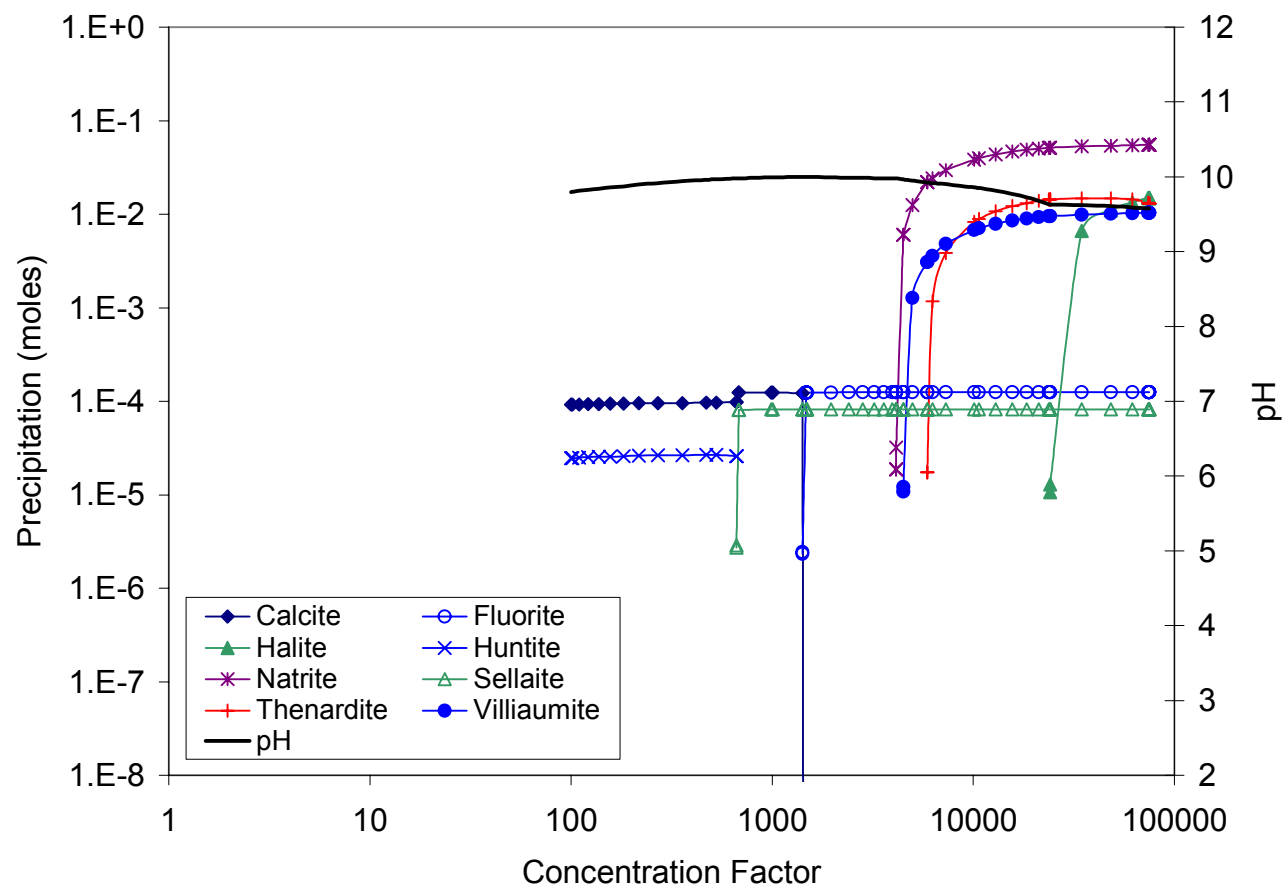

Output DTN: MO0303MWDJ13GD.000.

Figure 7-6. Predicted Mineral Evolution of 100x Synthetic J-13 Water for Evaporation Experiments (BSC 2001 [DIRS 155640]) 


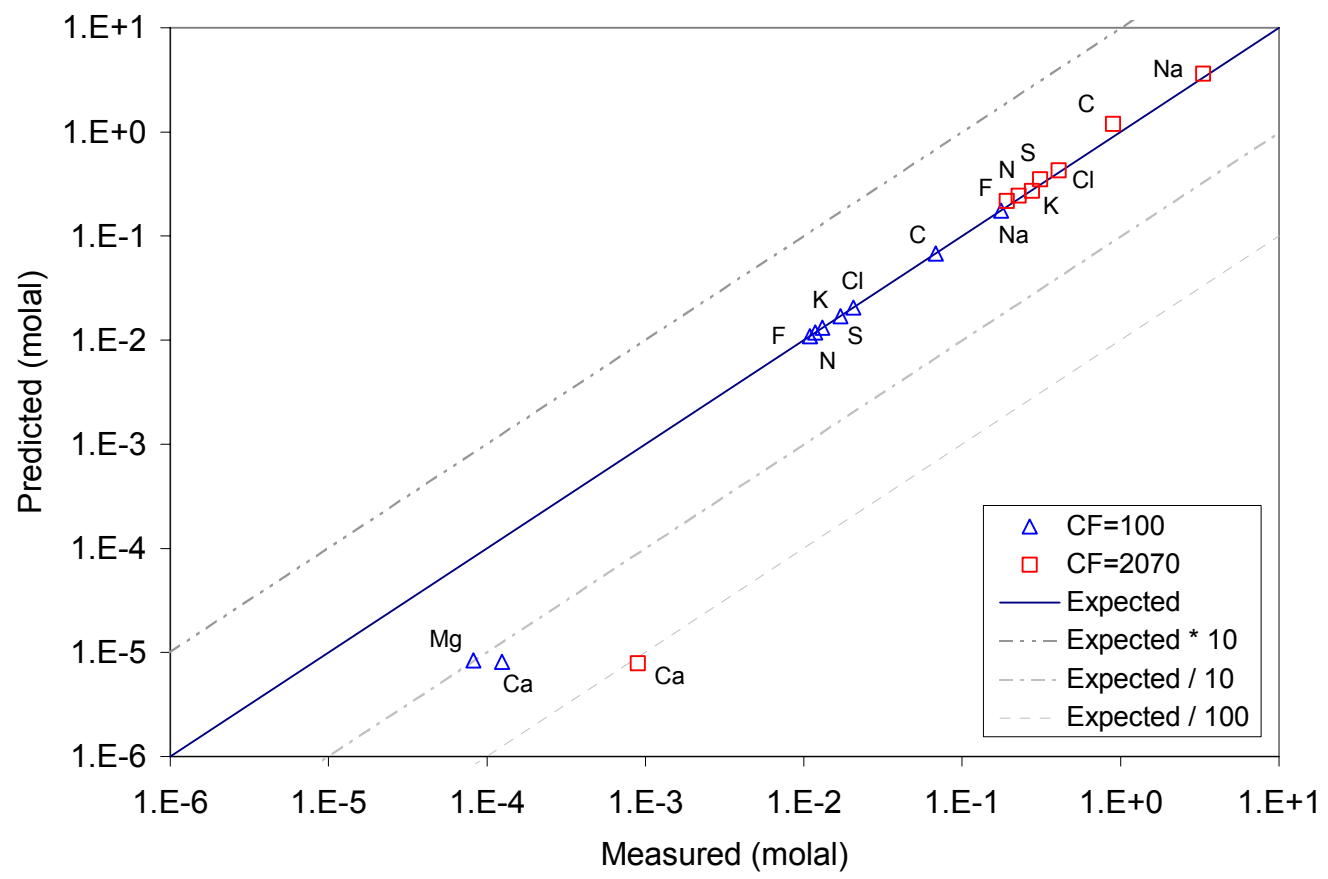

Output DTN: MO0303MWDJ13GD.000.

Figure 7-7. Predicted vs. Measured Concentrations for 100x Synthetic J-13 Water Evaporation Experiments (BSC 2001 [DIRS 155640])

\subsubsection{Evaporation of Topopah Spring Tuff Pore Water at $75^{\circ} \mathrm{C}$}

Synthetic Topopah Spring Tuff pore water was evaporated in an experiment reported by Rosenberg et al. (1999 [DIRS 125339]). The experiment, named evap3, was performed following the same procedures as in a second study by Rosenberg et al. (1999 [DIRS 125338]) presented in Section 7.1.1, except that the temperature was maintained at $75^{\circ} \mathrm{C}$. Both the starting and final solutions are provided in Table 4-10. The final solution was reported to have an approximate concentration factor of $1243 \pm 10$ percent. An x-ray diffraction analysis at this concentration factor detected gypsum. After complete evaporation, tachyhydrite was also detected.

These evaporation experiments were simulated using the IDPS model and the Pitzer database. Predictions of total aqueous concentrations, $\mathrm{pH}$, ionic strength, and mineral precipitation upon evaporation are documented in DTN: MO0303MWDTSWRB.000 and plotted in Figure 7-8 and Figure 7-9. These predictions are compared to the measurements in Figure 7-10 and Figure 7-11. As in the evaporation experiment in Section 7.1.1, the sepiolite log K was augmented by 6 $\log \mathrm{K}$ units to represent an amorphous sepiolite (see Section 7.1.1).

Figure 7-10 shows that the modeled results closely approximate the measured $\mathrm{Na}, \mathrm{Mg}, \mathrm{Ca}, \mathrm{Cl}$, and $\mathrm{K}$ concentrations. At a concentration factor of 1243, modeled results underestimate the measured $\mathrm{SO}_{4}$ and $\mathrm{Si}$ concentrations by approximately 0.5 and 2 orders of magnitude, respectively. Final $\mathrm{NO}_{3}, \mathrm{HCO}_{3}$, and $\mathrm{F}$ laboratory data are not reported (Rosenberg et al. 1999 [DIRS 125339]). 
Figure 7-11 shows close agreement between the laboratory measured $\mathrm{pH}$ and predicted $\mathrm{pH}$. Unlike the observations in the J-13 evaporation experiments, the $\mathrm{pH}$ decreased with increasing evaporation, resulting in a value around 6.3 by the end of the experiment. The predicted $\mathrm{pH}$ is largely controlled by the fugacity of carbon dioxide, which is fixed at $10^{-3.4}$ bars to approximate the laboratory condition of a beaker open to the atmosphere. There is some uncertainty associated with the $\mathrm{pH}$ measurements because details of the $\mathrm{pH}$ measurement procedure are not reported. Measuring $\mathrm{pH}$ at high temperature and high ionic strength requires special methods (Section 7.5.1), which may or may not have been adopted.

Gypsum was identified by x-ray diffraction in the laboratory experiment at the 1243 concentration factor. In contrast, the model predicted calcite, sepiolite, and anhydrite precipitation at $C F$ 1243. Anhydrite $\left(\mathrm{CaSO}_{4}\right)$ is predicted to be more stable than gypsum $\left(\mathrm{CaSO}_{4}: 2 \mathrm{H}_{2} \mathrm{O}\right)$ at the $75^{\circ} \mathrm{C}$ temperature of the experiment. However, the short term of the experiment may have prevented a perceivable accumulation of anhydrite. Other potential explanations for the difference are potential inaccuracies in experimental measurements or the Pitzer database. Regardless of the difference, however, either mineral provides a good explanation why the aqueous $\mathrm{Ca}$ and $\mathrm{SO}_{4}$ concentrations at $C F 1243$ are not nearly 1243 times their initial concentrations (Table 4-10).

Mass balance suggests that gypsum could not be the only mineral precipitating at $C F 1243$. As indicated in Table 4-10, the Si concentration did not nearly increase by a $C F$ of 1243 , nor did $\mathrm{HCO}_{3}$. Thus, some $\mathrm{Si}$ and $\mathrm{C}$ likely precipitated, which is consistent with the calcite and sepiolite precipitation that the IDPS model independently predicted based on aqueous solubilities.

Upon complete evaporation, the only other mineral identified to precipitate was tachyhydrite. The relative amounts of gypsum and tachyhydrite in the final mineral assemblage were not measured. The minerals predicted by the IDPS model to precipitate upon complete evaporation are displayed in Figure 7-9. No precipitation was identified in the experiment that contained $\mathrm{Na}$, $\mathrm{K}, \mathrm{CO}_{3}, \mathrm{~F}, \mathrm{Si}$, or $\mathrm{NO}_{3}$. Mass balance indicates that these components should be there. Without quantitative and nearly complete information on the composition of precipitation in an experiment, experimental measurements and model predictions of mineral assemblages cannot be easily corroborated.

Ionic strength was not directly measured in these experiments. However, a "measured" ionic strength was estimated from the reported evaporated water compositions using EQ3NR, as described in Section 7.1.1. These calculations are documented in DTN: MO0307MWDUNEVP.000 and are summarized in Table 7-3.

As in the average $\mathrm{J}-13$ well water evaporation experiment simulated in Section 7.1.1, the reported concentration factor in the Topopah Spring Tuff pore water evaporation experiment (Table 4-10) was overestimated. $\mathrm{Cl}$ and $\mathrm{NO}_{3}$ should have concentrated conservatively. No $\mathrm{Cl}$ and $\mathrm{NO}_{3}$ minerals were identified by x-ray diffraction at the reported 1243 concentration factor. The overestimate is substantiated by the measured concentrations of $\mathrm{Na}, \mathrm{K}, \mathrm{Ca}$, and $\mathrm{Mg}$, which also should have concentrated conservatively (or nearly conservatively in the case of $\mathrm{Ca}$ ), as predicted in Figure 7-8. The $\mathrm{NO}_{3}$ concentration was not measured in the evaporatively concentrated sample because the sample was mistakenly preserved with nitric acid. However, if the $\mathrm{Cl}$ concentration had been used to determine the concentration factor in the experiment 
(instead of indirectly estimating the concentration factor from measurements of amounts of water evaporated), then the measured concentration factor would have been around 680, not 1243. If this lower concentration factor had been reported, then the simulation would have been stopped at $C F 680$ and the differences between predictions and measurements of $\mathrm{Cl}, \mathrm{Ca}, \mathrm{Mg}, \mathrm{Na}$, and $\mathrm{K}$ (Figure 7-10) would have been much lower. Thus, the majority of the differences observed between the predicted and measured values for these components are an artifact of errors in the reported concentration factor. These errors also explain the considerable difference between the predicted and "measured" ionic strength values in Table 7-3 at CF 1243. Had the model been used to concentrate the starting solution to the correct concentration factor (around 680), the predicted ionic strength would have been much closer to the "measured" ionic strength.

Table 7-3. Calculation of "Measured" Ionic Strength in Topopah Spring Tuff Pore Water Evaporation Experiment

\begin{tabular}{|l|l|l|l|}
\hline $\begin{array}{c}\text { Concentration } \\
\text { Factor }\end{array}$ & \multicolumn{1}{|c|}{$\begin{array}{c}\text { EQ3NR Input/Output } \\
\text { Filenames }\end{array}$} & $\begin{array}{c}\text { "Measured" lonic } \\
\text { Strength } \\
\text { (molal) }\end{array}$ & $\begin{array}{c}\text { Predicted lonic } \\
\text { Strength } \\
\text { (molal) }\end{array}$ \\
\hline 1 & tspw3is.3i, tspw3is.3o & $6.73 \mathrm{E}-03$ & $6.60 \mathrm{E}-03$ \\
\hline 1243 & tsp1243i.3i, tsp1243i.3o & $2.27 \mathrm{E}+00$ & $3.79 \mathrm{E}+00$ \\
\hline
\end{tabular}

Output DTN: MO0307MWDUNEVP.000, File: "Experimental Uncert.xIs."

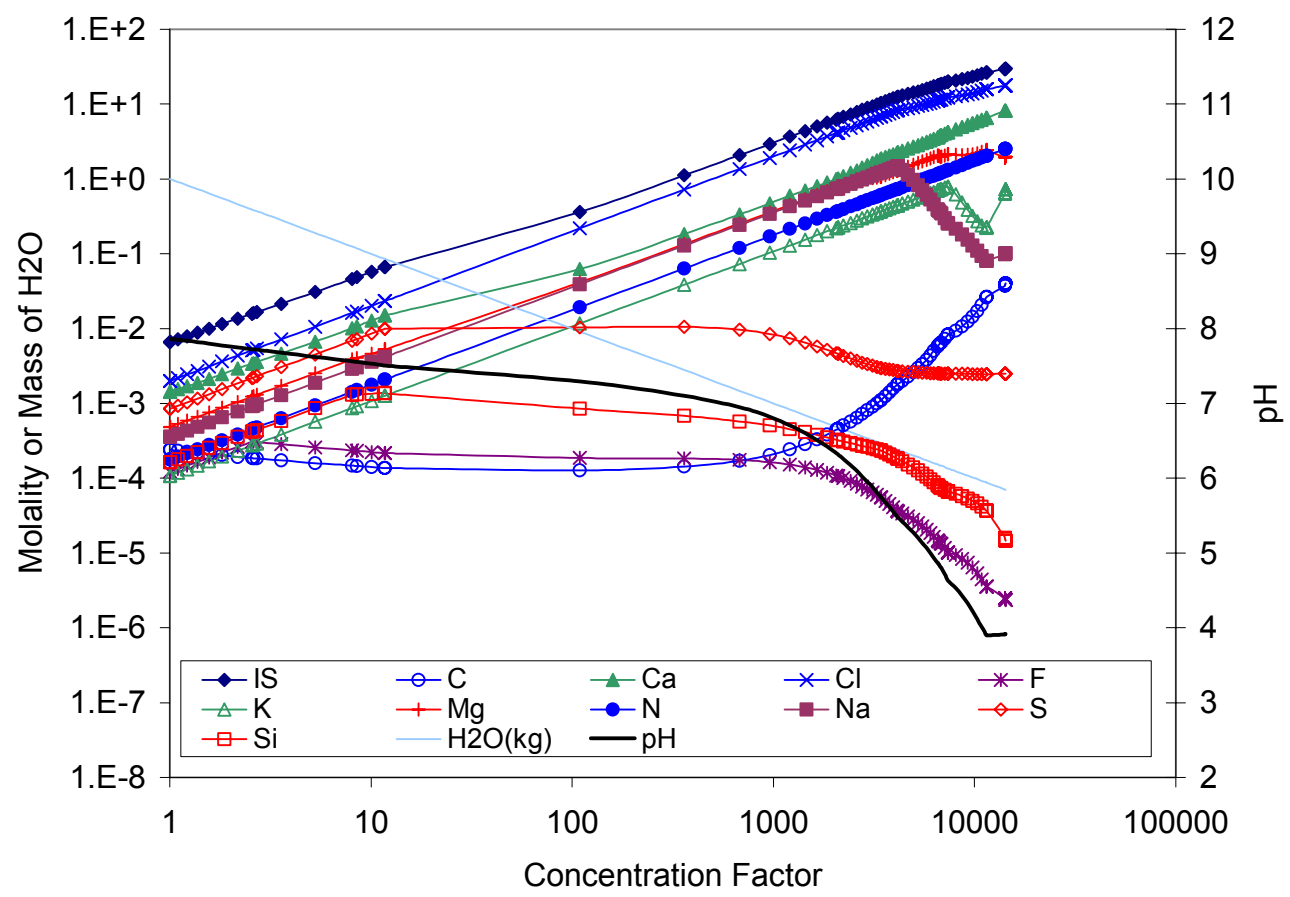

Output DTN: MO0303MWDTSWRB.000.

Figure 7-8. Predicted Aqueous Evolution of Synthetic Topopah Spring Tuff Pore Water for Evaporation Experiments of Rosenberg et al. (1999 [DIRS 125339]) 


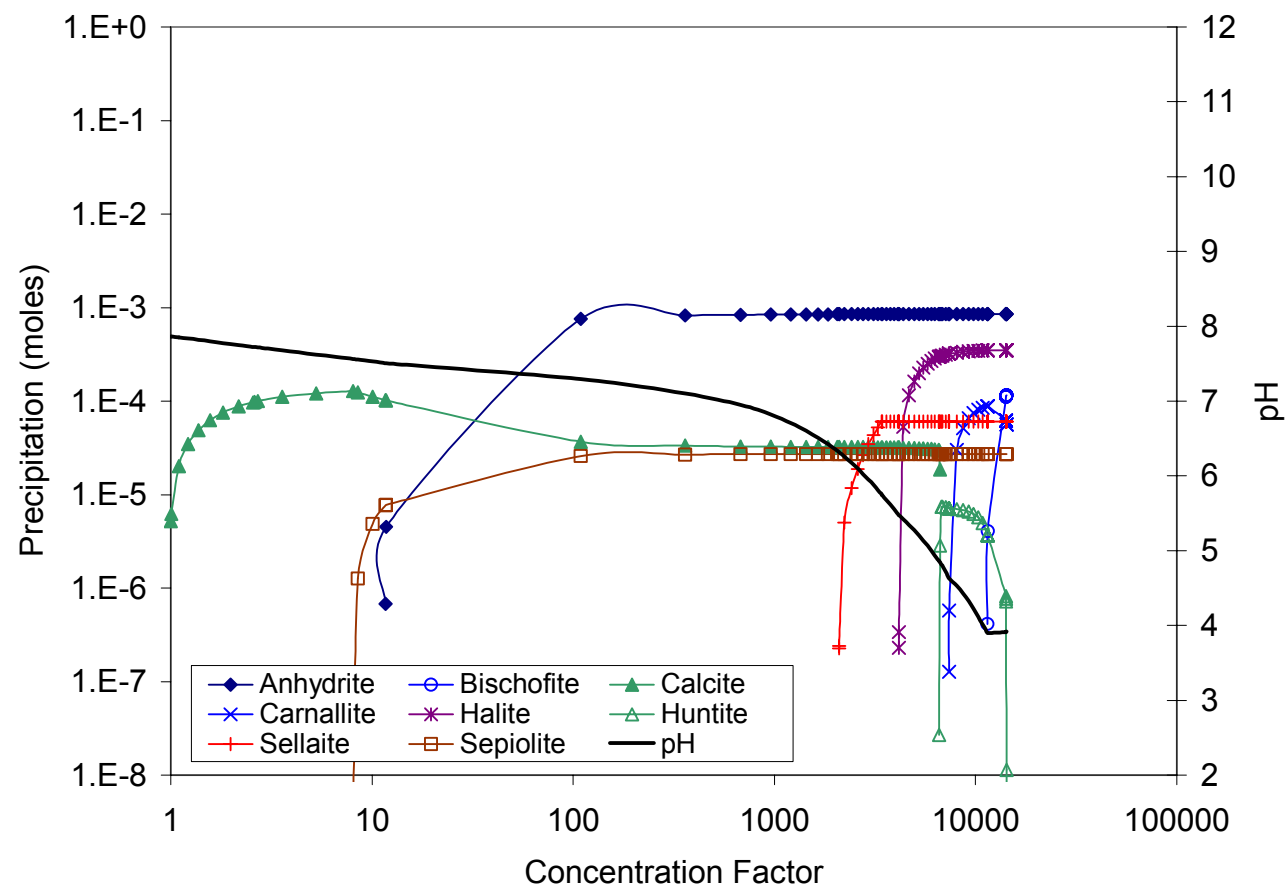

Output DTN: MO0303MWDTSWRB.000.

Figure 7-9. Predicted Mineral Evolution of Synthetic Topopah Spring Tuff Pore Water for Evaporation Experiments of Rosenberg et al. (1999 [DIRS 125339])

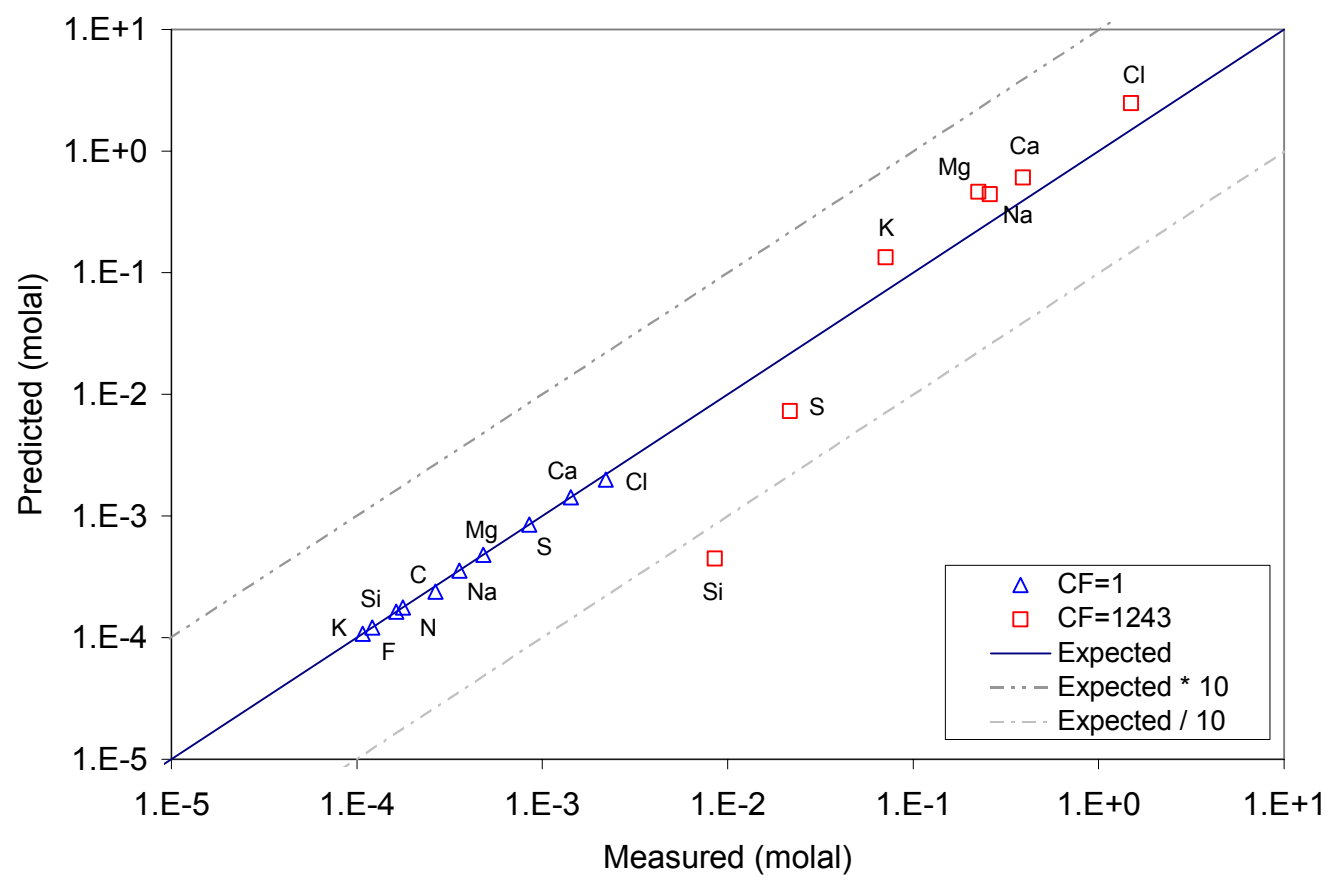

Output DTN: MO0303MWDTSWRB.000.

Figure 7-10. Predicted vs. Measured Concentrations for Synthetic Topopah Spring Tuff Pore Water from Evaporation Experiments of Rosenberg et al. (1999 [DIRS 125339]) 


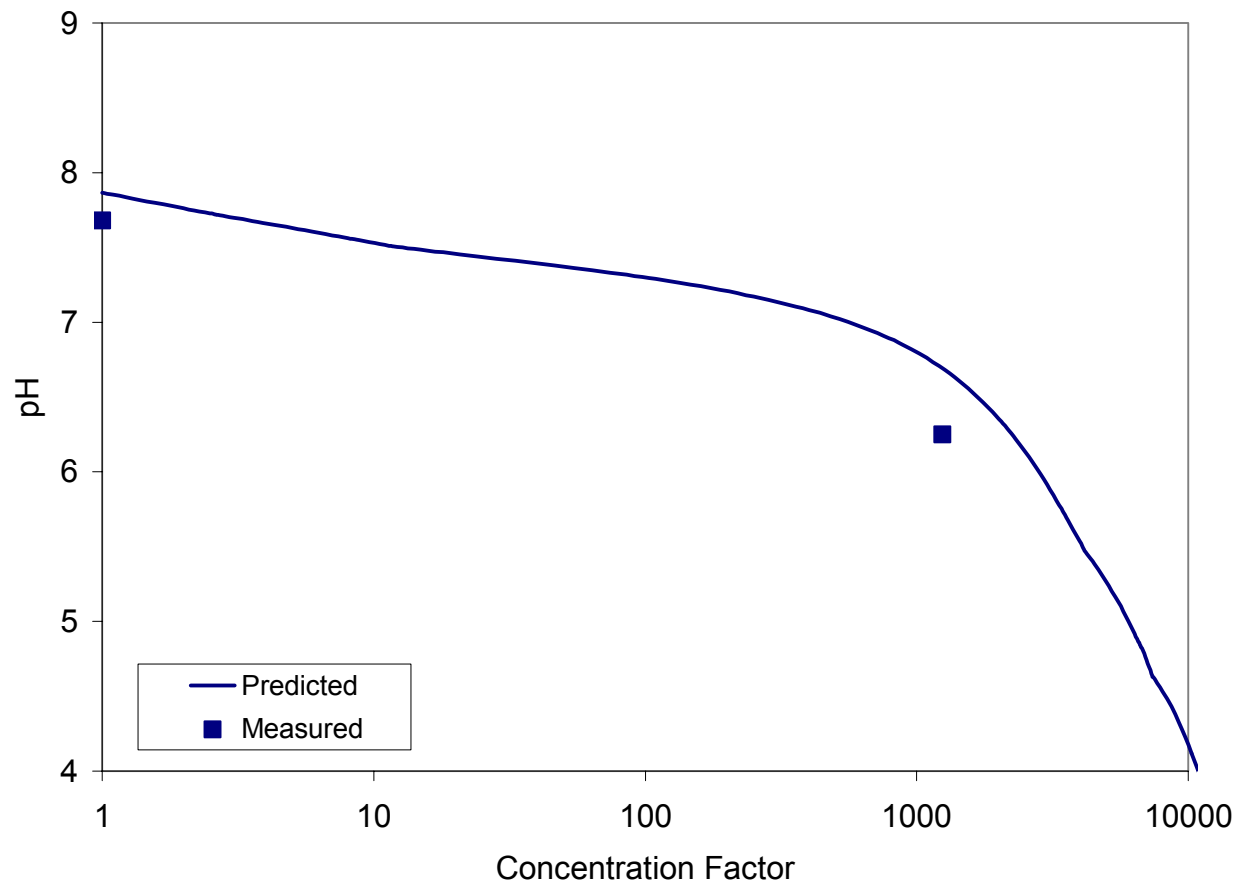

Output DTN: MO0303MWDTSWRB.000.

Figure 7-11. Predicted vs. Measured pH Values for Synthetic Topopah Spring Tuff Pore Water from Evaporation Experiments of Rosenberg et al. (1999 [DIRS 125339])

\subsubsection{Seawater Evaporation}

The Morton Bahamas solar salt production facility on Great Inagua Island in the Bahamas provides an excellent example of the evaporative chemical evolution of a natural multicomponent water. At this plant, seawater is evaporatively concentrated in a sequence of reservoirs to precipitate table salt (halite). This production process results in a final brine with a concentration factor near 40 with respect to seawater. One of the primary advantages of this data set compared to samples taken from saline lakes is that these reservoirs are not subject to large mixing effects from streams and rivers. In addition, the reservoirs are shallow and open to the atmosphere, facilitating equilibrium conditions with respect to atmospheric partial pressures of carbon dioxide and oxygen. Thus, the major processes affecting the evolution of seawater at the plant are the same processes incorporated in the IDPS model.

McCaffrey et al. (1987 [DIRS 164481]) sampled and analyzed the chemical compositions of the evolving seawater at the plant. Three of the most concentrated samples were evaporated even further in the laboratory. The data for both the reservoir samples and the laboratory evaporation experiments are presented in Table 4-11. The samples in the table that start with a "w" were collected directly from the plant reservoirs while the remainder were artificially evaporated from samples w36, w39, and w40. The reported degree of evaporation is equivalent to the concentration factors of conservative components. For degrees of evaporation up to 70 , the concentration factor for $\mathrm{Mg}$ was used to determine degree of evaporation. Beyond 70, the concentration factor of lithium was used. 
The IDPS model was used to simulate the seawater evaporation at the plant. The results are documented in DTN: MO0307MWDSEAEV.000. Sea intake water (sample w63) was used as the starting water. This sample, collected at the plant intake, had a degree of evaporation slightly less than seawater, perhaps because it was composed of seawater mixed with a small amount of fresh water from a nearby stream. In the simulation, the temperature was fixed at $31.25^{\circ} \mathrm{C}$, the average value of the reservoir samples. To balance the charge, the model decreased the $\mathrm{Cl}$ concentration by about 1.5 percent. The partial pressures of carbon dioxide and oxygen were set approximately at atmospheric values, $10^{-3.5}$ and $10^{-0.7}$ bars, respectively. Because carbonate was not measured, the concentration of dissolved carbonate was set at heterogeneous equilibrium with the partial pressure of carbon dioxide. Finally, the minerals listed in Table 6-3 were suppressed.

It is important to note that the laboratory evaporation experiments were closed to the atmosphere. These experiments resulted in the samples in Table 4-11 that have degrees of evaporation greater than 40 . These samples were derived by placing samples of w36, w39, and w40 in uncovered teflon vials and sealing them in desiccation chambers containing $\mathrm{CaCl}_{2}$ crystals, a desiccant (McCaffrey et al. 1987 [DIRS 164481], p. 931). Sealing the desiccation chambers does not allow for exchange of oxygen and carbon dioxide with the atmosphere. This could have caused partial pressure deviations from atmospheric values. Changes in carbon dioxide partial pressure affects $\mathrm{pH}$, which in turn has the potential to affect which minerals precipitate. No $\mathrm{pH}$ values were measured for these samples. Thus, the composition of these concentrated samples could represent the effects of processes not considered by the IDPS model and not expected to occur in the evaporation of seawater in an open system. Therefore, differences between IDPS model predictions and measurements at these high concentrations do not necessarily reflect poorly on the accuracy of the IDPS model.

The IDPS model predictions are compared to sample measurements in Figure 7-12, Figure 7-13, and Figure 7-14. These figures show that the IDPS model predictions are highly accurate. Comparison of the predicted mineral precipitation in Figure 7-15 to the dissolved concentrations confirms that halite precipitation begins to control the concentrations of $\mathrm{Na}$ and $\mathrm{Cl}$ at a degree of evaporation around 10. Degree of evaporation relative to seawater was calculated from the IDPS model output by multiplying the IDPS concentration factor $(C F)$ by 0.95 , the degree of evaporation of the sea intake water used as the starting water for the evaporation. The $C F$ calculated by the IDPS model reflects the degree of evaporation relative to the intake water.

Like halite, other minerals that control the evaporative concentration of the dissolved components are revealed by the trajectories of their concentrations in the figures. For example, McCaffrey et al. (1987 [DIRS 164481], p. 935) found that gypsum $\left(\mathrm{CaSO}_{4} \cdot 2 \mathrm{H}_{2} \mathrm{O}\right)$ begins to precipitate at a degree of evaporation around 3.8. This explains the decrease in $\mathrm{Ca}$ concentrations at this degree of evaporation. The IDPS model predicts that gypsum starts precipitating at a degree of evaporation of around 7 and is immediately replaced by anhydrite $\left(\mathrm{CaSO}_{4}\right)$. From that point until the degree of evaporation reaches about 10, anhydrite is the predicted controlling phase for $\mathrm{Ca}$. Above a degree of evaporation of 10 but below about 57, glauberite $\left(\mathrm{Na}_{2} \mathrm{Ca}\left(\mathrm{SO}_{4}\right)_{2}\right)$ replaces anhydrite as the controlling phase for $\mathrm{Ca}$ in the simulation. The differences between the minerals predicted to precipitate and those observed to precipitate may be due to several factors, such as errors in the equilibrium constants of the minerals, nonequilibrium conditions (e.g., mineral supersaturation), errors in boundary conditions (e.g., the 
partial pressure of carbon dioxide), and sampling error. The end result, however, is that above a degree of evaporation of 3.8 the model overestimates $\mathrm{Ca}$ concentrations by as much as a factor of six.

Figure 7-12 shows that measured K concentrations begin to decrease sharply after concentrations reach approximately 80 times that of seawater. McCaffrey et al. (1987 [DIRS 164481], p. 935) did not determine the $\mathrm{K}$-bearing phases precipitating at this degree of evaporation. In the IDPS model simulation, precipitation of polyhalite $\left(\mathrm{K}_{2} \mathrm{MgCa}_{2}\left(\mathrm{SO}_{4}\right)_{4} \cdot 2 \mathrm{H}_{2} \mathrm{O}\right)$ begins to control $\mathrm{K}$ concentrations starting around concentrations 45 times that of seawater. This difference results in a maximum overestimation of $\mathrm{K}$ by a factor of about five at a degree of evaporation around 73.

Model predictions of $\mathrm{Na}, \mathrm{Mg}, \mathrm{Cl}, \mathrm{Br}$, and $\mathrm{SO}_{4}$ compare well with sample concentrations for the entire range of measurements. Ignoring the most concentrated sample, which appears to be an outlier, the largest overestimate is a factor of about 2.3 for $\mathrm{Na}$ at a degree of evaporation of 87.9. The largest underestimate is a factor of about 2.2 for $\mathrm{SO}_{4}$ at a degree of evaporation of 69.2 . The marked decrease in $\mathrm{SO}_{4}$ measurements above this degree of evaporation is due to the precipitation of one or more magnesium sulfates (McCaffrey et al. 1987 [DIRS 164481], p. 935). The largest differences between predictions and measurements for $\mathrm{Mg}, \mathrm{Cl}$, and $\mathrm{Br}$ are approximately $-23 \%, 12 \%$, and $12 \%$, respectively, relative to the measurements. The $12 \%$ estimate for $\mathrm{Cl}$ does not consider the most concentrated sample because it appears to be an outlier based on Figure 7-14.

Figure 7-14 shows good agreement between measurements and predictions for $\mathrm{pH}$ and ionic strength. The largest difference observed for $\mathrm{pH}$ is approximately $0.76 \mathrm{pH}$ units. However, there is some uncertainty associated with the $\mathrm{pH}$ measurements. Measuring $\mathrm{pH}$ at high ionic strength requires special methods (Section 7.5.1), which may or may not have been used. Thus, the differences between model predictions and experimental measurements could partly (or largely) be a result of experimental error. For ionic strength, the largest difference is approximately 15 percent, except for the sample at the highest degree of evaporation, which is suspect because it is an outlier. The predicted activity of water is also plotted in this figure to show how it changes as a function of the degree of evaporation.

An additional simulation was performed in which huntite $\left(\mathrm{CaMg}_{3}\left(\mathrm{CO}_{3}\right)_{4}\right)$ was added to the list of suppressed minerals. In the simulation, documented in DTN: MO0307MWDSEAEV.000, calcite precipitates instead of huntite. This difference has a negligible effect on aqueous $\mathrm{Ca}$ and $\mathrm{Mg}$ concentrations but a considerable effect on predicted values for aqueous $\mathrm{CO}_{3}$ and $\mathrm{pH}$. The predicted aqueous $\mathrm{CO}_{3}$ concentration increases by a factor of around 1.5 to 3 while the $\mathrm{pH}$ predictions increase by about $0.2 \mathrm{pH}$ units. Though the $\mathrm{pH}$ predictions continue to underestimate $\mathrm{pH}$, the largest underestimate of $\mathrm{pH}$ in this sensitivity run is 0.56 , which is $0.20 \mathrm{pH}$ units less than the largest underestimate when huntite is allowed to precipitate. These results suggest that suppression of huntite in the IDPS model would slightly improve evaporation predictions for seawater and perhaps other natural waters under similar environmental conditions. 


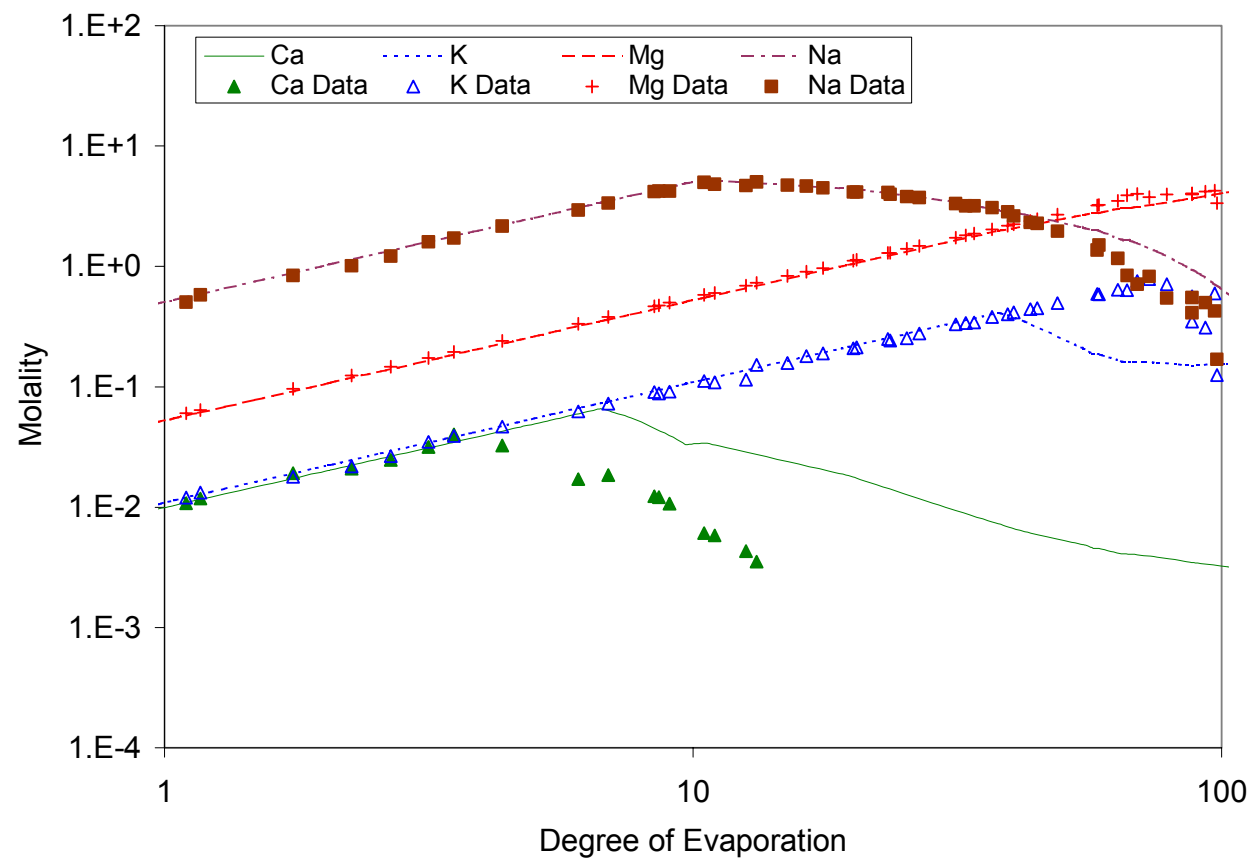

Output DTN: MO0307MWDSEAEV.000.

Source: McCaffrey et al. 1987 [DIRS 164481].

Figure 7-12. Predicted vs. Measured $\mathrm{Ca}, \mathrm{K}, \mathrm{Mg}$, and $\mathrm{Na}$ Concentrations from Evaporation of Inagua Seawater

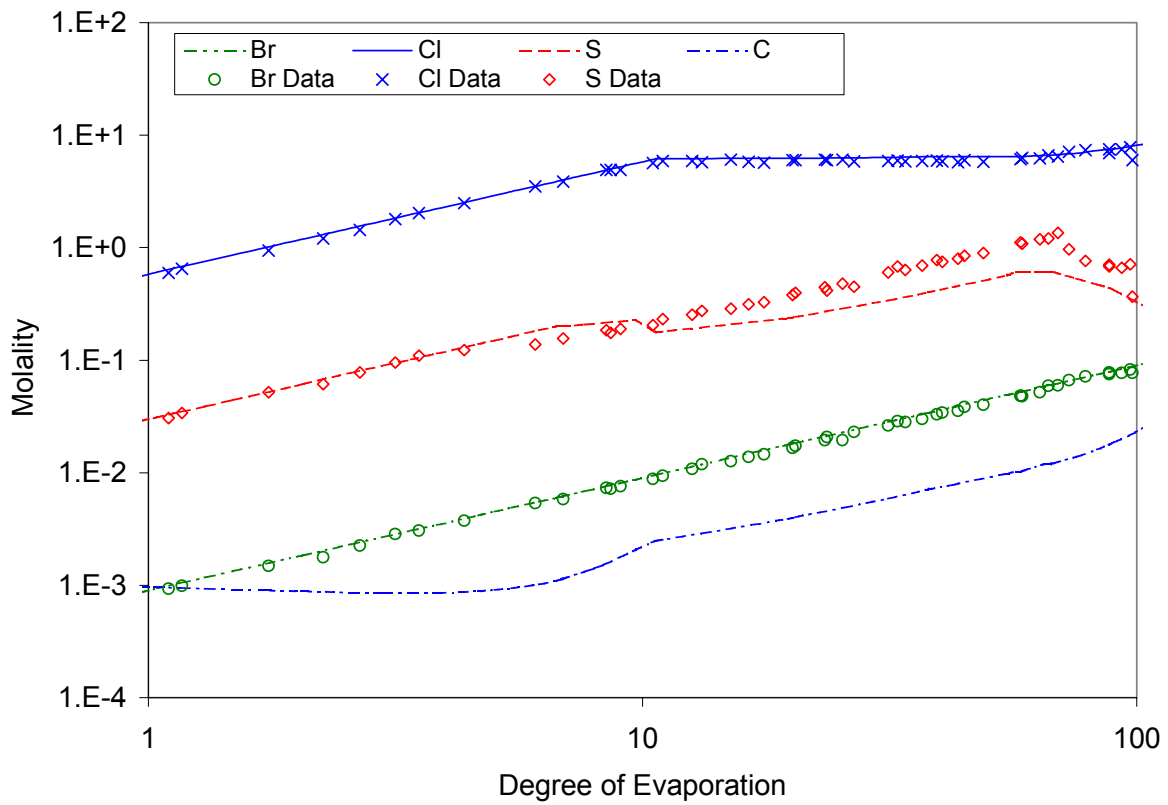

Output DTN: MO0307MWDSEAEV.000.

Source: McCaffrey et al. 1987 [DIRS 164481].

Figure 7-13. Predicted vs. Measured $\mathrm{Br}, \mathrm{Cl}$, and $\mathrm{SO}_{4}$ Concentrations from Evaporation of Inagua Seawater 


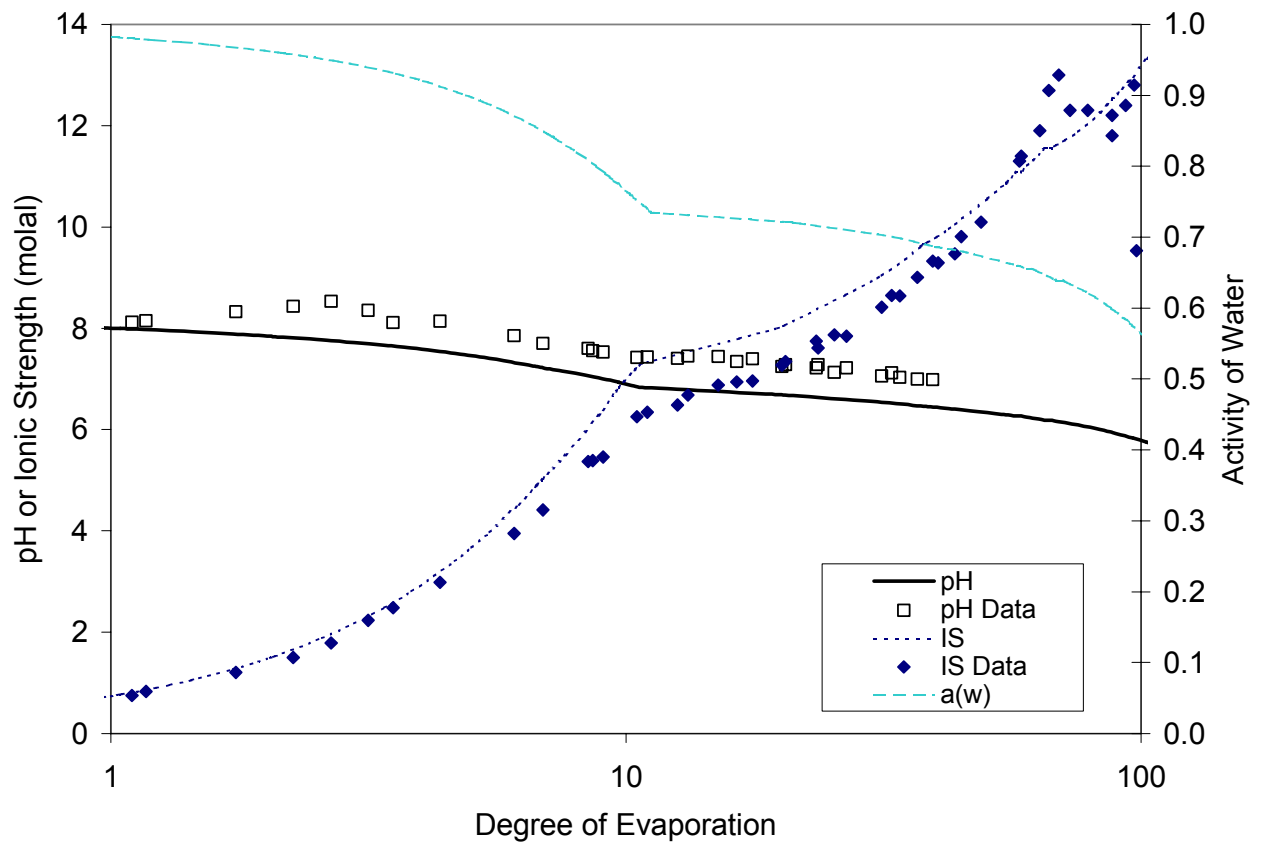

Output DTN: MO0307MWDSEAEV.000.

Source: McCaffrey et al. 1987 [DIRS 164481].

Figure 7-14. Predicted vs. Measured pH and lonic Strength from Evaporation of Inagua Seawater

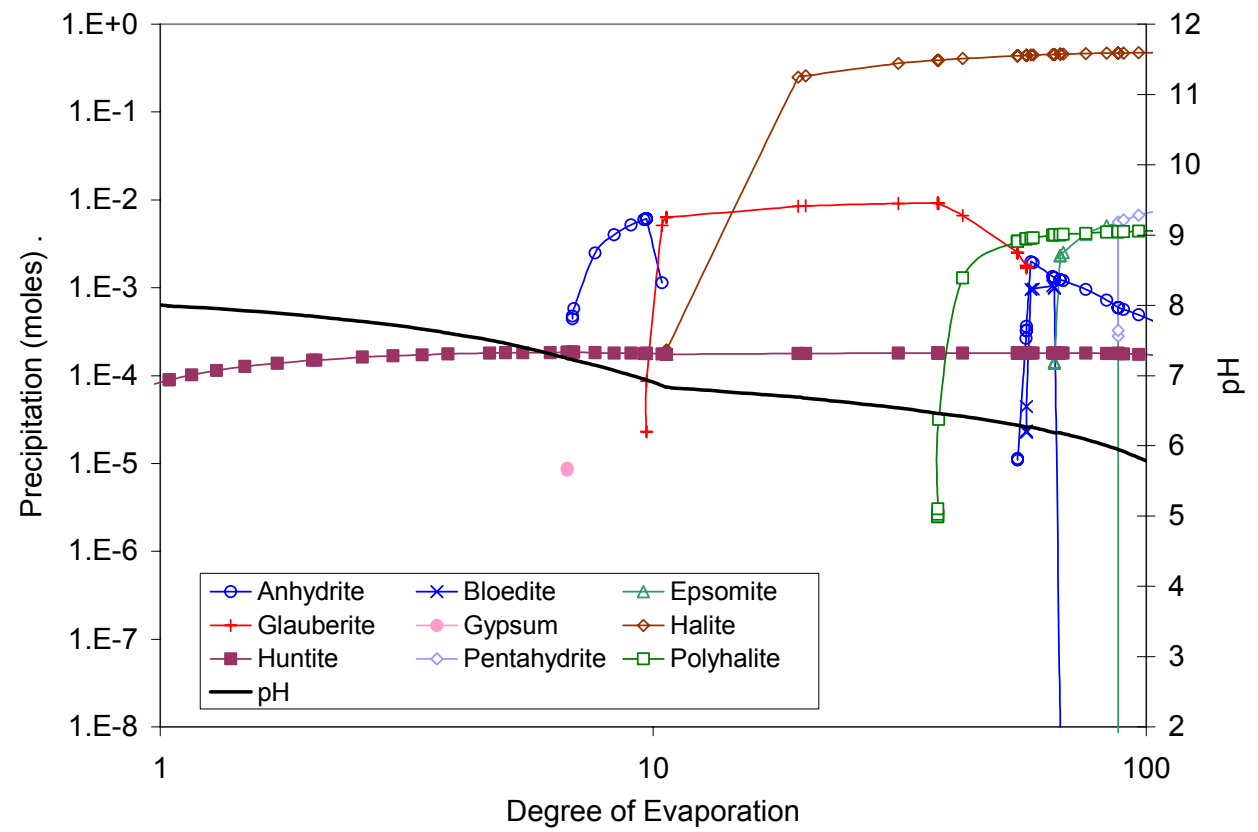

Output DTN: MO0307MWDSEAEV.000.

Figure 7-15. Predicted Mineral Precipitation from Evaporation of Inagua Seawater 


\subsection{EVAPORATION OF SIMPLE SALT SOLUTIONS}

Dilute salt solutions were evaporated to assess whether the IDPS model can accurately predict the deliquescence points and aqueous solubilities of salts in simple systems. Solubilities and deliquescence points of binary salts are predicted and compared to literature values in Section 7.2.1, and solubilities of salts in ternary systems are predicted and compared to literature values in Section 7.2.2.

Validation comparisons in the binary and ternary systems assess the differences between measured and predicted salt solubilities. Thus, these comparisons are useful for evaluating model validation and uncertainty when the solution has reached saturation with respect to one or all salts in the systems. These comparisons do not allow assessment of uncertainty in solutions that are undersaturated with respect to these salts. At solution concentrations below the measured and predicted solubilities of these salts, the model will accurately and precisely predict the effects of evaporation and condensation on aqueous salt concentrations.

\subsubsection{Binary Salt Systems}

In this report a binary salt system is defined as a mixture of pure water and one salt made up of one cation component and one anion component. To demonstrate model validation for predicting aqueous solubilities and deliquescence relative humidity values of individual salts in binary systems, IDPS model simulations were performed to compare against independent data from the literature.

Two sets of literature values are used in these comparisons. The first set is from various chemistry handbook sources. These data are compared to IDPS model predictions in Section 7.2.1.1. The second set of values come from non-handbook sources and extend to temperatures above $100^{\circ} \mathrm{C}$. They are compared to IDPS model predictions in Section 7.2.1.2.

\subsubsection{Comparisons to Chemistry Handbook Data}

\subsection{Aqueous Solubilities}

Table 4-12 lists temperature-dependent solubility values for individual salts in units of mass percent of solute $\left(w_{i}\right)$ as provided in the CRC Handbook of Chemistry and Physics (Lide 2000 [DIRS 162229], pp. 8-102 to 8-110). These solubilities are converted to molal concentrations $\left(C_{i}\right)$ in Table 7-4 using the following equation:

$$
C_{i}=\frac{1000 \frac{w_{i}}{100 \%}}{M W_{i}\left(1-\frac{w_{i}}{100 \%}\right)}
$$

where $M W_{i}$ is the molecular weight (in grams per mole) of salt $i$ (Lide 2000 [DIRS 162229], pp. 8 to 102$)$. 
The evaporations begin with a 0.0001 molal solution of the particular salt whose solubility is to be estimated. Because the $\mathrm{pH}$ of pure water can be affected by the salt dissolved in it and by the temperature, the starting solution is charge balanced on the hydrogen ion. The salt components added to the pure water are inherently charge balanced; thus, charge balancing on the hydrogen ion in these systems reflects a true equilibration process. For evaporations involving carbonate, a closed system is prescribed. An evaporation simulation is complete when the solution reaches saturation with respect to the salt components.

The results of the simulations are documented in DTN: MO0303MWDSEDSS.000 and displayed in Table 7-5, Figure 7-16, and Figure 7-17. The table provides the predicted solubilities, relative error with respect to handbook values, and the specific mineral phase that reached saturation at the given temperature. The comparison shows that for every salt in the table, the IDPS model predicted solubility within a factor of 10 of handbook values. Most predictions are within 20 percent. The implications of these results are discussed in Section 7.5 as applicable.

Three nitrate salts did not reach saturation in the calculations before their runs became unstable and terminated: $\mathrm{Ca}\left(\mathrm{NO}_{3}\right)_{2}\left(100^{\circ} \mathrm{C}\right), \mathrm{Mg}\left(\mathrm{NO}_{3}\right)_{2}\left(25^{\circ} \mathrm{C}\right.$ and $\left.100^{\circ} \mathrm{C}\right)$, and $\mathrm{KNO}_{3}\left(100^{\circ} \mathrm{C}\right)$. In IDPS model applications, these errors could only happen at low relative humidity (e.g., below 50 percent) and for those incoming waters whose chemical divides allow extensive concentration of the components of these salts. In the event that one or more of these salts does become concentrated in an application, using the end of the run as the maximum solubility is not expected to introduce unacceptable errors compared to the validation criteria. The absolute limit for the concentration of these salts is an ionic strength of 100 molal, which causes EQ6 to terminate the run. Thus, however the runs terminate, the predicted maximum concentrations of these salt components would remain well within one order of magnitude of the actual salt solubilities, meeting validation criteria. For example, for $\mathrm{Mg}\left(\mathrm{NO}_{3}\right)_{2}$ at $25^{\circ} \mathrm{C}$, the EQ6 evaporation terminates at a $\mathrm{Mg}$ concentration of 13.4 molal (Table 7-5). This concentration is only 2.8 times the measured solubility at this temperature (Table 7-4). Early termination of model runs like these is not considered non-convergence because the runs do converge to a satisfactory end point, as defined by the validation criteria. 
Table 7-4. Unit Conversion of Chemistry Handbook Aqueous Solubilities of $\mathrm{Na}, \mathrm{K}, \mathrm{Ca}$, and $\mathrm{Mg}$ Salts

\begin{tabular}{|c|c|c|c|c|c|}
\hline \multirow[b]{2}{*}{ Salt } & \multirow{2}{*}{$\begin{array}{c}\text { Molecular } \\
\text { Weight } \\
\text { (gram/mole) }\end{array}$} & \multicolumn{2}{|c|}{ Aqueous Solubility at $25^{\circ} \mathrm{C}$} & \multicolumn{2}{|c|}{ Aqueous Solubility at $100^{\circ} \mathrm{C}$} \\
\hline & & $\begin{array}{l}\text { Mass Percent of } \\
\text { Solute (\%) }\end{array}$ & (molal) & $\begin{array}{l}\text { Mass Percent of } \\
\text { Solute (\%) }\end{array}$ & (molal) \\
\hline $\mathrm{NaCl}$ & 58.44 & $26.45 \%$ & 6.153 & $28.05 \%$ & 6.671 \\
\hline $\mathrm{KCl}$ & 74.55 & $26.22 \%$ & 4.767 & $36.05 \%$ & 7.562 \\
\hline $\mathrm{CaCl}_{2}$ & 110.98 & $44.83 \%$ & 7.322 & $59.94 \%$ & 13.482 \\
\hline $\mathrm{MgCl}_{2}$ & 95.21 & $35.90 \%$ & 5.882 & $42.15 \%$ & 7.653 \\
\hline $\mathrm{NaHCO}_{3}$ & 84.01 & $9.32 \%$ & 1.22 & $19.10 \%$ & 2.81 \\
\hline $\mathrm{KHCO}_{3}$ & 100.12 & $26.6 \%$ & 3.62 & $40.45 \%$ at $70^{\circ} \mathrm{C}$ & 6.78 at $70^{\circ} \mathrm{C}$ \\
\hline $\mathrm{Na}_{2} \mathrm{CO}_{3}$ & 105.99 & $23.5 \%$ & 2.90 & $30.09 \%$ & 4.06 \\
\hline $\mathrm{K}_{2} \mathrm{CO}_{3}$ & 138.21 & $52.7 \%$ & 8.06 & $61.0 \%$ & 11.32 \\
\hline $\mathrm{NaF}$ & 41.99 & $3.97 \%$ & 0.985 & $4.82 \%$ & 1.206 \\
\hline $\mathrm{KF}$ & 58.10 & $50.4 \%$ & 17.5 & $60.0 \%$ at $80^{\circ} \mathrm{C}$ & 25.8 at $80^{\circ} \mathrm{C}$ \\
\hline $\mathrm{CaF}_{2}$ & 78.07 & $0.0016 \%$ & 0.00020 & $\begin{array}{l}\text { not reported above } \\
25^{\circ} \mathrm{C}\end{array}$ & $\begin{array}{l}\text { not reported above } \\
25^{\circ} \mathrm{C}\end{array}$ \\
\hline $\mathrm{MgF}_{2}$ & 62.30 & $0.013 \%$ & 0.0021 & $\begin{array}{l}\text { not reported above } \\
25^{\circ} \mathrm{C}\end{array}$ & $\begin{array}{l}\text { not reported above } \\
25^{\circ} \mathrm{C}\end{array}$ \\
\hline $\mathrm{Na}_{2} \mathrm{SO}_{4}$ & 142.04 & $21.94 \%$ & 1.979 & $29.67 \%$ & 2.970 \\
\hline $\mathrm{K}_{2} \mathrm{SO}_{4}$ & 174.26 & $10.7 \%$ & 0.688 & $19.3 \%$ & 1.372 \\
\hline $\mathrm{CaSO}_{4}$ & 136.14 & $0.205 \%$ & 0.0151 & $0.163 \%$ & 0.0120 \\
\hline $\mathrm{MgSO}_{4}$ & 120.37 & $26.3 \%$ & 2.96 & $33.3 \%$ & 4.15 \\
\hline $\mathrm{NaBr}$ & 102.89 & $48.6 \%$ & 9.19 & $54.9 \%$ & 11.83 \\
\hline $\mathrm{KBr}$ & 119.00 & $40.4 \%$ & 5.70 & $50.8 \%$ & 8.68 \\
\hline $\mathrm{CaBr}_{2}$ & 199.89 & $61.0 \%$ & 7.82 & $73.0 \%$ at $60^{\circ} \mathrm{C}$ & 13.53 at $60^{\circ} \mathrm{C}$ \\
\hline $\mathrm{MgBr}_{2}$ & 184.11 & $50.6 \%$ & 5.56 & $55.7 \%$ & 6.83 \\
\hline $\mathrm{NaNO}_{3}$ & 84.99 & $47.7 \%$ & 10.7 & $63.8 \%$ & 20.7 \\
\hline $\mathrm{KNO}_{3}$ & 101.10 & $27.7 \%$ & 3.79 & $70.8 \%$ & 23.98 \\
\hline $\mathrm{Ca}\left(\mathrm{NO}_{3}\right)_{2}$ & 164.09 & $59.0 \%$ & 8.77 & $78.5 \%$ & 22.25 \\
\hline $\mathrm{Mg}\left(\mathrm{NO}_{3}\right)_{2}$ & 148.31 & $41.6 \%$ & 4.80 & $72.0 \%$ & 17.34 \\
\hline
\end{tabular}

Output DTN: MO0303MWDSEDSS.000.

Source: Lide 2000 [DIRS 162229], pp. 8-102 to 8-110. 
Table 7-5. Comparison of Model Predictions to Chemistry Handbook Aqueous Solubilities

\begin{tabular}{|c|c|c|c|c|c|c|}
\hline \multirow[b]{2}{*}{ Salt } & \multicolumn{3}{|c|}{ Aqueous Solubility at $25^{\circ} \mathrm{C}$} & \multicolumn{3}{|c|}{ Aqueous Solubility at $100^{\circ} \mathrm{C}$} \\
\hline & $\begin{array}{c}\text { Predicted } \\
\text { (molal) }\end{array}$ & $\begin{array}{c}\text { Relative } \\
\text { Error } \\
(\%) \\
\end{array}$ & Mineral & $\begin{array}{c}\text { Predicted } \\
\text { (molal) }\end{array}$ & $\begin{array}{c}\text { Relative } \\
\text { Error } \\
(\%) \\
\end{array}$ & Mineral \\
\hline $\mathrm{NaCl}$ & 6.170 & $0.3 \%$ & Halite & 6.63 & $-0.6 \%$ & Halite \\
\hline $\mathrm{KCl}$ & 4.867 & $2.1 \%$ & Sylvite & 7.52 & $-0.6 \%$ & Sylvite \\
\hline $\mathrm{CaCl}_{2}$ & 7.603 & $3.8 \%$ & Antarcticite & 13.28 & $-1.5 \%$ & $\mathrm{CaCl}_{2}: 2 \mathrm{H}_{2} \mathrm{O}$ \\
\hline $\mathrm{MgCl}_{2}$ & 5.455 & $-7.3 \%$ & Bischofite & 7.62 & $-0.4 \%$ & Bischofite \\
\hline $\mathrm{NaHCO}_{3}$ & 0.808 & $-34.0 \%$ & Nahcolite & 2.38 & $-15.4 \%$ & Nahcolite \\
\hline $\mathrm{KHCO}_{3}$ & 4.22 & $16.6 \%$ & Kalicinite & 4.99 at $70^{\circ} \mathrm{C}$ & $-26.5 \%$ & Kalicinite \\
\hline $\mathrm{Na}_{2} \mathrm{CO}_{3}$ & 2.68 & $-7.6 \%$ & Natron & 3.43 & $-15.4 \%$ & Natrite \\
\hline $\mathrm{K}_{2} \mathrm{CO}_{3}$ & 8.36 & $3.7 \%$ & $\mathrm{~K}_{2} \mathrm{CO}_{3}: 1.5 \mathrm{H}_{2} \mathrm{O}$ & 9.54 & $-15.7 \%$ & $\mathrm{~K}_{2} \mathrm{CO}_{3}$ \\
\hline $\mathrm{NaF}$ & 1.42 & $44.5 \%$ & Villiaumite & 1.44 & $19.2 \%$ & Villiaumite \\
\hline $\mathrm{KF}$ & 18.77 & $7.3 \%$ & Carobbite & 16.64 at $80^{\circ} \mathrm{C}$ & $-35.6 \%$ & Carobbite \\
\hline $\mathrm{CaF}_{2}$ & 0.00030 & $48.6 \%$ & Fluorite & $\begin{array}{c}0.00033 \\
\left(100^{\circ} \mathrm{C}\right)\end{array}$ & $\begin{array}{l}\text { not applicable } \\
\left(100^{\circ} \mathrm{C}\right)\end{array}$ & Fluorite \\
\hline $\mathrm{MgF}_{2}$ & 0.00051 & $-75.6 \%$ & Sellaite & $\begin{array}{c}0.00028 \\
\left(100^{\circ} \mathrm{C}\right) \\
\end{array}$ & $\begin{array}{l}\text { not applicable } \\
\left(100^{\circ} \mathrm{C}\right)\end{array}$ & Sellaite \\
\hline $\mathrm{Na}_{2} \mathrm{SO}_{4}$ & 2.049 & $3.5 \%$ & Mirabilite & 2.98 & $0.5 \%$ & Thenardite \\
\hline $\mathrm{K}_{2} \mathrm{SO}_{4}$ & 0.689 & $0.3 \%$ & Arcanite & 1.33 & $-3.0 \%$ & Arcanite \\
\hline $\mathrm{CaSO}_{4}$ & 0.0141 & $-6.5 \%$ & Gypsum & 0.00567 & $-52.7 \%$ & Anhydrite \\
\hline $\mathrm{MgSO}_{4}$ & 2.65 & $-10.7 \%$ & Epsomite & 3.70 & $-10.9 \%$ & Kieserite \\
\hline $\mathrm{NaBr}$ & 10.45 & $13.7 \%$ & $\mathrm{NaBr}$ & 10.99 & $-7.1 \%$ & $\mathrm{NaBr}$ \\
\hline $\mathrm{KBr}$ & 5.23 & $-8.1 \%$ & $\mathrm{KBr}$ & 8.77 & $1.1 \%$ & $\mathrm{KBr}$ \\
\hline $\mathrm{CaBr}_{2}$ & 14.16 & $81.0 \%$ & $\mathrm{CaBr}_{2}$ & 12.27 at $60^{\circ} \mathrm{C}$ & $-9.3 \%$ & $\mathrm{CaBr}_{2}$ \\
\hline $\mathrm{MgBr}_{2}$ & 16.27 & $192.5 \%$ & $\mathrm{MgBr}_{2}$ & 13.02 & $90.6 \%$ & $\mathrm{MgBr}_{2}$ \\
\hline $\mathrm{NaNO}_{3}$ & 10.84 & $1.0 \%$ & Soda Niter & 20.70 & $-0.2 \%$ & Soda Niter \\
\hline $\mathrm{KNO}_{3}$ & 2.74 & $-27.7 \%$ & Niter & $>18.6$ & $>-22.4 \%$ & none \\
\hline $\mathrm{Ca}\left(\mathrm{NO}_{3}\right)_{2}$ & 6.69 & $-23.7 \%$ & $\mathrm{Ca}\left(\mathrm{NO}_{3}\right)_{2}: 4 \mathrm{H}_{2} \mathrm{O}$ & $>23.6$ & $>6.1 \%$ & none \\
\hline $\mathrm{Mg}\left(\mathrm{NO}_{3}\right)_{2}$ & $>13.4$ & $>179.0 \%$ & none & $>13.2$ & $>-23.9 \%$ & none \\
\hline
\end{tabular}

Output DTN: MO0303MWDSEDSS.000. 


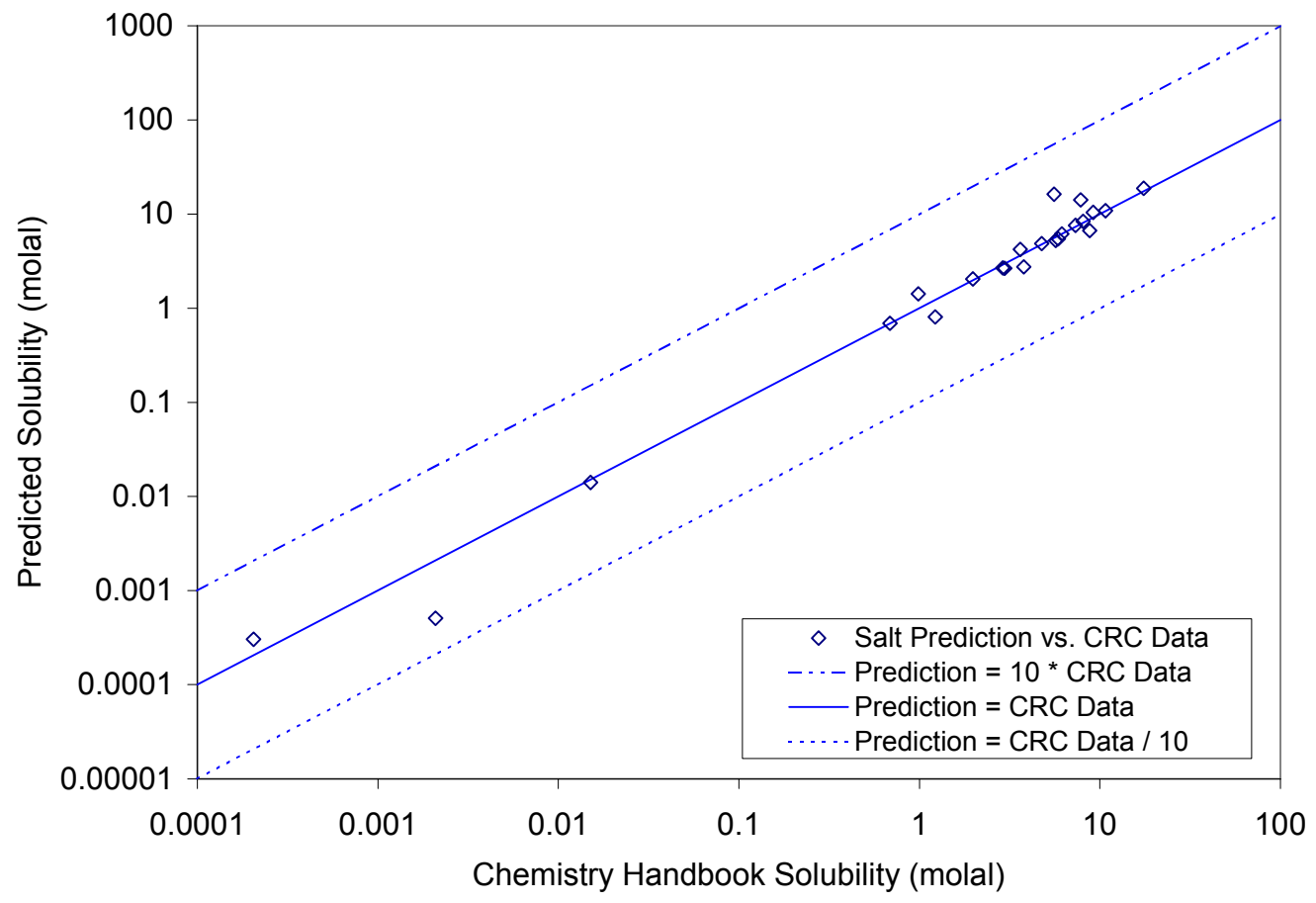

Output DTN: MO0303MWDSEDSS.000.

Figure 7-16. Predicted vs. Chemistry Handbook Mineral Solubilities at $25^{\circ} \mathrm{C}$

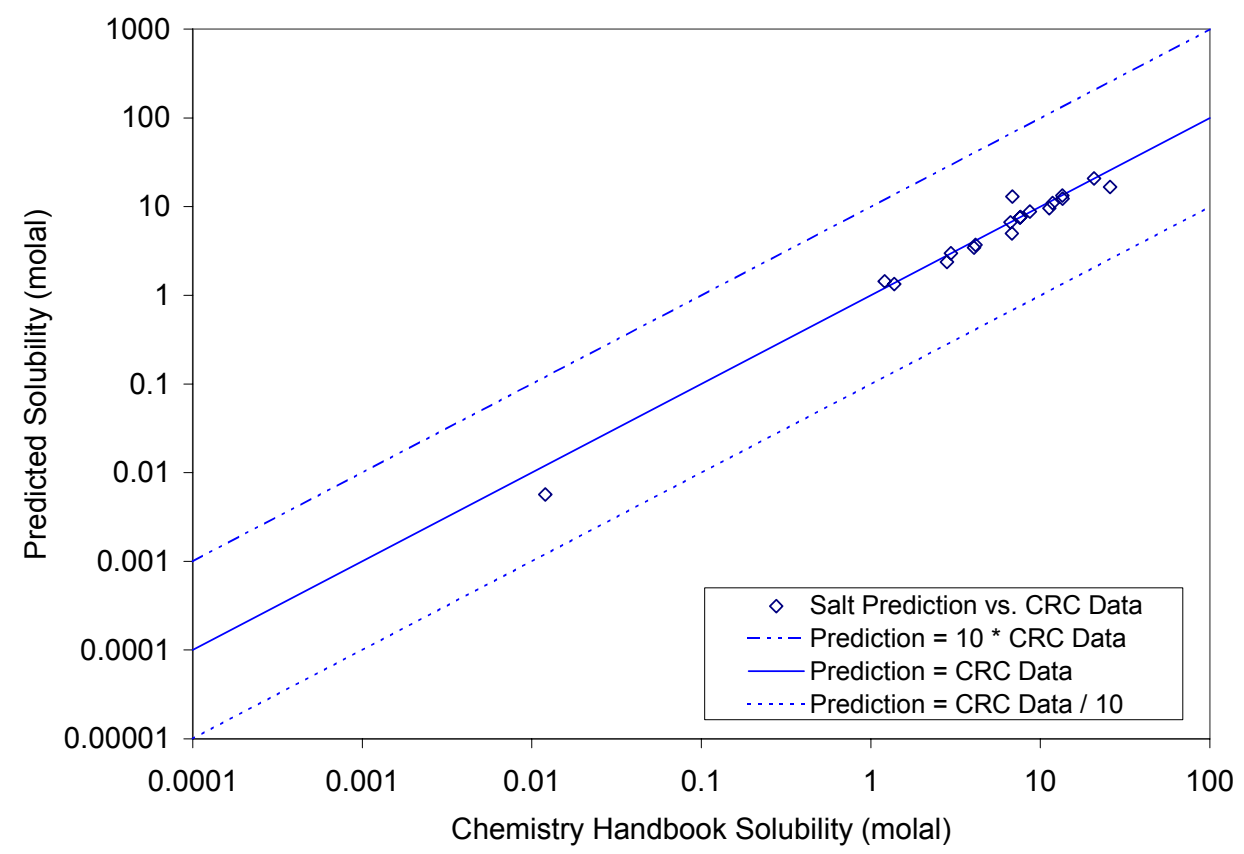

Output DTN: MO0303MWDSEDSS.000.

Figure 7-17. Predicted vs. Chemistry Handbook Mineral Solubilities at $100^{\circ} \mathrm{C}$ 


\subsection{Deliquescence Relative Humidity}

To demonstrate model validation for predicting the deliquescence relative humidity $\left(R H_{d}\right)$ of simple salts, the same approach as in Section 7.2.1.1.1 was used. The IDPS model was used to evaporate dilute binary solutions ( 0.0001 molal) of $\mathrm{Na}, \mathrm{K}, \mathrm{Ca}$, and $\mathrm{Mg}$ salts from Table $4-13$ to mineral saturation at the temperatures listed in the table. Predicted $R H_{d}$ values were then compared to those reported in Table 4-13.

The results of the simulations are documented in DTN: MO0307MWDUNEVP.000 and displayed in Table 7-6. This table lists the predicted deliquescence relative humidity values, the error with respect to handbook values, and the specific mineral phase that reached saturation in the evaporation. The comparison shows that the largest predicted difference in the value of the deliquescence relative humidity is 5.1 percent (in $R H$ percentage units). The implications of these results are discussed in Section 7.5 as applicable.

Table 7-6. Model Predictions of Equilibrium Relative Humidity for Saturated Aqueous Solutions in Contact with an Excess of Solid-Phase Salts

\begin{tabular}{|l|l|l|l|l|}
\hline \multicolumn{1}{|c|}{ Salt } & $\begin{array}{c}\text { Predicted } \\
\text { Equilibrium Relative } \\
\text { Humidity (or } \\
\text { Deliquescence } \\
\text { Point) }(\% \text { RH) }\end{array}$ & Temperature $\left({ }^{\circ} \mathrm{C}\right)$ & $\begin{array}{c}\text { Difference } \\
\text { Compared to } \\
\text { Handbook Values } \\
\text { Listed in Table 4-13 } \\
\text { (\%RH) }\end{array}$ & Precipitating Mineral \\
\hline $\mathrm{NaCl}$ & $74.7 \%$ & 80 & $-1.7 \%$ & Halite \\
\hline $\mathrm{KCl}$ & $77.0 \%$ & 80 & $-2.5 \%$ & Sylvite \\
\hline $\mathrm{MgCl}_{2} \cdot 6 \mathrm{H}_{2} \mathrm{O}$ & $36.9 \%$ & 25 & $3.9 \%$ & Bischofite \\
\hline $\mathrm{Na}_{2} \mathrm{CO}_{3} \cdot 10 \mathrm{H}_{2} \mathrm{O}$ & $90.2 \%$ & 24.5 & $3.2 \%$ & Natron \\
\hline $\mathrm{K}_{2} \mathrm{CO}_{3} \cdot 2 \mathrm{H}_{2} \mathrm{O}$ & $37.8 \%$ & 40 & $-4.2 \%$ & $\mathrm{~K}_{2} \mathrm{CO}_{3} \cdot 1.5 \mathrm{H}_{2} \mathrm{O}$ \\
\hline $\mathrm{NaF}$ & $95.9 \%$ & 100 & $-0.7 \%$ & Villiaumite \\
\hline $\mathrm{KF}$ & $28.0 \%$ & 100 & $5.1 \%$ & Carobbite \\
\hline $\mathrm{Na}_{2} \mathrm{SO}_{4} \cdot 10 \mathrm{H}_{2} \mathrm{O}$ & $95.6 \%$ & 20 & $2.6 \%$ & Mirabilite \\
\hline $\mathrm{K}_{2} \mathrm{SO}_{4}$ & $96.4 \%$ & 60 & $0.4 \%$ & Arcanite \\
\hline $\mathrm{NaNO}_{3}$ & $62.2 \%$ & 80 & $-3.3 \%$ & Soda Niter \\
\hline $\mathrm{KNO}_{3}$ & $77.8 \%$ & 60 & $-4.2 \%$ & Niter \\
\hline
\end{tabular}

Output DTN: MO0307MWDUNEVP.000.

\subsubsection{Comparisons to Non-Handbook Data}

\subsection{Aqueous Solubilities}

Aqueous solubilities of salts over a broad range of temperature for binary systems are compiled and documented in DTN: LL031106231032.007, an output of this report. These data, summarized in Table 4-14, are from Linke 1965 [DIRS 166191] and Linke 1958 [DIRS 166192], except where noted.

As in Section 7.2.1.1, each IDPS model evaporation begins with a 0.0001 molal solution of the particular salt whose solubility is to be estimated. Because the $\mathrm{pH}$ of pure water can be affected 
by the dissolved salt and by temperature, the starting solution is charge balanced on the hydrogen ion. The salt components added to the pure water are inherently charge balanced; thus, charge balancing on the hydrogen ion in these systems reflects a true equilibration process. For evaporations involving carbonate, a closed system is prescribed. An evaporation simulation is complete when the solution reaches saturation with respect to the salt components.

The only difference in these model evaporation runs compared to those in Section 7.2.1.1 is that the species $\mathrm{O}_{2}$ (aq) is suppressed. The presence of $\mathrm{O}_{2}$ (aq) hinders the ability of EQ6 to reach convergence in some cases. For example, suppression of this species allows $\mathrm{KNO}_{3}$ to reach saturation at high temperature. $\mathrm{O}_{2}$ (aq) does not directly affect the IDPS model system because the system does not include redox reactions. Termination of model runs before mineral saturations are reached is not considered non-convergence because the runs do converge to a satisfactory end point, as defined by the validation criteria.

The results of the simulations are documented in DTN: MO0311MWDMVBTS.000. Figures 7-18 through Figure 7-39 compare the aqueous solubilities documented in Linke 1965 [DIRS 166191] and Linke 1958 [DIRS 166192] to model predictions as a function of temperature from $25^{\circ} \mathrm{C}$ to $140^{\circ} \mathrm{C}$. These figures also contain model predictions of $R H_{d}$ (marked as DRH in the figures) as well as measurements of $R H_{d}$ where available (see Section 7.2.1.2.2). The implications of these results are discussed in Section 7.5 as applicable.

As shown in the figures, the salt solubility model predictions are within a factor of 2 of measurements for most of the salts evaluated. Occasionally, the model does not reach mineral saturation at some temperatures (e.g., Figure 7-23, Figure 7-34, Figure 7-35, Figure 7-36, Figure 7-38, and Figure 7-39). In these instances, the aqueous concentrations at the lowest $R H$ achieved are operationally defined as the model predictions of the salt solubilities. Regardless, the model predictions are always within a factor of 10 of measured solubilities (in accordance with model validation criteria shown in Table 7-1) and are usually within a factor of 3 . These uncertainties are captured and propagated in the model uncertainty estimates assessed in Section 7.5. Model bias in predicting output parameters used in TSPA-LA, such as $\mathrm{Cl}$ and $\mathrm{NO}_{3}$ concentrations, is addressed in Section 7.5 where all relevant comparisons in Sections 7.1 and 7.2 are summarized and evaluated as a whole.

The differences between model predictions and measured data do not necessarily reflect model uncertainty (or bias) alone because there is some uncertainty associated with the measured data. Uncertainty in solubility measurements is apparent in Figure 7-20, Figure 7-25, Figure 7-38, and Figure 7-39 where multiple data are provided for the same approximate temperature. 


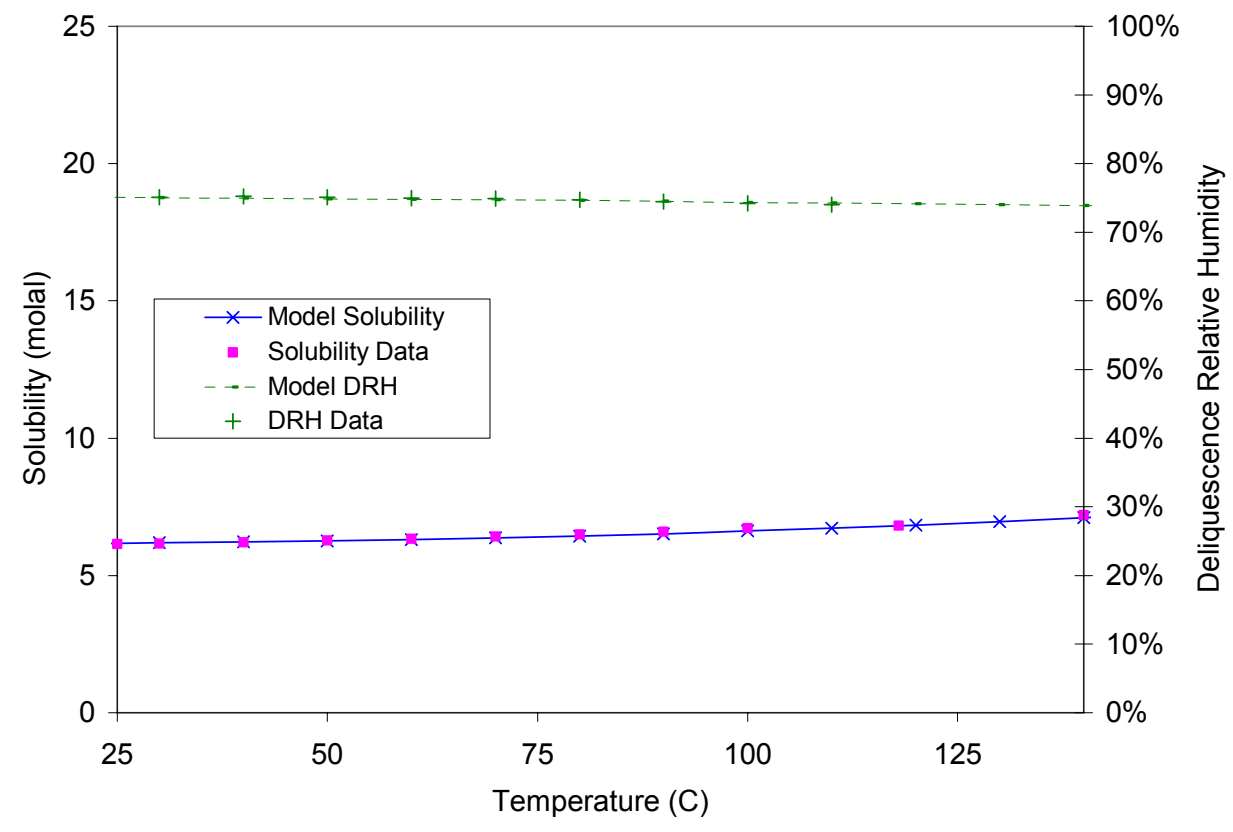

Output DTN: MO0311MWDMVBTS.000.

Figure 7-18. Solubility and Deliquescence $R H$ Predictions vs. Data for $\mathrm{NaCl}$

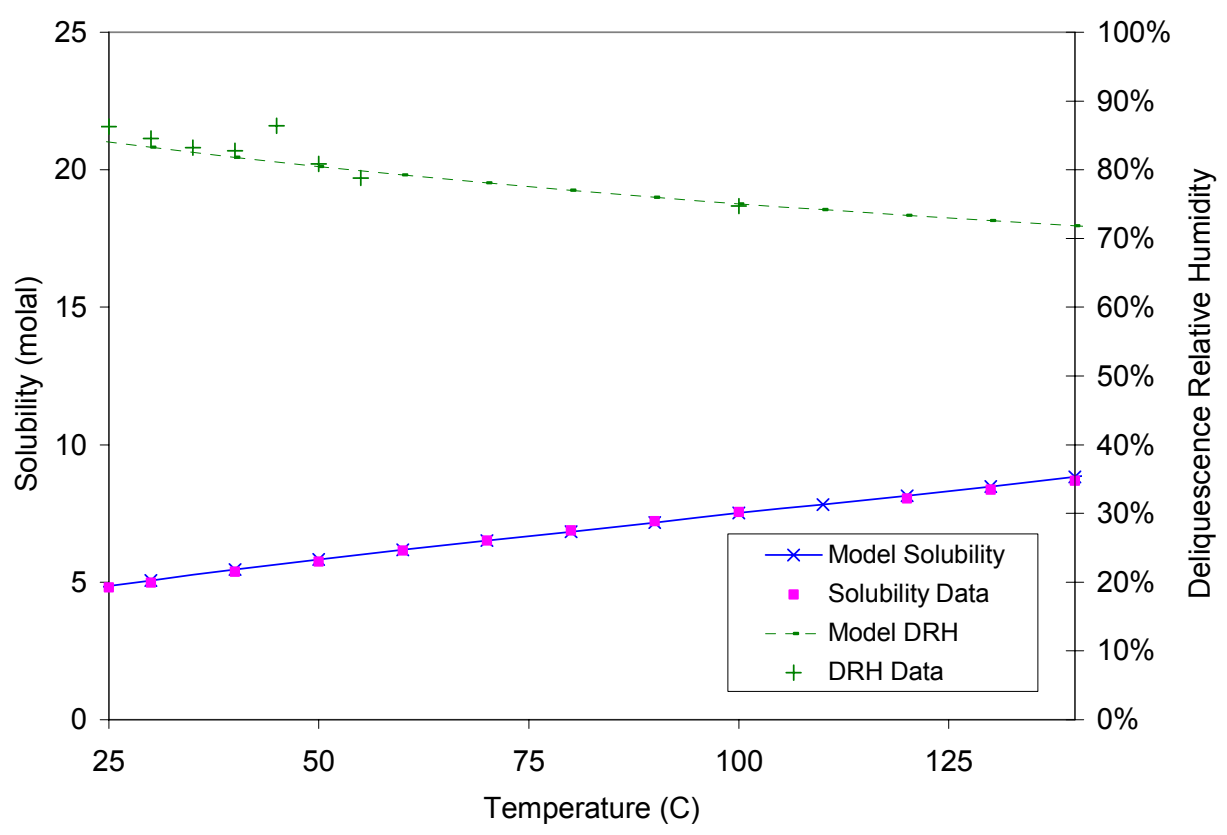

Output DTN: MO0311MWDMVBTS.000.

Figure 7-19. Solubility and Deliquescence $R H$ Predictions vs. Data for $\mathrm{KCl}$ 


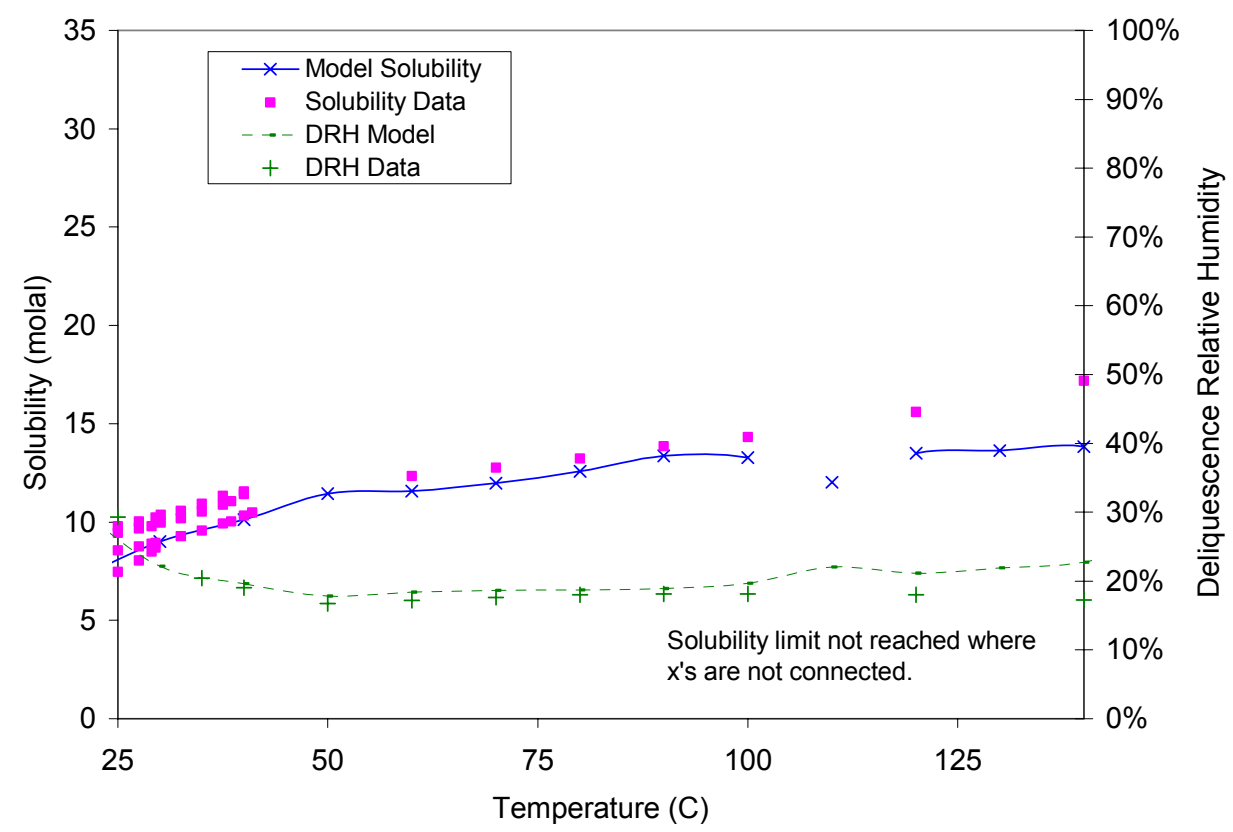

Output DTN: MO0311MWDMVBTS.000.

Figure 7-20. Solubility and Deliquescence $R H$ Predictions vs. Data for $\mathrm{CaCl}_{2}$

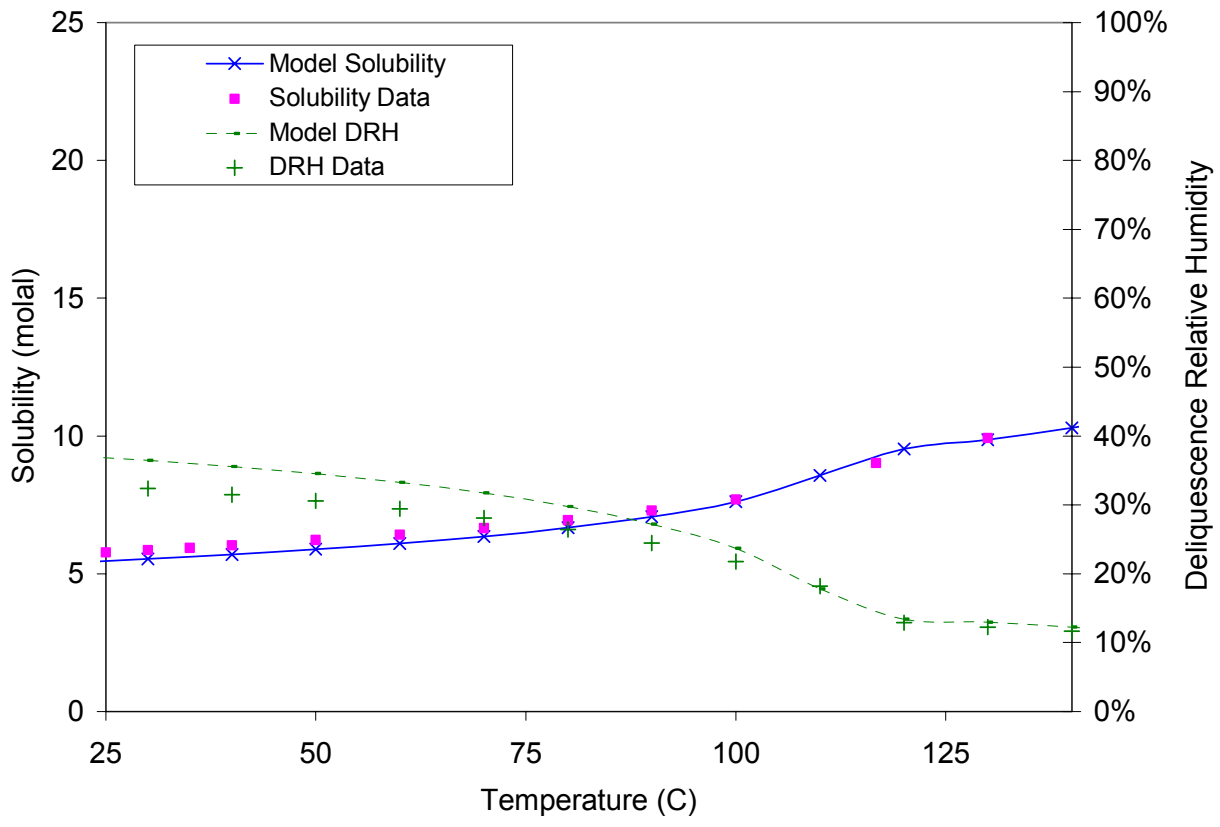

Output DTN: MO0311MWDMVBTS.000.

Figure 7-21. Solubility and Deliquescence $R H$ Predictions vs. Data for $\mathrm{MgCl}_{2}$ 


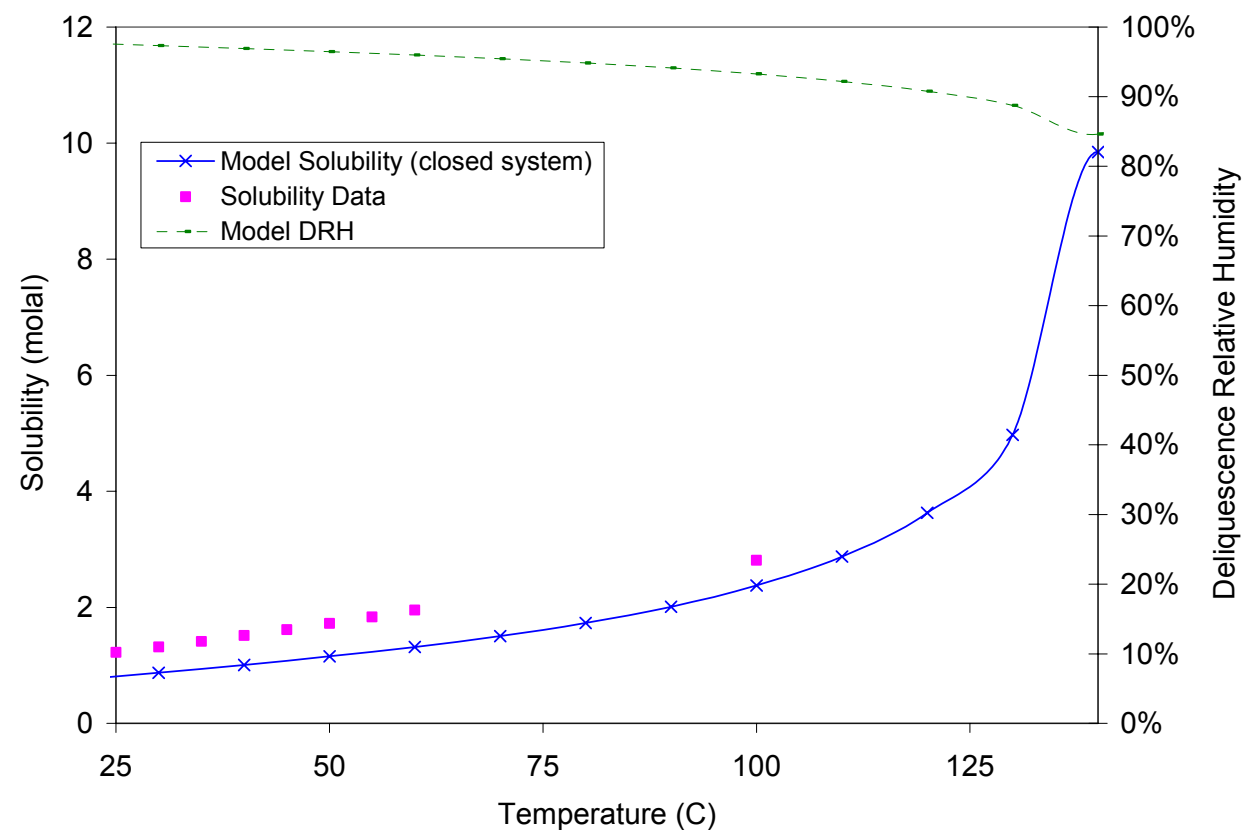

Output DTN: MO0311MWDMVBTS.000.

Figure 7-22. Solubility and Deliquescence $\mathrm{RH}$ Predictions vs. Data for $\mathrm{NaHCO}_{3}$

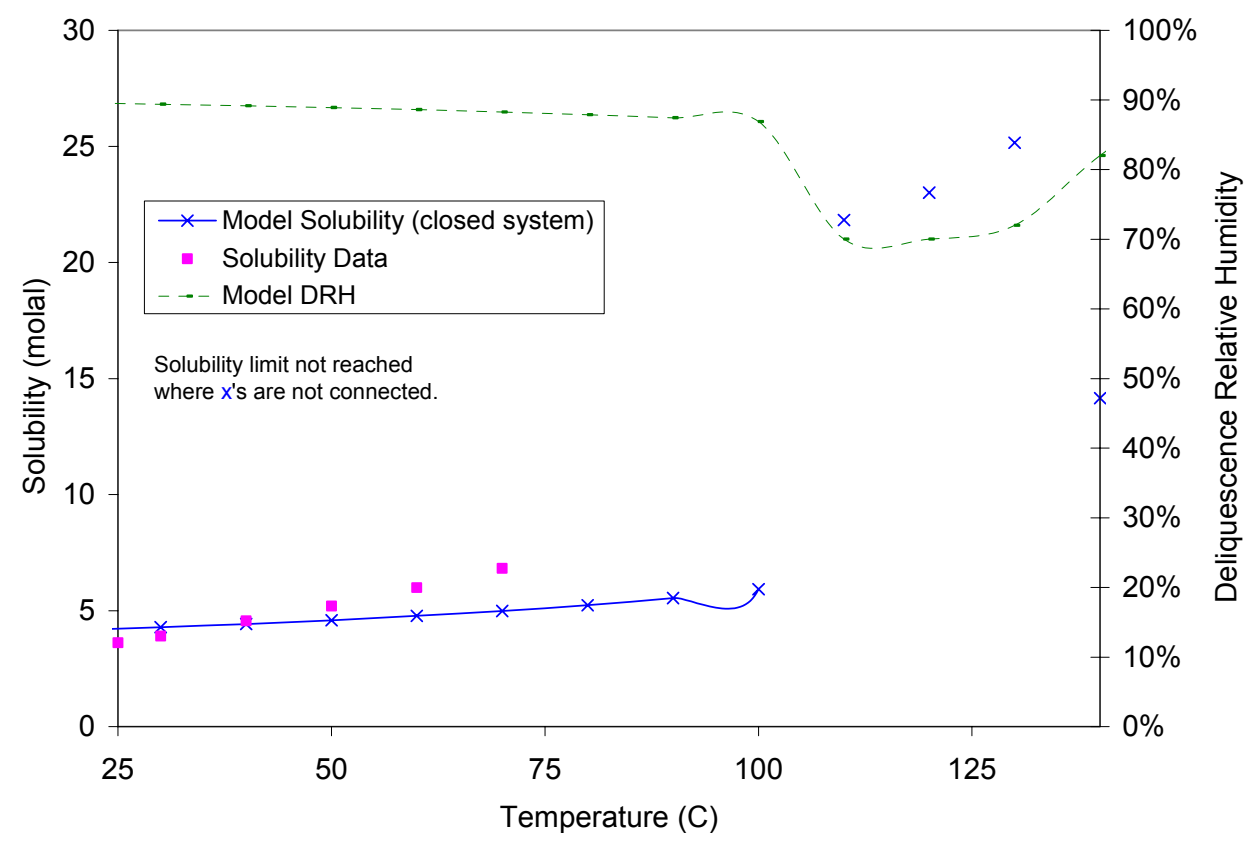

Output DTN: MO0311MWDMVBTS.000.

Figure 7-23. Solubility and Deliquescence $\mathrm{RH}$ Predictions vs. Data for $\mathrm{KHCO}_{3}$ 


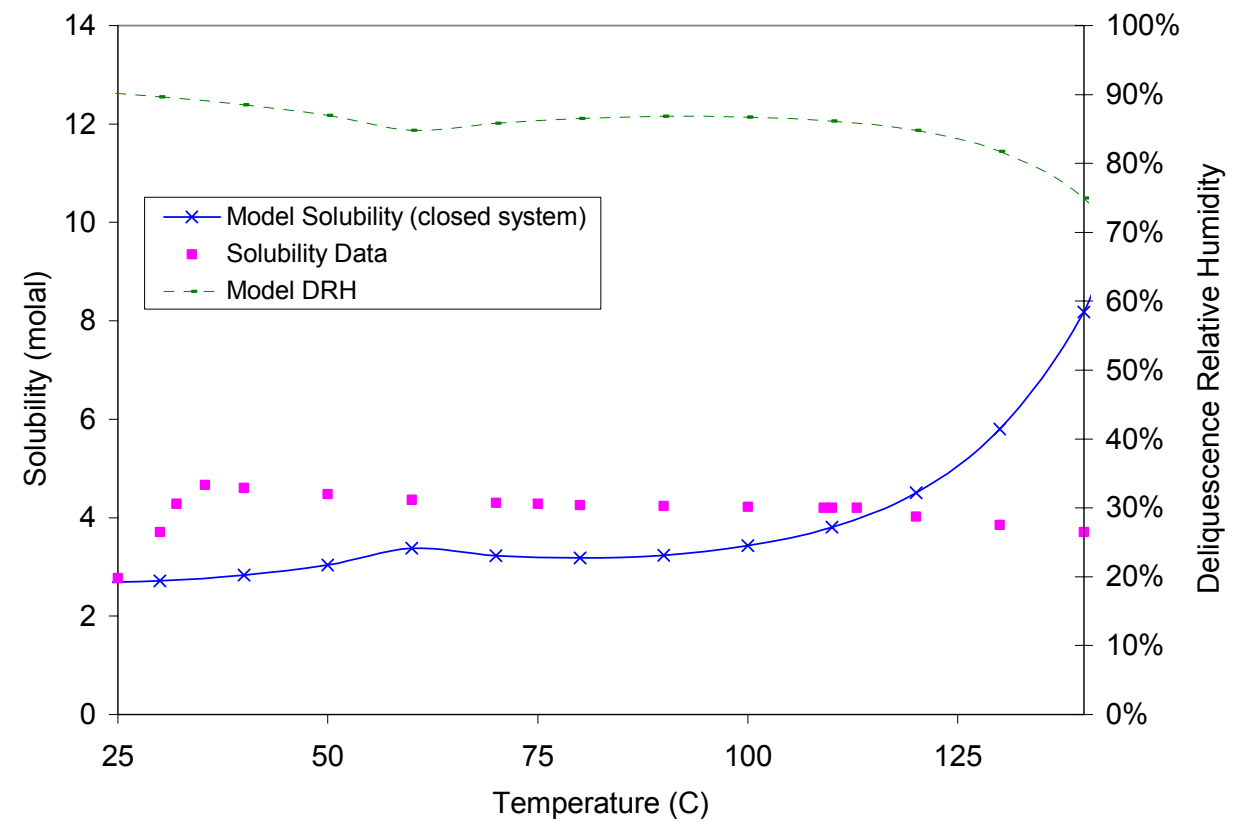

Output DTN: MO0311MWDMVBTS.000.

Figure 7-24. Solubility and Deliquescence $\mathrm{RH}$ Predictions vs. Data for $\mathrm{Na}_{2} \mathrm{CO}_{3}$

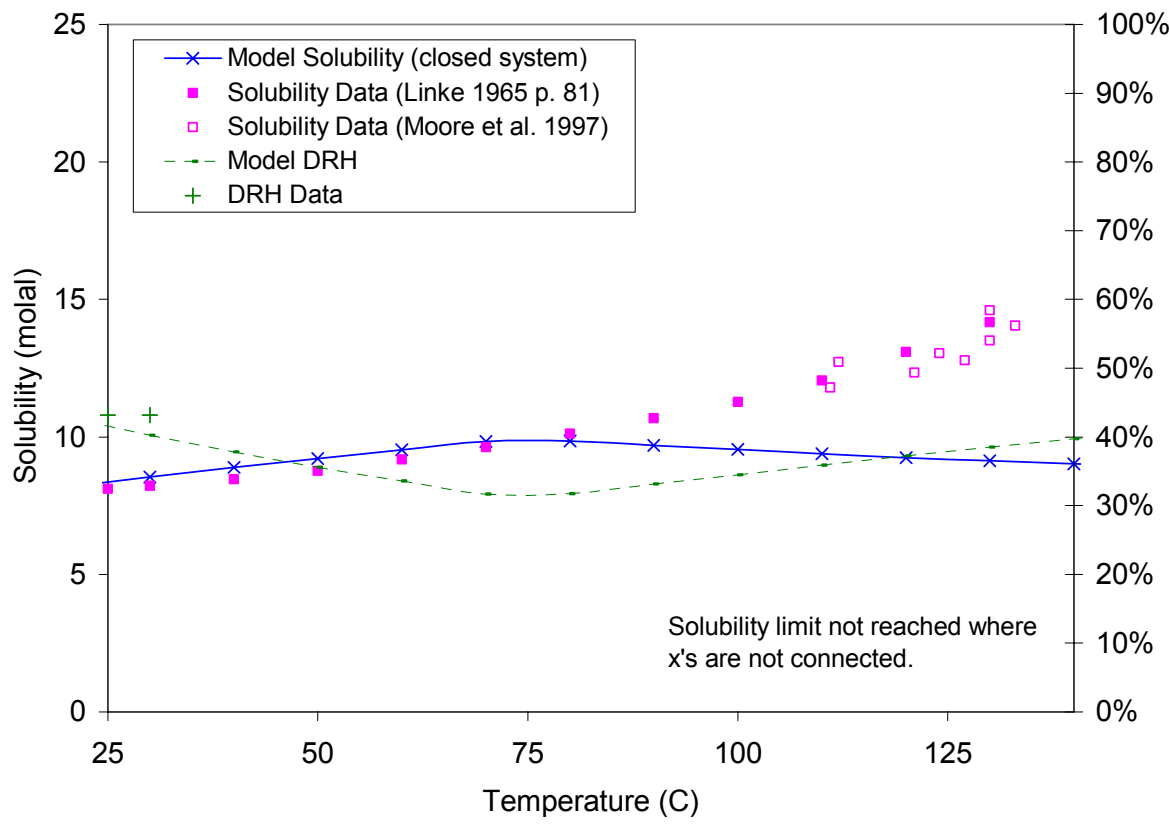

Output DTN: MO0311MWDMVBTS.000.

Figure 7-25. Solubility and Deliquescence $R H$ Predictions vs. Data for $\mathrm{K}_{2} \mathrm{CO}_{3}$ 


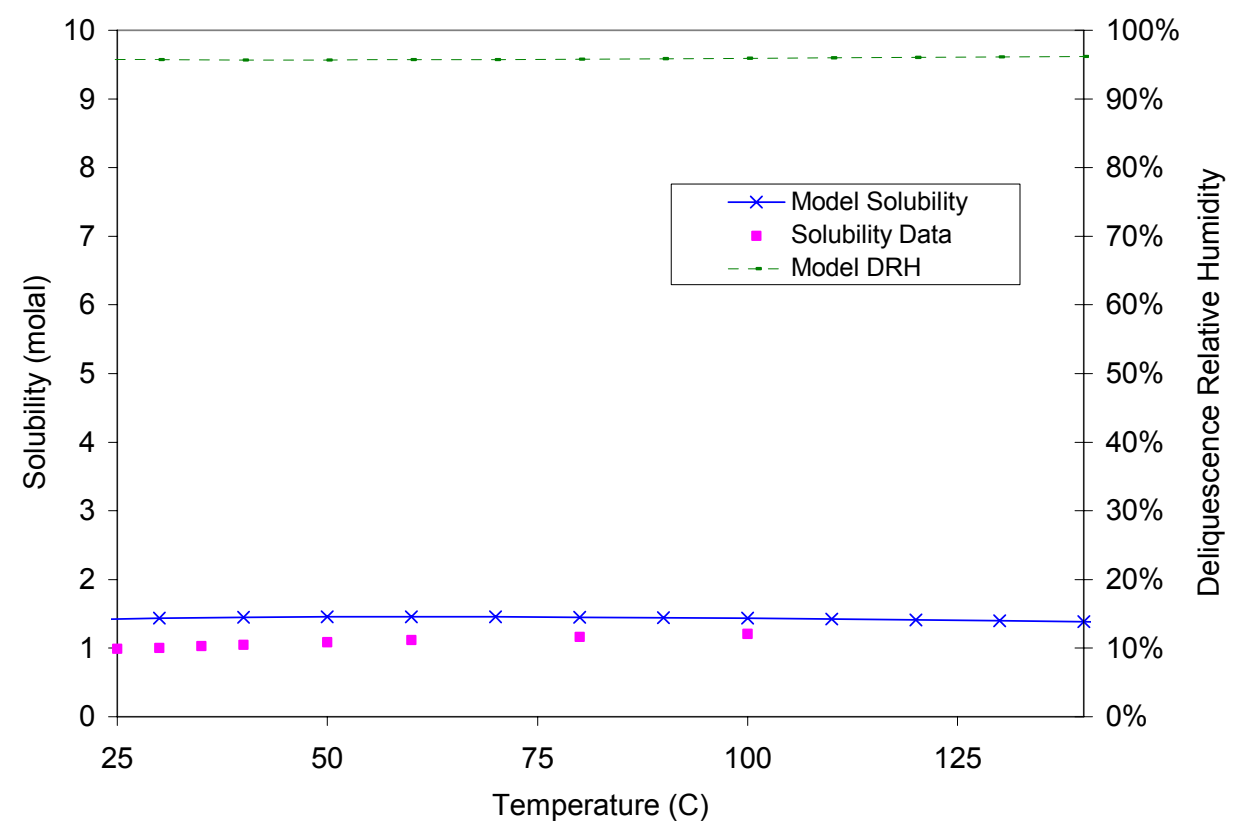

Output DTN: MO0311MWDMVBTS.000.

Figure 7-26. Solubility and Deliquescence $R H$ Predictions vs. Data for $\mathrm{NaF}$

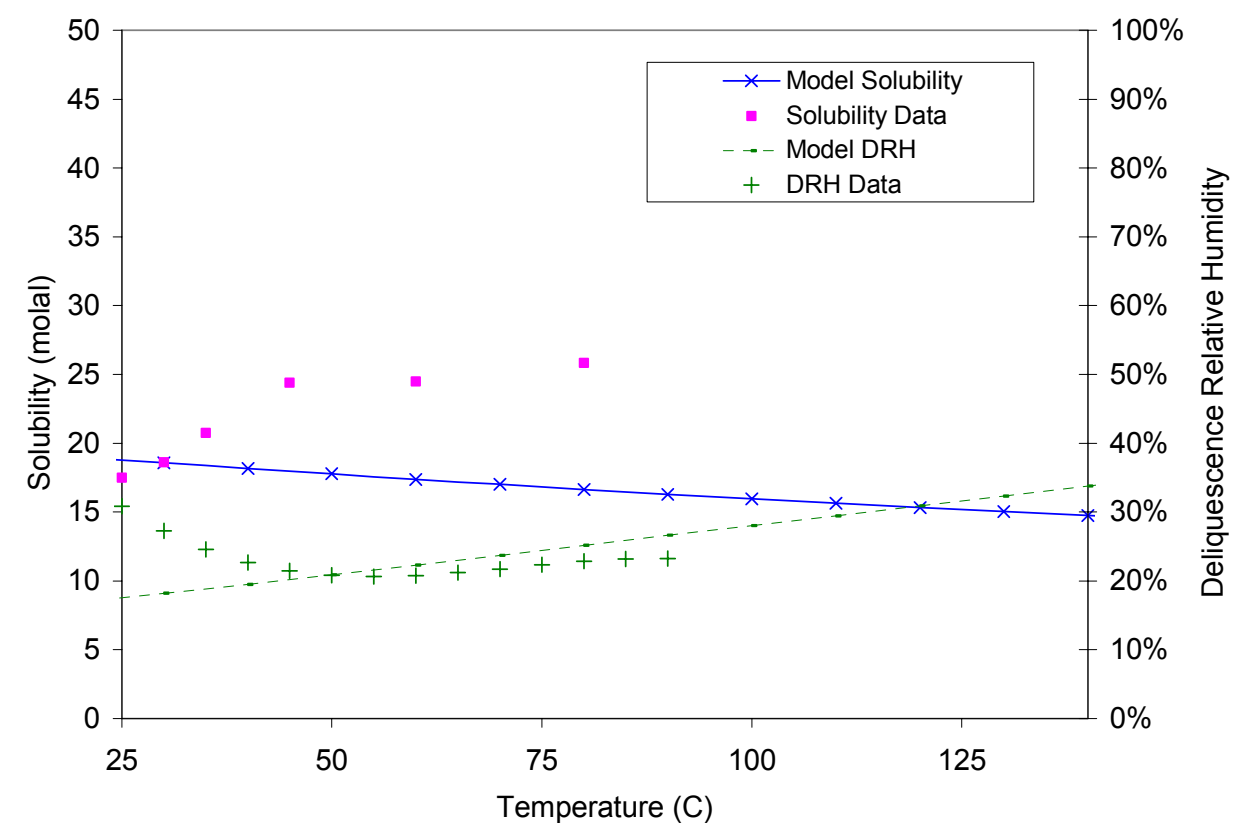

Output DTN: MO0311MWDMVBTS.000.

Figure 7-27. Solubility and Deliquescence $R H$ Predictions vs. Data for KF 


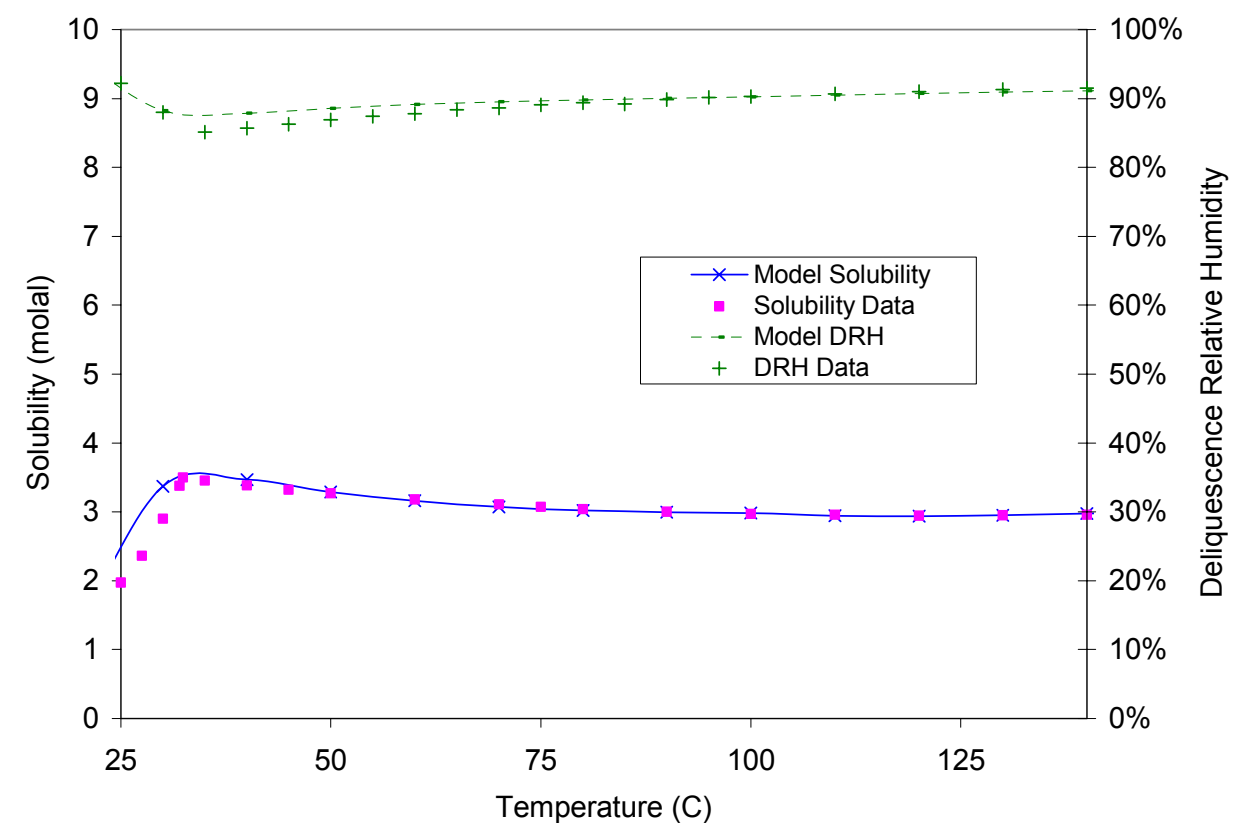

Output DTN: MO0311MWDMVBTS.000.

Figure 7-28. Solubility and Deliquescence $\mathrm{RH}$ Predictions vs. Data for $\mathrm{Na}_{2} \mathrm{SO}_{4}$

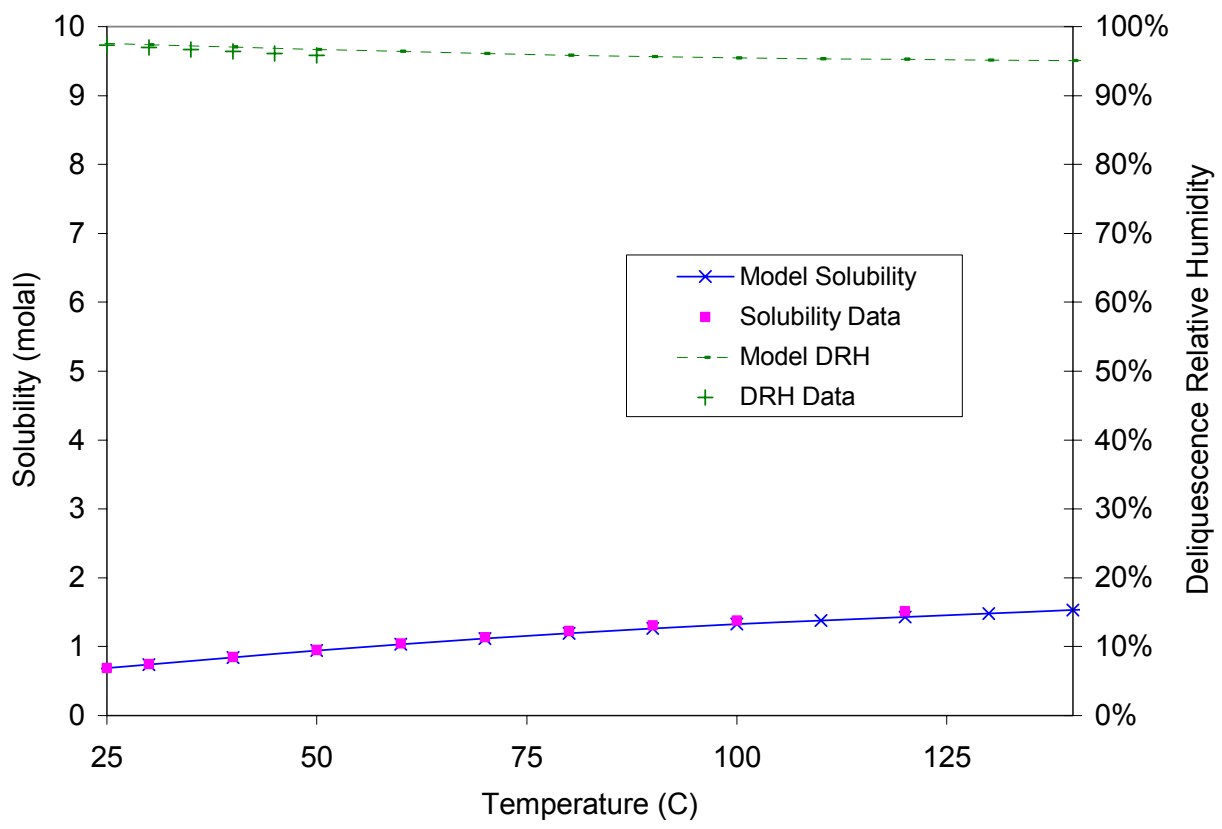

Output DTN: MO0311MWDMVBTS.000.

Figure 7-29. Solubility and Deliquescence $R H$ Predictions vs. Data for $\mathrm{K}_{2} \mathrm{SO}_{4}$ 


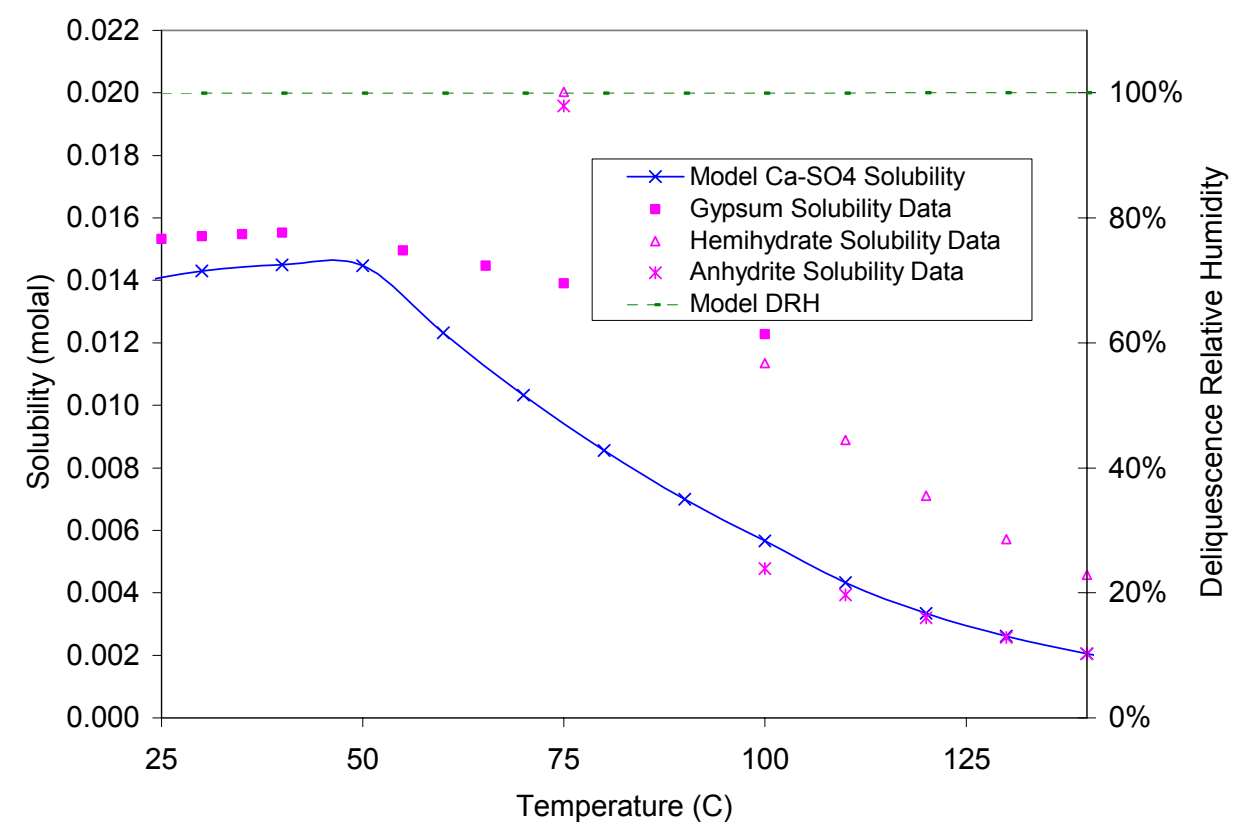

Output DTN: MO0311MWDMVBTS.000.

Figure 7-30. Solubility and Deliquescence $\mathrm{RH}$ Predictions vs. Data for $\mathrm{CaSO}_{4}$

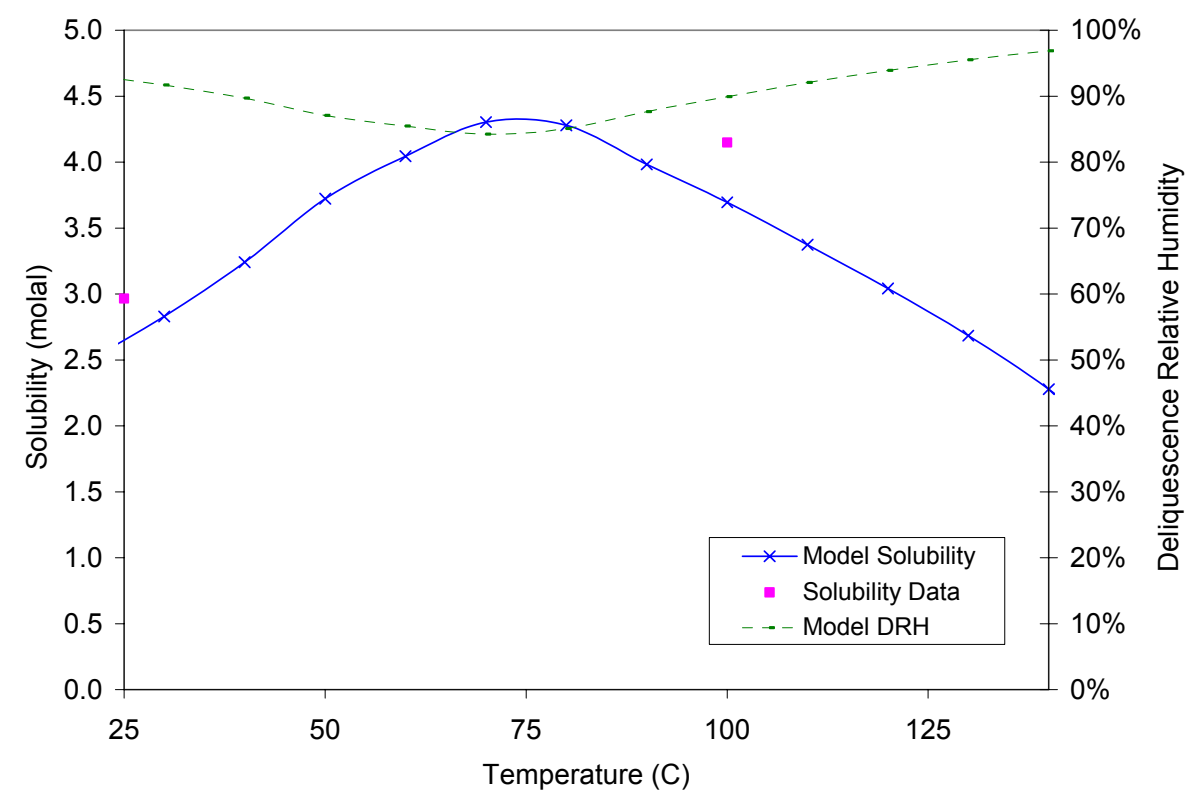

Output DTNs: MO0311MWDMVBTS.000, MO0303MWDSEDSS.000.

Figure 7-31. Solubility and Deliquescence $R H$ Predictions vs. Data for $\mathrm{MgSO}_{4}$ 


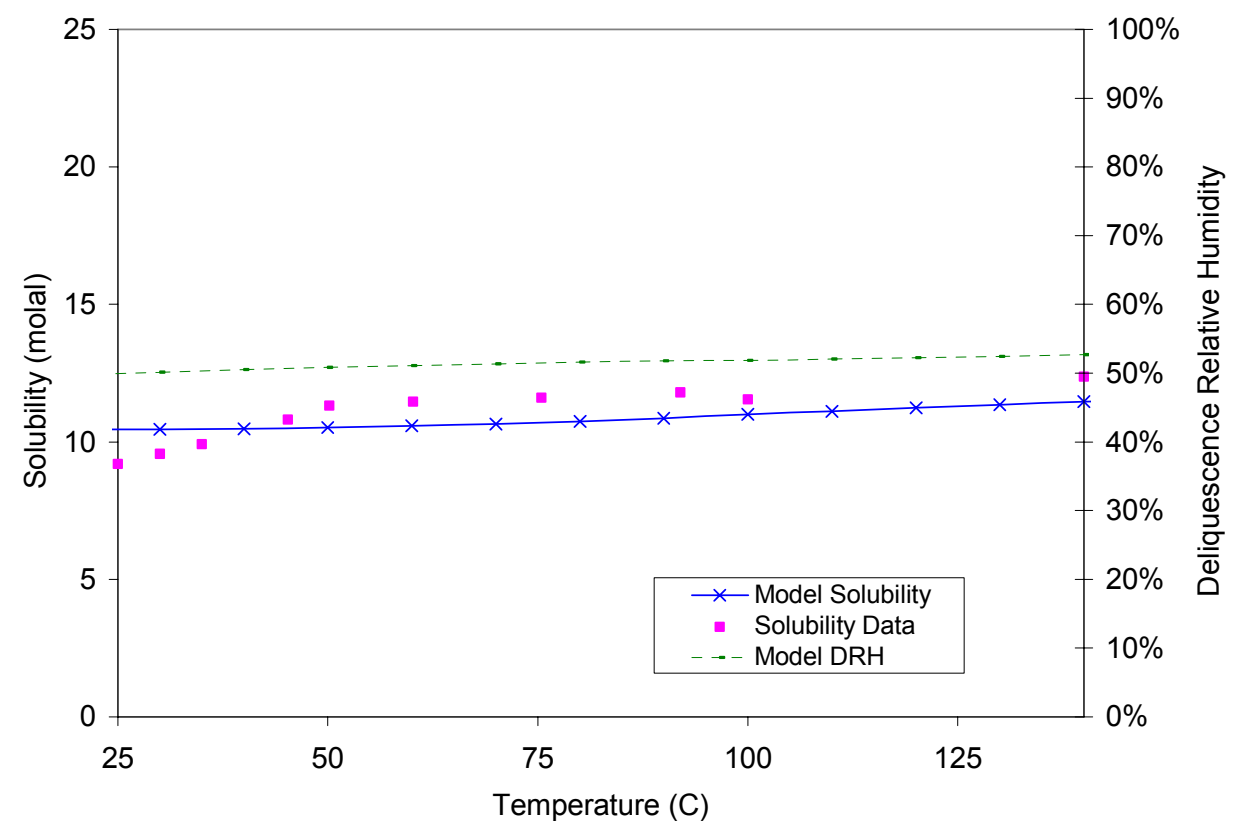

Output DTN: MO0311MWDMVBTS.000.

Figure 7-32. Solubility and Deliquescence $R H$ Predictions vs. Data for $\mathrm{NaBr}$

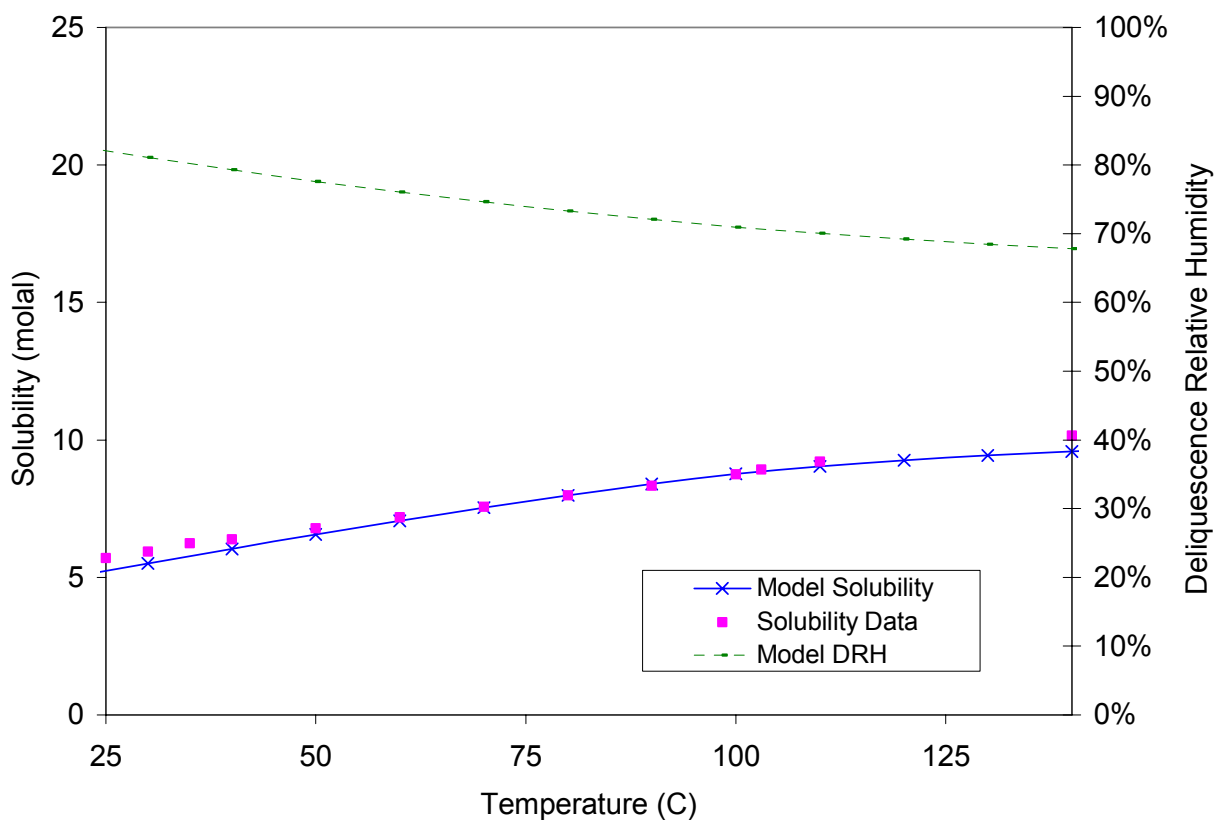

Output DTN: MO0311MWDMVBTS.000.

Figure 7-33. Solubility and Deliquescence $R H$ Predictions vs. Data for $\mathrm{KBr}$ 


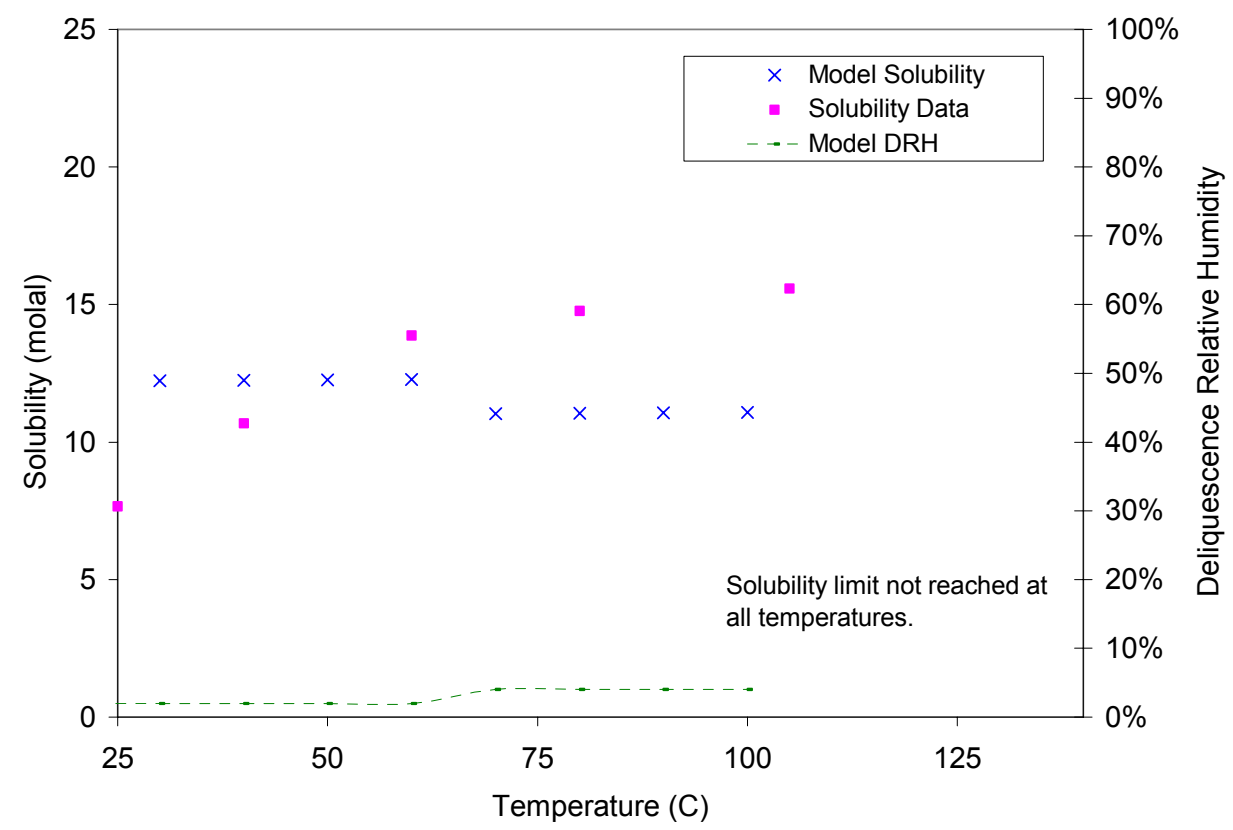

Output DTN: MO0311MWDMVBTS.000.

Figure 7-34. Solubility and Deliquescence $R H$ Predictions vs. Data for $\mathrm{CaBr}_{2}$

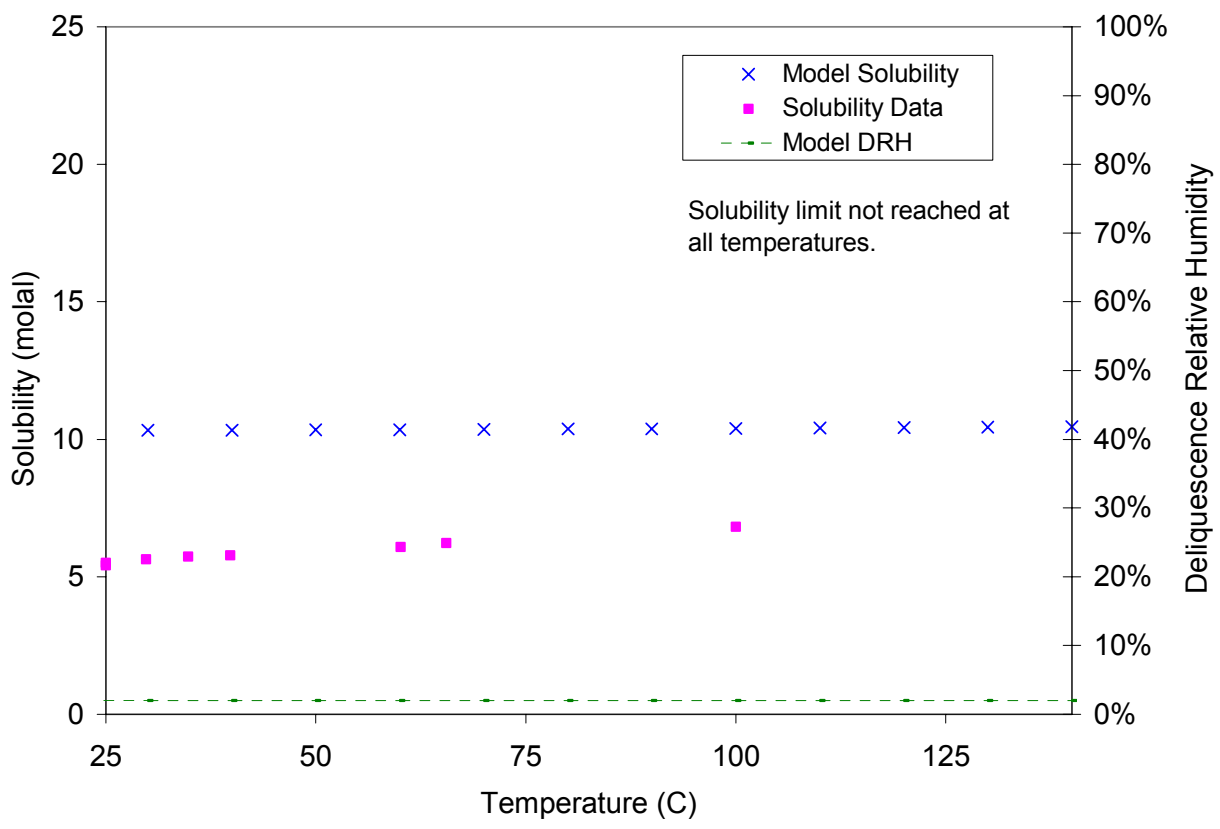

Output DTN: MO0311MWDMVBTS.000.

Figure 7-35. Solubility and Deliquescence $R H$ Predictions vs. Data for $\mathrm{MgBr}_{2}$ 


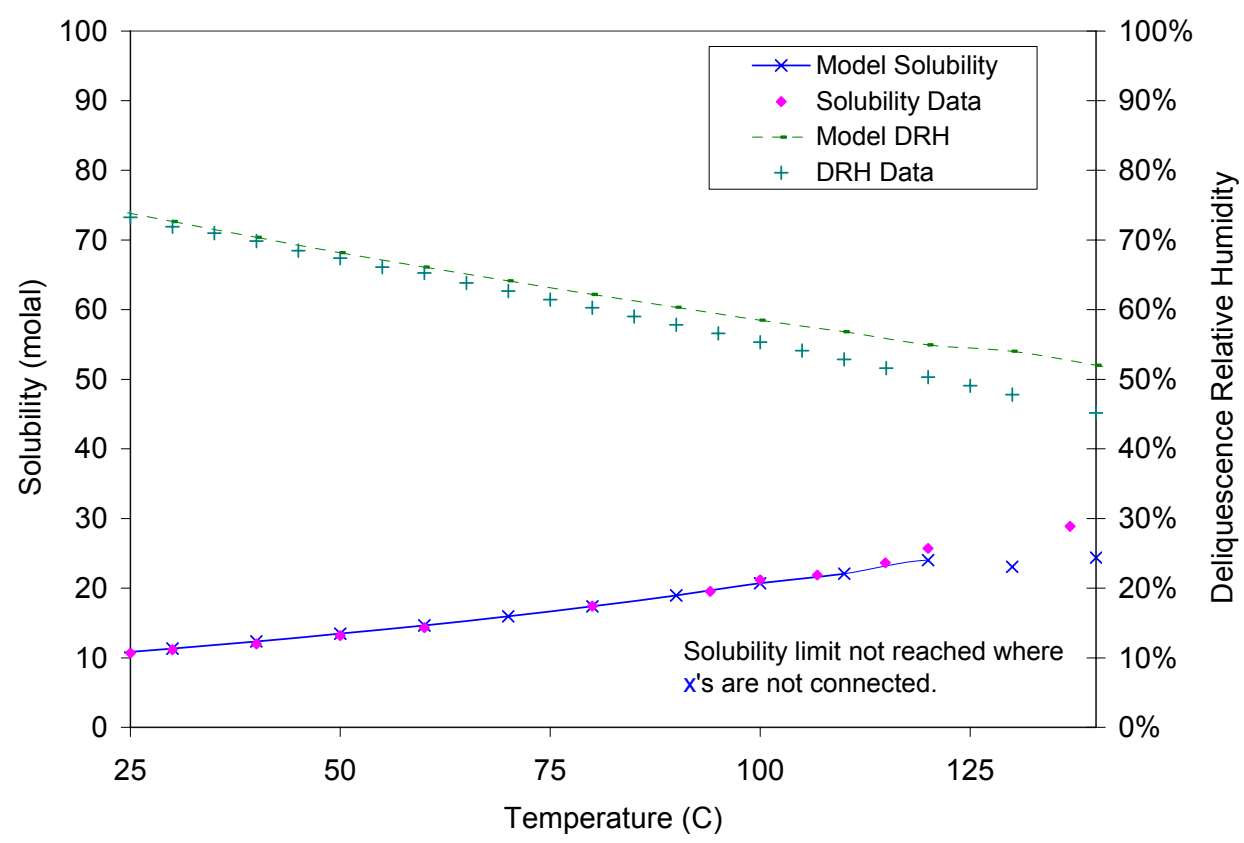

Output DTN: MO0311MWDMVBTS.000.

Figure 7-36. Solubility and Deliquescence $\mathrm{RH}$ Predictions vs. Data for $\mathrm{NaNO}_{3}$

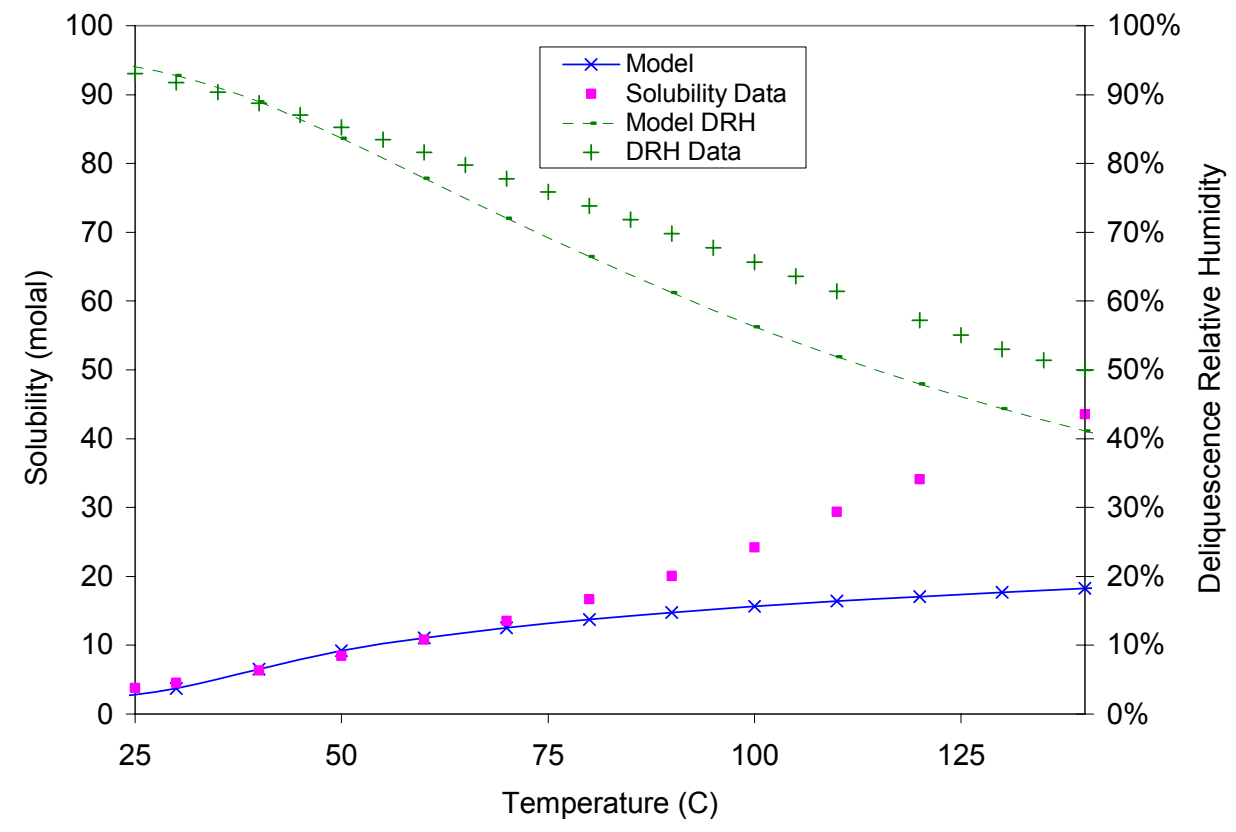

Output DTN: MO0311MWDMVBTS.000.

Figure 7-37. Solubility and Deliquescence $\mathrm{RH}$ Predictions vs. Data for $\mathrm{KNO}_{3}$ 


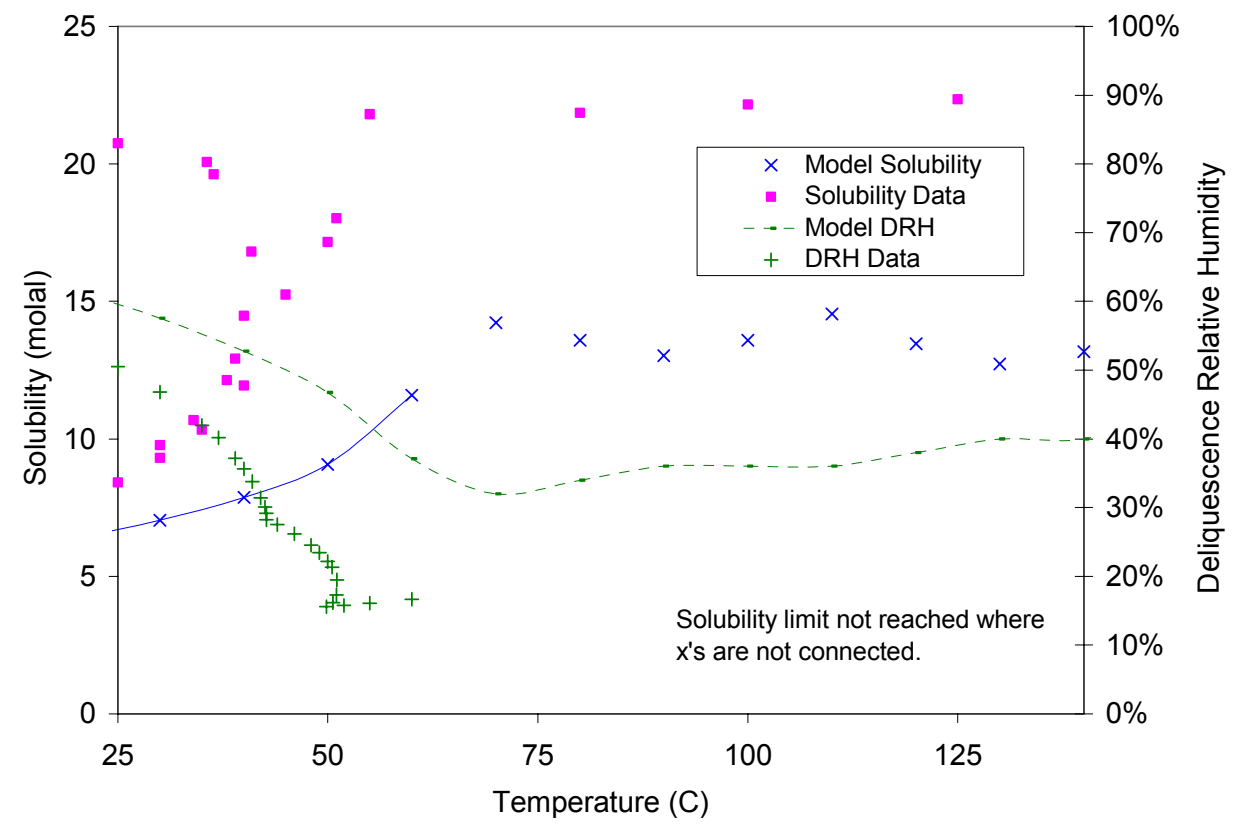

Output DTN: MO0311MWDMVBTS.000.

Figure 7-38. Solubility and Deliquescence $R H$ Predictions vs. Data for $\mathrm{Ca}\left(\mathrm{NO}_{3}\right)_{2}$

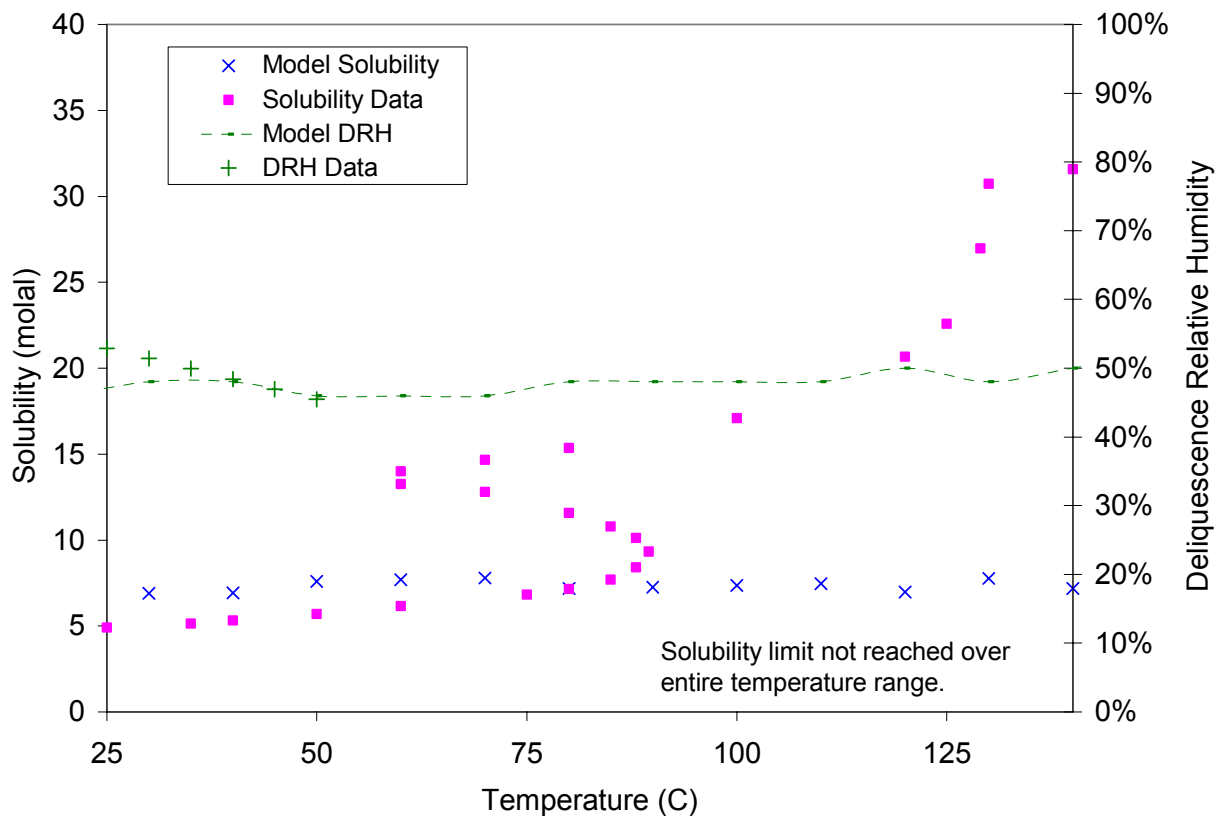

Output DTN: MO0311MWDMVBTS.000.

Figure 7-39. Solubility and Deliquescence $R H$ Predictions vs. Data for $\mathrm{Mg}\left(\mathrm{NO}_{3}\right)_{2}$ 


\subsection{Deliquescence Relative Humidity}

Non-handbook sources of deliquescence relative humidity $\left(R H_{d}\right)$ values used in the IDPS model validation are summarized in Table 4-15 through Table 4-17 in Section 4.4. Data referenced in Table 4-15 and Table 4-17 are reduced and compiled in DTN: LL031106231032.007, an output of this report. Data from Greenspan (1977 [DIRS 104945]) are listed in Table 4-16. These data sets are used in this section to compare to values of $R H_{d}$ predicted by the IDPS model.

$R H_{d}$ values are computed from vapor pressures of saturated salt solutions $\left(P_{\text {solution }}\right)$ using the following equation:

$$
R H_{d}=\frac{P_{\text {solution }}}{P_{H 2 O}}
$$

where $P_{H 2 O}$ is the vapor pressure of pure water. Values for $P_{H 2 O}$ as a function of temperature are listed in Table 4-17.

The IDPS model simulations in Section 7.2.1.2.1 provide the model predictions of $R H_{d}$. Figure 7-18 through Figure 7-39 provide plots of these predictions (marked as DRH in the charts) as a function of temperature from $25^{\circ} \mathrm{C}$ to $140^{\circ} \mathrm{C}$. Where available, $R H_{d}$ measurements are included in the figures for comparison. The results are documented in DTN: MO0311MWDMVBTS.000. The implications of these results are discussed in Section 7.5 as applicable.

As shown in the figures, the $R H_{d}$ predictions are within 5 percent in $R H$ units for most of the salts with $R H_{d}$ measurements. The differences generally increase with decreasing $R H_{d}$. For several salts whose $R H_{d}$ are less than about 60 percent, differences between predictions and measurements can be greater than 5 percent in $R H$ units (e.g., Figure 7-27, Figure 7-37, and Figure 7-38).

\subsubsection{Ternary Salt Systems}

The ternary salt systems evaluated in this report are mixtures of pure water and two different salts having a common cation or anion. To demonstrate model validation for predicting aqueous solubilities in ternary systems, IDPS model simulations were performed to compare against data reported by Linke (1965 [DIRS 166191]; 1958 [DIRS 166192]) and de Lima \& Pitzer (1983 [DIRS 162110]). The specific data used from these sources are listed in Table 4-18. These data are reduced and compiled in DTN: LL031106231032.007, an output of this report via qualification per AP-SIII.10Q, Section 5.2.1(k).

Two types of ternary systems are simulated. If both salts are at saturation in the data set, the IDPS model evaporations are simulated to the eutectic end points. Similar to the approach in Section 7.2.1.2.1, the simulations begin with a 0.0001 molal solution of each salt in the system. Because the $\mathrm{pH}$ of pure water can be affected by the dissolved salt and by temperature, the starting solution is charge balanced on the hydrogen ion. The salt components added to the pure water are inherently charge balanced; thus, charge balancing on the hydrogen ion in these systems reflects a true equilibration process. For evaporations involving carbonate, a closed 
system is prescribed. An evaporation simulation is complete when the solution reaches saturation with respect to both salts.

If only one salt is at saturation in the ternary system being simulated, then the simulations start with a solution that is saturated only with respect to that salt. The undersaturated salt is then incrementally added to the solution to cover the range of aqueous concentrations of the undersaturated salt in the data set. As the undersaturated salt is added, the salt at saturation is allowed to precipitate or dissolve to maintain aqueous saturation.

The results of the simulations are documented in DTN: MO0311MWDMVBTS.000. Figures 7-40 through 7-68 compare data to model predictions over a temperature range from $25^{\circ} \mathrm{C}$ to $140^{\circ} \mathrm{C}$ in DTN: LL031106231032.007. For the isothermal ternary systems in which only one solid phase salt is present in the system, model predictions and measurements of the aqueous concentrations of the saturated salt are plotted against the concentrations of the undersaturated salt. The implications of these results are discussed in Section 7.5 as applicable.

The figures show small differences between predictions and measurements for some ternary systems and larger differences for others. In some cases, differences are small at lower temperatures and large at high temperatures, such as in ternary systems involving $\mathrm{NaNO}_{3}$ or $\mathrm{KNO}_{3}$ (e.g., Figure 7-41, Figure 7-43, Figure 7-44, and Figure 7-48). These differences correlate with differences observed in the binary systems (e.g., Figure 7-36 and Figure 7-37). Although model predictions often indicate a bias in one direction or another, the bias is almost always within the uncertainty limits of the model validation criteria. Model bias in predicting output parameters important to TSPA-LA, such as concentrations of $\mathrm{Cl}$ and $\mathrm{NO}_{3}$ and the $\mathrm{Cl}_{2} \mathrm{NO}_{3}$ molar ratio, is addressed in Section 7.5 where all relevant comparisons in Sections 7.1 and 7.2 are summarized and evaluated as a whole.

Except for one case, all predictions are within a factor of 10 of the measurements (in accordance with model validation criteria shown in Table 7-1) and are usually within a factor of 3 . The exception is one of the two $\mathrm{Ca}\left(\mathrm{NO}_{3}\right)_{2}$ measurements in the $\mathrm{Ca}-\mathrm{Cl}-\mathrm{NO}_{3}$ eutectic system (Figure 7-61). The large difference between the two measurements suggests a large uncertainty in the measured data for this system. This is a clear example where observed differences between model predictions and measurements do not necessarily reflect model uncertainty (or bias) alone.

The uncertainties that appear in the comparisons are captured and propagated into model uncertainty estimates in Section 7.5. Potential model bias as it might relate to conservatism is also addressed in Section 7.5. 


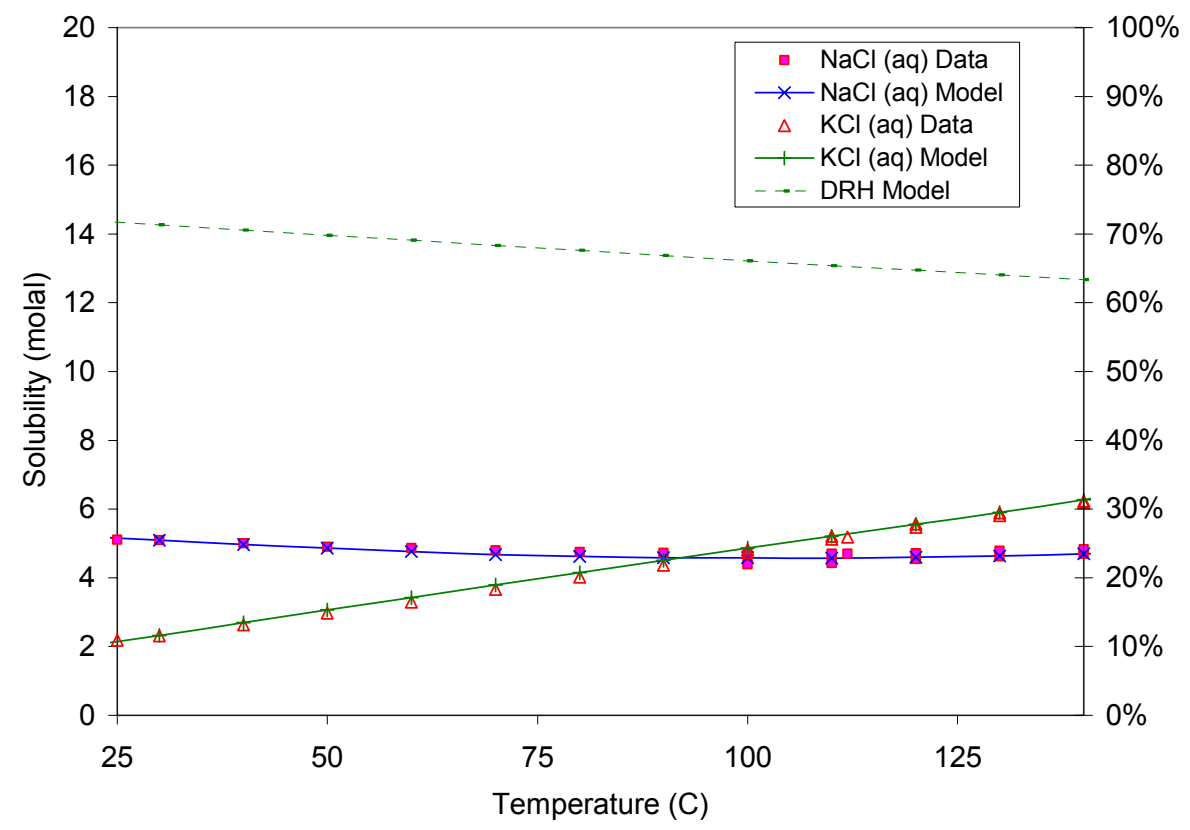

Output DTN: MO0311MWDMVBTS.000.

Figure 7-40. Model Predictions vs. Data for Na-K-Cl Eutectic System

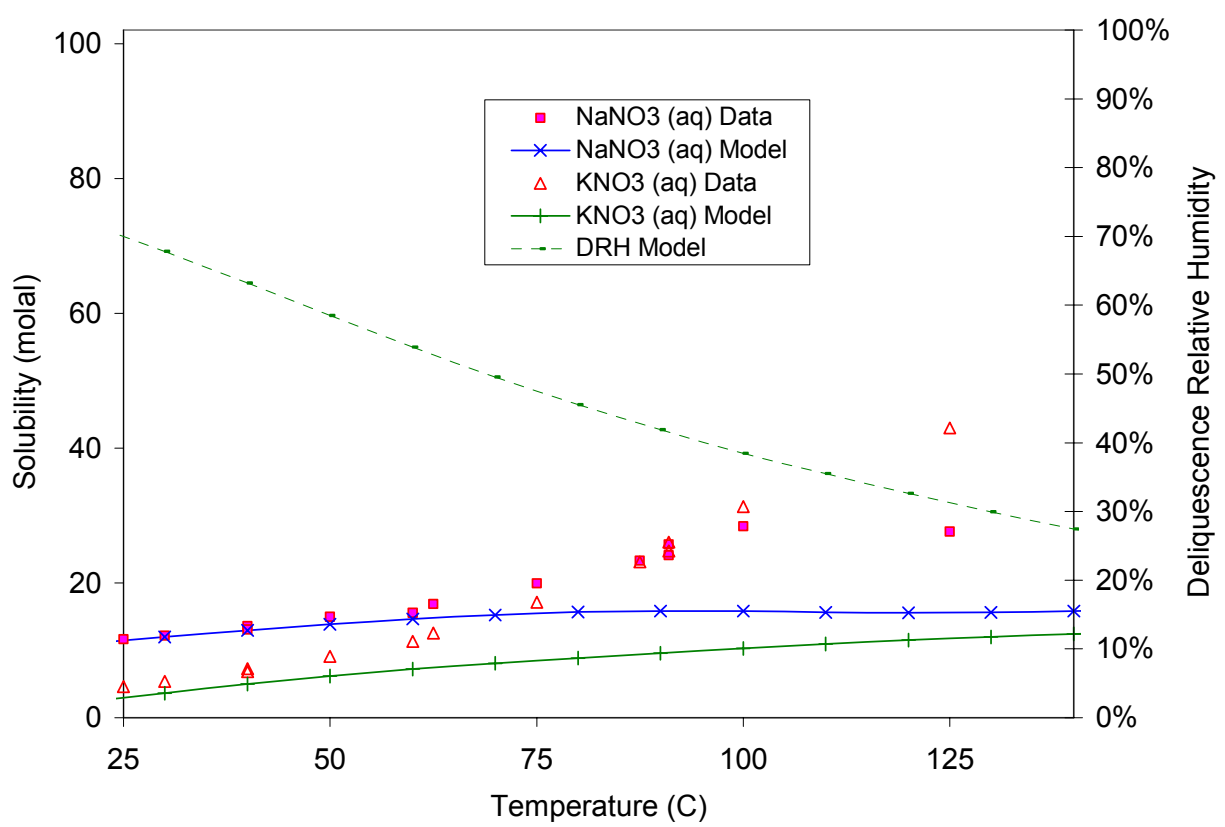

Output DTN: MO0311MWDMVBTS.000.

Figure 7-41. Model Predictions vs. Data for Na-K-NO ${ }_{3}$ Eutectic System 


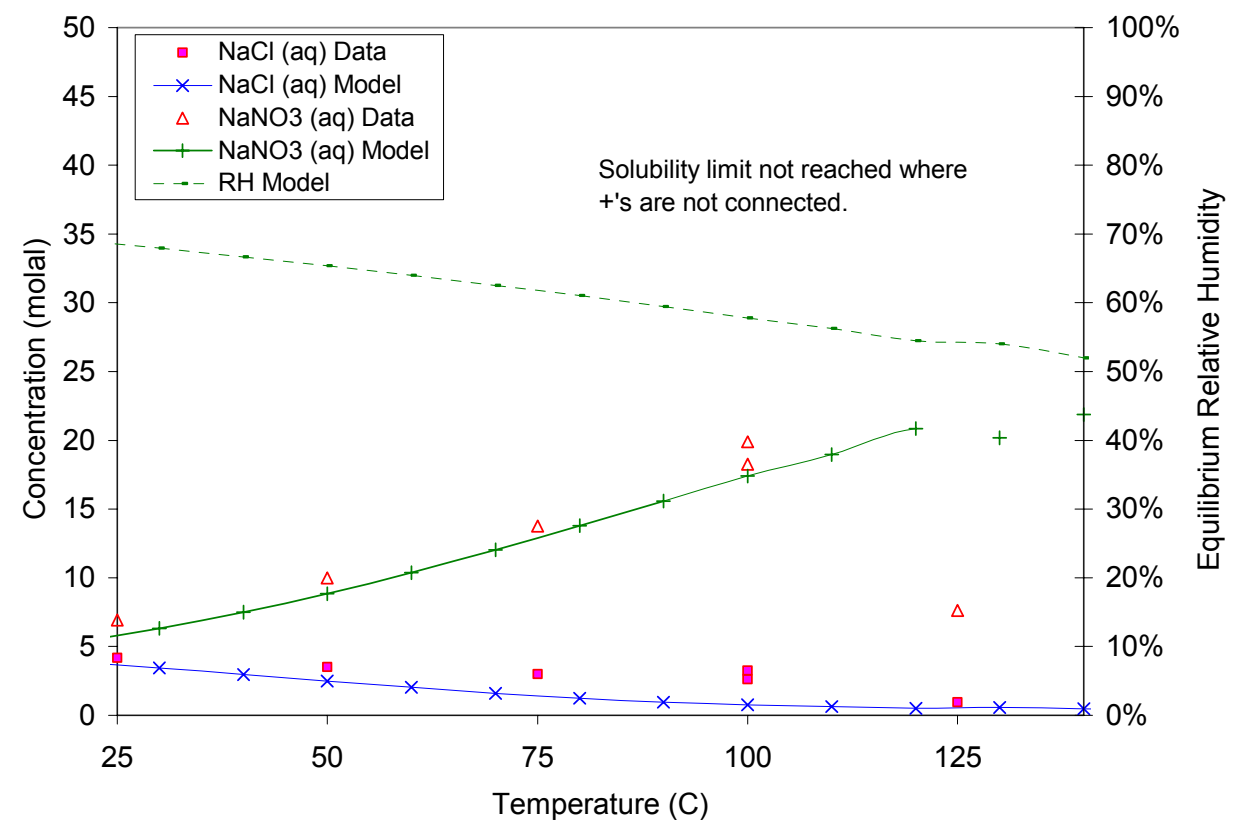

Output DTN: MO0311MWDMVBTS.000.

Figure 7-42. Model Predictions vs. Data for $\mathrm{Na}-\mathrm{Cl}-\mathrm{NO}_{3}$ Eutectic System

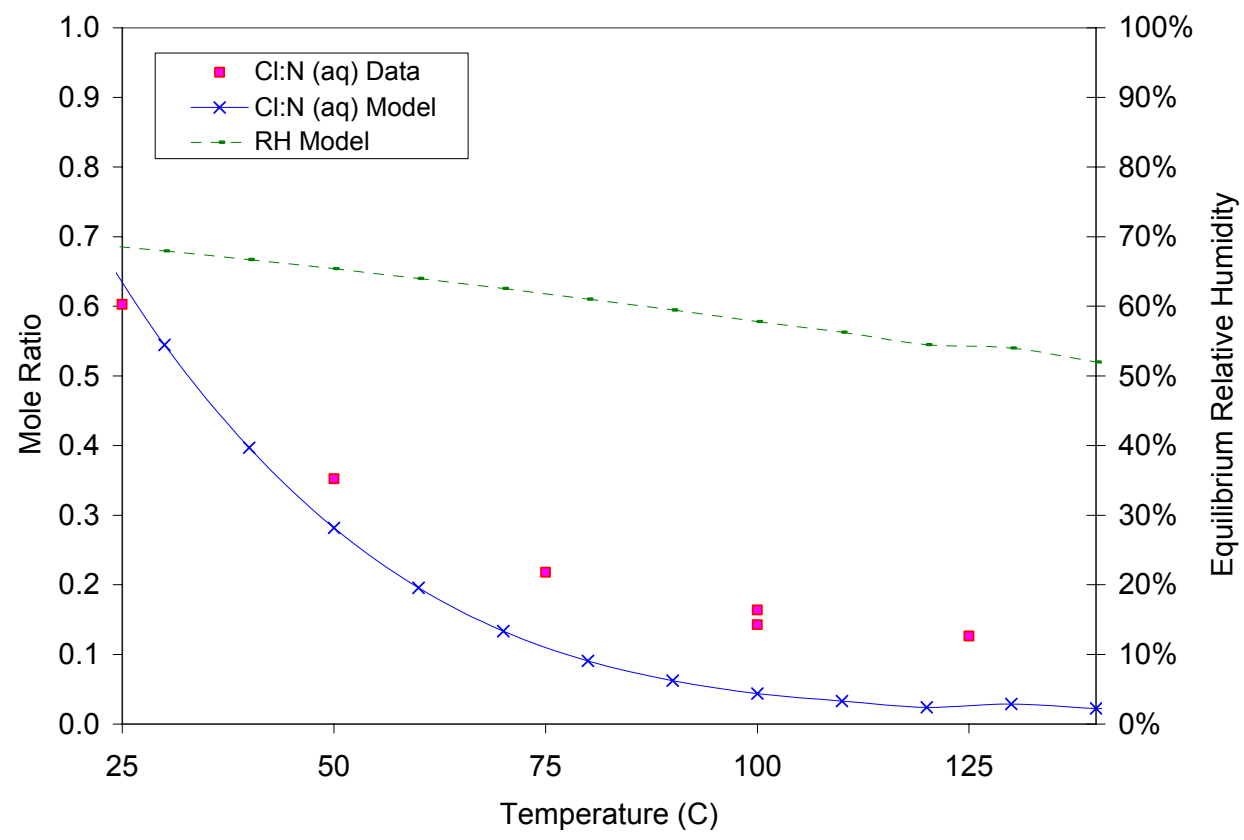

Output DTN: MO0311MWDMVBTS.000.

Figure 7-43. $\mathrm{Cl}: \mathrm{NO}_{3}$ Mole Ratio Predictions vs. Data for $\mathrm{Na}-\mathrm{Cl}-\mathrm{NO}_{3}$ Eutectic System 


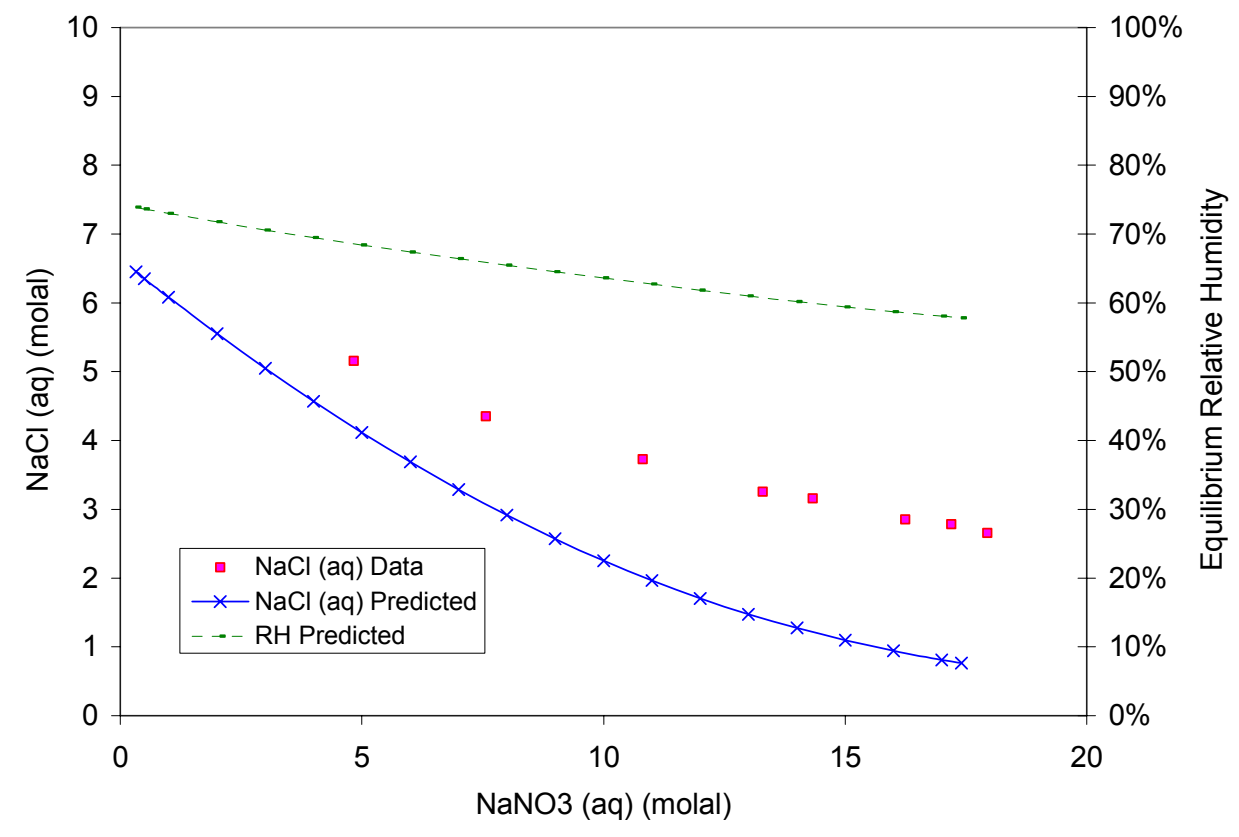

Output DTN: MO0311MWDMVBTS.000.

Figure 7-44. $\mathrm{NaCl}$ Solubility Predictions vs. Data as a Function of $\mathrm{NaNO}_{3}$ Concentration at $100^{\circ} \mathrm{C}$

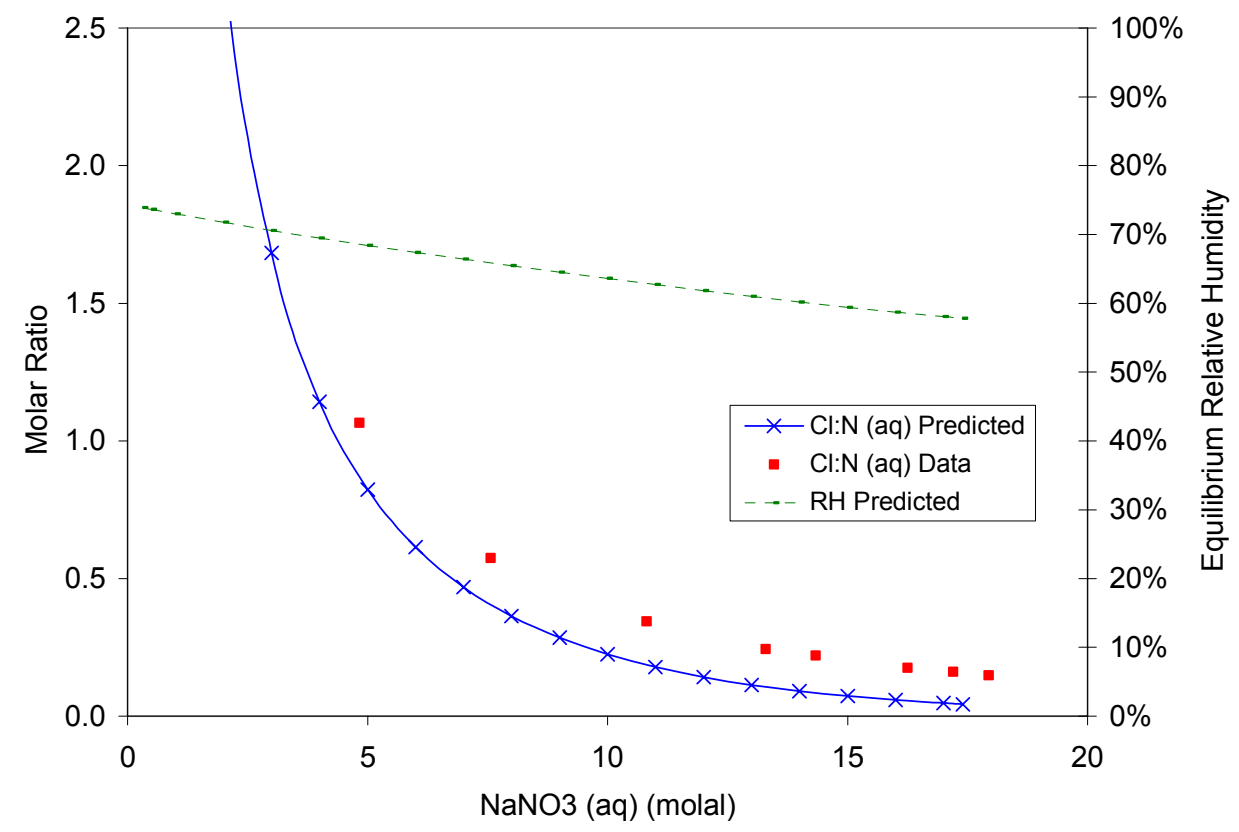

Output DTN: MO0311MWDMVBTS.000.

Figure 7-45. $\mathrm{Cl}: \mathrm{NO}_{3}$ Mole Ratio Predictions at $\mathrm{NaCl}$ Saturation vs. Data as a Function of $\mathrm{NaNO}_{3}$ Concentration at $100^{\circ} \mathrm{C}$ 


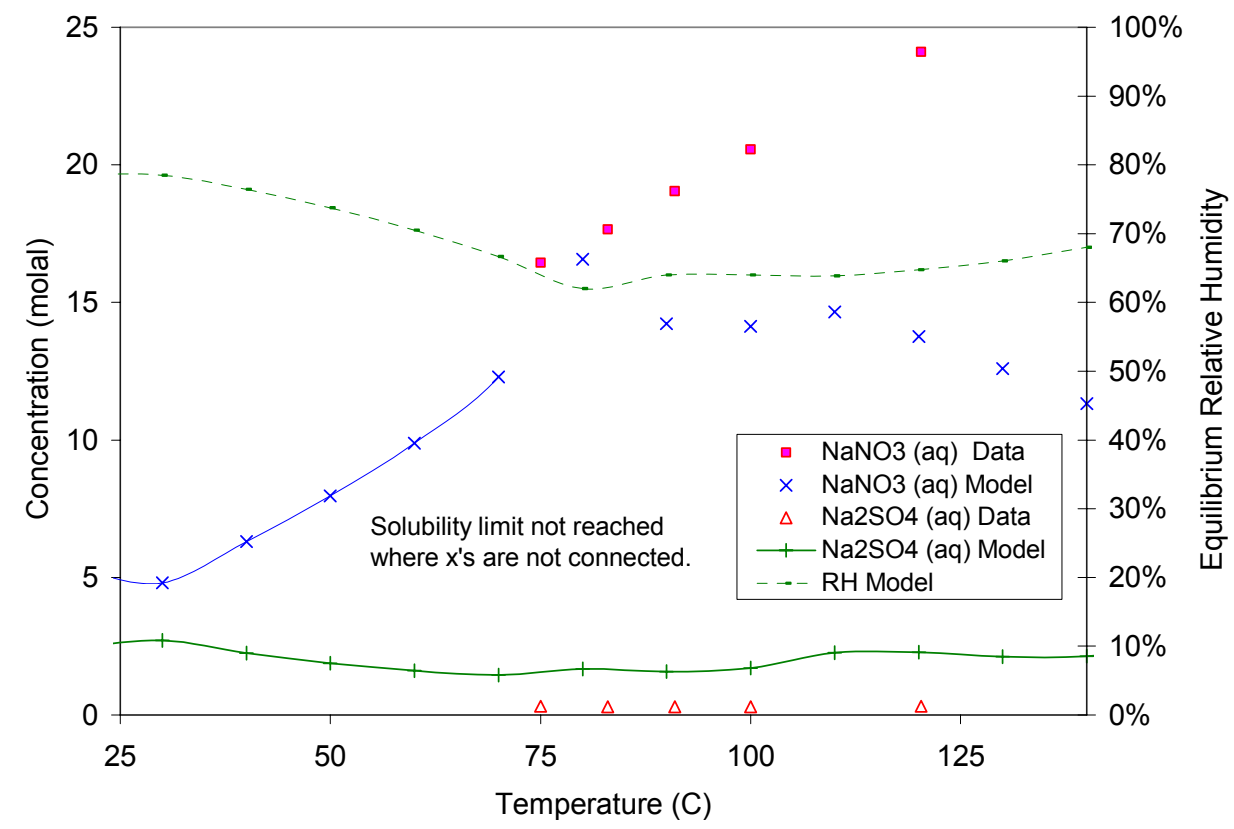

Output DTN: MO0311MWDMVBTS.000.

Figure 7-46. Model Predictions vs. Data for $\mathrm{Na}-\mathrm{NO}_{3}-\mathrm{SO}_{4}$ Eutectic System

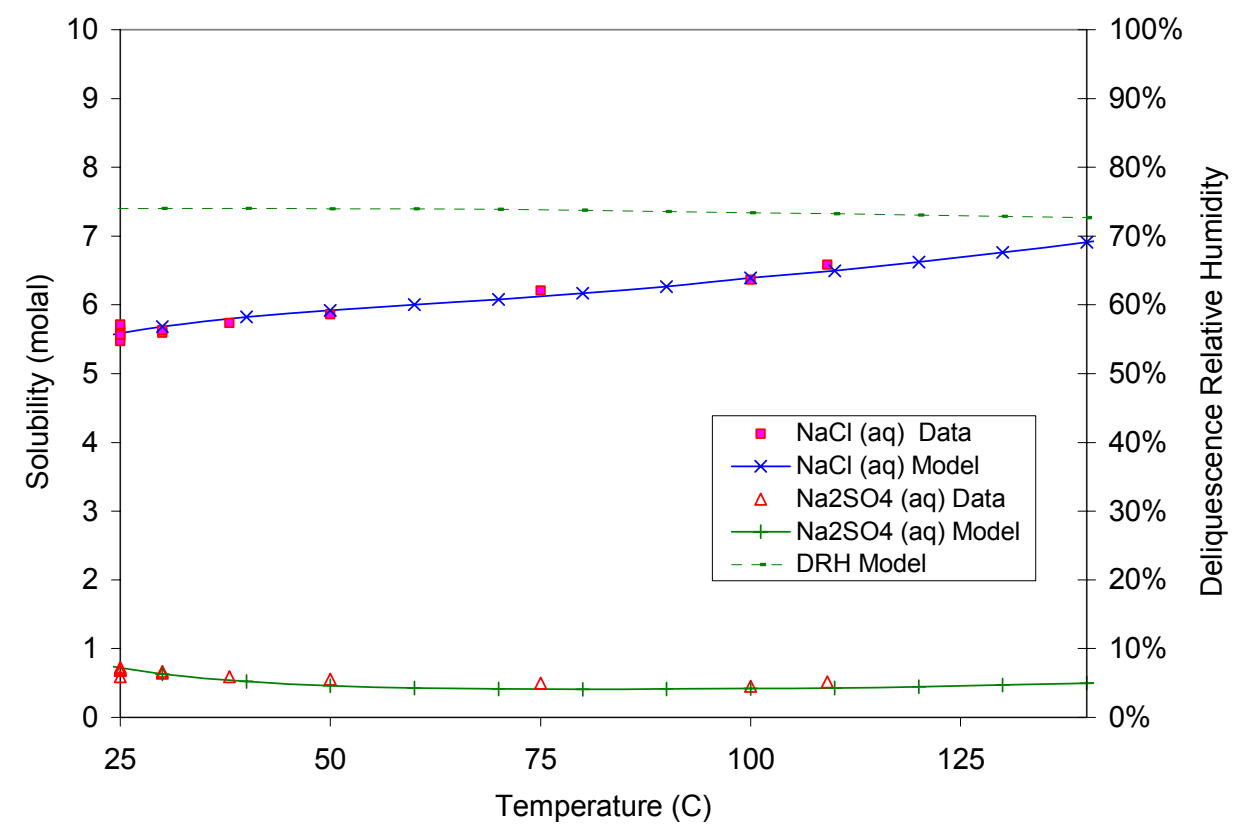

Output DTN: MO0311MWDMVBTS.000.

Figure 7-47. Model Predictions vs. Data for $\mathrm{Na}-\mathrm{Cl}-\mathrm{SO}_{4}$ Eutectic System 


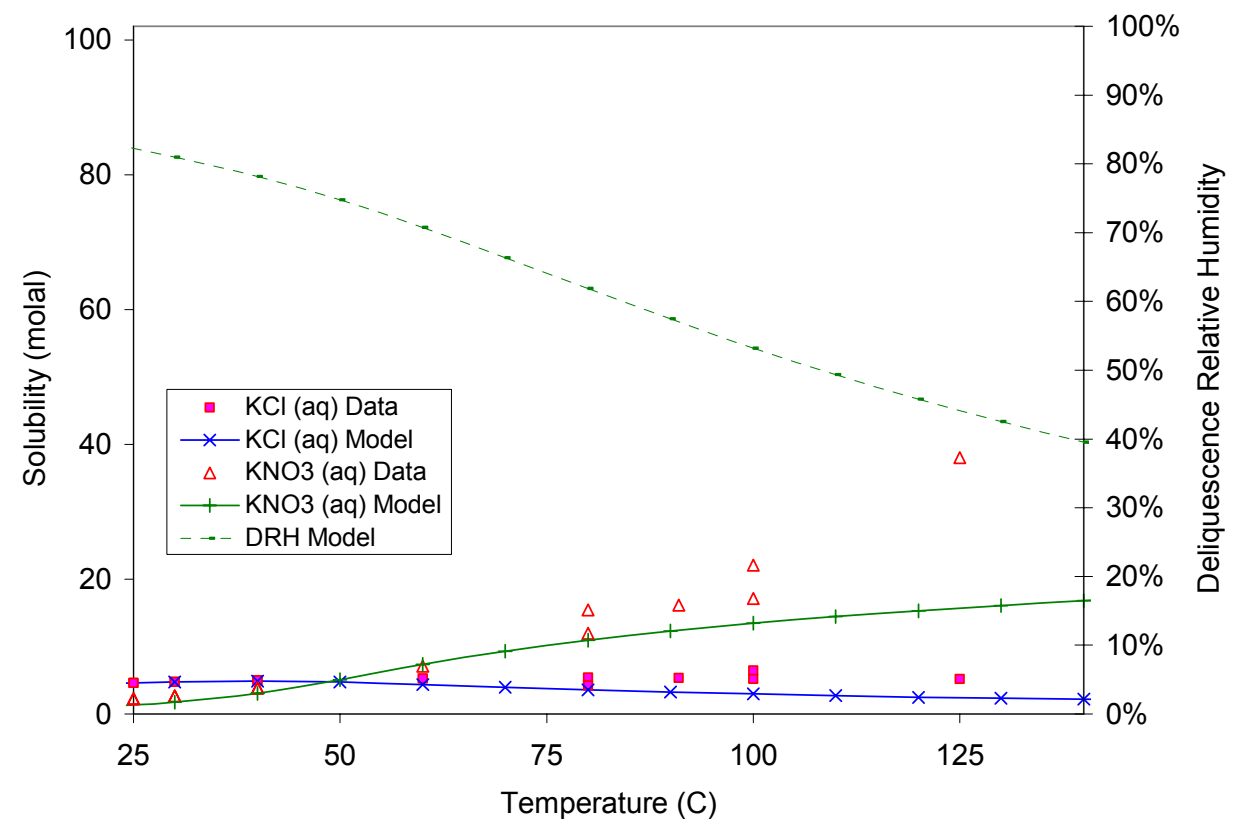

Output DTN: MO0311MWDMVBTS.000.

Figure 7-48. Model Predictions vs. Data for K-Cl-NO $\mathrm{N}_{3}$ Eutectic System

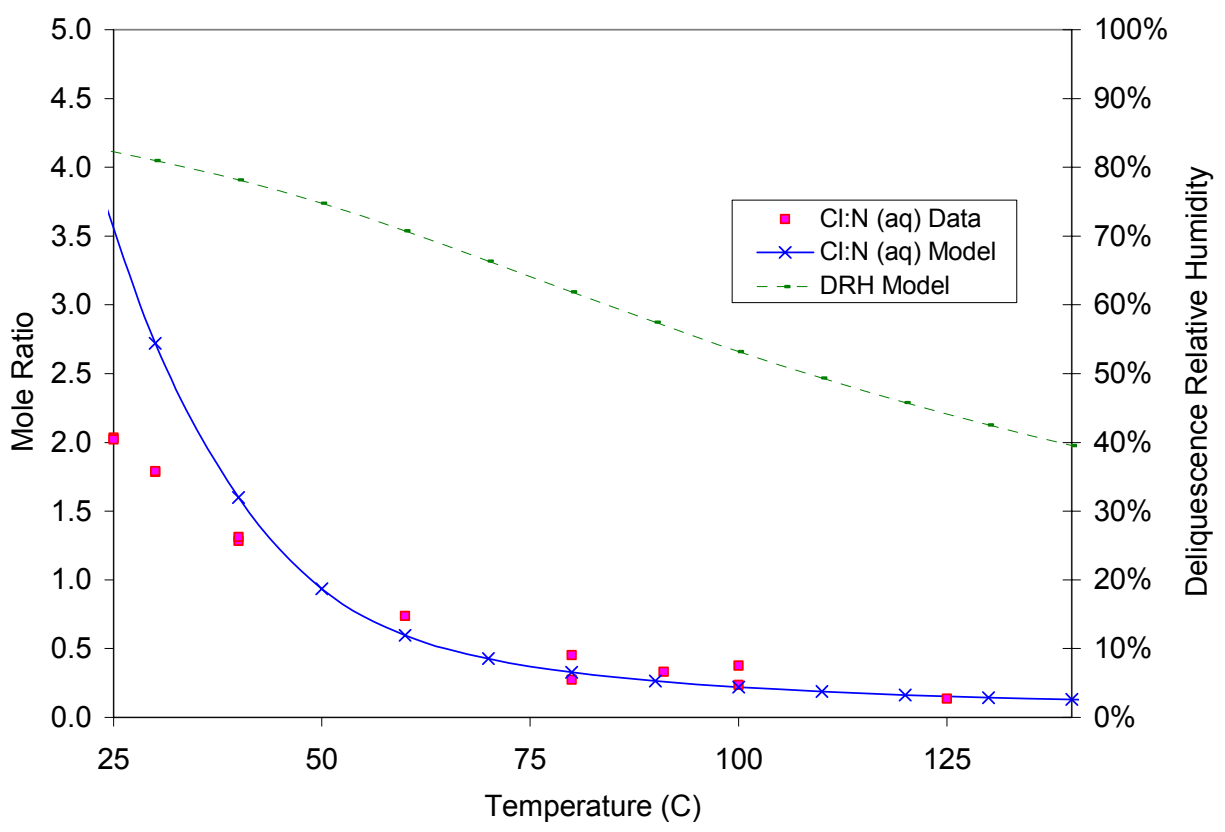

Output DTN: MO0311MWDMVBTS.000.

Figure 7-49. Cl: $\mathrm{NO}_{3}$ Mole Ratio Predictions vs. Data for $\mathrm{Na}-\mathrm{Cl}-\mathrm{NO}_{3}$ Eutectic System 


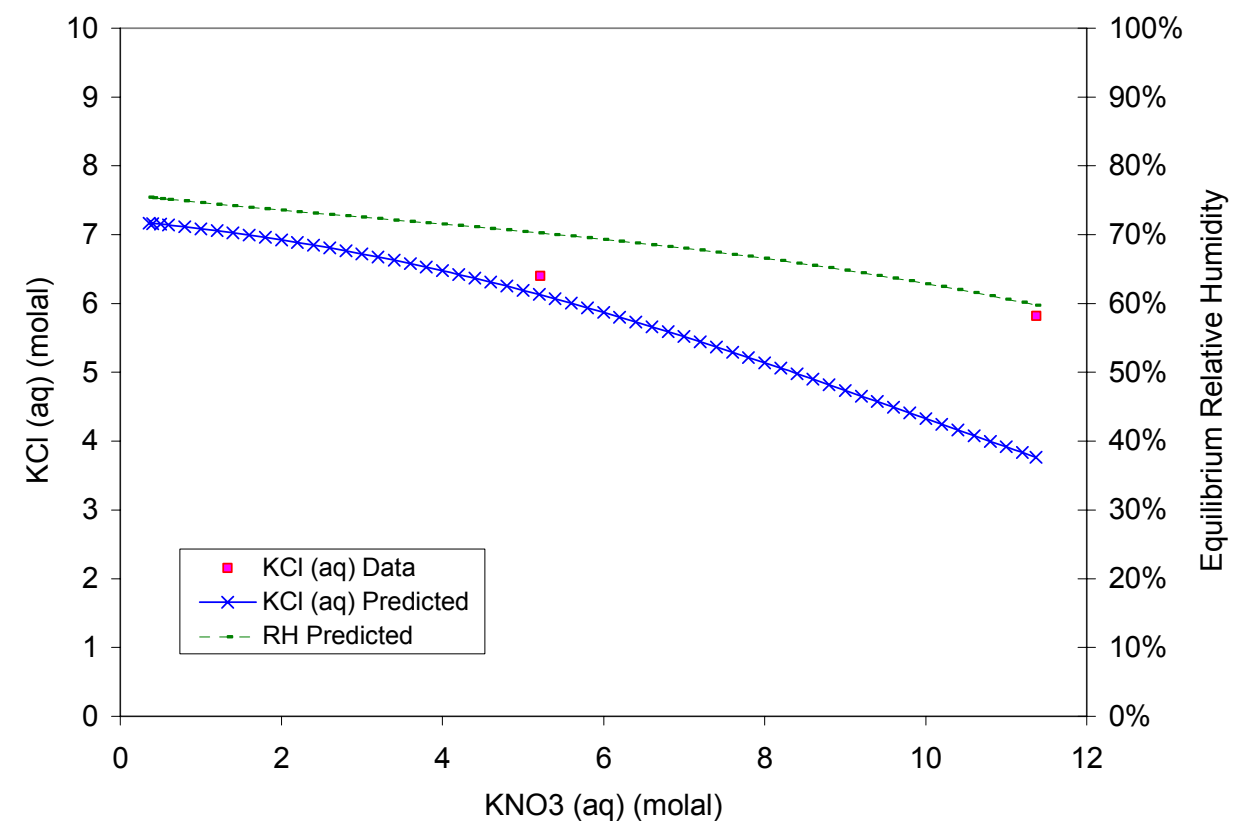

Output DTN: MO0311MWDMVBTS.000.

Figure 7-50. $\mathrm{KCl}$ Solubility Predictions vs. Data as a Function of $\mathrm{KNO}_{3}$ Concentration at $91^{\circ} \mathrm{C}$

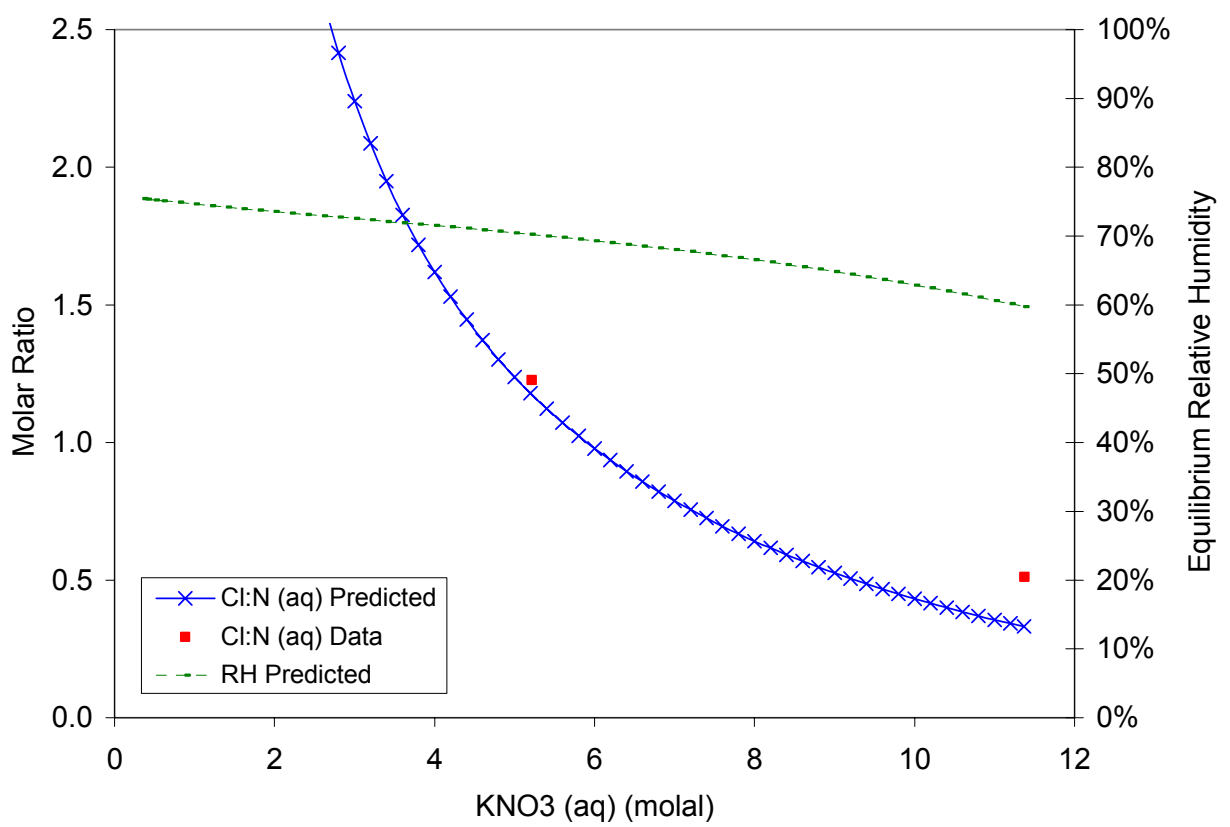

Output DTN: MO0311MWDMVBTS.000.

Figure 7-51. $\mathrm{Cl}: \mathrm{NO}_{3}$ Mole Ratio Predictions at $\mathrm{KCl}$ Saturation vs. Data as a Function of $\mathrm{KNO}_{3}$ Concentration at $91^{\circ} \mathrm{C}$ 


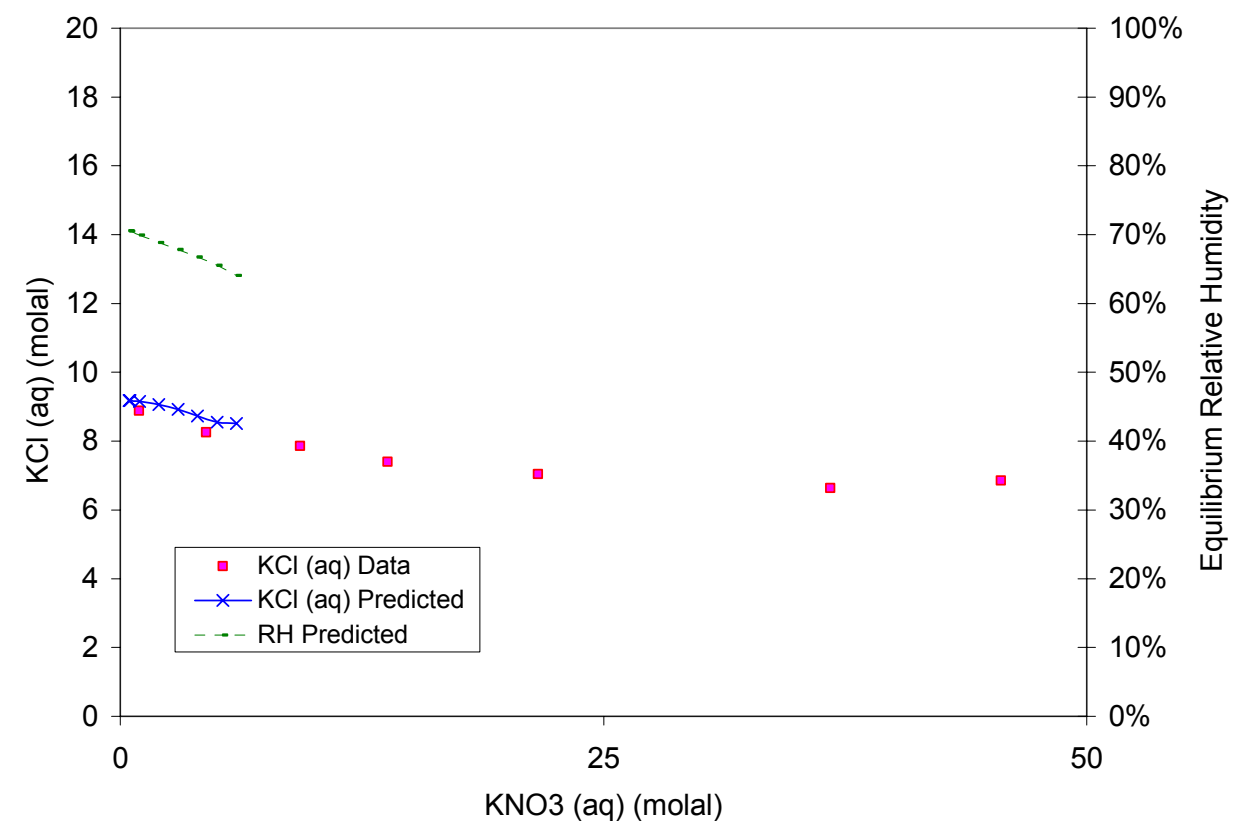

Output DTN: MO0311MWDMVBTS.000.

Figure $7-52 . \mathrm{KCl}$ Solubility Predictions vs. Data as a Function of $\mathrm{KNO}_{3}$ Concentration at $150^{\circ} \mathrm{C}$

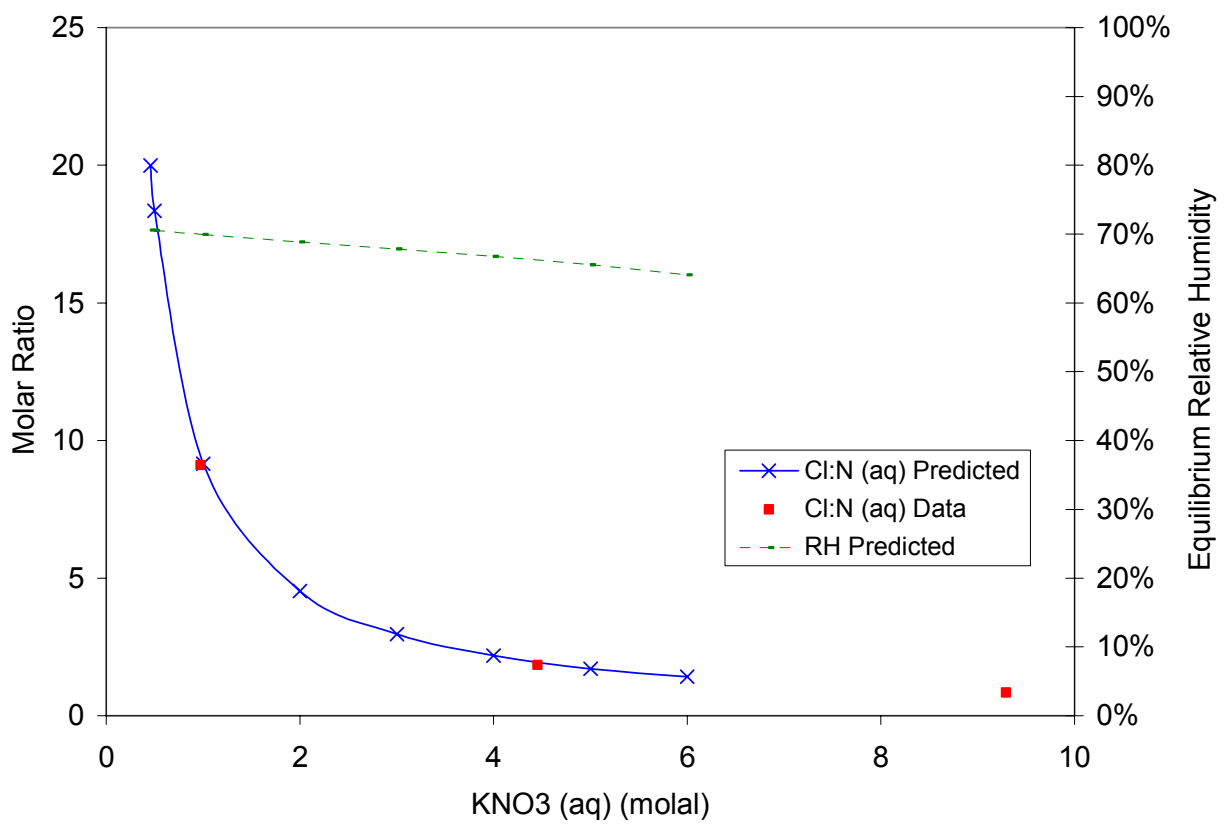

Output DTN: MO0311MWDMVBTS.000.

Figure 7-53. $\mathrm{Cl}: \mathrm{NO}_{3}$ Mole Ratio Predictions at $\mathrm{KCl}$ Saturation vs. Data as a Function of $\mathrm{KNO}_{3}$ Concentration at $150^{\circ} \mathrm{C}$ 


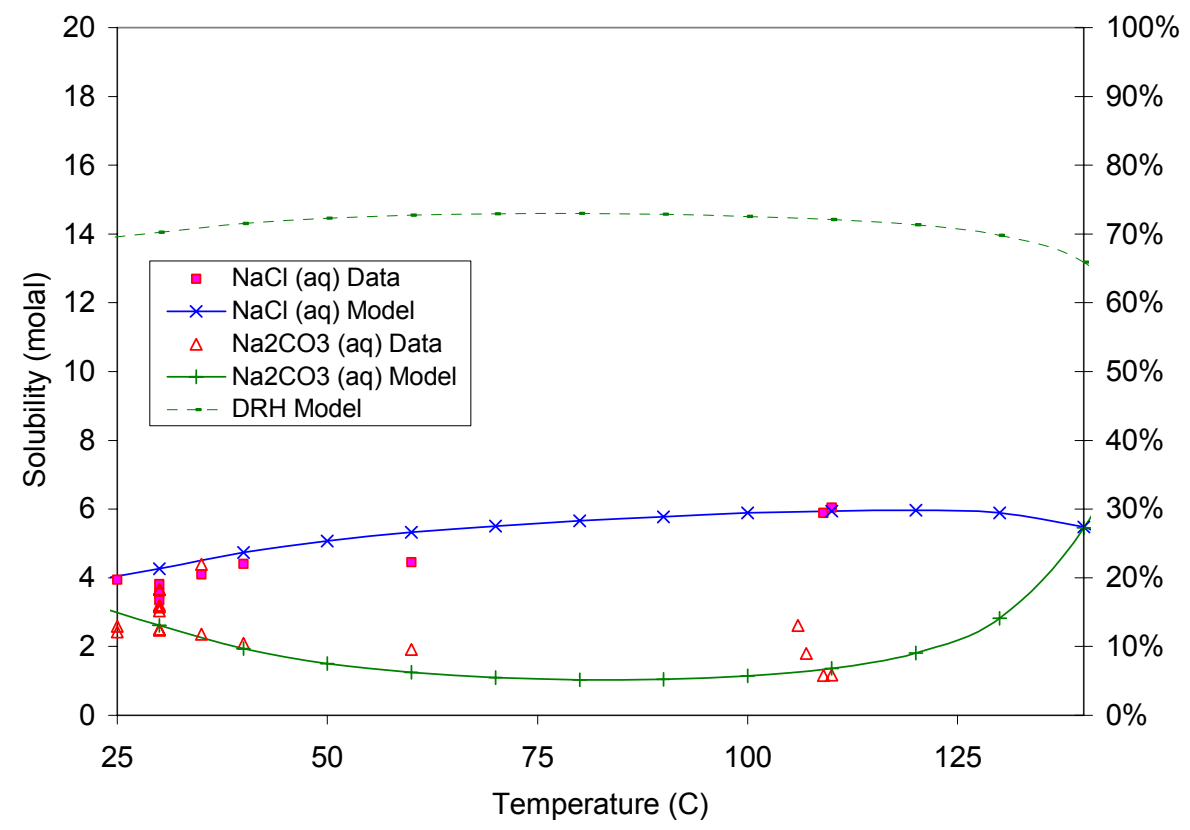

Output DTN: MO0311MWDMVBTS.000.

Figure 7-54. Model Predictions vs. Data for $\mathrm{Na}-\mathrm{Cl}-\mathrm{CO}_{3}$ Eutectic System

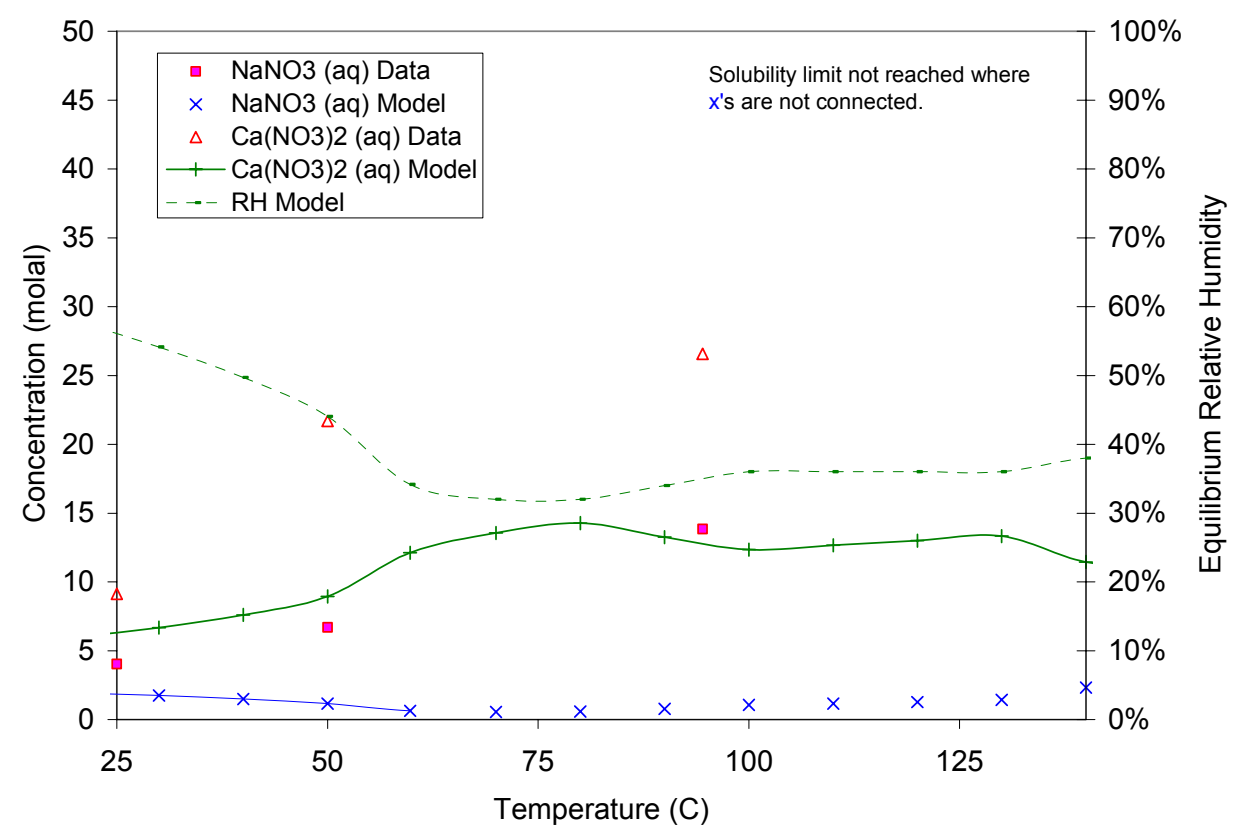

Output DTN: MO0311MWDMVBTS.000.

Figure 7-55. Model Predictions vs. Data for $\mathrm{Na}-\mathrm{Ca}-\mathrm{NO}_{3}$ Eutectic System 


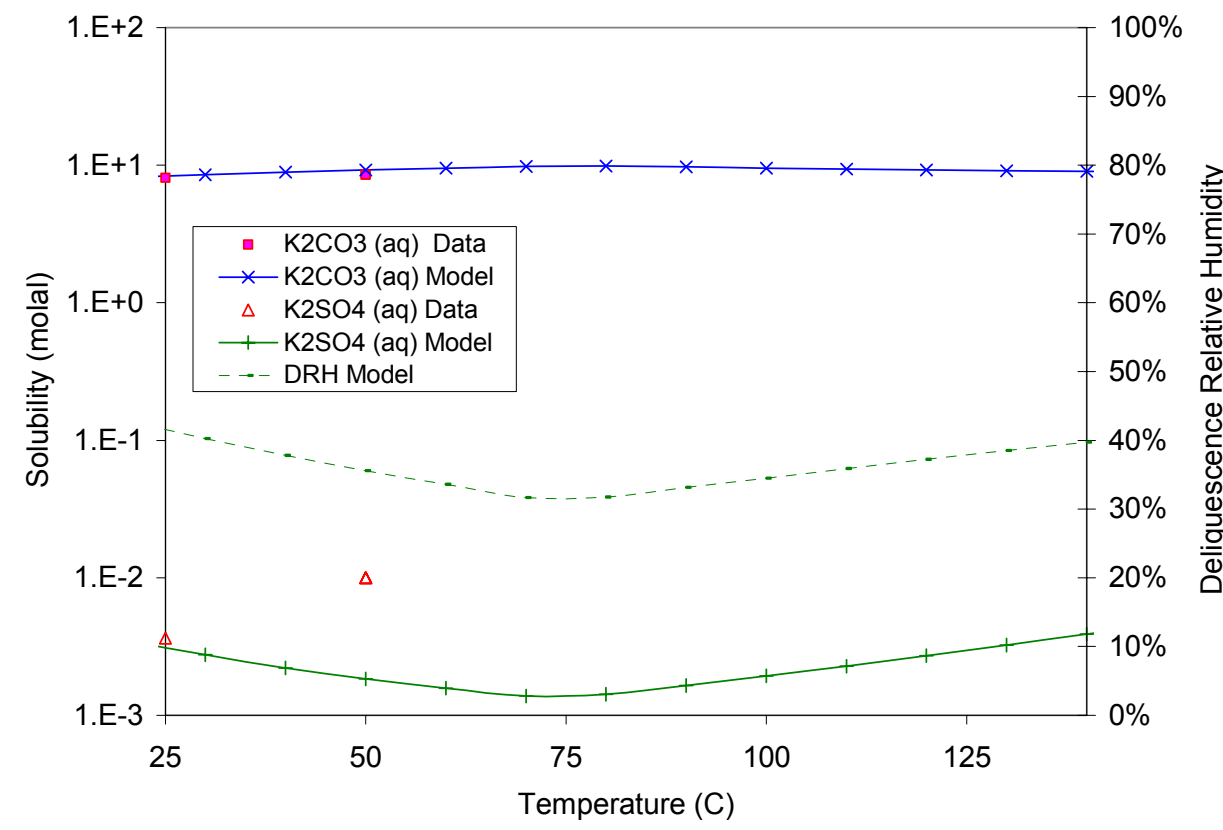

Output DTN: MO0311MWDMVBTS.000.

Figure 7-56. Model Predictions vs. Data for $\mathrm{K}-\mathrm{CO}_{3}-\mathrm{SO}_{4}$ Eutectic System

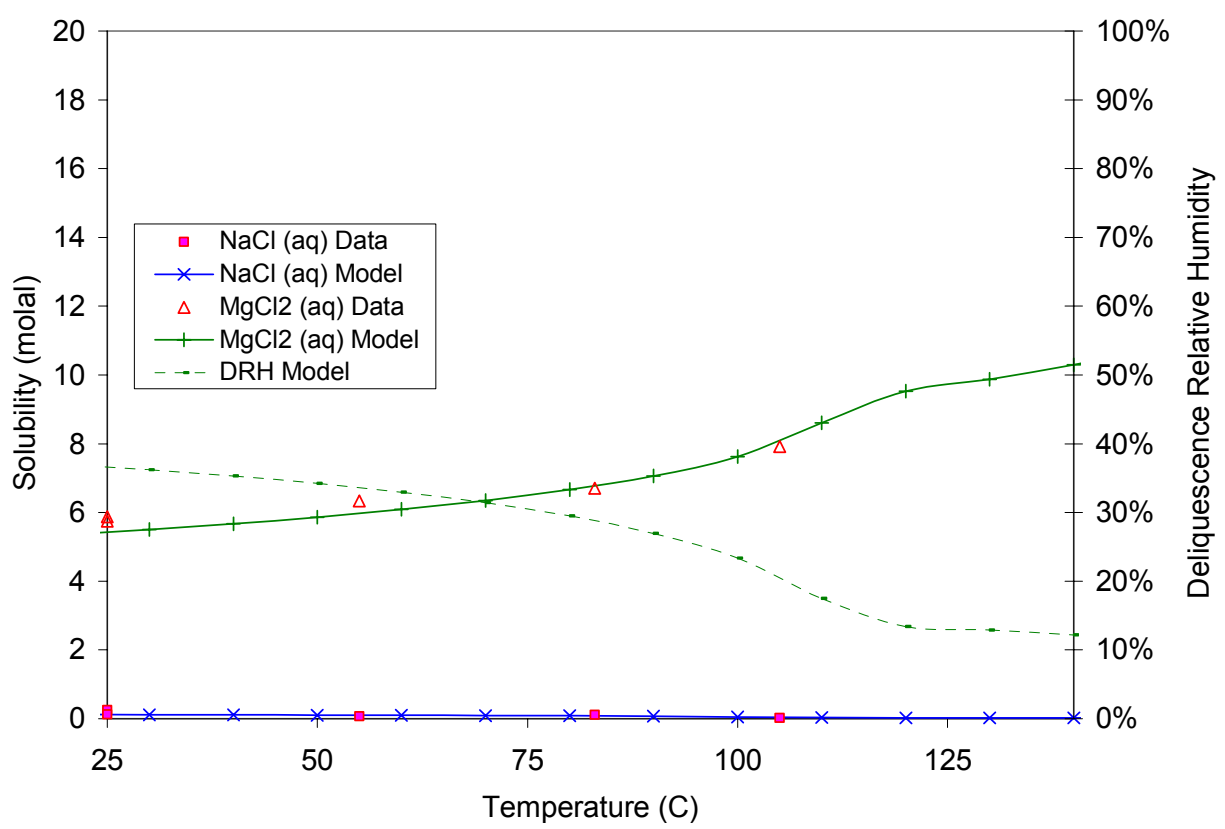

Output DTN: MO0311MWDMVBTS.000.

Figure 7-57. Model Predictions vs. Data for Na-Mg-Cl Eutectic System 


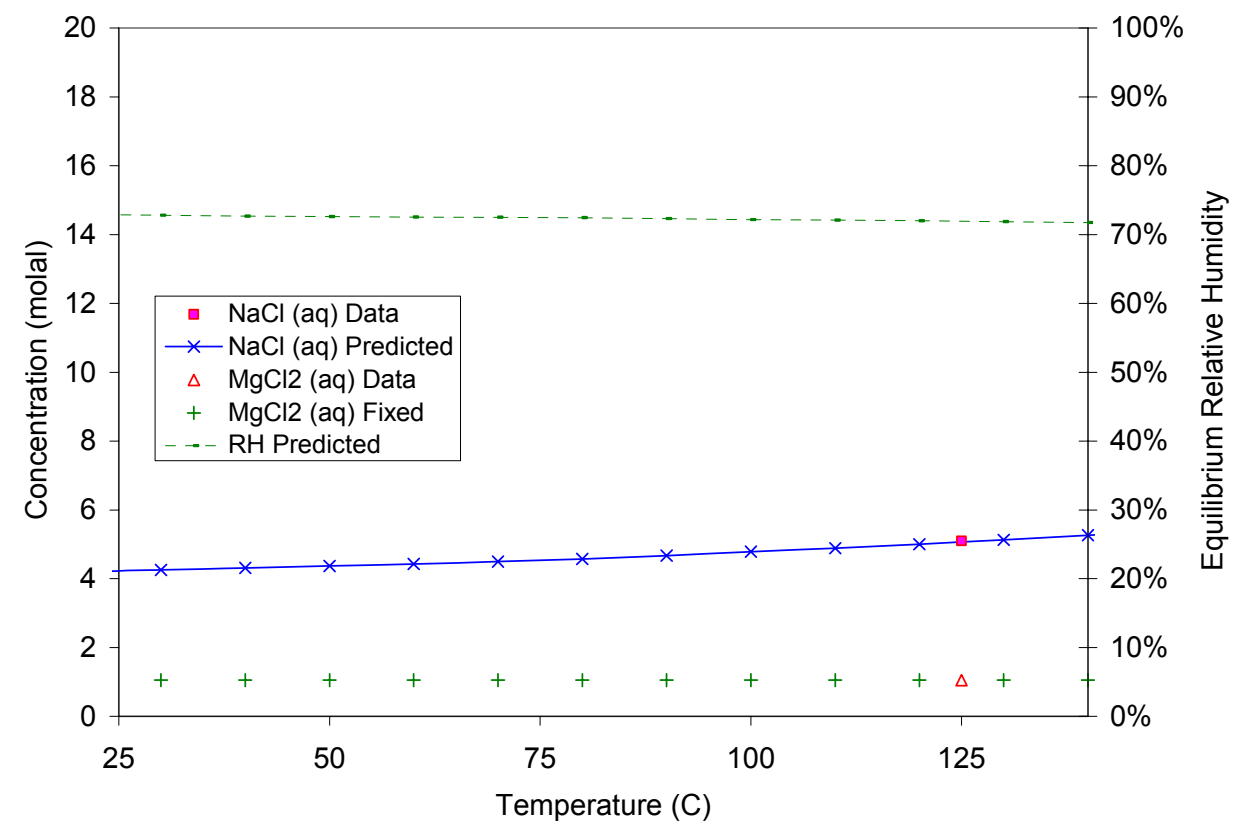

Output DTN: MO0311MWDMVBTS.000.

Figure 7-58. $\mathrm{NaCl}$ Solubility Predictions vs. Data in the Presence of $1.05 \mathrm{Molal} \mathrm{MgCl}_{2}$

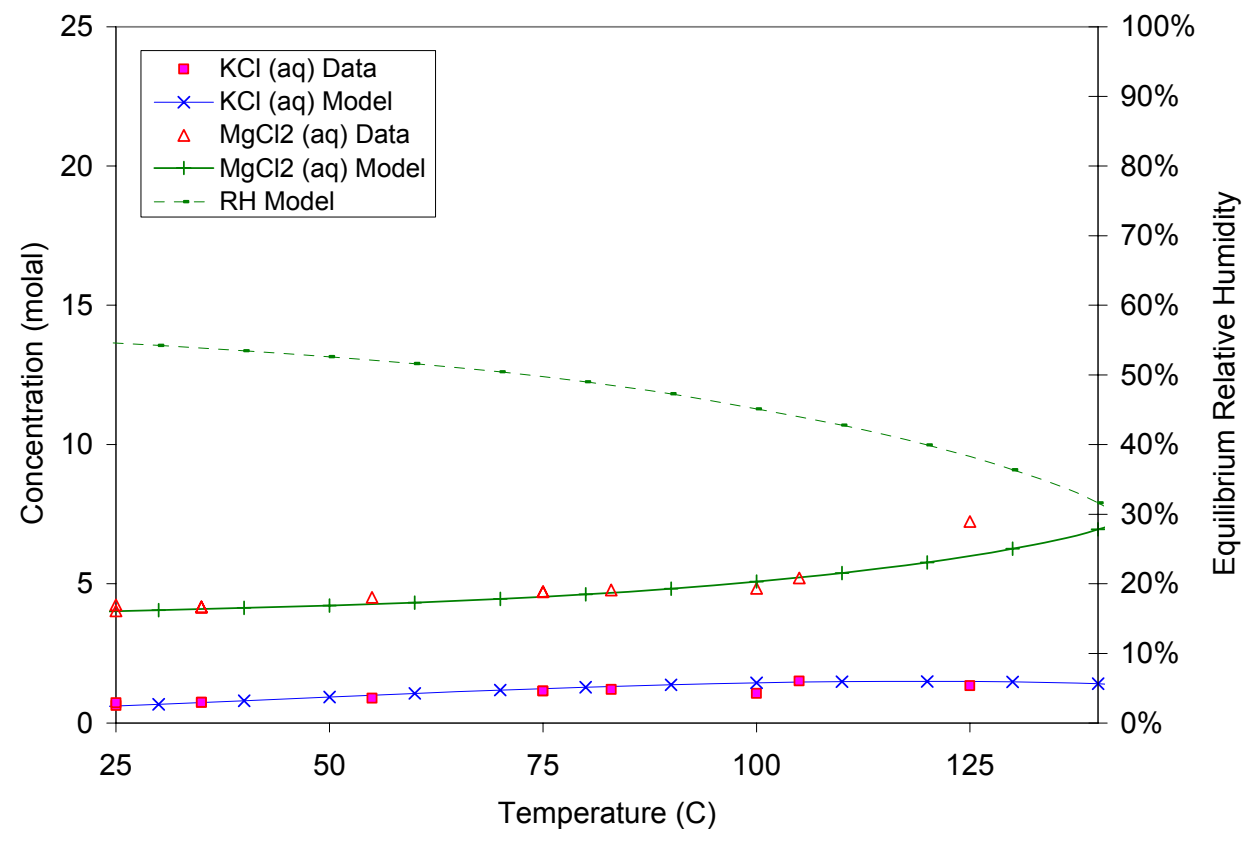

Output DTN: MO0311MWDMVBTS.000.

Figure 7-59. Model Predictions vs. Data for K-Mg-Cl Eutectic System 


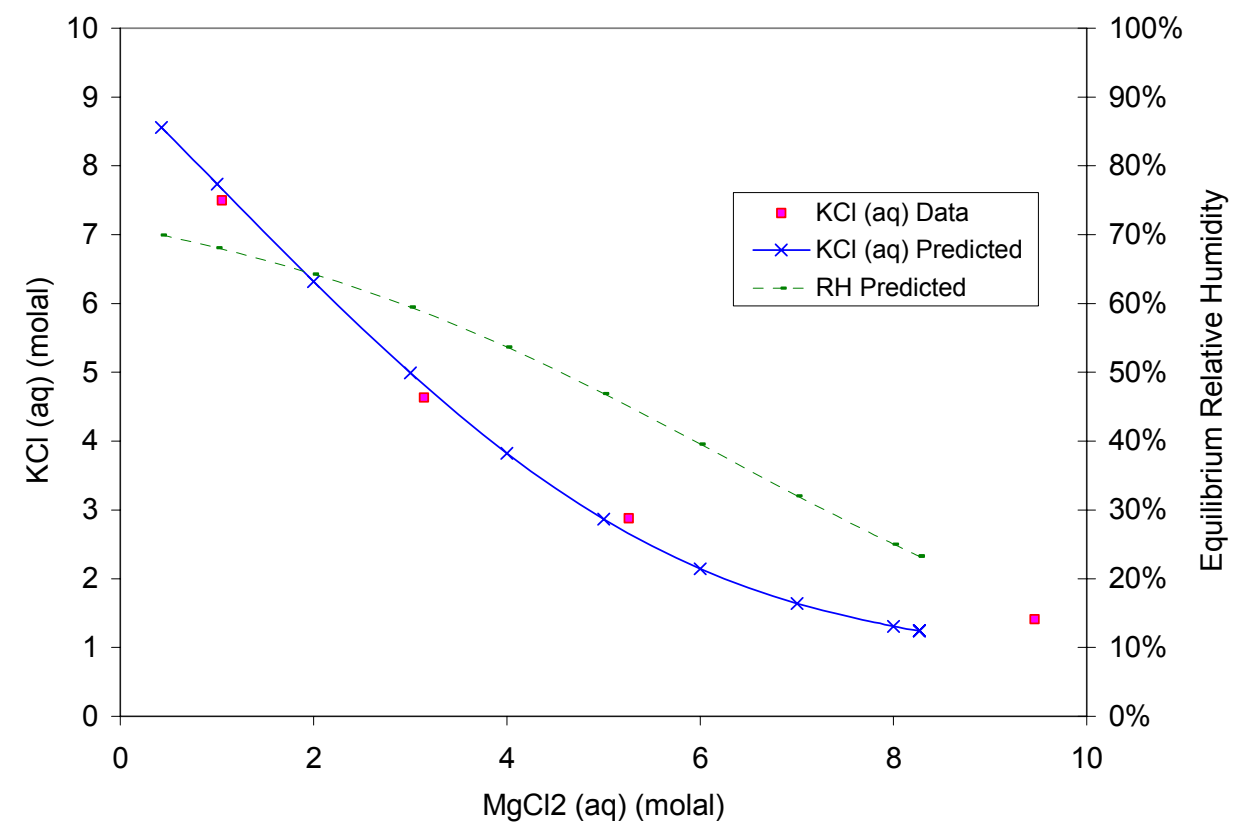

Output DTN: MO0311MWDMVBTS.000.

Figure 7-60. $\mathrm{KCl}$ Solubility Predictions vs. Data as a Function of $\mathrm{MgCl}_{2}$ Concentration at $150^{\circ} \mathrm{C}$

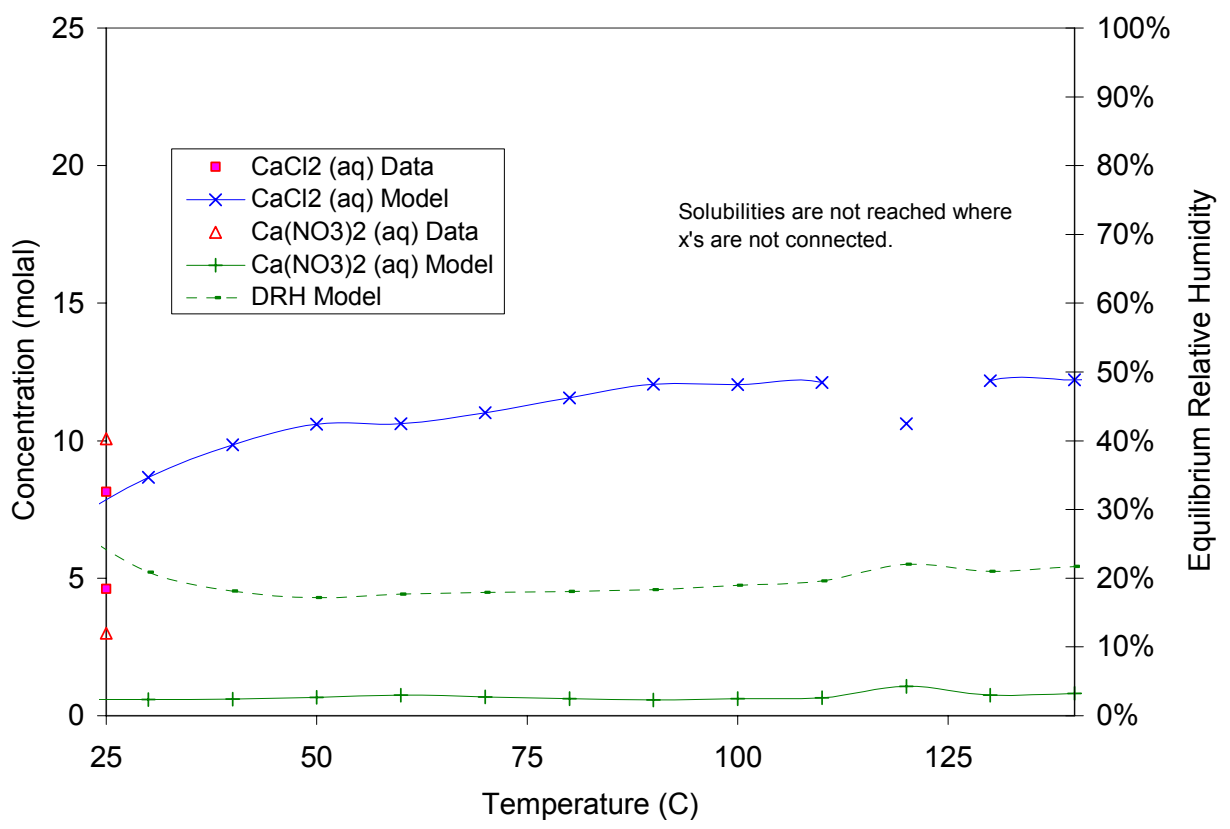

Output DTN: MO0311MWDMVBTS.000.

Figure 7-61. Model Predictions vs. Data for Ca-Cl-NO $\mathrm{N}_{3}$ Eutectic System 


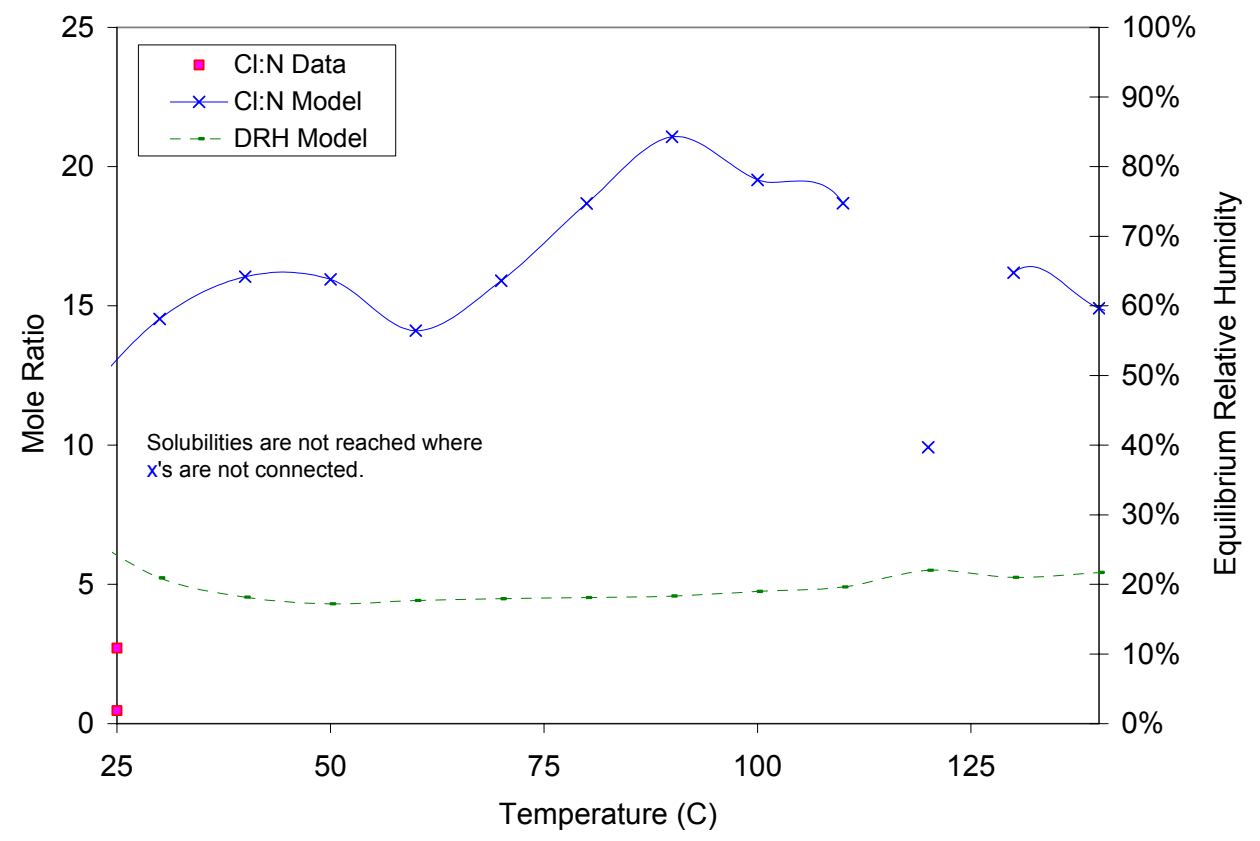

Output DTN: MO0311MWDMVBTS.000.

Figure 7-62. Cl: $\mathrm{NO}_{3}$ Mole Ratio Predictions vs. Data for $\mathrm{Ca}-\mathrm{Cl}-\mathrm{NO}_{3}$ Eutectic System

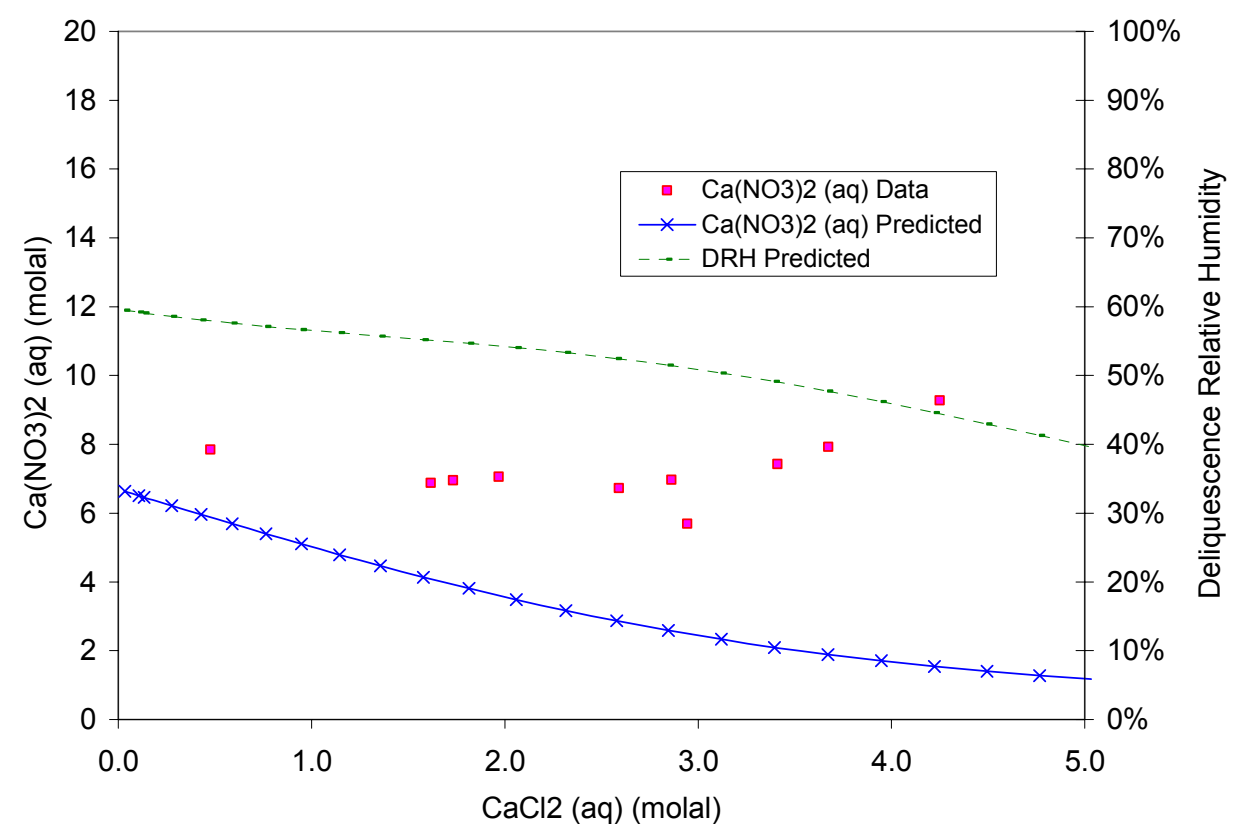

Output DTN: MO0311MWDMVBTS.000.

Figure 7-63. $\mathrm{Ca}\left(\mathrm{NO}_{3}\right)_{2}$ Solubility Predictions vs. Data as a Function of $\mathrm{CaCl}_{2}$ Concentration at $25^{\circ} \mathrm{C}$ 


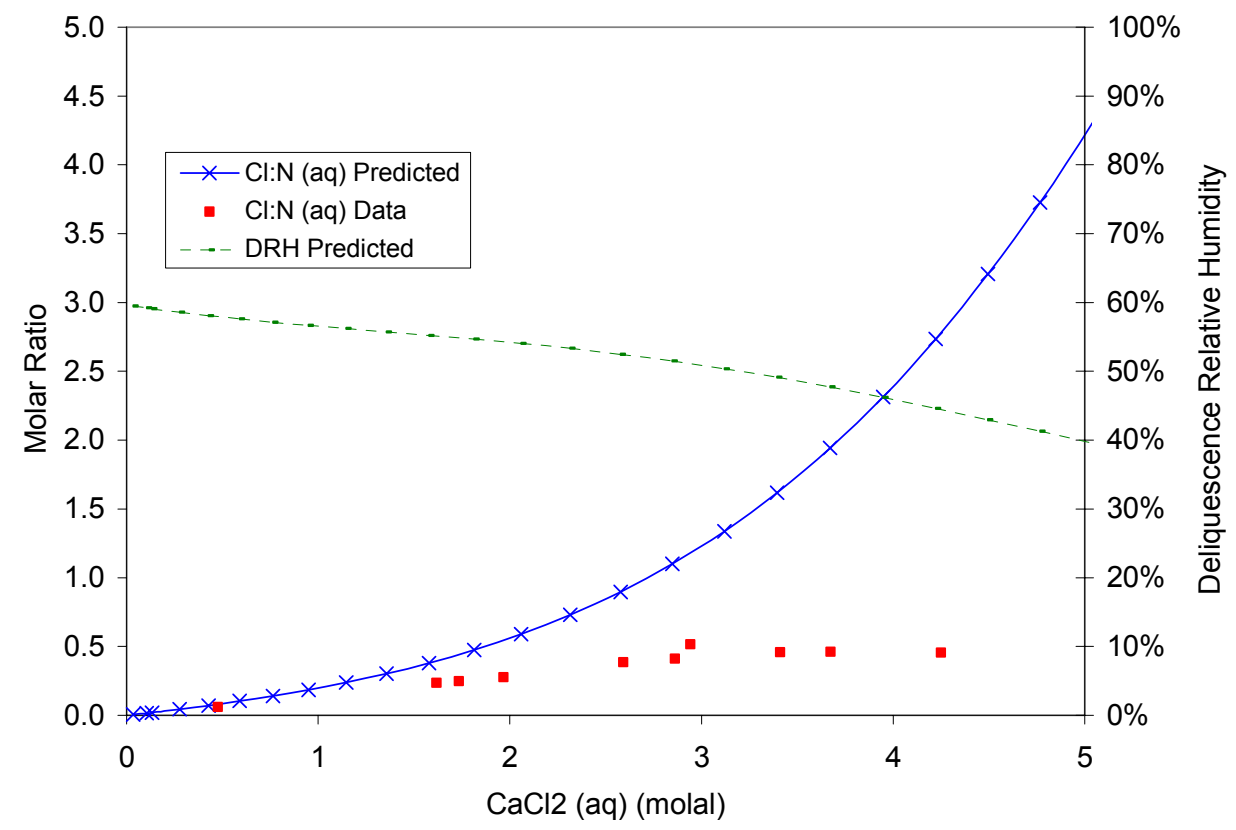

Output DTN: MO0311MWDMVBTS.000.

Figure 7-64. $\mathrm{Cl}: \mathrm{NO}_{3}$ Mole Ratio Predictions at $\mathrm{Ca}\left(\mathrm{NO}_{3}\right)_{2}$ Saturation vs. Data as a Function of $\mathrm{CaCl}_{2}$ Concentration at $25^{\circ} \mathrm{C}$

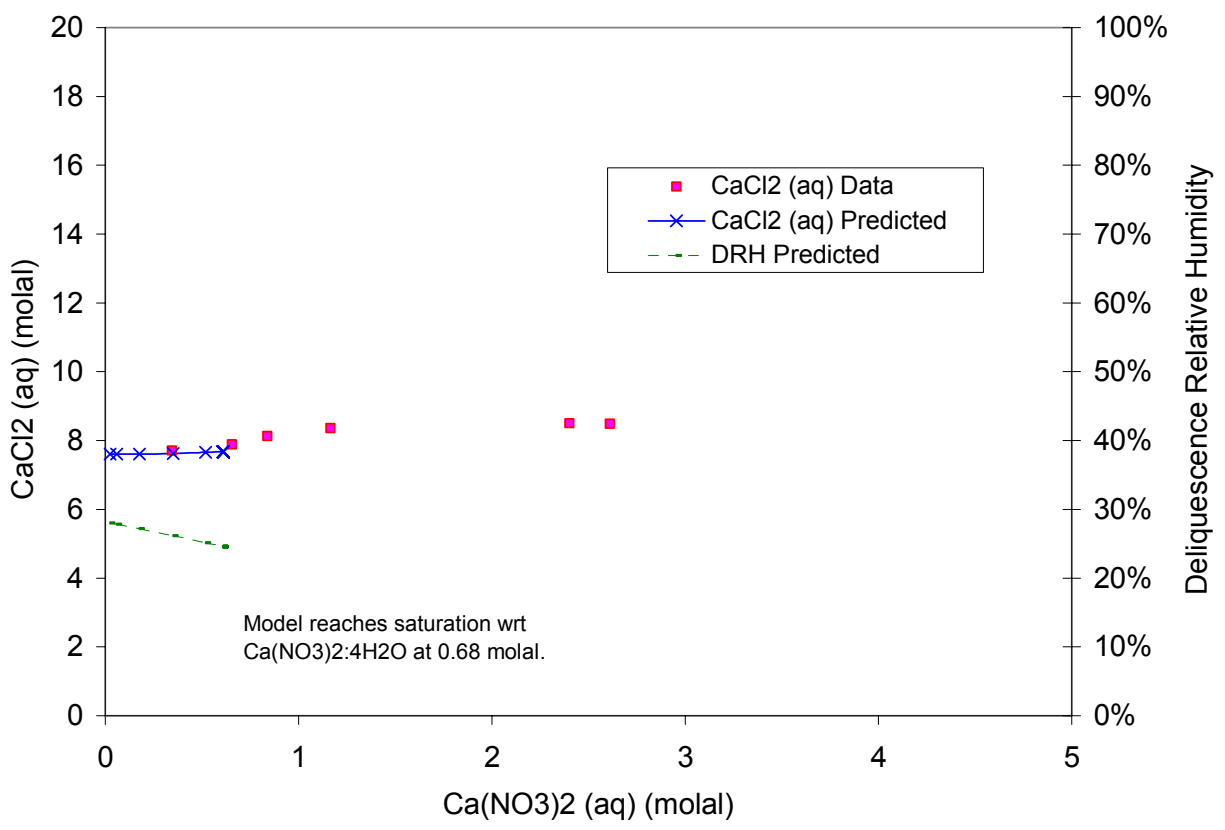

Output DTN: MO0311MWDMVBTS.000.

Figure 7-65. $\mathrm{CaCl}_{2}$ Solubility Predictions vs. Data as a Function of $\mathrm{Ca}\left(\mathrm{NO}_{3}\right)_{2}$ Concentration at $25^{\circ} \mathrm{C}$ 


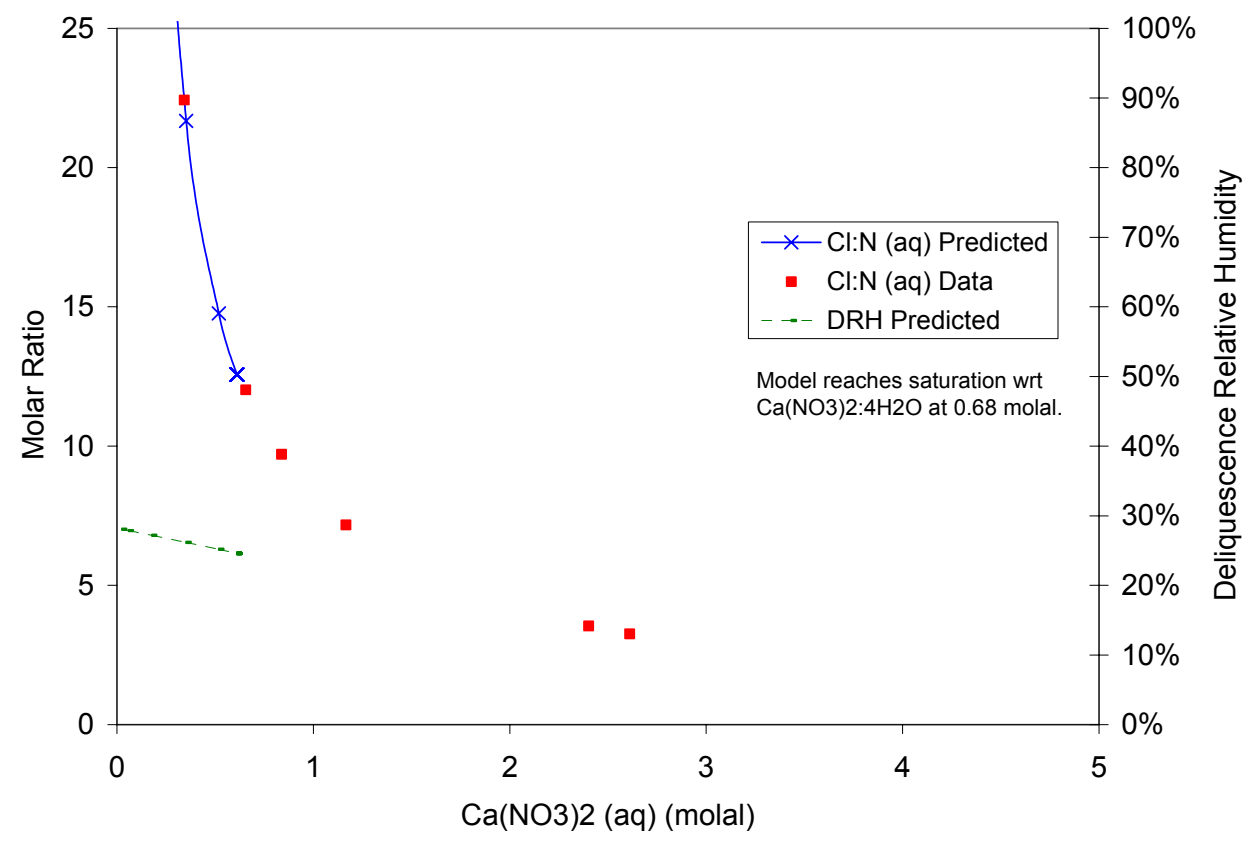

Output DTN: MO0311MWDMVBTS.000.

NOTE: "wrt" is short for "with respect to."

Figure 7-66. $\mathrm{Cl}: \mathrm{NO}_{3}$ Mole Ratio Predictions at $\mathrm{CaCl}_{2}$ Saturation vs. Data as a Function of $\mathrm{Ca}\left(\mathrm{NO}_{3}\right)_{2}$ Concentration at $25^{\circ} \mathrm{C}$

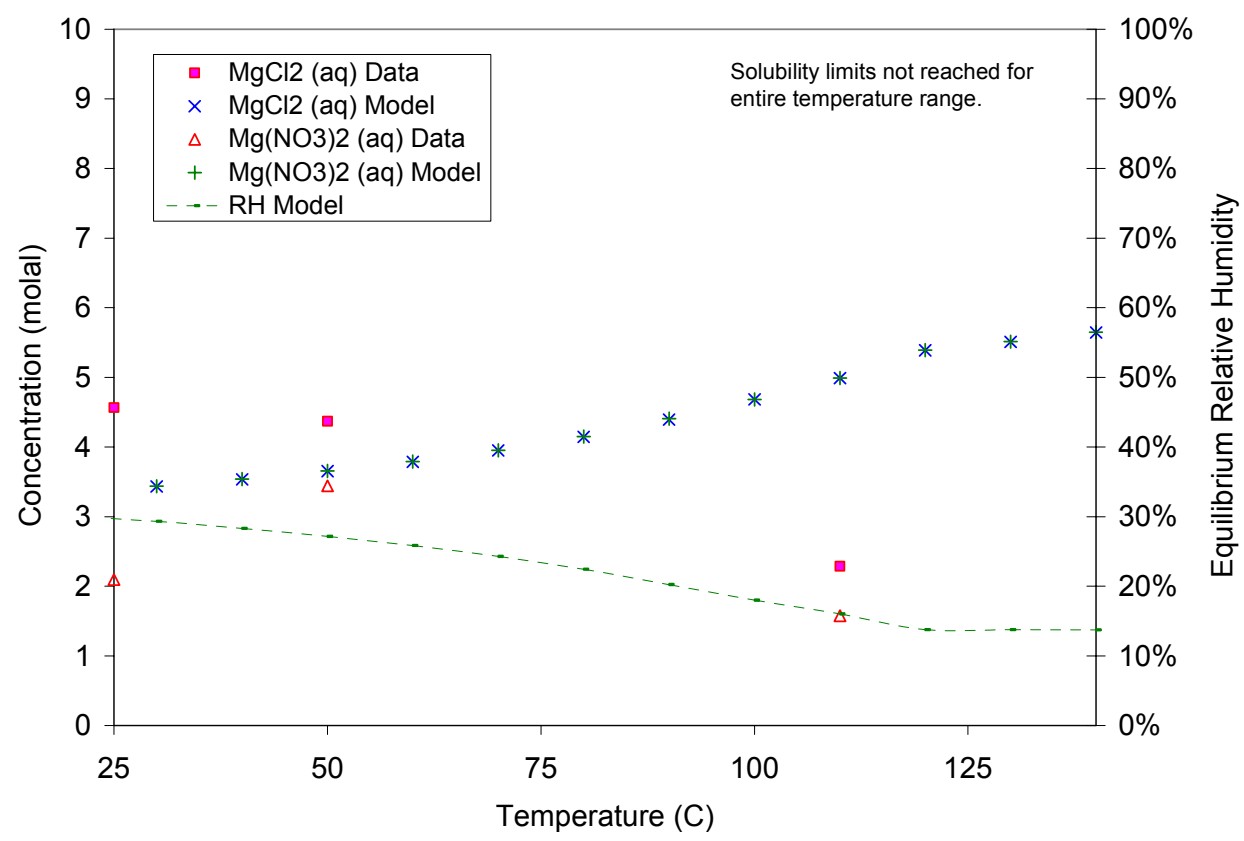

Output DTN: MO0311MWDMVBTS.000.

Figure 7-67. Model Predictions vs. Data for $\mathrm{Mg}-\mathrm{Cl}-\mathrm{NO}_{3}$ Eutectic System 


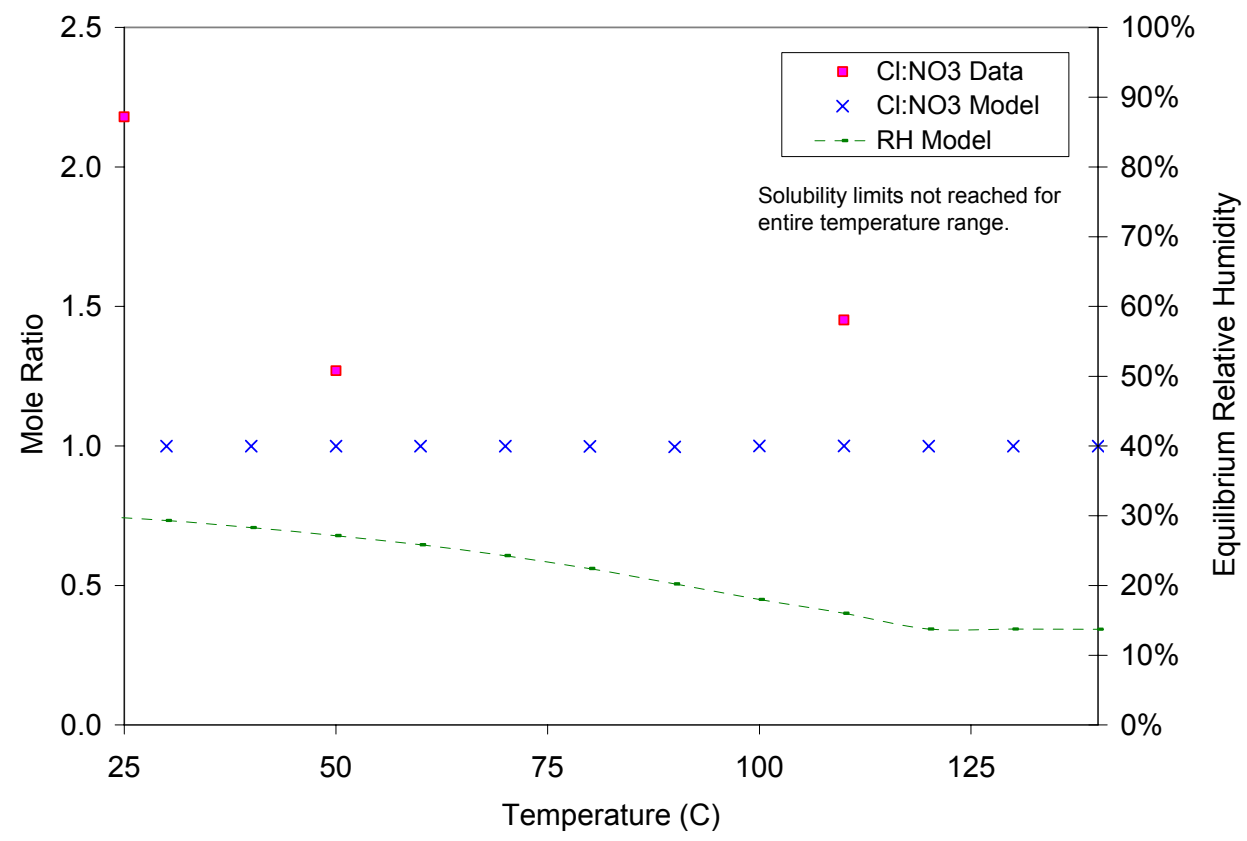

Output DTN: MO0311MWDMVBTS.000.

Figure 7-68. $\mathrm{Cl}: \mathrm{NO}_{3}$ Mole Ratio Predictions vs. Data for $\mathrm{Mg}-\mathrm{Cl}-\mathrm{NO}_{3}$ Eutectic System

\subsection{COMPARISON OF PITZER AND YMP.R2 DATABASE PREDICTIONS}

The model was further validated by comparing model predictions, using the Pitzer database, to those generated using the data0.ymp.R2 thermodynamic database (DTN: MO0302SPATHDYN.000 [DIRS 161756]). The J-13 example water in Section 6.7 was evaporated to an ionic strength of 1 molal using the data0.ymp.R2 database. The B-dot equation option was chosen for calculating the activity coefficients. This option is generally valid for solutions having ionic strength values up to 1 molal (SNL 2003 [DIRS 162494], Section B.2.1).

The results of this comparison are documented in DTN: MO0303MWDINJ13.000. Evaporating this J-13 water to an ionic strength of 1 molal using the data0.ymp.R2 database and B-dot equation results in a concentration factor of about 413 .

Two sets of results were generated using the data0.ymp.R2 database. In the first set, only the minerals in Table 6-3 were suppressed from forming. The results for this set are compared to the Pitzer database predictions in Figure 7-69 and Figure 7-70. Because the data0.ymp.R2 database contains many more minerals than the Pitzer database, two minerals not included in the Pitzer database (tridymite and dolomite-ord) precipitated in this set of results. These minerals are not predicted to form under the conditions of the repository. Tridymite is only stable at temperatures between $870^{\circ} \mathrm{C}$ and $1470^{\circ} \mathrm{C}$ at atmospheric pressure (Klein and Hurlbut 1999 [DIRS 124293], p. 530), and dolomite formation is slow (Vaniman et al. 1992 [DIRS 107066]). Despite these differences in the predicted mineral precipitation, the comparisons in Figure 7-69 and Figure 7-70 show strong agreement between the two databases in the values of the aqueous output parameters. 
In the second set of data0.ymp.R2 results, only the minerals that precipitated in the Pitzer results (calcite, amorphous silica, and sepiolite) were allowed to precipitate. The results for this set are compared to the Pitzer database predictions in Figure 7-71 and Figure 7-72. Except for Si, these results are almost identical to the Pitzer results.

These simulations demonstrate that the IDPS model produces similar aqueous output (up to an ionic strength of 1 molal) regardless of whether the Pitzer database or the data0.ymp.R2 database is used. As a result, the calculations for each aqueous output parameter in this example fall within model validation specifications.

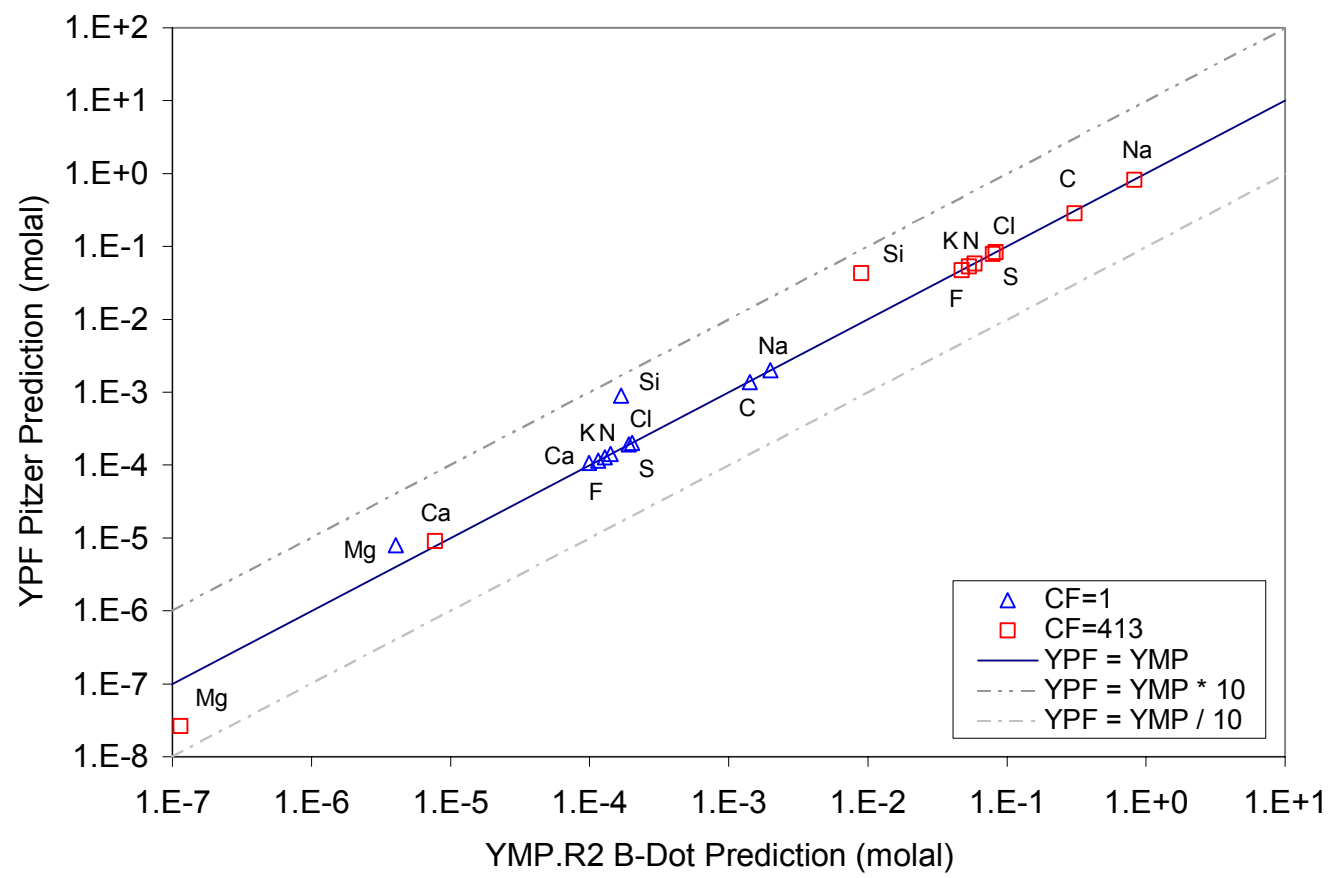

Output DTN: MO0303MWDINJ13.000.

Figure 7-69. Pitzer vs. Set 1 data0.ymp.R2 (YMP.R2) Aqueous Predictions for Average In Situ J-13 Well Water at $70^{\circ} \mathrm{C}$ and $\mathrm{CO}_{2}(\mathrm{~g})$ Fugacity of $10^{-3}$ Bars 


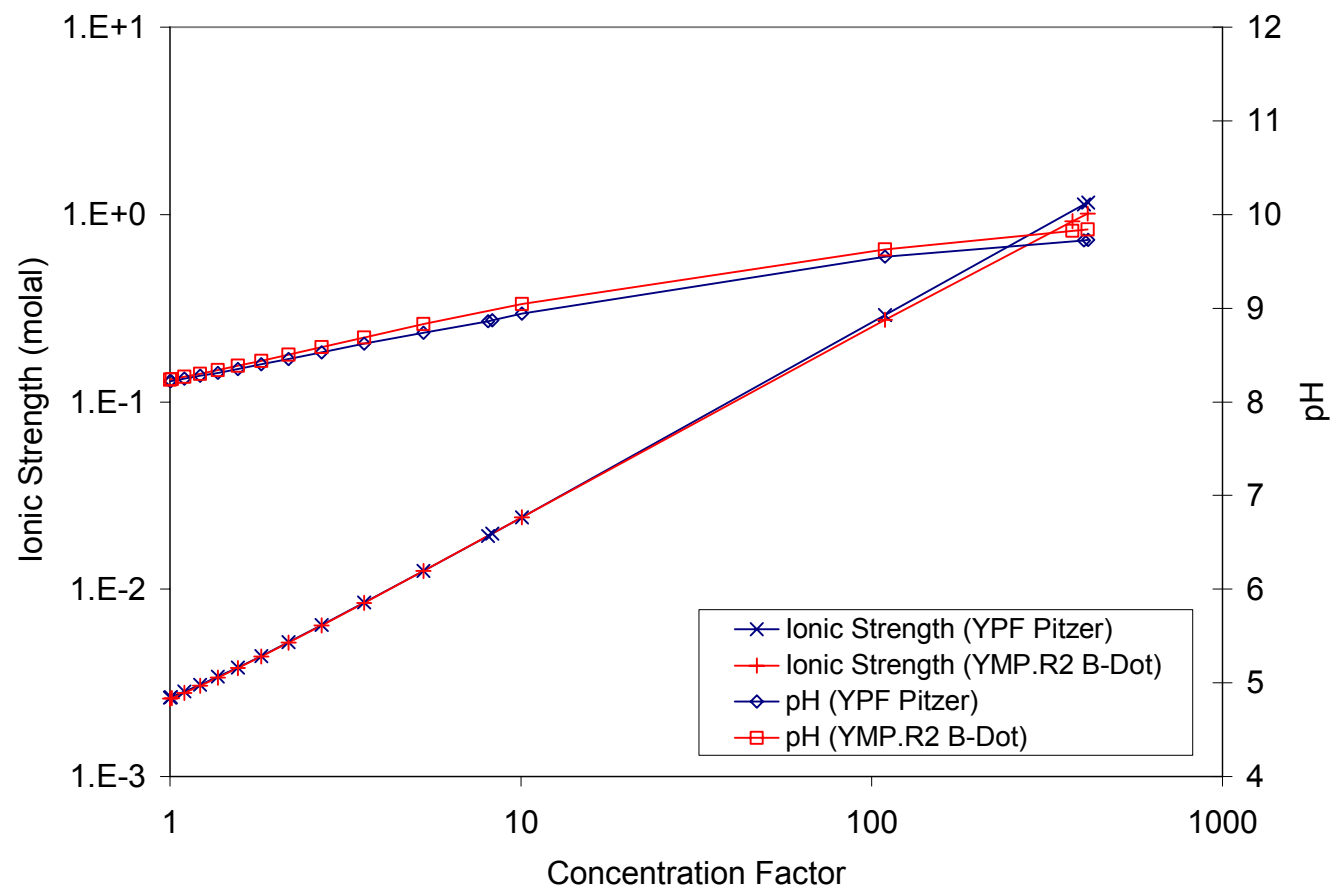

Output DTN: MO0303MWDINJ13.000.

Figure 7-70. Pitzer vs. Set 1 data0.ymp.R2 (YMP.R2) pH and lonic Strength Predictions for Average In Situ J-13 Well Water at $70^{\circ} \mathrm{C}$ and $\mathrm{CO}_{2}(\mathrm{~g})$ Fugacity of $10^{-3}$ Bars

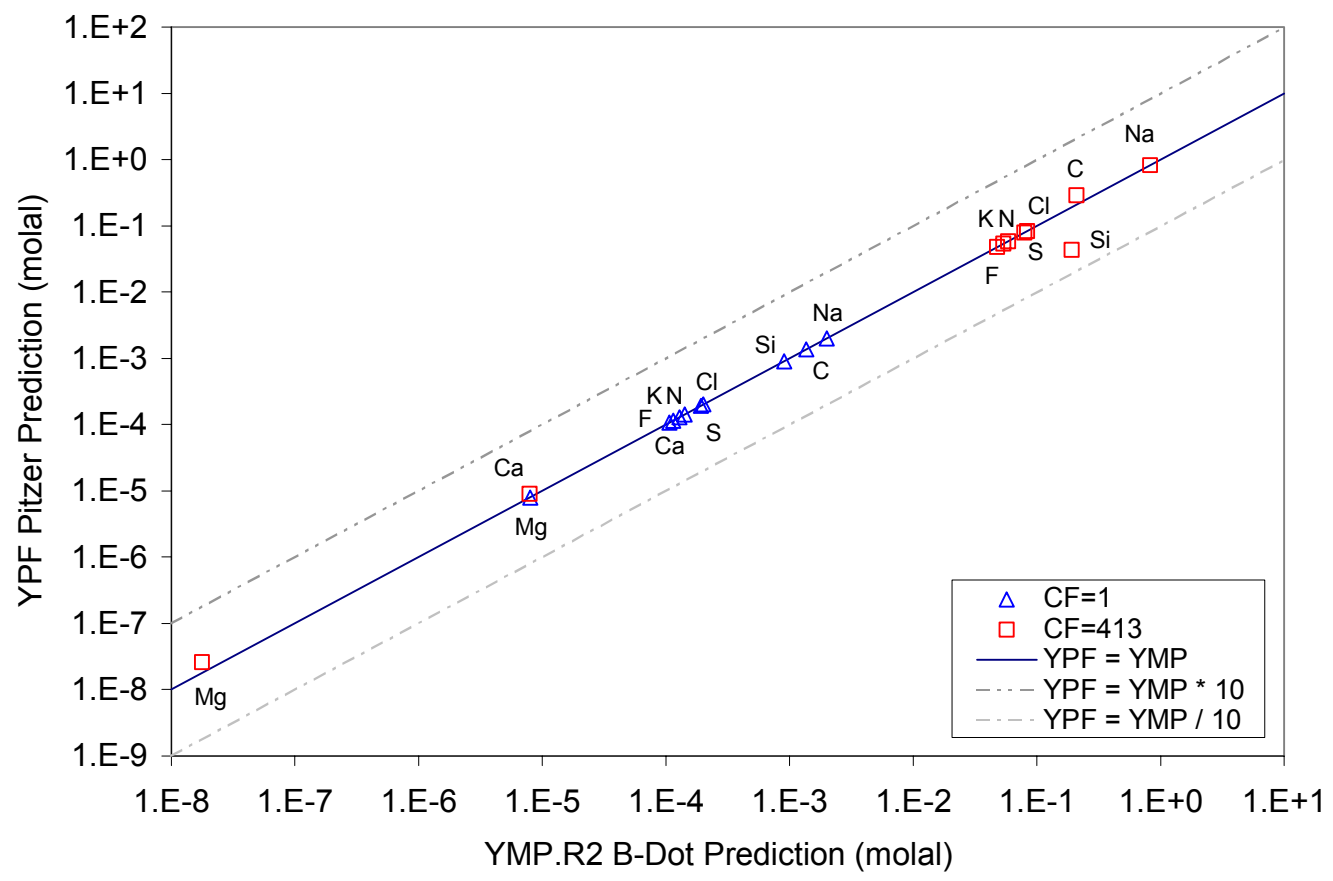

Output DTN: MO0303MWDINJ13.000.

Figure 7-71. Pitzer vs. Set 2 data0.ymp.R2 (YMP.R2) Aqueous Predictions for Average In Situ J-13 Well Water at $70^{\circ} \mathrm{C}$ and $\mathrm{CO}_{2}(\mathrm{~g})$ Fugacity of $10^{-3}$ Bars 


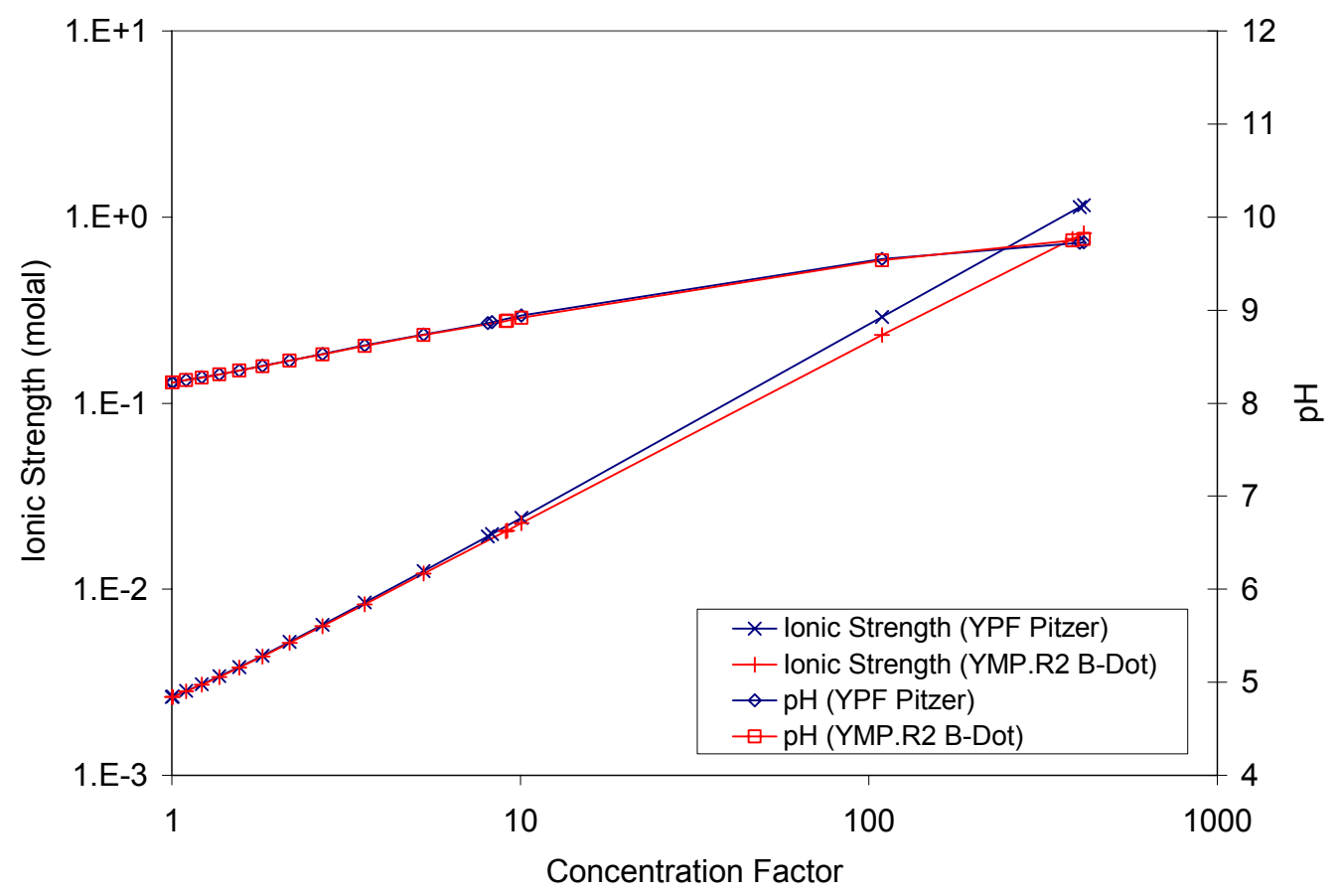

Output DTN: MO0303MWDINJ13.000.

Figure 7-72. Pitzer vs. Set 2 data0.ymp.R2 (YMP.R2) pH and lonic Strength Predictions for Average In Situ J-13 Well Water at $70^{\circ} \mathrm{C}$ and $\mathrm{CO}_{2}(\mathrm{~g})$ Fugacity of $10^{-3}$ Bars

\subsection{VALIDATION FOR MINERAL OUTPUTS}

A major feature of the IDPS model is the selection of minerals that are allowed (or not allowed) to precipitate upon saturation. Each mineral that precipitates creates a new chemical divide that has important consequences on the evolution of the aqueous phase (Section 6.3). Thus, mineral precipitation in the model determines the aqueous evolution of the evaporating solution. In the IDPS model, the minerals allowed to precipitate are those in the thermodynamic database that are not suppressed in the input file. The codependence of the evolving aqueous and mineral phases is imposed by the conservation of mass. At all times, the total mass of each component in the system is the sum of the masses of the component in the mineral and aqueous phases. Precipitation transfers a portion of the component mass from the aqueous to the mineral phase such that the total mass in the system remains constant. There are two components, however, whose masses do not remain constant in the system described by the IDPS model. They are water, which is incrementally removed by evaporation, and carbonate, which exchanges with the atmosphere via degassing and dissolution of carbon dioxide. Removal of water or carbonate (via carbon dioxide) does not affect the total masses of other components in the system.

Because the IDPS model imposes the principle of conservation of mass, the fact that the IDPS model predicts aqueous evolution within specified model validation criteria (Sections 7.1 through 7.3) validates the IDPS model for predicting bulk compositions of precipitated minerals. The bulk mineral composition is the set of the total masses of each elemental component in the total precipitation. While model validation for predicting the bulk mineral composition does not imply that the model accurately predicts exactly which minerals precipitate, this line of reasoning 
implies that the minerals predicted by the model to precipitate were adequate for predicting the evaporative evolution of the aqueous phase.

For TSPA-LA, it is the latter conclusion that is paramount - that the minerals predicted by the model to precipitate are adequate for predicting the composition of the aqueous phase. The minerals themselves do not affect performance of the repository. It is the potential aqueous solution that can be produced by deliquescence or dissolution of these minerals that is important to TSPA-LA in predicting corrosion rates and radionuclide mobility. Thus, predicting the specific mineral assemblage that would be generated by evaporation of a given water is not required. What is required, however, is predicting a mineral assemblage that will generate sufficiently accurate aqueous solutions upon deliquescence or dissolution. As Sections 7.1 through 7.3 show, the mineral assemblages predicted by the model accomplish this criterion, thereby validating the mineral outputs for their intended use.

This model validation argument is not as easily applied to the carbonate minerals because total carbonate in the system is not constant. The fixed partial pressure of carbon dioxide largely controls the mass of dissolved carbonate. If the solution becomes momentarily supersaturated with a non-suppressed carbonate mineral, that mineral is allowed to precipitate, thereby quantitatively transferring carbonate from the aqueous phase to the mineral phase. This loss of carbonate from the aqueous phase in turn permits additional dissolution of carbon dioxide. The code iterates on these mass transfers until equilibrium is attained.

Validating the open system IDPS model for carbonate minerals requires that the model adequately predict not only the aqueous evolution of dissolved carbonate but also the evolution of $\mathrm{pH}$. Removal and addition of carbonate from the aqueous phase via precipitation, dissolution, and degassing of carbon dioxide have important consequences on the evolution of $\mathrm{pH}$. The $\mathrm{pH}$ and carbonate concentrations are predicted within specifications in the open system laboratory evaporation tests in Section 7.1. In addition, calcite was observed as predicted in the synthesized $\mathrm{J}-13$ evaporation tests (Section 7.1.1). Adequate mineral identification was not performed in the other two evaporation tests, as explained in Sections 7.1.2 and 7.1.3.

The evaporation simulations of dilute salt solutions in Section 7.2, which include carbonate minerals, add to the validation of the IDPS model for mineral outputs. In essentially each of these evaporations, the solubility of the mineral phase was predicted within a factor of 10 and usually within 20 percent (Table 7-5, Figure 7-16, and Figure 7-17). In a few cases $\left(\mathrm{KNO}_{3}\right.$, $\mathrm{Ca}\left(\mathrm{NO}_{3}\right)_{2}$, and $\left.\mathrm{Mg}\left(\mathrm{NO}_{3}\right)_{2}\right)$, the solubility was never reached by the model; however, the potential impact of these salts on IDPS model results is negligible. These three salts are highly soluble salts and their precipitation in the IDPS model is not required to predict evaporative evolution within the uncertainty limitations prescribed by the model validation criteria. For additional verification of the accuracy of mineral solubility predictions, the reader is referred to the Pitzer database appendix.

\subsection{VALIDATION SUMMARY AND ESTIMATED UNCERTAINTIES}

This section addresses the validation of the IDPS model for temperatures from $0^{\circ} \mathrm{C}$ to $140^{\circ} \mathrm{C}$ by comparing the results of the validation simulations to the validation criteria in Table 7-1. In addition, this section evaluates the uncertainty associated with selected IDPS model output 
parameters. The selected parameters include $\mathrm{pH}$, ionic strength, $\mathrm{Cl}$ concentration, $\mathrm{NO}_{3}$ concentration, the $\mathrm{Cl}: \mathrm{NO}_{3}$ mole ratio, and deliquescence relative humidity $\left(R H_{d}\right)$.

Table 7-7 summarizes the maximum differences observed for selected parameters between model predictions and experimental data for the multi-component evaporation simulations in Section 7.1. $R H_{d}$ was not measured for these systems. For these data sets, only the evaporated seawater samples have predicted equilibrium $R H$ values below 91 percent. The seawater samples have predicted equilibrium $R H$ values as low as about 54 percent for $\mathrm{Cl}$ and ionic strength measurements and as low as 68 percent for $\mathrm{pH}$ measurements (Figure 7-14).

For the non-seawater evaporation experiments, the differences between $\mathrm{Cl}$ and $\mathrm{NO}_{3}$ are attributed to experimental error. As explained in Sections 7.1.1 and 7.1.3, the reported concentration factors for two of the experiments have large errors that account for a considerable amount of the differences between measurements and predictions. Furthermore, no phases containing $\mathrm{Cl}$ or $\mathrm{NO}_{3}$ should precipitate in the non-seawater experiments because the equilibrium $\mathrm{RH}$ does not decrease enough in the experiments to reach a saturation limit for $\mathrm{Cl}$ or $\mathrm{NO}_{3}$ phases. Thus, $\mathrm{Cl}$ and $\mathrm{NO}_{3}$ should concentrate conservatively, as they did in the simulations. Observed deviations from conservative concentrations of $\mathrm{Cl}$ or $\mathrm{NO}_{3}$ in the non-seawater evaporations are attributed to the errors in reported concentration factors and to inherent inaccuracies in analytical measurements.

Table 7-7. Maximum Differences Between Predictions and Measurements for $\mathrm{pH}$, lonic Strength, $\mathrm{Cl}, \mathrm{NO}_{3}$, and the $\mathrm{Cl}: \mathrm{NO}_{3}$ Ratio

\begin{tabular}{|c|c|c|c|c|c|c|}
\hline Evaporation Simulation & $\begin{array}{c}\mathrm{pH} \\
\text { (pH units) }\end{array}$ & $\begin{array}{c}\text { lonic } \\
\text { Strength } \\
\left(\text { RPD }^{\mathrm{a}}\right)\end{array}$ & $\begin{array}{c}\mathrm{Cl} \\
\text { (RPD) }\end{array}$ & $\begin{array}{l}\mathrm{NO}_{3} \\
\text { (RPD) }\end{array}$ & $\begin{array}{l}\mathrm{NO}_{3}: \mathrm{Cl} \\
\text { Ratio } \\
\text { (RPD) }\end{array}$ & $\begin{array}{l}\mathrm{Cl}: \mathrm{NO}_{3} \\
\text { Ratio } \\
\text { (RPD) }\end{array}$ \\
\hline $\begin{array}{l}\text { J-13 Evaporation Experiment } \\
\text { (Section 7.1.1) }\end{array}$ & 0.78 & $47 \%^{b}$ & $48 \%^{b}$ & $38 \%^{b}$ & $-14 \%$ & $16 \%$ \\
\hline $\begin{array}{l}\text { 100x J-13 Evaporation } \\
\text { Experiment (Section 7.1.2) }\end{array}$ & $\mathrm{nm}^{\mathrm{c}}$ & $n e^{d}$ & $5 \%$ & $7 \%$ & $3 \%$ & $-3 \%$ \\
\hline $\begin{array}{l}\text { Topopah Spring Tuff Pore Water } \\
\text { Evaporation Experiment } \\
\text { (Section 7.1.3) }\end{array}$ & 0.46 & $67 \%^{\mathrm{b}}$ & $66 \%^{\mathrm{b}}$ & $\mathrm{nm}^{\mathrm{c}}$ & $\mathrm{nm}^{\mathrm{c}}$ & $\mathrm{nm}^{\mathrm{c}}$ \\
\hline $\begin{array}{l}\text { Seawater Evaporation } \\
\text { (Section 7.1.4) }\end{array}$ & 0.76 & $15 \%{ }^{\mathrm{e}}$ & $10 \%{ }^{\mathrm{e}}$ & $\mathrm{nm}^{\mathrm{c}}$ & $\mathrm{nm}^{\mathrm{c}}$ & $\mathrm{nm}^{\mathrm{c}}$ \\
\hline
\end{tabular}

Output DTN: MO0308SPAUCIMV.000.

${ }^{a}$ RPD (relative percent difference) $=100 \%$ * ([predicted concentration] - [measured concentration]) $/$ [measured concentration].

${ }^{\mathrm{b}}$ Most of the difference is due to overestimation in the concentration factor reported in the data source (see Section 7.1.1 or Section 7.1.3 for details).

${ }^{c} \mathrm{~nm}=$ not measured.

${ }^{\mathrm{d}}$ ne $=$ not estimated, $\mathrm{pH}$ needed for estimate.

e This value ignores the sample with the highest degree of evaporation because it is an outlier (Figure 7-13 and Figure 7-14).

Differences between measurements and model predictions of $\mathrm{Cl}, \mathrm{NO}_{3}$, and the $\mathrm{Cl}: \mathrm{NO}_{3}$ mole ratio were also compiled for the ternary systems in Section 7.2.2 that involve both $\mathrm{Cl}$ and $\mathrm{NO}_{3}$. The results are plotted in Figure 7-73 as a function of equilibrium $R H$. These differences are documented in DTN: MO0312SPAESMUN.002. The plot shows differences in both directions. 
Positive differences indicate the model predictions are higher than measurements, and negative differences indicate the model predictions are lower than measurements.

Uncertainty in IDPS model predictions is strongly correlated with equilibrium $R H$, as illustrated in Figure 7-73. There is a strong theoretical basis for this relationship. As $R H$ decreases, solubility limits are reached that have important consequences on the concentrations of $\mathrm{Cl}, \mathrm{NO}_{3}$, and the $\mathrm{Cl}: \mathrm{NO}_{3}$ mole ratio. If the model starts to precipitate $\mathrm{Cl}$ or $\mathrm{NO}_{3}$ phases at $R H$ above or below the $R H$ that is consistent with measurements, then deviations begin to occur between model predictions and measurements as $R H$ decreases further. In addition, the EQ3/6 code and Pitzer database have calculation uncertainties that can become considerable at low $R H$, and the reliability and availability of experimental data decrease. The only available data relevant to the system below an $\mathrm{RH}$ of about 50 percent are data for $\mathrm{Ca}, \mathrm{Mg}$, and some $\mathrm{K}$ salts; the solubilities of $\mathrm{Na}$ salts inhibit $\mathrm{Na}$ from staying in solution in the binary and ternary systems at $R H$ below 50 percent.

Validation comparisons in the binary and ternary systems in Section 7.2 assess the differences between measured and predicted salt solubilities. These comparisons are useful for evaluating model validation and uncertainty when the solution has reached saturation with respect to one or all salts in the systems. These comparisons are essentially worst case scenarios for the IDPS model because they only reveal differences between predictions and measurements in highly concentrated solutions. In contrast, they do not provide uncertainty information for solutions that are undersaturated with respect to these salts. At solution concentrations below the measured and predicted solubilities of these salts, the model will accurately and precisely predict the effects of evaporation and condensation on aqueous salt concentrations.

Figure 7-73 reveals the possibility of model bias when salinities are high and $R H$ is below about 70 percent. Specifically, the figure shows that for certain $R H$ ranges there is potential bias in predicting $\mathrm{Cl}$ and $\mathrm{NO}_{3}$ concentrations and $\mathrm{Cl}: \mathrm{NO}_{3}$ mole ratios in ternary systems saturated with $\mathrm{Cl}$ and/or $\mathrm{NO}_{3}$ salts. For example, above an $\mathrm{RH}$ of about 50 percent, the predictions of the $\mathrm{Cl}: \mathrm{NO}_{3}$ ratio are both low and high with a slight bias to the low side. In this $R H$ range, both $\mathrm{Cl}$ and $\mathrm{NO}_{3}$ predictions tend to be lower than measured data, but the effect is essentially cancelled out in terms of the $\mathrm{Cl}: \mathrm{NO}_{3}$ ratio, which is of primary importance in estimating corrosion rates. Underestimates of the $\mathrm{Cl}: \mathrm{NO}_{3}$ mole ratio, as displayed in Figure 7-73 below the zero error line, are potentially non-conservative in TSPA-LA because high $\mathrm{Cl}: \mathrm{NO}_{3}$ mole ratios are necessary to initiate corrosion of the waste package outer barrier (BSC 2004 [DIRS 169984]). However, all of the data points in Figure 7-73 in the $\mathrm{RH}$ range of 50 to 70 percent that show negative errors in the $\mathrm{Cl}: \mathrm{NO}_{3}$ mole ratio (underestimates) have $\mathrm{Cl}: \mathrm{NO}_{3}$ mole ratios less than 2 . These data come from the Na-Cl-NO $\mathrm{NO}_{3}$ system (Figure 7-42 through Figure 7-45) and from the $\mathrm{K}-\mathrm{Cl}-\mathrm{NO}_{3}$ system (Figure 7-48 through Figure 7-53). According to General Corrosion and Localized Corrosion of Waste Package Outer Barrier (BSC 2004 [DIRS 169984]), corrosion does not occur when this ratio is less than 2 due to the corrosion-inhibiting effects of $\mathrm{NO}_{3}$. Thus, the bias toward non-conservatism that appears in Figure 7-73 in the $R H$ range of 50 to 70 percent is based on data in systems where the $\mathrm{Cl}: \mathrm{NO}_{3}$ mole ratio range is below the threshold required for corrosion. Regardless of potential model bias in the $\mathrm{Cl}: \mathrm{NO}_{3}$ ratio in this $R H$ range, this potential bias is small compared to the uncertainty shown in the figure for this ratio. 
Below an $R H$ of 50 percent, a potentially significant bias appears where predictions of the $\mathrm{Cl}: \mathrm{NO}_{3}$ mole ratio tend to exceed measurements on a generally consistent basis. In this $R H$ range, $\mathrm{Ca}, \mathrm{Mg}$, and potentially $\mathrm{K}$ salts control the solubilities of $\mathrm{Cl}$ and $\mathrm{NO}_{3}$. This apparent bias suggests that model predictions of the $\mathrm{Cl}: \mathrm{NO}_{3}$ mole ratio are generally conservative (i.e., biased toward predicting a more corrosive brine) at $R H$ below 50 percent. Although most points plot above the zero error line below an $R H$ of 50 percent in Figure 7-73, there are three data points in this $R H$ range that plot below -0.1, suggesting a potential for non-conservatism with respect to corrosion modeling in TSPA-LA. Each of these points, however, is from the $\mathrm{Mg}-\mathrm{Cl}-\mathrm{NO}_{3}$ system (Figure 7-67 and Figure 7-68), a system that does not occur in any of the evaporation or deliquescence abstractions for TSPA-LA, as documented in Engineered Barrier System: Physical and Chemical Environment Model (BSC 2004 [DIRS 169860]). Thus, it is more likely that the IDPS model may be biased toward producing conservative predictions of the $\mathrm{Cl}_{2} \mathrm{NO}_{3}$ mole ratio below an $R H$ of 50 percent in TSPA-LA calculations.

Estimates of IDPS model uncertainties for $\mathrm{Cl}, \mathrm{NO}_{3}$, and the $\mathrm{Cl}: \mathrm{NO}_{3}$ mole ratio are presented in Table 7-8 along with estimated model uncertainties for $\mathrm{pH}$, ionic strength, and $R H_{d}$. The estimates for $\mathrm{Cl}, \mathrm{NO}_{3}$, and the $\mathrm{Cl}: \mathrm{NO}_{3}$ mole ratio are largely based on the plot in Figure 7-73. For the $R H$ range of 85 percent and above, uncertainty in $\mathrm{Cl}, \mathrm{NO}_{3}$, and the $\mathrm{Cl}: \mathrm{NO}_{3}$ mole ratio is set at zero because $\mathrm{Cl}$ and $\mathrm{NO}_{3}$ behave conservatively in this $R H$ range (i.e., they do not precipitate in this range and therefore concentrate according to equation 6.6.2.5-4). Deviations observed between measurements and predictions for $\mathrm{Cl}$ and $\mathrm{NO}_{3}$ at $\mathrm{RH}$ greater than 85 percent (such as in the non-seawater evaporation experiments in Table 7-7) are attributed to experimental error.

In the subsections that follow, each validation criterion is compared to the results of the simulations. Where applicable, the results are also compared to the estimated model uncertainties listed in Table 7-8.

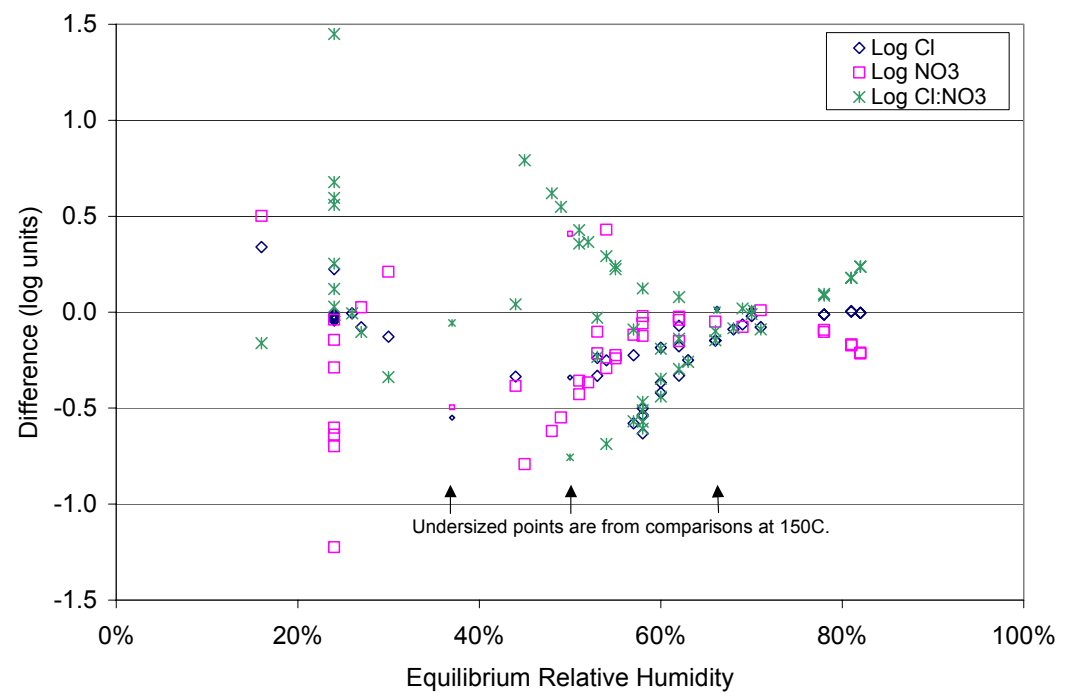

Output DTN: MO0312SPAESMUN.002.

Figure 7-73. Differences Between Measurements and Model Predictions of Salt Solubilities for Ternary Systems Involving Both $\mathrm{Cl}$ and $\mathrm{NO}_{3}$ 
Table 7-8. Estimated IDPS Model Uncertainties for Temperatures Between $25^{\circ} \mathrm{C}$ and $140^{\circ} \mathrm{C}$

\begin{tabular}{|c|c|c|c|c|c|c|}
\hline Parameter & Units & $\begin{array}{c}R H \text { Range } \\
100 \%-85 \%\end{array}$ & $\begin{array}{l}\text { RH Range } \\
85 \%-65 \%\end{array}$ & $\begin{array}{l}\text { RH Range } \\
65 \%-60 \%\end{array}$ & $\begin{array}{l}\text { RH Range } \\
60 \%-40 \%\end{array}$ & $\begin{array}{l}\text { RH Range } \\
40 \%-0 \%\end{array}$ \\
\hline $\mathrm{pH}$ & $\mathrm{pH}$ units & $+/-1$ & $+/-1$ & $+/-1$ & $+/-2$ & $+/-2$ \\
\hline Ionic Strength & log molal & $+/-0.1$ & $\mathrm{na}^{\mathrm{a}}$ & $\mathrm{na}^{\mathrm{a}}$ & $\mathrm{na}^{\mathrm{a}}$ & $\mathrm{na}^{\mathrm{a}}$ \\
\hline $\mathrm{Cl}$ & log molal & $+/-0.0$ & $+/-0.2$ & $+/-0.5$ & $+/-0.7$ & $+/-0.7$ \\
\hline $\mathrm{NO}_{3}$ & log molal & $+/-0.0$ & $+/-0.2$ & $+/-0.2$ & $+/-0.7$ & $+/-0.9$ \\
\hline $\mathrm{Cl}: \mathrm{NO}_{3}$ & log mole ratio & $+/-0.0$ & $+/-0.2$ & $+/-0.5$ & $+/-0.7$ & $+/-1$ \\
\hline$R H_{d}$ & $\% \mathrm{RH}$ units & $+/-5 \%$ & $+/-10 \%$ & $+/-10 \%$ & $+/-10 \%{ }^{b}$ & $+/-15 \%^{b}$ \\
\hline
\end{tabular}

Output DTN: MO0312SPAESMUN.002.

a Not applicable to TSPA-LA. Prediction of ionic strength is for colloids model. At $R H$ below 85 percent, ionic strength is greater than 1 molal, which is far above the critical ionic strength where colloids are unstable.

b The exception for this estimated uncertainty is for a brine with a large $\mathrm{Ca}\left(\mathrm{NO}_{3}\right)_{2}$ component. IDPS model predictions in binary $\mathrm{Ca}\left(\mathrm{NO}_{3}\right)_{2}$ systems operationally provide $R H_{d}$ values that are 20 to 25 percent higher than reported measurements. Because the validation criterion for the IDPS model is to predict $R H_{d}$ within $+/-10 \% R H$ (Table 7-1), the IDPS model is not valid for predicting $R H_{d}$ below $40 \%$ or when $\mathrm{Ca}\left(\mathrm{NO}_{3}\right)_{2}$ is a large component of the brine at $R H$ below $60 \%$.

\subsection{1 pH}

The IDPS model validation criterion for $\mathrm{pH}$ is to predict $\mathrm{pH}$ within one $\mathrm{pH}$ unit (Table 7-1). In each of the simulations in which $\mathrm{pH}$ data are available, $\mathrm{pH}$ is predicted within $0.78 \mathrm{pH}$ unit or less (Figure 7-4, Figure 7-11, and Figure 7-14). The maximum $\mathrm{pH}$ differences in each of the multi-component evaporation data sets are summarized in Table 7-7.

The set of validation data contains $\mathrm{pH}$ measurements only to temperatures as high as $85^{\circ} \mathrm{C}$ (Figure 7-4) and activities of water as low as 0.68 (Figure 7-14). The scientific literature appears to be devoid of reported measured $\mathrm{pH}$ values for concentrated salt solutions at temperatures above $100^{\circ} \mathrm{C}$ and/or at high ionic strengths. Consequently, the validation of the $\mathrm{pH}$ aspect of the IDPS model and Pitzer database at such temperatures and ionic strengths cannot be accomplished in the same manner as at lower temperatures and lower ionic strengths. A different, less direct approach must be taken. Before proceeding to that, however, the nature of $\mathrm{pH}$ and $\mathrm{pH}$ measurement are briefly reviewed to provide context for the problem. In brief, there are two problematic aspects, one associated with elevated temperature, the other with concentrated salt solutions (high ionic strength).

The measurement of $\mathrm{pH}$ in dilute solutions above $100^{\circ} \mathrm{C}$ in a manner analogous to measurement at lower temperatures is possible but relatively infrequent. Special electrodes must be utilized. A pressurized apparatus is often required to keep water in a liquid phase. In situ measurement then requires integration of the electrodes into the pressurized apparatus. An additional difficulty is the lack of widely accepted calibration buffers for use in high temperature measurement, though this is a relatively minor impediment from a technical standpoint.

One approach to obtaining high-temperature values for dilute solutions is to measure the $\mathrm{pH}$ of quenched solutions, then use a geochemical modeling code such as EQ3/6 to "correct" such quench values to the original temperature (cf. Knauss et al. 1985 [DIRS 143694]; Knauss et al. 1985 [DIRS 100150]). A closely related approach is to use the modeling code to compute the 
elevated temperature $\mathrm{pH}$ of buffer solutions to be used in experiments, such as in studies of mineral dissolution kinetics (cf. Knauss and Wolery 1986 [DIRS 160184]; Knauss and Wolery 1988 [DIRS 133140]). If all the relevant acid-base equilibria are properly represented with respect to the applicable temperature range, either approach should give reliable results. It must be noted the use of either approach requires avoiding mass transfer (e.g., mineral precipitation or degassing of volatiles such as $\mathrm{CO}_{2}$ ). Such mass transfer may occur during the quenching process (when quench $\mathrm{pH}$ is measured) or in heating of a buffer to elevated temperature. A quenched sample may be diluted into pure water prior to $\mathrm{pH}$ measurement to minimize such problems, with correction for this in the modeling code calculation. Such dilution intrinsically increases the uncertainty in the calculated result. However, it may be necessary to obtain an acceptable result.

Of all the potentially relevant acid-base equilibria, a key one for any aqueous system is that for the acid-base dissociation of water:

$$
\mathrm{H}_{2} \mathrm{O}_{(l)}=\mathrm{H}^{+}+\mathrm{OH}^{-}
$$

for which the mass-action equation can be written as:

$$
\log K_{w}=-p H-p O H-\log a_{w}
$$

where $K_{w}$ is the equilibrium constant for the reaction as written above, $p H=-\log a_{H^{+}}$(negative logarithm of the thermodynamic activity of $\mathrm{H}^{+}$), $\mathrm{pOH}=-\log a_{O H^{-}}$(analogous to $p H$ ), and $a_{w}$ is the thermodynamic activity of water (which has a value near unity in dilute solutions). Traditionally, "neutral $\mathrm{pH}$ " at any temperature is defined as $-1 / 2 \log K_{w}$ and the nominal maximum $\mathrm{pH}$ as $-\log K_{w}$. At $25^{\circ} \mathrm{C}, \log K_{w}$ has a value of -13.9951 (the negative of the value for the reverse reaction taken from data0.ypf.R1, DTN: SN0302T0510102.002). Hence the traditional neutral $\mathrm{pH}$ at this temperature has a value close to 7.0 and the nominal maximum $\mathrm{pH}$ is 14. The dielectric constant of water decreases as temperature is increased, creating a medium that is much less favorable for ionization reactions (cf. Helgeson and Kirkham 1974 [DIRS 157904]). This decrease is particularly notable between 25 and $100^{\circ} \mathrm{C}$. At $100^{\circ} \mathrm{C}$, $\log K_{w}$ has a value of -12.2551 (also from data0.ypf.R1), implying a neutral $\mathrm{pH}$ close to 6.13 and a nominal maximum $\mathrm{pH}$ of 12.26 . At $150^{\circ} \mathrm{C}, \log K_{w}$ has a value of -11.6308 (again from data0.ypf.R1), implying a neutral $\mathrm{pH}$ close to 5.82 and a nominal maximum $\mathrm{pH}$ of 11.63. These results imply that a solution with a $\mathrm{pH}$ of 8 at $100^{\circ} \mathrm{C}$ is more alkaline than one with a $\mathrm{pH}$ of 8 at $25^{\circ} \mathrm{C}$ because the $\mathrm{pOH}$ is lower for the former.

The measurement and reporting of $\mathrm{pH}$ in most of the modern scientific and technical literature are consistent with the "NBS" $\mathrm{pH}$ scale. A scale is required because (at least by thermodynamic methods) ionic activities can only be observed in combinations corresponding to electrical neutrality. Some kind of arbitrary convention to allow a "splitting" is required. For standard state Gibbs energies of the aqueous ions, such a splitting convention sets that quantity for $\mathrm{H}^{+}$ equal to zero. Ionic activities are related to molalities and activity coefficients by the relation:

$$
a_{i}=m_{i} \gamma_{i}
$$


where $a_{i}$ is the activity of the $i$-th ion, $m_{i}$ is the molality of that ion, and $\gamma_{i}$ is the corresponding activity coefficient. Individual ionic molalities are observable; individual ionic activity coefficients are not. A splitting convention for ionic activity coefficients is tantamount to one for ionic activities, and hence also tantamount to defining a scale for $\mathrm{pH}$. In fact, $\mathrm{pH}$ scales are generally defined by adopting some expression for the activity coefficient of some ion. In the case of the National Bureau of Standards (NBS) pH scale, this is the Bates-Guggenheim equation (e.g., Bates 1973 [DIRS 166051]):

$$
\log \gamma_{C l^{-}}=\frac{-A_{\gamma, 10} \sqrt{I}}{1+1.5 \sqrt{I}}
$$

where $A_{\gamma, 10}$ is the Debye-Hückel "A" parameter and $I$ is the ionic strength. Results for any set of model equations for ionic activity coefficients can be rescaled for consistency with this definition (cf. Knauss et al. 1990 [DIRS 166144]; Wolery 1992 [DIRS 100836], p. 43). This in fact is done in $\mathrm{EQ} 3 / 6$, which by default reports $\mathrm{pH}$ and ionic activities and activity coefficients on an extended NBS scale.

The Bates-Guggenheim equation is a simple "extended" Debye-Hückel equation that is consistent with the Debye-Hückel limiting law:

$$
\log \gamma_{i}=-A_{\gamma, 10} z_{i}^{2} \sqrt{I}
$$

where $z_{i}$ is the electrical charge number of the $i$-th ion. This applies accurately only in the limit of dilute aqueous solutions. One would expect the Bates-Guggenheim equation to be realistic (in some absolute sense) to higher but still relatively low ionic strength (e.g., less than about 0.1 molal). However, one would also expect the Bates-Guggenheim equation to become highly inaccurate in some absolute sense at high ionic strength. If one applies this convention to highly concentrated salt solutions, the usual understanding of numbers for $\mathrm{pH}$ as corresponding to solutions that are acidic, neutral, or alkaline may no longer apply. For example, at $25^{\circ} \mathrm{C}$, a pH value of 7 might be acidic or alkaline instead of neutral.

If one were to desire that the $\mathrm{pH}$ numbers for concentrated solutions correspond to their commonly accepted implications of solution character, one would be forced to consider alternative $\mathrm{pH}$ scales. One alternative would be to use the raw single-ion form of Pitzer's equations (no rescaling). That is also consistent with the limiting law; hence it is also consistent with the NBS pH scale at sufficiently low ionic strength. This alternative contains its own splitting convention, which is discussed for example by Wolery (1992 [DIRS 100836], pp. 44 to 61). A second alternative, the "Mesmer" scale (cf. Mesmer 1991 [DIRS 166053]), is based on the convention:

$$
\log a_{H^{+}}=\log m_{H^{+}}
$$

This is equivalent to setting $\log \gamma_{H^{+}}=0$. The Mesmer convention is not consistent with the limiting law. Therefore, it is also not consistent with the NBS pH scale at low ionic strength. It does have the advantage that the molality of the hydrogen ion in concentrated salt solutions can 
sometimes be determined experimentally. EQ3/6 (and various other geochemical modeling codes) typically allow code users to deal with any of several $\mathrm{pH}$ scales including those discussed here.

The measurement of $\mathrm{pH}$ in concentrated salt solutions at any temperature is another problem. The standard method for measuring $\mathrm{pH}$ at low temperature using a specific ion electrode (specific to $\mathrm{H}^{+}$) in combination with a reference electrode (commonly $\mathrm{Ag} / \mathrm{AgCl}$ ) is really designed for use in dilute solutions only. The NBS pH scale was originally recommended for application to solutions having a maximum ionic strength of 0.1 molal (e.g., Bates 1973 [DIRS 166051]). This is commonly exceeded in the treatment of natural waters including brackish waters and seawater (which has an ionic strength of approximately 0.7 molal). The problem with the standard measurement method is that at high ionic strengths the method is increasingly affected by a liquid junction potential error (e.g., Baes and Mesmer 1986 [DIRS 100702]). The liquid junction potential is associated with the reference electrode. This potential is non-zero in dilute solutions; however, it is approximately constant for any solution with relatively low ionic strength and therefore effectively zeroed out in the standard calibration process. However, it takes on different values in more concentrated solutions. There is no generally accepted model for correcting liquid junction potential errors. Such corrections are sometimes attempted, but they involve relatively severe approximations and it is not clear if the results are better or worse.

Knauss et al. (1990 [DIRS 166144]) proposed elimination of the liquid junction potential by replacing the standard reference electrode with another specific ion electrode, such as one specific to the chloride ion. The parameter measured would then be not $\mathrm{pH}$ but $\mathrm{pH}+\mathrm{pCl}$. Such an approach is generally feasible. However, there are no "standard" calibration buffer solutions for this type of measurement. In essence, one must compute compositions for possible calibration buffers using a modeling code such as EQ3/6 and a model for concentrated aqueous salt solutions, based for example on Pitzer's equations. EQ3/6 is capable of taking a quantity such as $\mathrm{pH}+\mathrm{pCl}$ in place of $\mathrm{pH}$, and computing a thermodynamic model of the aqueous solution that includes a value for the $\mathrm{pH}$ on whichever $\mathrm{pH}$ scale is desired (Wolery 1992 [DIRS 100836], pp. 19 to 21). This general approach appears to have been used only at low temperatures.

The above discussion should give the impression that $\mathrm{pH}$ cannot be measured in practice in the absence of a thermodynamic model for ionic activities and activity coefficients. That is in fact the correct impression, because without such a model (at least covering some small number of chemical components) it is not possible to develop calibration buffers to define in an operational sense what the $\mathrm{pH}$ is. In essence, $\mathrm{pH}$ measurement is based on a procedure which at a more basic level attempts to measure the difference between the $\mathrm{pH}$ in a water sample and the $\mathrm{pH}$ in a calibration buffer (though in standard practice two calibration buffer solutions bracketing the expected sample $\mathrm{pH}$ are to be used). Thus, the $\mathrm{pH}$ is basically a model construct. The activity of the hydrogen ion is likewise a model construct.

Nothing more is added by other methods to measure the $\mathrm{pH}$. For example, $\mathrm{pH}$ paper works by color changes of dyes in the paper. The dyes are buffers with their own thermodynamic properties. The $\mathrm{pH}$ values assigned to the color changes are calibrated against other, standard $\mathrm{pH}$ buffers. The expected response of the dyes will likely only occur for relatively dilute solutions. At high ionic strength, the color responses may be altered by interactions with ions other than the 
hydrogen ion. In general, $\mathrm{pH}$ paper is only intended to be used in dilute solutions (and at low temperatures).

In essence, one accepts the $\mathrm{pH}$ because one accepts the accuracy of the thermodynamic models for buffer-electrolyte systems, at least the key ones associated with the principal operational standards (as represented for example in commercial $\mathrm{pH}$ calibration buffer solutions). The acceptance of these thermodynamic models is based on their consistency with observations of speciation and solubilities. Here the observations of speciation may be tied to potentiometric or spectroscopic measurements. The $\mathrm{pH}$ as measured in standard practice is useful for correlating such data (at least in dilute solutions). That is the basic justification for defining and using this parameter.

Consequently, the $\mathrm{pH}$ aspect of the high-temperature IDPS model and Pitzer database above $100^{\circ} \mathrm{C}$ can be validated even in the absence of any direct $\mathrm{pH}$ measurements. It is only necessary to show that the model does a reasonable job of predicting things that depend on or strongly correlate with the $\mathrm{pH}$. Here the focus will be on solubilities, as the relevant data are more readily available than other types of data that correlate with $\mathrm{pH}$. Consider the case of portlandite $\left[\mathrm{Ca}(\mathrm{OH})_{2}\right]$. The dissolution reaction can be written as:

$$
\mathrm{Ca}(\mathrm{OH})_{2(c)}+2 \mathrm{H}^{+}=\mathrm{Ca}^{2+}+2 \mathrm{H}_{2} \mathrm{O}
$$

The corresponding mass action equation can be written as:

$$
\log K=\log a_{\mathrm{Ca}^{2+}}+2 \log a_{w}+2 p H
$$

The solubility of portlandite is more directly obtained by recasting this as:

$$
\log m_{C a^{2+}}=\log K-\left\{\log \gamma_{C a^{2+}}+2 \log a_{w}\right\}-2 p H
$$

(other potential dissolved calcium species that might contribute to the solubility are ignored here). Clearly the calculated solubility of this mineral is strongly correlated with $\mathrm{pH}$, such that a change of $0.5 \mathrm{pH}$ unit would change the calculated solubility by one log unit.

If there were no uncertainties in the equilibrium constant or the activity coefficient model (which determines the activity coefficient of the calcium ion and the activity of water), an uncertainty of one $\log$ unit in the solubility would imply an uncertainty of 0.5 unit in the $\mathrm{pH}$. Other uncertainties in the right hand side of the above equation must be addressed. The uncertainty in $\log K$ for such a reaction is likely relatively small, in the range 0.005 to 0.1 unit. The remaining quantity in braces $\left\{\log \gamma_{\mathrm{Ca}^{2+}}+2 \log a_{w}\right\}$ is a function of the activity coefficient model (here the high-temperature Pitzer model). The uncertainty is potentially highly variable, depending on the total aqueous solution composition. Portlandite itself (and many other common minerals whose solubilities correlate strongly with $\mathrm{pH}$ ) is sparingly soluble. In a two-aqueous-electrolyte system such as $\mathrm{Ca}(\mathrm{OH})_{2}-\mathrm{NaCl}-\mathrm{H}_{2} \mathrm{O}$ (where the other electrolyte is highly soluble and there is no common ion), the activity of water would depend almost entirely on the concentration of the second, more soluble electrolyte over most of the compositional range, and the activity coefficient of the calcium ion would depend mainly on the generalized ionic strength and the 
interactions of this ion with the sodium and chloride ions. In such a simple system, the activity coefficient model could carry relatively little uncertainty. One would therefore expect that $\mathrm{pH}$ values calculated from the model would carry uncertainties that correlate mainly with uncertainties in the solubility of the sparingly soluble mineral.

To the extent that systems meeting the above criteria are available, one can say that the uncertainty in calculated $\mathrm{pH}$ correlates with uncertainty in solubility. The exact degree of correlation depends on the charge of the cation in the sparingly soluble electrolyte. In the above example, that cation is divalent and a one log unit uncertainty in calculated solubility correlates with an uncertainty of 0.5 unit in the $\mathrm{pH}$. If one substituted a trivalent ion, such as $\mathrm{Al}^{3+}$, the one $\log$ unit uncertainty in calculated solubility correlates with 0.33 unit in the $\mathrm{pH}$. The correlation is less favorable for monovalent cations such as $\mathrm{Na}^{+}$and $\mathrm{K}^{+}$(one $\log$ unit in the solubility correlating to one $\mathrm{pH}$ unit). However, compounds such as $\mathrm{NaOH}$ and $\mathrm{KOH}$ are in addition highly soluble. Therefore, the uncertainties in the contributions from the activity coefficient model are likely much larger than for the other cases considered here, and the $\mathrm{pH}$ uncertainty for one log unit uncertainty in solubility is probably more like 2 units.

The carbonate systems in Section 7.2 also meet the criteria above for a strong correlation between $\mathrm{pH}$ and solubility. In all cases simulated, the solubilities of the carbonate salts are predicted within a factor of 10 and usually within a factor of 2 (Figure 7-22, Figure 7-23, Figure 7-24, Figure 7-25, Figure 7-54, and Figure 7-56).

In general, there are high temperature and/or high ionic strength solubility data for relatively few of the sorts of systems described above that are ideal for constraining uncertainty in $\mathrm{pH}$. However, the uncertainty in calculated solubilities for such $\mathrm{pH}$-correlative systems probably does not differ much from that in such results for non-pH-correlative systems. Overall, this validation study has indicated that the uncertainty in calculated solubilities in the temperature range of interest is generally better than one log unit, and in some cases much better. This indicates that a reasonable estimate of uncertainty in $\mathrm{pH}$ in all but the most concentrated solutions is one $\mathrm{pH}$ unit, and for the most concentrated solutions (e.g., equilibrium $R H$ less than 60 percent), two $\mathrm{pH}$ units (Table 7-8). These uncertainties are comparable to, and perhaps smaller than, uncertainties that may apply to reported $\mathrm{pH}$ measurements in high-ionic strength solutions at high temperature.

\subsubsection{Ionic Strength}

The model validation criterion for ionic strength is to predict ionic strength within a factor of 10 (Table 7-1). In each of the multi-component evaporation simulations in Section 7.1, ionic strength is predicted within a factor of 2 or less (Table 7-2, Table 7-3, and Figure 7-14). As shown in Table 7-7, the maximum observed ionic strength difference is 67 percent. However, as discussed below, only a small part of this difference is due to uncertainties in the IDPS model.

The estimated model uncertainty for ionic strength at $R H$ values above 85 percent is plus or minus 0.1 in $\log$ units (Table 7-8). This value is approximately equivalent to an uncertainty of plus or minus 30 percent. Most of the error reported in Table 7-7 for ionic strength is not due to model uncertainty. Rather, it is due to overestimates of the reported concentration factors. These overestimates are addressed and substantiated in Sections 7.1.1 and 7.1.3. Concentration factors were determined and reported more accurately in the seawater evaporation samples. 
Unlike the J-13 and Topopah Spring Tuff pore water evaporation experiments, the reported concentration factors for the seawater samples were directly determined from the measured concentration factors of non-reacting dissolved components. The maximum difference between measured and predicted ionic strength in the seawater samples is approximately 15 percent, except for an outlier at the highest degree of evaporation (Figure 7-14). Considering the accuracy in the predicted seawater ionic strength and the effects of the overestimated concentration factors in the J-13 and Topopah Spring Tuff pore water evaporation experiments, the estimated plus or minus 0.1 model uncertainty in log units for ionic strength at $R H$ values above 85 percent is supported and justified by the model validation analyses.

At $R H$ less than 85 percent, ionic strength is greater than 1 molal, as suggested in Figure 6-4 and Figure 7-14. Ionic strength outputs of the IDPS model are used as input to the colloids model in TSPA-LA. At ionic strengths above 0.05 molal, colloids are unstable (BSC 2004 [DIRS 170025], Section 6.3.1) and do not affect repository performance. Thus, uncertainties for ionic strength predictions are not required by TSPA-LA at the high ionic strengths that occur at $R H$ values below 85 percent.

\subsubsection{Deliquescence Relative Humidity}

The model validation criterion for deliquescence relative humidity $\left(R H_{d}\right)$ is to predict $R H_{d}$ within 10 percent in $R H$ units (Table 7-1). In each of the deliquescence simulations in Sections 7.2.1.1.2 and 7.2.1.2.2, the predicted $R H_{d}$ is within 10 percent $R H$ of available measurements, except for $\mathrm{Ca}\left(\mathrm{NO}_{3}\right)_{2}$ for all temperatures above $25^{\circ} \mathrm{C}$ (Figure 7-38) and for $\mathrm{KF}$ at $25^{\circ} \mathrm{C}$ (Figure 7-27). The 20 to 25 percent $R H$ difference between predictions and measurements of $R H_{d}$ for $\mathrm{Ca}\left(\mathrm{NO}_{3}\right)_{2}$ above a temperature of approximately $45^{\circ} \mathrm{C}$ indicates the model is not valid for predicting $R H_{d}$ when $\mathrm{Ca}\left(\mathrm{NO}_{3}\right)_{2}$ is a major component of the brine.

As presented in Table 7-8 and supported by the results in Sections 7.2.1.1.2 and 7.2.1.2.2, the estimated model uncertainty for $R H_{d}$ is plus or minus 5 percent in $R H$ units when $R H_{d}$ predictions are 85 percent or higher. From 40 to 85 percent, the model uncertainty for $R H_{d}$ is estimated to be plus or minus 10 percent in $R H$ units for systems that do not contain major quantities of $\mathrm{Ca}\left(\mathrm{NO}_{3}\right)_{2}$. Below 40 percent $R H$, the IDPS model cannot be validated for predicting $R H_{d}$ with the available data because the uncertainty is greater than validation criteria established in Table 7-1. Any prediction of $R H_{d}$ at low $R H$ (i.e., below 40 percent $R H$ or below 60 percent $R H$ when $\mathrm{Ca}\left(\mathrm{NO}_{3}\right)_{2}$ is a major component of the brine) will require information outside this report.

\subsubsection{Al, Br, $\mathrm{CO}_{3}, \mathrm{Cl}, \mathrm{F}, \mathrm{K}, \mathrm{Na}, \mathrm{NO}_{3}$, and $\mathrm{SO}_{4}$}

The model validation criterion for $\mathrm{Al}, \mathrm{Br}, \mathrm{CO}_{3}, \mathrm{Cl}, \mathrm{F}, \mathrm{K}, \mathrm{Na}, \mathrm{NO}_{3}$, and $\mathrm{SO}_{4}$ is to predict the total concentrations of these components within a factor of 10 (Table 7-1). Of these components, only $\mathrm{Cl}$ and $\mathrm{NO}_{3}$ predictions are used in downstream models in the TSPA-LA. However, $\mathrm{Al}, \mathrm{Br}, \mathrm{CO}_{3}$, $\mathrm{F}, \mathrm{K}, \mathrm{Na}$, and $\mathrm{SO}_{4}$ can potentially contribute directly or indirectly to IDPS model predictions of $\mathrm{Cl}$ and $\mathrm{NO}_{3}$ (Section 6.3.2), and each of the components can potentially affect predictions of $\mathrm{pH}$, ionic strength, and $R H_{d}$. 
In each of the multi-component evaporation experiments in Section 7.1, the total concentrations of $\mathrm{Br}, \mathrm{CO}_{3}, \mathrm{Cl}, \mathrm{F}, \mathrm{Na}, \mathrm{NO}_{3}$, and $\mathrm{SO}_{4}$ are predicted within a factor of 3 or less (Figure 7-3, Figure 7-7, Figure 7-10, Figure 7-12, and Figure 7-13). This factor is readily confirmed in the log-scale graphs because a line drawn at a factor of 3.16 would plot equidistantly between lines drawn at factors of 1 and 10 (i.e., $10^{1 / 2}=3.16$ ). Al was not evaluated because of a lack of evaporation data involving $\mathrm{Al}$. $\mathrm{K}$ was predicted within a factor of 3 or less in all cases except the later stages of the seawater evaporation, where K predictions differed from measurements by nearly a factor of 5 (Figure 7-12). In one of the seawater evaporation samples, the predicted Na concentration was not within a factor of 3 . However, this sample was the most concentrated sample in the seawater data set (Figure 7-12) and appears to be an outlier because of its conspicuous and implausible divergence from the general trend (e.g., Figure 7-14). Acceptance of the last data point is unjustifiable for two reasons. First, the trends established by the last data point are not supported by the trends of the preceding 48 data points. Second, as water evaporates from solution, the total molality of dissolved components in the solution cannot decrease.

For the simple salt systems evaluated in Section 7.2, model predictions of $\mathrm{Br}, \mathrm{CO}_{3}, \mathrm{Cl}, \mathrm{F}, \mathrm{K}, \mathrm{Na}$, $\mathrm{NO}_{3}$, and $\mathrm{SO}_{4}$ solubilities were almost always within a factor of 10 and nearly always within a factor of 3. In the $\mathrm{Na}-\mathrm{Ca}-\mathrm{NO}_{3}$ ternary system, the dissolved $\mathrm{NaNO}_{3}$ concentration (and associated $\mathrm{Na}$ concentration) was not predicted within a factor of 10 (Figure 7-55); however, the total dissolved $\mathrm{NO}_{3}$ concentration was predicted within a factor of 3 .

The ability of the model to predict solubilities of $\mathrm{Br}, \mathrm{CO}_{3}, \mathrm{Cl}, \mathrm{F}, \mathrm{K}, \mathrm{Na}, \mathrm{NO}_{3}$, and $\mathrm{SO}_{4}$ within a factor of 10 or better in nearly every validation simulation indicates that the model is valid for its intended use. Because $\mathrm{Cl}$ and $\mathrm{NO}_{3}$ are the only components in this group that are model outputs used directly or indirectly in TSPA-LA calculations, only the estimation of model uncertainty associated with $\mathrm{Cl}$ and $\mathrm{NO}_{3}$ is addressed below.

The maximum differences in predictions and measurements for $\mathrm{Cl}$ and $\mathrm{NO}_{3}$ in each of the Section 7.1 evaporation data sets are summarized in Table 7-7. The larger differences observed in the J-13 and Topopah Spring Tuff pore water evaporation experiments are attributed to experimental error. The J-13 and pore water evaporation experiments did not produce samples in which the activity of water decreased below about 0.91. At the temperatures of the experiments, $\mathrm{Cl}$ and $\mathrm{NO}_{3}$ should concentrate conservatively until halite precipitates. In multi-component aqueous systems, halite should not precipitate until the activity of water falls to around 0.7 or lower (e.g., Figure 6-8). Thus, the differences listed in Table 7-7 for the J-13 and pore water experiments are not attributed to model uncertainty. Instead, the differences are attributed to overestimates of the reported concentration factors, as explained and substantiated in Sections 7.1.1 and 7.1.3, and to errors inherent in analytical measurements.

The seawater samples achieve much higher salinities and lower activities of water than the J-13 and pore water evaporation experiments (Figure 7-14). Thus, $\mathrm{Cl}$ does not concentrate conservatively in the seawater evaporation, except during the early stages. At a seawater concentration factor of about 10 , the activity of water falls to approximately 0.7 whereupon halite begins to precipitate, as indicated by the plateau of the $\mathrm{Cl}$ concentration curve in Figure 7-13. Concentration factors were determined and reported more accurately in the seawater evaporation samples. Unlike the J-13 and Topopah Spring Tuff pore water evaporation experiments, the reported concentration factors for the seawater samples were directly 
determined from the measured concentration factors of non-reacting dissolved components. The maximum difference between measured and predicted $\mathrm{Cl}$ in the seawater samples is approximately 10 percent, except for an outlier at the highest degree of evaporation (Figure 7-14). $\mathrm{NO}_{3}$ was not measured in the seawater study.

The estimated model uncertainties for $\mathrm{Cl}$ and $\mathrm{NO}_{3}$ are presented in Table 7-8 as a function of $R H$. Above 85 percent $R H, \mathrm{Cl}$ and $\mathrm{NO}_{3}$ should not precipitate, as implied in Figure 7-73 by the absence of data points at $R H$ greater than 85 percent. Instead, $\mathrm{Cl}$ and $\mathrm{NO}_{3}$ should simply concentrate (or become more dilute) conservatively as water evaporates (or condenses) whenever the $R H$ is between 100 and 85 percent. Thus, the model uncertainty in $\mathrm{Cl}$ and $\mathrm{NO}_{3}$ predictions is set at zero for $R H$ between 100 and 85 percent.

As $R H$ decreases below 85 percent, the model uncertainty in $\mathrm{Cl}$ and $\mathrm{NO}_{3}$ increases, as indicated in Table 7-8 and Figure 7-73. Between 85 and 60 percent $R H$, the concentrations of these anions can be controlled by the solubilities of $\mathrm{Na}$ and $\mathrm{K}$ salts of $\mathrm{Cl}$ and $\mathrm{NO}_{3}$ (e.g., Figure 7-18, Figure 7-19, Figure 7-36, and Figure 7-37). The estimated model uncertainties in $\mathrm{Cl}$ and $\mathrm{NO}_{3}$ predictions in this $\mathrm{RH}$ range consider effects of other dissolved components, such as $\mathrm{SO}_{4}$ (Figure 7-46 and Figure 7-47), $\mathrm{CO}_{3}$ (Figure 7-54), and the effects of ternary systems involving both $\mathrm{Cl}$ and $\mathrm{NO}_{3}$ (Figure 7-73).

Based on Figure 7-73, the model appears to have a bias towards underpredicting $\mathrm{Cl}$ and $\mathrm{NO}_{3}$ concentrations in concentrated ternary salt solutions. However, a definitive conclusion along these lines is not foolproof because the data in Figure 7-73 are patchy, largely uncorroborated, and not necessarily representative of the more complex systems predicted to occur in the repository. In addition, potential bias is generally system-specific. The various ternary systems are unevenly dispersed across Figure 7-73, and the sizes of the data sets for each system are unequal. For example, most of the data shown at 24 percent $R H$ and in the 45 to 55 percent $R H$ range are for the $\mathrm{Ca}-\mathrm{Cl}-\mathrm{NO}_{3}$ system (Figure 7-61 through Figure 7-66). The data for the Na-Cl$\mathrm{NO}_{3}$ system are confined to the 50 to 70 percent $R H$ range (Figure 7-42 through Figure 7-45). While $\mathrm{Cl}$ and $\mathrm{NO}_{3}$ concentrations are generally underpredicted in these systems, it is not known whether these biases persist in more complex systems (i.e., systems involving more than three components). The contribution of experimental error in these data sets is also unknown but could be large, as suggested in Figure 7-61. Regardless of the potential bias in predicting $\mathrm{Cl}$ and $\mathrm{NO}_{3}$ concentrations, the results suggest much less overall bias in predicting the $\mathrm{Cl}_{2} \mathrm{NO}_{3}$ mole ratio, which is of paramount importance in predicting corrosion rates. For this reason and the unavailability of a sufficient set of corroborating data for multi-component systems, potential bias in predicting $\mathrm{Cl}$ and $\mathrm{NO}_{3}$ concentrations is not quantified. Instead, the potential bias is subsumed in the estimates of model uncertainty for these parameters (Table 7-8).

Below 60 percent $R H$, uncertainties in $\mathrm{Cl}$ and $\mathrm{NO}_{3}$ predictions increase markedly. In this low $R H$ range, $\mathrm{Cl}$ and $\mathrm{NO}_{3}$ concentrations can be controlled by the solubilities of $\mathrm{Ca}$ and $\mathrm{Mg}$ salts (e.g., Figure 7-20, Figure 7-21, Figure 7-38, and Figure 7-39). In addition, when temperatures are above approximately $90^{\circ} \mathrm{C}$ in this $R H$ range, $\mathrm{NO}_{3}$ concentrations can be controlled by the solubility of $\mathrm{KNO}_{3}$ (Figure 7-37). The larger differences between predictions and measurements shown in these figures justify the higher estimated model uncertainties in $\mathrm{Cl}$ and $\mathrm{NO}_{3}$ predictions at these low $R H$ values (Table 7-8). The uncertainty estimates in $\mathrm{Cl}$ and $\mathrm{NO}_{3}$ predictions in this 
RH range consider effects of $\mathrm{Na}$ (Figure 7-55 and Figure 7-57) and $\mathrm{K}$ (Figure 7-59 and Figure 7-60) and the effects of ternary systems involving both $\mathrm{Cl}$ and $\mathrm{NO}_{3}$ (Figure 7-73).

\subsubsection{Ca, $\mathrm{Mg}$, and $\mathrm{SiO}_{2}$}

The model validation criterion for $\mathrm{Ca}, \mathrm{Mg}$, and $\mathrm{SiO}_{2}$ is to predict the total concentrations of these components within a factor of 100 (Table 7-1). The larger validation range for $\mathrm{Ca}, \mathrm{Mg}$, and $\mathrm{SiO}_{2}$ recognizes the importance of kinetic limitations in the precipitation of $\mathrm{Ca}, \mathrm{Mg}$, and $\mathrm{SiO}_{2}$ minerals. Equilibrium in the short timeframes of laboratory experiments may not be attained with respect to $\mathrm{Ca}, \mathrm{Mg}$, or $\mathrm{SiO}_{2}$ species and minerals; however, they may be nearly or completely attained in the repository timeframes that the IDPS model is intended to simulate. Thus, the differences observed between IDPS model predictions and laboratory measurements may be due to slow formation of $\mathrm{Ca}, \mathrm{Mg}$, and $\mathrm{SiO}_{2}$ minerals in short-term evaporation experiments. For $\mathrm{Ca}$ and $\mathrm{Mg}$, whose solubilities are strongly affected by $\mathrm{pH}$ and total carbonate, differences may also be due to errors in the presumed values of carbon dioxide fugacity during the experiments and/or to errors in the predicted $\mathrm{pH}$ value. These effects are discussed in more detail in Section 7.1.2. As a result, the larger uncertainty in the predicted concentrations of $\mathrm{Ca}$, $\mathrm{Mg}$, and $\mathrm{SiO}_{2}$ is reflected in the validation criteria for these outputs.

The model validation criterion for $\mathrm{Ca}, \mathrm{Mg}$, and $\mathrm{SiO}_{2}$ is met in nearly every validation simulation in Section 7.1 (Figure 7-3, Figure 7-7, Figure 7-10, and Figure 7-12). The one exception is for $\mathrm{Ca}$ in the 100x J-13 evaporation experiment (Figure 7-7). The Ca concentration predicted by the IDPS model was slightly more than two orders of magnitude lower than the measured concentration. This exception may be due to the importance of slow calcite precipitation in the short-term laboratory evaporation experiments (Section 7.1.2). Processes that are only important in the short term do not fall into the scope of the intended use of the IDPS model.

In the binary evaporation simulations in Section 7.2, $\mathrm{Ca}$ and $\mathrm{Mg}$ solubilities are predicted within a factor of 10 and usually within a factor of 2 (Table 7-5, Figure 7-20, Figure 7-21, Figure 7-30, Figure 7-31, Figure 7-34, Figure 7-35, Figure 7-38, and Figure 7-39). In the ternary systems, they are always predicted within a factor of 10 and usually within a factor of 2 (Figure 7-55, Figure 7-57, Figure 7-59, Figure 7-61, Figure 7-63, Figure 7-65, and Figure 7-67).

\subsubsection{Minerals}

Because the IDPS model imposes the principle of conservation of mass, the fact that the IDPS model predicts aqueous evolution within specified model validation criteria validates the IDPS model for predicting bulk compositions of precipitated minerals. While model validation for predicting the bulk mineral composition does not imply that the model accurately predicts the exact minerals observed to precipitate in laboratory evaporation experiments (and for various reasons, it often does not, as explained in Section 7.4), this line of reasoning implies that the minerals predicted by the model to precipitate are adequate for predicting the evaporative evolution of the aqueous phase. This is important because the minerals themselves do not affect the performance of the repository. It is the potential aqueous solution produced by deliquescence or dissolution of these minerals that is important in predicting corrosion rates and radionuclide mobility. 


\subsubsection{Cl: $\mathrm{NO}_{3}$ Ratio}

Model validation criteria were not established for the $\mathrm{Cl}: \mathrm{NO}_{3}$ ratio because criteria were already established for $\mathrm{Cl}$ and $\mathrm{NO}_{3}$ separately (Table 7-1). However, the uncertainty in the $\mathrm{Cl}_{2} \mathrm{NO}_{3}$ ratio is an important consideration in corrosion calculations. Consequently, uncertainty in the $\mathrm{Cl}: \mathrm{NO}_{3}$ ratio due to IDPS model uncertainty was estimated for propagation in TSPA-LA (Table 7-8).

The maximum differences in predictions and measurements for the $\mathrm{Cl}: \mathrm{NO}_{3}$ mole ratio in the evaporation data sets in Section 7.1 are summarized in Table 7-7. Only the J-13 evaporation experiments provided measurements of both $\mathrm{Cl}$ and $\mathrm{NO}_{3}$. These experiments did not produce samples in which the activity of water decreased below about 0.91 . Because $\mathrm{Cl}$ and $\mathrm{NO}_{3}$ should concentrate conservatively in this water activity range, the differences listed in Table 7-7 are not attributed to model uncertainty. Instead, they are attributed to errors inherent in analytical measurements.

The estimated model uncertainties for the $\mathrm{Cl}: \mathrm{NO}_{3}$ mole ratio are presented in Table 7-8 as a function of $R H$. Above 85 percent $R H, \mathrm{Cl}$ and $\mathrm{NO}_{3}$ should not precipitate, as implied in Figure 7-73 by the absence of data points at $R H$ greater than 85 percent. Instead, $\mathrm{Cl}$ and $\mathrm{NO}_{3}$ should concentrate (or become more dilute) conservatively as water evaporates (or condenses) whenever the $R H$ is between 100 and 85 percent. Thus, the model uncertainty in the $\mathrm{Cl}: \mathrm{NO}_{3}$ mole ratio predictions is set at zero for $R H$ between 100 and 85 percent.

As $R H$ decreases below 85 percent, the model uncertainty in $\mathrm{Cl}$ and $\mathrm{NO}_{3}$ predictions increases, as indicated in Table 7-8 and Figure 7-73. Between 85 and 60 percent $R H$, the concentrations of $\mathrm{Cl}$ and $\mathrm{NO}_{3}$ can be controlled by the solubilities of $\mathrm{Na}$ and $\mathrm{K}$ salts (e.g., Figure 7-18, Figure 7-19, Figure 7-36, and Figure 7-37). The estimated model uncertainties in this $R H$ range consider effects of ternary systems involving both $\mathrm{Cl}$ and $\mathrm{NO}_{3}$ (Figure 7-73).

The results displayed in Figure 7-73 show no consistent bias across the $R H$ range in predicting the $\mathrm{Cl}: \mathrm{NO}_{3}$ mole ratio. The data as a whole in Figure 7-73 are patchy, largely uncorroborated, and not necessarily representative of the more complex systems predicted to occur in the repository. The experimental error in these data sets is also unknown but could be large, as suggested in Figure 7-61. For these reasons, potential bias is not quantified for predicting the $\mathrm{Cl}: \mathrm{NO}_{3}$ mole ratio. Instead, the potential bias is subsumed in the estimates of model uncertainty for this ratio (Table 7-8). Bias and its potential effect on conservatism are discussed at the beginning of Section 7.5 where Figure 7-73 is introduced.

Below 60 percent $R H$, uncertainties in $\mathrm{Cl}$ and $\mathrm{NO}_{3}$ predictions increase markedly. In this low $R H$ range, $\mathrm{Cl}$ and $\mathrm{NO}_{3}$ concentrations can be controlled by the solubilities of $\mathrm{Ca}$ and $\mathrm{Mg}$ salts (e.g., Figure 7-20, Figure 7-21, Figure 7-38, and Figure 7-39). In addition, when temperatures are above approximately $90^{\circ} \mathrm{C}$ in this $R H$ range, $\mathrm{NO}_{3}$ concentrations can be controlled by the solubility of $\mathrm{KNO}_{3}$ (Figure 7-37). Regardless of which salt controls $\mathrm{NO}_{3}$ concentrations below 60 percent $\mathrm{RH}, \mathrm{NO}_{3}$ solubility is high. The larger differences between predictions and measurements shown in these figures justify the larger estimated model uncertainties in $\mathrm{Cl}: \mathrm{NO}_{3}$ mole ratio predictions at these low $R H$ values (Table 7-8). The uncertainty estimates in $\mathrm{Cl}: \mathrm{NO}_{3}$ mole ratio predictions in this $R H$ range consider effects of ternary systems involving both $\mathrm{Cl}$ and $\mathrm{NO}_{3}$ (Figure 7-73). 


\section{INTENTIONALLY LEFT BLANK}




\section{CONCLUSIONS}

Evaporation can have a profound effect on the chemical composition of water that could potentially seep into the repository. It can turn dilute ground water into a corrosive brine, and complete evaporation can result in the precipitation of hygroscopic salts. The in-drift precipitates/salts (IDPS) model is developed to predict the effects of evaporation on water composition and mineral precipitation in the repository for TSPA-LA. This report documents the development, validation, use, limitations, and uncertainties of this model.

\subsection{MODEL DESCRIPTION}

In accordance with the purpose and scope of this modeling activity, a model is developed, validated, and documented to predict the effects of evaporation and deliquescence on the chemical evolution of potential aqueous solutions within the repository. The resulting model, called the IDPS model, is designed for the system Na-K-H-Mg-Ca-Al-Cl-F-NO $\mathrm{N}_{3}-\mathrm{SO}_{4}-\mathrm{Br}_{-} \mathrm{CO}_{3}-$ $\mathrm{SiO}_{2}-\mathrm{CO}_{2}-\mathrm{O}_{2}-\mathrm{H}_{2} \mathrm{O}$. This system encompasses the major ion chemistry output parameters potentially important to downstream models used to predict corrosion, colloid stability, degradation of EBS materials, dust deliquescence, and radionuclide transport. These output parameters include $\mathrm{pH}$, ionic strength, total aqueous concentrations of chemical components, deliquescence relative humidity, aqueous concentrations of species that potentially contribute to acid-neutralizing capacity, and mineral precipitation. A full description of the model and its integration is provided in Section 6.

\subsection{DEVELOPED OUTPUTS}

The outputs developed in this report are listed in Table 8-1 along with references to their associated uncertainty. Titles and descriptions of outputs are modified in the table to improve readability. Actual titles can be found in Section 9. A more complete discussion of uncertainty is presented in Section 8.4.

Table 8-1. Developed Output

\begin{tabular}{|c|c|c|}
\hline Output DTN & Output Description & Output Uncertainty \\
\hline $\begin{array}{l}\text { SN0306T0510102.007 } \\
\text { Pitzer database } \\
\text { spreadsheets and EQ3/6 } \\
\text { input/output files }\end{array}$ & $\begin{array}{l}\text { Spreadsheet collection of } \\
\text { thermodynamic data for Pitzer ion- } \\
\text { interaction parameters and related } \\
\text { EQ3/6 input/output files. Output used } \\
\text { indirectly in TSPA-LA calculations. }\end{array}$ & $\begin{array}{l}\text { Output uncertainty is within model validation } \\
\text { criteria specified in the TWP (BSC } 2004 \\
\text { [DIRS 171156]) (Section 7). }\end{array}$ \\
\hline $\begin{array}{l}\text { SN0302T0510102.002 } \\
\text { Pitzer thermodynamic } \\
\text { database data0.ypf }\end{array}$ & $\begin{array}{l}\text { The Pitzer thermodynamic database } \\
\text { developed in Appendix I. Output used } \\
\text { indirectly in TSPA-LA calculations. }\end{array}$ & $\begin{array}{l}\text { This database is validated for the intended } \\
\text { use of the IDPS model by the results of the } \\
\text { validation runs. Model output predictions } \\
\text { are within the uncertainty ranges specified in } \\
\text { the validation criteria (Table } 7-1 \text { ). }\end{array}$ \\
\hline $\begin{array}{l}\text { LL031106231032.007 } \\
\text { Solubility and vapor } \\
\text { pressure data for aqueous } \\
\text { systems containing single } \\
\text { and multiple salts }\end{array}$ & $\begin{array}{l}\text { Compilation and unit conversion of } \\
\text { solubility and vapor pressure data in } \\
\text { binary and ternary salt systems for a } \\
\text { wide range of temperatures. Output } \\
\text { used indirectly in TSPA-LA calculations. }\end{array}$ & $\begin{array}{l}\text { Uncertainty in these data are due to source } \\
\text { uncertainty in original experiments and } \\
\text { measurements. }\end{array}$ \\
\hline
\end{tabular}


Table 8-1. Developed Output (Continued)

\begin{tabular}{|c|c|c|}
\hline Output DTN & Output Description & Output Uncertainty \\
\hline $\begin{array}{l}\text { MO0303SPAMNSUP.000 } \\
\text { Base case mineral } \\
\text { suppressions }\end{array}$ & $\begin{array}{l}\text { A list of minerals typically suppressed in } \\
\text { the IDPS model when using the Pitzer } \\
\text { thermodynamic database. Output not } \\
\text { used directly or indirectly in TSPA-LA } \\
\text { calculations. }\end{array}$ & $\begin{array}{l}\text { This list is validated for the intended use of } \\
\text { the IDPS model by the results of the } \\
\text { validation runs. Model output predictions } \\
\text { are within the uncertainty ranges specified in } \\
\text { the validation criteria (Table } 7-1 \text { ). }\end{array}$ \\
\hline $\begin{array}{l}\text { MO0303SPAMEQ36.000 } \\
\text { IDPS model input file } \\
\text { templates }\end{array}$ & $\begin{array}{l}\text { EQ3/6 input file templates for the IDPS } \\
\text { model. Output used indirectly in TSPA- } \\
\text { LA calculations. }\end{array}$ & Not applicable. \\
\hline $\begin{array}{l}\text { MO0303MWDJ13RB.000 } \\
\mathrm{J}-13 \text { validation runs }\end{array}$ & $\begin{array}{l}\text { EQ3/6 files resulting from IDPS model } \\
\text { simulation of the synthetic J-13 } \\
\text { evaporation experiments performed by } \\
\text { Rosenberg et al. } 1999 \text { [DIRS } 125338 \text { ]. } \\
\text { Output not used directly or indirectly in } \\
\text { TSPA-LA calculations. }\end{array}$ & $\begin{array}{l}\text { Predictions for all model output parameters } \\
\text { are within the uncertainty ranges specified in } \\
\text { the validation criteria (Table } 7-1 \text { ). }\end{array}$ \\
\hline $\begin{array}{l}\text { MO0303MWDJ13GD.000 } \\
\text { 100x J-13 validation runs }\end{array}$ & $\begin{array}{l}\text { EQ3/6 files resulting from IDPS model } \\
\text { simulation of the synthetic } 100 x \mathrm{~J}-13 \\
\text { starting water evaporation experiment } \\
\text { documented in BSC } 2001 \text { [DIRS } \\
\text { 155640], pp. } 6 \text { to } 16 \text {. Output not used } \\
\text { directly or indirectly in TSPA-LA } \\
\text { calculations. }\end{array}$ & $\begin{array}{l}\text { Predictions for all model output parameters } \\
\text { are within the uncertainty ranges specified in } \\
\text { the validation criteria (Table } 7-1 \text { ). }\end{array}$ \\
\hline $\begin{array}{l}\text { MO0303MWDTSWRB. } 000 \\
\text { TSw pore water validation } \\
\text { runs }\end{array}$ & $\begin{array}{l}\text { EQ3/6 files resulting from IDPS model } \\
\text { simulation of the synthetic Topopah } \\
\text { Spring Tuff pore water evaporation } \\
\text { experiments performed by Rosenberg } \\
\text { et al. } 1999 \text { [DIRS 125339]. Output not } \\
\text { used directly or indirectly in TSPA-LA } \\
\text { calculations. }\end{array}$ & $\begin{array}{l}\text { Predictions for all model output parameters } \\
\text { are within the uncertainty ranges specified in } \\
\text { the validation criteria (Table } 7-1 \text { ). }\end{array}$ \\
\hline $\begin{array}{l}\text { MO0303MWDSEDSS.000 } \\
\text { Simple salt validation runs }\end{array}$ & $\begin{array}{l}\text { EQ3/6 files resulting from IDPS model } \\
\text { simulations of the evaporation of dilute } \\
\text { salt solutions at } 25^{\circ} \mathrm{C} \text { and } 100^{\circ} \mathrm{C} \text {. } \\
\text { Output not used directly or indirectly in } \\
\text { TSPA-LA calculations. }\end{array}$ & $\begin{array}{l}\text { Predictions for all model output parameters } \\
\text { are within the uncertainty ranges specified in } \\
\text { the validation criteria (Table 7-1). }\end{array}$ \\
\hline $\begin{array}{l}\text { MO0303MWDINJ13.000 } \\
\text { Pitzer vs. data0.ymp.R2 } \\
\text { validation runs }\end{array}$ & $\begin{array}{l}\text { EQ3/6 files resulting from IDPS model } \\
\text { simulations of the evaporation of in situ } \\
\mathrm{J}-13 \text { well water using different } \\
\text { thermodynamic databases (Pitzer } \\
\text { versus data0.ymp.R2). Output not used } \\
\text { directly or indirectly in TSPA-LA } \\
\text { calculations. }\end{array}$ & $\begin{array}{l}\text { Predictions for all model output parameters } \\
\text { are within the uncertainty ranges specified in } \\
\text { the validation criteria (Table 7-1). }\end{array}$ \\
\hline $\begin{array}{l}\text { MO0303MWDIOJ13.000 } \\
\text { J-13 example abstraction } \\
\text { runs }\end{array}$ & $\begin{array}{l}\text { Example IDPS model EQ3/6 } \\
\text { input/output files for in situ J-13 well } \\
\text { water. Output not used directly or } \\
\text { indirectly in TSPA-LA calculations. }\end{array}$ & $\begin{array}{l}\text { Uncertainty in input values are not identified } \\
\text { and propagated in this example application. } \\
\text { Propagation of uncertainty is performed in } \\
\text { downstream analyses that use the model. } \\
\text { Uncertainty due to model uncertainty is } \\
\text { estimated and summarized in Section 7.5. }\end{array}$ \\
\hline $\begin{array}{l}\text { MO0304SPAJ13IS.001 } \\
\text { J-13 example lookup } \\
\text { tables }\end{array}$ & $\begin{array}{l}\text { Example IDPS model EQ3/6 lookup } \\
\text { tables for in situ J-13 well water. } \\
\text { Output not used directly or indirectly in } \\
\text { TSPA-LA calculations. }\end{array}$ & $\begin{array}{l}\text { Uncertainty in input values are not identified } \\
\text { and propagated in this example application. } \\
\text { Propagation of uncertainty is performed in } \\
\text { downstream analyses that use the model. } \\
\text { Uncertainty due to model uncertainty is } \\
\text { estimated and summarized in Section } 7.5 \text {. }\end{array}$ \\
\hline
\end{tabular}


Table 8-1. Developed Output (Continued)

\begin{tabular}{|c|c|c|}
\hline Output DTN & Output Description & Output Uncertainty \\
\hline $\begin{array}{l}\text { MO0307MWDSEAEV.000 } \\
\text { Seawater evaporation } \\
\text { predictions using the IDPS } \\
\text { model }\end{array}$ & $\begin{array}{l}\text { EQ3/6 files and spreadsheets resulting } \\
\text { from IDPS model simulation of the } \\
\text { evaporation of seawater. Output not } \\
\text { used directly or indirectly in TSPA-LA } \\
\text { calculations. }\end{array}$ & $\begin{array}{l}\text { Uncertainty due to model uncertainty is } \\
\text { estimated and summarized in Section } 7.5 \text {. }\end{array}$ \\
\hline $\begin{array}{l}\text { MO0307MWDUNEVP.000 } \\
\text { Uncertainties in } \\
\text { evaporation predictions } \\
\text { using the IDPS model }\end{array}$ & $\begin{array}{l}\text { EQ3/6 files and spreadsheets resulting } \\
\text { from IDPS model prediction of } \\
\text { deliquescence points and "measured" } \\
\text { ionic strength. Output not used directly } \\
\text { or indirectly in TSPA-LA calculations. }\end{array}$ & $\begin{array}{l}\text { Uncertainty due to model uncertainty is } \\
\text { estimated and summarized in Section } 7.5 \text {. }\end{array}$ \\
\hline $\begin{array}{l}\text { MO0308SPAUCIMV.000 } \\
\text { Uncertainty comparisons } \\
\text { in IDPS model validation } \\
\text { cases }\end{array}$ & $\begin{array}{l}\text { Summary of the relative percent } \\
\text { differences (RPD values) between } \\
\text { predictions and measurements in all of } \\
\text { the IDPS model validation runs with } \\
\text { regard to } \mathrm{pH} \text {, ionic strength, } \mathrm{Cl} \\
\text { concentration, } \mathrm{NO}_{3} \text { concentration, } \\
\mathrm{Cl}: \mathrm{NO}_{3} \text { concentration ratio, and } \\
\text { deliquescence relative humidity. } \\
\text { Output not used directly or indirectly in } \\
\text { TSPA-LA calculations. }\end{array}$ & $\begin{array}{l}\text { There is no uncertainty in these data. The } \\
\text { accuracy of these data can be checked by } \\
\text { consulting the source DTNs. }\end{array}$ \\
\hline $\begin{array}{l}\text { MO0311MWDMVBTS.000 } \\
\text { IDPS model validation files } \\
\text { for binary and ternary } \\
\text { systems }\end{array}$ & $\begin{array}{l}\text { EQ3/6 files and spreadsheets resulting } \\
\text { from IDPS model simulation of binary } \\
\text { and ternary systems. Output not used } \\
\text { directly or indirectly in TSPA-LA } \\
\text { calculations. }\end{array}$ & $\begin{array}{l}\text { Uncertainty due to model uncertainty is } \\
\text { estimated and summarized in Section } 7.5 \text {. }\end{array}$ \\
\hline $\begin{array}{l}\text { MO0312SPAESMUN.002 } \\
\text { Estimated model } \\
\text { uncertainties in IDPS } \\
\text { model outputs }\end{array}$ & $\begin{array}{l}\text { Estimated model uncertainties in } \mathrm{pH} \text {, } \\
\text { ionic strength, } \mathrm{Cl} \text { concentration, } \mathrm{NO}_{3} \\
\text { concentration, } \mathrm{Cl}: \mathrm{NO}_{3} \text { concentration } \\
\text { ratio, and deliquescence relative } \\
\text { humidity. Output used indirectly in } \\
\text { TSPA-LA calculations. }\end{array}$ & $\begin{array}{l}\text { These estimates of uncertainties are justified } \\
\text { and supported by the results of the model } \\
\text { validation simulations, as explained in } \\
\text { Section } 7.5 \text {. }\end{array}$ \\
\hline $\begin{array}{l}\text { MO0410SPAPITZR.000 } \\
\text { Revised Pitzer } \\
\text { thermodynamic database } \\
\text { data0.yp1 }\end{array}$ & $\begin{array}{l}\text { The Pitzer database revised to correct } \\
\text { the log } \mathrm{K} \text { values of seven zeolites }\end{array}$ & $\begin{array}{l}\text { This database is validated for the intended } \\
\text { use of the IDPS model by the qualification of } \\
\text { the inputs. Model output predictions are } \\
\text { within the uncertainty ranges specified in the } \\
\text { validation criteria (Table } 7-1 \text { ). }\end{array}$ \\
\hline $\begin{array}{l}\text { MO0410MWDIDPSM.000 } \\
\text { IDPS model calculations } \\
\text { addressing model } \\
\text { sensitivity of zeolite log K } \\
\text { corrections }\end{array}$ & $\begin{array}{l}\text { EQ3/6 files and spreadsheets resulting } \\
\text { from IDPS model sensitivity analysis } \\
\text { used to evaluate the effects of log K } \\
\text { corrections of seven zeolites. }\end{array}$ & $\begin{array}{l}\text { Predictions for all model output parameters } \\
\text { are within the uncertainty ranges specified in } \\
\text { the validation criteria (Table } 7-1 \text { ). }\end{array}$ \\
\hline
\end{tabular}




\subsection{MODEL ABSTRACTION}

The IDPS model can be used to generate lookup tables for downstream modeling and uncertainty analyses. The model is primarily designed to generate lookup tables for the incoming water compositions predicted by the thermal-hydrological-chemical model and for the deliquescence of dust. The resulting lookup tables are documented elsewhere, such as in Engineered Barrier System: Physical and Chemical Environment Model (BSC 2004 [DIRS 169860]).

IDPS model lookup tables provide model parameter outputs for a full range of equilibrium relative humidity values and steady-state relative evaporation rate values (Section 6.6.3.5). These tables are designed to define a response surface from which IDPS model outputs can be obtained or interpolated for given incoming water compositions.

\subsection{UNCERTAINTY AND LIMITATIONS}

The IDPS model has several uncertainties and limitations. Model uncertainties include uncertainties related to individual aspects of the IDPS model, such as the conceptual model, model equations, selected mineral suppressions, and constants in the thermodynamic database. Model limitations include simplifying assumptions and validation ranges.

The IDPS model is a simplification of the effects of evaporation and deliquescence on the chemistry and quantity of liquid water within the drift. Use of the model is limited to the system $\mathrm{Na}-\mathrm{K}-\mathrm{H}-\mathrm{Mg}-\mathrm{Ca}-\mathrm{Al}-\mathrm{Cl}-\mathrm{F}-\mathrm{NO}_{3}-\mathrm{SO}_{4}-\mathrm{Br}-\mathrm{CO}_{3}-\mathrm{SiO}_{2}-\mathrm{CO}_{2}-\mathrm{O}_{2}-\mathrm{H}_{2} \mathrm{O}$ and temperatures between $0^{\circ} \mathrm{C}$ and $140^{\circ} \mathrm{C}$. This system implies oxidizing conditions at all times, which is defined in this report as maintaining an oxygen fugacity of at least $10^{-9}$ bars (Section 4.1.2). Two assumptions also limit the model. The aqueous solutions in the drift are assumed to be at standard state (Section 5.1), and chemical equilibrium conditions are assumed for all reactions except for certain minerals that are not allowed to precipitate (Section 5.2). Another exception to Assumption 5.2 is that the solution does not have to be at equilibrium with respect to relative humidity when necessary inputs are provided for steady-state predictions (Section 6.6.3.3).

With one exception, the IDPS model is validated for its intended use. The intended use of this model is to estimate and tabulate, within an appropriate level of confidence, the effects of evaporation, deliquescence, and potential environmental conditions on the $\mathrm{pH}$, ionic strength, and chemical compositions of water and minerals on the drip shield or other location within the drift during the postclosure period for temperatures between $0^{\circ} \mathrm{C}$ and $140^{\circ} \mathrm{C}$. The exception is the prediction of deliquescence relative humidity at $R H$ below 40 percent and whenever $\mathrm{Ca}\left(\mathrm{NO}_{3}\right)_{2}$ is a major component of the brine at $R H$ below 60 percent. Under these conditions, the deliquescence relative humidity predictions are often more than 20 percent in $R H$ units above reported values. This difference exceeds both the \pm 10 percent ( $R H$ units) validation criterion adopted in Section 7 (Table 7-1) and the \pm 15 percent ( $R H$ units) validation criterion suggested in the TWP (BSC 2004 [DIRS 171156]). In this lower $R H$ range, larger uncertainties in solute behavior result in larger differences between model predictions and reported measurements. Because the validation criteria are exceeded for predicting deliquescence relative humidity when $R H$ is below 40 percent and whenever $\mathrm{Ca}\left(\mathrm{NO}_{3}\right)_{2}$ is a major component of the brine at $R H$ below 60 percent, any predictions of deliquescence relative humidity under these conditions will require information outside of this report. 
There are several sources for model uncertainty. First, there is uncertainty associated with the conceptual model. To evaluate this uncertainty, a number of alternative conceptual models are considered (Section 6.5). Most are not utilized, however, because they either are not as realistic as the IDPS model, do not provide the types of outputs requested of the IDPS model, or do not cover the necessary ranges of applicability. The two conceptual models that are retained and incorporated into the IDPS model are the equilibrium model (Figure 6-1) and the steady-state alternative conceptual model (Figure 6-3). Both of these conceptual models are represented in the IDPS model output templates (Section 6.6.3.5).

Another model uncertainty is the choice of mineral suppressions. Not all minerals in the Pitzer database are expected to precipitate rapidly upon supersaturation under the temperature and pressure conditions anticipated in the repository. Because the IDPS model is used to produce model abstractions that are time-invariant, decisions must be made regarding which minerals are allowed and not allowed to precipitate in the repository. A methodology is developed in this report to aid in making these decisions (Section 6.6.2.6). For instances in which the decision is uncertain, uncertainty analyses are recommended.

Additional model uncertainties are uncertainties in the thermodynamic constants, such as equilibrium constants and Pitzer coefficients. The values of these constants control the interactions and solubilities of dissolved components, which ultimately control the evaporative evolution of a given input water and the deliquescence of a given salt assemblage.

The IDPS model uncertainties identified above are assessed as a whole in the model validation section by comparing model predictions to independent evaporation data, solubility data, and deliquescence relative humidity data (Section 7). This assessment is summarized in Section 7.5. Specifically, the validation involved comparisons of model predictions to:

- four sets of evaporation data (synthetic average J-13 well water, synthetic average 100x J-13 well water, synthetic Topopah Spring Tuff pore water, and seawater) (Section 7.1)

- solubilities of 24 salts in binary systems at temperatures ranging from $25^{\circ} \mathrm{C}$ to $140^{\circ} \mathrm{C}$ (Sections 7.2.1.1.1 and 7.2.1.2.1)

- solubilities of numerous salts in ternary salt systems at various temperatures (Section 7.2.2)

- deliquescence relative humidity $\left(R H_{d}\right)$ of numerous binary salt solutions at various temperatures (Sections 7.2.1.1.2 and 7.2.1.2.2)

- evaporation predictions using the data0.ymp.R2 database up to an ionic strength of 1 molal (Section 7.3).

The results of the comparisons include the following:

- $\mathrm{pH}$ was always predicted within $0.78 \mathrm{pH}$ units or less of reported measurements (Section 7.5.1).

- Ionic strength was always predicted within 67 percent or less (Section 7.5.2). 
- Deliquescence relative humidity $\left(R H_{d}\right)$ of single salt solutions was always (except for $\left.\mathrm{Ca}\left(\mathrm{NO}_{3}\right)_{2}\right)$ predicted within 10 percent of reported measurements (in $R H$ units) when the predicted $R H_{d}$ exceeded 40 percent (Section 7.5.3).

- $\mathrm{Br}, \mathrm{CO}_{3}, \mathrm{Cl}, \mathrm{F}, \mathrm{Na}, \mathrm{K}, \mathrm{NO}_{3}$, and $\mathrm{SO}_{4}$ concentrations were nearly always predicted within a factor of 3 or less (Section 7.5.4).

- $\mathrm{Ca}, \mathrm{Mg}$, and $\mathrm{Si}$ concentrations were always predicted within a factor of approximately 100 or less (Section 7.5.5).

These observed differences between predictions and measurements are attributed to three types of uncertainties: model uncertainties, uncertainties in analytical measurements, and errors in the reported concentration factors in two of the laboratory evaporation experiments (Section 7.5).

Uncertainties owing to model uncertainty alone are estimated for $\mathrm{pH}$, ionic strength, $\mathrm{Cl}$ concentration, $\mathrm{NO}_{3}$ concentration, the $\mathrm{Cl}: \mathrm{NO}_{3}$ ratio, and $R H_{d}$, as presented in Table 7-8. These estimates are established as a function of $R H$ because the uncertainties are highly correlated with $R H$ (Figure 7-73). At high $R H$ (i.e., dilute solutions), uncertainty is low because the evaporative evolution of the aqueous solution is undersaturated with respect to the major salt solubility boundaries that primarily control the concentrations of the major ions in the aqueous phase. At lower $R H$, ionic strength rises into the range where Pitzer interaction coefficients begin to control the chemical divides. In this lower $R H$ range, uncertainties owing to Pitzer interaction coefficients, salt solubility products in the Pitzer database, and other model uncertainties result in larger differences between model predictions and reported measurements. The estimated model uncertainties are supported and justified by the validation in Section 7, as summarized in Section 7.5. Potential model bias is not quantified but appears to be generally in the direction of conservatism with respect to TSPA-LA corrosion modeling, as discussed in Section 7.5.

\subsection{YUCCA MOUNTAIN REVIEW PLAN CRITERIA ASSESSMENT}

This section provides responses to the YMRP acceptance criteria identified in the TWP as applicable to this report. The acceptance criteria for the quantity and chemistry of water contacting engineered barriers and waste forms are referenced from Section 2.2.1.3.3.3 of NRC (2003 [DIRS 163274]) and 10 CFR 63.114(a)-(c) and (e)-(g).

\subsubsection{Acceptance Criterion 1 - System Description and Model Integration Are Adequate}

(1) Total system performance assessment adequately incorporates important design features, physical phenomena, and couplings, and uses consistent and appropriate assumptions throughout the quantity and chemistry of water contacting engineered barriers and waste forms abstraction process.

Development of the model documented in this report requires only qualitative design information and is based on physical phenomena expected within repository drifts (Section 6.4). Thermal-chemical coupled processes are incorporated in the model. Other coupled processes, in addition to thermal-chemical coupled processes, are primarily addressed in Engineered Barrier System Features, Events, and Processes (BSC 2004 [DIRS 169898]). Model assumptions are 
consistent and appropriate for the quantity and chemistry of water contacting engineered barriers and waste forms abstraction process (Section 5).

(2) The abstraction of the quantity and chemistry of water contacting engineered barriers and waste forms uses assumptions, technical bases, data, and models, that are appropriate and consistent with other related U.S. Department of Energy abstractions. For example, the assumptions used for the quantity and chemistry of water contacting engineered barriers and waste forms are consistent with the abstractions of "Degradation of Engineered Barriers" (Section 2.2.1.3.1); "Mechanical Disruption of Waste Packages" (Section 2.2.1.3.2); "Radionuclide Release Rates and Solubility Limits" (Section 2.2.1.3.4); "Climate and Infiltration" (Section 2.2.1.3.5); and "Flow Paths in the Unsaturated Zone" (Section 2.2.1.3.6). The descriptions and technical bases provide transparent and traceable support for the abstraction of quantity and chemistry of water contacting engineered barriers and waste forms.

The model developed in this report uses the same technical bases and other information as are used in other TSPA-LA supporting documents concerned with the chemistry of water contacting engineered barriers and waste forms. The conceptual model and assumptions that form the basis for this report are consistent with other system conceptual models and assumptions. One of the primary purposes of this model is to take abstracted output from the unsaturated zone thermalhydrological-chemical model to predict in-drift water chemistry. These predictions are documented in Engineered Barrier System: Physical and Chemical Environment Model (BSC 2004 [DIRS 169860]). Input water fluxes are addressed in Seepage Model for PA Including Drift Collapse (BSC 2003 [DIRS 167652]).

(3) Important design features, such as waste package design and material selection, drip shield, ground support, thermal loading strategy, and degradation processes, are adequate to determine the initial and boundary conditions for calculations of the quantity and chemistry of water contacting engineered barriers and waste forms.

Initial and boundary conditions are taken from the predictions of the thermal-hydrologicalchemical model. Design features of the engineered barrier systems affect the predictions of the thermal-hydrological-chemical model, which in turn adequately determine the initial and boundary conditions for the IDPS model. Input water fluxes are addressed in Seepage Model for PA Including Drift Collapse (BSC 2004 [DIRS 167652]).

(4) Spatial and temporal abstractions appropriately address physical couplings (thermal-hydrologic-mechanical-chemical). For example, the U.S. Department of Energy evaluates the potential for focusing of water flow into drifts, caused by coupled thermal-hydrologic-mechanical-chemical processes.

This report develops and validates a process model in support of TSPA-LA. Abstractions using this model are documented in Engineered Barrier System: Physical and Chemical Environment Model (BSC 2004 [DIRS 169860]). 
(5) Sufficient technical bases and justification are provided for total system performance assessment assumptions and approximations for modeling coupled thermal-hydrologic-mechanical-chemical effects on seepage and flow, the waste package chemical environment, and the chemical environment for radionuclide release. The effects of distribution of flow on the amount of water contacting the engineered barriers and waste forms are consistently addressed, in all relevant abstractions.

Thermal-chemical effects are included in this model. Other coupled thermal-hydrologicalmechanical-chemical effects, in addition to thermal-chemical coupled effects, are primarily discussed in Engineered Barrier System Features, Events, and Processes (BSC 2004 [DIRS 169898]). Distribution of flow within the drift is addressed in Seepage Model for PA Including Drift Collapse (BSC 2004 [DIRS 167652]).

(6) The expected ranges of environmental conditions within the waste package emplacement drifts, inside of breached waste packages, and contacting the waste forms and their evolution with time are identified. These ranges may be developed to include: (i) the effects of the drip shield on the quantity and chemistry of water (e.g., the potential for condensate formation and dripping from the underside of the shield); (ii) conditions that promote corrosion of engineered barriers and degradation of waste forms; (iii) irregular wet and dry cycles; (iv) gamma-radiolysis; and (v) size and distribution of penetrations of engineered barriers.

The model is developed for the expected ranges of environmental conditions within the drifts, including temperature, relative humidity, redox conditions, fugacity of carbon dioxide, and relevant aqueous component concentrations (Section 4.1.2). The model is designed to predict the stability and composition of water contacting engineered barriers resulting from processes of evaporation, deliquescence, condensation, and chemical equilibria.

(7) The model abstraction for quantity and chemistry of water contacting engineered barriers and waste forms is consistent with the detailed information on waste package design and other engineered features. For example, consistency is demonstrated for: (i) dimensionality of the abstractions; (ii) various design features and site characteristics; and (iii) alternative conceptual approaches. Analyses are adequate to demonstrate that no deleterious effects are caused by design or site features that the U.S. Department of Energy does not take into account in this abstraction.

This report develops and validates a process model in support of TSPA-LA. Abstractions using this model are documented in Engineered Barrier System: Physical and Chemical Environment Model (BSC 2004 [DIRS 169860]).

(8) Adequate technical bases are provided, including activities such as independent modeling, laboratory or field data, or sensitivity studies, for inclusion of any thermal-hydrologic-mechanical-chemical couplings and features, events, and processes. 
Adequate technical bases are provided in Sections 6.4 and 6.6 for thermal-chemical couplings included in the IDPS model. Technical bases for features, events, and processes included in the model are provided in Sections 4.1.2, 5.2, 6.4, and 6.6.3.5, as summarized in Section 6.2. Technical bases for this model include laws of thermodynamics, conservation of mass, and chemical reaction data as a function of temperature.

(9) Performance-affecting processes that have been observed in thermal-hydrologic tests and experiments are included in the performance assessment. For example, the U.S. Department of Energy either demonstrates that liquid water will not reflux into the underground facility or incorporates refluxing water into the performance assessment calculation, and bounds the potential adverse effects of alteration of the hydraulic pathway that result from refluxing water.

The IDPS model incorporates processes of evaporation, deliquescence, condensation, and chemical equilibria to predict the chemical composition and presence of liquid water in the drift, which are potentially important to total system performance assessment. The model is used in Engineered Barrier System: Physical and Chemical Environment Model (BSC 2004 [DIRS 169860]) to include these processes in the performance assessment. Water fluxes are addressed in Seepage Model for PA Including Drift Collapse (BSC 2004 [DIRS 167652]).

(10) Likely modes for container corrosion (Section 2.2.1.3.1 of the Yucca Mountain Review Plan) are identified and considered in determining the quantity and chemistry of water entering the engineered barriers and contacting waste forms. For example, the model abstractions consistently address the role of parameters, such as $\mathrm{pH}$, carbonate concentration, and the effect of corrosion on the quantity and chemistry of water contacting engineered barriers and waste forms.

The IDPS model addresses the roles of chemical and physical parameters on the chemical evolution and stability of water contacting engineered barriers. Abstractions using this model are documented in Engineered Barrier System: Physical and Chemical Environment Model (BSC 2004 [DIRS 169860]). Corrosion and its effects are addressed in General Corrosion and Localized Corrosion of Waste Package Outer Barrier (BSC 2004 [DIRS 169984]). Water fluxes are addressed in Seepage Model for PA Including Drift Collapse (BSC 2004 [DIRS 167652]).

(12) Guidance in NUREG-1297 (Altman et al. 1988 [DIRS 103597]) and NUREG1298 (Altman et al. 1988 [DIRS 103750]), or other acceptable approaches, is followed.

Technical inputs were selected and documented according to applicable BSC procedures, which comply with NUREG-1298 (see Section 4.1).

\subsubsection{Acceptance Criterion 2 - Data Are Sufficient for Model Justification}

(1) Geological, hydrological, and geochemical values used in the license application are adequately justified. Adequate description of how the data were used, interpreted, and appropriately synthesized into the parameters is provided. 
Sources of input data are contained in Section 4.1.2 and tabulated in the DIRS. The thermodynamic data used in this model are internationally accepted (Appendix I) and other geochemical data are adequately justified (Sections 6 and 7). Site specific data are used to justify and validate the model (Section 4.4 and 7.1). The data providing the basis for characterizing model uncertainty include laboratory evaporation data obtained from evaporation experiments of synthetic J-13 well water and Topopah Spring Tuff pore water (Sections 7.1.1 through 7.1.3), seawater evaporation data (Section 7.1.4), and salt solubility and vapor pressure data for binary and ternary salt solutions from chemistry handbooks and literature compilations (Section 7.2). Adequate description of how the data were used, interpreted, and synthesized are included in these sections.

(2) Sufficient data were collected on the characteristics of the natural system and engineered materials to establish initial and boundary conditions for conceptual models of thermal-hydrologic-mechanical-chemical coupled processes, that affect seepage and flow and the waste package chemical environment.

Data collected for this model are sufficient to establish initial and boundary conditions for the thermal-chemical coupled processes that affect the composition and chemical stability of seepage water in the drift chemical environment (Section 4.1). Abstractions using this model are documented in Engineered Barrier System: Physical and Chemical Environment Model (BSC 2004 [DIRS 169860]). Water fluxes are addressed in Seepage Model for PA Including Drift Collapse (BSC 2004 [DIRS 167652]).

(4) Sufficient information to formulate the conceptual approach(es) for analyzing water contact with the drip shield, engineered barriers, and waste forms is provided.

Sufficient information to formulate the conceptual approach for predicting the chemical evolution and chemical stability of water in contact with the drip shield and other engineered barriers is provided in Section 6.4. In-Package Chemistry Abstraction (BSC 2004 [DIRS 167621]) addresses water in contact with the waste form.

\subsubsection{Acceptance Criterion 3 - Data Uncertainty Is Characterized and Propagated Through the Model Abstraction}

(1) Models use parameter values, assumed ranges, probability distributions, and bounding assumptions that are technically defensible, reasonably account for uncertainties and variabilities, and do not result in an under-representation of the risk estimate.

The parameter ranges and bounding assumptions of the model are defined in Sections 4.1 .2 and 5 and are considered representative of the system. Although the model is designed for use in downstream abstractions, input parameters (Table 4-5) are developed in this report to be consistent with the expected ranges of values for upstream and downstream modeled systems. Values and ranges of these parameters are reasonable and do not result in under-representation of the risk estimate. Values for these parameters are determined in applications of the model, such 
as the TSPA application documented in Engineered Barrier System: Physical and Chemical Environment Model (BSC 2004 [DIRS 169860]).

(2) Parameter values, assumed ranges, probability distributions, and bounding assumptions used in the total system performance assessment calculations of quantity and chemistry of water contacting engineered barriers and waste forms are technically defensible and reasonable, based on data from the Yucca Mountain region (e.g., results from large block and drift-scale heater and niche tests), and a combination of techniques that may include laboratory experiments, field measurements, natural analog research, and process-level modeling studies.

Validation of this model uses data obtained in laboratory evaporation experiments in which the initial waters reflect water types observed at Yucca Mountain (Section 7.1). These experiments provide adequate data for justification of the model and its parameters for Yucca Mountain applications.

(3) Input values used in the total system performance assessment calculations of quantity and chemistry of water contacting engineered barriers (e.g., drip shield and waste package) are consistent with the initial and boundary conditions and the assumptions of the conceptual models and design concepts for the Yucca Mountain site. Correlations between input values are appropriately established in the U.S. Department of Energy total system performance assessment. Parameters used to define initial conditions, boundary conditions, and computational domain in sensitivity analyses involving coupled thermal-hydrologic-mechanicalchemical effects on seepage and flow, the waste package chemical environment, and the chemical environment for radionuclide release, are consistent with available data. Correlations of uncertainties in IDPS model outputs are propagated in TSPA as discussed in Section 6.12 of Engineered Barrier System: Physical and Chemical Environment Model (BSC 2004 [DIRS 169860]). Reasonable or conservative ranges of parameters or functional relations are established.

The ranges of parameters developed in this report are consistent with initial and boundary conditions common to other TSPA conceptual models and are compatible with design concepts. This report uses the same technical bases and other information as are used in other LA supporting documents concerned with waste package and waste form performance, such as General Corrosion and Localized Corrosion of Waste Package Outer Barrier (BSC 2004 [DIRS 169984]) and In-Package Chemistry Abstraction (BSC 2004 [DIRS 167621] Section 4) and supporting documents. The conceptual model that forms the basis for this report is consistent with other engineered system models and repository design. Reasonable ranges of parameters are established in Section 4.1.2.

(4) Adequate representation of uncertainties in the characteristics of the natural system and engineered materials is provided in parameter development for conceptual models, process-level models, and alternative conceptual models. The U.S. Department of Energy may constrain these uncertainties using sensitivity analyses or conservative limits. For example, the U.S. Department of Energy 
demonstrates how parameters used to describe flow through the engineered barrier system bound the effects of excavation-induced changes.

Uncertainty in the natural system is adequately characterized in parameter development for conceptual models, process-level models, and alternative conceptual models. Model uncertainties are summarized in Sections 7.5 and 8.4. IDPS model uncertainty propagated into TSPA-LA calculations includes the uncertainty characterized in the model validation. Uncertainties in natural system characteristics are further explored in Engineered Barrier System: Physical and Chemical Environment Model (BSC 2004 [DIRS 169860]).

\subsubsection{Acceptance Criterion 4 - Model Uncertainty Is Characterized and Propagated Through the Model Abstraction}

(1) Alternative modeling approaches of features, events, and processes are considered and are consistent with available data and current scientific understanding, and the results and limitations are appropriately considered in the abstraction.

FEPs and alternative conceptual models specific to this document are discussed with their technical bases and limitations in Sections 6.2 and 6.5. They are consistent with available data and current scientific understanding.

(2) Alternative modeling approaches are considered and the selected modeling approach is consistent with available data and current scientific understanding. A description that includes a discussion of alternative modeling approaches not considered in the final analysis and the limitations and uncertainties of the chosen model is provided.

Alternative conceptual models along with their limitations and uncertainties are discussed in Section 6.5. Approaches not considered in the final analysis are also discussed in Section 6.5. The selected modeling approach is consistent with available data and current scientific understanding.

(3) Consideration of conceptual model uncertainty is consistent with available site characterization data, laboratory experiments, field measurements, natural analog information and process-level modeling studies; and the treatment of conceptual model uncertainty does not result in an under-representation of the risk estimate.

Uncertainties in the conceptual model (Section 7.5) are based on natural analogues, model comparisons, and laboratory experiments (Sections 6.3, 6.6.2.6, and 7). Model validation is consistent with these uncertainties. Treatment of conceptual model uncertainty does not result in a biased under-representation of the risk estimate (Section 7.5).

(4) Adequate consideration is given to effects of thermal-hydrologic-mechanicalchemical coupled processes in the assessment of alternative conceptual models. These effects may include: (i) thermal-hydrologic effects on gas, water, and mineral chemistry; (ii) effects of microbial processes on the waste package chemical environment and the chemical environment for radionuclide release; (iii) changes in water chemistry that may result from the release of corrosion products 
from the waste package and interactions between engineered materials and ground water; and (iv) changes in boundary conditions (e.g., drift shape and size) and hydrologic properties, relating to the response of the geomechanical system to thermal loading.

Thermal-chemical processes and their effects are adequately considered in the assessment of alternative conceptual models (Section 6.2). The chosen modeling approach includes thermal-chemical processes of evaporation, deliquescence, condensation, and chemical equilibria (Section 6.4). Additional coupling of processes is addressed in Engineered Barrier System: Physical and Chemical Environment Model (BSC 2004 [DIRS 169860]) and in Engineered Barrier System Features, Events, and Processes (BSC 2004 [DIRS 169898]).

\subsubsection{Acceptance Criterion 5 - Model Abstraction Output Is Supported by Objective Comparisons}

(3) Accepted and well-documented procedures are used to construct and test the numerical models that simulate coupled thermal-hydrologic-mechanical-chemical effects on seepage and flow, waste package chemical environment, and the chemical environment for radionuclide release. Analytical and numerical models are appropriately supported. Abstracted model results are compared with different mathematical models, to judge robustness of results.

The quality assurance program governing development of this report is discussed in Section 2. This model has been constructed and documented according to AP-SIII.10Q, Models. The model predicts the effects of thermal-chemical processes on the composition and stability of water in the drift. Validation complies with AP-SIII.10Q and applicable guidance. Qualified software codes are used in accordance with procedure to execute the model (Section 3). This report was generated according to the requirements of the Technical Work Plan (BSC 2004 [DIRS 171156]) as directed by AP-2.27Q. Model predictions are compared to ion association model results in Section 7.3 to judge robustness of results. They are also compared to laboratory evaporation data obtained from evaporation experiments of synthetic J-13 well water and Topopah Spring Tuff pore water (Sections 7.1.1 through 7.1.3), seawater evaporation data (Section 7.1.4), and salt solubility and vapor pressure data for binary and ternary salt solutions from chemistry handbooks and literature compilations (Section 7.2). 


\section{INTENTIONALLY LEFT BLANK}




\section{INPUTS AND REFERENCES}

\subsection{DOCUMENTS}

Altman, W.D.; Donnelly, J.P.; and Kennedy, J.E. 1988. Qualification of Existing

103750 Data for High-Level Nuclear Waste Repositories: Generic Technical Position. NUREG-1298. Washington, D.C.: U.S. Nuclear Regulatory Commission. TIC: 200652.

Altman, W.D.; Donnelly, J.P.; and Kennedy, J.E. 1988. Peer Review for HighLevel Nuclear Waste Repositories: Generic Technical Position. NUREG-1297. Washington, D.C.: U.S. Nuclear Regulatory Commission. TIC: 200651.

Archer, D.G. 1999. "Thermodynamic Properties of the $\mathrm{KCl}+\mathrm{H}_{2} \mathrm{O}$ System." Journal of Physical and Chemical Reference Data, 28, (1), 1-17. New York, New York: American Chemical Society. TIC: 253882.

Archer, D.G. 2000. "Thermodynamic Properties of the $\mathrm{NaNO}_{3}+\mathrm{H}_{2} \mathrm{O}$ System." Journal of Physical and Chemical Reference Data, 29, (5), 1141-1156. New York, New York: American Chemical Society. TIC: 253379.

Arthur, R.C. and Murphy, W.M. 1989. “An Analysis of Gas-Water-Rock Interactions During Boiling in Partially Saturated Tuff." Science Geology Bulletin, 42, (4), 313-327. Strasbourg, France: Sciences Geologiques Bulletin Publisher Strasbourg, Universite Louis Pasteur de Strasbourg. TIC: 235013.

Baes, C.F., Jr. and Mesmer, R.E. 1986. The Hydrolysis of Cations. Malabar, Florida: Krieger Publishing Company. TIC: 223481.

Barin, I. and Platzki, G. 1995. Thermochemical Data of Pure Substances. 3rd 103597 Edition. Two volumes. New York, New York: VCH Publishers. TIC: 251934.

Bates, R.G. 1973. Determination of $p H$, Theory and Practice. 2nd Edition. New York, New York: John Wiley \& Sons. TIC: 245388.

Bethke, C.M. 1996. Geochemical Reaction Modeling, Concepts and Applications. New York, New York: Oxford University Press. TIC: 252884.

Bodine, M.W., Jr. and Jones, B.F. 1986. The Salt Norm: A Quantitative 162065 Chemical-Mineralogical Characterization of Natural Waters. Water Resources Investigations Report 86-4086. Reston, Virginia: U.S. Geological Survey. TIC: 254009.

Borchardt, G. 1995. "Smectites." Chapter 14 of Minerals in Soil Environments. 2nd Edition. Dixon J.B. and Weed, S.B., eds. SSSA Book Series, No. 1. Madison, Wisconsin: Soil Science Society of America. TIC: 237222. 
BSC (Bechtel SAIC Company) 2001. Environment on the Surfaces of the Drip

Shield and Waste Package Outer Barrier. ANL-EBS-MD-000001 REV 00 ICN

02. Las Vegas, Nevada: Bechtel SAIC Company. ACC: MOL.20010724.0082.

Freeze, G.A.; Brodsky, N.S.; and Swift, P.N. 2001. The Development of

154365

Information Catalogued in REV00 of the YMP FEP Database.

TDR-WIS-MD-000003 REV 00 ICN 01. Las Vegas, Nevada: Bechtel SAIC

Company. ACC: MOL.20010301.0237.

BSC 2002. The Enhanced Plan for Features, Events, and Processes (FEPs) at Yucca Mountain. TDR-WIS-PA-000005 REV 00. Las Vegas, Nevada: Bechtel SAIC Company. ACC: MOL.20020417.0385.

BSC 2004. Engineered Barrier System Features, Events, and Processes.

169898

ANL-WIS-PA-000002, Rev. 03. Las Vegas, Nevada: Bechtel SAIC Company.

BSC 2004. Drift-Scale THC Seepage Model. MDL-NBS-HS-000001, Rev. 03.

Las Vegas, Nevada: Bechtel SAIC Company.

BSC 2004. Engineered Barrier System: Physical and Chemical Environment Model. ANL-EBS-MD-000033, Rev. 03. Las Vegas, Nevada: Bechtel SAIC Company.

BSC 2004. Environment on the Surfaces of the Drip Shield and Waste Package Outer Barrier. ANL-EBS-MD-000001, Rev. 01. Las Vegas, Nevada: Bechtel SAIC Company. ACC: DOC.20041004.0001.

BSC 2004. General Corrosion and Localized Corrosion of Waste Package Outer 169984 Barrier. ANL-EBS-MD-000003, Rev. 02. Las Vegas, Nevada: Bechtel SAIC Company. ACC: DOC.20041004.0001.

BSC 2004. In-Drift Precipitates/Salts Model. ANL-EBS-MD-000045 REV 01 ICN 01. Las Vegas, Nevada: Bechtel SAIC Company.

ACC: DOC.20040202.0001.

BSC 2004. In-Package Chemistry Abstraction. ANL-EBS-MD-000037, Rev. 03. Las Vegas, Nevada: Bechtel SAIC Company.

BSC 2004. Qualification of Thermodynamic Data for Geochemical Modeling of Mineral-Water Interactions in Dilute Systems. ANL-WIS-GS-000003 REV 00. Las Vegas, Nevada: Bechtel SAIC Company.

BSC 2004. Seepage Model for PA Including Drift Collapse.

MDL-NBS-HS-000002, Rev. 03. Las Vegas, Nevada: Bechtel SAIC Company. ACC: DOC.20040922.0008. ACC: DOC.20040922.0008. 
BSC 2004. Technical Work Plan for: Near-Field Environment and Transport

171156 In-Drift Geochemistry Model Report Integration. TWP-MGR-PA-000016 REV 02. Las Vegas, Nevada: Bechtel SAIC Company. ACC: DOC.20040806.0008.

BSC 2004. Technical Work Plan for: Regulatory Integration Team Revision of 170408 Features, Events, and Processes (FEPs) Analysis Reports Integration. TWP-MGR-PA-000022 REV 00. Las Vegas, Nevada: Bechtel SAIC Company. ACC: DOC.20040706.0006.

BSC 2004. Waste Form and In-Drift Colloids-Associated Radionuclide 170025 Concentrations: Abstraction and Summary. MDL-EBS-PA-000004, Rev. 01. Las Vegas, Nevada: Bechtel SAIC Company. ACC: DOC.20041028.0007.

Canori, G.F. and Leitner, M.M. 2003. Project Requirements Document. 166275 TER-MGR-MD-000001 REV 02. Las Vegas, Nevada: Bechtel SAIC Company. ACC: DOC.20031222.0006.

Carlos, B.A.; Chipera, S.J.; Bish, D.L.; and Raymond, R. 1995. "Distribution and 105213 Chemistry of Fracture-Lining Zeolites at Yucca Mountain, Nevada." Natural Zeolites '93: Occurrence, Properties, Use, Proceedings of the 4th International Conference on the Occurrence, Properties, and Utilization of Natural Zeolites, June 20-28, 1993, Boise, Idaho. Ming, D.W. and Mumpton, F.A., eds. Pages 547-563. Brockport, New York: International Committee on Natural Zeolites. TIC: 243086.

Chen, C.-T.A. and Marshall, W.L. 1982. "Amorphous Silica Solubilities IV. Behavior in Pure Water and Aqueous Sodium Chloride, Sodium Sulfate, Magnesium Chloride, and Magnesium Sulfate Solutions up to $350^{\circ} \mathrm{C}$.' Geochimica et Cosmochimica Acta, 46, 279-287. New York, New York: Pergamon Press. TIC: 235346.

Clarke, E.C.W. and Glew, D.N. 1985. "Evaluation of the Thermodynamic Functions for Aqueous Sodium Chloride from Equilibrium and Calorimetric Measurements below $154^{\circ} \mathrm{C}$." Journal of Physical and Chemical Reference Data, 14, (2), 489-610. New York, New York: American Chemical Society. TIC: 253934.

Clegg, S.L. and Brimblecombe, P. 1990. "Equilibrium Partial Pressures and 162067 Mean Activity and Osmotic Coefficients of $0-100 \%$ Nitric Acid as a Function of Temperature." Journal of Physical Chemistry, 94, (13), 5369-5380. Washington, D.C.: American Chemical Society. TIC: 253935.

Clegg, S.L. and Brimblecombe, P. 1990. "Solubility of Volatile Electrolytes in 160453 Multicomponent Solutions with Atmospheric Applications." Chapter 5 of Chemical Modeling of Aqueous Systems II. Melchior, D.C. and Bassett, R.L., eds. ACS Symposium Series 416. Washington, D.C.: American Chemical Society. TIC: 241139. 
Clegg, S.L. and Brimblecombe, P. 1990. "The Solubility and Activity 162089

Coefficient of Oxygen in Salt Solutions and Brines." Geochimica et Cosmochimica Acta, 54, (12), 3315-3328. New York, New York: Pergamon Press. TIC: 253874.

Clegg, S.L.; Milioto, S.; and Palmer, D.A. 1996. "Osmotic and Activity 162068 Coefficients of Aqueous $\left(\mathrm{NH}_{4}\right)_{2} \mathrm{SO}_{4}$ as a Function of Temperature, and Aqueous $\left(\mathrm{NH}_{4}\right)_{2} \mathrm{SO}_{4}-\mathrm{H}_{2} \mathrm{SO}_{4}$ Mixtures at $298.15 \mathrm{~K}$ and $323.15 \mathrm{~K}$." Journal of Chemical and Engineering Data, 41, (3), 455-467. Washington, D.C.: American Chemical Society. TIC: 253389.

Clegg, S.L.; Rard, J.A.; and Pitzer, K.S. 1994. "Thermodynamic Properties of 152734 0-6 mol kg(-1) Aqueous Sulfuric Acid from 273.15 to 328.15 K." Journal of the Chemical Society Faraday Transactions, 90, (13), 1875-1894. Cambridge, England: Royal Society of Chemistry. TIC: 248984.

CRWMS (Civilian Radioactive Waste Management System) M\&O (Management and Operating Contractor) 1998. "Near-Field Geochemical Environment." Chapter 4 of Total System Performance Assessment-Viability Assessment (TSPA-VA) Analyses Technical Basis Document. B00000000-01717-4301-00004 REV 01. Las Vegas, Nevada: CRWMS M\&O. ACC: MOL.19981008.0004.

CRWMS M\&O 2000. Total System Performance Assessment for the Site

Recommendation. TDR-WIS-PA-000001 REV 00 ICN 01. Las Vegas, Nevada: CRWMS M\&O. ACC: MOL.20001220.0045.

de Lima, M.C.P. and Pitzer, K.S. 1983. "Thermodynamics of Saturated Electrolyte Mixtures of $\mathrm{NaCl}$ with $\mathrm{Na}_{2} \mathrm{SO}_{4}$ and with $\mathrm{MgCl}_{2}$." Journal of Solution Chemistry, 12, (3), 187-199. New York, New York: Plenum Publishing Corporation. TIC: 253875.

Dean, J.A. 1992. Lange's Handbook of Chemistry. 14th Edition. New York, New York: McGraw-Hill. TIC: 240690.

Deer, W.A.; Howie, R.A.; and Zussman, J. 1966. An Introduction to the Rock-Forming Minerals. New York, New York: John Wiley \& Sons. TIC: 245492.

Dingemans, P. and Dijkgraaf, L.L. 1948. "The Vapour Pressure of Saturated 166149 Solutions of Sodium Nitrate in Water." Recueil des Travaux Chimiques des Pays-Bas, 67, 231-234. Leyden, The Netherlands: Société Chimique Neerlandaise. TIC: 255168.

Drever, J.I. 1988. The Geochemistry of Natural Waters. 2nd Edition. 
Dutrizac, J.E. 2002. "Calcium Sulphate Solubilities in Simulated Zinc Processing 166148 Solutions." Hydrometallurgy, 65, (2-3), 109-135. New York, New York:

Elsevier. TIC: 255132.

Eugster, H.P. and Hardie, L.A. 1978. "Saline Lakes." Lakes, Chemistry, 100743 Geology, Physics. Lerman, A., ed. Pages 237-293. New York, New York: Springer-Verlag. TIC: 240782.

Eugster, H.P. and Jones, B.F. 1979. "Behavior of Major Solutes During Closed123175 Basin Brine Evolution." American Journal of Science, 279, 609-631. New Haven, Connecticut: Yale University, Kline Geology Laboratory. TIC: 234258.

Faust, G.T. 1953. "Huntite, $\mathrm{Mg}_{3} \mathrm{Ca}\left(\mathrm{CO}_{3}\right)_{4}$, a New Mineral." American 162282 Mineralogist, 38, (1-2), 4-24. Washington, D.C.: Mineralogical Society of America. TIC: 252888.

Felmy, A.R.; Rustad, J.R.; Mason, M.J.; and de la Bretonne, R. 1994. A Chemical Model for the Major Electrolyte Components of the Hanford Waste Tanks: The Binary Electrolytes in the System: $\mathrm{Na}-\mathrm{NO}_{3}-\mathrm{NO}_{2}-\mathrm{SO}_{4}-\mathrm{CO}_{3}-\mathrm{F}-\mathrm{PO}_{4}-$ $\mathrm{OH}-\mathrm{AI}(\mathrm{OH})_{4}-\mathrm{H}_{2} \mathrm{O}$. PNL-SA-23952. Richland, Washington: Pacific Northwest Laboratory. TIC: 253271.

Felmy, A.R.; Schroeder, C.C.; and Mason, M.J. 1994. A Solubility Model for Amorphous Silica in Concentrated Electrolytes. PNL-SA-25345. Richland, Washington: Pacific Northwest Laboratory. TIC: 253270.

Fleischer, M. and Efremov, N. 1954. "New Mineral Names." American 162312 Mineralogist, 39, (3-4), 402-408. Washington, D.C.: Mineralogical Society of America. TIC: 252897.

Fleischer, M. and Pabst, A. 1983. "New Mineral Names." Journal of the Mineralogical Society of America, 68, (1-2), 281-283. Washington, D.C.: Mineralogical Society of America. TIC: 252898.

Garrels, R.M. and Christ, C.L. 1990. Solutions, Minerals, and Equilibria. Boston, Massachusetts: Jones and Bartlett Publishers. TIC: 223483.

Garrels, R.M. and Mackenzie, F.T. 1967. "Origin of the Chemical Compositions 123636 of Some Springs and Lakes?" Equilibrium Concepts in Natural Water Systems. American Chemical Society Advances in Chemistry Series 67. Pages 222-242. Washington, D.C.: American Chemical Society. TIC: 246519.

Glassley, W. 1997. Chemical Composition of Water Before Contact with 100742 Repository Materials. Milestone SPLA1M4, Rev. 1. Livermore, California: Lawrence Livermore National Laboratory. ACC: MOL.19971210.0031. 
Glassley, W.E. 1994. Report on Near-Field Geochemistry: Water Composition

Changes Due to Evaporation. Milestone M0L26. Draft. Livermore, California: Lawrence Livermore National Laboratory. ACC: MOL.19950406.0153.

Greenberg, J.P. and Moller, N. 1989. "The Prediction of Mineral Solubilities in

152684

Natural Waters: A Chemical Equilibrium Model for the Na-K-Ca-Cl-SO4-H2O System to High Concentration from 0 to $250^{\circ} \mathrm{C}$." Geochimica et Cosmochimica Acta, 53, 2503-2518. New York, New York: Pergamon Press. TIC: 249020.

Greenspan, L. 1977. "Humidity Fixed Points of Binary Saturated Aqueous 104945 Solutions." Journal of Research of the National Bureau of Standards, 81A, (1), 89-96. Washington, D.C.: U.S. Department of Commerce. TIC: 241138.

Grønvold, F. and Meisingset, K.K. 1983. "Thermodynamic Properties and Phase 162069

Transitions of Salt Hydrates between 270 and 400 K. II. $\mathrm{Na}_{2} \mathrm{CO}_{3} \cdot \mathrm{H}_{2} \mathrm{O}$ and $\mathrm{Na}_{2} \mathrm{CO}_{3} \cdot 10 \mathrm{H}_{2} \mathrm{O}$." Journal of Chemical Thermodynamics, 15, (9), 881-889. New York, New York: Academic Press. TIC: 253936.

Hardin, E.L. 1998. Near-Field/Altered-Zone Models Report. UCRL-ID-129179. 100123 Livermore, California: Lawrence Livermore National Laboratory.

ACC: MOL.19980630.0560.

Harrar, J.E.; Carley, J.F.; Isherwood, W.F.; and Raber, E. 1990. Report of the 100814 Committee to Review the Use of J-13 Well Water in Nevada Nuclear Waste Storage Investigations. UCID-21867. Livermore, California: Lawrence Livermore National Laboratory. ACC: NNA.19910131.0274.

Harvie, C.E.; Moller, N.; and Weare, J.H. 1984. "The Prediction of Mineral 118163 Solubilities in Natural Waters: The Na-K-Mg-Ca-H-Cl-SO $\mathrm{S}_{4}-\mathrm{OH}-\mathrm{HCO}_{3}-\mathrm{CO}_{3}-$ $\mathrm{CO}_{2}-\mathrm{H}_{2} \mathrm{O}$ System to High Ionic Strengths at $25^{\circ} \mathrm{C}$." Geochimica et Cosmochimica Acta, 48, (4), 723-751. New York, New York: Pergamon Press. TIC: 239849.

Hay, R.L. 1966. Zeolites and Zeolitic Reactions in Sedimentary Rocks. Special 105965 Paper 85. Boulder, Colorado: Geological Society of America. TIC: 238294.

Hay, R.L. and Wiggins, B. 1980. "Pellets, Ooids, Sepiolite and Silica in Three 162281 Calcretes of the Southwestern United States." Sedimentology, 27, 559-576. Malden, Massachusetts: Blackwell Publishing. TIC: 222806.

He, S. and Morse, J.W. 1993. "The Carbonic Acid System and Calcite Solubility 162090 in Aqueous Na-K-Ca-Mg-Cl-SO 4 Solutions from 0 to $90^{\circ} \mathrm{C}$." Geochimica et Cosmochimica Acta, 57, (15), 3533-3554. New York, New York: Pergamon Press. TIC: 253894. 
Helgeson, H.C. and Kirkham, D.H. 1974. "Theoretical Prediction of the

Thermodynamic Behavior of Aqueous Electrolytes at High Pressures and Temperatures: II. Debye-Hückel Parameters for Activity Coefficients and Relative Partial Molal Properties." American Journal of Science, 274, (7), 1199-1261. New Haven, Connecticut: Yale University, Kline Geology Laboratory. TIC: 240952.

Helgeson, H.C.; Kirkham, D.H.; and Flowers, G.C. 1981. "Theoretical 106024 Prediction of the Thermodynamic Behavior of Aqueous Electrolytes at High Pressures and Temperatures: IV. Calculation of Activity Coefficients, Osmotic Coefficients, and Apparent Molal and Standard and Relative Partial Molal Properties to $600^{\circ} \mathrm{C}$ and $5 \mathrm{~kb}$." American Journal of Science, 281, (10), 1249-1516. New Haven, Connecticut: Yale University, Kline Geology Laboratory. TIC: 238264.

Holmes, H.F. and Mesmer, R.E. 1983. "Thermodynamic Properties of Aqueous 162073 Solutions of the Alkali Metal Chlorides to $250{ }^{\circ}$ C." Journal of Physical Chemistry, 87, (7), 1242-1255. Washington, D.C.: American Chemical Society. TIC: 253375.

Holmes, H.F. and Mesmer, R.E. 1986. "Thermodynamics of Aqueous Solutions of the Alkali Metal Sulfates." Journal of Solution Chemistry, 15, (6), 495-518. New York, New York: Plenum Press. TIC: 253633.

Holmes, H.F. and Mesmer, R.E. 1992. "Isopiestic Studies of $\mathrm{H}_{2} \mathrm{SO}_{4}$ (aq) at Elevated Temperatures, Thermodynamic Properties." Journal of Chemical Thermodynamics, 24, (3), 317-328. New York, New York: Academic Press. TIC: 253881.

Holmes, H.F. and Mesmer, R.E. 1993. "Isopiestic Studies of $\mathrm{NaHSO}_{4}$ (aq) at Elevated Temperatures. Thermodynamic Properties." Journal of Chemical Thermodynamics, 25, (1), 99-110. New York, New York: Academic Press. TIC: 253937.

Holmes, H.F. and Mesmer, R.E. 1994. "An Isopiestic Study of $\left\{(1-\mathrm{y}) \mathrm{NaHSO}_{4}\right\}$ 162078 $\left.+\mathrm{yNa}_{2} \mathrm{SO}_{4}\right\}(\mathrm{aq})$ at Elevated Temperatures." Journal of Chemical Thermodynamics, 26, (6), 581-594. New York, New York: Academic Press. TIC: 253880.

Holmes, H.F. and Mesmer, R.E. 1998. "An Isopiestic Study of Aqueous 162083 Solutions of the Alkali Metal Bromides at Elevated Temperatures." Journal of Chemical Thermodynamics, 30, (6), 723-741. New York, New York: Academic Press. TIC: 253377. 
Holmes, H.F. and Mesmer, R.E. 1998. "Isopiestic Molalities for Aqueous

Solutions of the Alkali Metal Hydroxides at Elevated Temperatures." Journal of Chemical Thermodynamics, 30, (3), 311-326. New York, New York: Academic Press. TIC: 253939.

Holmes, H.F.; Baes, C.F., Jr.; and Mesmer, R.E. 1979. "Isopiestic Studies of 162071 Aqueous Solutions at Elevated Temperatures. II. NaCl + Mixtures." Journal of Chemical Thermodynamics, 11, 1035-1050. New York, New York: Academic Press. TIC: 253876.

Holmes, H.F.; Baes, C.F., Jr.; and Mesmer, R.E. 1981. "Isopiestic Studies of Aqueous Solutions at Elevated Temperatures. III. $\left\{(1-\mathrm{y}) \mathrm{NaCl}+\mathrm{yCaCl}_{2}\right\}^{\mathrm{a}}$." Journal of Chemical Thermodynamics, 13, 101-113. New York, New York: Academic Press. TIC: 253877.

Holmes, H.F.; Busey, R.H.; Simonson, J.M.; Mesmer, R.E.; Archer, D.G.; and 162075 Wood, R.H. 1987. "The Enthalpy of Dilution of $\mathrm{HCl}(\mathrm{aq})$ to $648 \mathrm{~K}$ and $40 \mathrm{MPa}$, Thermodynamic Properties." Journal of Chemical Thermodynamics, 19, (7), 863-890. New York, New York: Academic Press. TIC: 253390.

Holmes, H.F.; Simonson, J.M.; and Mesmer, R.E. 1997. "Aqueous Solutions of the Alkaline Earth Metal Chlorides. Corrected Constants for the Ion-Interaction Model." Journal of Chemical Thermodynamics, 29, (11), 1363-1373. New York, New York: Academic Press. TIC: 253938.

Jones, B.F. 1983. "Occurrence of Clay Minerals in Surficial Deposits of Southwestern Nevada.” Sciences Géologiques, 2, (72), 81-92. Strasbourg, France: Université Louis Pasteur de Strasbourg, Institut de Géologie.

TIC: 254010.

Jones, B.F. and Galan, E. 1988. "Sepiolite and Palygorskite." Hydrous 162347 Phyllosilicates. Bailey, S.W., ed. Reviews in Mineralogy Volume 19. Pages 631-674. Washington, D.C.: Mineralogical Society of America. TIC: 254011.

Jones, B.F.; Eugster, H.P.; and Rettig, S.L. 1977. "Hydrochemistry of the Lake Magadi Basin, Kenya." Geochimica et Cosmochimica Acta, 41, 53-72. New York, New York: Pergamon Press. TIC: 246224.

Jones, B.F.; Rettig, S.L.; and Eugster, H.P. 1967. "Silica in Alkaline Brines." Science, 158, 1310-1314. Washington, D.C.: American Association for the Advancement of Science. TIC: 235387.

Kent, D.B. and Kastner, M. 1985. " $\mathrm{Mg}^{2+}$ Removal in the System $\mathrm{Mg}^{2+}$-Amorphous $\mathrm{SiO}_{2}-\mathrm{H}_{2} \mathrm{O}$ by Adsorption and Mg-Hydroxysilicate Precipitation." Geochimica et Cosmochimica Acta, 49, 1123-1136. New York, New York: Pergamon Press. TIC: 253981. 
Kerr, P.F. 1977. Optical Mineralogy. 4th Edition. New York, New York:

Kinsman, D.J.J. 1976. "Evaporites: Relative Humidity Control of Primary

Mineral Facies." Journal of Sedimentary Petrology, 46, 273-279. Tulsa,

Oklahoma: Society of Economic Paleontologists and Mineralogists.

TIC: 238672.

Klein, C. and Hurlbut, C.S., Jr. 1999. Manual of Mineralogy. 21st Edition,

Revised. New York, New York: John Wiley \& Sons. TIC: 246258.

Knauss, K.G. and Wolery, T.J. 1986. "Dependence of Albite Dissolution

Kinetics on $\mathrm{pH}$ and Time at $25^{\circ} \mathrm{C}$ and $70^{\circ} \mathrm{C}$." Geochimica et Cosmochimica Acta, 50, (11), 2481-2497. Elmsford, New York: Pergamon Journals. TIC: 221756.

Knauss, K.G. and Wolery, T.J. 1988. "The Dissolution Kinetics of Quartz as a Function of $\mathrm{pH}$ and Time at $70^{\circ} \mathrm{C}$." Geochimica et Cosmochimica Acta, 52, (1), 43-53. New York, New York: Pergamon Press. TIC: 203242.

Knauss, K.G.; Beiriger, W.J.; and Peifer, D.W. 1985. Hydrothermal Interaction of Crushed Topopah Spring Tuff and J-13 Water at 90, 150, and $250^{\circ} \mathrm{C}$ Using Dickson-Type, Gold-Bag Rocking Autoclaves. UCRL-53630. Livermore, California: Lawrence Livermore National Laboratory.

ACC: NNA.19931005.0010.

Knauss, K.G.; Beiriger, W.J.; Peifer, D.W.; and Piwinskii, A.J. 1985.

100150

Hydrothermal Interaction of Solid Wafers of Topopah Spring Tuff with J-13

Water and Distilled Water at 90, 150, and $250^{\circ} \mathrm{C}$, Using Dickson-Type, Gold-Bag Rocking Autoclaves. UCRL-53645. Livermore, California: Lawrence

Livermore National Laboratory. ACC: NNA.19900207.0282.

Knauss, K.G.; Wolery, T.J.; and Jackson, K.J. 1990. "A New Approach to 166144 Measuring $\mathrm{pH}$ in Brines and Other Concentrated Electrolytes." Geochimica et Cosmochimica Acta, 54, (5), 1519-1523. New York, New York: Pergamon. TIC: 253592.

Königsberger, E. 2001. "Prediction of Electrolyte Solubilities from Minimal Thermodynamic Information." Monatshefte für Chemie, 132, 1363-1386. Vienna, Austria: Springer-Verlag. TIC: 253382.

Koorevaar, P.; Menelik, G.; and Dirksen, C. 1983. Elements of Soil Physics. Developments in Soil Science 13. New York, New York: Elsevier. TIC: 246286. 
Kracek, F.C. 1928. "P-T-X Relations for Systems of Two or More Components and Containing Two or More Phases (L-V, $\mathrm{L}_{\mathrm{I}}-\mathrm{L}_{\mathrm{II}}-\mathrm{V}$ and S-L-V Systems)." International Critical Tables of Numerical Data, Physics, Chemistry and Technology. Washburn, E.W., ed. Volume III. 1st Edition. New York, New York: McGraw-Hill. TIC: 243268.

Krauskopf, K.B. 1979. Introduction to Geochemistry. 2nd Edition. New York, New York: McGraw-Hill. TIC: 242816.

105909

Krauskopf, K.B. and Bird, D.K. 1995. Introduction to Geochemistry. 3rd

101702

Edition. New York, New York: McGraw-Hill. TIC: 239316.

Langmuir, D. 1997. Aqueous Environmental Geochemistry. Upper Saddle River, 100051 New Jersey: Prentice Hall. TIC: 237107.

Li, G.; Peacor, D.R.; Coombs, D.S.; and Kawachi, Y. 1997. "Solid Solution in 159034 the Celadonite Family: The New Minerals Ferroceladonite, $\mathrm{K}_{2} \mathrm{Fe}_{2}^{2}+\mathrm{Fe}^{3}{ }_{2}+\mathrm{Si}_{8} \mathrm{O}_{20}(\mathrm{OH})_{4}$, and Ferroaluminoceladonite,

$\mathrm{K}_{2} \mathrm{Fe}_{2}^{2}+\mathrm{Al}_{2} \mathrm{Si}_{8} \mathrm{O}_{20}(\mathrm{OH})_{4}$." American Mineralogist, 82, (5-6), 503-511.

Washington, D.C.: Mineralogical Society of America. TIC: 252472.

Lichtner, P.C. and Seth, M. 1996. "Multiphase-Multicomponent Nonisothermal Reactive Transport in Partially Saturated Porous Media." Proceedings of the 1996 International Conference on Deep Geological Disposal of Radioactive Waste, September 16-19, 1996, Winnipeg, Manitoba, Canada. Toronto, Ontario, Canada: Canadian Nuclear Society. TIC: 233923.

Lide, D.R., ed. 2000. CRC Handbook of Chemistry and Physics. 81st Edition. Boca Raton, Florida: CRC Press. TIC: 253056.

Linke, W.F. 1958. Solubilities, Inorganic and Metal-Organic Compounds. 4th Edition. Volume I, A-Ir. Washington, D.C.: American Chemical Society.

TIC: 255159.

Linke, W.F. 1965. Solubilities, Inorganic and Metal-Organic Compounds. 4th 166191 Edition. Volume II, K-Z. Washington, D.C.: American Chemical Society. TIC: 222176

Mahan, B.H. 1975. University Chemistry. 3rd Edition. Reading, Massachusetts: 125331 Addison-Wesley Publishing. TIC: 240721.

Marshall, W.L. 1980. "Amorphous Silica Solubilities-I. Behavior in Aqueous 100771 Sodium Nitrate Solutions; $25-300^{\circ} \mathrm{C}, 0-6$ Molal." Geochimica et Cosmochimica Acta, 44, (7), 907-913. New York, New York: Pergamon Press. TIC: 250701. 
Marshall, W.L. 1980. "Amorphous Silica Solubilities-III. Activity Coefficient

Relations and Predictions of Solubility Behavior in Salt Solutions, 0-350 C."

Geochimica et Cosmochimica Acta, 44, (7), 925-931. New York, New York:

Pergamon Press. TIC: 250702.

Marshall, W.L. and Chen, C-T.A. 1982. “Amorphous Silica Solubilities-V.

Predictions of Solubility Behavior in Aqueous Mixed Electrolyte Solutions to $300^{\circ}$ C." Geochimica et Cosmochimica Acta, 46, (2), 289-291. New York, New York: Pergamon Press. TIC: 250703.

Marshall, W.L. and Chen, C-T.A. 1982. "Amorphous Silica Solubilities-VI.

162086

Postulated Sulfate-Silicic Acid Solution Complex." Geochimica et

Cosmochimica Acta, 46, (3), 367-370. New York, New York: Pergamon Press.

TIC: 250704.

Marshall, W.L. and Warakomski, J.M. 1980. "Amorphous Silica SolubilitiesII. Effect of Aqueous Salt Solutions at $25^{\circ}$ C." Geochimica et Cosmochimica Acta, 44, (7), 915-924. New York, New York: Pergamon Press. TIC: 250705.

McCaffrey, M.A.; Lazar, B.; and Holland, H.D. 1987. "The Evaporation Path of Seawater and the Coprecipitation of $\mathrm{Br}^{-}$and $\mathrm{K}^{+}$with Halite." Journal of Sedimentary Petrology, 57, (5), 928-937. Tulsa, Oklahoma: Society of Economic Paleontologists and Mineralogists. TIC: 254627.

Meisingset, K.K. and Grønvold, F. 1986. "Thermodynamic Properties and Phase 162094 Transitions of Salt Hydrates between 270 and $400 \mathrm{~K}$. IV. $\mathrm{CaCl}_{2} \cdot 6 \mathrm{H}_{2} \mathrm{O}$, $\mathrm{CaCl}_{2} \bullet 4 \mathrm{H}_{2} \mathrm{O}, \mathrm{CaCl}_{2} \bullet 2 \mathrm{H}_{2} \mathrm{O}$, and $\mathrm{FeCl}_{3} \bullet 6 \mathrm{H}_{2} \mathrm{O}$." Journal of Chemical Thermodynamics, 18, 159-173. New York, New York: Academic Press. TIC: 253388.

Mesmer, R.E. 1991. "Comments on 'A New Approach to Measuring pH in 166053 Brines and Other Concentrated Electrolytes' by K.G. Knauss, T.J. Wolery, and K.J. Jackson." Geochimica et Cosmochimica Acta, 55, (4), 1175-1176. New York, New York: Pergamon Press. TIC: 253594.

Millero, F.J. and Pierrot, D. 1998. "A Chemical Equilibrium Model for Natural Waters." Aquatic Geochemistry, 4, (1), 153-199. New York, New York: Kluwer Academic Publishers. TIC: 254365.

Moller, N. 1988. "The Prediction of Mineral Solubilities in Natural Waters: A 152695 Chemical Equilibrium Model for the Na-Ca-Cl-SO4-H2O System, to High Temperature and Concentration." Geochimica et Cosmochimica Acta, 52, 821-837. New York, New York: Pergamon Press. TIC: 248981. 
Monnin, C. 1999. "A Thermodynamic Model for the Solubility of Barite and

Celestite in Electrolyte Solutions and Seawater to $200^{\circ} \mathrm{C}$ and to $1 \mathrm{kBar}$."

Chemical Geology, 153, (1-4), 187-209. New York, New York: Elsevier.

TIC: 254364.

Moore, R.C.; Mesmer, R.E.; and Simonson, J.M. 1997. "Solubility of Potassium

166150

Carbonate in Water between 384 and 529 K Measured Using the Synthetic

Method." Journal of Chemical Engineering Data, 42, (6), 1078-1081.

Washington, D.C.: American Chemical Society. TIC: 255169.

Murphy, W.M. 1993. "Geochemical Models for Gas-Water-Rock Interactions in

100804

a Proposed Nuclear Waste Repository at Yucca Mountain." Proceedings of the

Topical Meeting on Site Characterization and Model Validation, FOCUS '93,

September 26-29, 1993, Las Vegas, Nevada. Pages 115-121. La Grange Park,

Illinois: American Nuclear Society. TIC: 102245.

Murphy, W.M. and Pabalan, R.T. 1994. Geochemical Investigations Related to

100805

the Yucca Mountain Environment and Potential Nuclear Waste Repository.

NUREG/CR-6288. San Antonio, Texas: Southwest Research Institute.

TIC: 227032.

Nordstrom, D.K. and Munoz, J.L. 1986. Geochemical Thermodynamics. Palo

Alto, California: Blackwell Scientific Publications. TIC: 208228.

NRC (U.S. Nuclear Regulatory Commission) 2003. Yucca Mountain Review

163274

Plan, Final Report. NUREG-1804, Rev. 2. Washington, D.C.: U.S. Nuclear

Regulatory Commission, Office of Nuclear Material Safety and Safeguards.

TIC: 254568.

Oakes, C.S.; Felmy, A.R.; and Sterner, S.M. 2000. "Thermodynamic Properties

162102 of Aqueous Calcium Nitrate $\left\{\mathrm{Ca}\left(\mathrm{NO}_{3}\right)_{2}\right\}$ to the Temperature $373 \mathrm{~K}$ Including New Enthalpy of Dilution Data." Journal of Chemical Thermodynamics, 32, (1), 29-54. New York, New York: Academic Press. TIC: 253509.

Pabalan, R.T. and Pitzer, K.S. 1987. "Thermodynamics of Concentrated 162096

Electrolyte Mixtures and the Prediction of Mineral Solubilities to High Temperatures for Mixtures in the System Na-K-Mg-Cl-SO $\mathrm{S}_{4}-\mathrm{OH}-\mathrm{H}_{2} \mathrm{O}$."

Geochimica et Cosmochimica Acta, 51, (9), 2429-2443. New York, New York:

Pergamon Journals. TIC: 253508.

Pabalan, R.T. and Pitzer, K.S. 1987. "Thermodynamics of $\mathrm{NaOH}(\mathrm{aq})$ in

Hydrothermal Solutions." Geochimica et Cosmochimica Acta, 51, (4), 829-837.

New York, New York: Pergamon Press. TIC: 253383. 
Palache, C.; Berman, H.; and Frondel, C. 1951. Halides, Nitrates, Borates,

Carbonates, Sulfates, Phosphates, Arsenates, Tungstates, Molybdates, Etc.

Volume II of The System of Mineralogy of James Dwight Dana and Edward

Salisbury Dana, Yale University 1837-1892. 7th Edition. New York, New

York: John Wiley \& Sons. TIC: 209332.

Papke, K.G. 1976. Evaporites and Brines in Nevada Playas. Nevada Bureau of

Mines and Geology Bulletin 87. Reno, Nevada: University of Nevada, Reno, Mackay School of Mines. TIC: 211869.

Peiper, J.C. and Pitzer, K.S. 1982. "Thermodynamics of Aqueous Carbonate 162097 Solutions Including Mixtures of Sodium Carbonate, Bicarbonate, and Chloride." Journal of Chemical Thermodynamics, 14, (7), 613-638. New York, New York: Academic Press. TIC: 240175.

Phutela, R.C. and Pitzer, K.S. 1986. "Heat Capacity and Other Thermodynamic Properties of Aqueous Magnesium Sulfate to 473 K." Journal of Physical Chemistry, 90, (5), 895-901. Washington, D.C.: American Chemical Society. TIC: 253940.

Pitzer, K.S. 1973. "Thermodynamics of Electrolytes. I. Theoretical Basis and General Equations." Journal of Physical Chemistry, 77, (2), 268-277. Washington, D.C.: American Chemical Society. TIC: 239503.

Pitzer, K.S. 1991. "Ion Interaction Approach: Theory and Data Correlation." 152709 Chapter 3 of Activity Coefficients in Electrolyte Solutions. 2nd Edition. Pitzer, K.S., ed. Boca Raton, Florida: CRC Press. TIC: 251799.

Pitzer, K.S. and Kim, J.J. 1974. "Thermodynamics of Electrolytes. IV. Activity and Osmotic Coefficients for Mixed Electrolytes." Journal of the American Chemical Society, 96, (18), 5701-5707. Washington, D.C.: American Chemical Society. TIC: 246223.

Pitzer, K.S. and Mayorga, G. 1973. "Thermodynamics of Electrolytes. II. 152742 Activity and Osmotic Coefficients for Strong Electrolytes with One or Both Ions Univalent." Journal of Physical Chemistry, 77, (19), 2300-2308. Washington, D.C.: American Chemical Society. TIC: 249019.

Pitzer, K.S. and Oakes, C.S. 1994. "Thermodynamics of Calcium Chloride in 163583 Concentrated Aqueous Solutions and in Crystals." Journal of Chemical and Engineering Data, 39, (3), 553-559. Washington, D.C.: American Chemical Society. TIC: 253384.

Pitzer, K.S. and Shi, Y. 1993. "Thermodynamics of Calcium Chloride in Highly Concentrated Aqueous Solution and in Hydrated Crystals." Journal of Solution Chemistry, 29, (2), 99-105. New York, New York: Plenum Press. TIC: 253385. 
Pitzer, K.S.; Peiper, J.C.; and Busey, R.H. 1984. "Thermodynamic Properties of 162099 Aqueous Sodium Chloride Solutions." Journal of Physical and Chemical Reference Data, 13, (1), 1-102. Washington, D.C.: American Chemical Society. TIC: 253809.

Pokrovskii, V.A. and Helgeson, H.C. 1995. "Thermodynamic Properties of 101699 Aqueous Species and the Solubilities of Minerals at High Pressures and Temperatures: The System $\mathrm{Al}_{2} \mathrm{O}_{3}-\mathrm{H}_{2} \mathrm{O}-\mathrm{NaCl}$." American Journal of Science, 295, 1255-1342. New Haven, Connecticut: Yale University, Kline Geology Laboratory. TIC: 236803.

Polya, D.A.; Woolley, E M.; Simonson, J.M.; and Mesmer, R.E. 2001. "The Enthalpy of Dilution and Thermodynamics of $\mathrm{Na}_{2} \mathrm{CO}_{3}$ (aq) and $\mathrm{NaHCO}_{3}$ (aq) from $\mathrm{T}=298 \mathrm{~K}$ to $\mathrm{T}=523.15 \mathrm{~K}$ and Pressure of $40 \mathrm{MPa}$." Journal of Chemical Thermodynamics, 33, (2), 205-243. New York, New York: Academic Press. TIC: 253386.

Rard, J.A. and Archer, D.G. 1995. "Isopiestic Investigation of the Osmotic and 162104 Activity Coefficients of Aqueous $\mathrm{NaBr}$ and the Solubility of $\mathrm{NaBr} \cdot 2 \mathrm{H}_{2} \mathrm{O}$ (cr) at 298.15 K: Thermodynamic Properties of the $\mathrm{NaBr}+\mathrm{H}_{2} \mathrm{O}$ System over Wide Ranges of Temperature and Pressure." Journal of Chemical and Engineering Data, 40, (1), 170-185. Washington, D.C.: American Chemical Society. TIC: 253941.

Rard, J.A. and Clegg, S.L. 1997. "Critical Evaluation of the Thermodynamic 152759

Properties of Aqueous Calcium Chloride. 1. Osmotic and Activity Coefficients of 0-10.77 mol $\times \mathrm{kg}(-1)$ Aqueous Calcium Chloride Solutions at $298.15 \mathrm{~K}$ and Correlation with Extended Pitzer Ion-Interaction Models." Journal of Chemical \& Engineering Data, 42, (5), 819-849. Washington, D.C.: American Chemical Society. TIC: 249002.

Rard, J.A. and Platford, R.F. 1991. "Experimental Methods: Isopiestic." Activity Coefficients in Electrolyte Solutions. 2nd Edition. Pitzer, K.S., ed. 209-277. Boca Raton, Florida: CRC Press. TIC: 251798.

Rard, J.A. and Wijesinghe, A.M. 2003. "Conversion of Parameters Between 162327 Different Variants of Pitzer's Ion-Interaction Model, both With and Without Ionic Strength Dependent Higher-Order Terms." Journal of Chemical Thermodynamics, 35, (3), 439-473. New York, New York: Academic Press. TIC: 253943.

Rard, J.A.; Clegg, S.L.; and Palmer, D.A. 2000. "Isopiestic Determination of the 162105 Osmotic Coefficients of $\mathrm{Na}_{2} \mathrm{SO}_{4}(\mathrm{aq})$ at 25 and $50^{\circ} \mathrm{C}$, and Representation with Ion-Interaction (Pitzer) and Mole Fraction Thermodynamic Models." Journal of Solution Chemistry, 29, (1), 1-49. New York, New York: Plenum.

TIC: 253942. 
Robie, R.A. and Hemingway, B.S. 1995. Thermodynamic Properties of Minerals and Related Substances at $298.15 \mathrm{~K}$ and 1 Bar (10 ${ }^{5}$ Pascals) Pressure and at Higher Temperatures. Bulletin 2131. Reston, Virginia: U.S. Geological Survey. TIC: 249441.

Robinson, R.A. and Stokes, R.H. 1965. Electrolyte Solutions, The Measurement 108567 and Interpretation of Conductance, Chemical Potential and Diffusion in Solutions of Simple Electrolytes. 2nd Edition (Revised). Washington, D.C.: Butterworth. TIC: 242575.

Rogers, P.S.Z. and Pitzer, K.S. 1981. "High-Temperature Thermodynamic 162107 Properties of Aqueous Sodium Sulfate Solutions." Journal of Physical Chemistry, 85, (20), 2886-2895. Washington, D.C.: American Chemical Society. TIC: 253810.

Rosenberg, N.D.; Knauss, K.G.; and Dibley, M.J. 1999. Evaporation of J13 Water: Laboratory Experiments and Geochemical Modeling. UCRL-ID-134852. Livermore, California: Lawrence Livermore National Laboratory. TIC: 246322.

Rosenberg, N.D.; Knauss, K.G.; and Dibley, M.J. 1999. Evaporation of Topopah 125339 Spring Tuff Pore Water. UCRL-ID-135765. Livermore, California: Lawrence Livermore National Laboratory. TIC: 246231.

Saxton, B.; Austin, J.B.; Dietrich, H.G.; Fenwick, F.; Fleischer, A.; Frear, G.L.; Roberts, E.J.; Smith, R.P.; Solomon, M.; and Spurlin, H.M. 1928. "Boiling-Point Elevations, Non-Volatile Solutes." International Critical Tables of Numerical Data, Physics, Chemistry and Technology. Volume III. 1st Edition. Pages 324-350. New York, New York: McGraw-Hill. TIC: 243268.

Smith, W.R. and Missen, R.W. 1991. Chemical Reaction Equilibrium Analysis: Theory and Algorithms. Malabar, Florida: Krieger Publishing Company. TIC: 252885.

SNL (Sandia National Laboratories) 2003. Software User's Manual, EQ3/6, Version 8.0. SDN: 10813-UM-8.0-00. Albuquerque, New Mexico: Sandia National Laboratories. ACC: MOL.20030312.0084.

Spencer, R.J.; Moller, N.; and Weare, J.H. 1990. "The Prediction of Mineral 152713 Solubilities in Natural Waters: A Chemical Equilibrium Model for the Na-K-Ca$\mathrm{Mg}-\mathrm{Cl}-\mathrm{SO}_{4}-\mathrm{H}_{2} \mathrm{O}$ System at Temperatures Below $25^{\circ} \mathrm{C}$." Geochimica et Cosmochimica Acta, 54, 575-590. New York, New York: Pergamon Press. TIC: 248999. 
Sterner, S.M.; Felmy, A.R.; Oakes, C.S.; and Pitzer, K.S. 1998. "Correlation of 162116 Thermodynamic Data for Aqueous Electrolyte Solutions to Very High Ionic Strength Using INSIGHT: Vapor Saturated Water Activity in the System $\mathrm{CaCl}_{2}$ $\mathrm{H}_{2} \mathrm{O}$ to $250^{\circ} \mathrm{C}$ and Solid Saturation." International Journal of Thermophysics, 19, (3), 761-770. New York, New York: Plenum Publishing. TIC: 253387.

Stoessell, R.K. 1988. " $25^{\circ} \mathrm{C}$ and 1 Atm Dissolution Experiments of Sepiolite and Kerolite." Geochimica et Cosmochimica Acta, 52, 365-374. New York, New York: Pergamon Press. TIC: 246452.

Stumm, W. and Morgan, J.J. 1996. Aquatic Chemistry, Chemical Equilibria and Rates in Natural Waters. 3rd Edition. New York, New York: John Wiley \& Sons. TIC: 246296.

Thiessen, W.E. and Simonson, J.M. 1990. "Enthalpy of Dilution and the Thermodynamics of $\mathrm{NH}_{4} \mathrm{Cl}(\mathrm{aq})$ to $523 \mathrm{~K}$ and $35 \mathrm{MPa}$." Journal of Physical Chemistry, 94, (20), 7794-7800. Washington, D.C.: American Chemical Society. TIC: 253883.

Tsang, Y.W. 1999. Yucca Mountain Single Heater Test Final Report. Report 124334 42537. Berkeley, California: Lawrence Berkeley National Laboratory. ACC: MOL.19990809.0191.

Van Zeggeren, F. and Storey, S.H. 1970. The Computation of Chemical 161603 Equilibria. New York, New York: Cambridge University Press. TIC: 252891.

Vaniman, D.T.; Ebinger, M.H.; Bish, D.L.; and Chipera, S. 1992. "Precipitation 107066 of Calcite, Dolomite, Sepiolite, and Silica from Evaporated Carbonate and Tuffaceous Waters of Southern Nevada, USA." Proceedings of the 7th International Symposium on Water-Rock Interaction, Park City, Utah, July $13-$ 18, 1992. Kharaka, Y.K. and Maest, A., eds. 1, 687-691. Brookfield, Vermont: A.A. Balkema. TIC: 208527.

Wadley, S. and Buckley, C.A. 1997. Chemical Speciation Self-Study Work 162329 Manual. WRC Project No. K8/208. Durban, South Africa: University of Natal, Department of Chemical Engineering, and Water Research Commission.

TIC: 252923.

Walling, E.M.; Rock, P.A.; and Casey, W.H. 1995. "The Gibbs Energy of Formation of Huntite, $\mathrm{CaMg}_{3}\left(\mathrm{CO}_{3}\right)_{4}$, at $298 \mathrm{~K}$ and 1 Bar from Electrochemical Cell Measurements." American Mineralogist, 80, (3-4), 355-360. Washington, D.C.: Mineralogical Society of America. TIC: 252890.

Walton, J.C. 1994. "Influence of Evaporation on Waste Package Environment and Radionuclide Release from a Tuff Repository." Water Resources Research, 30, (12), 3479-3487. Washington, D.C.: American Geophysical Union.

TIC: 246921. 
Wang, P.; Pitzer, K.S.; and Simonson, J.M. 1998. "Thermodynamic Properties of 162109 Aqueous Magnesium Chloride Solutions from 250 to $600 \mathrm{~K}$ and to $100 \mathrm{MPa}$." Journal of Physical and Chemical Reference Data, 27, (5), 971-991. Washington, D.C.: American Chemical Society. TIC: 249693.

Weast, R.C. and Astle, M.J., eds. 1981. CRC Handbook of Chemistry and 100833 Physics. 62nd Edition. Boca Raton, Florida: CRC Press. TIC: 240722.

Wesolowski, D.J. 1992. "Aluminum Speciation and Equilibria in Aqueous Solution: I. The Solubility of Gibbsite in the System Na-K-Cl-OH-Al $(\mathrm{OH})_{4}$ from 1 to $100^{\circ}$ C." Geochimica et Cosmochimica Acta, 56, (3), 1065-1091. New York, New York: Pergamon Press. TIC: 253946.

Wilder, D.G., ed. 1996. Volume II: Near-Field and Altered-Zone Environment Report. UCRL-LR-124998. Livermore, California: Lawrence Livermore National Laboratory. ACC: MOL.19961212.0121; MOL.19961212.0122.

Wolery, T.J. 1992. EQ3NR, A Computer Program for Geochemical Aqueous Speciation-Solubility Calculations: Theoretical Manual, User's Guide, and Related Documentation (Version 7.0). UCRL-MA-110662 PT III. Livermore, California: Lawrence Livermore National Laboratory.

ACC: MOL.19980717.0626.

Wollast, R.; Mackenzie, F.T.; and Bricker, O.P. 1968. "Experimental Precipitation and Genesis of Sepiolite at Earth-Surface Conditions." American Mineralogist, 53, 1645-1662. Washington, D.C.: Mineralogical Society of America. TIC: 253980.

\subsection{CODES, STANDARDS, REGULATIONS, AND PROCEDURES}

10 CFR 63. Energy: Disposal of High-Level Radioactive Wastes in a Geologic Repository at Yucca Mountain, Nevada. Readily available.

AP-2.14Q, Rev. 3, ICN 0. Document Review. Washington, D.C.: U.S. Department of Energy, Office of Civilian Radioactive Waste Management. ACC: DOC.20030827.0018.

AP-2.27Q, Rev. 1, ICN 5. Planning for Science Activities. Washington, D.C.: U.S. Department of Energy, Office of Civilian Radioactive Waste Management. ACC: DOC.20041014.0001.

AP-SIII.10Q, Rev. 2, ICN 7. Models. Washington, D.C.: U.S. Department of Energy, Office of Civilian Radioactive Waste Management.

ACC: DOC.20040920.0002. 
AP-SV.1Q, Rev. 1, ICN 1. Control of the Electronic Management of

Information. Washington, D.C.: U.S. Department of Energy, Office of Civilian

Radioactive Waste Management. ACC: DOC.20040308.0001.

LP-SI.11Q-BSC, Rev. 0, ICN 1. Software Management. Washington, D.C.:

U.S. Department of Energy, Office of Civilian Radioactive Waste Management.

ACC: DOC.20041005.0008.

\subsection{SOURCE DATA, LISTED BY TRACKING NUMBER}

LL000202905924.117. Environment on the Surfaces of the Drip Shield and

144913

Waste Package Outer Barrier. Submittal date: 02/18/2000.

LL991008004241.041. Evaporation of Topopah Spring Tuff Pore Water.

120487

Submittal date: $10 / 21 / 1999$.

LL991008104241.042. Evaporation of J13 Water: Laboratory Experiments and

120489

Geochemical Modeling. Submittal date: 10/21/1999.

MO0006J13WTRCM.000. Recommended Mean Values of Major Constituents in

151029

J-13 Well Water. Submittal date: 06/07/2000.

MO0302SPATHDYN.000. Thermodynamic Data Input Files - Data0.YMP.R2.

161756

Submittal date: $02 / 05 / 2003$.

MO0302SPATHDYN.001. Thermodynamic Data Supporting Spreadsheet Files -

161886

Data0.YMP.R2. Submittal date: 02/05/2003.

MO0407SEPFEPLA.000. LA FEP List. Submittal date: 07/20/2004.

170760

\subsection{OUTPUT DATA, LISTED BY DATA TRACKING NUMBER}

LL031106231032.007. High Temperature Solubility and Vapor Pressure (Relative Humidity) Data for Aqueous Systems Containing Single and Multiple Salts. Submittal Date: 11/19/2003.

MO0303MWDINJ13.000. Comparison of In-Drift Precipitates/Salts Model Simulations of Evaporation of In Situ J-13 Well Water Using Different Databases (YPF Pitzer vs. YMP.R2). Submittal Date: 03/04/2003.

MO0303MWDIOJ13.000. Example EQ3/6 In-Drift Precipitates/Salts Model Input/Output Files for In Situ J-13 Well Water. Submittal Date: 03/04/2003.

MO0303MWDJ13GD.000. In-Drift Precipitates/Salts Model Simulation of Synthetic J-13 Water Evaporation Experiments Documented in ANL-EBS-MD-000001. Submittal Date: 03/04/2003.

MO0303MWDJ13RB.000. In-Drift Precipitates/Salts Model Simulation of Synthetic J-13 Water Evaporation Experiments Documented in Rosenberg et al. 1999a. Submittal Date: 03/04/2003. 
MO0303MWDSEDSS.000. In-Drift Precipitates/Salts Model Simulations of Evaporation of Dilute Salt Solutions at 25C and 100C. Submittal Date: 03/04/2003.

MO0303MWDTSWRB.000. In-Drift Precipitates/Salts Model Simulation of Synthetic Topopah Spring Tuff Pore Water Evaporation Experiments Documented in Rosenberg et al. 1999b.

Submittal Date: 03/04/2003.

MO0303SPAMEQ36.000. General Formats of In-Drift Precipitates/Salts Model EQ3/6 Input Files. Submittal Date: 03/04/2003.

MO0303SPAMNSUP.000. Baseline YPF Pitzer Database Mineral Suppressions for the In-Drift Precipitates/Salts Model. Submittal Date: 03/04/2003.

MO0304SPAJ13IS.001. Example EQ3/6 In-Drift Precipitates/Salts Model Lookup Tables for In Situ J-13 Well Water. Submittal Date: 04/15/2003.

MO0307MWDSEAEV.000. Seawater Evaporation Predictions Using the IDPS Model. Submittal Date: 07/31/2003.

MO0307MWDUNEVP.000. Uncertainties in Evaporation Predictions Using the IDPS Model. Submittal Date: 07/31/2003.

MO0312SPAESMUN.002. Estimated Model Uncertainties in IDPS Model Outputs. Submittal Date: $12 / 03 / 2003$.

MO0308SPAUCIMV.000. Uncertainty Comparisons in IDPS Model Validation Cases. Submittal Date: 08/08/2003.

MO0311MWDMVBTS.000. IDPS Model Validation Files for Binary and Ternary Systems. Submittal Date: 11/05/2003.

MO0410SPAPITZR.000. Pitzer Thermodynamic Database (Revision 1.1). Submittal Date: $10 / 20 / 2004$.

MO0410MWDIDPSM.000. IDPS Model Sensitivity Calculations Addressing Zeolite Log K Corrections. Submittal Date: 10/20/2004.

SN0302T0510102.002. Pitzer Thermodynamic Database (Data0.YPF, Revision 1). Submittal Date: $02 / 06 / 2003$.

SN0306T0510102.007. Revised Pitzer Thermodynamic Database Spreadsheets and EQ3/6 Input and Output Files. Submittal Date: 06/30/2002. 


\subsection{SOFTWARE CODES}

EQ3/6. V8.0. PC w/ Windows 95/98/2000/NT 4.0. 10813-8.0-00.

162228

GetEQData. V1.0.1. PC w/Windows 2000. 10809-1.0.1-0.

161900

SUPCRT92. V1.0. PC w/Windows OS and MAC w/MAC OS. 10058-1.0-00.

153218 


\section{APPENDIX I}

PITZER DATABASE DEVELOPMENT: DESCRIPTION OF THE PITZER GEOCHEMICAL THERMODYNAMIC DATABASE (data0.ypf) 


\section{CONTENTS}

Page

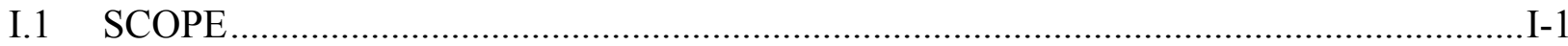

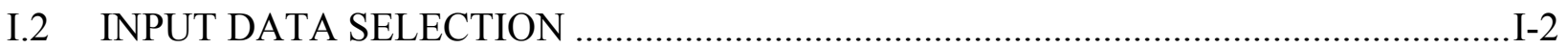

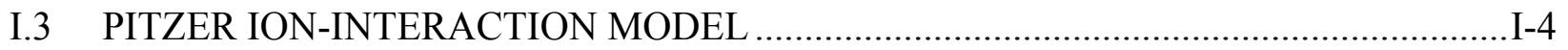

I.3.1 GENERAL PITZER ELECTROLYTE THEORY …….........................................-4

I.3.1.1 Pitzer's Model for Aqueous Binary Electrolytes.................................... -5

I.3.1.2 Pitzer's Model for Aqueous Electrolyte Mixtures...................................

I.3.1.3 Extension of Pitzer's Model to Include Dissolved Neutral Molecules......................................................................................

I.3.1.4 Thermodynamic Data Used to Derive Parameters of Pitzer's Model........................................................................................

I.3.2 TEMPERATURE FUNCTIONS FOR PITZER INTERACTION

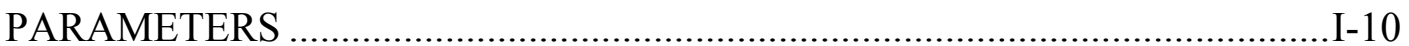

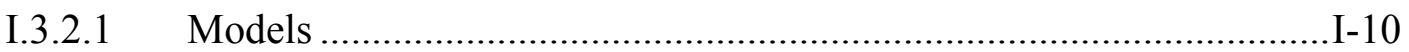

I.3.2.2 Constant Enthalpy.......................................................................

I.3.2.3 Constant Heat Capacity ..................................................................

I.3.2.4 Parabolic Heat Capacity ……............................................................

I.3.2.5 Other Comments on Existing Temperature Functions .......................... I-16

I.4 EVALUATION, COMPILATION AND CONVERSION OF PITZER

INTERACTION PARAMETERS FROM PUBLISHED SOURCES ………..................... I-17

I.4.1 FITPITZERNC METHODOLOGY …………............................................

I.4.2 PROCEDURE FOR FITTING TEMPERATURE FUNCTIONS TO PITZER

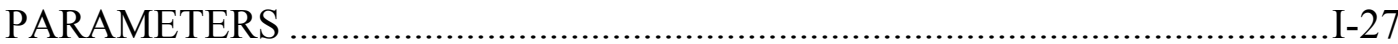

I.4.2.1 FitPitzerNC Worksheet Implementation ............................................

I.4.2.2 Example Calculation for FitPitzerNC_MX_NaCl.xls Workbook ........I-29

I.4.3 CONPITZERNC METHODOLOGY ……………….....................................-32

I.4.3.1 Procedure for Determining Standard Pitzer Model Parameters from Archer Model Parameters .............................................................

I.4.3.2 ConPitzerNC Workbook Implementation ........................................... I-35

I.4.3.3 Example Calculation for ConPitzerNC_MX_CaCl2.xls Workbook...I-35

I.4.4 BINARY PITZER INTERACTION PARAMETERS ……….............................-37

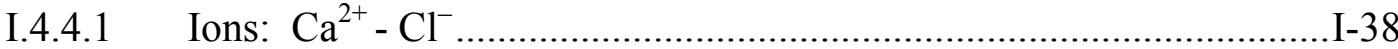

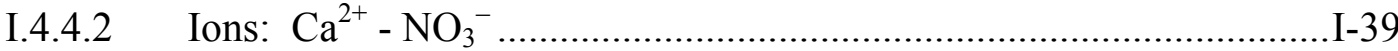

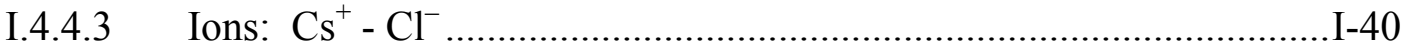

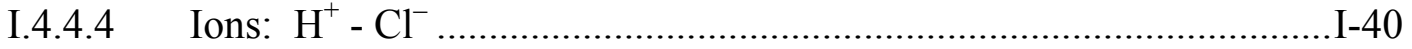

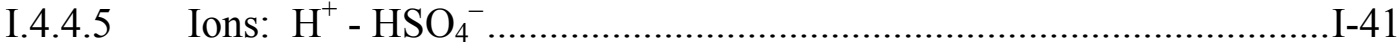

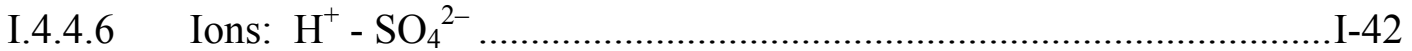

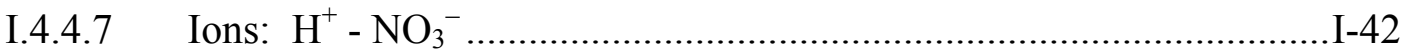

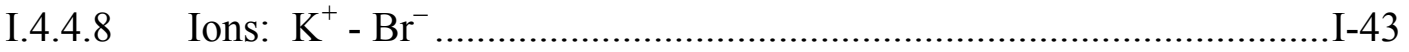

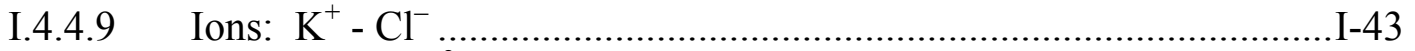

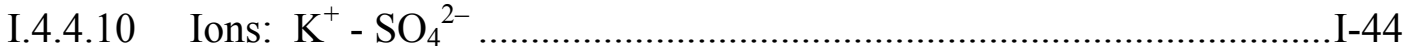

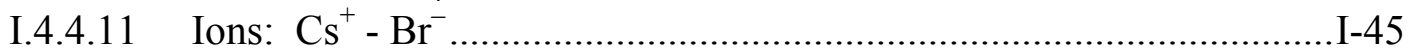

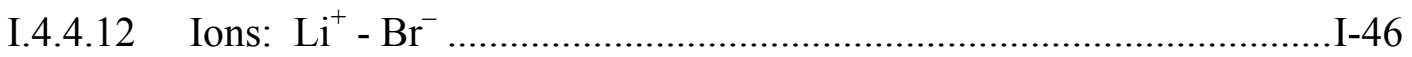




\section{CONTENTS (Continued)}

Page

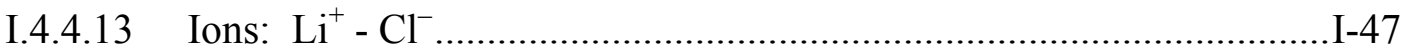

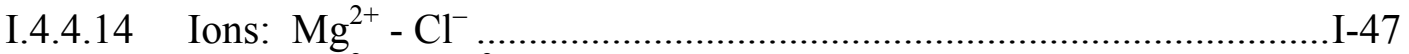

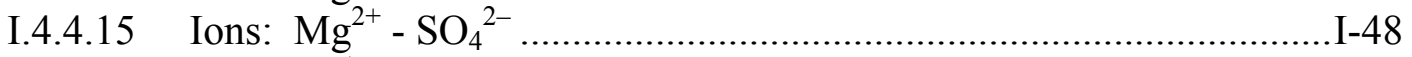

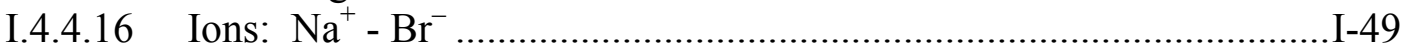

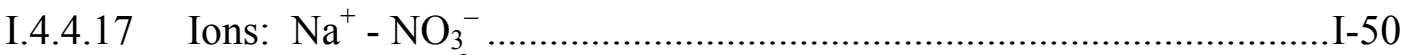

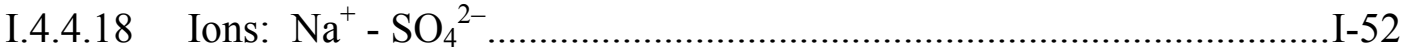

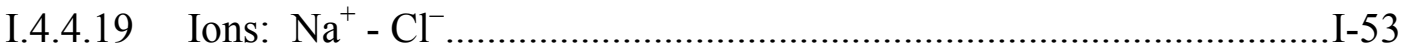

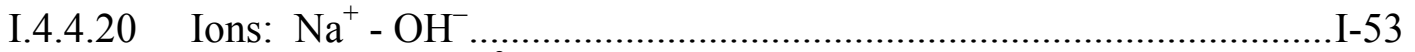

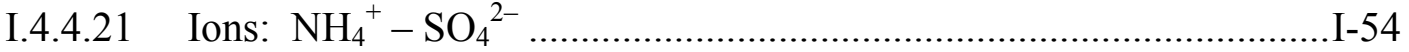

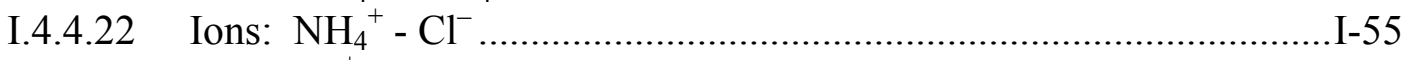

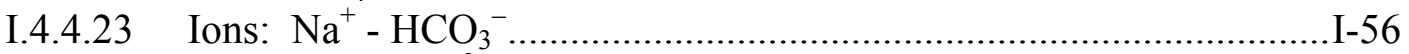

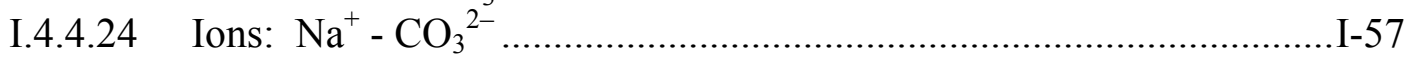

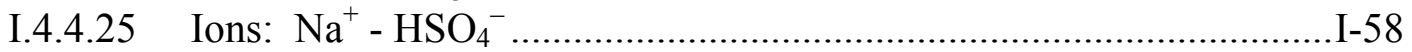

I.4.4.26 Ions: $\mathrm{Na}^{+}-\mathrm{AlO}_{2}{ }^{-}$(equivalent to $\mathrm{Na}^{+}-\mathrm{Al}(\mathrm{OH})_{4}{ }^{-}$) ........................... I-59

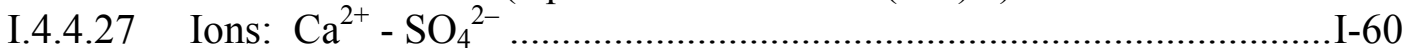

I.4.5 TERNARY PITZER INTERACTION PARAMETERS .......................................-61

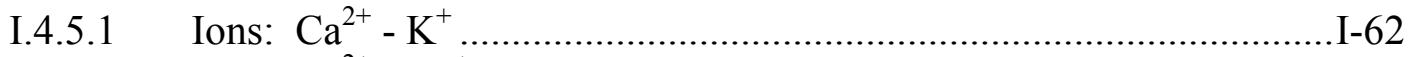

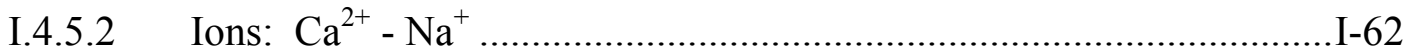

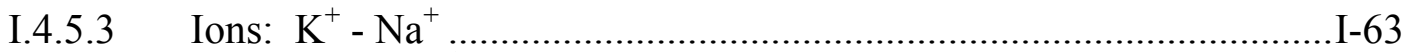

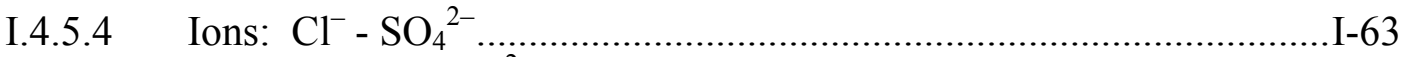

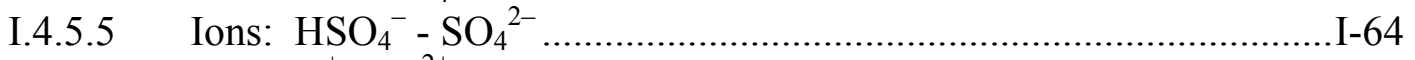

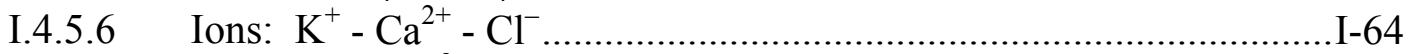

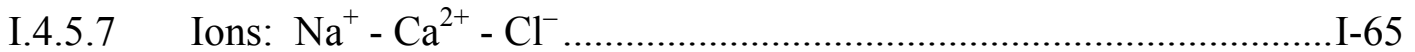

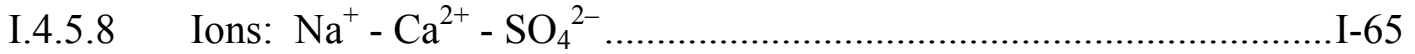

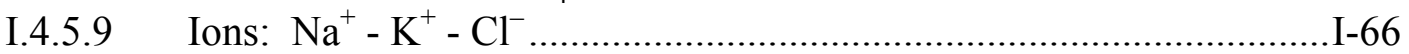

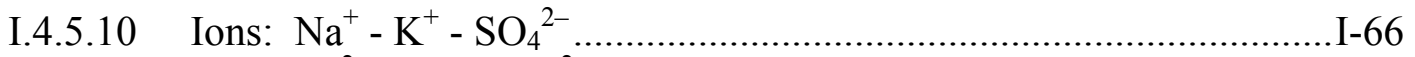

I.4.5.11 Ions: $\mathrm{Ca}^{2+}-\mathrm{Cl}^{-}-\mathrm{SO}_{4}{ }^{2-}$..........................................................

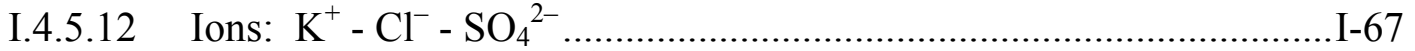

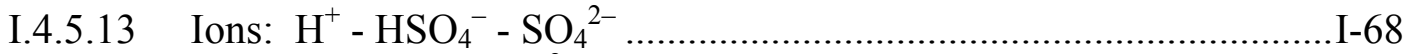

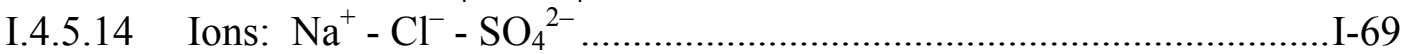

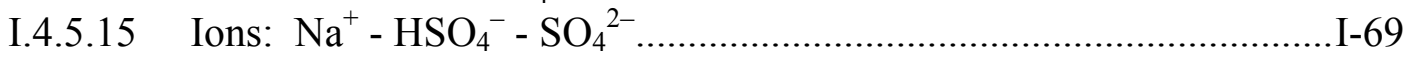

I.4.5.16 Neutral Species: Doublets and Triplets Parameters Among

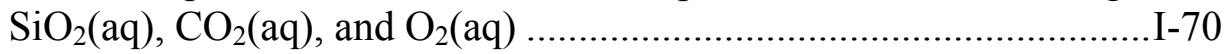

I.4.5.17 Ions: MMX Ternary Parameters in the System Na-K-Mg-Cl-OH-

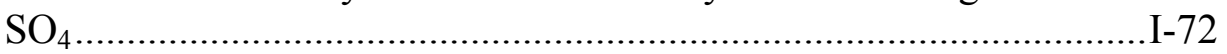

I.4.6 VARIOUS MX AND MM PARAMETERS FROM TABLE I-2 AT $25^{\circ} \mathrm{C}$ THAT DO NOT REQUIRE REFITTING ……………....................................

I.5 DATA FOR SOLID PHASES, AQUEOUS SPECIES AND GASES................................

I.5.1 $\mathrm{CaCl}_{2}$ HYDRATES $\left(\mathrm{CaCl}_{2} \bullet \mathrm{NH}_{2} \mathrm{O}\right.$ WHERE N EQUALS 2, 4, AND 6).............. I-82

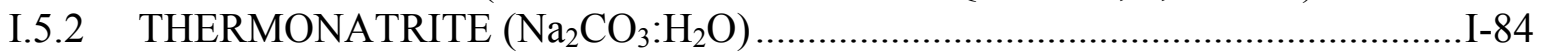

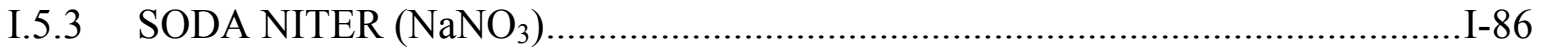




\section{FIGURES}

Page

I-1. Archer's Calculated Osmotic Coefficients Compared to Fitted Spreadsheet Results.... I-51

I-2. Comparison of Saturation Molalities for Gypsum ………………...............................

I-3. Comparison of Predicted and Compiled Saturation Molalities (msat) for $\mathrm{CaCl}_{2}$ Hydrates.........................................................................................................

I-4. Comparison of Initial and Fitted $\log \mathrm{K}$ Values for the Reaction Describing Thermonatrite Solubility as Implemented in the data0.ypf Database.

I-5. Comparison of Predicted Saturation Molalities for Thermonatrite Using EQ3/6 (Version 8.0) and data0.ypf to Those Reported by Linke

I-6. Comparison of $\log \mathrm{K}$ Values for Soda Niter $\left(\mathrm{NaNO}_{3}(\mathrm{~s})\right)$ Dissolution from Various Sources and Those Obtained by Fitting Saturation Molalities Reported by Archer ......I-87

I-7. Comparison of Saturation Molalities for Soda Niter $\left(\mathrm{NaNO}_{3}(\mathrm{~s})\right)$ Predicted by EQ3/6 Version 8.0 Using data0.ypf and Fitted $\log \mathrm{K}$ to Those in Archer up to a Temperature of $100^{\circ} \mathrm{C}$

\section{TABLES}

Page

I-1. Catalog of Pitzer Ion-Interaction Parameter Spreadsheets

I-2. Pitzer Ion-Interaction Parameters Not Requiring Refitting (Values Only Valid at $\left.25^{\circ} \mathrm{C}\right)$

I-3. Fitting Coefficient Definitions for the 3-4 Parameter $25^{\circ} \mathrm{C}$ Centric Equations Used in the FitPitzerNC/ConPitzerNC Spreadsheets and data0.ypf Database File

I-4. Comparison of Osmotic Coefficients $(\phi)$ from the 3 to 4 Term Fit to Those Measured for $\mathrm{CaCl}_{2}$ at $25^{\circ} \mathrm{C}$

I-5. Comparison of Osmotic Coefficients ( $\phi)$ from the 3-4 Term Fit to Those Measured for $\mathrm{CsCl}$ at $25^{\circ} \mathrm{C}$

I-6. Comparison of Osmotic Coefficients $(\phi)$ from the 3- to 4 Term Fit to Those Measured for $\mathrm{HCl}$ at $25^{\circ} \mathrm{C}$

I-7. Comparison of Osmotic Coefficients ( $\phi)$ from the 3-4 Term Fit to Those Measured for $\mathrm{KBr}$ at $25^{\circ} \mathrm{C}$

I-8. Comparison of Osmotic Coefficients $(\phi)$ Values from the 3-4 Term Fit to Those Measured for $\mathrm{KCl}$ at 25 and $100^{\circ} \mathrm{C}$.

I-9. Comparison of Osmotic Coefficients $(\phi)$ Values from the 3-4 Term Fit to Those Measured for $\mathrm{K}_{2} \mathrm{SO}_{4}$ at 25 and $150^{\circ} \mathrm{C}$.

I-10. Comparison of Source Osmotic Coefficients $(\phi)$ to Those Measured for $\mathrm{CsBr}$ at $25^{\circ} \mathrm{C}$

I-11. Comparison of Source Osmotic Coefficients $(\phi)$ to Those Measured for $\mathrm{LiBr}$ at $25^{\circ} \mathrm{C}$

I-12. Comparison of Source Osmotic Coefficients $(\phi)$ to Those Measured for $\mathrm{LiCl}$ at $25^{\circ} \mathrm{C}$ 
I-13. Comparison of Source Osmotic Coefficients ( $\phi)$ to Those Measured for $\mathrm{MgCl}_{2}$ at $25^{\circ} \mathrm{C}$

I-14. Comparison of Source Osmotic Coefficients $(\phi)$ to Those Measured for $\mathrm{MgCl}_{2}$ at $100^{\circ} \mathrm{C}$

I-15. Comparison of 3-4 Term Fitting Osmotic Coefficients $(\phi)$ to Those Measured for $\mathrm{MgSO}_{4}$ at 25 and $100^{\circ} \mathrm{C}$.....

I-16. Comparison of Source Osmotic Coefficients $(\phi)$ to Those Measured for $\mathrm{NaBr}$ at $25^{\circ} \mathrm{C}$

I-17. Comparison of Source Osmotic Coefficients $(\phi)$ to Those Measured for $\mathrm{NaBr}$ at $200^{\circ} \mathrm{C}$.

I-18. Comparison of Fitted Osmotic Coefficients $(\phi)$ to Those Measured for $\mathrm{Na}_{2} \mathrm{SO}_{4}$ at 25 and $100^{\circ} \mathrm{C}$

I-19. Comparison of Fitted Osmotic Coefficients $(\phi)$ to Those Measured for $\mathrm{NaCl}$ at 25 and $100^{\circ} \mathrm{C}$

I-20. Comparison of Fitted 3-4 Term Osmotic Coefficients $(\phi)$ to Those Measured for $\mathrm{NaOH}$ at $25^{\circ} \mathrm{C}$

I-21. Comparison of Fitted 3-4 Term Osmotic Coefficients $(\phi)$ to Those Measured for $\mathrm{NaOH}$ at $170^{\circ} \mathrm{C}$

I-22. Comparison of Fitted 3-4 Term Osmotic Coefficients $(\phi)$ to Those Measured for (NH4)2SO4 at 25 and $100^{\circ} \mathrm{C}$

I-23. Comparison of 3-4 Term Fitted Osmotic Coefficients $(\phi)$ to Measured for $\mathrm{NH}_{4} \mathrm{Cl}$ at $25^{\circ} \mathrm{C}$

I-24. Comparison of Fitted 3-4 Term Osmotic Coefficients $(\phi)$ to Those Measured for $\mathrm{NaHCO}_{3}$ at 25 and $45^{\circ} \mathrm{C}$....

I-25. Comparison of Fitted 3-4 Term Osmotic Coefficients $(\phi)$ to Measured for $\mathrm{Na}_{2} \mathrm{CO}_{3}$ at 25 and $45^{\circ} \mathrm{C}$.....

I-26. Comparison of the Degree of Sulfuric Acid Dissociation as a Function of Temperature and Ionic Strength ..............................................................................

I-27. Solid Minerals Sourced from the Data0.ymp.R2 Database........................................... I-74

I-28. Cement Phases Sourced from the Data0.ymp.R2 Database .......................................

I-29. Salt Solids Sourced from Various Spreadsheets ........................................................... I-77

I-30. Auxiliary Basis Aqueous Species Data Sources ....................................................... I-80

I-31. Aqueous Species Data Sources …………………..............................................

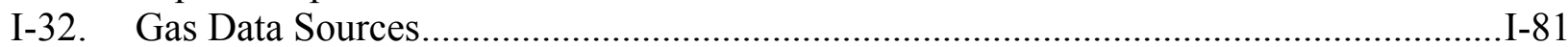

I-33. Comparison of Initial and Fitted $\log \mathrm{K}$ Values for $\mathrm{CaCl}_{2}$ Hydrates Used in the

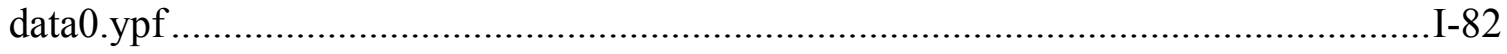




\section{I.1 SCOPE}

The Pitzer database data0.ypf (DTN: SN0302T0510102.002) was developed to calculate concentrations of electrolyte solutions resulting from the compositional evolution of waters from the unsaturated zone that are likely to seep into the waste emplacement drifts. These calculations are performed using the computer code EQ3/6 Version 8.0 (STN: 10813-8.0-00) for which a Pitzer parameter database has been created.

As a result of above-ambient temperature conditions within the repository, water from the unsaturated zone undergoes evaporation to evolve into a concentrated electrolyte solution. These concentrated waters may accelerate degradation processes (e.g., metal corrosion) thereby affecting the integrity of Engineered Barrier System (EBS) components such as waste packages and drip shields. For this reason, electrolyte component concentrations under long-term evaporative conditions need to be estimated to provide input for downstream total system performance assessment (TSPA) models.

Geochemical modeling using data appropriate for dilute solutions, such as those data contained in the geochemical database data0.ymp.R, (DTN: MO0302SPATHDYN.000 [DIRS 161756]) is not accurate or valid when applied to the concentrated (high ionic strength) solutions that result from the evaporation of seepage waters within the disposal drifts. As explained in Section I-3, the Pitzer database represents a more accurate way of predicting chemical behavior in concentrated aqueous electrolyte solutions. Modeling of water compositions associated with the in-drift physical and chemical environment under long-term evaporative repository conditions therefore relies upon this Pitzer database. Development of this database involves a comprehensive compilation of Pitzer model parameters reported in the literature, focusing mostly on those functional at relatively elevated temperatures (i.e., above $25^{\circ} \mathrm{C}$ ). Data above $25^{\circ} \mathrm{C}$ are needed since the estimated long-term conditions in the repository will be above ambient temperatures.

The steps taken to develop the Pitzer database are as follows:

- Compilation of recent Pitzer parameter data focusing on temperatures at and above $25^{\circ} \mathrm{C}$ for major aqueous species present in natural waters that might seep into the repository drift.

- Validation and testing of compiled Pitzer data to predict osmotic coefficients and therefore water activity when compared to source literature data.

- Estimation and fitting of solubility constants ( $\log \mathrm{Ks}$ ) for selected salt solids using tabulated thermodynamic and solubility data in concert with the estimated Pitzer parameters defining the activity model for the relevant salt system. This is done to bridge consistency between the compiled Pitzer electrolyte parameter data and the reported salt phase solubility reported in the scientific literature.

- Incorporation of silicate mineral $\log \mathrm{K}$ data from the recent thermodynamic data compilation data0.ymp.R2 (DTN: MO0302SPATHDYN.000 [DIRS 161756]) that include clays, zeolites, and cement phases. 


\section{I.2 INPUT DATA SELECTION}

The Pitzer database was developed in this document using primary input data selected from a variety of published sources. The status of these input data is summarized in the DIRS. One primary source for input data is the YMP-generated database data0.ymp.R2. Additional input data are selected from widely used handbook sources, and the remainder of the data used is selected from internationally recognized peer-reviewed journals. Data sources for Pitzer parameters are entirely restricted to peer-reviewed journals. The data sources for binary electrolyte solutions are listed in Table 4-1 of Section 4.1.1 of this report, and the data sources for ternary solutions are listed in Table 4-2 of that section. The rationale for the selection of these data is discussed in the subsections of Sections I-4.4 and I-4.5.

The most important rationale for adopting the Pitzer modeling approach and related parameter data is their wide acceptance by the scientific and international community. As documented below, this acceptance is comparable to that for scientific and technical handbooks. Since the early publications on the subject by Professor Kenneth S. Pitzer of the Department of Chemistry, the University of California at Berkeley (e.g., Pitzer 1973 [DIRS 152738]; Pitzer and Mayorga 1973 [DIRS 152742]; Pitzer and Kim 1974 [DIRS 123206]), Pitzer's approach to the thermodynamics of highly concentrated aqueous electrolytes has been widely accepted. This is evident not only by the large number of citations of publications by him (including co-authors) and citations of publications by other independent authors who used the same approach, but also by the range of organizations represented. Examples of this wide acceptance include use of the Pitzer approach by the staff at the University of California, San Diego (Møller 1988 [DIRS 152695]; Spencer et al. 1990 [DIRS 152713]); the Chemistry and Analytical Sciences Division, Oak Ridge National Laboratory (Holmes and Mesmer 1994 [DIRS 162078]); Lawrence Livermore National Laboratory (Rard and Wijesinghe 2003 [DIRS 162327]); Johns Hopkins University (Eugster and Jones 1979 [DIRS 123175]; see the citations list in the body of this report); the Physical and Chemical Properties Division, National Institute of Standards and Technology (Archer 2000 [DIRS 162065]); Pacific Northwest National Laboratory in collaboration with Fluid Inclusion Technologies (Oakes et al. 2000 [DIRS 162102]); Plymouth Marine Laboratory, UK, in collaboration with School of Environmental Sciences, University of East Anglia, UK (Clegg and Brimblecombe 1990 [DIRS 159187]); the Department of Chemistry, University of Coimbra, Portugal, in collaboration with the Department of Chemistry, the University of California at Berkeley (de Lima and Pitzer 1983 [DIRS 162110]); the Department of Geology, Texas A\&M University (He and Morse 1993 [DIRS 162090]); the Department of Chemistry, Murdoch University, Australia (Königsberger 2001 [DIRS 162093]); the Department of Chemistry and Geochemistry, Colorado School of Mines (author was one of the first members of the Nuclear Waste Technical Review Board) (Langmuir 1997 [DIRS 100051], pp. 138-143; see the citations list in the body of this report); the Center for Nuclear Waste Regulatory Analyses (Pabalan and Pitzer 1987 [DIRS 162147]; Pabalan and Pitzer 1987 [DIRS 162096]); and others. The group at Oak Ridge National Laboratory (Holmes and Mesmer 1994 [DIRS 162078]) are well-known for producing high quality isopiestic data at elevated temperatures thanks to their considerable improvements on this experimental technique (see Rard and Platford 1991 [DIRS 152715], section C, p. 246-249). Isopiestic experiments on electrolytes provide osmotic coefficient data that are then used to obtain Pitzer parameter data. Papers by all these authors have been extensively cited, so much so as to indicate acceptance 
rather than rejection, as documented below in Sections I-4.4 through I-4.6 for individual ion doublets and triplets.

The Pitzer database data0.ypf is divided in four sections composed of data blocks containing thermodynamic data representing: 1) coefficient data for temperature-dependent interaction parameters defined in the Pitzer standard formulations in accord with the 3-4 term $25^{\circ} \mathrm{C}$-centric parameter equation to describe temperature dependence (see Section I-3.2) and implemented in the code EQ3/6 Version 8.0; 2) selected log Ks for ion pair speciation reactions; 3) log Ks for solids obtained from existing thermodynamic data compilations except those salts for which log $\mathrm{K}$ values were obtained in the current effort; and 4) $\log \mathrm{K}$ solubility data for selected gases also from existing data compilations.

A thorough evaluation of existing Pitzer parameter data is required for inclusion into the database. The criteria used for accepting data from a published source are as follows:

Criterion 1: Pitzer ion-interaction parameters for a specific electrolyte should be reproduced by the equations given by the source publication to express their temperature dependence. Failure to satisfy this criterion will result in either rejection of the data or refitting of actual parameter if tabulated in the source. Parameter data given only at $25^{\circ} \mathrm{C}$ do not need to satisfy this criterion since they do not require refitting.

Criterion 2: Pitzer parameter data satisfying criterion 1 for a given range of temperatures and electrolyte concentrations will be used in the conversion (if necessary) and refitting procedures described in sections I-4.1, I-4.2, and I-4.3. Upon refitting to the temperature function embedded in EQ3/6 Version 8.0 (see Section I-3.2.1.3), the ion interaction parameters are compared to check that these closely match the input values obtained from the source. The comparison between refitted and input values of osmotic coefficients should be a close match (see comparison analyses in the attached spreadsheets). Failure to satisfy this criterion will result in rejection of parameter data. Parameter data given only at $25^{\circ} \mathrm{C}$ do not need to satisfy this criterion since these do not need refitting.

Further tests in most of the fitted parameter data involve comparison of experimentally determined osmotic coefficients for specific electrolytes from alternate sources. Due to the limited amount of osmotic coefficient data available for many electrolytes of interest, this comparison is not done on all binary parameters considered in this attachment. Nevertheless, it represents a robust validation of the predictive capabilities of the database. This test does not apply to parameter data obtained only at $25^{\circ} \mathrm{C}$.

Most of the $\log \mathrm{K}$ data for solids comes from one source (e.g., data0.ymp.R2). Only few $\log \mathrm{K}$ values for salt solids are needed and these were obtained through a calibration method bound by tabulated salt solubilities and the compiled Pitzer activity model. Calibration of solubility constants or $\log \mathrm{Ks}$ for the salt solids is achieved by fitting $\log \mathrm{K}$ values to the salt saturation molality using the obtained Pitzer activity model. Saturation molalities for salt solids as a function of temperature are obtained from tabulated handbook data or peer-review journals. For comparison, the resulting $\log \mathrm{K}$ values are then compared to those obtained by using tabulated standard Gibbs free energy data (e.g., Robie and Hemingway 1995 [DIRS 153683]). The percent difference in $\log \mathrm{K}$ values between those obtained through calibration and those from tabulated 
thermodynamic data should be less than $15 \%$. Percent differences exceeding the latter value should be regarded as unsatisfactory and will not be considered for inclusion in the database. All $\log \mathrm{K}$ values obtained for the salt solids through the calibration method have percent differences of less than $10 \%$ rendering the calibrated values as satisfactory within the predictive capabilities of the database.

\section{I.3 PITZER ION-INTERACTION MODEL}

The theory behind the development of Pitzer equations for describing the thermodynamic properties of electrolyte solutions is rather complex, and a detailed description goes beyond the scope needed for this thermodynamic database description. The interested reader should consult the works of Pitzer (1973 [DIRS 152738]; 1991 [DIRS 152709] and references therein) for details on fundamental theoretical groundwork on the formalism and applications of this thermodynamic model as applied to concentrated aqueous electrolyte solutions. Basically, the Pitzer model is an extension of the Debye-Hückel model for ionic solutions. Ion interactions beyond the Debye-Hückel approximation are represented by a set of ion-interaction coefficients that form an integral feature of Pitzer semi-empirical equations. These equations are described in detail in the EQ3/6 Version 8.0 User Manual (SDN: 10813-UM-8.0-00). For completeness, the fundamental equations pertinent to pure aqueous electrolytes and mixtures will be briefly summarized here.

\section{I.3.1 GENERAL PITZER ELECTROLYTE THEORY}

The starting point for the formulation of Pitzer's model is the equation for the excess Gibbs free energy $\left(G^{\mathrm{EX}}\right)$ of the total solution:

$$
G^{\mathrm{EX}} / w_{\mathrm{w}}=R T \sum_{l} m_{\mathrm{i}}\left(1-\phi+\ln \gamma_{\mathrm{i}}\right)
$$

where $G^{\mathrm{EX}}$ is the difference or "excess" in the Gibbs free energy between a real solution and an ideal solution defined on the molality composition scale, $w_{w}$ is the mass of water in the solution in kilograms, $m_{i}$ is the molality of the $\mathrm{i}$ th type of ion, $\phi$ is the molality based osmotic coefficient of the solvent, and $\gamma_{i}$ is the molality based activity coefficient of the $i$ th type of ion. $R$ is the universal gas constant and $T$ is the absolute temperature. Once an expression has been assumed for the dependence of GEX on the ionic composition of the solution, the osmotic coefficient of the solvent and the activity coefficient of each ionic solute may be calculated by taking the appropriate partial derivatives:

$$
\begin{gathered}
\ln \gamma_{\mathrm{i}}=\left[\partial\left\{G^{\mathrm{EX}} / R T w_{\mathrm{w}}\right\} / \partial m_{\mathrm{i}}\right]_{n_{\mathrm{w}}} \\
\phi=1-\left[\left\{\partial G^{\mathrm{EX}} / R T \sum_{l} m_{\mathrm{i}}\right\} / \partial w_{\mathrm{w}}\right]_{n_{\mathrm{i}}}
\end{gathered}
$$

where $n_{\mathrm{w}}$ and $n_{\mathrm{i}}$ are the numbers of moles of water and of ion $i$, respectively. The osmotic coefficient is directly related to the water activity of the solution, $a_{\mathrm{w}}$, by the relation:

$$
\ln a_{\mathrm{w}}=-\left(\sum_{l} m_{\mathrm{i}}\right) \phi / \Omega
$$


where the quantity $\Omega=\left(1 \mathrm{~kg} / 0.018015 \mathrm{~kg} \cdot \mathrm{mol}^{-1}\right)=55.508 \mathrm{~mol} \cdot \mathrm{kg}^{-1}$ is the number of moles of water present in one kilogram of water.

Pitzer (1973 [DIRS 152738]) initially wrote his expression for $G^{\mathrm{EX}}$ in the following form (except for minor differences in notation):

$$
G^{\mathrm{EX}} /(R T)=\mathrm{w}_{\mathrm{w}} \mathrm{f}^{\mathrm{G}}(I)+\left(1 / w_{\mathrm{w}}\right) \sum_{\mathrm{ij}} \lambda_{\mathrm{ij}}(I) n_{\mathrm{i}} n_{\mathrm{j}}+\left(1 / \mathrm{w}_{\mathrm{w}}{ }^{2}\right) \sum_{\mathrm{ijk}} \mu_{\mathrm{ijk}} n_{\mathrm{i}} n_{\mathrm{j}} n_{\mathrm{k}}
$$

where $\mathrm{f}^{G}(I)$ represents the total contribution of long-range electrostatic forces between ions, $\lambda_{\mathrm{ij}}(I)$ represents the short-range specific interactions between pairs of ions $i$ and $j$, and $\mu_{\mathrm{ijk}}$ represents the short-range specific interactions between triplets of ion $i, j$, and $k$. The $\mathrm{f}(I)$ and $\lambda_{\mathrm{ij}}(I)$ are assumed to be functions of the ionic strength $I$. The ionic strength of the solution is defined on the molality concentration scale as:

$$
I=(1 / 2) \sum_{l} m_{\mathrm{i}} z_{\mathrm{i}}^{2}
$$

where $z_{\mathrm{i}}$ is the valence of the $i$ th ion. Pitzer tested two different variants of the Debye-Hückel equation for the long-range electrostatic term, and selected the Debye-Hückel "osmotic" function. For the osmotic coefficient, this function has the form:

$$
\mathrm{f}^{\phi}(I)=-\mathrm{A}_{\phi} \sqrt{I} /(1+b \sqrt{I})
$$

where $\mathrm{f}^{\phi}(I)$ depends only on the ionic strength $I$, and $\mathrm{A}_{\phi}$ is the Debye-Hückel limiting law slope for the osmotic coefficient. Pitzer further selected $b=1.2$ for all aqueous electrolytes, assumed that the $\lambda_{\mathrm{ij}}$ and $\mu_{\mathrm{ijk}}$ functions are symmetrical in their indices, e.g. $\lambda_{\mathrm{ij}}=\lambda_{\mathrm{ji}}$, and noted that the ratios of moles of solute ion $i$ to the number of kilograms of water yields the molality of that ion, i.e., $n_{\mathrm{i}} / \mathrm{w}_{\mathrm{w}}=m_{\mathrm{i}}$.

The corresponding equation for the Debye-Hückel "osmotic" function $\mathrm{f}^{G}(I)$ for the excess Gibbs free energy is:

$$
\mathrm{f}^{G}(I)=-\left(4 I \mathrm{~A}_{\phi} / b\right) \ln (1+b \sqrt{I})
$$

Similarly, Debye-Hückel "osmotic" function $\mathrm{f}^{\prime}(I)$ for the activity coefficient is:

$$
\mathrm{f}^{\prime}(I)=-\mathrm{A}_{\phi}\{\sqrt{I} /(1+b \sqrt{I})+(2 / b) \ln (1+b \sqrt{I})\}
$$

\section{I.3.1.1 Pitzer's Model for Aqueous Binary Electrolytes}

Equation I-5 could be used as the starting point for deriving the expressions for the thermodynamic properties of the solvent and the solute ions. However, Pitzer (1973 [DIRS 152738]) rewrote his equations in terms of $B_{\mathrm{MX}}$ and $C_{\mathrm{MX}}$ functions which are now more commonly used, and which will be used in the subsequent discussion. Anyone interested in the explicit equations for $\phi$ and $\ln \gamma_{\mathrm{i}}$ written in terms of the $\lambda_{\mathrm{ij}}$ and $\mu_{\mathrm{ijk}}$ should consult Pitzer's (1973 [DIRS 152738]; 1991 [DIRS 152709]) publications and Software User's Manual, EQ3/6, 
Version 8.0. (SNL 2003 [DIRS 162494]). The equations relating these two types of functions for a single aqueous electrolyte containing a cation $\mathrm{M}$ and anion $\mathrm{X}$ are:

$$
B_{\mathrm{MX}}^{\phi}(I)=\lambda_{\mathrm{MX}}+I \lambda_{\mathrm{MX}}{ }^{\prime}+\left(v_{\mathrm{M}} / 2 v_{\mathrm{X}}\right)\left(\lambda_{\mathrm{MM}}+I \lambda_{\mathrm{MM}}{ }^{\prime}\right)+\left(v_{\mathrm{X}} / 2 v_{\mathrm{M}}\right)\left(\lambda_{\mathrm{XX}}+I \lambda_{\mathrm{XX}}{ }^{\prime}\right)
$$

and

$$
C_{\mathrm{MX}}^{\phi}=3\left(v_{\mathrm{M}} \mu_{\mathrm{MMX}}+v_{\mathrm{X}} \mu_{\mathrm{MXX}}\right) / \sqrt{v_{\mathrm{M}} v_{\mathrm{X}}}
$$

where the primes denote the derivative of a function with regard to the ionic strength (e.g., $\lambda_{\mathrm{Mx}}{ }^{\prime}$ $\left.=\partial \lambda_{\mathrm{MX}} / \partial I\right), v_{\mathrm{M}}$ is the stoichiometric number of cations formed by dissociation of one molecule of the solute, and $v_{X}$ is the stoichiometric number of anions formed by dissociation of one molecule of the solute.

Pitzer (1973 [DIRS 152738]) allowed the $B_{\mathrm{MX}}^{\phi}(I)$ to vary with the ionic strength, but assumed that $C_{\mathrm{MX}}^{\phi}$ could be approximated as a parameter that is independent of ionic strength but which may vary with temperature and pressure. After testing two possible variants for the ionic-strength dependence of $B_{\mathrm{MX}}^{\phi}(I)$, Pitzer (1973 [DIRS 152738]; 1991 [DIRS 152709]) chose the functional form,

$$
B_{\mathrm{MX}}^{\phi}(I)=\beta_{\mathrm{MX}}^{(0)}+\beta_{\mathrm{MX}}^{(1)} \cdot \mathrm{e}^{-\alpha_{1} \sqrt{I}}+\beta_{\mathrm{MX}}^{(2)} \cdot \mathrm{e}^{-\alpha_{2} \sqrt{I}}
$$

The $\beta_{\mathrm{MX}}^{(2)} \cdot \mathrm{e}^{-\alpha_{2} \sqrt{I}}$ term is normally included only when modeling the thermodynamic properties of divalent metal sulfates and other high-valence electrolytes that exhibit significant association at low ionic strengths, but it is set equal to zero for strong electrolytes. The $\beta_{\mathrm{MX}}^{(0)}, \beta_{\mathrm{MX}}^{(1)}$, $\beta_{\mathrm{MX}}^{(2)}$, and $C_{\mathrm{MX}}^{\phi}$ coefficients are usually referred to as ion-interaction or Pitzer parameters. These Pitzer parameters may vary with temperature and pressure, but they do not depend on the ionic strength. The exponential coefficient $\alpha_{1}$ is generally fixed at $\alpha_{1}=2.0$ for strong electrolytes, but for divalent metal sulfates and other 2:2 type electrolytes its value is usually fixed at $\alpha_{1}=1.4$ (Pitzer 1991 [DIRS 152709]). The value of $\alpha_{2}$ for 2:2 type electrolytes is usually fixed at $\alpha_{2}=$ 12.0 at $25.0^{\circ} \mathrm{C}(298.15 \mathrm{~K})$, but $\alpha_{2}$ is either kept at this same value for all other temperatures or is assumed to vary with temperature as $\alpha_{2}=\mathrm{k} \cdot \mathrm{A}_{\phi}$, where $\mathrm{k}$ is a constant (Pitzer 1991 [DIRS 152709]).

In terms of these ion-interaction parameters, the Pitzer equation for a binary electrolyte solution has the familiar form:

$$
\begin{aligned}
\phi & =1-\left|\mathrm{z}_{\mathrm{M}} \mathrm{Z}_{\mathrm{X}}\right| \mathrm{A}_{\phi} \sqrt{I} /(1+b \sqrt{I})+\left\{2\left(v_{\mathrm{M}} v_{\mathrm{X}}\right) / v\right\} m\left\{\beta_{\mathrm{MX}}^{(0)}+\beta_{\mathrm{MX}}^{(1)} \cdot \mathrm{e}^{-\alpha_{1} \sqrt{I}}+\beta_{\mathrm{MX}}^{(2)} \cdot \mathrm{e}^{-\alpha_{2} \sqrt{I}}\right\} \\
& +\left\{2\left(v_{\mathrm{M}} v_{\mathrm{X}}\right)^{3 / 2} / v\right\} m^{2} \cdot C_{\mathrm{MX}}^{\phi}
\end{aligned}
$$

for the osmotic coefficient, where $m$ denotes the stoichiometric molality of the solution. For the mean molal activity coefficient $\gamma_{ \pm}$of the electrolyte: 


$$
\begin{aligned}
\ln \gamma_{ \pm} & =-\left|\mathrm{z}_{\mathrm{M}} \mathrm{Z}_{\mathrm{X}}\right| \mathrm{A}_{\phi}\{\sqrt{I} /(1+b \sqrt{I})+(2 / b) \ln (1+b \sqrt{I})\}+\left\{2\left(v_{\mathrm{M}} v_{\mathrm{X}}\right) / v\right\} m\left[2 \beta_{\mathrm{MX}}^{(0)}\right. \\
& +2\left\{\beta_{\mathrm{MX}}^{(1)} / \alpha_{1}^{2} I\right\}\left\{1-\left(1+\alpha_{1} \sqrt{I}-\alpha_{1}^{2} I / 2\right) \mathrm{e}^{-\alpha_{1} \sqrt{I}}\right\} \\
& \left.+2\left\{\beta_{\mathrm{MX}}^{(2)} / \alpha_{2}^{2} I\right\}\left\{1-\left(1+\alpha_{2} \sqrt{I}-\alpha_{2}{ }^{2} I / 2\right) \mathrm{e}^{-\alpha_{2} \sqrt{I}}\right\}\right] \\
& +\left\{3\left(v_{\mathrm{M}} v_{\mathrm{X}}\right)^{3 / 2} / v\right\} m^{2} \cdot C_{\mathrm{MX}}^{\phi}
\end{aligned}
$$

The corresponding expression for the excess Gibbs free energy is:

$$
\begin{aligned}
G^{\mathrm{EX}} /\left(n_{\mathrm{w}} R T\right)= & -\left(4 I \mathrm{~A}_{\phi} b\right) \ln (1+b \sqrt{I})+\left(2 v_{\mathrm{M}} v_{\mathrm{X}}\right) m^{2}\left[\beta_{\mathrm{MX}}^{(0)}\right. \\
& +2\left\{\beta_{\mathrm{MX}}^{(1)} / \alpha_{1}^{2} I\right\}\left\{1-\left(1+\alpha_{1} \sqrt{I}\right) \mathrm{e}^{-\alpha_{1} \sqrt{I}}\right\} \\
& \left.+2\left\{\beta_{\mathrm{MX}}^{(2)} / \alpha_{2}^{2} I\right\}\left\{1-\left(1+\alpha_{2} \sqrt{I}\right) \mathrm{e}^{-\alpha_{2} \sqrt{I}}\right\}\right] \\
& +\left(v_{\mathrm{MZ}}\right) m C_{\mathrm{MX}}
\end{aligned}
$$

where

$$
C_{\mathrm{MX}}=\left(C_{\mathrm{MX}}^{\phi} / 2 \sqrt{\left|z_{\mathrm{M}} z_{\mathrm{X}}\right|}\right)
$$

\section{I.3.1.2 Pitzer's Model for Aqueous Electrolyte Mixtures}

The corresponding Pitzer model equations for mixed electrolyte solutions of arbitrary complexity are more complicated, in part because they include mixing terms. For a system containing anions a and cations $\mathrm{c}$ (anions and cations chemically distinct from a and $\mathrm{c}$ are denoted with primes), the excess Gibbs free energy is given:

$$
\begin{aligned}
G^{\mathrm{EX}} /\left(w_{\mathrm{w}} R T\right)= & \mathrm{f}^{G}(I)+2 \sum_{\mathrm{c}} \sum_{\mathrm{a}} m_{\mathrm{c}} m_{\mathrm{a}}\left[B_{\mathrm{ca}}+\left(\underset{\mathrm{c}}{\sum} m_{\mathrm{c}} z_{\mathrm{c}}\right) C_{\mathrm{ca}}\right] \\
& +\sum_{\mathrm{c} \neq \mathrm{c}^{\prime}} m_{\mathrm{c}} m_{\mathrm{c}^{\prime}}\left[2 \Phi_{\mathrm{cc}^{\prime}}+\sum_{\mathrm{a}} m_{\mathrm{a}} \psi_{\mathrm{cc}^{\prime} \mathrm{a}}\right] \\
& +\sum_{\mathrm{a} \neq \mathrm{a}^{\prime}} m_{\mathrm{a}} m_{\mathrm{a}^{\prime}}\left[2 \Phi_{\mathrm{aa}^{\prime}}+\sum_{\mathrm{c}} m_{\mathrm{c}} \psi_{\mathrm{caa}^{\prime}}\right]
\end{aligned}
$$

where $\mathrm{f}^{G}(I)$ was defined by equation (I-8), and $C_{\mathrm{ca}}$ is equivalent to $C_{\mathrm{MX}}$ defined by equation (I-16). The $B_{\mathrm{ca}}$ term is a function of the ion-interaction parameters and the ionic strength as given by:

$$
\begin{aligned}
B_{\mathrm{ca}}= & \beta_{\mathrm{ca}}^{(0)}+2\left\{\beta_{\mathrm{ca}}^{(1)} / \alpha_{1}^{2} I\right\}\left\{1-\left(1+\alpha_{1} \sqrt{I}\right) \mathrm{e}^{-\alpha_{1} \sqrt{I}}\right\} \\
& +2\left\{\beta_{\mathrm{ca}}^{(2)} / \alpha_{2}^{2} I\right\}\left\{1-\left(1+\alpha_{2} \sqrt{I}\right) \mathrm{e}^{-\alpha_{2} \sqrt{I}}\right\}
\end{aligned}
$$

The $\psi_{\text {cc'a }}$ and $\psi_{\text {caa' }}$ are mixing parameters for interactions among three distinct ions, two of which are of the same sign and the other of opposite sign, and the $\Phi_{\mathrm{cc}^{\prime}}$ and $\Phi_{\mathrm{aa}^{\prime}}$ are mixing functions for two different ions of the same sign. The $\Phi_{\mathrm{cc}^{\prime}}$ and $\Phi_{\mathrm{aa}^{\prime}}$ mixing functions will be described in more detail below.

The corresponding expression for the osmotic coefficient of the mixed electrolyte solutions of arbitrary complexity is given by (Pitzer 1991 [DIRS 152709]): 


$$
\begin{aligned}
\phi= & 1-\left(2 / \sum_{\mathrm{i}} m_{\mathrm{i}}\right)\left[-\mathrm{A}_{\phi} I^{3 / 2} /(1+b \sqrt{I})+\sum_{\mathrm{c}} \sum_{\mathrm{a}} m_{\mathrm{c}} m_{\mathrm{a}}\left\{B_{\mathrm{ca}}^{\phi}(I)+\mathrm{Z} C_{\mathrm{ca}}\right\}\right. \\
& +\sum_{\mathrm{c} \neq \mathrm{c}^{\prime}} m_{\mathrm{c}} m_{\mathrm{c}^{\prime}}\left[\left(\Phi_{\mathrm{cc}^{\prime}}+I \Phi_{\mathrm{cc}^{\prime}}\right)+\sum_{\mathrm{a}} m_{\mathrm{a}} \psi_{\mathrm{cc}^{\prime} \mathrm{a}}\right]+\sum_{\mathrm{a} \neq \mathrm{a}^{\prime}} m_{\mathrm{a}} m_{\mathrm{a}^{\prime}}\left[\left(\Phi_{\mathrm{aa}^{\prime}}+I \Phi_{\mathrm{aa}^{\prime}}\right)+\sum_{\mathrm{c}} m_{\mathrm{c}} \psi_{\mathrm{caa}^{\prime}}\right]
\end{aligned}
$$

where

$$
\mathrm{Z}=\sum_{\mathrm{i}} m_{\mathrm{i}}\left|z_{\mathrm{i}}\right|
$$

is the total ionic molality. For a particular cation in this mixture, $\mathrm{M}$, the ionic activity coefficient is given by:

$$
\begin{aligned}
\ln \gamma_{\mathrm{M}}=z_{\mathrm{M}}^{2} \mathrm{~F}+\sum_{\mathrm{a}} m_{\mathrm{a}}\left(2 B_{\mathrm{Ma}}\right. & \left.+\mathrm{Z} C_{\mathrm{Ma}}\right)+\sum_{\mathrm{c}} m_{\mathrm{c}}\left(2 \Phi_{\mathrm{Mc}}+\sum_{\mathrm{a}} m_{\mathrm{a}} \psi_{\mathrm{Mca}}\right) \\
& +\sum_{\mathrm{a} \neq \mathrm{a}^{\prime}} m_{\mathrm{a}} m_{\mathrm{a}^{\prime}} \psi_{\mathrm{Maa}^{\prime}}+z_{M} \sum_{\mathrm{c}} \sum_{\mathrm{a}} m_{\mathrm{c}} m_{\mathrm{a}} C_{\mathrm{ca}}
\end{aligned}
$$

and for a particular anion in this mixture, $\mathrm{X}$, the ionic activity coefficient is given by:

$$
\begin{aligned}
\ln \gamma_{\mathrm{X}}=z_{\mathrm{X}}^{2} \mathrm{~F} & +\sum_{\mathrm{c}} m_{\mathrm{c}}\left(2 B_{\mathrm{cX}}+\mathrm{Z} C_{\mathrm{cX}}\right)+\sum_{\mathrm{a}} m_{\mathrm{a}}\left(2 \Phi_{\mathrm{Xa}}+\sum_{\mathrm{c}} m_{\mathrm{c}} \psi_{\mathrm{cXa}}\right) \\
& +\sum_{\mathrm{c} \neq \mathrm{c}^{\prime}} \sum_{\mathrm{c}} m_{\mathrm{c}^{\prime}} \psi_{\mathrm{cc}^{\prime} \mathrm{X}}+\left|z_{\mathrm{X}}\right| \underset{\mathrm{c}}{\sum} \sum_{\mathrm{a}} m_{\mathrm{c}} m_{\mathrm{a}} C_{\mathrm{c}}
\end{aligned}
$$

The quantity $\mathrm{F}$ that is present in both equations (Eq. I-21) and (Eq. I-22) includes the Debye-Hückel "osmotic" function $\mathrm{f}^{\prime}(I)$ along with several other terms:

$$
\mathrm{F}=\mathrm{f}^{\prime}(I)+\sum_{\mathrm{c}} \sum_{\mathrm{a}} m_{\mathrm{c}} m_{\mathrm{a}} B_{\mathrm{ca}}{ }^{\prime}+\sum_{\mathrm{c} \neq \mathrm{c}^{\prime}} \sum_{\mathrm{c}} m_{\mathrm{c}^{\prime}} \Phi_{\mathrm{cc}^{\prime}}+\sum_{\mathrm{a} \neq \mathrm{a}^{\prime}} m_{\mathrm{a}} m_{\mathrm{a}} \cdot \Phi_{\mathrm{aa}^{\prime}}
$$

where $\Phi_{\mathrm{cc}^{\prime}}=\left(\partial \Phi_{\mathrm{cc}^{\prime}} / \partial I\right), \Phi_{\mathrm{aa}^{\prime}}{ }^{\prime}=\left(\partial \Phi_{\mathrm{aa}} / \partial I\right)$, and $B_{\mathrm{ca}}{ }^{\prime}=\left(\partial B_{\mathrm{ca}} / \partial I\right)$ are the ionic strength derivatives of the corresponding functions.

Equations I-17, I-19, and I-21 through I-13 contain the $\Phi_{\mathrm{cc}^{\prime}}$ and $\Phi_{\mathrm{aa}^{\prime}}$ and/or $\Phi_{\mathrm{cc}^{\prime}}$ and $\Phi_{\mathrm{aa}^{\prime}}$ mixing functions. For the ions $i$ and $j$ this function can be rewritten as

$$
\Phi_{\mathrm{ij}}={ }^{\mathrm{S}} \theta_{\mathrm{ij}}+{ }^{\mathrm{E}} \theta_{\mathrm{ij}}(I)
$$

The values of the high-order electrostatic function ${ }^{\mathrm{E}} \theta_{\mathrm{ij}}(I)$ may be calculated from theory as described by Pitzer (1991 [DIRS 152709]). For ions of opposite charge, and for ions of the same sign and electrical charge, ${ }^{\mathrm{E}} \theta_{\mathrm{ij}}(I)=0$, and the mixing function $\Phi_{\mathrm{ij}}$ becomes equal to a simple (ionic strength independent) fitting parameter $\theta_{\mathrm{ij}}$. However, when the ions $i$ and $j$ are of the same sign but have different charges, then equation (I-24) should be used. Numerical analysis of integrals contributing to ${ }^{\mathrm{E}} \theta_{\mathrm{ij}}(I)$ is discussed by Pitzer (1991 [DIRS 152709]). For further details see SNL (2003 [DIRS 162494]), equations B-134 through B-147. The code EQ3/6 includes ${ }^{\mathrm{E}} \theta_{\mathrm{ij}}(I)$ in the calculation of $\Phi_{\mathrm{ij}}$ whenever appropriate.

According to Pitzer's model (Pitzer 1991 [DIRS 152709]), the thermodynamic properties of an electrolyte solution of arbitrary complexity may be represented using only the $\beta_{\mathrm{MX}}^{(0)}, \beta_{\mathrm{MX}}^{(1)}$, $\beta_{\mathrm{MX}}^{(2)}$ (if 
needed), and $C_{\mathrm{MX}}^{\phi}$ ion-interaction parameters for binary solutions, the two-ion ${ }^{\mathrm{s}} \theta_{\mathrm{MM}^{\prime}}$ and ${ }^{\mathrm{s}} \theta_{\mathrm{XX}}$ and the three-ion $\psi_{\mathrm{MM}^{\prime} \mathrm{X}}$ and $\psi_{\mathrm{MXX}} \mathrm{x}^{\prime}$ mixing parameters. Within the framework of this model, the values of the mixing parameters are independent of the possible presence of other types of ions in the solution, and once their values have been determined for a particular system, then the same values may be used for all other systems. However, in a thermodynamically consistent database, it is essential that same values of the mixing parameters be used for all systems containing those particular combinations of anions and cations.

\section{I.3.1.3 Extension of Pitzer's Model to Include Dissolved Neutral Molecules}

The equations given above apply to single electrolytes and to their mixtures. Neutral chemical species including dissolved gases such as $\mathrm{O}_{2}(\mathrm{aq}), \mathrm{CO}_{2}(\mathrm{aq})$, or $\mathrm{NH}_{3}(\mathrm{aq})$, and non-electrolytes such as $\mathrm{SiO}_{2}(\mathrm{aq})$, are often present at low concentrations in natural waters and brines. Pitzer's ion-interaction model can be modified to include the effects of neutral solutes, by adding terms arising from the interactions between different neutral species, terms for the interactions between neutral species and the cations, and terms for the interactions between neutral species and the anions. For the excess Gibbs free energy, for example, Pitzer (1991 [DIRS 152709]) added interaction terms of the form $m_{\mathrm{n}} m_{\mathrm{c}} \lambda_{\mathrm{nc}}, m_{\mathrm{n}} m_{\mathrm{a}} \lambda_{\mathrm{na}}, m_{\mathrm{n}} m_{\mathrm{n}} \lambda_{\mathrm{nn}}$, and $m_{\mathrm{n}}{ }^{2} \lambda_{\mathrm{nn}}$ for binary interactions, and terms of the form $m_{\mathrm{n}} m_{\mathrm{n}} m_{\mathrm{c}} \mu_{\mathrm{nn}} \mathbf{c}, m_{\mathrm{n}} m_{\mathrm{n}} \cdot m_{\mathrm{a}} \mu_{\mathrm{nn}} \mathbf{a}, m_{\mathrm{n}} m_{\mathrm{c}} m_{\mathrm{a}} \mu_{\mathrm{nca}}$, etc. for ternary interactions. Pitzer also defined two additional quantities, $\zeta_{\text {nca }}$ and $\eta_{\text {ncc' }}$, that are linear combinations of the $\mu_{\mathrm{ijk}}$. A detailed presentation of the equations for the interactions neutral species and electrolytes is beyond the scope of this document, but detailed presentations are available in Appendix F of Pitzer's review (1991 [DIRS 152709]), in the article by Clegg and Brimblecombe (1990 [DIRS 159187]), and in SNL 2003 ([DIRS 162494]).

\section{I.3.1.4 Thermodynamic Data Used to Derive Parameters of Pitzer's Model}

The ion-interaction parameters of Pitzer's model are empirical parameters. That is, they are obtained by fitting their values to best represent the experimental thermodynamic properties of aqueous electrolyte solutions. For most fairly soluble electrolytes, the types of thermodynamic data typically used to determine the Pitzer parameters are osmotic coefficients (generally obtained from isopiestic measurements), the emfs of reversible electrochemical cells, enthalpies of dilution, and heat capacities. Mixing parameters are frequently obtained for solutes of limited solubility by modeling the variation of solubility of that component with changes in the molalities of the other solutes. These less soluble solutes include many important salts such as gypsum and calcite, $\mathrm{CaSO}_{4} \cdot 2 \mathrm{H}_{2} \mathrm{O}$ (cr) and $\mathrm{CaCO}_{3}$ (cr), and dissolved atmospheric gases such as $\mathrm{O}_{2}(\mathrm{aq})$ and $\mathrm{CO}_{2}(\mathrm{aq})$ that affect $\mathrm{E}_{\mathrm{h}}$ and $\mathrm{pH}$ of solutions.

The Debye-Hückel limiting law slope used in Pitzer's model, $\mathrm{A}_{\phi}$, is that for the osmotic coefficient. Other authors sometimes present their equations in terms of the Debye-Hückel limiting law slope for activity coefficient, $\mathrm{A}_{\gamma}$, where $\mathrm{A}_{\phi}=\mathrm{A}_{\gamma} / 3$. Also, some values of $\mathrm{A}_{\gamma}$ reported in the literature may also differ by a factor of $\ln (10)=2.302585$, depending on whether the equations are written in terms of the decadic (natural) logarithm of the activity coefficient or in terms of the decadic (base 10) logarithm of the activity coefficient. See Pitzer (1973 [DIRS 152738] and 1991 [DIRS 152709]) for a definition of $\mathrm{A}_{\phi}$ in terms of fundamental constants and the properties of pure water. 


\section{I.3.2 TEMPERATURE FUNCTIONS FOR PITZER INTERACTION PARAMETERS}

Extension of the Pitzer approach to temperatures above $25^{\circ} \mathrm{C}$ is necessary to expand its application to concentrated electrolyte solutions in many natural systems. The works of Møller (1988 [DIRS 152695]), and Greenberg and Møller (1989 [DIRS 152684]) exemplify such efforts by generating empirical functions that fit Pitzer interaction parameters as a function of both ionic strength (I) and temperature. Their approach utilizes a formulation containing eight fitting coefficients to describe the variations in the Pitzer interaction parameter as a function of temperature:

$$
\chi(T)=a_{1}+a_{2} T+\frac{a_{3}}{T}+a_{4} \ln T+\frac{a_{5}}{(T-263)}+a_{6} T^{2}+\frac{a_{7}}{(680-T)}+\frac{a_{8}}{(T-227)}
$$

where $\chi$ represents any parameter of interest within the Pitzer model. Møller 1988 [DIRS 152695]) and Greenberg and Møller (1989 [DIRS 152684]) used " $P$ " in their notation, and $T$ corresponds to the absolute temperature. $a_{1}, a_{2}, a_{3}, \ldots, a_{8}$ are the coefficients used for fitting the temperature dependence of the parameter. Some parameters will generate relatively smooth curves with a very small number or no additional fitting coefficients. Therefore, not all seven or eight parameters will be needed. Sometimes a parameter will exhibit a different set of fitting terms between different temperature ranges, but this is rarely observed. When mixed electrolytes are modeled, then one must be cautious on how to approach the problem, checking always for internal consistency in the data being used and how it applies to the model.

Variations in Pitzer's equations have been developed to explain data for relatively simple experimental systems. These variations may include the use of non-customary values for the Pitzer alpha coefficients, addition of terms to temperature functions in order to fit data to very high temperatures, and including or excluding species such as ion pairs, complexes (along with their association constants) and partially dissociated acids. When combining results from these modified Pitzer models, these variations must be dealt with to obtain an internally consistent database.

Temperature functions have been developed to support the calculation of activity coefficients in geochemical models that are valid for the temperature ranges and chemical species considered. These will be compared with the functions used by Greenberg and Møller (1989 [DIRS 152684]) as well as experimental data.

\section{I.3.2.1 Models}

All of the following models are suggested by the van't Hoff equation, the most common expression of which is (e.g., Garrels and Christ 1990 [DIRS 144877], eq. 9.100, p. 348):

$$
\frac{\partial \ln K}{\partial T}=\frac{\Delta H_{r}^{o}}{R T^{2}}
$$

where $K$ is an equilibrium constant, $T$ is the absolute temperature, $\Delta H_{r}^{o}$ is the standard partial molar enthalpy of reaction, and $R$ is the universal gas constant. This equation is often used as a 
basis for computing the temperature dependence of equilibrium constants. The general integrated form can be written as:

$$
\ln K(T)=K\left(T_{0}\right)+\int_{T_{0}}^{T} \frac{\Delta H_{r}^{0}}{R T^{2}} d T
$$

where $T_{0}$ is normally $298.15 \mathrm{~K}\left(25^{\circ} \mathrm{C}\right)$. As an example, the "constant enthalpy" approximation sometimes used in low-temperature geochemical modeling is given by:

$$
\ln K(T)=\ln K\left(T_{0}\right)-\frac{\Delta H_{r}^{0}}{R}\left[\frac{1}{T}-\frac{1}{T_{0}}\right]
$$

More generally, it is recognized that $\Delta H_{r}^{o}$ is itself a function of temperature. A key relationship is:

$$
\frac{\partial \Delta H_{r}^{o}}{\partial T}=\Delta C_{p, r}^{o}
$$

where $\Delta C_{p, r}^{o}$ is the standard partial molar heat capacity (at constant pressure) of reaction. This in turn is given by:

$$
\Delta C_{p, r}^{o}=\sum_{i} b_{i r} C_{p, i}^{o}
$$

where the $b_{i r}$ are reaction coefficients (defined as positive for products, negative for reactants) and $C_{p, i}^{o}$ is the standard molal heat capacity of the $i^{\text {th }}$ chemical species. Although the heat capacity of a species can be treated as a constant, usually it is represented by some temperature function, such as the Maier-Kelley formula (cf. Nordstrom and Munoz 1985 [DIRS 153965], p. 56) that is commonly applied to describe the heat capacities of solids:

$$
C_{p, i}^{o}=a+b T-\frac{c}{T^{2}}
$$

The van't Hoff relation can also be written as:

$$
\frac{\partial\left(\Delta G_{r}^{o} / R T\right)}{\partial T}=\frac{-\Delta H_{r}^{o}}{R T^{2}}
$$

(recall that $\Delta G_{r}^{o}=-R T \ln K$ ). A more general "van't Hoff" relationship is given by:

$$
\frac{\partial(G / R T)}{\partial T}=\frac{-H}{R T^{2}}
$$


where $G$ is any type of Gibbs energy (for a reaction or a species, total, standard, ideal, or excess) and $\mathrm{H}$ is the corresponding enthalpy. Activity coefficients have a defining relationship with the excess Gibbs energy (cf. Pitzer 1973 [DIRS 152738]):

$$
\ln \gamma_{i}=\frac{G_{i}^{E X}}{R T}
$$

where $\gamma_{i}$ is the activity coefficient of the $i^{\text {th }}$ chemical species and $G_{i}^{E X}$ is the excess partial molar Gibbs energy of the same species (note that $G_{i}^{E X}=\partial G^{E X} / \partial n_{i}$, where $G^{E X}$ is the excess Gibbs energy, and $n_{i}$ is the number of moles of the $\mathrm{i}^{\text {th }}$ species). The above two equations can be combined to yield:

$$
\frac{\partial \ln \gamma_{i}}{\partial T}=\frac{-H_{i}^{E X}}{R T^{2}}
$$

where $H_{i}^{E X}$ is the excess partial molar enthalpy of the $i^{\text {th }}$ species. This equation can be viewed as the van't Hoff equation for activity coefficients.

In Pitzer's equations, $\ln \gamma_{i}$ depends on a series of terms that are linear with respect to the interaction coefficients. The dependence of the activity coefficient of an ion in solution on the second-order $\beta_{i j}^{(0)}$ parameter is expressed by:

$$
\ln \gamma_{i}=\ldots+\beta_{i j}^{(0)} m_{j}+\ldots
$$

(this parameter is second-order because in the equation for the total excess Gibbs energy of the solution, it appears multiplied by $m_{i} m_{j}$ ). This line of thinking suggests the following van't Hoff equation for interaction parameters:

$$
\frac{\partial \chi}{\partial T}=\frac{-\chi^{(H)}}{R T^{2}}
$$

where $\chi$ is any interaction parameter (either second- or third-order; $\beta_{i j}^{(0)} \beta_{i j}^{(1)}, \beta_{i j}^{(2)}, C_{i j k}^{\varphi}, \theta_{i j}, \psi_{i j k}$, $\zeta_{i j n}, \lambda_{i n}$, or $\lambda_{n n^{\prime}}$ ) and $\chi^{(H)}$ is the corresponding parameter appearing in the calculation of the excess partial molar enthalpy. It follows that:

$$
\frac{\partial \chi^{(H)}}{\partial T}=\chi^{\left(C_{p}\right)}
$$

where $\chi^{\left(C_{p}\right)}$ is the corresponding parameter appearing in the calculation of the excess partial molar heat capacity. 


\section{I.3.2.2 Constant Enthalpy}

The simplest case is for the equivalent of constant enthalpy. Letting $b_{1}=\chi^{(H)}$, one can write that:

$$
\frac{\partial \chi}{\partial T}=\frac{-b_{1}}{R T^{2}}
$$

Integration then yields:

$$
\chi=b_{0}+\frac{b_{1}}{R}\left[\frac{1}{T}-\frac{1}{T_{0}}\right]
$$

where $b_{0}=\chi\left(T_{0}\right)$. This can also be written as:

$$
\chi=a_{0}+\frac{a_{1}}{T}
$$

where:

$$
\begin{gathered}
a_{0}=b_{0}-\frac{b_{1}}{R T_{0}} \\
a_{1}=\frac{b_{1}}{R}
\end{gathered}
$$

Comparison of Equation I-41 with Equation I-25 shows that the former is a subset of the latter (allowing for a different system of numbering the coefficients). What this suggests is that the constant and 1/T terms in Equation I-25 are likely the most important, in terms of having a physical basis.

\section{I.3.2.3 Constant Heat Capacity}

Here one begins by writing $b_{2}=\chi^{\left(C_{p}\right)}$. The first integration yields:

$$
\chi^{(H)}=b_{1}+b_{2}\left(T-T_{0}\right)
$$

where $b_{1}=\chi^{(H)}\left(T_{0}\right)$. The second integration, this time using the "van't Hoff relation," gives:

$$
\chi=b_{0}+\frac{\left(b_{1}-b_{2} T_{0}\right)}{R}\left[\frac{1}{T}-\frac{1}{T_{0}}\right]-\frac{b_{2}}{R}\left(\ln T-\ln T_{0}\right)
$$

where once more $b_{0}=\chi\left(T_{0}\right)$. This can also be written as: 


$$
\chi=a_{0}+\frac{a_{1}}{T}+a_{2} \ln T
$$

where:

$$
\begin{gathered}
a_{0}=b_{0}+\frac{b_{2}}{R}-\frac{b_{1}}{R T_{0}}+\frac{b_{2}}{R} \ln T_{0} \\
a_{1}=\frac{b_{1}-b_{2} T_{0}}{R} \\
a_{2}=-\frac{b_{2}}{R}
\end{gathered}
$$

Comparison of Equation I-46 with Equation I-25 will show that the former, like Equation I-41, is a subset of the latter (again allowing for a different system of numbering the coefficients). What this suggests is that after the constant and $1 / T$ terms in Equation I-25, the term in $\ln T$ is likely the most important term with respect to having a physical basis.

\section{I.3.2.4 Parabolic Heat Capacity}

The standard partial molar heat capacity of aqueous electrolytes does not closely follow the Maier-Kelley form commonly exhibited by solids. Rather, it is described by temperature functions that appear parabolic, at least to a first order (cf. Helgeson et al. 1981 [DIRS 106024], p. 1413-1426). Here it is assumed that $\chi^{\left(C_{p}\right)}$ will behave in a similar fashion. One may then write:

$$
\chi^{\left(C_{p}\right)}=b_{2}+b_{3}\left(T-T_{x}\right)^{2}
$$

where $b_{2}=\chi^{\left(C_{p}\right)}\left(T_{0}\right)$ and $T_{x}$ is some temperature that may be unique for each distinct Pitzer interaction parameter. If that is so, then in effect a five-parameter model is obtained. Differentiation gives:

$$
\frac{d \chi^{\left(C_{p}\right)}}{d T}=2 b_{3}\left(T-T_{x}\right)
$$

The extremis of the parabola occurs where this derivative is zero: that is, where $T=T_{x}$. Another step of differentiation gives:

$$
\frac{d^{2} \chi^{\left(C_{p}\right)}}{d T^{2}}=2 b_{3}
$$

The parabola will be convex up (the extremis will be a maximum) if $b_{3}$ is negative. Otherwise, it will be convex down (the extremis will be a minimum). Actual examples of the standard partial molar heat capacity of aqueous electrolytes are convex up, and the maximum of curves that 
visually resemble parabolas occurs at various different values of $T$ (cf. Helgeson et al. 1981 [DIRS 106024], p. 1413-1424). Thus, $b_{3}$ is expected to be a negative number.

The first integration yields:

$$
\chi^{(H)}=b_{1}+b_{2}\left(T-T_{0}\right)+b_{3}\left(\frac{\left(T^{3}-T_{0}^{3}\right)}{3}-T_{x}\left(T^{2}-T_{0}^{2}\right)+T_{x}^{2}\left(T-T_{0}\right)\right)
$$

where again $b_{1}=\chi^{(H)}\left(T_{0}\right)$. Before continuing, it is convenient to rearrange this into terms organized by power of $T$ :

$$
\chi^{(H)}=\left[b_{1}-b_{2} T_{0}-b_{3}\left(T_{x}^{2} T_{0}-T_{x} T_{0}^{2}+\frac{T_{0}^{3}}{3}\right)\right]+\left[b_{2}+b_{3} T_{x}^{2}\right] T-\left[b_{3} T_{x}\right] T^{2}+\left[\frac{b_{3}}{3}\right] T^{3}
$$

More simply, this can be written as:

$$
\chi^{(H)}=c_{1}+c_{2} T+c_{3} T^{2}+c_{4} T^{3}
$$

where $c_{1}, c_{2}, c_{3}$, and $c_{4}$ are given by the corresponding quantities in squared brackets in Equation I-54. The second integration, performed after substituting Equation I-55 into the "van't Hoff relation," gives:

$$
\chi=c_{0}+\frac{c_{1}}{R}\left(\frac{1}{T}-\frac{1}{T_{0}}\right)-\frac{c_{2}}{R}\left(\ln T-\ln T_{0}\right)-\frac{c_{3}}{R}\left(T-T_{0}\right)-\frac{c_{4}}{2 R}\left(T^{2}-T_{0}^{2}\right)
$$

where $c_{0}=\chi\left(T_{0}\right)$; in order to complete the relationships between the $b$ and $c$ coefficients, one may take that $c_{0}=b_{0}$. Rearranging Equation I-56 into terms organized by power of $T$ gives:

$$
\chi=\left[c_{0}-\frac{c_{1}}{R T_{0}}+\frac{c_{2}}{R} \ln T_{0}+\frac{c_{3}}{R} T_{0}+\frac{c_{4}}{2 R} T_{0}^{2}\right]+\left[\frac{c_{1}}{R}\right] \frac{1}{T}+\left[\frac{-c_{2}}{R}\right] \ln T+\left[\frac{-c_{3}}{R}\right] T+\left[\frac{-c_{4}}{2 R}\right] T^{2}(\text { Eq. I-57) }
$$

This can be written more simply as:

$$
\chi=a_{0}+\frac{a_{1}}{T}+a_{2} \ln T+a_{3} T+a_{4} T^{2}
$$

where $a_{0}, a_{1}, a_{2}, a_{3}$, and $a_{4}$ are given by the corresponding quantities in square brackets in Equation I-57. Equation I-58 as implemented in EQ3/6 Version 8.0 only takes into account up to the $a_{3}$ coefficient term. Also, the increasing order of coefficients is shifted by one as defined in the data0.ypf database. That is, $a_{0}$ in Equation I-58 equals $a_{1}$ in the data.ypf database and so on. The $T^{2}$ term in Equation I-58 is not used in the data0.ypf database.

The additional terms in $T$ and $T^{2}$ are also present in Equation I-25. The presence of $T_{x}$ in the equation for the heat capacity interaction parameter has resulted in a five- rather than a 
four-parameter model, though $T_{x}$ itself does not appear explicitly in the final result as represented by Equation I-58.

Note that the addition of a term linear in $T$ to the equation for $\chi^{\left(C_{p}\right)}$ would not result in an additional term in the equivalent of Equation I-58. Adding such a term to Equation I-50 gives:

$$
\chi^{\left(C_{p}\right)}=b_{2}+b_{3}\left(T-T_{x}\right)^{2}+b_{4} T
$$

This would add a term in $T^{2}$ in the corresponding equation for $\chi^{(H)}$. Substitution of that result into the "van't Hoff" relation would just add to the constant term under the integral. After integration, this would result in additional contributions to $a_{0}$ and $a_{3}$ in Equation I-58, but no new term. Similarly, adding a term in $T^{2}$ to the equation for $\chi^{\left(C_{p}\right)}$ would result in no new term in the equivalent of Equation I-58.

\section{I.3.2.5 Other Comments on Existing Temperature Functions}

Recall that Equation I-25 is:

$$
\chi(T)=a_{1}+a_{2} T+\frac{a_{3}}{T}+a_{4} \ln T+\frac{a_{5}}{(T-263)}+a_{6} T^{2}+\frac{a_{7}}{(680-T)}+\frac{a_{8}}{(T-227)}
$$

The terms not suggested by the theoretical analysis given above are the fifth, seventh, and eighth. Each of these terms has the difference between $\mathrm{T}$ and some constant in the denominator, and thus a singularity. These occur at $-10.15,406.85$, and $-46.15^{\circ} \mathrm{C}$, respectively. The fifth and seventh terms trace back to Rogers and Pitzer (1981 [DIRS 162107]). They have no theoretical origin, but were introduced as empirical devices to assist in fitting data for the system $\mathrm{Na}_{2} \mathrm{SO}_{4}-\mathrm{H}_{2} \mathrm{O}$ over a wide range of temperatures. The eighth term is from Pitzer et al. (1984 [DIRS 162099]), who used it to fit data for the system $\mathrm{NaCl}-\mathrm{H}_{2} \mathrm{O}$ over a very wide temperature range. Again, the origin of the term was purely empirical. The singularity at $406.85^{\circ} \mathrm{C}(680 \mathrm{~K})$ is well above the critical temperature of water.

Spencer et al.(1990 [DIRS 152713]) developed a model for the system Na-K-Ca-Mg-Cl-SO $\mathrm{H}_{2} \mathrm{O}$ for the temperature range -60 to $+25^{\circ} \mathrm{C}$. They recognized the above-noted singularities (two of which were in their target range) and eliminated them by using a function of the form:

$$
\chi(T)=a_{1}+a_{2} T+\frac{a_{3}}{T}+a_{4} \ln T+a_{6} T^{2}+a_{9} T^{3}
$$

All but one of the terms in this equation carry forward from Equation I-25. The origin of the new term in $T^{3}$ is obscure. Spencer et al. (1990 [DIRS 152713]) do not discuss it; nor do they discuss the consequences of not including this term. They do use the new term universally in their model, applying it not only to Pitzer interaction coefficients, but also to the $A^{\varphi}$ Debye-Hückel parameter and the dimensionless standard chemical potentials $\left(\mu^{\mathrm{o}} / R T\right)$ of both aqueous species and minerals. This term would imply a term in $T^{2}$ in the equation for $\chi^{(H)}$ and one in $T^{3}$ in the equation for $\chi^{\left(C_{p}\right)}$. 


\section{I.4 EVALUATION, COMPILATION AND CONVERSION OF PITZER INTERACTION PARAMETERS FROM PUBLISHED SOURCES}

As part of the current effort to develop an internally consistent thermodynamic Pitzer parameter database for EQ3/6 Version 8.0, an extensive search for Pitzer interaction parameters and experimental data from the scientific literature was undertaken for ionic species of interest to the Yucca Mountain Project. Because operating temperatures in the repository are expected to rise substantially above the boiling temperature of water, the primary focus of the work was on developing the Pitzer parameter database to higher temperatures up to $250^{\circ} \mathrm{C}$. Unfortunately, high temperature Pitzer parameter data are not available in the literature for all of the required chemical species, so that the data for certain ionic species included in the database are limited to lower temperature ranges. Some parameter data only applicable at $25^{\circ} \mathrm{C}$ are included in the database to extend the usefulness of the database to species that do not have high temperature data but, nevertheless, are of interest to the Yucca Mountain Project. A difficulty in the compilation of Pitzer binary and ternary parameters is that some data at elevated temperatures and pressures are reported from variants and extensions of the original Pitzer formulations (Rard and Clegg 1997 [DIRS 152759]; Sterner et al. 1998 [DIRS 162116]; Archer 2000 [DIRS 162065]; Oakes et al. 2000 [DIRS 162102]; Rard et al. 2000) that are potentially more accurate than the standard Pitzer model, but which cannot be used directly with the standard Pitzer model

Different authors have used different functions of temperature for the fitting of parameters to experimental data (see Section I-3.2). These different schemes make only minor differences in the goodness of fit, as stated by some of the authors themselves, and are documented for individual binary and ternary parameters in Sections I-4.4 through I-4.6. For the purposes of this report these refinements of the fits are unimportant. This is true even in the case of the ternary parameters (Section I-4.5), in which the percentage changes between one author and another are large, because the ternary interactions make only minor contributions to the calculation of the osmotic coefficients and activity coefficients. To develop an integrated database that encompasses the widest possible selection of ionic species with the smallest number of temperature coefficients, it is necessary to have a rational, thermodynamically motivated basis for selecting these temperature functions. To accomplish this, a comprehensive examination of the published Pitzer parameter data was undertaken to assess the accuracy and validity of the data and the associated temperature functions for each electrolyte of interest for a wide range of temperatures and ionic strength. On the basis of this assessment, a standard form of the temperature functions was developed. The standard Pitzer parameters for each electrolyte are either refitted in this standard form of the temperature functions, or nonstandard Pitzer model parameters are first converted to standard Pitzer model parameters and are then fitted to the standard form of the temperature functions. This last step requires refitting of the source Pitzer parameters to the temperature functions represented by a 4-parameter form of Equation I-58 in Section I-3.2.1.3 that includes the constant, linear, inverse and logarithmic terms, but excludes the quadratic term.

To compile, analyze, validate, refit, and convert Pitzer parameters to a form usable by EQ3/6 Version 8.0, Microsoft Excel 2000 spreadsheets (see Tables I-1 and I-2) were developed. The temperature function fitting method and the conversion method documented in Rard and Wijesinghe (2003 [DIRS 162327]) are incorporated in most of the spreadsheets and are 
explained in subsequent sections. Most of the spreadsheets are used to refit standard Pitzer parameters without conversion from an extended Pitzer model. These spreadsheets are named "FitPitzerNC_Type_IonicSpecies.xls". A second type of spreadsheet involves the conversion of parameters from an extended Pitzer model to the parameters of the standard Pitzer model, followed by fitting new temperature functions of the standard form. These spreadsheets are given the generic name "ConPitzerNC_Type_IonicSpecies.xls" and were prepared only for the electrolytes for which source models were not available in the standard Pitzer form $[\mathrm{CaCl} 2$, $\mathrm{Ca}(\mathrm{NO} 3) 2, \mathrm{NaNO} 3$, and (NH4)2SO4]. The Pitzer data defined in the 'ConPitzerNC' spreadsheets are for binary cation-anion parameters only. The spreadsheets named 'FitPitzerNC_ Int_Param_CFJC.xls' do not use the 'FitPitzerNC' methodology but refit parameters using the regression tool in MS Excel (see Tables I-1 and I-2). In all spreadsheets, error analyses including parameter and osmotic coefficient plots, root mean square (RMS) errors, and MS Excel regression statistics are given in the 'FitPitzer' and 'Result Summary' worksheets or below the 'SUMMARY OUTPUT' title within each worksheet. The 'Int_Param' part of the spreadsheet name refers to the type of binary or ternary parameters consistent with the notation given by:

$$
\begin{aligned}
& \mathrm{MX}=\mathrm{Cation}(\mathrm{M}) \text {-Anion }(\mathrm{X}) \text { binary system parameters } \beta_{M X}^{(0)}, \beta_{M X}^{(1)}, \beta_{M X}^{(2)}, C_{M X}^{\phi} \\
& \mathrm{MM}=\text { Cation(M1)-Cation(M2) ternary system parameter } \theta_{M 1 M 2} \\
& \mathrm{XX}=\mathrm{Anion}(\mathrm{X} 1) \text {-Anion }(\mathrm{X} 2) \text { ternary system parameter } \theta_{X 1 X 2} \\
& \text { MMX = Cation(M1)-Cation(M2)-Anion(X) ternary system parameter } \psi_{M 1 M 2 X} \\
& \mathrm{MXX}=\text { Cation(M)-Anion(X1)-Anion(X2) ternary system parameter } \psi_{M X 1 X 2} \\
& \mathrm{NM}=\operatorname{Neutral}(\mathrm{N}) \text {-Cation }(\mathrm{M}) \text { ternary system parameter } \lambda_{N M} \\
& \mathrm{NX}=\operatorname{Neutral}(\mathrm{N}) \text {-Cation }(\mathrm{M}) \text { ternary system parameter } \lambda_{N X} \\
& \mathrm{NMX}=\operatorname{Neutral}(\mathrm{N}) \text {-Cation }(\mathrm{M})-\text { Anion }(\mathrm{X}) \text { ternary system parameter } \zeta_{N M X}
\end{aligned}
$$

Only functions intrinsic to MS Excel were used in the calculations. The following sections describe the theoretical foundations of the Pitzer parameter fitting/conversion approaches mentioned above. Tables I-1 and I-2 summarize the types of parameters compiled for specific ions and the original sources of Pitzer parameter data.

The Debye-Hückel $\mathrm{A}_{\varphi}$ parameter, which depends on the electrostatic properties of pure liquid water, is an intrinsic part of any Pitzer model. This parameter is also treated by the use of a temperature function. The representation used in the IDPS model is based on that given by Greenberg and Møller (1989 [DIRS 152684]). However, the data were refitted to a different temperature function, the same one used in the IDPS model for the Pitzer interaction coefficients. This refitting of $\mathrm{A}_{\varphi}$ was done in FitPitzerNC_MX_NaCl.xls (first row of Table I-1). This refitting is repeated in analogous binary coefficient refitting spreadsheets (because the functionality was built into the template, not because it was necessary). 
Table I-1. Catalog of Pitzer lon-Interaction Parameter Spreadsheets

\begin{tabular}{|c|c|c|c|c|}
\hline Ion Group & Spreadsheet File Name & Original Data Source & Type & $\begin{array}{c}\text { T Range } \\
\left({ }^{\circ} \mathrm{C}\right)\end{array}$ \\
\hline $\mathrm{Na} \_\mathrm{Cl}$ & FitPitzerNC_MX_NaCl.xls & $\begin{array}{l}\text { Greenberg and Møller } 1989 \text { [DIRS } \\
\text { 152684] }\end{array}$ & $\mathrm{MX}$ & $0-250$ \\
\hline K_Cl & FitPitzerNC_MX_KCl.xls & $\begin{array}{l}\text { Greenberg and Møller } 1989 \text { [DIRS } \\
\text { 152684] }\end{array}$ & $\mathrm{MX}$ & $0-250$ \\
\hline $\mathrm{Na} \_\mathrm{Br}$ & FitPitzerNC_MX_NaBr.xls & $\begin{array}{l}\text { Holmes and Mesmer } 1998 \text { [DIRS } \\
\text { 162083] }\end{array}$ & MX & $0-250$ \\
\hline $\mathrm{K} \_\mathrm{Br}$ & FitPitzerNC_MX_KBr.xls & $\begin{array}{l}\text { Holmes and Mesmer } 1998 \text { [DIRS } \\
\text { 162083] }\end{array}$ & $\mathrm{MX}$ & $0-250$ \\
\hline Li_Cl & FitPitzerNC_MX_LiCl.xls & $\begin{array}{l}\text { Holmes and Mesmer } 1983 \text { [DIRS } \\
\text { 162073] }\end{array}$ & $\mathrm{MX}$ & $0-250$ \\
\hline $\mathrm{Li} \_\mathrm{Br}$ & FitPitzerNC_MX_LiBr.xls & $\begin{array}{l}\text { Holmes and Mesmer } 1998 \text { [DIRS } \\
\text { 162083] }\end{array}$ & $\mathrm{MX}$ & $0-250$ \\
\hline Cs_Cl & FitPitzerNC_MX_CsCl.xls & $\begin{array}{l}\text { Holmes and Mesmer } 1983 \text { [DIRS } \\
\text { 162073] }\end{array}$ & $\mathrm{MX}$ & $0-250$ \\
\hline Cs_Br & FitPitzerNC_MX_CsBr.xls & $\begin{array}{l}\text { Holmes and Mesmer } 1998 \text { [DIRS } \\
\text { 162083] }\end{array}$ & $\mathrm{MX}$ & $0-250$ \\
\hline $\mathrm{Na}$ & FitPitzerNC_MX_Na2SO4.xls & $\begin{array}{l}\text { Greenberg and Møller } 1989 \text { [DIRS } \\
152684]\end{array}$ & $\mathrm{MX}$ & $0-250$ \\
\hline K_SO4 & FitPitzerNC_MX_K2SO4.Xls & $\begin{array}{l}\text { Greenberg and Møller } 1989 \text { [DIRS } \\
\text { 152684] }\end{array}$ & MX & $0-250$ \\
\hline Ca_SO4 & FitPitzerNC_MX_CaSO4.xls & $\begin{array}{l}\text { Greenberg and Møller } 1989 \text { [DIRS } \\
152684]\end{array}$ & $\mathrm{MX}$ & $0-250$ \\
\hline Mg_SO4 & FitPitzerNC_MX_MgSO4.xls & $\begin{array}{l}\text { Pabalan and Pitzer } 1987 \text { [DIRS } \\
\text { 162096] }\end{array}$ & $\mathrm{MX}$ & $0-250$ \\
\hline $\mathrm{Na} \_\mathrm{CO} 3$ & FitPitzerNC_MX_Na2CO3.xls & $\begin{array}{l}\text { He and Morse } 1993 \text { [DIRS } \\
162090]\end{array}$ & $\mathrm{MX}$ & $0-90$ \\
\hline $\mathrm{Ca} \_\mathrm{Cl}$ & ConPitzerNC_MX_CaCl2.xls & Sterner et al. 1998 [DIRS 162116] & $\mathrm{MX}$ & $25-250$ \\
\hline Mg_Cl & FitPitzerNC_MX_MgCl2.xls & $\begin{array}{l}\text { Pabalan and Pitzer } 1987 \text { [DIRS } \\
\text { 162096] }\end{array}$ & $\mathrm{MX}$ & $0-250$ \\
\hline $\mathrm{Na} \_\mathrm{HSO} 4$ & FitPitzerNC_MX_NaHSO4.xls & $\begin{array}{l}\text { Holmes and Mesmer } 1994 \text { [DIRS } \\
\text { 162078] }\end{array}$ & MX & $25-220$ \\
\hline $\mathrm{Na}$ _HCO3 & FitPitzerNC_MX_NaHCO3.xls & $\begin{array}{l}\text { He and Morse } 1993 \text { [DIRS } \\
162090]\end{array}$ & $\mathrm{MX}$ & $0-90$ \\
\hline $\mathrm{Na}$ AIO2 & FitPitzerNC_MX_Na_AlO2.xls ${ }^{a}$ & Felmy et al. 1994 [DIRS 162112] & $\mathrm{MX}$ & $0-250$ \\
\hline $\mathrm{Na} \_\mathrm{OH}$ & FitPitzerNC_MX_NaOH.xls & $\begin{array}{l}\text { Pabalan and Pitzer } 1987 \text { [DIRS } \\
\text { 162147] }\end{array}$ & $\mathrm{MX}$ & $0-250$ \\
\hline H_SO4 & FitPitzerNC_MX_H2SO4.xls & $\begin{array}{l}\text { Holmes and Mesmer } 1994 \text { [DIRS } \\
\text { 162078] }\end{array}$ & $\mathrm{MX}$ & $25-200$ \\
\hline H_HSO4 & FitPitzerNC_MX_HHSO4.xls & $\begin{array}{l}\text { Holmes and Mesmer } 1994 \text { [DIRS } \\
\text { 162078] }\end{array}$ & $\mathrm{MX}$ & $25-200$ \\
\hline $\mathrm{H} \_\mathrm{Cl}$ & FitPitzerNC_MX_HCl.xls & Holmes et al. 1987 [DIRS 162075] & $M X$ & $0-250$ \\
\hline $\mathrm{Na} \_\mathrm{NO} 3$ & ConPitzerNC_MX_NaNO3.xls & $\begin{array}{l}\text { Rard and Wijesinghe } 2003 \text { [DIRS } \\
\text { 162327]; Archer } 2000 \text { [DIRS } \\
\text { 162065] }\end{array}$ & MX & $0-152$ \\
\hline $\mathrm{H} \_\mathrm{NO} 3$ & FitPitzerNC_MX_H_NO3_CFJC.xls ${ }^{a}$ & $\begin{array}{l}\text { Felmy et al. } 1994 \text { [DIRS 162111]; } \\
\text { Clegg and Brimblecombe } 1990 \\
\text { [DIRS 162067] }\end{array}$ & $M X$ & $25-100$ \\
\hline
\end{tabular}


Table I-1. Catalog of Pitzer Ion-Interaction Parameter Spreadsheets (Continued)

\begin{tabular}{|c|c|c|c|c|}
\hline Ion Group & Spreadsheet File Name & Original Data Source & Type & $\begin{array}{l}\text { T Range } \\
\left({ }^{\circ} \mathrm{C}\right)\end{array}$ \\
\hline Ca_NO3 & ConPitzerNC_MX_Ca(NO3)2.xls & $\begin{array}{l}\text { Rard and Wijesinghe } 2003 \text { [DIRS } \\
\text { 162327]; Oakes et al. } 2000 \text { [DIRS } \\
\text { 162102] }\end{array}$ & $\mathrm{MX}$ & $25-100$ \\
\hline NH4_SO4 & ConPitzerNC_MX_(NH4)2SO4.xls & Clegg et al. 1996 [DIRS 162068] & $\mathrm{MX}$ & $0-250$ \\
\hline $\mathrm{NH} 4 \_\mathrm{Cl}$ & FitPitzerNC_MX_NH4Cl.xls & $\begin{array}{l}\text { Thiessen and Simonson } 1990 \\
\text { [DIRS 162108] }\end{array}$ & $\mathrm{MX}$ & $25-250$ \\
\hline $\mathrm{Na} \_\mathrm{K}$ & FitPitzerNC_MM_Na_K.xls & $\begin{array}{l}\text { Greenberg and Møller } 1989 \text { [DIRS } \\
\text { 152684] }\end{array}$ & MM & $0-250$ \\
\hline $\mathrm{Na}$ & FitPitzerNC_MM_Na_Ca.xls & $\begin{array}{l}\text { Greenberg and Møller } 1989 \text { [DIRS } \\
\text { 152684] }\end{array}$ & MM & $0-250^{b}$ \\
\hline K_Ca & FitPitzerNC_MM_K_Ca.xls & $\begin{array}{l}\text { Greenberg and Møller } 1989 \text { [DIRS } \\
\text { 152684] }\end{array}$ & MM & $0-250^{b}$ \\
\hline Cl_SO4 & FitPitzerNC_XX_Cl_SO4.xls & $\begin{array}{l}\text { Greenberg and Møller } 1989 \text { [DIRS } \\
\text { 152684] }\end{array}$ & $x x$ & $0-250^{c}$ \\
\hline HSO4_SO4 & FitPitzerNC_XX_HSO4_SO4.xls & $\begin{array}{l}\text { Holmes and Mesmer } 1994 \text { [DIRS } \\
\text { 162078] }\end{array}$ & $x x$ & $25-200$ \\
\hline $\mathrm{Na}$ _K_Cl & FitPitzerNC_MMX_Na_K_Cl.xls & $\begin{array}{l}\text { Greenberg and Møller } 1989 \text { [DIRS } \\
\text { 152684] }\end{array}$ & MMX & $0-250$ \\
\hline $\mathrm{Na}$ _K_SO4 & FitPitzerNC_MMX_Na_K_SO4.xls & $\begin{array}{l}\text { Greenberg and Møller } 1989 \text { [DIRS } \\
\text { 152684] }\end{array}$ & MMX & $0-250$ \\
\hline $\mathrm{Na} \_\mathrm{Ca} \_\mathrm{Cl}$ & FitPitzerNC_MMX_Na_Ca_Cl.xls & $\begin{array}{l}\text { Greenberg and Møller } 1989 \text { [DIRS } \\
\text { 152684] }\end{array}$ & MMX & $0-250^{b}$ \\
\hline $\mathrm{Na}$ _Ca_SO4 & FitPitzerNC_MMX_Na_Ca_SO4.xls & $\begin{array}{l}\text { Greenberg and Møller } 1989 \text { [DIRS } \\
\text { 152684] }\end{array}$ & MMX & $0-250^{b}$ \\
\hline K_Ca_Cl & FitPitzerNC_MMX_K_Ca_Cl.xls & $\begin{array}{l}\text { Greenberg and Møller } 1989 \text { [DIRS } \\
\text { 152684] }\end{array}$ & MMX & $0-250$ \\
\hline $\mathrm{Na}$ & FitPitzerNC_MXX_Na_Cl_SO4.xls & $\begin{array}{l}\text { Greenberg and Møller } 1989 \text { [DIRS } \\
\text { 152684] }\end{array}$ & $M X X$ & $0-250^{c}$ \\
\hline K_Cl_SO4 & FitPitzerNC_MXX_K_Cl_SO4.xls & $\begin{array}{l}\text { Greenberg and Møller } 1989 \text { [DIRS } \\
\text { 152684] }\end{array}$ & $M x X$ & $0-250$ \\
\hline Ca_Cl_SO4 & FitPitzerNC_MXX_Ca_Cl_SO4.xls & $\begin{array}{l}\text { Greenberg and Møller } 1989 \text { [DIRS } \\
\text { 152684] }\end{array}$ & $M X X$ & $0-250^{b}$ \\
\hline H_HSO4_SO4 & FitPitzerNC_MXX_H_HSO4_SO4.xls & $\begin{array}{l}\text { Holmes and Mesmer } 1994 \text { [DIRS } \\
\text { 162078] }\end{array}$ & MXX & $25-200$ \\
\hline $\mathrm{Na}$ & FitPitzerNC_MXX_Na_HSO4_SO4.xls & $\begin{array}{l}\text { Holmes and Mesmer } 1994 \text { [DIRS } \\
\text { 162078] }\end{array}$ & $M X X$ & $25-225$ \\
\hline $\mathrm{CO} 2 \_\mathrm{Ca}$ & FitPitzerNC_NaHCO3_Na2CO3_CFJC.xls ${ }^{a}$ & $\begin{array}{l}\text { He and Morse } 1993 \text { [DIRS } \\
162090]\end{array}$ & NM & $25-90$ \\
\hline CO2_K & FitPitzerNC_NaHCO3_Na2CO3_CFJC.xls ${ }^{a}$ & $\begin{array}{l}\text { He and Morse } 1993 \text { [DIRS } \\
162090]\end{array}$ & NM & $25-90$ \\
\hline CO2_Mg & FitPitzerNC_NaHCO3_Na2CO3_CFJC.xls ${ }^{a}$ & $\begin{array}{l}\text { He and Morse } 1993 \text { [DIRS } \\
\text { 162090] }\end{array}$ & NM & $25-90$ \\
\hline $\mathrm{CO} 2 \_\mathrm{Na}$ & FitPitzerNC_NaHCO3_Na2CO3_CFJC.xls ${ }^{a}$ & $\begin{array}{l}\text { He and Morse } 1993 \text { [DIRS } \\
\text { 162090] }\end{array}$ & NM & $25-90$ \\
\hline $\mathrm{CO} 2 \mathrm{H}$ & FitPitzerNC_NaHCO3_Na2CO3_CFJC.xls ${ }^{a}$ & $\begin{array}{l}\text { He and Morse } 1993 \text { [DIRS } \\
\text { 162090] }\end{array}$ & NM & $25-90$ \\
\hline
\end{tabular}


Table I-1. Catalog of Pitzer Ion-Interaction Parameter Spreadsheets (Continued)

\begin{tabular}{|c|c|c|c|c|}
\hline Ion Group & Spreadsheet File Name & Original Data Source & Type & $\begin{array}{l}\text { T Range } \\
\left({ }^{\circ} \mathrm{C}\right)\end{array}$ \\
\hline $\mathrm{CO} 2 \_\mathrm{Cl}$ & FitPitzerNC_NaHCO3_Na2CO3_CFJC.xls ${ }^{a}$ & $\begin{array}{l}\text { He and Morse } 1993 \text { [DIRS } \\
\text { 162090] }\end{array}$ & $N X$ & $25-90$ \\
\hline CO2_HSO4 & FitPitzerNC_NaHCO3_Na2CO3_CFJC.xls ${ }^{a}$ & $\begin{array}{l}\text { He and Morse } 1993 \text { [DIRS } \\
\text { 162090] }\end{array}$ & $N X$ & $25-90$ \\
\hline CO2_SO4 & FitPitzerNC_NaHCO3_Na2CO3_CFJC.xls ${ }^{a}$ & $\begin{array}{l}\text { He and Morse } 1993 \text { [DIRS } \\
162090]\end{array}$ & $N X$ & $25-90$ \\
\hline $\mathrm{CO} 2$ _H_Cl & FitPitzerNC_NaHCO3_Na2CO3_CFJC.xls ${ }^{a}$ & $\begin{array}{l}\text { He and Morse } 1993 \text { [DIRS } \\
\text { 162090] }\end{array}$ & NMX & $25-90$ \\
\hline CO2_Na_Cl & FitPitzerNC_NaHCO3_Na2CO3_CFJC.xls ${ }^{a}$ & $\begin{array}{l}\text { He and Morse } 1993 \text { [DIRS } \\
\text { 162090] }\end{array}$ & NMX & $25-90$ \\
\hline CO2_K_Cl & FitPitzerNC_NaHCO3_Na2CO3_CFJC.xls ${ }^{a}$ & $\begin{array}{l}\text { He and Morse } 1993 \text { [DIRS } \\
\text { 162090] }\end{array}$ & NMX & $25-90$ \\
\hline $\mathrm{CO} 2$ Ca_Cl & FitPitzerNC_NaHCO3_Na2CO3_CFJC.xls ${ }^{a}$ & $\begin{array}{l}\text { He and Morse } 1993 \text { [DIRS } \\
162090]\end{array}$ & NMX & $25-90$ \\
\hline CO2_Mg_Cl & FitPitzerNC_NaHCO3_Na2CO3_CFJC.xls ${ }^{a}$ & $\begin{array}{l}\text { He and Morse } 1993 \text { [DIRS } \\
\text { 162090] }\end{array}$ & NMX & $25-90$ \\
\hline $\mathrm{CO} 2$ _H_SO4 & FitPitzerNC_NaHCO3_Na2CO3_CFJC.xls ${ }^{a}$ & $\begin{array}{l}\text { He and Morse } 1993 \text { [DIRS } \\
\text { 162090] }\end{array}$ & NMX & $25-90$ \\
\hline CO2_Na_SO4 & FitPitzerNC_NaHCO3_Na2CO3_CFJC.xls ${ }^{a}$ & $\begin{array}{l}\text { He and Morse } 1993 \text { [DIRS } \\
\text { 162090] }\end{array}$ & NMX & $25-90$ \\
\hline CO2_K_SO4 & FitPitzerNC_NaHCO3_Na2CO3_CFJC.xls ${ }^{a}$ & $\begin{array}{l}\text { He and Morse } 1993 \text { [DIRS } \\
\text { 162090] }\end{array}$ & NMX & $25-90$ \\
\hline CO2_Mg_SO4 & FitPitzerNC_NaHCO3_Na2CO3_CFJC.xls ${ }^{a}$ & $\begin{array}{l}\text { He and Morse } 1993 \text { [DIRS } \\
\text { 162090] }\end{array}$ & NMX & $25-90$ \\
\hline O2_Al & FitPitzerNC_lambdas_zetas_O2_CFJC.xls ${ }^{a}$ & $\begin{array}{l}\text { Clegg and Brimblecombe } 1990 \\
\text { [DIRS 162089] }\end{array}$ & NM & $25-100$ \\
\hline $\mathrm{O} 2 \_\mathrm{Ba}$ & FitPitzerNC_lambdas_zetas_O2_CFJC.xls ${ }^{a}$ & $\begin{array}{l}\text { Clegg and Brimblecombe } 1990 \\
\text { [DIRS 162089] }\end{array}$ & NM & $25-100$ \\
\hline $\mathrm{O} 2 \_\mathrm{Ca}$ & FitPitzerNC_lambdas_zetas_O2_CFJC.xls ${ }^{a}$ & $\begin{array}{l}\text { Clegg and Brimblecombe } 1990 \\
\text { [DIRS 162089] }\end{array}$ & NM & $25-100$ \\
\hline $\mathrm{O} 2 \_\mathrm{H}$ & FitPitzerNC_lambdas_zetas_O2_CFJC.xls ${ }^{a}$ & $\begin{array}{l}\text { Clegg and Brimblecombe } 1990 \\
\text { [DIRS 162089] }\end{array}$ & NM & $25-100$ \\
\hline O2_K & FitPitzerNC_lambdas_zetas_O2_CFJC.xls ${ }^{a}$ & $\begin{array}{l}\text { Clegg and Brimblecombe } 1990 \\
\text { [DIRS 162089] }\end{array}$ & NM & $25-100$ \\
\hline O2_Li & FitPitzerNC_lambdas_zetas_O2_CFJC.xls ${ }^{a}$ & $\begin{array}{l}\text { Clegg and Brimblecombe } 1990 \\
\text { [DIRS 162089] }\end{array}$ & NM & $25-100$ \\
\hline O2_Mg & FitPitzerNC_lambdas_zetas_O2_CFJC.xls ${ }^{a}$ & $\begin{array}{l}\text { Clegg and Brimblecombe } 1990 \\
\text { [DIRS 162089] }\end{array}$ & NM & $25-100$ \\
\hline $\mathrm{O} 2 \_\mathrm{Na}$ & FitPitzerNC_lambdas_zetas_O2_CFJC.xls ${ }^{a}$ & $\begin{array}{l}\text { Clegg and Brimblecombe } 1990 \\
\text { [DIRS 162089] }\end{array}$ & NM & $25-100$ \\
\hline O2_NH4 & FitPitzerNC_lambdas_zetas_O2_CFJC.xls ${ }^{a}$ & $\begin{array}{l}\text { Clegg and Brimblecombe } 1990 \\
\text { [DIRS 162089] }\end{array}$ & NM & $25-100$ \\
\hline $\mathrm{O} 2 \_\mathrm{Cl}$ & FitPitzerNC_lambdas_zetas_O2_CFJC.xls ${ }^{a}$ & $\begin{array}{l}\text { Clegg and Brimblecombe } 1990 \\
\text { [DIRS 162089] }\end{array}$ & NX & $25-100$ \\
\hline $\mathrm{O} 2 \_\mathrm{Br}$ & FitPitzerNC_lambdas_zetas_O2_CFJC.xls ${ }^{a}$ & $\begin{array}{l}\text { Clegg and Brimblecombe } 1990 \\
\text { [DIRS 162089] }\end{array}$ & NX & $25-100$ \\
\hline
\end{tabular}


Table I-1. Catalog of Pitzer Ion-Interaction Parameter Spreadsheets (Continued)

\begin{tabular}{|c|c|c|c|c|}
\hline Ion Group & Spreadsheet File Name & Original Data Source & Type & $\begin{array}{l}\text { T Range } \\
\left({ }^{\circ} \mathrm{C}\right)\end{array}$ \\
\hline O2_CO3 & FitPitzerNC_lambdas_zetas_O2_CFJC.xls ${ }^{a}$ & $\begin{array}{l}\text { Clegg and Brimblecombe } 1990 \\
\text { [DIRS 162089] }\end{array}$ & NX & $25-100$ \\
\hline $\mathrm{O} 2 \_\mathrm{HCO} 3$ & FitPitzerNC_lambdas_zetas_O2_CFJC.xls ${ }^{a}$ & $\begin{array}{l}\text { Clegg and Brimblecombe } 1990 \\
\text { [DIRS 162089] }\end{array}$ & NX & $25-100$ \\
\hline O2_I & FitPitzerNC_lambdas_zetas_O2_CFJC.xls ${ }^{a}$ & $\begin{array}{l}\text { Clegg and Brimblecombe } 1990 \\
\text { [DIRS 162089] }\end{array}$ & NX & $25-100$ \\
\hline O2_NO3 & FitPitzerNC_lambdas_zetas_O2_CFJC.xls ${ }^{a}$ & $\begin{array}{l}\text { Clegg and Brimblecombe } 1990 \\
\text { [DIRS 162089] }\end{array}$ & NX & $25-100$ \\
\hline $\mathrm{O} 2 \_\mathrm{OH}$ & FitPitzerNC_lambdas_zetas_O2_CFJC.xls ${ }^{\mathrm{a}}$ & $\begin{array}{l}\text { Clegg and Brimblecombe } 1990 \\
\text { [DIRS 162089] }\end{array}$ & NX & $25-100$ \\
\hline O2_SO4 & FitPitzerNC_lambdas_zetas_O2_CFJC.xls ${ }^{a}$ & $\begin{array}{l}\text { Clegg and Brimblecombe } 1990 \\
\text { [DIRS 162089] }\end{array}$ & NX & $25-100$ \\
\hline $\mathrm{O} 2 \_\mathrm{Na} \_\mathrm{Cl}$ & FitPitzerNC_lambdas_zetas_O2_CFJC.xls ${ }^{a}$ & $\begin{array}{l}\text { Clegg and Brimblecombe } 1990 \\
\text { [DIRS 162089] }\end{array}$ & NMX & $25-100$ \\
\hline O2_Na_Br & FitPitzerNC_lambdas_zetas_O2_CFJC.xls ${ }^{a}$ & $\begin{array}{l}\text { Clegg and Brimblecombe } 1990 \\
\text { [DIRS 162089] }\end{array}$ & NMX & $25-100$ \\
\hline O2_Na_NO3 & FitPitzerNC_lambdas_zetas_O2_CFJC.xls ${ }^{\mathrm{a}}$ & $\begin{array}{l}\text { Clegg and Brimblecombe } 1990 \\
\text { [DIRS 162089] }\end{array}$ & NMX & $25-100$ \\
\hline O2_Na_SO4 & FitPitzerNC_lambdas_zetas_O2_CFJC.xls ${ }^{a}$ & $\begin{array}{l}\text { Clegg and Brimblecombe } 1990 \\
\text { [DIRS 162089] }\end{array}$ & NMX & $25-100$ \\
\hline $\mathrm{O} 2 \_\mathrm{K} \_\mathrm{Cl}$ & FitPitzerNC_lambdas_zetas_O2_CFJC.xls ${ }^{a}$ & $\begin{array}{l}\text { Clegg and Brimblecombe } 1990 \\
\text { [DIRS 162089] }\end{array}$ & NMX & $25-100$ \\
\hline O2_K_Br & FitPitzerNC_lambdas_zetas_O2_CFJC.xls ${ }^{\mathrm{a}}$ & $\begin{array}{l}\text { Clegg and Brimblecombe } 1990 \\
\text { [DIRS 162089] }\end{array}$ & NMX & $25-100$ \\
\hline O2_K_OH & FitPitzerNC_lambdas_zetas_O2_CFJC.xls ${ }^{a}$ & $\begin{array}{l}\text { Clegg and Brimblecombe } 1990 \\
\text { [DIRS 162089] }\end{array}$ & NMX & $25-100$ \\
\hline O2_K_NO3 & FitPitzerNC_lambdas_zetas_O2_CFJC.xls ${ }^{a}$ & $\begin{array}{l}\text { Clegg and Brimblecombe } 1990 \\
\text { [DIRS 162089] }\end{array}$ & NMX & $25-100$ \\
\hline O2_K_SO4 & FitPitzerNC_lambdas_zetas_O2_CFJC.xls ${ }^{a}$ & $\begin{array}{l}\text { Clegg and Brimblecombe } 1990 \\
\text { [DIRS 162089] }\end{array}$ & NMX & $25-100$ \\
\hline O2_Mg_Cl & FitPitzerNC_lambdas_zetas_O2_CFJC.xls ${ }^{a}$ & $\begin{array}{l}\text { Clegg and Brimblecombe } 1990 \\
\text { [DIRS 162089] }\end{array}$ & NMX & $25-100$ \\
\hline O2_Mg_SO4 & FitPitzerNC_lambdas_zetas_O2_CFJC.xls ${ }^{a}$ & $\begin{array}{l}\text { Clegg and Brimblecombe } 1990 \\
\text { [DIRS 162089] }\end{array}$ & NMX & $25-100$ \\
\hline $\mathrm{O} 2 \_\mathrm{Ca} \_\mathrm{Cl}$ & FitPitzerNC_lambdas_zetas_O2_CFJC.xls ${ }^{a}$ & $\begin{array}{l}\text { Clegg and Brimblecombe } 1990 \\
\text { [DIRS 162089] }\end{array}$ & NMX & $25-100$ \\
\hline O2_Ca_NO3 & FitPitzerNC_lambdas_zetas_O2_CFJC.xls ${ }^{a}$ & $\begin{array}{l}\text { Clegg and Brimblecombe } 1990 \\
\text { [DIRS 162089] }\end{array}$ & NMX & $25-100$ \\
\hline O2_Al_Cl & FitPitzerNC_lambdas_zetas_O2_CFJC.xls ${ }^{a}$ & $\begin{array}{l}\text { Clegg and Brimblecombe } 1990 \\
\text { [DIRS 162089] }\end{array}$ & NMX & $25-100$ \\
\hline O2_Al_SO4 & FitPitzerNC_lambdas_zetas_O2_CFJC.xls ${ }^{a}$ & $\begin{array}{l}\text { Clegg and Brimblecombe } 1990 \\
\text { [DIRS 162089] }\end{array}$ & NMX & $25-100$ \\
\hline $\mathrm{O} 2 \_\mathrm{H} \_\mathrm{Cl}$ & FitPitzerNC_lambdas_zetas_O2_CFJC.xls ${ }^{a}$ & $\begin{array}{l}\text { Clegg and Brimblecombe } 1990 \\
\text { [DIRS 162089] }\end{array}$ & NMX & $25-100$ \\
\hline O2_Li_Cl & FitPitzerNC_lambdas_zetas_O2_CFJC.xls ${ }^{a}$ & $\begin{array}{l}\text { Clegg and Brimblecombe } 1990 \\
\text { [DIRS 162089] }\end{array}$ & NMX & $25-100$ \\
\hline $\mathrm{O} 2 \_\mathrm{Na} \_\mathrm{HCO} 3$ & FitPitzerNC_lambdas_zetas_O2_CFJC.xls ${ }^{a}$ & $\begin{array}{l}\text { Clegg and Brimblecombe } 1990 \\
\text { [DIRS 162089] }\end{array}$ & NMX & $25-100$ \\
\hline
\end{tabular}


Table I-1. Catalog of Pitzer Ion-Interaction Parameter Spreadsheets (Continued)

\begin{tabular}{|c|c|c|c|c|}
\hline Ion Group & Spreadsheet File Name & Original Data Source & Type & $\begin{array}{l}\text { T Range } \\
\left({ }^{\circ} \mathrm{C}\right)\end{array}$ \\
\hline O2_Na_CO3 & FitPitzerNC_lambdas_zetas_O2_CFJC.xls ${ }^{a}$ & $\begin{array}{l}\text { Clegg and Brimblecombe } 1990 \\
\text { [DIRS 162089] }\end{array}$ & NMX & $25-100$ \\
\hline O2_K_I & FitPitzerNC_lambdas_zetas_O2_CFJC.xls ${ }^{a}$ & $\begin{array}{l}\text { Clegg and Brimblecombe } 1990 \\
\text { [DIRS 162089] }\end{array}$ & NMX & $25-100$ \\
\hline O2_NH4_SO4 & FitPitzerNC_lambdas_zetas_O2_CFJC.xls ${ }^{a}$ & $\begin{array}{l}\text { Clegg and Brimblecombe } 1990 \\
\text { [DIRS 162089] }\end{array}$ & NMX & $25-100$ \\
\hline O2_Ba_Cl & FitPitzerNC_lambdas_zetas_O2_CFJC.xls ${ }^{a}$ & $\begin{array}{l}\text { Clegg and Brimblecombe } 1990 \\
\text { [DIRS 162089] }\end{array}$ & NMX & $25-100$ \\
\hline $\mathrm{SiO} 2 \_\mathrm{H}$ & Pitzer_NMX_SiO2.xls ${ }^{a}$ & Felmy et al. 1994 [DIRS 162111] & NX & $25-100$ \\
\hline $\mathrm{SiO} 2 \_\mathrm{Mg}$ & Pitzer_NMX_SiO2.xls ${ }^{a}$ & Felmy et al. 1994 [DIRS 162111] & NM & $25-100$ \\
\hline $\mathrm{SiO} 2 \_\mathrm{Na}$ & Pitzer_NMX_SiO2.xls ${ }^{a}$ & Felmy et al. 1994 [DIRS 162111] & NM & $25-100$ \\
\hline $\mathrm{SiO} 2 \_\mathrm{Cl}$ & Pitzer_NMX_SiO2.xls ${ }^{a}$ & Felmy et al. 1994 [DIRS 162111] & NX & $25-100$ \\
\hline $\mathrm{SiO} 2 \_\mathrm{NO} 3$ & Pitzer_NMX_SiO2.xls ${ }^{a}$ & Felmy et al. 1994 [DIRS 162111] & NX & $25-100$ \\
\hline SiO2_SO4 & Pitzer_NMX_SiO2.xls ${ }^{a}$ & Felmy et al. 1994 [DIRS 162111] & NX & $25-100$ \\
\hline K_Mg_Cl & Pabalan_icf_TJW.xls & $\begin{array}{l}\text { Pabalan and Pitzer } 1987 \text { [DIRS } \\
\text { 162096] }\end{array}$ & MMX & $0-250$ \\
\hline $\mathrm{Na}$ _Mg_Cl & Pabalan_icf_TJW.xls & $\begin{array}{l}\text { Pabalan and Pitzer } 1987 \text { [DIRS } \\
\text { 162096] }\end{array}$ & MMX & $0-250$ \\
\hline Mg_Cl_SO4 & Pabalan_icf_TJW.xls & $\begin{array}{l}\text { Pabalan and Pitzer } 1987 \text { [DIRS } \\
\text { 162096] }\end{array}$ & MMX & $0-250$ \\
\hline $\mathrm{Na}$ K_Cl & Pabalan_icf_TJW.xls & $\begin{array}{l}\text { Pabalan and Pitzer } 1987 \text { [DIRS } \\
\text { 162096] }\end{array}$ & MMX & $0-250$ \\
\hline $\mathrm{Cl} \_\mathrm{OH} \_\mathrm{Na}$ & Pabalan_icf_TJW.xls & $\begin{array}{l}\text { Pabalan and Pitzer } 1987 \text { [DIRS } \\
\text { 162096] }\end{array}$ & MMX & $0-250$ \\
\hline $\mathrm{Na} \_\mathrm{OH} \_\mathrm{SO} 4$ & Pabalan_icf_TJW.xls & $\begin{array}{l}\text { Pabalan and Pitzer } 1987 \text { [DIRS } \\
\text { 162096] }\end{array}$ & MMX & $0-250$ \\
\hline
\end{tabular}

Output DTN: SN0306T0510102.007.

NOTE: For Details On The Valid Composition Salt Range of These Parameters, the User is Referred to The Corresponding Sources

a Spreadsheet refitting calculations do not entail the use of the "FitPitzerNC" methodology. Refitting of Pitzer parameters was conducted using the MS Excel regression function.

$\mathrm{b}$ The evaluation of these mixing parameters was based on the model and parameters of Greenberg and Møller 1989 [DIRS 152684]. Although these authors used a constant value for this parameter (rather than a temperaturedependent function), its value was chosen to represent solubilities over a wide temperature range, and thus it can be used over the indicated temperature range.

c The evaluation of these mixing parameters is based on the model and parameters of Greenberg and Møller 1989 [DIRS 152684]. These authors used a constant value for this parameter from 0 to $150^{\circ} \mathrm{C}$ (rather than a temperature-dependent function), and then used a temperature-dependent function at higher temperatures. Since the constant value below $150^{\circ} \mathrm{C}$ was chosen to represent solubilities over a wide temperature range, it can be used over the indicated temperature range. 
Table I-2. Pitzer lon-Interaction Parameters Not Requiring Refitting (Values Only Valid at $25^{\circ} \mathrm{C}$ )

\begin{tabular}{|c|c|c|c|}
\hline Ion Group & Spreadsheet File Name & Original Data Source & Type \\
\hline Ca_Br & Some2-1Salts25C_TJW.xls & Pitzer 1991 [DIRS 152709] & $M X$ \\
\hline Ca_HCO3 & Some2-1Salts25C_TJW.xls & Pitzer 1991 [DIRS 152709] & $M X$ \\
\hline $\mathrm{Ca} \_\mathrm{HSO} 3$ & Some2-1Salts25C_TJW.xls & Pitzer 1991 [DIRS 152709] & MX \\
\hline Ca_I & Some2-1Salts25C_TJW.xls & Pitzer 1991 [DIRS 152709] & $\mathrm{MX}$ \\
\hline Cs_I & Some1-1Salts25C_TJW.xls & Pitzer 1991 [DIRS 152709] & $\mathrm{MX}$ \\
\hline Cs_F & Some1-1Salts25C_TJW.xls & Pitzer 1991 [DIRS 152709] & MX \\
\hline Cs_NO3 & Some2-1Salts25C_TJW.xls & Pitzer 1991 [DIRS 152709] & $\mathrm{MX}$ \\
\hline Cs_OH & Some1-1Salts25C_TJW.xls & Pitzer 1991 [DIRS 152709] & $\mathrm{MX}$ \\
\hline Cs_SO4 & Some2-1Salts25C_TJW.xls & Pitzer 1991 [DIRS 152709] & MX \\
\hline $\mathrm{H} \_\mathrm{Br}$ & Some1-1Salts25C_TJW.xls & Pitzer 1991 [DIRS 152709] & $\mathrm{MX}$ \\
\hline $\bar{H} \_\mathrm{I}$ & Some1-1Salts25C_TJW.xls & Pitzer 1991 [DIRS 152709] & MX \\
\hline K_CO3 & Some2-1Salts25C_TJW.xls & Pitzer 1991 [DIRS 152709] & $M X$ \\
\hline K_HCO3 & Some2-1Salts25C_TJW.xls & Pitzer 1991 [DIRS 152709] & $\mathrm{MX}$ \\
\hline K_CrO4 & Some2-1Salts25C_TJW.xls & Pitzer 1991 [DIRS 152709] & $\mathrm{MX}$ \\
\hline K_F & Some2-1Salts25C_TJW.xls & Pitzer 1991 [DIRS 152709] & MX \\
\hline K_HPO4 & Some2-1Salts25C_TJW.xls & Pitzer 1991 [DIRS 152709] & $M X$ \\
\hline K_SO4 & Some2-1Salts25C_TJW.xls & Pitzer 1991 [DIRS 152709] & $M X$ \\
\hline K_I & Some2-1Salts25C_TJW.xls & Pitzer 1991 [DIRS 152709] & $M X$ \\
\hline K_NO3 & Some2-1Salts25C_TJW.xls & Pitzer 1991 [DIRS 152709] & $M X$ \\
\hline K_OH & Some2-1Salts25C_TJW.xls & Pitzer 1991 [DIRS 152709] & $M X$ \\
\hline Li_I & Some2-1Salts25C_TJW.xls & Pitzer 1991 [DIRS 152709] & $M X$ \\
\hline Li_NO3 & Some2-1Salts25C_TJW.xls & Pitzer 1991 [DIRS 152709] & MX \\
\hline $\mathrm{Li} \_\mathrm{OH}$ & Some2-1Salts25C_TJW.xls & Pitzer 1991 [DIRS 152709] & $\mathrm{MX}$ \\
\hline Li_SO4 & Some2-1Salts25C_TJW.xls & Pitzer 1991 [DIRS 152709] & $M X$ \\
\hline$\overline{\mathrm{Mg}} \_\mathrm{Br}$ & Some2-1Salts25C_TJW.xls & Pitzer 1991 [DIRS 152709] & $\mathrm{MX}$ \\
\hline Mg_HCO3 & Some2-1Salts25C_TJW.xls & Pitzer 1991 [DIRS 152709] & $\mathrm{MX}$ \\
\hline Mg_SO4 & Some2-1Salts25C_TJW.xls & Pitzer 1991 [DIRS 152709] & $M X$ \\
\hline Mg_I & Some2-1Salts25C_TJW.xls & Pitzer 1991 [DIRS 152709] & $\mathrm{MX}$ \\
\hline Mg_NO3 & Some2-1Salts25C_TJW.xls & Pitzer 1991 [DIRS 152709] & $\mathrm{MX}$ \\
\hline $\mathrm{MgOH} \_\mathrm{Cl}$ & Some2-1Salts25C_TJW.xls & Pitzer 1991 [DIRS 152709] & MX \\
\hline $\mathrm{Na}$ & Some2-1Salts25C_TJW.xls & Pitzer 1991 [DIRS 152709] & $\mathrm{MX}$ \\
\hline $\mathrm{Na} \_\mathrm{F}$ & Some2-1Salts25C_TJW.xls & Pitzer 1991 [DIRS 152709] & $M X$ \\
\hline $\mathrm{Na} \_\mathrm{HPO} 4$ & Some2-1Salts25C_TJW.xls & Pitzer 1991 [DIRS 152709] & MX \\
\hline$\overline{\mathrm{Na}} \_\mathrm{I}$ & Some2-1Salts25C_TJW.xls & Pitzer 1991 [DIRS 152709] & $\mathrm{MX}$ \\
\hline $\mathrm{NH} 4 \_\mathrm{Br}$ & Some2-1Salts25C_TJW.xls & Pitzer 1991 [DIRS 152709] & $\mathrm{MX}$ \\
\hline $\mathrm{NH} 4 \_\mathrm{HCO} 3$ & Some2-1Salts25C_TJW.xls & Pitzer 1991 [DIRS 152709] & MX \\
\hline $\mathrm{NH} 4 \_\mathrm{I}$ & Some2-1Salts25C_TJW.xls & Pitzer 1991 [DIRS 152709] & $\mathrm{MX}$ \\
\hline $\mathrm{NH} 4 \_\mathrm{NO} 3$ & Some2-1Salts25C_TJW.xls & Pitzer 1991 [DIRS 152709] & $M X$ \\
\hline Sr_Br & Some2-1Salts25C_TJW.xls & Pitzer 1991 [DIRS 152709] & MX \\
\hline Sr_Cl & Some2-1Salts25C_TJW.xls & Pitzer 1991 [DIRS 152709] & $\mathrm{MX}$ \\
\hline Sr_l & Some2-1Salts25C_TJW.xls & Pitzer 1991 [DIRS 152709] & $\mathrm{MX}$ \\
\hline Sr_NO3 & Some2-1Salts25C_TJW.xls & Pitzer 1991 [DIRS 152709] & $M X$ \\
\hline$\overline{\mathrm{Ca}} \_\mathrm{H}$ & No Spreadsheet & Pitzer 1991 [DIRS 152709] & MM \\
\hline $\mathrm{Ca}$-K & No Spreadsheet & Pitzer 1991 [DIRS 152709] & MM \\
\hline $\mathrm{Ca} \_\mathrm{Na}$ & No Spreadsheet & Pitzer 1991 [DIRS 152709] & MM \\
\hline
\end{tabular}


Table I-2. Pitzer lon-Interaction Parameters Not Requiring Refitting (Values Only Valid at $25^{\circ} \mathrm{C}$ ) (Continued)

\begin{tabular}{|c|c|c|c|}
\hline Ion Group & Spreadsheet File Name & Original Data Source & Type \\
\hline Ca_Mg & No Spreadsheet & Pitzer 1991 [DIRS 152709] & MM \\
Cs_H & No Spreadsheet & Pitzer 1991 [DIRS 152709] & MM \\
Cs_K & No Spreadsheet & Pitzer 1991 [DIRS 152709] & MM \\
Cs_Li & No Spreadsheet & Pitzer 1991 [DIRS 152709] & MM \\
Cs_Na & No Spreadsheet & Pitzer 1991 [DIRS 152709] & MM \\
H_K & No Spreadsheet & Pitzer 1991 [DIRS 152709] & MM \\
H_Li & No Spreadsheet & Pitzer 1991 [DIRS 152709] & MM \\
H_Mg & No Spreadsheet & Pitzer 1991 [DIRS 152709] & MM \\
H_Na & No Spreadsheet & Pitzer 1991 [DIRS 152709] & MM \\
H_NH4 & No Spreadsheet & Pitzer 1991 [DIRS 152709] & MM \\
H_Sr & No Spreadsheet & Pitzer 1991 [DIRS 152709] & MM \\
K_Li & No Spreadsheet & Pitzer 1991 [DIRS 152709] & MM \\
K_Mg & No Spreadsheet & Pabalan and Pitzer 1987 [DIRS 162096] & MM \\
K_Na & No Spreadsheet & Pitzer 1991 [DIRS 152709] & MM \\
Li_Na & No Spreadsheet & Pitzer 1991 [DIRS 152709] & MM \\
Mg_Na & No Spreadsheet & Pabalan and Pitzer 1987 [DIRS 162096] & MM \\
\hline
\end{tabular}

Output DTN: SN0306T0510102.007

NOTE: "No Spreadsheet" means that values were taken directly from tables listed in Pitzer 1991 [DIRS 152709$].$

\section{I.4.1 FITPITZERNC METHODOLOGY}

In the FitPitzerNC spreadsheets it is assumed that the Pitzer parameters are given as functions of the system temperature, $T$, and pressure, $P$. A new output temperature-pressure function $f(T, P)$ is fitted to each Pitzer parameter that is defined in the source document in terms of a temperature-pressure function $f^{\theta}(T, P)$. Usually, both the input and output temperature-pressure functions are given as the sum of a finite series of numeric terms, each of which is the product of a constant coefficient $\left(a_{i}, a_{i}^{0}\right)$, and a temperature-pressure interpolation basis function $\left(g_{i}(T, P)\right.$, $\left.g_{i}^{0}(T, P)\right)$, as in:

$$
\begin{gathered}
f(T, P)=\sum_{i=1}^{i=n_{f}} a_{i} g_{i}(T, P) \\
f^{0}(T, P)=\sum_{i=1}^{i=n_{f}^{0}} a_{i}^{0} g_{i}^{0}(T, P)
\end{gathered}
$$

where, $\left(n_{f}, n_{f}^{0}\right)$ are the numbers of terms in the two series. While the basis functions for the input model parameters are specified in the source document, the new basis functions of the output model parameters are selected by the user of the FitPitzerNC spreadsheets from a list of up to eight basis functions. It is important to note that the fitting coefficients $a_{1}, \ldots, a_{5}$ specified in the 'FitPitzerNC' and 'ConPitzerNC' spreadsheets do not directly correspond to those specified 
for the data0.ypf database. Table I-3 provides the actual correspondence between these parameters:

Table I-3. Fitting Coefficient Definitions for the 3-4 Parameter $25^{\circ} \mathrm{C}$ Centric Equations Used in the FitPitzerNC/ConPitzerNC Spreadsheets and data0.ypf Database File

\begin{tabular}{|c|c|c|}
\hline FitPitzerNC/ConPitzerNC & data0.ypf & $\begin{array}{c}\text { Temperature } \\
\text { Function }\end{array}$ \\
\hline $\mathrm{a}_{1}$ & $\mathrm{a}_{1}$ & Constant \\
\hline $\mathrm{a}_{2}$ & $\mathrm{a}_{4}$ & $\mathrm{~T}$ \\
\hline $\mathrm{a}_{3}$ & not used & $\mathrm{T}^{2}$ \\
\hline $\mathrm{a}_{4}$ & $\mathrm{a}_{2}$ & $1 / \mathrm{T}$ \\
\hline $\mathrm{a}_{5}$ & $\mathrm{a}_{3}$ & $\ln \mathrm{T}$ \\
\hline
\end{tabular}

Spreadsheets not using the 'FitPitzerNC' or 'ConPitzerNC' methodology express the fitting coefficients as in the data0.ypf database file.

In the FitPitzerNC spreadsheets, it is assumed that a temperature dependent standard system pressure $\mathrm{P}(\mathrm{T})$ is equal to 1 atmosphere below $100^{\circ} \mathrm{C}$, and is equal to the liquid-vapor saturation vapor pressure of pure water above $100^{\circ} \mathrm{C}$. The reason for making this assumption is that this is the definition of system pressure used in Software User's Manual, EQ3/6, Version 8.0 (SNL 2003 [DIRS 162494]). Consequently, the functional dependence of the output temperaturepressure functions of the Pitzer parameters can be simplified according to $g_{i}(T, P)=g_{i}(T, P(T))=$ $g_{i}(T)$, and expressed as functions of the temperature only.

On the basis of thermodynamic arguments, and parameter fitting accuracy considerations, the following set of eight functions for the output basis functions $g_{i}(T)$ was selected:

$$
\begin{aligned}
& g_{1}(T)=1 \\
& g_{2}(T)=T \\
& g_{3}(T)=T^{2} \\
& g_{4}(T)=T^{-1} \\
& g_{5}(T)=\ln (T) \\
& g_{6}(T)=T^{3} \\
& g_{7}(T)=T^{-2} \\
& g_{8}(T)=T^{-3}
\end{aligned}
$$

This series of basis functions not only spans the entire sequence of powers of the temperature $T$ increasing from -3 to +2 (i.e., $\left.T^{-3}, T^{-2}, T^{-1}, T^{-k}(k<<1), T^{0}, T^{k}(k<<1), T^{l}, T^{2}\right)$, but it also incorporates as subsets important temperature function forms for the Pitzer parameters that can be justified on the basis of fundamental thermodynamic considerations.

It is convenient for parameter data verification purposes to directly represent the coefficient $a_{l}$ of the constant basis function $g_{l}(T)$ as the value of the fitted parameter at some reference absolute 
temperature $T_{\text {ref, }}$ usually $298.15 \mathrm{~K}$. This can be achieved by redefining the basis functions $g_{i}(T)$ as:

$$
\begin{aligned}
& g_{1}(T)=1 \\
& g_{2}(T)=T-T_{\text {ref }} \\
& g_{3}(T)=T^{2}-T_{\text {ref }}^{2} \\
& g_{4}(T)=T^{-1}-T_{\text {ref }}^{-1} \\
& g_{5}(T)=\ln \left(\frac{T}{T_{\text {ref }}}\right) \\
& g_{6}(T)=T^{3}-T_{\text {ref }}^{3} \\
& g_{7}(T)=T^{-2}-T_{\text {ref }}^{-2} \\
& g_{8}(T)=T^{-3}-T_{\text {ref }}^{-3}
\end{aligned}
$$

In the FitPitzerNC spreadsheet, this feature for centering the fitted functions at any specified absolute reference temperature $T_{\text {ref }}$ has been implemented and can be selected as an option.

\section{I.4.2 PROCEDURE FOR FITTING TEMPERATURE FUNCTIONS TO PITZER PARAMETERS}

A least-squares error minimization method was devised for fitting the new temperature functions to the input source functions with minimum error by first defining a measure $E^{2}\left(a_{i}\right)$ of the cumulative square error between the fitted function $f(T)$ and the input function $f^{0}(T, P)$ over the desired temperature range $\left(T_{\min }, T_{\max }\right)$ by:

$$
E^{2}\left(a_{i}\right)=\frac{1}{n_{T}} \sum_{j=1}^{j=n_{T}}\left\{f\left(T_{j}\right)-f^{0}\left(T_{j}, P_{j}\right)\right\}^{2}
$$

where $T_{j}$ are the $n_{T}$ discrete temperatures at which the parameters are evaluated, $T_{1}=T_{\min }$, $T_{2}=T_{\max }$, and $P_{j}=P\left(T_{j}\right)$.

Setting the partial derivatives of $E$ with respect to the output temperature coefficients $a_{i}$ equal to zero now minimizes the error measure:

$$
\frac{\partial E^{2}}{\partial a_{i}}=\frac{2}{n_{T}} \sum_{j=1}^{j=n_{T}} \frac{\partial f}{\partial a_{i}}\left\{f\left(T_{j}\right)-f^{0}\left(T_{j}, P_{j}\right)\right\}=0
$$

Substituting the series representations for the temperature function given by Equations I-61 and I-62 into equation I-66, and re-arranging the terms, yields the equation:

$$
\sum_{k=1}^{k=n_{f}} \sum_{j=1}^{j=n_{T}} g_{i}\left(T_{j}\right) g_{k}\left(T_{j}\right) a_{k}=\sum_{j=1}^{j=n_{T}} g_{i}\left(T_{j}\right) f^{0}\left(T_{j}, P_{j}\right)
$$


Equation $\mathrm{I}-67$ can be recast in a more compact and transparent form as the matrix equations:

$$
\begin{gathered}
{\left[A_{i k}\right]\left(a_{k}\right)=\left(b_{i}\right) \quad ; \quad i, k=1 \ldots n_{f}} \\
A_{i k} \equiv \sum_{j=1}^{j=n_{T}} g_{i}\left(T_{j}\right) g_{k}\left(T_{j}\right) \\
b_{i} \equiv \sum_{j=1}^{j=n} g_{i}\left(T_{j}\right) f^{0}\left(T_{j}, P_{j}\right)
\end{gathered}
$$

The matrix Equations I-68 through I-70 can be solved by standard matrix equation solution methods for the unknown vector of temperature coefficients $\left(a_{k}\right)$ in terms of the known righthand-side vector $\left(b_{i}\right)$, and known interpolation function matrix $\left[A_{i k}\right]$.

When the temperature coefficients $a_{i}$ have been determined by solving equation I-68 in this way, the input and fitted parameters $f^{\theta}\left(T_{j}\right)$ and $f\left(T_{j}\right)$ are evaluated using the values of the determined coefficients in the temperature function representations of Equation I-62. The binary and ternary system osmotic coefficients can then be calculated by substituting the input and fitted parameter values evaluated as a function of temperature in Equations I-13 and I-14, respectively.

This mathematical procedure has been implemented in each FitPitzerNC worksheet to fit new temperature functions to the source Pitzer parameters.

\section{I.4.2.1 FitPitzerNC Worksheet Implementation}

The full set of temperature basis functions given by Equation I-63 and I-64 spans the entire sequence of powers of the temperature $T$ increasing from -3 to +2 (i.e., $T^{3}, T^{2}, T^{1}, T^{k}(k<<1)$, $\left.T^{0}, T^{k}(k<<1), T^{l}, T^{2}\right)$. However, when implementing the FitPitzerNC methodology, it is necessary to allow for the fact that only a sub-set of the full set of basis functions may be activated, or chosen, for a particular Pitzer parameter database. A spreadsheet that does not treat each choice as a special case can be developed, by solving for all temperature coefficients in a way that forces the de-activated temperature coefficients $a_{k}$ to be equal to zero. In this no-code version of the FitPitzer spreadsheet, this feature is implemented using only spreadsheet macro functions in the following way.

An activation-index vector $I A_{i}$ (row 22 in RunSettings Worksheet) is first set up to reflect the user's choice of temperature basis functions such that

$$
\begin{aligned}
& L A_{i} \equiv 1 \quad ; \quad a_{i} \neq 0 ; \quad i=1,2 \ldots 8 \\
& L A_{i} \equiv 0 \quad ; \quad a_{i}=0 ; \quad i=1,2 \ldots 8
\end{aligned}
$$

The matrix equation that is to be solved for the unknown temperature coefficients is then given by

$$
\left[A_{i k}\right]\left(a_{k}^{p}\right)=\left(b_{i}^{p}\right) \quad ; \quad i, k=1 \ldots n_{f}
$$




$$
\begin{gathered}
A_{i k} \equiv A_{i k}^{0} \cdot I A M_{i k} ; \quad i, k=1 \ldots n_{f} \\
b_{i}^{p} \equiv b_{i}^{0 p} \cdot I A_{i} ; \quad i=1 \ldots n_{f}
\end{gathered}
$$

where $\mathrm{p}$ is the parameter index The activation-index matrix $I A M_{i j}$ is defined in terms of the activation-index vector $I A_{i}$ by

$$
\begin{gathered}
I A M_{i j} \equiv 1 \quad ; i=j \\
I A M_{i j} \equiv I A_{i} \cdot I A_{j} \quad ; \quad i \neq j
\end{gathered}
$$

In this way, the correct matrix coefficients and right-hand side vector values for the set of activated temperature coefficients are retrieved, while forcing the deactivated temperature coefficients to be equal to zero. All matrix-vector and matrix-matrix multiplications are performed using the MMULT and TRANSPOSE spreadsheet functions, inversion of the matrix equation I-73 is performed using the MINVERSE spreadsheet function, and the individual elements of the vector and matrix arrays are accessed using the INDEX function. These spreadsheet functions are standard intrinsic features of MS-Excel 2000 (and above).

\section{I.4.2.2 Example Calculation for FitPitzerNC_MX_NaCl.xls Workbook}

For the purpose of illustrating the specific manner in which these calculations are carried out, the sequence of calculations performed in the FitPitzerNC_MX_NaCl.xls workbook are presented below:

1. CoverPage worksheet: On this worksheet, software identification information and spreadsheet checker review comments are first presented. Next, spreadsheet user information on a contents roadmap, an overview of methodology and data sources, protection of data and computational integrity and manner of presentation of results, are given.

2. Directions worksheet: This worksheet gives directions for fitting different temperature functions selected by the user.

3. RunSettings worksheet: Select the desired temperature basis functions.

4. RunSettings worksheet: Select, if desired Temperature centering and Reference Temperature.

5. FitPitzerNC worksheet: Constant input (Archer) and output (Standard Pitzer) model parameters are defined in lines A13:L13 and A14:L14.

6. FitPitzerNC worksheet: The input Standard Pitzer Model temperature coefficients are set in cells B17:I20, and for the Aphi Debye-Huckel parameter in cells B21:I21.

7. FitPitzerNC worksheet: The input Standard Pitzer Model parameters and the Aphi Debye-Huckel parameter are calculated as functions of temperature in cells B31:AB35. 
8. FitPitzerNC worksheet: The matrix array, $G_{i j}=g_{i}\left(T_{j}\right)$, is calculated in accordance with equations I-64 or I-78 (along with the option chosen for the Tref switch), and the results placed in the range of cells, B78:AB85. The corresponding $A^{0}{ }_{i k}$ matrix is calculated according to equation I-69 (or equation I-79 below), specifically, MMULT(G,TRANSPOSE(G))/27, and the results placed in the range of cells, B88:I95. Division by 27 is convenient for keeping the entry for $\mathrm{A}^{\circ}(1,1)$ the same as that for $\mathrm{g}-1$ at $0^{\circ} \mathrm{C}$ :

$$
\begin{gathered}
G=\$ B \$ 78: \$ A B \$ 85 \\
A^{0}=\operatorname{MMULT}(G, T R A N S P O S E(G))=\$ B \$ 88: \$ I 95
\end{gathered}
$$

9. FitPitzerNC worksheet: The input parameter function matrix array, $F^{O p}{ }_{i}=f^{\theta p}\left(T_{i}\right)$, where $p$ stands for the parameter index and $i$ signifies the temperature value index is calculated in accordance with equation I-62 (entered as equation I-80 below), and the results placed in the range of cells, B31:AB34. The corresponding $B^{0 p}{ }_{i}$ matrix is calculated according to equation I-70 (or equation I-81 below), specifically, MMULT(G,TRANSPOSE $\left.\left(\mathrm{F}^{0}\right)\right) / 27$, and the results placed in the range of cells, B128:E135. Division by 27 is needed to keep both sides of equation I-68 compatible:

$$
\begin{gathered}
F^{0}=\$ B \$ 31: \$ A B \$ 34 \\
B^{0}=\operatorname{MMULT}\left(G, T R A N \operatorname{SPOSE}\left(F^{0}\right)\right)=\$ B \$ 128: \$ E \$ 135
\end{gathered}
$$

10. FitPitzerNC worksheet: The temperature basis function activation vector $I A_{i}$ and activation matrix $I A M_{i j}$ are setup according to Equations I-82 (or Equation I-76) and I-83 (or Equation I-77), respectively:

$$
\begin{gathered}
I A=\$ B \$ 24: \$ I \$ 24 \\
I A M=\$ B \$ 98: \$ I \$ 105
\end{gathered}
$$

11. FitPitzerNC worksheet: The modified coefficient matrix $A_{i k}$ and the modified matrix of righthand side vectors $B_{i}^{p}$ are calculated according to Equations I-84 (or Equation I-74) and I-85 (or Equation I-75), respectively:

$$
\begin{aligned}
& A=\$ B \$ 108: \$ I \$ 115 \\
& B=\$ B \$ 138: \$ I \$ 145
\end{aligned}
$$

12. FitPitzerNC worksheet: Equation I-73 is solved to obtain the desired matrix of temperature coefficient vectors CoefFIT $=a^{p}{ }_{i}$ by inverting the coefficient matrix $A$ to obtain its inverse $A I N V$ and then multiplying the inverse matrix by the modified matrix of right-hand side vectors $B_{i}^{p}$ :

$$
\begin{gathered}
A I N V=\operatorname{MINVERSE}(A)=\$ B \$ 118: \$ I \$ 125 \\
\text { CoefFIT }=\operatorname{MMULT}(A I N V, B)=\$ B \$ 25: \$ I \$ 28
\end{gathered}
$$


13. FitPitzerNC worksheet: The input Standard Pitzer Model parameters, and the fitted parameters for the same model, are calculated as functions of temperature according to Equations I-88 and I-89, respectively:

$$
\begin{gathered}
\text { ParamDAT }=\$ B \$ 31: \$ A B \$ 34 \\
\text { ParamFIT }=M M U L T(\text { TRANSPOSE }(\text { CoefFIT }), G)=\$ B \$ 38: \$ A B \$ 41
\end{gathered}
$$

14. FitPitzerNC worksheet: The ionic strength dependent factors in the Debye-Huckel and exponential Beta-parameter terms in the equation for the osmotic coefficient are calculated and stored as follows:

$$
\begin{gathered}
D H D A T=\$ D \$ 148: \$ D \$ 153 \\
\text { DHFIT }=\$ D \$ 156: \$ D \$ 161 \\
\text { PFuncDAT }=\$ E \$ 148: \$ H \$ 153 \\
\text { PFuncFIT }=\$ E \$ 156: \$ H \$ 161
\end{gathered}
$$

15. FitPitzerNC worksheet: The osmotic coefficient from the Debye-Huckel and Beta-parameter terms are calculated according to the equations:

$$
\begin{aligned}
& A P h i=\$ B \$ 35: \$ A B \$ 35 \\
& \text { PhiM1DAT }=\text { MMULT }(\text { DHDAT }, A P h i)+\text { MMULT }(\text { PFuncDAT, ParamDAT }) ; \\
& \text { PhiM1FIT }=\text { MMULT }(\text { DHFIT }, \text { APhi })+\text { MMULT }(\text { PFuncFIT, ParamFIT }) \\
& \text { PhiDAT }=1+P h i M 1 D A T=\$ B \$ 50: \$ A B \$ 55 \\
& P h i F I T=1+P h i M 1 F I T=\$ B \$ 58: \$ A B \$ 63
\end{aligned}
$$

16. FitPitzerNC worksheet: This completes the fitting of new temperature functions to the input Standard Pitzer Model parameters, the calculation of the input and fitted Pitzer parameters as functions of temperature, and the computation of the osmotic coefficient as a function of ionic strength and temperature from the input and fitted Pitzer parameter values at each temperature. These are used to evaluate the accuracy of fitting the Standard Pitzer parameters.

17. FitPitzerNC worksheet: The temperature function fitting error in the osmotic coefficient is calculated as the difference between the osmotic coefficients from the input and fitted Standard Pitzer Models in cells B67:AB72 as a function of temperature and ionic strength. The RMS error (cells AC67:AC72) and the Average, Maximum and Minimum values of the osmotic coefficient are also calculated for the two models in cells AD50:AF55 and AD58:AF63, respectively. 
18. FitPitzerNC worksheet: Pitzer parameters, osmotic coefficients and their errors, calculated from the input and fitted Standard Pitzer Models, are plotted in charts on the extreme right hand side of each FitPitzerNC worksheet.

19. ResultsSummary worksheet: The input and fitted temperature coefficients for the Standard Pitzer Model are summarized in cells B17:I21 and B25:I28, respectively.

20. ResultsSummary worksheet: The RMS errors, Average, Maximum and Minimum values of the Pitzer parameters (B31:E34) and osmotic coefficients (A37:E42) calculated from the input and fitted Standard Pitzer Models are summarized here. These statistics enable the errors incurred in temperature function fitting to be assessed.

\section{I.4.3 CONPITZERNC METHODOLOGY}

In the "ConPitzerNC_MX_Electrolyte.xls" type spreadsheet, the parameters given as a function of temperature for an extended Pitzer model in the data source document are converted to the parameters of the standard Pitzer model. Temperature coefficients for a user specified temperature function are then fit to these standard parameters in the "FitPitzerNC" worksheet of the spreadsheet as described in Section I-4.1 above. Currently, only spreadsheets for converting binary system parameters have been developed.

This section summarizes the procedure developed by Rard and Wijesinghe (2003 [DIRS 162327]) used in the "ConPitzerNC" worksheets for converting parameters between the 4parameter (i.e., $\beta^{(0)}{ }_{M X}(T, P), \beta^{(1)}{ }_{M X}(T, P), \beta^{(2)}{ }_{M X}(T, P), C^{\phi}{ }_{M X}(T, P)$ ) standard Pitzer model presented in Section I-3, and the 6-parameter (i.e., $\beta^{(0)}{ }_{M X}(T, P), \beta^{(1)}{ }_{M X}(T, P), \beta^{(2)}{ }_{M X}(T, P)$, $\left.C^{(0)}{ }_{M X}(T, P), \quad C^{(1)}{ }_{M X}(T, P), C^{(2)}{ }_{M X}(T, P)\right)$ extended Pitzer model developed by Archer $(2000$ [DIRS 162065]) and further extended by Oakes et al. (2000 [DIRS 162102]).

The expression for the osmotic coefficient in the 4-parameter standard Pitzer model, denoted by the superscript $P$, is given by:

$$
\phi^{P}=1-\frac{\left|z_{M} z_{X}\right| A_{\phi} I^{1 / 2}}{\left(1+b I^{1 / 2}\right)}+\left(\frac{2 v_{M} v_{X} m}{v_{M}+v_{X}}\right)\left\{B_{M X}^{\phi, P}+m\left(v_{M} v_{X}\right)^{1 / 2} C_{M X}^{\phi, P}\right\}
$$

where

$$
B_{M X}^{\phi, P}(I, T, P) \equiv \beta_{M X}^{(0, P)}(T, P)+\beta_{M X}^{(1, P)}(T, P) e^{-\alpha_{1} \sqrt{I}}+\beta_{M X}^{(2, P)}(T, P) e^{-\alpha_{2} \sqrt{I}}
$$

and $C^{\phi, P}{ }_{M X}$ is a function of $(T, P)$ only. The expression for the osmotic coefficient in the 6-parameter Extended Archer model (see Rard and Wijesinghe 2003 [DIRS 162327] for more details), denoted by the superscript $E A$, is given by:

$$
\phi^{E A}=1-\frac{\left|z_{M} z_{X}\right| A_{\phi} I^{1 / 2}}{\left(1+b I^{1 / 2}\right)}+\left(\frac{2 v_{M} v_{X} m}{v_{M}+v_{X}}\right)\left\{B_{M X}^{\phi, E A}+m\left(v_{M} v_{X}\right)^{1 / 2} C_{M X}^{E A}\right\}
$$


where

$$
\begin{gathered}
B_{M X}^{\phi, E A}(I, T, P) \equiv \beta_{M X}^{(0, E A)}(T, P)+\beta_{M X}^{(1, E A)}(T, P) e^{-\alpha_{1} \sqrt{I}}+\beta_{M X}^{(2, E A)}(T, P) e^{-\alpha_{2} \sqrt{I}} \\
C_{M X}^{E A}(I, T, P) \equiv C_{M X}^{(0, E A)}(T, P)+C_{M X}^{(1, E A)}(T, P) e^{-\omega_{1} \sqrt{I}}+C_{M X}^{(2, E A)}(T, P) e^{-\omega_{2} \sqrt{I}}
\end{gathered}
$$

$\omega_{1}$ and $\omega_{2}$ are constant coefficients for $C_{M X}^{(1, E A)}$ and $C_{M X}^{(2, E A)}$ parameters, respectively, as defined in the Archer model (see Rard and Wijesinghe 2003 [DIRS 162327]). In contrast to $C_{M X}^{\phi, P}$ in the standard Pitzer model, the $C_{M X}{ }^{E A}$ is a function of ionic strength in addition to temperature and pressure, and is expressed as the sum of an ionic strength dependent parameter and two terms that decay exponentially with the square root of ionic strength. Equation I-101 is the analogue of Equation I-99 for the standard Pitzer model with the same values assigned to exponents of the terms that decay exponentially with increasing ionic strength. It is important to note here that the coefficient of these functions in Equations I-98 and I-100 are not equal.

\section{I.4.3.1 Procedure for Determining Standard Pitzer Model Parameters from Archer Model Parameters}

A least-squares error minimization method was devised for determining with minimum error the set Standard Pitzer Model Parameters $X_{i}^{P}=\left\{\beta^{(0, P)}{ }_{M X}(T, P), \quad \beta^{(1, P)}{ }_{M X}(T, P), \beta^{(2, P)}{ }_{M X}(T, P)\right.$, $\left.C^{\phi, P}{ }_{M X}(T, P)\right\}$ from the set of Archer Model parameters $X_{j}^{E A}=\left\{\beta^{(0, E A)}{ }_{M X}(T, P), \beta^{(1, E A)}{ }_{M X}(T, P)\right.$, $\left.\beta^{(2, E A)}{ }_{M X}(T, P), C^{(0, E A)}{ }_{M X}(T, P), C^{(1, E A)}{ }_{M X}(T, P), C^{(2, E A)}{ }_{M X}(T, P)\right\}$ by first defining a measure $E^{2}\left(X_{i}^{P}\right.$, $\left.X_{j}^{E A}\right)$ of the cumulative square error $\left(\phi^{P}-\phi^{E A}\right)$ between the osmotic coefficient in the two models over the desired ionic strength range $\left(0, I_{\max }\right)$

$$
E^{2}\left(X_{i}^{P}, X_{j}^{E A}\right)=\frac{1}{2} \int_{0}^{I_{\max }}\left\{\phi^{P}\left(I, X_{i}^{P}\right)-\phi^{E A}\left(I, X_{j}^{E A}\right)\right\}^{2} d I
$$

The subsequent mathematical expressions can be simplified considerably, by recasting the difference between the errors in osmotic coefficient in terms of the differences in the model parameters as follows:

$$
\begin{aligned}
& \phi^{P}-\phi^{E A}=I \Delta \beta_{M X}^{(0)}+I e^{-\alpha_{1} I^{1 / 2}} \Delta \beta_{M X}^{(1)}+I e^{-\alpha_{2} I^{1 / 2}} \Delta \beta_{M X}^{(2)} \\
& +I^{2} \Delta C_{M X}^{(0)}-\left(\frac{4 v_{M}}{\left(v_{M}+v_{X}\right) \mid z_{M}}\right)\left\{I^{2} e^{-\varpi_{1} I^{1 / 2}} C_{M X}^{(1, E A)}+I^{2} e^{-\varpi_{2} I^{1 / 2}} C_{M X}^{(2, E A)}\right\}
\end{aligned}
$$

where,

$$
\begin{gathered}
\Delta X_{1} \equiv \Delta \beta_{M X}^{(0)} \equiv \beta_{M X}^{(0, p)}-\beta_{M X}^{(0, E A)} \\
\Delta X_{2} \equiv \Delta \beta_{M X}^{(1)} \equiv \beta_{M X}^{(1, p)}-\beta_{M X}^{(1, E A)}
\end{gathered}
$$




$$
\begin{gathered}
\Delta X_{3} \equiv \Delta \beta_{M X}^{(2)} \equiv \beta_{M X}^{(2, p)}-\beta_{M X}^{(2, E A)} \\
\Delta X_{4} \equiv \Delta C_{M X}^{(0)} \equiv\left(\frac{2\left(v_{M} v_{X}\right)^{1 / 2}}{\left(v_{M}+v_{X}\right)\left|z_{M} z_{X}\right|}\right) C_{M X}^{(\phi, P)}-\left(\frac{4 v_{M}}{\left(v_{M}+v_{X}\right)\left|z_{X}\right|}\right) C_{M X}^{(0, E A)}
\end{gathered}
$$

The error measure $E$ is now minimized by setting the partial derivatives of $E$ with respect to the unknown parameter differences $\Delta X_{i}$ equal to zero

$$
\frac{\partial E^{2}}{\partial \Delta X_{i}}=\int_{0}^{I_{\max }} \frac{\partial\left(\phi^{P}-\phi^{E A}\right)}{\partial \Delta X_{i}}\left(\phi^{P}-\phi^{E A}\right) d I=0
$$

Substituting for the osmotic coefficient error from Equation I-104 in Equation I-109, and re-arranging the terms, yields the matrix equation

$$
\left[A_{i k}\right]\left(\Delta X_{k}\right)=\left(B_{i}\right) \quad ; \quad i, k=1 \ldots 4
$$

where,

$$
\begin{gathered}
A_{i k} \equiv \int_{0}^{I_{\max }} \frac{\partial\left(\phi^{P}-\phi^{E A}\right)}{\partial \Delta X_{i}} \frac{\partial\left(\phi^{P}-\phi^{E A}\right)}{\partial \Delta X_{k}} d I \\
B_{i} \equiv\left(\frac{4 v_{M}}{\left(v_{M}+v_{X}\right)\left|z_{X}\right|}\right) \int_{0}^{I_{\max }} \frac{\partial\left(\phi^{P}-\phi^{E A}\right)}{\partial \Delta X_{i}}\left\{I^{2} \cdot e^{-\omega_{1} I^{1 / 2}} C_{M X}^{(1, E A)}+I 2 \cdot e^{-\omega_{2} I^{1 / 2}} C_{M X}^{(2, E A)}\right\} d I
\end{gathered}
$$

and,

$$
\frac{\partial\left(\phi^{P}-\phi^{E A}\right)}{\partial \Delta X_{i}}=\left\{I, I e^{-\alpha_{1} I^{1 / 2}}, I e^{-\alpha_{2} I^{1 / 2}}, I^{2}\right\}
$$

The integrals in the definitions I-111 and 112 above can be evaluated in closed form as analytical expressions and are given in the paper by Rard and Wijesinghe (2003 [DIRS 162327]). The matrix equation I-110 can be solved by standard matrix equation solution methods for the unknown parameter differences $\Delta X_{i}$. The unknown Standard Pitzer Model parameters can then be evaluated using these parameter differences and the known Archer Model parameters from Equations I-105-108 recast as follows:

$$
\begin{aligned}
& \beta_{M X}^{(0, P)}=\Delta X_{1}+\beta_{M X}^{(0, E A)}=\Delta \beta_{M X}^{(0)}+\beta_{M X}^{(0, E A)} \\
& \beta_{M X}^{(1, P)}=\Delta X_{2}+\beta_{M X}^{(1, E A)}=\Delta \beta_{M X}^{(1)}+\beta_{M X}^{(1, E A)}
\end{aligned}
$$




$$
\begin{gathered}
\beta_{M X}^{(2, P)}=\Delta X_{3}+\beta_{M X}^{(2, E A)}=\Delta \beta_{M X}^{(2)}+\beta_{M X}^{(2, E A)} \\
C_{M X}^{(\phi, P)}=\left(\frac{\left(v_{M}+v_{X}\left|z_{M} z_{X}\right|\right.}{2\left(v_{M} v_{X}\right)^{1 / 2}}\right)\left(\Delta X 4+\left(\frac{4 v_{M}}{\left(v_{M}+v_{X}\right)\left|z_{X}\right|}\right) C_{M X}^{(0, E A)}\right) \\
=\left(\frac{v_{M}+v_{X}\left|z_{M} z_{X}\right|}{2\left(v_{M} v_{X}\right)^{1 / 2}}\right)\left(\Delta C_{M X}^{(0)}+\left(\frac{4 v_{M}}{\left(v_{M}+v_{X}\right)\left|z_{X}\right|}\right) C_{M X}^{(0, E A)}\right)
\end{gathered}
$$

This mathematical procedure has been implemented in the ConPitzerNC worksheet of each ConPitzerNC workbook, to determine the Standard Pitzer Model parameters from the Archer Model Parameters at each temperature and pressure. The Pitzer parameter values at each temperature determined in this way are then used by the FitPitzerNC worksheet in each ConPitzerNC workbook to fit new temperature functions and determine the corresponding temperature coefficients.

\section{I.4.3.2 ConPitzerNC Workbook Implementation}

The ConPitzerNC workbooks are designed to first compute the Standard Pitzer Model parameters from Archer Model parameters in a ConPitzerNC type worksheet and then fit new temperature functions to these values using a FitPitzerNC type worksheet. The FitPitzerNC worksheet methodology and implementation are the same as that described in Section I-3, and will not be discussed further in this Section. The only user specifiable parameters in the ConPitzerNC worksheets are the values IDmax and DImax used to specify the method of imposing the upper limit $I_{\max }$ of the range of ionic strength over which the parameter conversion between models is valid. They are used together to implement three different options, as follows:

1. IDmax $=1$ Maximum Ionic Strength Limit $I_{\max }=$ DImax, a user assigned value

2. IDmax $=2$ Maximum Ionic Strength Limit $I_{\max }=$ Solubility Limit as a function of temperature

3. IDmax $=3$ Maximum Ionic Strength Limit $I_{\max }=$ Smaller of (DImax, Solubility Limit).

\section{I.4.3.3 Example Calculation for ConPitzerNC_MX_CaCl2.xls Workbook}

For the purpose of illustrating the specific manner in which these calculations are carried out, the sequence of calculations performed in the ConPitzerNC_MX_CaCl2.xls workbook are presented below:

1. CoverPage worksheet: On this worksheet, software identification information and spreadsheet checker review comments are first presented. Next, spreadsheet user information on a contents roadmap, an overview of methodology and data sources, protection of data and computational integrity and manner of presentation of results, are given. 
2. Directions worksheet: This worksheet gives directions for converting parameters from Archer to Standard Pitzer Models and fitting different temperature functions selected by the user to the converted parameters.

3. RunSettings worksheet: Select the desired temperature basis functions.

4. RunSettings worksheet: Select, if desired, Temperature centering and Reference Temperature.

5. RunSettings worksheet: Select Maximum Ionic Strength Option and Maximum Ionic Strength Cut-off Value.

6. ConPitzerNC worksheet: Constant input (Archer) and output (Standard Pitzer) model parameters are defined in lines B13:L13 and B14:L14.

7. ConPitzerNC worksheet: The input Archer model temperature coefficients are set in cells B17:I21 and for the Aphi Debye-Huckel parameter in cells B22:I22.

8. ConPitzerNC worksheet: The input Archer parameters and the Aphi Debye-Huckel parameter are calculated as functions of temperature in cells B32:AB37.

9. ConPitzerNC worksheet: Solubilities as a function of temperature are defined on lines B37:AB37 (molality) and B38:AB38 (ionic strength).

10. ConPitzerNC worksheet: Maximum Ionic Strength is calculated as a function of temperature according to the selected option in cells B81:AB81.

11. ConPitzerNC worksheet: The least-squares coefficient matrix A is calculated at each temperature in cells B87:AB95.

12. ConPitzerNC worksheet: The right-hand side vector B is calculated at each temperature in cells B96:AB98.

13. ConPitzerNC worksheet: The matrix equation solution is carried out at each temperature in cells B99:AB105 and the final solution for parameter differences is calculated in cells B106:AB108.

14. ConPitzerNC worksheet: The Standard Pitzer Model parameters are calculated from the parameter differences obtained in Step 11, and entered in cells B42:AB45.

15. ConPitzerNC worksheet: The osmotic coefficient is calculated for the Archer Model in cells B54:AB59 as a function of temperature and ionic strength.

16. ConPitzerNC worksheet: The osmotic coefficient is calculated for the Standard Pitzer Model in cells B62:AB67 as a function of temperature and ionic strength. 
17. ConPitzerNC worksheet: The model conversion error in the osmotic coefficient is calculated as the difference between the osmotic coefficients from the Standard Pitzer and Archer Models in cells B71:AB76 as a function of temperature and ionic strength.

18. The RMS error (cells AC71:AC76) and the Average, Maximum and Minimum values of the osmotic coefficient are also calculated for the two models in cells AD54:AF59 and AD62:AF67, respectively.

19. ConPitzerNC worksheet: Pitzer parameters, osmotic coefficients and their errors, calculated from the two models, are plotted in charts on the extreme right hand side of each ConPitzerNC worksheet.

20. FitPitzerNC worksheet: Standard Pitzer Model parameters are accessed from cells B42:AB45 and are used to fit the temperature coefficients displayed in cells B25:I28. The implementation is the same as previously described in Section I-3.

21. FitPitzerNC worksheet: Pitzer parameters, osmotic coefficients and their errors, calculated from the input Standard Pitzer Model parameters and the temperature functions fitted to the same model, are plotted in charts on the extreme right hand side of the FitPitzerNC worksheet of the ConPitzerNC workbook.

22. ResultsSummary worksheet: The fitted temperature coefficients for the Standard Pitzer Model are summarized in cells B25:I28.

23. ResultsSummary worksheet: The RMS errors, Average, Maximum and Minimum values of the osmotic coefficients calculated from the output Standard Pitzer Model and the input Archer Model are summarized here separately for the model conversion and temperature function steps. These statistics enable the errors incurred in the model conversion and temperature function fitting steps to be separately assessed.

The testing and validation of the Pitzer parameters involves the comparison of computed osmotic coefficients from the binary (MX), and ternary (MMX, MXX) spreadsheets with the predictions obtained between different Pitzer models reported in the literature sources in order to examine the accuracy of the conversion. This process also includes evaluation of the accuracy of temperature functions of the refitted parameters. Pitzer parameters obtained through the refitting of reported values will be discussed individually in the following section. Parameters obtained for $25{ }^{\circ} \mathrm{C}$ only will be summarized in a single section since those did not require refitting.

\section{I.4.4 BINARY PITZER INTERACTION PARAMETERS}

In this section, the selected Pitzer ion interaction parameters for major salt constituents included in the data0.ypf database will be described. All these parameters and associated spreadsheets are listed in Tables I-1 and I-2 as Type MX. The discussions on the compilation of parameter data are focused on those that needed refitting due to their temperature dependence. Many parameters did not require any refitting since the gathered values are only valid at $25^{\circ} \mathrm{C}$. For these, only simple conversions were necessary. 
The user is advised of the limited ranges listed in Table I-1 for several Pitzer parameters. The user must consult the original sources for more information on the permissible physico-chemical conditions for which the parameters are valid. Use of these parameters outside their respective ranges of validation is inadvisable and is not permitted for applications on the Yucca Mountain Project unless specific justification is provided.

\section{I.4.4.1 Ions: $\mathrm{Ca}^{2+}-\mathrm{Cl}^{-}$}

Associated Spreadsheet: ConPitzerNC_MX_CaCl2.xls

Source: Sterner et al. 1998 [DIRS 162116].

Description: Input parameters and equations from Sterner et al. (1998 [DIRS 162116], Model 2 in Table II and Table I) in the ConPitzerNC model parameter conversion worksheet were verified for $\beta_{M X}^{(0)}, \beta_{M X}^{(1)}, \beta_{M X}^{(2)}, C_{M X}^{(0)}, C_{M X}^{(1)}$ (termed $\operatorname{Beta}(0)$, $\operatorname{Beta}(1)$, $\operatorname{Beta}(2), \mathrm{C}(0)$, and $\mathrm{C}(1)$, respectively, in the spreadsheets) input parameters from the approach of Archer (2000 [DIRS 162065]). Sterner et al. (1998 [DIRS 162116]) did not report tabulated values of the osmotic coefficients calculated using their 4-parameter Archer-type model. A visual comparison of the values computed using their model in the ConPitzerNC worksheet against the plotted values in Figure 2 of Sterner et al. (1998 [DIRS 162116]) indicates general agreement. The standard Pitzer model parameters $\beta_{M X}^{(0)}, \beta_{M X}^{(1)}$, and $C^{\phi}$ were determined from the Archer model parameters using the methodology presented by Rard and Wijesinghe (2003 [DIRS 162327]). The temperature coefficients for the standard form of Pitzer parameters $\beta_{M X}^{(0)}, \beta_{M X}^{(1)}$, and $C^{\phi}$ are calculated in the FitPitzerNC worksheet using the parameter values computed as a function of temperature in the ConPitzerNC worksheet. Comparison of the osmotic coefficient calculated using these temperature coefficients with the input values from the ConPitzerNC worksheet confirms the accuracy of the temperature coefficient fits. The temperature coefficient fitting errors are acceptable for this database and negligible compared to the model parameter conversion errors that result from constraining the output model to three parameters instead of the four parameters of the source model. It should be noted that the Sterner et al. model was claimed to be valid from 25 to $250{ }^{\circ} \mathrm{C}$. Because of the considerable range of ionic strengths being fitted here $(\mathrm{I}=0-45 \mathrm{~mol} / \mathrm{kg})$, the 3-parameter standard Pitzer model is less accurate than for many other systems. However, the present converted model should yield more accurate solubility predictions than the model presented for $\mathrm{CaCl}_{2}$ by Greenberg and Møller (1989 [DIRS 152684]), which had not been developed for such high ionic strengths. Table I-4 compares the current model's 3 to 4 term osmotic coefficients to experimental results from Robinson and Stokes (1965 [DIRS 108567]) at $25^{\circ} \mathrm{C}$. There is a notable deviation (10.5\%) in the mid-ionic strength range $(9 \mathrm{~mol} / \mathrm{kg})$, which is acceptable given the large range being fitted as indicated previously. 
Table I-4. Comparison of Osmotic Coefficients $(\phi)$ from the 3 to 4 Term Fit to Those Measured for $\mathrm{CaCl}_{2}$ at $25^{\circ} \mathrm{C}$

\begin{tabular}{|c|c|c|c|}
\hline Molality of $\mathrm{CaCl}_{\mathbf{2}}$ & 3-4 Term Fit & Measurements & Difference (\%) \\
\hline 1.0 & 1.052 & 1.046 & 0.6 \\
\hline 3.0 & 1.964 & 1.779 & 10.5 \\
\hline 6.0 & 2.847 & 2.891 & 1.5 \\
\hline 8.0 & 3.114 & 3.151 & 1.2 \\
\hline 10.0 & 3.123 & 3.169 & 1.5 \\
\hline
\end{tabular}

NOTE: Measurements taken from Robinson and Stokes 1965 [DIRS 108567, Appendix 8.5, Table 1, p. 478.

\section{I.4.4.2 Ions: $\mathrm{Ca}^{2+}-\mathrm{NO}_{3}^{-}$}

\section{Associated Spreadsheet: ConPitzerNC_MX_Ca(NO3)2.xls}

Source: Rard and Wijesinghe 2003 [DIRS 162327]; Oakes et al. 2000 [DIRS 162102].

Description: Input parameters and equations from Oakes et al. (2000 [DIRS 162102], Table 4 and Equation 49) in the ConPitzerNC model parameter conversion worksheet were verified for $\beta_{M X}^{(0)}, \beta_{M X}^{(1)}, C_{M X}^{(0)}, C_{M X}^{(1)}$, and $C_{M X}^{(2)}$ input parameters (termed $\operatorname{Beta}(0), \operatorname{Beta}(1), \mathrm{C}(0), \mathrm{C}(1)$ and $\mathrm{C}(2)$, respectively in the spreadsheet). The osmotic coefficients from the Oakes et al. (2000 [DIRS 162102]) model parameters calculated at selected temperatures and molalities in the worksheet agreed exactly with the values given by Oakes et al. (2000 [DIRS 162102], Table 5), except for occasional differences of 0.001 related to rounding errors. The standard Pitzer model parameters $\beta_{M X}^{(0)}, \beta_{M X}^{(1)}$, and $C^{\phi}$ were determined from the Oakes et al. (2000 [DIRS 162102]) model parameters using the methodology presented by Rard and Wijesinghe (2003 [DIRS 162327]). The standard Pitzer model parameters calculated in this manner from the Oakes et al. (2000 [DIRS 162102]) parameters were verified by comparing the standard Pitzer model parameters calculated in the ConPitzerNC worksheet against the values given by Rard and Wijesinghe (2003 [DIRS 162327]). The osmotic coefficients calculated in the ConPitzerNC worksheet also agree with the plots of osmotic coefficients given by Rard and Wijesinghe (2003 [DIRS 162327]). The two verification methods by Rard and Wijesinghe (2003 [DIRS 162327]) explained in the previous section also apply in this case.

The temperature coefficients for the standard Pitzer parameters $\beta_{M X}^{(0)}, \beta_{M X}^{(1)}$, and $C^{\phi}$ are calculated in the FitPitzerNC worksheet using the parameter values computed as a function of temperature in the ConPitzerNC worksheet. Comparison of the osmotic coefficient calculated using these temperature coefficients with the input values from both the ConPitzerNC worksheet and the values fitted from Oakes et al. (2000 [DIRS 162102]). Model values in the ConPitzerNC worksheet, confirm the accuracy of the temperature coefficient fits. On average, the temperature coefficient fitting errors are a factor of 10 smaller than the model parameter conversion errors that result from constraining the output model to three parameters instead of the five parameters in the source model. In both ConPitzerNC and FitPitzerNC worksheets, the parameters are evaluated at $5{ }^{\circ} \mathrm{C}$ intervals, whereas in the paper by Rard and Wijesinghe (2003 [DIRS 162327]) parameter values were given at only seven selected temperatures. The fine temperature grid in the FitPitzerNC worksheet yields sufficiently accurate fits for the temperature coefficients. It 
should be noted that the original Oakes et al. model (2000 [DIRS 162102]) was claimed to be valid from 25 to $100^{\circ} \mathrm{C}$, so that the results presented in this spreadsheet outside this temperature range represent extrapolations beyond the confirmed range of validity. The fitting errors demonstrate the acceptability of these coefficients for this database.

\section{I.4.4.3 Ions: $\mathrm{Cs}^{+}-\mathrm{Cl}^{-}$}

\section{Associated Spreadsheet: FitPitzerNC_MX_CsCl.xls}

Source: Holmes and Mesmer 1983 [DIRS 162073]; cited 114 times by 3/2003.

Description: Input parameters and equations from Holmes and Mesmer (1983 [DIRS 162073], Table $\mathrm{V}$ and Equation 25) were verified for $\beta_{M X}^{(0)}, \beta_{M X}^{(1)}$, and $C^{\phi}$. Calculated values of the osmotic coefficient from this spreadsheet were compared with those listed in a supplement to the data source paper by Holmes and Mesmer (1983 [DIRS 162073], Supplementary Material). There was nearly exact agreement with values calculated in this spreadsheet, with a maximum difference of less than 0.001 over the full range of molality and temperature given in the spreadsheet. This agreement is a confirmation of the validity of the osmotic coefficient calculations reported in this spreadsheet. Additionally, Table I-5 contains a comparison of osmotic coefficients from the 3 to 4 term fitting to experimental results (Robinson and Stokes 1965 [DIRS 108567], Appendix 8.10, Table 3, p 485), with excellent agreement achieved $(\leq 0.5 \%$ difference $)$.

Table I-5. Comparison of Osmotic Coefficients $(\phi)$ from the 3-4 Term Fit to Those Measured for CsCl at $25^{\circ} \mathrm{C}$

\begin{tabular}{|c|c|c|c|}
\hline Molality of CsCl & 3-4 Term Fit & Measurements & Difference (\%) \\
\hline 0.1 & 0.916 & 0.917 & 0.1 \\
\hline 0.5 & 0.872 & 0.869 & 0.3 \\
\hline 1.0 & 0.861 & 0.857 & 0.5 \\
\hline 3.0 & 0.881 & 0.880 & 0.1 \\
\hline 6.0 & 0.950 & 0.945 & 0.5 \\
\hline
\end{tabular}

NOTE: $\quad$ Measurements taken from Robinson and Stokes 1965 [DIRS 108567, Appendix 8.10, Table 3, p. 485.

\section{I.4.4.4 Ions: $\mathrm{H}^{+}-\mathrm{Cl}^{-}$}

Associated Spreadsheet: FitPitzerNC_MX_HCl.xls

Source: Holmes et al. 1987 [DIRS 162075]; cited 65 times by 3/2003.

Description: Input parameters and equation from Holmes et al. (1987 [DIRS 162075], Table 3 [first column] and Equation 31) were verified for $\beta_{M X}^{(0)}, \beta_{M X}^{(1)}, C^{\phi}$, and $A^{\phi}$. The RMS error in the osmotic coefficient over the fitted temperature range (see spreadsheet tab "Results Summary") for the 3-4 term conversion was $>0.001$. Calculated values of the osmotic coefficient from this spreadsheet were compared with those listed at $25^{\circ} \mathrm{C}$ in the extensive tables from Robinson and Stokes (1965 [DIRS 108567], Table 1, Appendix 8.10, p. 483). There was very good agreement with the spreadsheet values at $25^{\circ} \mathrm{C}$ as shown in Table I-6, with a 
maximum difference of 0.006 at $\mathrm{I}=3 \mathrm{~mol} / \mathrm{kg}$. Model $\mathrm{I}$ in Holmes et al. (1987 [DIRS 162075], Table 3 and text p. 876) is stated to be valid up to an ionic strength of $7.0 \mathrm{~mol} / \mathrm{kg}$. This agreement is considered to be sufficient confirmation of the validity of the osmotic coefficient calculations reported in the spreadsheet.

Table I-6. Comparison of Osmotic Coefficients $(\phi)$ from the 3- to 4 Term Fit to Those Measured for $\mathrm{HCl}$ at $25^{\circ} \mathrm{C}$

\begin{tabular}{|c|c|c|c|}
\hline Molality of HCl & 3-4 Term Fit & Measurements & Difference (\%) \\
\hline 0.1 & 0.944 & 0.943 & 0.1 \\
\hline 0.5 & 0.974 & 0.974 & $<0.1$ \\
\hline 1.0 & 1.039 & 1.039 & $<0.1$ \\
\hline 3.0 & 1.342 & 1.348 & 0.4 \\
\hline 6.0 & 1.844 & 1.845 & $<0.1$ \\
\hline
\end{tabular}

NOTE: $\quad$ Measurements taken from Robinson and Stokes 1965 [DIRS 108567], Appendix 8.10, Table 1, p. 483.

\section{I.4.4.5 Ions: $\mathrm{H}^{+}-\mathrm{HSO}_{4}^{-}$}

Associated Spreadsheet: FitPitzerNC_MX_HHSO4.xls

Source: Holmes and Mesmer 1994 [DIRS 162078].

Description: Input parameters and equation from Holmes and Mesmer (1994 [DIRS 162078], Table 4 and Equation 28) were verified for $\beta_{M X}^{(0)}, \beta_{M X}^{(1)}$, and $C^{\phi}$. Note that there is an error in Table 4 of the source document (Holmes and Mesmer 1994 [DIRS 162078]); it gives incorrect p1 parameter values that are too large by a factor of 1000. Calculated values of the hypothetical fully dissociated binary osmotic coefficient from this spreadsheet cannot be compared with any experimental values because experimentally determined values include the effects of partial dissociation into $\mathrm{H}^{+}, \mathrm{HSO}_{4}{ }^{-}$and $\mathrm{SO}_{4}{ }^{2-}$ ions rather than $\mathrm{H}^{+}$and $\mathrm{HSO}_{4}{ }^{-}$ions only. However, the values of the calculated osmotic coefficient are reasonable for a fully dissociated 1-1 electrolyte, except at the highest ionic strengths where the source parameters are not constrained by experimental measurements and are larger than expected for an electrolyte of this charge type. The binary parameters for $\mathrm{H}^{+}$and $\mathrm{HSO}_{4}^{-}$should only be used in combination with the $\mathrm{H}^{+}$and $\mathrm{SO}_{4}{ }^{2-}$ parameters and the mixing parameters $(\theta, \psi=0)$ should be taken from the same source document. It should also be noted that the higher order electrostatic interactions represented by the ${ }^{\mathrm{E}} \theta$ and ${ }^{\mathrm{E}} \theta^{\prime}$ third order terms of the Pitzer model were taken into account in this source document. In an earlier paper (Holmes and Mesmer 1992 [DIRS 162076]) the authors did not account for these interactions. Holmes and Mesmer (1994 [DIRS 162078]) demonstrate that their new fits result in calculations that agree well with the experimental measurements over a range of conditions that include different degrees of dissociation of $\mathrm{HSO}_{4}{ }^{-}$. In fact they found that the earlier models also result in acceptable fits. 


\section{I.4.4.6 Ions: $\mathrm{H}^{+}-\mathrm{SO}_{4}{ }^{2-}$}

\section{Associated Spreadsheet: FitPitzerNC_MX_H2SO4.xls}

Source: Holmes and Mesmer 1994 [DIRS 162078].

Description: Input parameters and equation from Holmes and Mesmer (1994 [DIRS 162078], Table 4 and Equation 28) were verified for $\beta_{M X}^{(0)}, \beta_{M X}^{(1)}$, and $C^{\phi}$. Calculated values of the hypothetical fully dissociated binary osmotic coefficient from this spreadsheet cannot be compared with any experimental values because experimentally determined values include the effects of partial dissociation into $\mathrm{H}^{+}, \mathrm{HSO}_{4}{ }^{-}$and $\mathrm{SO}_{4}{ }^{2-}$ ions rather than $\mathrm{H}^{+}$and $\mathrm{SO}_{4}{ }^{2-}$ ions only. However, the values of the calculated osmotic coefficient are reasonable for a fully dissociated 1-2 electrolyte, except at the highest ionic strengths where the source parameters are not constrained by experimental measurements and are unrealistically large. The binary parameters for $\mathrm{H}^{+}$and $\mathrm{SO}_{4}{ }^{2-}$ should only be used in combination with the $\mathrm{H}^{+}$and $\mathrm{HSO}_{4}{ }^{-}$parameters and the mixing parameters $(\theta, \psi=0)$ should be taken from the same source document. In addition, several values of $C^{\phi}$ were independently calculated using the input source data and underlying equations, and exact agreement was obtained with the values calculated in the spreadsheet. It should also be noted that the higher order electrostatic interactions represented by the ${ }^{\mathrm{E}} \theta$ and ${ }^{\mathrm{E}} \theta^{\prime}$ third order terms of the Pitzer model were taken into account in this source document. In an earlier paper (Holmes and Mesmer 1992 [DIRS 162076]) the authors did not account for these interactions. Holmes and Mesmer (1994 [DIRS 162078]) demonstrate that their new fits result in calculations that agree well with the experimental measurements over a range of conditions that include different degrees of dissociation of $\mathrm{HSO}_{4}{ }^{-}$. In fact they found that the earlier models also result in acceptable fits.

\section{I.4.4.7 Ions: $\mathrm{H}^{+}-\mathrm{NO}_{3}^{-}$ \\ Associated Spreadsheet: FitPitzerNC_MX_H_NO3_CFJC.xls}

Source: Felmy et al. 1994 [DIRS 162111] and Clegg and Brimblecombe 1990 [DIRS 162067]; cited 47 times by $3 / 2003$.

Description: The binary parameters $\beta_{M X}^{(0)}, \beta_{M X}^{(1)}$, and $C^{\phi}$ listed by Clegg and Brimblecombe (1990 [DIRS 162067], Table X) at $298.15 \mathrm{~K}$ were confirmed against the values generated with the coefficients reported by Felmy et al. (1994 [DIRS 162111], Table 1 with Equation 2), who used the former source for derivation of Pitzer temperature-dependent parameter data. Unlike the previous FitPitzerNC spreadsheets, the binary parameters were refitted using the standard regression function in MS Excel. The reproducibility of the refitted binary parameters when compared with those tabulated from Clegg and Brimblecombe (1990 [DIRS 162067], Table 10, p. 5378) at $298.15 \mathrm{~K}$ was identical. Visual comparison of mean activity and rational osmotic coefficients (Clegg and Brimblecombe 1990 [DIRS 162067], Figures 1 and 9) calculated using these binary parameters indicate a strong agreement with those given by Clegg and Brimblecombe (1990 [DIRS 162067]) up to an $\mathrm{HNO}_{3}$ concentration of $\sim 6$ molal. These favorable comparisons demonstrate the acceptability of these coefficients for this database. The Clegg and Brimblecombe model (1990 [DIRS 162067]) is mole fraction based, and these authors 
suggested this upper concentration value for the binary parameters they report for the Pitzer model that is molality-based.

\section{I.4.4.8 Ions: $\mathrm{K}^{+}-\mathrm{Br}^{-}$}

Associated Spreadsheet: FitPitzerNC_MX_KBr.xls

Source: Holmes and Mesmer 1998 [DIRS 162083].

Description: Input parameters and equation from Holmes and Mesmer (1998 [DIRS 162083], Table 4 and Equation 14) were verified for $\beta_{M X}^{(0)}, \beta_{M X}^{(1)}$, and $C^{\phi}$. The RMS error in the osmotic coefficient over the fitted temperature range (see spreadsheet tab "Results Summary") from the 3-4 term conversion is typically $\sim 0.001$, except at higher ionic strengths where the deviation becomes 0.005 and 0.026 at $\mathrm{I}=3$ and $6 \mathrm{~mol} / \mathrm{kg}$, respectively. Values of the osmotic coefficient calculated using the source equation were compared with experimental values listed at $25^{\circ} \mathrm{C}$ in Robinson and Stokes (1965 [DIRS 108567], Appendix 8.10, Table 2, p. 484) and at $200^{\circ} \mathrm{C}$ in the source document (Holmes and Mesmer 1998 [DIRS 162083], Table 1, p. 728). Results of the comparison at $25^{\circ} \mathrm{C}$ are shown in Table I-7; there was good agreement with the $3-4$ term values calculated in this spreadsheet, with a maximum difference of 0.005 at $\mathrm{I}=3.0 \mathrm{~mol} / \mathrm{kg}$. Good agreement is also obtained at $200{ }^{\circ} \mathrm{C}$ up to high ionic strengths, e.g. at $\mathrm{I}=6.097 \mathrm{~mol} / \mathrm{kg}$ $\phi=1.0264$, while in Holmes and Mesmer (1998 [DIRS 162083], Table 1 p. 728) at I=6 mol/kg the value of $\phi=1.0258$. It should be noted that there are two errors in Equation 14 of Holmes and Mesmer (1998 [DIRS 162083], p. 734) in the functional form of the temperature function, and in the reference temperature $T_{\mathrm{r}}$ that was incorrectly reported as $413.15 \mathrm{~K}$ instead of 298.15 $\mathrm{K}$. The correct version of this equation is given in the spreadsheet cover page and it is equivalent to the equation as first derived by Holmes and Mesmer (1983 [DIRS 162073], Equation 25).

Table 1-7. Comparison of Osmotic Coefficients $(\phi)$ from the 3-4 Term Fit to Those Measured for $\mathrm{KBr}$ at $25^{\circ} \mathrm{C}$

\begin{tabular}{|c|c|c|c|}
\hline Molality of $\mathrm{KBr}$ & 3-4 Term Fit & Measurements & Difference (\%) \\
\hline 0.1 & 0.928 & 0.928 & 0.0 \\
\hline 0.5 & 0.905 & 0.904 & 0.1 \\
\hline 1.0 & 0.907 & 0.907 & $<0.0$ \\
\hline 3.0 & 0.960 & 0.955 & 0.5 \\
\hline
\end{tabular}

NOTE: $\quad$ Measurements taken from Robinson and Stokes 1965 [DIRS 108567], Appendix 8.10, Table 2, p. 484.

\section{I.4.4.9 Ions: $\mathrm{K}^{+}-\mathrm{Cl}^{-}$}

\section{Associated Spreadsheet: FitPitzerNC_MX_KCl.xls}

Source: Greenberg and Møller 1989 [DIRS 152684]; cited 51 times as of 3/2003.

Description: Input parameters and equation from Greenberg and Møller (1989 [DIRS 152684], Table 1 and 3, and Equation 3) were verified for $\beta_{M X}^{(0)}, \beta_{M X}^{(1)}, C^{\phi}$, and $A^{\phi}$. The RMS error in the osmotic coefficient over the fitted temperature range (see spreadsheet tab "Results Summary") for source to 3-4 term conversion was $\Delta \phi<0.001$. In addition, several values of $\beta_{M X}^{(0)}$ were 
independently calculated using the input source data and underlying equations, and exact agreement was obtained with the values calculated in the spreadsheet. Calculated values of the osmotic coefficient from this spreadsheet were compared with those from the recent critical review of Archer (1999 [DIRS 162064], Table 7). There was good agreement with values calculated in this spreadsheet, with a maximum difference of 0.006 , but with much better agreement at most temperatures and molalities. Direct comparison at 25 and $100^{\circ} \mathrm{C}$ is shown in Table I-8 below. These minor differences most likely arise from the differences in the underlying data sources. This agreement is considered to be sufficient confirmation of the validity of the osmotic coefficient calculations reported in this spreadsheet.

Table I-8. Comparison of Osmotic Coefficients $(\phi)$ Values from the 3-4 Term Fit to Those Measured for $\mathrm{KCl}$ at 25 and $100^{\circ} \mathrm{C}$

\begin{tabular}{|c|c|c|c|}
\hline \multicolumn{5}{|c|}{$\mathbf{2 5}^{\circ} \mathbf{C}$} \\
\hline Molality of $\mathbf{~ C l}$ & 3-4 Term Fit & Measurements & Difference (\%) \\
\hline 0.1 & 0.926 & 0.9261 & $<0.1$ \\
\hline 0.5 & 0.900 & 0.9000 & 0.1 \\
\hline 1.0 & 0.898 & 0.8992 & 0.1 \\
\hline \multicolumn{7}{|c|}{$\mathbf{1 0 0 ^ { \circ } \mathbf { C }}$} \\
\hline 0.1 & 0.918 & 0.9168 & 0.1 \\
\hline 0.5 & 0.895 & 0.8939 & 0.1 \\
\hline 1.0 & 0.899 & 0.8984 & 0.1 \\
\hline 6.0 & 1.032 & 1.0341 & 0.2 \\
\hline
\end{tabular}

NOTE: $\quad$ Measurements taken from Archer 1999 [DIRS 162064], Table 7.

\section{I.4.4.10 Ions: $\mathrm{K}^{+}-\mathrm{SO}_{4}{ }^{2-}$}

Associated Spreadsheet: FitPitzerNC_MX_K2SO4.xls

Source: Greenberg and Møller 1989 [DIRS 152684]; cited 51 times as of 3/2003.

Description: Input parameters and equation from Greenberg and Møller (1989 [DIRS 152684], Tables 1 and 3, and Equation 3) were verified for $\beta_{M X}^{(0)}, \beta_{M X}^{(1)}, C^{\phi}$, and $A^{\phi}$. The RMS error in the osmotic coefficient over the fitted temperature range (see spreadsheet tab "Results Summary") for the 3-4 term fitting conversion was very negligible $\left(<10^{-10}\right)$. In addition, several values of $\beta_{M X}^{(0)}, \beta_{M X}^{(1)}$, and $C^{\phi}$ were independently calculated using the input source data and underlying equations, and exact agreement was obtained with the values calculated in the spreadsheet. In Table I-9 below, calculated values of the osmotic coefficient from this spreadsheet were compared with those listed in Holmes and Mesmer (1986 [DIRS 162074], Table V; cited 55 times as of 3/2003). There was reasonable agreement of the values reported in this paper with values calculated in the spreadsheet (differences in osmotic coefficient, $\Delta \phi \leq 0.02)$, except at $200{ }^{\circ} \mathrm{C}$ where the error was relatively high $\left(\Delta \phi_{\max }=0.11\right)$. Because the available data do not extend beyond $\mathrm{I}=2 \mathrm{~mol} / \mathrm{kg}$ at low temperatures and $\mathrm{I}=7 \mathrm{~mol} / \mathrm{kg}$ at high temperatures, and due to solubility limitations, the values calculated in this spreadsheet at the higher ionic strengths are not physically relevant. The agreement at lower ionic strengths and 
temperatures is confirmation of the validity of the osmotic coefficient calculations reported in this spreadsheet.

Table 1-9. Comparison of Osmotic Coefficients $(\phi)$ Values from the 3-4 Term Fit to Those Measured for $\mathrm{K}_{2} \mathrm{SO}_{4}$ at 25 and $150^{\circ} \mathrm{C}$.

\begin{tabular}{|c|c|c|c|}
\hline \multicolumn{5}{|c|}{$\mathbf{2 5 ^ { \circ } \mathbf { C }}$} \\
\hline Molality of $\mathbf{K}_{\mathbf{2}} \mathbf{S O}_{\mathbf{4}}$ & $\mathbf{3 - 4} \mathbf{T e r m} \mathbf{~ F i t}$ & Measurements & Difference (\%) \\
\hline 0.1 & 0.784 & 0.779 & 0.6 \\
\hline 0.5 & 0.686 & 0.690 & 0.6 \\
\hline 1.0 & 0.631 & 0.651 & 3.1 \\
\hline \multicolumn{4}{|c|}{$\mathbf{1 5 0 ^ { \circ } \mathbf { C }}$} \\
\hline 0.1 & 0.743 & 0.726 & 2.3 \\
\hline 1.0 & 0.652 & 0.646 & 1.2 \\
\hline
\end{tabular}

NOTE: Measurements taken from Holmes and Mesmer 1986 [DIRS 162074], Table V.

\section{I.4.4.11 Ions: $\mathrm{Cs}^{+}-\mathrm{Br}^{-}$}

Associated Spreadsheet: FitPitzerNC_MX_CsBr.xls

Source: Holmes and Mesmer 1998 [DIRS 162083].

Description: Input parameters and equations from Holmes and Mesmer (1998 [DIRS 162083], Table 4 and Equation 14) were verified for $\beta_{M X}^{(0)}, \beta_{M X}^{(1)}$, and $C^{\phi}$. The RMS fitting errors over the corresponding fitted temperatures between the Holmes and Mesmer (1998 [DIRS 162083]) Equation 14 and the spreadsheets 3-4 term fit were mostly $\Delta \phi<0.001$, with the exception at I $=6 \mathrm{~mol} / \mathrm{kg}$ where $\Delta \phi=0.0045$. Values of the osmotic coefficient calculated using the source equation were compared with experimental values listed in the source document at $200^{\circ} \mathrm{C}$ (Holmes and Mesmer 1998 [DIRS 162083], Table 1), and at $25^{\circ} \mathrm{C}$ against Robinson and Stokes (1965 [DIRS 108567], Appendix 8.10, Table 3, p. 485). At $25^{\circ} \mathrm{C}$, there was good agreement with values calculated in this spreadsheet, with a maximum difference of $\Delta \phi_{\max }=0.003$ at $\mathrm{I}=0.1$ $\mathrm{mol} / \mathrm{kg}$ as shown in Table $\mathrm{I}-10$. At $200^{\circ} \mathrm{C}$, good agreement is also obtained with $\Delta \phi=0.055$ at $\sim 6 \mathrm{~mol} / \mathrm{kg}$. It should be noted that there are two errors in Equation 14 of Holmes and Mesmer (1998 [DIRS 162083], p. 734): 1) an error in the formula of the temperature function; and 2) an error in the reference temperature $T_{\mathrm{r}}$, which was incorrectly reported as $413.15 \mathrm{~K}$ instead of $298.15 \mathrm{~K}$. The corrected version of this equation given on the spreadsheet cover page and is equivalent to the correct form of this equation as first derived by Holmes and Mesmer (1983 [DIRS 162073], Equation 25). 
Table I-10. Comparison of Source Osmotic Coefficients $(\phi)$ to Those Measured for $\mathrm{CsBr}$ at $25^{\circ} \mathrm{C}$

\begin{tabular}{|c|c|c|c|}
\hline Molality of CsBr & Source Equation & Measurements & Difference (\%) \\
\hline 0.1 & 0.914 & 0.917 & 0.3 \\
\hline 0.5 & 0.867 & 0.865 & 0.2 \\
\hline 1.0 & 0.852 & 0.850 & 0.2 \\
\hline 3.0 & 0.866 & 0.866 & 0.0 \\
\hline
\end{tabular}

NOTE: $\quad$ Measurements Taken from Robinson and Stokes 1965 [DIRS 108567], Appendix 8.10, Table 3, p. 485.

\section{I.4.4.12 Ions: $\mathrm{Li}^{+}-\mathrm{Br}^{-}$}

Associated Spreadsheet: FitPitzerNC_MX_LiBr.xls

Source: Holmes and Mesmer 1998 [DIRS 162083].

Description: Input parameters and equations from Table 4 (p. 737) and Equation 14 (p. 734) of Holmes and Mesmer (1998 [DIRS 162083]) were verified for $\beta_{M X}^{(0)}, \beta_{M X}^{(1)}$, and $C^{\phi}$. The RMS error in the osmotic coefficient over the fitted temperature range (see spreadsheet tab "Results Summary") for the 3-4 term conversion is typically $\sim 0.001$, except towards higher ionic strengths, e.g. deviations approach 0.02 at $\mathrm{I}=6 \mathrm{~mol} / \mathrm{kg}$. Values of the osmotic coefficient calculated using the source equation were compared with experimental values listed in Holmes and Mesmer (1998 [DIRS 162083], Table 1, p. 728) at $200^{\circ} \mathrm{C}$ and at $25^{\circ} \mathrm{C}$ against Robinson and Stokes (1965 [DIRS 108567], Appendix 8.10, Table 3). For $25^{\circ} \mathrm{C}$ the comparison is shown in Table I-11; there was good agreement with values calculated in this spreadsheet, with a maximum difference of $\Delta \phi=0.007$ at $\mathrm{I}=3.0 \mathrm{~mol} / \mathrm{kg}$, increasing to $\Delta \phi=0.01$ at $\mathrm{I}=6.0 \mathrm{~mol} / \mathrm{kg}$. Good agreement is also obtained at $200 \mathrm{C}$, e.g. $\phi=1.146$ at 3.07 molality (Holmes and Mesmer 1998 [DIRS 162083], Table 1, p. 728) compared with $\phi=1.138$ from the source equation at exactly 3.0 molality. It should be noted that there is are two errors in Equation 14 of Holmes and Mesmer (1998 [DIRS 162083], p. 734) for the functional form of the temperature function, and an error in the reference temperature $T_{\mathrm{r}}$, which was incorrectly reported as $413.15 \mathrm{~K}$ instead of $298.15 \mathrm{~K}$. The correct version of this equation is given in the spreadsheet cover page and it is equivalent to the correct form of this equation as first derived by Holmes and Mesmer (1983 [DIRS 162073], Equation 25).

Table I-11. Comparison of Source Osmotic Coefficients $(\phi)$ to Those Measured for $\mathrm{LiBr}$ at $25^{\circ} \mathrm{C}$

\begin{tabular}{|c|c|c|c|}
\hline Molality of LiBr & Source Equation & Measurements & Difference (\%) \\
\hline 0.1 & 0.942 & 0.943 & 0.1 \\
\hline 0.5 & 0.972 & 0.970 & 0.2 \\
\hline 1.0 & 1.038 & 1.035 & 0.3 \\
\hline 3.0 & 1.373 & 1.364 & 0.7 \\
\hline 6.0 & 1.999 & 1.989 & 0.5 \\
\hline
\end{tabular}

NOTE: $\quad$ Measurements Taken from Robinson and Stokes 1965 [DIRS 108567], Appendix 8.10, Table 1, p. 483. 


\section{I.4.4.13 Ions: $\mathrm{Li}^{+}-\mathrm{Cl}^{-}$}

Associated Spreadsheet: FitPitzerNC_MX_LiCl.xls

Source: Holmes and Mesmer 1983 [DIRS 162073]; cited 114 times by 3/2003.

Description: Input parameters and equation from the source document were verified for $\beta_{M X}^{(0)}$, $\beta_{M X}^{(1)}$, and $C^{\phi}$ data from Holmes and Mesmer (1983 [DIRS 162073], Table V and Equation 25). Fitting errors between the source and spreadsheet 3-4 term equation were negligible and resulted in osmotic coefficient differences of $<10^{-5}$. Values of the osmotic coefficient at $\sim 1.0 \mathrm{~mol} / \mathrm{kg}$ calculated using the source equation (Holmes and Mesmer 1983 [DIRS 162073], Equation 25) were compared with experimental values listed in the source document (Table III) at $250^{\circ} \mathrm{C}$ at $\phi$ $=0.8292$ and 0.825 , respectively. For the comparison at $25^{\circ} \mathrm{C}$ against Robinson and Stokes (1965 [DIRS 108567], Appendix 8.10, Table 1, p. 483) there is good agreement with values calculated in this spreadsheet, with a maximum difference of $\Delta \phi=0.004$ at $\mathrm{I}=6.0 \mathrm{~mol} / \mathrm{kg}$ as shown in Table I-12 below.

Table I-12. Comparison of Source Osmotic Coefficients $(\phi)$ to Those Measured for $\mathrm{LiCl}$ at $25^{\circ} \mathrm{C}$

\begin{tabular}{|c|c|c|c|}
\hline Molality of LiCl & Source Equation & Measurements & Difference (\%) \\
\hline 0.1 & 0.941 & 0.939 & 0.2 \\
\hline 0.5 & 0.963 & 0.963 & 0.0 \\
\hline 1.0 & 1.016 & 1.018 & 0.2 \\
\hline 3.0 & 1.287 & 1.286 & 0.1 \\
\hline 6.0 & 1.795 & 1.791 & 0.2 \\
\hline
\end{tabular}

NOTE: $\quad$ Measurements Taken from Robinson and Stokes 1965 [DIRS 108567], Appendix 8.10, Table 1, p. 483.

\section{I.4.4.14 Ions: $\mathrm{Mg}^{2+}-\mathrm{Cl}^{-}$}

Associated Spreadsheet: FitPitzerNC_MX_MgCl2.xls

Source: Pabalan and Pitzer 1987 [DIRS 162096]; cited 104 times by 3/2003.

Description: Input parameters and equations from the source document by Pabalan and Pitzer (1987 [DIRS 162096], Appendix, p. 2442) were verified for $\beta_{M X}^{(0)}, \beta_{M X}^{(1)}$, and $C^{\phi}$ by independently calculating these parameters, and agreement was obtained with the values calculated in the spreadsheet. The RMS error in the osmotic coefficient over the fitted temperature range (see spreadsheet tab "Results Summary") for the 3-4 term conversion is typically $<0.001$, except at $\mathrm{I}=18 \mathrm{~mol} / \mathrm{kg}$ when it is 0.0015 . In addition, osmotic coefficients were calculated from the source equation (Pabalan and Pitzer 1987 [DIRS 162096], Appendix, p. 2442) and compared with those listed in the tables from Holmes et al. (1997 [DIRS 162080], Table 2), and Wang et al. (1998 [DIRS 162109], Table 4). There was fair agreement with values calculated in this spreadsheet, within 0.013 at $25^{\circ} \mathrm{C}$ (see Table I-13), within 0.2 at $100^{\circ} \mathrm{C}$ (see Table I-14), within 0.25 at $150^{\circ} \mathrm{C}$, and within 0.2 at $200^{\circ} \mathrm{C}$. These larger differences at higher temperatures arise from the differences in the data used to calculate the values in these two papers and the generally lower accuracy in high temperature thermodynamic measurements. 
Table I-13. Comparison of Source Osmotic Coefficients $(\phi)$ to Those Measured for $\mathrm{MgCl}_{2}$ at $25^{\circ} \mathrm{C}$

\begin{tabular}{|c|c|c|c|}
\hline Molality of $\mathbf{M g C l}_{\mathbf{2}}$ & Source Equation & Measurements & Difference (\%) \\
\hline 0.1 & 0.8618 & 0.8606 & 0.14 \\
\hline 0.5 & 0.9439 & 0.9439 & 0.00 \\
\hline 1.0 & 1.1088 & 1.1100 & 0.11 \\
\hline 3.0 & 2.0205 & 2.0070 & 0.67 \\
\hline
\end{tabular}

NOTE: $\quad$ Measurements taken from Holmes et al. 1997 [DIRS 162080], Table 2, p. 1369.

Table I-14. Comparison of Source Osmotic Coefficients $(\phi)$ to Those Measured for $\mathrm{MgCl}_{2}$ at $100^{\circ} \mathrm{C}$

\begin{tabular}{|c|c|c|c|}
\hline Molality of $\mathbf{~ M g C l}_{\mathbf{2}}$ & Source Equation & Measurements & Difference (\%) \\
\hline 0.05 & 0.8429 & 0.8460 & 0.4 \\
\hline 0.1 & 0.8324 & 0.8332 & 0.1 \\
\hline 0.5 & 0.8737 & 0.8628 & 1.3 \\
\hline 1.0 & 0.9856 & 0.9921 & 0.7 \\
\hline 3.0 & 1.6634 & 1.6891 & 1.5 \\
\hline 6.0 & 2.8450 & 3.0357 & 6.3 \\
\hline
\end{tabular}

NOTE: $\quad$ Measurements taken from Wang et al. 1998 [DIRS 162109], Table 4, p. 979.

\section{I.4.4.15 Ions: $\mathrm{Mg}^{2+}-\mathrm{SO}_{4}{ }^{2-}$}

\section{Associated Spreadsheet: FitPitzerNC_MX_MgSO4.xls}

Source: Pabalan and Pitzer 1987 [DIRS 162096]; cited 104 times by 3/2003.

Description: Input parameters and equations from Pabalan and Pitzer (1987 [DIRS 162096], Appendix, p. 2443) were verified for $\beta_{M X}^{(0)}, \beta_{M X}^{(1)}$, and $C^{\phi}$. The RMS error in the osmotic coefficient over the fitted temperature range (see spreadsheet tab "Results Summary") for the 3-4 term conversion is typically $<0.01$, except at very high ionic strengths; e.g. at I $=12$ and 24 $\mathrm{mol} / \mathrm{kg}$ then $\Delta \phi=0.014$ and 0.132 , respectively. Calculated values of the osmotic coefficient from this spreadsheet were compared with those listed in the Table V of Phutela and Pitzer (1986 [DIRS 162097]), which is the original source of the temperature coefficients used by Pabalan and Pitzer (1987 [DIRS 162096]). There is good agreement with source equation values calculated in this spreadsheet, with a maximum difference of $\sim 0.001$. The minor differences that exist most likely arise from differences in the Debye-Hückel $A^{\varphi}$ (phi) coefficient. In the original source paper by Phutela and Pitzer (1986 [DIRS 162098]), models with both constant and temperature dependent alpha2 parameters were mentioned, but the model from which the listed osmotic coefficient results were generated was not clearly specified. However, Pabalan and Pitzer (1987 [DIRS 162096]) implied the use of a constant alpha2 parameter, and this was confirmed by the good agreement with the calculations in this spreadsheet. It should be noted that the highest ionic strengths, for which unrealistic osmotic coefficients are calculated in this spreadsheet, greatly exceed the concentration range for which the model was parameterized. The model should provide reasonably accurate results at ionic strengths below the solubility limit. This is supported by a comparison with experimental measurements at $25^{\circ} \mathrm{C}$ in Table I- 15 below, where the 3-4 term fitted results are compared to the experiments at 25 and $100^{\circ} \mathrm{C}$ with a $\Delta \phi_{\max }=0.012$. 
Table I-15. Comparison of 3-4 Term Fitting Osmotic Coefficients $(\phi)$ to Those Measured for $\mathrm{MgSO}_{4}$ at 25 and $100^{\circ} \mathrm{C}$

\begin{tabular}{|c|c|c|c|}
\hline \multicolumn{5}{|c|}{$\mathbf{2 5}^{\circ} \mathbf{C}$} \\
\hline Molality of MgSO $_{4}$ & 3-4 Term Fit & Measurements & Difference (\%) \\
\hline 0.1 & 0.597 & 0.596 & 0.2 \\
\hline 0.5 & 0.530 & 0.527 & 0.6 \\
\hline 1.0 & 0.531 & 0.527 & 0.8 \\
\hline 3.0 & 0.915 & 0.925 & 1.1 \\
\hline \multicolumn{4}{|c|}{$\mathbf{1 0 0}^{\circ} \mathbf{C}$} \\
\hline 0.1 & 0.527 & 0.529 & 0.4 \\
\hline 1.0 & 0.438 & 0.444 & 1.3 \\
\hline 3.0 & 0.412 & 0.419 & 1.9 \\
\hline
\end{tabular}

NOTE: $\quad$ Measurements taken from Phutela and Pitzer 1986 [DIRS 162098], Table V, p. 899.

\section{I.4.4.16 Ions: $\mathrm{Na}^{+}-\mathrm{Br}^{-}$}

\section{Associated Spreadsheet: FitPitzerNC_MX_NaBr.xls}

Source: Holmes and Mesmer 1998 [DIRS 162083].

Description: Input parameters and equations from Table 4 (p. 737) and Equation 14 (p.734) of Holmes and Mesmer (1998 [DIRS 162083]) were verified for $\beta_{M X}^{(0)}, \beta_{M X}^{(1)}$, and $C^{\phi}$. The average of the RMS error in the osmotic coefficient over the fitted temperature range (see spreadsheet tab "Results Summary") for the 3-4 term conversion was 0.0013 , with a $\Delta \phi_{\max }=0.0023$. Values of the osmotic coefficient calculated using the source equation were compared with experimental values listed in Holmes and Mesmer (1998 [DIRS 162083], Table 1, p. 728) at $200^{\circ} \mathrm{C}$, and at $25^{\circ} \mathrm{C}$ against both Robinson and Stokes (1965 [DIRS 108567]) and Rard and Archer (1995 [DIRS 162104]). Comparison at $25^{\circ} \mathrm{C}$ is shown in Table I-16, where there was good agreement with values calculated in this spreadsheet, with a maximum difference of 0.008 at $\mathrm{I}=6.0 \mathrm{~mol} / \mathrm{kg}$. At $200^{\circ} \mathrm{C}$, good agreement is obtained over this range of molalities as seen in Table I-17. It should be noted that there are two errors in Equation (14) of Holmes and Mesmer (1998 [DIRS 162083], p. 734) for the functional form of the temperature function, and an error in the reference temperature $T_{\mathrm{r}}$ which was incorrectly reported as $413.15 \mathrm{~K}$ instead of $298.15 \mathrm{~K}$. The correct version of this equation is given in the spreadsheet cover page and it is equivalent to the correct form of this equation as first derived by Holmes and Mesmer (1983 [DIRS 162073], Equation 25). 
Table I-16. Comparison of Source Osmotic Coefficients $(\phi)$ to Those Measured for $\mathrm{NaBr}$ at $25^{\circ} \mathrm{C}$

\begin{tabular}{|c|c|c|c|}
\hline Molality of $\mathrm{NaBr}$ & Source Equation & Measurements & Difference (\%) \\
\hline 0.1 & 0.935 & $0.934^{\mathrm{a}}$ & 0.1 \\
\hline 0.5 & 0.933 & $0.933^{\mathrm{a}}$ & 0.0 \\
\hline 1.0 & 0.959 & $0.958^{\mathrm{a}}$ & 0.1 \\
\hline 3.0 & 1.109 & $1.107^{\mathrm{a}}$ & 0.2 \\
\hline 6.0 & 1.381 & $1.389^{\mathrm{b}}$ & 0.6 \\
\hline
\end{tabular}

${ }^{\text {a }}$ Taken from Robinson and Stokes 1965 [DIRS 108567], Appendix 8.10, Table 1, p. 483.

b Taken from Rard and Archer 1995 [DIRS 162104], Table 3; $\phi$ at 6.0 mol/kg was linearly interpolated from 5.9151 and $6.1073 \mathrm{~mol} / \mathrm{kg}$ values.

Table I-17. Comparison of Source Osmotic Coefficients $(\phi)$ to Those Measured for $\mathrm{NaBr}$ at $200^{\circ} \mathrm{C}$

\begin{tabular}{|c|c|c|c|}
\hline \multicolumn{2}{|c|}{ Spreadsheet Calculated Values } & \multicolumn{2}{c|}{ Experimental Values } \\
\hline Molality of $\mathrm{NaBr}$ & Source Equation & Molality of $\mathrm{NaBr}$ & Measured \\
\hline 1.0 & 0.921 & 0.9814 & 0.9225 \\
\hline 3.0 & 1.049 & 2.8264 & 1.0431 \\
\hline 6.0 & 1.234 & 6.1392 & 1.2401 \\
\hline
\end{tabular}

NOTE: Experimental values taken from Holmes and Mesmer 1998 [DIRS 162083], Table1, p.728.

\section{I.4.4.17 Ions: $\mathrm{Na}^{+}-\mathrm{NO}_{3}^{-}$}

Associated Spreadsheet: ConPitzerNC_MX_NaNO3.xls

Source: Archer 2000 [DIRS 162065].

Description: Input parameters and equations from Archer (2000 [DIRS 162065], Table 4 and Equations 19 through 23) in the ConPitzerNC model parameter conversion worksheet were verified for $\beta_{M X}^{(0)}, \beta_{M X}^{(1)}, C_{M X}^{(1)}$, and $C_{M X}^{(1)}$ input parameters. The osmotic coefficient and Archer model parameters calculated at selected temperatures and molalities in the worksheet agreed exactly with the values given by Archer (2000 [DIRS 162065], Tables 5 and 7). Note that there is a mistake in Archer's (2000 [DIRS 162065]) Table 5 column header for the $C_{M X}^{(1)}$ parameter and that it was not multiplied by $10^{3}$ as indicated. The standard Pitzer model parameters $\beta_{M X}^{(0)}$, $\beta_{M X}^{(1)}$, and $C^{\phi}$ were determined from Archer's model parameters using the method presented by Rard and Wijesinghe (2003 [DIRS 162327]). The standard Pitzer model parameters calculated in this manner from the Archer parameters were verified by comparing the standard Pitzer model parameters calculated in the ConPitzerNC worksheet against those presented by Rard and Wijesinghe (2003 [DIRS 162327]). The osmotic coefficients calculated in the ConPitzerNC worksheet also agree with the plots of osmotic coefficient given by Rard and Wijesinghe (2003 [DIRS 162327]). The two verification methods used by Rard and Wijesinghe (2003 [DIRS 162327]) explained in Section I-4.4.1 also apply to this case. Both methods generated almost identical results. In the ConPitzerNC worksheet, method (1) based on exact analytical matrix coefficient integration, which is more accurate than the approximate method (2), was used. The temperature coefficients for the standard Pitzer parameters $\beta_{M X}^{(0)}, \beta_{M X}^{(1)}$, and $C^{\phi}$ are calculated in the FitPitzerNC worksheet using the parameter values computed as a function of 
temperature in the ConPitzerNC worksheet. Comparison of the osmotic coefficient calculated using these temperature coefficients against the input values from both the ConPitzerNC worksheet and the verified values calculated using the Archer model in the ConPitzerNC worksheet, confirm the accuracy of the temperature coefficient fits. On average, the temperature coefficient fitting errors are a factor of 100 smaller than the model parameter conversion errors that result from constraining the output model to three parameters instead of the four parameters in the source model. The final fitted parameters were compared with the calculated osmotic coefficients in Archer (2000 [DIRS 162065], Table 7) calculated osmotic coefficients. This is shown in Figure $\mathrm{I}-1$ at 4 temperatures $\left(0,25,50\right.$ and $\left.100^{\circ} \mathrm{C}\right)$ for $\mathrm{I}=0.1$ to $10 \mathrm{~mol} / \mathrm{kg}$, where the Archer results have solid symbols and the spreadsheet fitted results have open symbols, and the symbol colors are based on the temperature. The results fit Archer's osmotic coefficients well in the molality range of $\sim 1$ to 10 .

In both ConPitzerNC and FitPitzerNC worksheets, the parameters are evaluated at $5^{\circ} \mathrm{C}$ intervals, whereas in the paper by Rard and Wijesinghe (2003 [DIRS 162327]) parameter values were given at only seven selected temperatures. The fine temperature grid in the FitPitzerNC worksheet yields sufficiently accurate fits for the temperature coefficients. It should be noted that Archer's original model was claimed to be valid from -37 to $152^{\circ} \mathrm{C}$, so that the results presented in this spreadsheet at higher temperatures represent an extrapolation beyond the confirmed range of validity of the source model.

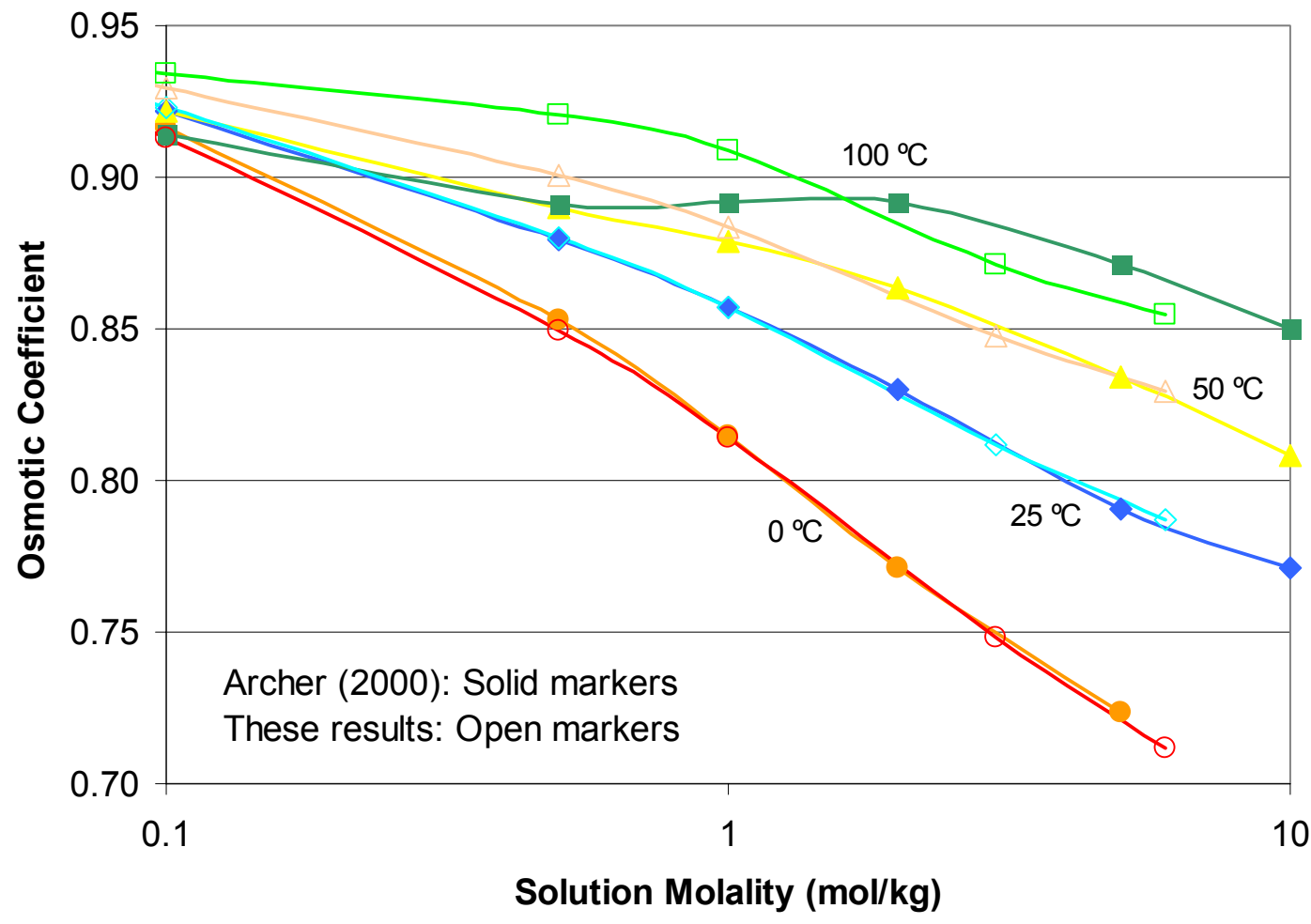

Output DTN: SN0306T0510102.007.

Source: Archer 2000 [DIRS 162065].

Figure I-1. Archer's Calculated Osmotic Coefficients Compared to Fitted Spreadsheet Results 


\section{I.4.4.18 Ions: $\mathrm{Na}^{+}-\mathrm{SO}_{4}{ }^{2-}$}

\section{Associated Spreadsheet: FitPitzerNC_MX_Na2SO4.xls}

Source: Greenberg and Møller 1989 [DIRS 152684]; cited 51 times as of 3/2003.

Description: Input parameters and equation from Greenberg and Møller (1989 [DIRS 152684], Tables 1 and 3 and Equation 3) were verified for $\beta_{M X}^{(0)}, \beta_{M X}^{(1)}, C^{\phi}$, and $A^{\phi}$. The average of the RMS errors in the osmotic coefficient over the fitted temperature range (see spreadsheet tab "Results Summary") for the 34 term conversion was 0.012 , with $\Delta \phi_{\max }=0.0436$ at I $=18$ $\mathrm{mol} / \mathrm{kg}$, which is well above the solubility limit and not physically relevant. Calculated values of the osmotic coefficient from this spreadsheet were also compared with those listed in (1) Holmes and Mesmer (1986 [DIRS 162074]; Table IV) and (2) Rard et al. (2000 [DIRS 162105], Table XI). There was reasonable agreement of the values reported in these two papers with values calculated in this spreadsheet, as indicated in the summary on the associated spreadsheet cover page, and specifically as shown in Table I-18 comparing the spreadsheet results to Rard et al. (2000 [DIRS 162105]) at 25 and $100{ }^{\circ} \mathrm{C}$. The differences between the values in the two papers arise from differences in the underlying data sources. Also note that because the solubility does not extend to $\mathrm{I}=18 \mathrm{~mol} / \mathrm{kg}$, the reported values in this spreadsheet at this high ionic are not physically relevant. This agreement is considered to be sufficient confirmation of the validity of the osmotic coefficient calculations reported in this spreadsheet. In addition, several values of $\beta_{M X}^{(0)}, \beta_{M X}^{(1)}$, and $C^{\phi}$ were independently calculated using the input source data and underlying equations, and exact agreement was obtained with the values calculated in the spreadsheet.

Table I-18. Comparison of Fitted Osmotic Coefficients $(\phi)$ to Those Measured for $\mathrm{Na}_{2} \mathrm{SO}_{4}$ at 25 and $100^{\circ} \mathrm{C}$

\begin{tabular}{|l|c|c|c|}
\hline \multicolumn{5}{|c|}{$\mathbf{2 5}^{\circ} \mathbf{C}$ Comparison } \\
\hline Molality of $\mathrm{Na}_{2} \mathbf{S O}_{4}$ & Fitted Equation & Measurements & Difference (\%) \\
\hline 0.05 & 0.8281 & 0.8260 & 0.3 \\
\hline 0.1 & 0.7927 & 0.7902 & 0.3 \\
\hline 0.5 & 0.6871 & 0.6931 & 0.9 \\
\hline 1.0 & 0.6345 & 0.6451 & 1.6 \\
\hline 3.0 & 0.6602 & 0.6700 & 0.1 \\
\hline \multicolumn{7}{|c|}{$\mathbf{1 0 0}{ }^{\circ} \mathbf{C}$ Comparison } \\
\hline 0.05 & 0.8041 & 0.8036 & 0.1 \\
\hline 0.1 & 0.7686 & 0.7682 & 0.8 \\
\hline 0.5 & 0.6860 & 0.6595 & 0.1 \\
\hline 1.0 & 0.6591 & 0.6387 & 0.1 \\
\hline 3.0 & 0.6380 & 0
\end{tabular}

NOTE: Measurements taken from Rard et al. 2000 [DIRS 162105], Table XI. 


\section{I.4.4.19 Ions: $\mathrm{Na}^{+}-\mathrm{Cl}^{-}$}

\section{Associated Spreadsheet: FitPitzerNC_MX_NaCl.xls}

Source: Greenberg and Møller 1989 [DIRS 152684]; cited 51 times as of 3/2003.

Description: Input parameters and equations from Greenberg and Møller (1989 [DIRS 152684], Tables 1 and 3, and Equation 3) were verified for $\beta_{M X}^{(0)}, \beta_{M X}^{(1)}, C^{\phi}$ and $A^{\phi}$. The RMS error in the osmotic coefficient over the fitted temperature range (see spreadsheet tab "Results Summary") for the 3-4 term conversion was $\Delta \phi<0.001$. Calculated values of the osmotic coefficient from this spreadsheet were compared with those listed in the extensive tables from Clarke and Glew (1985 [DIRS 162066], Table 19 A). There was good agreement with values calculated in this spreadsheet, with a maximum difference of 0.005 , but with much better agreement at most temperatures and molalities; this is shown in Table I-19. These minor differences most likely arise from the differences in the underlying data sources. This agreement is considered to be sufficient confirmation of the validity of the osmotic coefficient calculations reported in this spreadsheet. In addition, several values of $\beta_{M X}^{(1)}$ parameters were independently calculated using the input source data and underlying equations, and exact agreement was obtained with the values calculated in the spreadsheet.

Table I-19. Comparison of Fitted Osmotic Coefficients $(\phi)$ to Those Measured for $\mathrm{NaCl}$ at 25 and $100^{\circ} \mathrm{C}$

\begin{tabular}{|c|c|c|c|}
\hline \multicolumn{5}{|c|}{$\mathbf{2 5}^{\circ} \mathbf{C}$ Comparison } & Difference (\%) \\
\hline Molality of NaCl & Fitted Equation & Measurements & $<0.1$ \\
\hline 0.05 & 0.9435 & 0.9436 & $<0.1$ \\
\hline 0.1 & 0.9324 & 0.9325 & $<0.1$ \\
\hline 0.5 & 0.9214 & 0.9222 & 0.2 \\
\hline 1.0 & 0.9354 & 0.9373 & 0.5 \\
\hline 3.0 & 1.0431 & 1.0485 & 0.2 \\
\hline 6.0 & 1.2716 & 1.2688 & $<0.1$ \\
\hline & \multicolumn{2}{|c|}{$\mathbf{1 0 0}{ }^{\circ} \mathbf{C}$ Comparison } & $<0.1$ \\
\hline 0.05 & 0.9345 & 0.9346 & $<0.1$ \\
\hline 0.1 & 0.9222 & 0.9223 & 0.1 \\
\hline 0.5 & 0.9139 & 0.9142 & 0.2 \\
\hline 1.0 & 0.9332 & 0.9341 & 0.2 \\
\hline 3.0 & 1.0439 & 1.0458 & 1.2083 \\
\hline
\end{tabular}

NOTE: $\quad$ Measurements taken from Clarke and Glew 1985[DIRS 162066], Table 19 A, pp. 525 and 526.

\section{I.4.4.20 Ions: $\mathrm{Na}^{+}-\mathrm{OH}^{-}$}

Associated Spreadsheet: FitPitzerNC_MX_NaOH.xls

Source: Pabalan and Pitzer 1987 [DIRS 162147]; cited 42 times as of 3/2003.

Description: Input parameters and equations from Pabalan and Pitzer (1987 [DIRS 162147], Table 3 and Equations 28 through 30) were verified for $\beta_{M X}^{(0)}, \beta_{M X}^{(1)}, C^{\phi}$, and $A^{\phi}$. The average of 
the RMS errors in the osmotic coefficient over the fitted temperature range (see spreadsheet tab "Results Summary") for the 3-4 term conversion was $0.002(\sim 0.2 \%)$. In addition, several values of $\beta_{M X}^{(0)}, \beta_{M X}^{(1)}$, and $C^{\phi}$ were independently calculated using the input source data and underlying equations, and exact agreement was obtained with the values calculated in the spreadsheet. Calculated values of the osmotic coefficient from this spreadsheet are compared in Table I-20 below, against those listed for $25^{\circ} \mathrm{C}$ in Robinson and Stokes (1965 [DIRS 108567], Appendix 8.10, Table 1, p. 483). There was good agreement with the fitted spreadsheet values at $25^{\circ} \mathrm{C}$, with a maximum difference of $1.3 \%$. There was also good agreement over $110-170^{\circ} \mathrm{C}$ with the osmotic coefficient values reported by Holmes and Mesmer (1998 [DIRS 162082]). The direct comparison shown at $170^{\circ} \mathrm{C}$ below in Table I-21. These comparisons are considered to be sufficient confirmation of the validity of the osmotic coefficient calculations reported in this spreadsheet.

Table I-20. Comparison of Fitted 3-4 Term Osmotic Coefficients $(\phi)$ to Those Measured for $\mathrm{NaOH}$ at $25^{\circ} \mathrm{C}$

\begin{tabular}{|c|c|c|c|}
\hline Molality of $\mathbf{N a O H}$ & 3-4 Term Fit & Measurements $^{\mathbf{a}}$ & Difference (\%) $^{\text {(\%) }}$ \\
\hline 0.1 & 0.932 & 0.925 & 0.8 \\
\hline 0.5 & 0.925 & 0.937 & 1.3 \\
\hline 1.0 & 0.947 & 0.958 & 1.1 \\
\hline 3.0 & 1.104 & 1.094 & 0.9 \\
\hline 6.0 & 1.442 & 1.434 & 0.6 \\
\hline
\end{tabular}

NOTE: $\quad$ Measurements taken from Robinson and Stokes 1965 [DIRS 108567], Appendix 8.10, Table 1, p. 483.

Table I-21. Comparison of Fitted 3-4 Term Osmotic Coefficients $(\phi)$ to Those Measured for $\mathrm{NaOH}$ at $170^{\circ} \mathrm{C}$

\begin{tabular}{|l|l|l|l|}
\hline \multicolumn{2}{|c|}{ Spreadsheet Calculated Values } & \multicolumn{2}{c|}{ Experimental Values } \\
\hline \multicolumn{1}{|c|}{ Molality of $\mathrm{NaOH}$} & \multicolumn{1}{c|}{ Fitted 3-4 Term $\phi$} & \multicolumn{1}{c|}{ Molality of $\mathrm{NaOH}$} & \multicolumn{1}{c|}{ Measured $\phi$} \\
\hline 1.0 & 0.875 & 1.0495 & 0.8547 \\
\hline 3.0 & 0.906 & 3.0341 & 0.8922 \\
\hline 6.0 & 1.001 & $6.0^{\mathrm{a}}$ & 1.0126 \\
\hline
\end{tabular}

${ }^{a}$ Linearly interpolated from the average results between 5.6 and 6.4 molality.

NOTE: Experimental values taken from Holmes and Mesmer 1998 [DIRS 162082], Table1, p.315.

\section{I.4.4.21 Ions: $\mathrm{NH}_{4}{ }^{+}-\mathrm{SO}_{4}{ }^{2-}$}

Associated Spreadsheet: ConPitzerNC_MX_(NH4)2SO4.xls

Source: Clegg et al. 1996 [DIRS 162068]; cited 13 times by 3/2003.

Description: Input temperature coefficients and equation from Clegg et al. (1996 [DIRS 162068], Table 5, equation therein) in the ConPitzerNC model parameter conversion worksheet were verified for $\beta_{M X}^{(0)}, \beta_{M X}^{(1)}, C_{M X}^{(0)}$, and $C_{M X}^{(1)}$ input parameters. The model used by Clegg et al. (1996 [DIRS 162068]) is an Archer-type extended Pitzer model with four parameters, for which conversion of model data to the standard Pitzer model was presented by Rard and Wijesinghe (2003 [DIRS 162327]). The osmotic coefficient calculated at selected 
molalities using the input model in the worksheet agreed exactly with the values given by Clegg et al. (1996 [DIRS 162068], Table 7) at $25^{\circ} \mathrm{C}$. The 3-4 term fitting results differed from those osmotic coefficient values by less than 0.0009 over the $0-100{ }^{\circ} \mathrm{C}$ range. Values presented in the worksheet above $100{ }^{\circ} \mathrm{C}$ also agree well with the those calculated using the input model, but these extrapolations are beyond the range of validity claimed for the input model. The 3-4 term calculated values of the osmotic coefficient from this spreadsheet are compared with those listed at 25 and $100{ }^{\circ} \mathrm{C}$ in Clegg et al. (1996 [DIRS 162068], Table 7) in Table I-22. There was very good agreement with the spreadsheet values at $25{ }^{\circ} \mathrm{C}$ with a maximum difference of $0.9 \%$, and reasonable agreement over the $100{ }^{\circ} \mathrm{C}$ range with an $\mathrm{RMS}$ difference of $2.3 \%$. The model conversion errors for the osmotic coefficient, in going from a 4-parameter Archer-type input model to the 3-parameter standard Pitzer model, as a function of temperature ranged from 0.0010 to 0.0256 from 0 to $100{ }^{\circ} \mathrm{C}$, respectively (see spreadsheet cover page). The model conversion error can be as large as 0.06 at higher temperatures, but this is beyond the range of validity of the input model. Generally, the model conversion errors are much larger than the temperature coefficient fitting errors.

Table I-22. Comparison of Fitted 3-4 Term Osmotic Coefficients $(\phi)$ to Those Measured for (NH4)2SO4 at 25 and $100^{\circ} \mathrm{C}$

\begin{tabular}{|c|c|c|c|}
\hline \multicolumn{5}{|c|}{$\mathbf{2 5}^{\circ} \mathbf{C}$} \\
\hline Molality of $\mathbf{( N H}_{\mathbf{4}} \mathbf{2}_{\mathbf{2}} \mathbf{S O}_{\mathbf{4}}$ & $\mathbf{3 - 4}$ Term Fit & Measurements & Difference (\%) \\
\hline 0.05 & 0.8160 & 0.8127 & 0.4 \\
\hline 0.1 & 0.7760 & 0.7723 & 0.5 \\
\hline 0.5 & 0.6756 & 0.6774 & 0.2 \\
\hline 1.0 & 0.6379 & 0.6420 & 0.9 \\
\hline 3.0 & 0.6398 & 0.6382 & 0.3 \\
\hline 6.0 & 0.7177 & 0.7138 & 0.6 \\
\hline \multicolumn{4}{|l|}{$\mathbf{1 0 0}{ }^{\circ} \mathbf{C}$} \\
\hline 0.05 & 0.7902 & 0.7687 & 2.8 \\
\hline 0.1 & 0.7466 & 0.7198 & 3.7 \\
\hline 0.5 & 0.6358 & 0.6316 & 0.7 \\
\hline 1.0 & 0.5923 & 0.6027 & 1.7 \\
\hline 3.0 & 0.5832 & 0.5810 & 0.4 \\
\hline 6.0 & 0.6036 & 0.6202 & 2.7 \\
\hline
\end{tabular}

NOTE: Measurements taken from Clegg et al. 1996 [DIRS 162068], Table 7.

\section{I.4.4.22 Ions: $\mathrm{NH}_{4}^{+}-\mathrm{Cl}^{-}$}

\section{Associated Spreadsheet: FitPitzerNC_MX_NH4Cl.xls}

Source: Thiessen and Simonson 1990 [DIRS 162108]; cited 12 times by 3/2003.

Description: Input parameters and equations from Thiessen and Simonson (1990 [DIRS 162108], Table IV and Equation 24) were verified for $\beta_{M X}^{(0)}, \beta_{M X}^{(1)}$, and $C^{\phi}$. Calculated values of the parameter term coefficients in the spreadsheet agreed very well with the values reported by the authors, with near exact agreement in most cases but with an occasional 
difference 0.001-0.002. Each osmotic coefficient RMS error over the fitted temperature range (as shown on "Results Summary" spreadsheet) was below 0.0004, with a maximum individual difference of 0.0007 . This is considered to be excellent agreement, with the minor differences attributable to the $A^{\phi}$ parameter and the water saturation vapor pressure equation used to establish the system pressure. Calculated values of the osmotic coefficient from this spreadsheet were compared with those listed for $25^{\circ} \mathrm{C}$ in the extensive tables from Robinson and Stokes (1965 [DIRS 108567], Appendix 8.10, Table 3, p. 485). There was good agreement with the final fitted spreadsheet values at $25^{\circ} \mathrm{C}$, with $\Delta \phi_{\max }=0.002$ (Table I-23).

Table I-23. Comparison of 3-4 Term Fitted Osmotic Coefficients $(\phi)$ to Measured for $\mathrm{NH}_{4} \mathrm{Cl}$ at $25^{\circ} \mathrm{C}$

\begin{tabular}{|c|c|c|c|}
\hline Molality of $\mathbf{~ N H}_{\mathbf{4}} \mathbf{C l}$ & 3-4 Term Fitting & Measurements & Difference (\%) \\
\hline 0.1 & 0.925 & 0.927 & 0.2 \\
\hline 0.5 & 0.899 & 0.899 & $<0.1$ \\
\hline 1.0 & 0.897 & 0.897 & $<0.1$ \\
\hline 3.0 & 0.927 & 0.926 & 0.1 \\
\hline 6.0 & 0.969 & 0.969 & $<0.1$ \\
\hline
\end{tabular}

NOTE: $\quad$ Measurements taken from Robinson and Stokes 1965 [DIRS 108567], Appendix 8.10, Table 3, p. 485.

\section{I.4.4.23 Ions: $\mathrm{Na}^{+}-\mathrm{HCO}_{3}^{-}$}

\section{Associated Spreadsheet: FitPitzerNC_MX_NaHCO3.xls}

Source: He and Morse 1993 [DIRS 162090]; cited 21 times by 3/2003.

Description: Input parameters and equation from He and Morse (1993 [DIRS 162090], Table 7 and the Equation on page 3548) were verified for $\beta_{M X}^{(0)}, \beta_{M X}^{(1)}$, and $C^{\phi}$. The RMS error in the osmotic coefficient over the fitted temperature range (see spreadsheet tab "Results Summary") for source to 3-4 term conversion is zero (to within calculation precision) as both use the same functional form. Calculated values of these coefficients at $25^{\circ} \mathrm{C}$ from this spreadsheet agreed with the values reported by Peiper and Pitzer (1982 [DIRS 162097], Table 1). The source document used Pitzer parameter values at $25^{\circ} \mathrm{C}$ from this paper to determine the temperature coefficients. The osmotic coefficients calculated from the input parameters were compared with those listed in tables from Peiper and Pitzer (1982 [DIRS 162097], Table 6, pp. 631 through 636). There was good agreement with values calculated in this spreadsheet, with a maximum difference raging from 0.001 to 0.002 over 0 to $1.0 \mathrm{~mol} / \mathrm{kg}$ ionic strength at 25 and $45^{\circ} \mathrm{C}$ as seen in Table I-24. This agreement is considered to be sufficient for the validity of the osmotic coefficient calculations reported in this spreadsheet. Pitzer parameter values over a wider temperature range than $0-90{ }^{\circ} \mathrm{C}$ have been reported in the literature, but these are limited to smaller ranges of concentration. For example, the Pitzer data given by Polya et al. (2001 [DIRS 162101]) are limited to an ionic strength range of $0-4.5 \mathrm{~mol} / \mathrm{kg}$ for $\mathrm{Na}_{2} \mathrm{CO}_{3}$, and $0-1.0$ $\mathrm{mol} / \mathrm{kg}$ for $\mathrm{NaHCO}_{3}$. Furthermore, reproduction of the results of Polya et al. (2001 [DIRS 162101]), which were calibrated against the $25^{\circ} \mathrm{C}$ parameter values of Peiper and Pitzer (1982 [DIRS 162097]), using the equations given by Polya et al. (2001 [DIRS 162101]) was unsuccessful. Communication with these authors did not resolve the uncertainties. The model of He and Morse (1993 [DIRS 162090]), although it is limited to 0-90 C, was parameterized to very high ionic strengths and is therefore suitable for calculation of $\mathrm{Na}_{2} \mathrm{CO}_{3}$ solubility. 
Table I-24. Comparison of Fitted 3-4 Term Osmotic Coefficients $(\phi)$ to Those Measured for $\mathrm{NaHCO}_{3}$ at 25 and $45^{\circ} \mathrm{C}$

\begin{tabular}{|c|c|c|c|}
\hline \multicolumn{5}{|c|}{$\mathbf{2 5}^{\circ} \mathbf{C}$} \\
\hline Molality of $\mathrm{NaHCO}_{3}$ & $\mathbf{3 - 4}$ Term Fit & Measurements & Difference (\%) \\
\hline 0.05 & 0.934 & 0.933 & 0.1 \\
\hline 0.1 & 0.915 & 0.914 & 0.1 \\
\hline 1.0 & 0.856 & 0.854 & 0.2 \\
\hline \multicolumn{4}{|c|}{$\mathbf{4 5}^{\circ} \mathbf{C}$} \\
\hline 0.1 & $0.932^{\mathrm{a}}$ & 0.931 & 0.1 \\
\hline 1.0 & $0.914^{\mathrm{a}}$ & 0.913 & 0.1 \\
\hline
\end{tabular}

${ }^{a}$ Linearly interpolated by hand from spreadsheet data between 40 and $50^{\circ} \mathrm{C}$.

NOTE: $\quad$ Measurements taken from Peiper and Pitzer 1982 [DIRS 162097], Table 6, pp 631-636.

\section{I.4.4.24 Ions: $\mathrm{Na}^{+}-\mathrm{CO}_{3}{ }^{2-}$}

Associated Spreadsheet: FitPitzerNC_MX_Na2CO3.xls

Source: He and Morse 1993 [DIRS 162090]; cited 21 times by 3/2003.

Description: Input parameters and equations from He and Morse (1993 [DIRS 162090], Table 7 and the Equation on page 3548) were verified for $\beta_{M X}^{(0)}, \beta_{M X}^{(1)}$, and $C^{\phi}$. The RMS error in the osmotic coefficient over the fitted temperature range (see spreadsheet tab "Results Summary") for the 3-4 term conversion is zero (to within calculation precision) as both use the same functional form. Calculated values of these coefficients at $25^{\circ} \mathrm{C}$ from this spreadsheet agreed with the values reported by Peiper and Pitzer (1982 [DIRS 162097], Table 1). The source document used the Pitzer parameter values at $25{ }^{\circ} \mathrm{C}$ from this paper to determine the temperature coefficients. The osmotic coefficients calculated from the input parameters were compared with those listed in Peiper and Pitzer (1982 [DIRS 162097], Table 6) and shown in Table I-25 at 25 and $45^{\circ} \mathrm{C}$. There was good agreement with values calculated in this spreadsheet, with a maximum difference ranging from 0.002 to 0.01 over 0 to $9 \mathrm{~mol} / \mathrm{kg}$ ionic strength. This agreement is considered to be sufficient confirmation of the validity of the osmotic coefficient calculations reported in this spreadsheet. Just like the $\mathrm{NaHCO}_{3}$, Pitzer parameter values over a wider temperature range than 0 to $90{ }^{\circ} \mathrm{C}$ have been reported for $\mathrm{Na}_{2} \mathrm{CO}_{3}$ in the literature but these are limited to smaller ranges of concentration. For example, the Pitzer data given by Polya et al. (2001 [DIRS 162101]) are limited to an ionic strength range of 0 to $4.5 \mathrm{~mol} / \mathrm{kg}$ for $\mathrm{Na}_{2} \mathrm{CO}_{3}$, and 0 to $1.0 \mathrm{~mol} / \mathrm{kg}$ for $\mathrm{NaHCO}_{3}$. Furthermore, reproduction of the results of Polya et al. (2001 [DIRS 162101]), which were adjusted using the $25^{\circ} \mathrm{C}$ parameter values of Peiper and Pitzer (1992 [DIRS 162097]), using the equations given by them was not possible. The uncertainties could not be resolved. The solubility of $\mathrm{Na}_{2} \mathrm{CO}_{3}$ above $25{ }^{\circ} \mathrm{C}$ exceeds the ionic strength range of the model at high temperatures, and as was shown by Königsberger (2001 [DIRS 162093]), does not yield reliable solubility predictions above about $50^{\circ} \mathrm{C}$. The model of $\mathrm{He}$ and Morse (1993 [DIRS 162090]), although limited to $0-90{ }^{\circ} \mathrm{C}$, was parameterized to very high ionic strengths and is suitable for calculation of solubility. 
Table I-25. Comparison of Fitted 3-4 Term Osmotic Coefficients $(\phi)$ to Measured for $\mathrm{Na}_{2} \mathrm{CO}_{3}$ at 25 and $45^{\circ} \mathrm{C}$

\begin{tabular}{|c|c|c|c|}
\hline \multicolumn{5}{|c|}{$\mathbf{2 5}^{\circ} \mathbf{C}$} \\
\hline Molality of $\mathrm{Na}_{2} \mathbf{C O}_{3}$ & 3-4 Term Fit & Measurements & Difference (\%) \\
\hline 0.05 & 0.842 & 0.847 & 0.6 \\
\hline 0.1 & 0.814 & 0.817 & 0.4 \\
\hline 1.0 & 0.681 & 0.683 & 0.3 \\
\hline 3.0 & 0.737 & 0.739 & 0.3 \\
\hline \multicolumn{4}{|c|}{$\mathbf{4 5}^{\circ} \mathrm{C}$} \\
\hline 0.05 & $0.835^{\mathrm{a}}$ & 0.845 & 1.2 \\
\hline 0.1 & $0.806^{\mathrm{a}}$ & 0.815 & 0.9 \\
\hline
\end{tabular}

a Linearly interpolated by hand from spreadsheet data between 40 and $50^{\circ} \mathrm{C}$.

NOTE: $\quad$ Measurements taken from Peiper and Pitzer 1982 [DIRS 162097], Table 6, pp 631-636.

\section{I.4.4.25 Ions: $\mathrm{Na}^{+}-\mathrm{HSO}_{4}^{-}$}

Associated Spreadsheet: FitPitzerNC_MX_NaHSO4.xls

Source: Holmes and Mesmer 1994 [DIRS 162078].

Description: Input parameters and equations from Holmes and Mesmer (1994 [DIRS 162078], Table 4 and Equation 28) were verified for $\beta_{M X}^{(0)}, \beta_{M X}^{(1)}$, and $C^{\phi}$, and $A^{\phi}$. Calculated values of the osmotic coefficient for the fully dissociated binary electrolyte from this spreadsheet cannot be compared with any experimental values because experimentally determined values include the effects of partial dissociation into $\mathrm{Na}^{+}, \mathrm{H}^{+}, \mathrm{HSO}_{4}{ }^{-}$and $\mathrm{SO}_{4}{ }^{2-}$ ions rather than $\mathrm{Na}^{+}$and $\mathrm{HSO}_{4}{ }^{-}$ions only. However, the values of the calculated osmotic coefficient are reasonable for a fully dissociated 1-1 electrolyte. The binary parameters for $\mathrm{Na}^{+}$and $\mathrm{HSO}_{4}{ }^{-}$should only be used in combination with the mixing parameters $(\theta$ and $\psi)$ from the same document. Furthermore, to be consistent, these parameters should only be used in combination with the binary and mixing parameters for $\mathrm{HSO}_{4}{ }^{-}$and $\mathrm{SO}_{4}{ }^{2-}$ ions given in the source document and for $\mathrm{Na}_{2} \mathrm{SO}_{4}$ in $\mathrm{Holmes}$ and Mesmer (1986 [DIRS 162074]). Of the two models given in the latter paper, Model I with alpha1 $=1.4$ instead of 2 , should be used for $\mathrm{Na}_{2} \mathrm{SO}_{4}$. Note that there is an error in Table 4 of the source document (Holmes and Mesmer 1994 [DIRS 162078]); it gives incorrect p1 parameter values that are too large by a factor of 1000 . It should also be noted that the higher order electrostatic interactions represented by the ${ }^{E} \theta$ and ${ }^{E} \theta^{\prime}$ third order terms of the Pitzer model were taken into account in this source document. In an earlier paper by Holmes and Mesmer (1993 [DIRS 162077]), the authors did not account for these interactions. Note that there is an error in Table 2 of this document for isothermal fits; it gives incorrect $C^{\phi}$ values that are too large by a factor of 1000 . 


\section{I.4.4.26 Ions: $\mathrm{Na}^{+}-\mathrm{AlO}_{2}^{-}$(equivalent to $\left.\mathrm{Na}^{+}-\mathrm{Al}(\mathrm{OH})_{4}{ }^{-}\right)$}

Associated Spreadsheet: FitPitzerNC_MX_Na_AlO2.xls

Source: Felmy et al. 1994 [DIRS 162112].

Description: The binary parameters $\beta_{M X}^{(0)}, \beta_{M X}^{(1)}$, and $C^{\phi}$ generated with the coefficients and equations reported by Felmy et al. (1994 [DIRS 162112], Table 1 and Equation 1) were examined and compared with the data reported by Wesolowski (1992 [DIRS 162148], Table 13) based on gibbsite solubility at alkaline conditions. Unlike previous FitPitzerNC spreadsheets, the binary parameters were refitted using the regression function intrinsic to MS Excel. The conventions used for representing aqueous aluminate ion as $\mathrm{AlO}_{2}{ }^{-}$instead of $\mathrm{Al}(\mathrm{OH})_{4}{ }^{-}$are different from those reported by Felmy et al. (1994 [DIRS 162112]) and Wesolowski (1992 [DIRS 162148]). The convention used to denote the aluminate ion $\mathrm{AlO}_{2}{ }^{-}$is equivalent to $\mathrm{Al}(\mathrm{OH})_{4}{ }^{-}$in the two latter studies and thermodynamically consistent with the chemical reactions for aqueous and solid species in the current data0.ypf or Pitzer database and those obtained from the data0.ymp.R2 database (see Pokrovskii and Helgeson 1995 [DIRS 101699] for more details on the adopted convention).

The binary parameter values obtained after refitting agree with those generated by Felmy et al. (1994 [DIRS 162112]), depending on temperature. Comparison of generated parameter values with those reported by Wesolowski (1992 [DIRS 162148], table 13, p.1087) for a temperature range of 25 to $100{ }^{\circ} \mathrm{C}$ are also in good agreement. Somewhat larger differences are observed for the $\beta_{M X}^{(1)}$ values but in general these are considered reasonable when all parametric differences are taken as a whole. An error in table 1 of Felmy et al. (1994 [DIRS 162112]) was detected for the $\beta_{M X}^{(0)}$ parameter where the listed a3 coefficient is actually a 4 in the fitting equation used by the authors. When the fitting coefficient is corrected, the $\beta_{M X}^{(0)}$ values obtained are nearly identical to those reported by Wesolowski (1992 [DIRS 162148], Table 13).

Felmy et al. (1994 [DIRS 162112]) conducted a gibbsite solubility study at ambient temperature and noticed that in order to model the effect of $\mathrm{NaNO}_{3}$ concentration in $\mathrm{NaOH}$ solutions, two additional ternary parameters ( $\theta$ and $\psi$, see Felmy et al. 1994 [DIRS 162112]) were needed. These were modified by Felmy et al. (1994 [DIRS 162112]) to fit their solubility data for a mixed $\mathrm{Na}-\mathrm{OH}-\mathrm{NO}_{3}-\mathrm{H}_{2} \mathrm{O}$ electrolyte. A further test of these parameters was the prediction of the equilibrium solubility for gibbsite in a concentrated $\mathrm{NaOH}$ solution at $70{ }^{\circ} \mathrm{C}$ with the code $E Q 3 / 6$ Version 8.0 for a total $\mathrm{Na}$ concentration of 3.045 molal. The $\log \mathrm{K}$ value for gibbsite was taken from the data0.ymp. $\mathrm{R} 2$ database. The calculated total $\mathrm{Al}$ (equivalent to $\mathrm{AlO}_{2}^{-}$or $\mathrm{Al}(\mathrm{OH})_{4}^{-}$) was nearly identical to that in Wesolowski (1992 [DIRS 162148], Table 4) for the same $\mathrm{Na}^{+}$ concentration (See EQ3NR output file, gibbs_weso_sol.3o in the accompanying CD). 


\section{I.4.4.27 Ions: $\mathrm{Ca}^{2+}-\mathrm{SO}_{4}{ }^{2-}$}

Associated Spreadsheet: No Spreadsheet

Source: Møller 1988 [DIRS 152695]; Greenberg and Møller 1989 [DIRS 152684].

Description: Binary parameters from Greenberg and Møller (1989 [DIRS 152684]) were verified for $\beta_{M X}^{(0)}, \beta_{M X}^{(1)}$, and $C^{\phi}$ given without any temperature dependence. The refit based on these authors work given in the spreadsheet 'FitPitzerNC_MX_CaSO4.xls' is not used here. It appears from the work of Greenberg and Møller (19899 [DIRS 152684]) that an explicit $\mathrm{CaSO}_{4}(\mathrm{aq})$ ion pair constant was used to fit a temperature range above $50^{\circ} \mathrm{C}$. The explicit use of this ion pair is what actually brings the temperature dependence to the model. As incorporated in the data0.ypf database, the $\beta_{M X}^{(0)}$ term is set to zero and the $\mathrm{CaSO}_{4}(\mathrm{aq})$ ion pair represented in the $\log \mathrm{K}$ data block for aqueous species is used all throughout the valid temperature range. It is suspected that the ion pair was not actually used in Greenberg and Møller (1989 [DIRS 152684]) at temperatures less than $50^{\circ} \mathrm{C}$ and extrapolation to this lower temperature range might add some additional error. Even though the ion pair is used and $\beta_{M X}^{(2)}$ is not, it appears that an $\alpha_{1}$ value of 1.4 was retained. A corrected value of 'al' for $\beta_{M X}^{(0)}$ was used after noticing that it differs from the original source of Møller (1988 [DIRS 152695]). Møller (1988 [DIRS 152695]) reports a value of 0.15 for the 'a1' coefficient instead of 0.015 as reported by Greenberg and Møller (1989 [DIRS 152684]). Millero and Pierrot (1998 [DIRS 163594]) and Monnin (1999 [DIRS 163593]) adopted a value of 0.15 for this coefficient in their Pitzer models. Monnin (1999 [DIRS 163593]) states in his study that the value of 0.015 reported by Greenberg and Møller (1989 [DIRS 152684]) appears to be incorrect since it yields significant discrepancies. Therefore, a corrected value of 0.15 is adopted in his study (Monnin 1999 [DIRS 163593], Table 3, footnote f). The solubility of gypsum in water (Figure I-2) was calculated using the Pitzer parameters and compared to the curve given by Møller (1988 [DIRS 152695], Figure 3, p. 827). The computed solubility by the code underestimates the saturation molalities by $\sim 18 \%$ to $\sim 60 \%$ for the temperature range of 25 to $100{ }^{\circ} \mathrm{C}$, respectively. These differences are relatively large but not grossly unreasonable. No attempt was made to improve the predictions of gypsum solubility other than to adopt the parameter values and ion pair constant in the manner described above. 


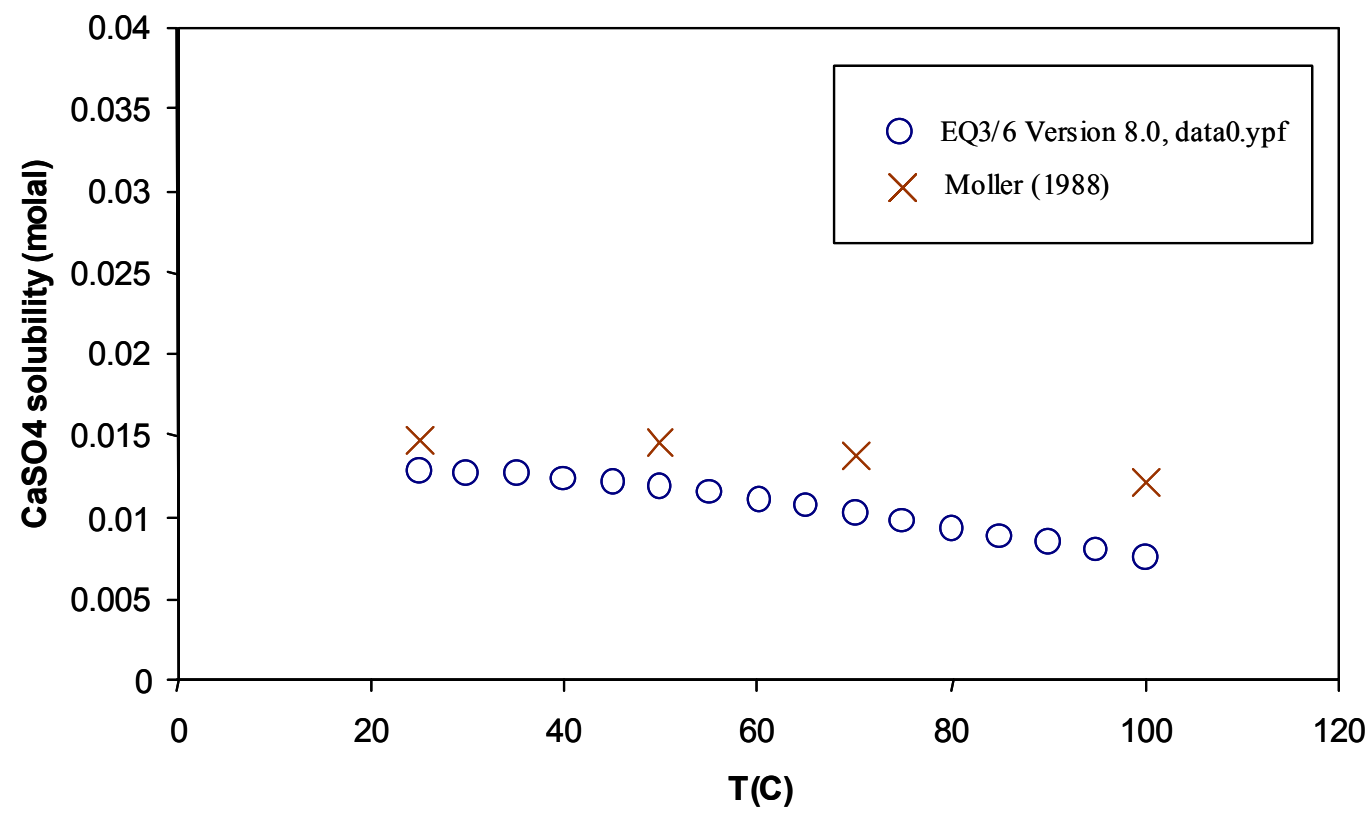

NOTE: $\quad$ Predicted msat values (DTN: SN0306T0510102.007) were computed using data0.ypf and EQ3/6 Version 8.0. The saturation molalities for gypsum were obtained from Figure 3 in Møller (1988 [DIRS 152695]).

Figure I-2. Comparison of Saturation Molalities for Gypsum

\section{I.4.5 TERNARY PITZER INTERACTION PARAMETERS}

In this section, the selected ternary Pitzer ion interaction parameters for major salt constituents included in the developed data0.ypf database for EQ3/6 Version 8.0 will be described. All these parameters and associated spreadsheets are listed in Tables I-1 and I-2 as "Types other than MX". Remarks on the refitting and reproducibility of gathered Pitzer parameter data will be discussed here and on the associated spreadsheet cover pages. Discussions of parameter data are focused on the parameters that needed refitting due to their temperature dependence. Many parameters did not require any refitting since the gathered values are only valid at $25^{\circ} \mathrm{C}$ and were obtained directly from tabulated data. For these, only simple conversions were necessary. The reader is reminded that ternary interaction parameters make relatively small contributions to the calculation of osmotic coefficients and activity coefficients. Thus, even large percentage differences in the values used by different authors make only small differences in the final results. For details see the individual papers cited which generally evaluate the magnitude of these differences.

Significant limitations exist for the application of the parameters discussed in the following subsections. Most have been determined only at $25^{\circ} \mathrm{C}$ and many only for relatively simple systems. For more complex systems, such as for most groundwater and other temperatures, refitting of the parameters to the changed conditions may be necessary to obtain accurate results. Failure to make such adjustments can lead to significant errors in some applications, e.g., modeling of evaporation of a water to near dryness, because of the accumulation of small deviations of the model from the actual chemistry. To mitigate this problem, data were taken from consistent or single sources to the extent possible. For example, many parameters were taken from Greenberg and Møller (1989 [DIRS 152684]), who studied the rather complex Na-K$\mathrm{Ca}-\mathrm{Cl}-\mathrm{SO}_{4}-\mathrm{H}_{2} \mathrm{O}$ system. Still, this study lacked some important constituents, notably $\mathrm{Mg}$ and 
carbonate, present in most natural waters, and did not fit the Ca poor portion of the system well. For some applications Al and Si need to be included, and, less often, other elements that are generally present in groundwater in minor to trace amounts. Thus, in spite of qualification of these data from the point of view that they generally suffice to reproduce individual details of the experimental results well, they need to be viewed with caution in respect to modeling chemical processes that change the composition of the solution.

\section{I.4.5.1 Ions: $\mathrm{Ca}^{2+}-\mathrm{K}^{+}$}

Associated Spreadsheet: FitPitzerNC_MM_K_Ca.xls

Source: Greenberg and Møller 1989 [DIRS 152684].

Description: Input parameters and equations from Greenberg and Møller (1989 [DIRS 152684]) were verified for $\theta$ and $A^{\phi}$. The authors used a constant value of $\theta$ for all temperatures. At $25^{\circ} \mathrm{C}$, Pitzer and Kim (1974 [DIRS 123206]) reported values of $\theta=-0.040$ and $\psi=-0.015$ for $\mathrm{K}-\mathrm{Ca}-\mathrm{Cl}$ system compared to $\theta=0.1156$ and $\psi=-0.04319$ from the spreadsheet, and $\theta=0.032$ and $\psi=-0.025$ by Pitzer (1991 [DIRS 152709]). Unlike the calculations of both Pitzer and this spreadsheet, Pitzer and Kim (1974 [DIRS 123206]) did not account for the higher order electrostatic terms ${ }^{E} \theta$ and ${ }^{E} \theta^{\prime}$ in their model. Therefore, the evaluation of $\theta$ is dominated by the differences in the models used by different authors. In particular, Pitzer and Kim (1974 [DIRS 123206]) based their parameter evaluations using isopiestic data. Although Greenberg and Møller (1989 [DIRS 152684]) also considered this isopiestic data they adjusted the mixing parameters to better represent solubility of sylvite $(\mathrm{KCl})$ in mixed $\mathrm{KCl}-\mathrm{CaCl}_{2}$ solutions.

\section{I.4.5.2 Ions: $\mathrm{Ca}^{2+}-\mathrm{Na}^{+}$}

\section{Associated Spreadsheet: FitPitzerNC_MM_Na_Ca.xls}

Source: Greenberg and Møller 1989 [DIRS 152684].

Description: Input parameters and equations from Greenberg and Møller (1989 [DIRS 152684]) were verified for $\theta$ and $A^{\phi}$. The authors used a constant value of $\theta$ for all temperatures. There are no independent studies of this $\theta$ parameter reported in the literature that would enable a meaningful comparison. In Holmes et al. (1981 [DIRS 162072]), the authors represent $\theta$ from isopiestic data by the equation $\theta=(10.7 / \mathrm{T})-0.0316$. Holmes et al. (1981 [DIRS 162072]) state that the osmotic coefficients could be represented reproduced to $0.5 \%$ or better even without mixing parameters, which indicates that mixing effects are small. The equation given by Holmes et al. (1981 [DIRS 162072]) yields values that vary from 0.0043 to $-0.0090 \mathrm{~kg} / \mathrm{mol}$ over 25 to $201{ }^{\circ} \mathrm{C}$. Because $\theta$ has only a very small influence on the osmotic coefficient of the system, the evaluation of this parameter is dominated by differences in the models used by different authors. These differences include neglect of the higher order electrostatic terms ${ }^{E} \theta$ and ${ }^{E} \theta^{\prime}$. Greenberg and Møller (1989 [DIRS 152684]), for example, included these terms while Holmes et al. (1981 [DIRS 162072]) did not include them. Therefore, the adequacy of this $\theta$ parameter estimate should be assessed in combination with other binary and ternary parameters by examining the accuracy of the osmotic coefficients calculated in the MMX-type ternary parameter spreadsheets for the $\mathrm{Na}-\mathrm{Ca}$ ion combination. 


\section{I.4.5.3 Ions: $\mathrm{K}^{+}-\mathrm{Na}^{+}$}

Associated Spreadsheet: FitPitzerNC_MM_Na_K.xls

Source: Greenberg and Møller 1989 [DIRS 152684].

Description: Input parameters and equations from Greenberg and Møller (1989 [DIRS 152684]) were verified for $\theta$ and $A^{\phi}$. There are no independent studies of this $\theta$ parameter reported in the literature that would enable a meaningful comparison. Holmes et al. (1979 [DIRS 162071], p. $1044)$ represent $\theta$ from isopiestic data by the equation $\theta=-(6.726 / \mathrm{T})+0.0039$, whereas Greenberg and Møller (1989 [DIRS 152684]) give the expression $\theta=(14.021314 / \mathrm{T})$ 0.0502312 for 0 to $250{ }^{\circ} \mathrm{C}$. Greenberg and Møller (1989 [DIRS 152684]) used the same basic model and experimental data as Holmes et al. (1979 [DIRS 162071]), but adjusted the mixing parameter $\theta$ to better represent solubility data for the $\mathrm{NaCl}-\mathrm{KCl}-\mathrm{H}_{2} \mathrm{O}$ system at temperatures above $150^{\circ} \mathrm{C}$. Holmes et al. (1979 [DIRS 162071]) state that the osmotic coefficients could be reproduced to within $1 \%$ or better even without mixing parameters, which indicates that mixing effects are small. The equation given by Holmes et al. (1979 [DIRS 162071]) yields values that vary from -0.01866 to $-0.01032 \mathrm{~kg} / \mathrm{mol}$ over 25 to $200{ }^{\circ} \mathrm{C}$ whereas the corresponding values from Greenberg and Møller (1989 [DIRS 152684]) vary from -0.00320 to $-0.02060 \mathrm{~mol} / \mathrm{kg}$. Because $\theta$ has only a very small influence on the osmotic coefficient of the system, its evaluation is sensitive to differences in the models used by the different authors. Therefore, the adequacy of this estimate of the $\theta$ parameter should be assessed in combination with other binary and ternary parameters by examining the accuracy of the osmotic coefficients calculated in the MMX-type ternary parameter spreadsheets for the $\mathrm{Na}-\mathrm{K}$ ion combination.

\section{I.4.5.4 Ions: $\mathrm{Cl}^{-}-\mathrm{SO}_{4}{ }^{2-}$}

Associated Spreadsheet: FitPitzerNC_XX_Cl_SO4.xls

Source: Greenberg and Møller 1989 [DIRS 152684].

Description: Input parameters and equations from Greenberg and Møller (1989 [DIRS 152684]) were verified for $\theta$ and $A^{\phi}$. The temperature function given in the source document for $\theta$ has a discontinuity in slope at $150{ }^{\circ} \mathrm{C}$. This discontinuity is not accurately accommodated by the fitted continuous temperature function causing the largest error in $\theta$ (about 10\%) to occur in the immediate vicinity of $150{ }^{\circ} \mathrm{C}$. De Lima and Pitzer (1983 [DIRS 162110]) fitted the $\mathrm{Na}-\mathrm{Cl}-\mathrm{SO}_{4}$ system solubilities from 25 to $100{ }^{\circ} \mathrm{C}$ with $\theta=-0.02$ and $\psi=0.004$ taken from an earlier evaluation by Pitzer at $25^{\circ} \mathrm{C}$. Both of these studies imply that ternary mixing contributions to the osmotic coefficient are small. 


\section{I.4.5.5 Ions: $\mathrm{HSO}_{4}^{-}-\mathrm{SO}_{4}{ }^{2-}$}

\section{Associated Spreadsheet: FitPitzerNC_XX_HSO4_SO4.xls}

Source: Holmes and Mesmer 1994 [DIRS 162078].

Description: Input parameters and equations from Holmes and Mesmer (1994 [DIRS 162078]) were verified for the parameter $\theta$. These authors regressed the model parameters simultaneously for the $\mathrm{H}-\mathrm{HSO}_{4}-\mathrm{SO}_{4}$ and $\mathrm{Na}-\mathrm{HSO}_{4}-\mathrm{SO}_{4}$ systems, including the ${ }^{E} \theta$ and ${ }^{E} \theta^{\prime}$ higher order electrostatic interactions. Clegg et al. (1994 [DIRS 152734]) were able to fit the thermodynamic properties of sulfuric acid without including either $\theta$ or $\psi$ Pitzer mixing parameters, but with an additional $\mathrm{C}(1)$ extended binary parameter and the ${ }^{E} \theta$ and ${ }^{E} \theta^{\prime}$ higher order electrostatic interaction parameters. It was found by Clegg et al. (1994 [DIRS 152734]) that these model enhancements were significant in improving the accuracy of the fit at concentrations much lower than those considered by Holmes and Mesmer (1994 [DIRS 162078]). Both of these studies imply that the contributions of the ternary mixing parameters are negligible in the $\mathrm{H}-\mathrm{HSO}_{4}-\mathrm{SO}_{4}$ system, but not always negligible in the $\mathrm{Na}_{-} \mathrm{HSO}_{4}-\mathrm{SO}_{4}$ system. In an earlier paper by Holmes and Mesmer (1992 [DIRS 162076]), the authors did not account for these interactions.

\section{I.4.5.6 Ions: $\mathrm{K}^{+}-\mathrm{Ca}^{2+}-\mathrm{Cl}^{-}$}

Associated Spreadsheet: FitPitzerNC_MMX_K_Ca_Cl.xls

Source: Greenberg and Møller 1989 [DIRS 152684].

Description: Input parameters and equations from Greenberg and Møller (1989 [DIRS 152684]) were verified for the $\theta$ ternary Pitzer parameter and $A^{\phi}$. At $25^{\circ} \mathrm{C}$, Pitzer and $\mathrm{Kim}(1974$ [DIRS 123206]) reported values of $\theta=-0.040$ and $\psi=-0.015$ for $\mathrm{K}-\mathrm{Ca}-\mathrm{Cl}$ system compared to $\theta$ $=0.1156$ and $\psi=-0.04319$ from the spreadsheet, and $\theta=0.032$ and $\psi=-0.025$ by Pitzer (1991 [DIRS 152709]). Unlike the calculations by Pitzer and those presented in this spreadsheet, Pitzer and Kim (1974 [DIRS 123206]) did not account for the higher order electrostatic terms ${ }^{E} \theta$ and ${ }^{E} \theta^{\prime}$ in their model. Therefore, the evaluation of $\theta$ is dominated by the differences in the models used by different authors. In particular, Pitzer and Kim (1974 [DIRS 123206]) based their parameter evaluations using these isopiestic data. Although Greenberg and Møller (1989 [DIRS 152684]) also considered this isopiestic data they adjusted the mixing parameters to better represent solubility of sylvite $(\mathrm{KCl})$ in mixed $\mathrm{KCl}-\mathrm{CaCl}_{2}$ solutions. It should be noted that the osmotic coefficient values presented in the spreadsheet for an ionic strength of $\mathrm{I}=18 \mathrm{~mol} / \mathrm{kg}$ are not realistic because they fall outside the range of validity of the model parameters, especially for potassium-rich solutions at low temperatures. Exact agreement was obtained between the osmotic coefficients for the limiting binary solutions, $\mathrm{KCl}(\mathrm{aq})$ and $\mathrm{CaCl}_{2}(\mathrm{aq})$, calculated by the ternary and the binary spreadsheets, for both input and fitted Pitzer parameters. 


\section{I.4.5.7 Ions: $\mathrm{Na}^{+}-\mathrm{Ca}^{2+}-\mathrm{Cl}^{-}$}

\section{Associated Spreadsheet: FitPitzerNC_MMX_Na_Ca_Cl.xls}

Source: Greenberg and Møller 1989 [DIRS 152684].

Description: Input parameters and equations from Greenberg and Møller (1989 [DIRS 152684]) were verified for $\psi$ and $A^{\phi}$. Holmes et al. (1981 [DIRS 162072]) found that the osmotic coefficients could be reproduced to within $0.5 \%$ or better even without mixing parameters, which indicates that mixing effects are small. Holmes et al. (1981 [DIRS 162072]) also found that while using the $\theta$ mixing parameter improved the standard deviation for isothermal fits by a factor of 2 , including both $\theta$ and $\psi$ did not yield a significant improvement over using $\theta$ alone. $\theta$ varied between 0.0056 and -0.0081 over 25 to $201{ }^{\circ} \mathrm{C}$. Because $\psi$ has only a very small influence on the osmotic coefficient of the system, its value is dominated by differences in the models used by the different authors. These differences include the neglect of the higher order electrostatic terms ${ }^{E} \theta$ and ${ }^{E} \theta^{\prime}$. Greenberg and Møller (1989 [DIRS 152684]), for example, included these terms while Holmes et al. (1981 [DIRS 162072]) did not. Therefore, the adequacy of this estimate of the $\psi$ parameter should be assessed in combination with other binary and ternary parameters by examining the accuracy of the osmotic coefficients calculated in the MMX-type ternary parameter spreadsheets for the $\mathrm{Na}-\mathrm{Ca}$ ion combination. Exact agreement was obtained between the osmotic coefficients for the limiting binary solutions, $\mathrm{NaCl}(\mathrm{aq})$ and $\mathrm{CaCl}_{2}(\mathrm{aq})$, calculated by the ternary and the binary spreadsheets, for both input and fitted Pitzer parameters.

\section{I.4.5.8 Ions: $\mathrm{Na}^{+}-\mathrm{Ca}^{2+}-\mathrm{SO}_{4}{ }^{2-}$}

\section{Associated Spreadsheet: FitPitzerNC_MMX_Na_Ca_SO4.xls}

Source: Greenberg and Møller 1989 [DIRS 152684].

Description: Input parameters and equations from Greenberg and Møller (1989 [DIRS 152684]) were verified for the $\theta$ ternary Pitzer parameter and $A^{\phi}$. The authors used constant values of $\theta$ and $\psi$ for all temperatures. At $25^{\circ} \mathrm{C}$, Pitzer (1991 [DIRS 152709]) used the values $\theta=0.07$ and $\psi=-0.055$ compared to $\theta=0.05$ and $\psi=-0.012$ calculated from the correlation of Greenberg and Møller (1989 [DIRS 152684]). Both sets of values account for the higher order terms $\theta$ and ${ }^{E} \theta^{\prime}$. At low temperatures, the calculated values of the osmotic coefficient from this spreadsheet are plausible, but, for $\mathrm{CaSO}_{4}$-rich solutions, they become unrealistic in magnitude at temperatures beyond 100 to $150{ }^{\circ} \mathrm{C}$. Because of the relatively low solubility of $\mathrm{CaSO}_{4}$, the high concentrations cannot be achieved experimentally. The parameters were designed to represent solubility in mixed electrolyte solutions and are inadequate for representing the properties of the hypothetical pure- $\mathrm{CaSO}_{4}(\mathrm{aq})$ solutions. Exact agreement was obtained between the osmotic coefficients for the limiting binary solutions, $\mathrm{Na}_{2} \mathrm{SO}_{4}(\mathrm{aq})$ and $\mathrm{CaSO}_{4}(\mathrm{aq})$, calculated by the ternary and the binary spreadsheets, for both input and fitted Pitzer parameters. 


\section{I.4.5.9 Ions: $\mathrm{Na}^{+}-\mathrm{K}^{+}-\mathrm{Cl}^{-}$}

\section{Associated Spreadsheet: FitPitzerNC_MMX_Na_K_Cl.xls}

Source: Greenberg and Møller 1989 [DIRS 152684].

Description: Input parameters and equations from Greenberg and Møller (1989 [DIRS 152684]) were verified for $\psi$ and $A^{\phi}$. In Holmes et al. (1979 [DIRS 162071]), the authors state that the osmotic coefficients could be reproduced to within $1 \%$ or better even without mixing parameters, which indicates that mixing effects are small. However, Holmes et al. (1979 [DIRS 162071]) found that including the $\theta$ mixing parameter caused a significant improvement in the accuracy of representing the data with the standard deviation for isothermal fits decreasing by a factor of 2 to 4. Including both $\theta$ and $\psi$, resulted in no further improvement, and they recommended using $\theta$ only in the Pitzer model. Greenberg and Møller (1989 [DIRS 152684]) used the same basic model and experimental data as Holmes et al. (1979 [DIRS 162071]) but adjusted the mixing parameter $\theta$ to better represent the solubility data for the $\mathrm{NaCl}-\mathrm{KCl}-\mathrm{H}_{2} \mathrm{O}$ system at temperatures above $150{ }^{\circ} \mathrm{C}$. Because $\psi$ has only a very small influence on the osmotic coefficient of the system, its evaluation is sensitive to differences in the models used by the different authors. Therefore, the adequacy of the $\psi$ parameter estimation should be assessed in combination with other binary and ternary parameters by examining the accuracy of the osmotic coefficients calculated in the MMX-type ternary parameter spreadsheets for the $\mathrm{Na}-\mathrm{K}$ ion combination. Exact agreement was obtained between the osmotic coefficients for the limiting binary solutions, $\mathrm{NaCl}(\mathrm{aq})$ and $\mathrm{KCl}(\mathrm{aq})$, calculated by the ternary and the binary spreadsheets, for both input and fitted Pitzer parameters.

\section{I.4.5.10 Ions: $\mathrm{Na}^{+}-\mathrm{K}^{+}-\mathrm{SO}_{4}{ }^{2-}$}

\section{Associated Spreadsheet: FitPitzerNC_MMX_Na_K_SO4.xls}

Source: Greenberg and Møller 1989 [DIRS 152684].

Description: Input parameters and equations from Greenberg and Møller (1989 [DIRS 152684]) were verified for the $\psi$ ternary Pitzer parameter and $A^{\phi}$. Greenberg and Møller (1989 [DIRS 152684]) used a 2-term temperature function for $\psi$ with different sets of parameters from 0 to $150{ }^{\circ} \mathrm{C}$ and 150 to $250{ }^{\circ} \mathrm{C}$. The value of $\psi$ was optimized using both osmotic coefficient and solubility data. Table 18 of Pitzer (1991 [DIRS 152709]), includes the values of $\theta=-0.012$ and $\psi=-0.010$ at $25^{\circ} \mathrm{C}$ taken from the original paper by Pitzer and Kim (1974 [DIRS 123206]). This should be compared with the values of $\theta=-0.0032$ and $\psi=0.0073$ at $25^{\circ} \mathrm{C}$ calculated from Greenberg and Møller (1989 [DIRS 152684]) correlations. Both of these studies imply that ternary mixing contributions to the osmotic coefficient are small, but that the mixing parameter values should always be evaluated in combination with the binary and other ternary parameters for the electrolyte system. It should be noted here that the osmotic coefficient values presented in the spreadsheet for an ionic strength of $\mathrm{I}=18 \mathrm{~mol} / \mathrm{kg}$ are not realistic because they fall outside the range of validity of the model parameters. Exact agreement was obtained between the osmotic coefficients for the limiting binary solutions, $\mathrm{Na}_{2} \mathrm{SO}_{4}(\mathrm{aq})$ and $\mathrm{K}_{2} \mathrm{SO}_{4}(\mathrm{aq})$, calculated by the ternary and the binary spreadsheets, for both input and fitted Pitzer parameters. 


\section{I.4.5.11 Ions: $\mathrm{Ca}^{2+}-\mathrm{Cl}^{-}-\mathrm{SO}_{4}{ }^{2-}$}

\section{Associated Spreadsheet: FitPitzerNC_MXX_Ca_Cl_SO4.xls}

Source: Greenberg and Møller 1989 [DIRS 152684].

Description: Input parameters and equations from Greenberg and Møller (1989 [DIRS 152684]) were verified for the $\psi$ ternary Pitzer parameter and $A^{\phi}$. The authors used a constant value of $\psi$ for all temperatures. At $25^{\circ} \mathrm{C}$, Pitzer (1991 [DIRS 152709]) used the values of $\theta=0.030$ and $\psi$ $=-0.002$ compared to $\theta=0.070$ and $\psi=-0.018$ calculated from the correlation of Greenberg and Møller (1989 [DIRS 152684]). Both sets of values account for the higher order terms $\theta$ and ${ }^{E} \theta^{\prime}$. At low temperatures, the calculated values of the osmotic coefficient from this spreadsheet are plausible, but, for $\mathrm{CaSO}_{4}$-rich solutions, they become unrealistic in magnitude at temperatures beyond 100 to $150{ }^{\circ} \mathrm{C}$. Because of the low solubility of $\mathrm{CaSO}_{4}$, the high concentrations cannot be achieved experimentally. The parameters were designed to represent solubility in mixed electrolyte solutions and are inadequate for representing the properties of the hypothetical pure- $\mathrm{CaSO}_{4}(\mathrm{aq})$ solutions. Exact agreement was obtained between the osmotic coefficients for the limiting binary solutions, $\mathrm{CaCl}_{2}(\mathrm{aq})$ and $\mathrm{CaSO}_{4}(\mathrm{aq})$, calculated by the ternary and the binary spreadsheets, for both input and fitted Pitzer parameters.

\section{I.4.5.12 Ions: $\mathrm{K}^{+}-\mathrm{Cl}^{-}-\mathrm{SO}_{4}{ }^{2-}$}

\section{Associated Spreadsheet: FitPitzerNC_MXX_K_Cl_SO4.xls}

Source: Greenberg and Møller 1989 [DIRS 152684].

Description: Input parameters and equations from Greenberg and Møller (1989 [DIRS 152684]) were verified for $\psi$ and $A^{\phi}$. At $25^{\circ} \mathrm{C}$, Pitzer and Kim (1974 [DIRS 123206]) reported values of $\theta=-0.035$ and $\psi=0$ compared to $\theta=0.07$ and $\psi=-0.0016152$ from the spreadsheet. In Pitzer (1991 [DIRS 152709]), the higher order interaction terms were included with $\theta=0.030$ and $\psi=$ -0.005 at $25^{\circ} \mathrm{C}$. These differences arise from differences in the binary parameters as well as model differences such as inclusion of the higher order electrostatic parameters ${ }^{E} \theta$ and ${ }^{E} \theta^{\prime}$ in the spreadsheet. Therefore, the adequacy of this estimate of the $\psi$ parameter should be assessed in combination with other binary and ternary parameters by examining the accuracy of the osmotic coefficients calculated in the MXX-type ternary parameter spreadsheets for the $\mathrm{Cl}_{-} \mathrm{SO}_{4}$ ion combination. Because of the limited solubility of potassium sulfate, the calculated osmotic coefficients in the spreadsheet at certain high ionic strengths will exceed the range of validity of the model and may not be realistic. Exact agreement was obtained between the osmotic coefficients for the limiting binary solutions, $\mathrm{KCl}(\mathrm{aq})$ and $\mathrm{K}_{2} \mathrm{SO}_{4}(\mathrm{aq})$, calculated by the ternary and the binary spreadsheets, for both input and fitted Pitzer parameters. 


\section{I.4.5.13 Ions: $\mathrm{H}^{+}-\mathrm{HSO}_{4}^{-}-\mathrm{SO}_{4}{ }^{2-}$}

\section{Associated Spreadsheet: FitPitzerNC_MXX_H_HSO4_SO4.xls}

Source: Holmes and Mesmer 1994 [DIRS 162078].

Description: Input parameters and equations from Holmes and Mesmer (1994 [DIRS 162078]) were verified for $\psi$, which were set equal to zero. They regressed the model parameters simultaneously for the $\mathrm{H}-\mathrm{HSO}_{4}-\mathrm{SO}_{4}$ and $\mathrm{Na}-\mathrm{HSO}_{4}-\mathrm{SO}_{4}$ systems, including the ${ }^{E} \theta$ and ${ }^{E} \theta^{\prime}$ higher order electrostatic interactions (The subscript $M B S$ on $\psi$ in Table 4 refers to $\mathrm{Na}^{+}-\mathrm{HSO}_{4}{ }^{-}-$ $\mathrm{SO}_{4}{ }^{2-}$, not $\mathrm{H}^{+}-\mathrm{HSO}_{4}{ }^{-}-\mathrm{SO}_{4}{ }^{2}$. See Holmes and Mesmer 1994 [DIRS 162078], p. 582). Clegg et al. (1994 [DIRS 152734]), were able to fit the thermodynamic properties of sulfuric acid without including both $\theta$ and $\psi$ Pitzer mixing parameters, but with an additional $\mathrm{C}(1)$ extended binary ion-interaction parameter and the ${ }^{E} \theta$ and ${ }^{E} \theta^{\prime}$ higher order electrostatic interaction parameters. It was found by Clegg et al. (1994 [DIRS 152734]) that these model enhancements were significant in improving the accuracy of the fit at concentrations much lower than those considered by Holmes and Mesmer (1994 [DIRS 162078]). Both of these studies imply that the contributions of the ternary mixing parameters are negligible in the $\mathrm{H}-\mathrm{HSO}_{4}-\mathrm{SO}_{4}$ system, but are not always negligible in the $\mathrm{Na}-\mathrm{HSO}_{4}-\mathrm{SO}_{4}$ system. In an earlier paper, Holmes and Mesmer (1992 [DIRS 162076]) did not account for these interactions. Exact agreement was obtained between the osmotic coefficients for the limiting binary solutions, $\mathrm{H}-\mathrm{HSO}_{4}$ and $\mathrm{H}_{2} \mathrm{SO}_{4}$, calculated by the ternary and the binary spreadsheets, for both input and fitted Pitzer parameters. The osmotic coefficients were calculated for arbitrary speciations that range from one pure component to the other, but under real conditions the equilibrium ionic concentrations would be determined by iterative speciation calculations. The $\mathrm{H}-\mathrm{HSO}_{4}-\mathrm{SO}_{4}$ ternary system ionic strength differs from stoichiometric value because of incomplete disassociation of hydrogen ions from the bisulfate ions. The dependence of the actual ionic strength of the solution on the degree of dissociation of the sulfuric acid leads to a strong dependence of the ionic strength on the molality and temperature of the solution. For example, using the degree of dissociation given in Figure 3 of Holmes and Mesmer (1992 [DIRS 162076]) the degree of sulfuric acid dissociation in Table I-26 can be estimated.

Table I-26. Comparison of the Degree of Sulfuric Acid Dissociation as a Function of Temperature and lonic Strength

\begin{tabular}{|c|c|c|c|c|}
\hline $\begin{array}{c}\text { Temperature } \\
\left({ }^{\circ} \mathrm{C}\right)\end{array}$ & $\begin{array}{c}\text { Disassociation } \\
\% \mathrm{SO}_{4}{ }^{2-}\end{array}$ & $\begin{array}{c}\text { Stoichiometric } \\
\text { Molality } \\
(\mathrm{mol} / \mathrm{kg})\end{array}$ & $\begin{array}{c}\text { Stoichiometric } \\
\text { Ionic Strength } \\
\text { (mol/kg) }\end{array}$ & $\begin{array}{c}\text { Actual lonic } \\
\text { Strength } \\
\text { (mol/kg) }\end{array}$ \\
\hline 25 & 17 & 4 & 12 & 5.4 \\
\hline 100 & 4 & 4 & 12 & 4.3 \\
\hline 175 & 1.5 & 4 & 12 & 4.1 \\
\hline
\end{tabular}

The ionic strengths given in the last column of the above table were calculated from the values given in the 2 nd and 3 rd columns using the equation:

Actual Ionic Strength $=[1+2 *(\text { Fractional Disassociation })]^{*}($ Stoichiometric Molality $)$. 
Because the data reported in this paper were based on stoichiometric molalities that only ranged from 0.5 to $5.6 \mathrm{~mol} / \mathrm{kg}$ (depending on temperature), the osmotic coefficients calculated at certain high ionic strengths fall outside the valid range of ionic strengths for their model.

\section{I.4.5.14 Ions: $\mathrm{Na}^{+}-\mathrm{Cl}^{-}-\mathrm{SO}_{4}{ }^{2-}$}

Associated Spreadsheet: FitPitzerNC_MXX_Na_Cl_SO4.xls

Source: Greenberg and Møller 1989 [DIRS 152684].

Description: Input parameters and equations from Greenberg and Møller (1989 [DIRS 152684]) were verified for $\psi$ and $A^{\phi}$. Greenberg and Møller (1989 [DIRS 152684]) use $\theta=0.07$ for 0 to $150^{\circ} \mathrm{C}$ and $\psi=-0.009$ for 0 to $250^{\circ} \mathrm{C}$. De Lima and Pitzer (1983 [DIRS 162110]) fitted the Na$\mathrm{Cl}-\mathrm{SO}_{4}$ system solubilities from 25 to $100{ }^{\circ} \mathrm{C}$ with $\theta=-0.02$ and $\psi=0.004$ taken from an earlier evaluation by Pitzer at $25^{\circ} \mathrm{C}$ (Pitzer 1979 [DIRS 152738]). In the latter model higher order electrostatic interaction terms ${ }^{E} \theta$ and ${ }^{E} \theta^{\prime}$ were not included. In Pitzer (1991 [DIRS 152709]), the higher order interaction terms were included with $\theta=0.030$ and $\psi=0.0$ at $25^{\circ} \mathrm{C}$. Both of these studies imply that ternary mixing contributions to the osmotic coefficient are small, but that the mixing parameter values should always be evaluated in combination with the binary and other ternary parameters for the electrolyte system. It should be noted here, that the osmotic coefficient values presented in the spreadsheet for an ionic strength of $\mathrm{I}=18 \mathrm{~mol} / \mathrm{kg}$ may not be realistic because they fall outside the range of validity of the model parameters. The input temperature function given by Greenberg and Møller (1989 [DIRS 152684]) for the $\psi$ parameter is discontinuous with a constant value assigned from 0 to $150{ }^{\circ} \mathrm{C}$ and with varying values over the temperature range of 150 to $250{ }^{\circ} \mathrm{C}$. Since a single continuous output function was adopted over the entire 0 to $250{ }^{\circ} \mathrm{C}$ range, the fitting equation loses accuracy around $150{ }^{\circ} \mathrm{C}$ resulting in a maximum error of about $20 \%$ at this temperature. Exact agreement was obtained between the osmotic coefficients for the limiting binary solutions, $\mathrm{NaCl}(\mathrm{aq})$ and $\mathrm{Na}_{2} \mathrm{SO}_{4}(\mathrm{aq})$, calculated by the ternary and the binary spreadsheets, for both input and fitted Pitzer parameters.

\section{I.4.5.15 Ions: $\mathrm{Na}^{+}-\mathrm{HSO}_{4}^{-}-\mathrm{SO}_{4}{ }^{2-}$}

Associated Spreadsheet: FitPitzerNC_MXX_Na_HSO4_SO4.xls

Source: Holmes and Mesmer 1994 [DIRS 162078].

Description: Input parameters and equations from Holmes and Mesmer (1994 [DIRS 162078]) were verified for $\psi$. They regressed the model parameters simultaneously for the $\mathrm{H}-\mathrm{HSO}_{4}-\mathrm{SO}_{4}$ and $\mathrm{Na}-\mathrm{HSO}_{4}-\mathrm{SO}_{4}$ systems, including the ${ }^{E} \theta$ and ${ }^{E} \theta^{\prime}$ higher order electrostatic interactions. Clegg et al. (1994 [DIRS 152734]) were able to fit the properties of sulfuric acid without including both the $\theta$ and $\psi$ Pitzer mixing parameters, but with an additional $\mathrm{C}(1)$ extended binary ion-interaction parameter and the ${ }^{E} \theta$ and ${ }^{E} \theta^{\prime}$ higher order electrostatic interaction parameters. It was found by Clegg et al. (1994 [DIRS 152734]) that these model enhancements were significant in improving the accuracy of the fit at concentrations much lower than those considered by Holmes and Mesmer (1994 [DIRS 162078]). Both of these studies imply that the contributions of the ternary mixing parameters are negligible in the $\mathrm{H}-\mathrm{HSO}_{4}-\mathrm{SO}_{4}$ system, but are 
not always negligible in the $\mathrm{Na}-\mathrm{HSO}_{4}-\mathrm{SO}_{4}$ system. In an earlier paper by Holmes and Mesmer (1993 [DIRS 162077]), the authors did not account for these higher order electrostatic interactions. Exact agreement was obtained between the osmotic coefficients for the limiting binary solutions, $\mathrm{NaHSO}_{4}(\mathrm{aq})$ and $\mathrm{Na}_{2} \mathrm{SO}_{4}(\mathrm{aq})$, calculated by the ternary and the binary spreadsheets, for both input and fitted Pitzer parameters. The osmotic coefficients were calculated for arbitrary speciations that range from one pure component to the other, but under real conditions the equilibrium ionic concentrations would be determined by iterative speciation calculations. The Na-H-HSO $4-\mathrm{SO}_{4}$ system ionic strength differs from stoichiometric value because of incomplete disassociation of hydrogen ions from the bisulfate ions. The dependence of the actual ionic strength of the solution on the degree of dissociation of the bisulfate ion leads to a strong dependence of the ionic strength on the molality and temperature of the solution. The osmotic coefficients calculated at certain high ionic strengths, especially for solutions with high molality fractions of $\mathrm{Na}_{2} \mathrm{SO}_{4}$, fall outside the valid range of ionic strengths for their model. The temperature range of 0 to $250{ }^{\circ} \mathrm{C}$ also falls outside the range $\left(25\right.$ to $\left.225^{\circ} \mathrm{C}\right)$ of parameterization of the model.

\section{I.4.5.16 Neutral Species: Doublets and Triplets Parameters Among $\mathrm{SiO}_{2}(\mathrm{aq}), \mathrm{CO}_{2}(\mathrm{aq})$, and $\mathrm{O}_{2}(\mathbf{a q})$}

See Table I-1 for a listing of doublets and triplets parameters among $\mathrm{SiO}_{2}(\mathrm{aq}), \mathrm{CO}_{2}(\mathrm{aq})$, and $\mathrm{O}_{2}(\mathrm{aq})$.

Associated Spreadsheets: FitPitzerNC_NaHCO3_Na2CO3_CFJC.xls, FitPitzerNC_lambdas_zetas_O2_CFJC.xls, and Pitzer_NMX_SiO2.xls

Source: He and Morse 1993 [DIRS 162090], Clegg and Brimblecombe 1990 [DIRS 162089], and Felmy et al. 1994 [DIRS 162111].

\section{Description:}

- Acid Carbonate System (data source: He and Morse 1993 [DIRS 162090]): The binary, lambda $(\lambda)$, and ternary, zeta $(\zeta)$, parameters for $\mathrm{CO}_{2}(\mathrm{aq})$ listed by He and Morse (1993 [DIRS 162090]) up to a temperature of $90^{\circ} \mathrm{C}$ were refitted and verified against their reported values in Table 4 of the source. The refit resulted in an exact match given the few data points and limited temperature range from 25 to $90^{\circ} \mathrm{C}$. In validating these parameters, calcite solubility was modeled at $60^{\circ} \mathrm{C}$ using EQ3/6 Version 8.0 with increasing $\mathrm{NaCl}$ concentration at a fixed partial pressure of $\mathrm{CO}_{2}$ of $\sim 0.0078$ bars and compared visually with that depicted in Figure 6A of He and Morse (1993 [DIRS 162090]). A reasonable agreement was obtained between the curves depicted in this figure and the author's model. Minor differences could be attributed to a different set of $\log \mathrm{K}$ 's representing calcite and $\mathrm{CO}_{2}(\mathrm{~g})$ solubility, which in this case were taken from the data0.ymp.R2 database. Visual comparison of the ion activity product calculated from these computations is very close to that depicted in Figure 8 of $\mathrm{He}$ and Morse (1993 [DIRS 162090]). Some fairly large discrepancies were found when the reported fitting coefficients and the associated equations to reproduce parameter values from the source (He and Morse 1993 [DIRS 162090], Table 6) were used. The fitting equations in the source failed to reproduce their tabulated values as a function of temperature. For 
this reason, the refitting was done on the original source data listed in Table 4 of He and Morse (1993 [DIRS 162090]).

- $\mathrm{O}_{2}$ solubility (data source: Clegg and Brimblecombe, 1990 [DIRS 162089]): Parameters representing binary neutral-cation (NM and NX), $\left(\lambda_{\mathrm{NM}}, \lambda_{\mathrm{NX}}\right)$, and ternary neutral-cation-anion (NMX) ( $\left.\zeta_{\mathrm{NMX}}\right)$ interactions were obtained from the source equations and compared to data parameters reported by Clegg and Brimblecombe (1990 [DIRS 162089]). The authors used $\mathrm{O}_{2}$ solubility data from multiple sources. The generated parameters were refitted to almost the exact value reported by the authors. Visual comparison of reported activity coefficients at $298.15 \mathrm{~K}$ for $\mathrm{O}_{2}$ (aq) depicted in Clegg and Brimblecombe (1990 [DIRS 162089]) in the presence of various salts such as $\mathrm{NaNO}_{3}, \mathrm{NaCl}$, and $\mathrm{MgCl}_{2}$ at relatively high concentrations indicate a strong agreement with computed values using EQ3/6 Version 8.0. Due to the manner in which the authors treated their model (i.e., selection of solubility data from different origins and, in many cases, applying density conversions), a straightforward comparison or corroboration with alternate data sources was not possible. The authors parameterized the model up to $100{ }^{\circ} \mathrm{C}$ but many of the ion parameters for some doublets and triplets do not have temperature dependence and are given only at $298.15 \mathrm{~K}$.

- $\mathrm{SiO}_{2}$ (aq) (data source: Felmy et al. 1994 [DIRS 162111]): Parameters representing binary neutral-cation (NM and $\mathrm{NX}),\left(\lambda_{\mathrm{NM}}\right.$ and $\left.\lambda_{\mathrm{NX}}\right)$, and ternary neutral-cation-anion (NMX), ( $\left.\zeta_{\text {NMX }}\right)$ interactions were obtained from the relevant source equations and compared with those reported by Felmy et al. (1994 [DIRS 162111]). The parameter fitting was based on experimental data on amorphous silica solubility at elevated temperatures as a function electrolyte type and concentration as reported by Marshall (1980 [DIRS 162085]), Marshall (1980 [DIRS 160481]), Marshall and Warakomski (1980 [DIRS 160483]), Marshall and Chen (1982 [DIRS 162086]), Marshall and Chen (1982 [DIRS 162087]), and Chen and Marshall (1982 [DIRS 160453]). In some cases, the authors needed to vary not only the parameter but also the standard chemical potential defining the equilibrium between solution and solid phase. According to Felmy et al. (1994 [DIRS 162111]), the standard chemical potential of amorphous silica was one of the most difficult parameters to fix for the ion interaction parameter fitting. As explained by Felmy et al. (1994 [DIRS 162111]) and Marshall (1980 [DIRS 162085]), the complex nature and ill-defined particle size of this phase, together with experimental difficulties, could create significant variability in solubility data under different temperatures and electrolyte concentrations. Another possible source for discrepancies is the use of different Pitzer parameters for some binary salts than those used by Felmy et al. (1994 [DIRS 162111]). Further, the log K values for amorphous silica in the current data0.ypf database are taken from the data0.ymp.R2 database. Therefore, differences between calculated amorphous silica solubility and that reported by Felmy et al. (1994 [DIRS 162111]) are expected. Due to the apparent variability in reported values for this phase, no attempt was made to fit amorphous silica solubility or to reproduce the values presented in Felmy et al. (1994 [DIRS 162111]). Nevertheless, a validation test involving a visual comparison of the prediction of amorphous silica as a function of $\mathrm{NaNO}_{3}$ at $25^{\circ} \mathrm{C}$ with the Felmy et al. (1994 [DIRS 162111], Figure 3a) model, suggests differences that are approximately 2 to $15 \%$ of those they report. At 
$100^{\circ} \mathrm{C}$ (Felmy et al. 1994 [DIRS 162111], Figure 3b), the differences are slightly smaller at low $\mathrm{NaNO}_{3}$ concentrations but they increase significantly at concentrations larger than 2 molal. Prediction of amorphous silica solubility in other electrolytes shows approximately the same magnitude of uncertainties. Overall, these differences appear to be reasonable given the plausible existence of uncertainties in the amorphous silica solubility data and the different $\log \mathrm{K}$ 's used in the calculations to represent the equilibrium solubility of this phase.. The parameters for $\mathrm{SiO}_{2}(\mathrm{aq})$ are valid only for neutral to acid conditions, in keeping with the experimental range studied.

\section{I.4.5.17 Ions: MMX Ternary Parameters in the System Na-K-Mg-Cl-OH-SO}

See Table I-1 for MMX ternary parameters in the system Na-K-Mg-Cl-OH-SO . $^{-}$

Associated Spreadsheet: Pabalan_icf_TJW.xls

Source: Pabalan and Pitzer 1987 [DIRS 162096].

Description: Some ternary parameters encompassing cation(M), cation(M), and anion (X) $\left(\psi_{\mathrm{M} 1 \mathrm{M} 2 \mathrm{X}}\right)$ in the system $\mathrm{Na}-\mathrm{K}-\mathrm{Mg}-\mathrm{Cl}-\mathrm{OH}-\mathrm{SO}_{4}$ were refitted from equations and data by Pabalan and Pitzer (1987 [DIRS 162096]). Some of these parameters are expressed as constants and do not need refitting.

\section{I.4.6 VARIOUS MX AND MM PARAMETERS FROM TABLE I-2 AT $25^{\circ} \mathrm{C}$ THAT DO NOT REQUIRE REFITTING}

Associated Spreadsheets: Some2-1Salts25C_TJW.xls and Some1-1Salts25C_TJW.xls

Source: Pitzer 1991 [DIRS 152709] (no spreadsheet in Table I-2 means that values were taken directly from the tables in this source).

Description: Binary and ternary parameters reported at $25^{\circ} \mathrm{C}$ in Pitzer (1991 [DIRS 152709]) were also incorporated in the data0.ypf database. These parameters did not require any refitting but are expressed in the source as the product of the parameter multiplied by constant factors. The associated spreadsheets recalculate the parameter value without the multipliers so these can be incorporated in the data0.ypf database file.

\section{I.5 DATA FOR SOLID PHASES, AQUEOUS SPECIES AND GASES}

The majority of solid phases included in the data0.ypf database in the form of $\log \mathrm{K}$ data to represent solubility are taken from the data0.ymp.R2 database (DTN: MO0302SPATHDYN.000 [DIRS 161756]; see Table I-27) or derived from thermodynamic data for solids reported by Barin and Platzki (1995 [DIRS 157865]). Log K data for most salt phases are taken from various sources such as Harvie et al. (1984 [DIRS 118163]), Greenberg and Møller (1989 [DIRS 152684]), and Pabalan and Pitzer (1987 [DIRS 162096]) which is in many cases given in the form of standard chemical potentials (see Table I-28 for spreadsheets Minerals_gmo.xls and Minerals_hmw.xls). For a few salts $\left(\mathrm{CaCl}_{2}, \mathrm{Na}_{2} \mathrm{CO}_{3}: \mathrm{H}_{2} \mathrm{O}\right.$, and $\left.\mathrm{NaNO}_{3}\right)$, solubility data in the literature were scant and $\log \mathrm{K}$ values for the salt dissolution reactions were estimated from combined sources of thermodynamic data such as heat capacity and standard enthalpy. For these 
few salts, these data were used with the code SUPCRT92 Version 1.0 (STN: 10058-1.0-00) by addition to the SUPCRT92 thermodynamic database. The SUPCRT92 configuration run file (liqvap.con) and output files used for the Windows NT (suptest.tab in supcrt92test_Yueting_Chen.zip) and Windows 2000 (nano3_soda_niter.tab, thermonatrite.tab, cacl2_solub.tab) runs are included in the DTN SN0306T0510102.007. Also included in this DTN is the input file 'supcrt_runs.rxn' that describes the input reactions for salt dissolution as used in all SUPCRT92 runs. The modified SUPCRT92 thermodynamic database (sprons96_mod2.dat and dprons96_mod2.dat) is included in the DTN: SN0306T0510102.007. In a similar fashion, MS Excel spreadsheet calculations were used to calculate the many log K's for reactions denoting salt solubility using this type of thermodynamic data as a source. Either approach allowed for the initial estimates of $\log \mathrm{K}$ values which were then modified and fitted to the Pitzer activity model of the relevant system to predict the reported salt saturation molality values obtained from recognized sources such as Linke (1965 [DIRS 166191]), among others. This is done to bridge consistency between the activity model and salt solubility within the bounds of model applicability to accurately predict saturation molalities for the relevant salt. This type of fitting and optimization approach is necessary given the multiple sources of data obtained in different ways (e.g., calorimetry vs. solubility). The resulting differences in $\log$ K's before and after fitting were reasonable given the associated uncertainties. Information on the fitting procedure and results is detailed in the corresponding Excel spreadsheets given in Table I-29. Only information on salt $\log \mathrm{K}$ 's that required fitting, the $\mathrm{CaCl}_{2}$ hydrates, thermonatrite $\left(\mathrm{Na}_{2} \mathrm{CO}_{3}: \mathrm{H}_{2} \mathrm{O}\right)$, and soda niter $\left(\mathrm{NaNO}_{3}\right)$, will be summarized below. As mentioned above, $\log \mathrm{K}$ values for other salt solids were obtained from Greenberg and Møller (1989 [DIRS 152684]) and Pabalan and Pitzer (1987 [DIRS 162096]) where no solubility constant fitting/optimization was needed due to their self-consistency with the Pitzer activity model of salt components adopted in this database development. Log K's of aqueous species were also taken from the data0.ymp.R2 database (see Tables I-30 and I-31) except for $\mathrm{CaSO}_{4}(\mathrm{aq})$ which was taken directly from Greenberg and Møller (1989 [DIRS 152684]) to be consistent with their activity model. Two redox related auxiliary species $\left(\mathrm{NH}_{4}{ }^{+}\right.$and $\left.\mathrm{NO}_{2}{ }^{-}\right)$data were also derived from data0.ymp.R2 but were obtained through a combination of reaction $\log \mathrm{K}$ 's to generate the values incorporated in data0.ypf. The $\log \mathrm{K}$ values for the gases were also obtained from the data0.ymp.R2 database. Table I-27 through Table I-32 below show a list of solid phases, aqueous species, and gases plus relevant spreadsheets where calculations of log K's were performed. 
Table I-27. Solid Minerals Sourced from the Data0.ymp.R2 Database

\begin{tabular}{|c|c|}
\hline Solid Mineral & Molecular Formula \\
\hline Albite & $\mathrm{NaAlSi}_{3} \mathrm{O}_{8}$ \\
\hline Alunite & $\mathrm{KAl}_{3}(\mathrm{OH})_{6}\left(\mathrm{SO}_{4}\right)_{2}$ \\
\hline Amesite-7A & $\mathrm{Mg}_{2} \mathrm{Al}_{2} \mathrm{SiO}_{5}(\mathrm{OH})_{4}$ \\
\hline Amesite-14A & $\mathrm{Mg}_{4} \mathrm{Al}_{4} \mathrm{Si}_{2} \mathrm{O}_{10}(\mathrm{OH})_{8}$ \\
\hline Analcime & $\mathrm{Na}_{0.96} \mathrm{Al}_{0.96} \mathrm{Si}_{2.04} \mathrm{O}_{6}: \mathrm{H}_{2} \mathrm{O}$ \\
\hline Analcime-dehy & $\mathrm{Na}_{0.96} \mathrm{Al}_{0.96} \mathrm{Si}_{2.04} \mathrm{O}_{6}$ \\
\hline Aragonite & $\mathrm{CaCO}_{3}$ \\
\hline Artinite & $\mathrm{Mg}_{2} \mathrm{CO}_{3}(\mathrm{OH})_{2}: 3 \mathrm{H}_{2} \mathrm{O}$ \\
\hline Beidellite-Mg & $\mathrm{Mg}_{0.165} \mathrm{Al}_{2.33} \mathrm{Si}_{3.67} \mathrm{O}_{10}(\mathrm{OH})_{2}$ \\
\hline Beidellite-Ca & $\mathrm{Ca}_{0.165} \mathrm{Al}_{2.33} \mathrm{Si}_{3.67} \mathrm{O}_{10}(\mathrm{OH})_{2}$ \\
\hline Beidellite-K & $\mathrm{K}_{0.33} \mathrm{Al}_{2.33} \mathrm{Si}_{3.67} \mathrm{O}_{10}(\mathrm{OH})_{2}$ \\
\hline Beidellite-Na & $\mathrm{Na}_{0.33} \mathrm{Al}_{2.33} \mathrm{Si}_{3.67} \mathrm{O}_{10}(\mathrm{OH})_{2}$ \\
\hline Beidellite-H & $\mathrm{H}_{0.33} \mathrm{Al}_{2.33} \mathrm{Si}_{3.67} \mathrm{O}_{10}(\mathrm{OH})_{2}$ \\
\hline Boehmite & $\mathrm{AlOOH}$ \\
\hline Brucite & $\mathrm{Mg}(\mathrm{OH})_{2}$ \\
\hline Calcite & $\mathrm{CaCO}_{3}$ \\
\hline Celadonite & $\mathrm{KMgAISi}_{4} \mathrm{O}_{10}(\mathrm{OH})_{2}$ \\
\hline Celestite & $\mathrm{SrSO}_{4}$ \\
\hline Chabazite & $\mathrm{K}_{0.6} \mathrm{Na}_{0.2} \mathrm{Ca}_{1.55} \mathrm{Al}_{3.8} \mathrm{Si}_{8.2} \mathrm{O}_{24}: 10 \mathrm{H}_{2} \mathrm{O}$ \\
\hline Chamosite-7A & $\mathrm{Fe}_{2} \mathrm{Al}_{2} \mathrm{SiO}_{5}(\mathrm{OH})_{4}$ \\
\hline Clinoptilolite & $\mathrm{Na}_{0.954} \mathrm{~K}_{0.543} \mathrm{Ca}_{0.761} \mathrm{Mg}_{0.124} \mathrm{Sr}_{0.036} \mathrm{Ba}_{0.062} \mathrm{Mn}_{0.002} \mathrm{Al}_{3.45} \mathrm{~F}$ \\
\hline Clinoptilolite-dehy & $\mathrm{Sr}_{0.036} \mathrm{Mg}_{0.124} \mathrm{Ca}_{0.761} \mathrm{Mn}_{0.002} \mathrm{Ba}_{0.062} \mathrm{~K}_{0.543} \mathrm{Na}_{0.954} \mathrm{Al}_{3.45} \mathrm{~F}$ \\
\hline Clinoptilolite-Ca & $\mathrm{Ca}_{1.7335} \mathrm{Al}_{3.45} \mathrm{Fe}_{0.017} \mathrm{Si}_{14.533} \mathrm{O}_{36}: 10.922 \mathrm{H}_{2} \mathrm{O}$ \\
\hline Clinoptilolite-Cs & $\mathrm{Ca}_{3.467} \mathrm{Al}_{3.45} \mathrm{Fe}_{0.017} \mathrm{Si}_{14.533} \mathrm{O}_{36}: 10.922 \mathrm{H}_{2} \mathrm{O}$ \\
\hline Clinoptilolite-K & $\mathrm{K}_{3.467} \mathrm{Al}_{3.45} \mathrm{Fe}_{0.017} \mathrm{Si}_{14.533} \mathrm{O}_{36}: 10.922 \mathrm{H}_{2} \mathrm{O}$ \\
\hline Clinoptilolite-NH4 & $\left(\mathrm{NH}_{4}\right)_{3.467} \mathrm{Al}_{3.45} \mathrm{Fe}_{0.017} \mathrm{Si}_{14.533} \mathrm{O}_{36}: 10.922 \mathrm{H}_{2} \mathrm{O}$ \\
\hline Clinoptilolite-Na & $\mathrm{Na}_{3.467} \mathrm{Al}_{3.45} \mathrm{Fe}_{0.017} \mathrm{Si}_{14.533} \mathrm{O}_{36}: 10.922 \mathrm{H}_{2} \mathrm{O}$ \\
\hline Clinoptilolite-Sr & $\mathrm{Sr}_{1.7335} \mathrm{Al}_{3.45} \mathrm{Fe}_{0.017} \mathrm{Si}_{14.533} \mathrm{O}_{36}: 10.922 \mathrm{H}_{2} \mathrm{O}$ \\
\hline Corundum & $\mathrm{Al}_{2} \mathrm{O}_{3}$ \\
\hline Cristobalite(alpha) & $\mathrm{SiO}_{2}$ \\
\hline Cronstedtite-7A & $\mathrm{Fe}_{2} \mathrm{Fe}_{2} \mathrm{SiO}_{5}(\mathrm{OH})_{4}$ \\
\hline Daphnite-14A & $\mathrm{Fe}_{5} \mathrm{AlAISi}_{3} \mathrm{O}_{10}(\mathrm{OH})_{8}$ \\
\hline Daphnite-7A & $\mathrm{Fe}_{5} \mathrm{AlAISi}_{3} \mathrm{O}_{10}(\mathrm{OH})_{8}$ \\
\hline Dawsonite & $\mathrm{NaAlCO}_{3}(\mathrm{OH})_{2}$ \\
\hline Dolomite & $\mathrm{CaMg}\left(\mathrm{CO}_{3}\right)_{2}$ \\
\hline Erionite & $\mathrm{K}_{1.5} \mathrm{Na}_{0.9} \mathrm{Ca}_{0.9} \mathrm{Al}_{4.2} \mathrm{Si}_{13.8} \mathrm{O}_{36}: 13 \mathrm{H}_{2} \mathrm{O}$ \\
\hline Ferroaluminoceladonite & $\mathrm{KFeAISi}_{4} \mathrm{O}_{10}(\mathrm{OH})_{2}$ \\
\hline Ferroceladonite & $\mathrm{KFeFeSi}_{4} \mathrm{O}_{10}(\mathrm{OH})_{2}$ \\
\hline $\mathrm{Fe} 2(\mathrm{MoO} 4) 3$ & $\mathrm{Fe}_{2}\left(\mathrm{MoO}_{4}\right)_{3}$ \\
\hline FeF3 & $\mathrm{FeF}_{3}$ \\
\hline $\mathrm{Fe}(\mathrm{OH}) 3$ & $\mathrm{Fe}(\mathrm{OH})_{3}$ \\
\hline $\mathrm{Fe} 2(\mathrm{SO} 4) 3$ & $\mathrm{Fe}_{2}\left(\mathrm{SO}_{4}\right)_{3}$ \\
\hline Fluorapatite & $\mathrm{Ca}_{5}\left(\mathrm{PO}_{4}\right)_{3} \mathrm{~F}$ \\
\hline
\end{tabular}


Table I-27. Solid Minerals Sourced from the Data0.ymp.R2 Database (Continued)

\begin{tabular}{|c|c|}
\hline Solid Mineral & Molecular Formula \\
\hline Fluorite & $\mathrm{CaF}_{2}$ \\
\hline Gibbsite & $\mathrm{Al}(\mathrm{OH})_{3}$ \\
\hline Goethite & $\mathrm{FeOOH}$ \\
\hline Greenalite & $\mathrm{Fe}_{3} \mathrm{Si}_{2} \mathrm{O}_{5}(\mathrm{OH})_{4}$ \\
\hline Hematite & $\mathrm{Fe}_{2} \mathrm{O}_{3}$ \\
\hline Heulandite & $\mathrm{Ba}_{0.065} \mathrm{Sr}_{0.175} \mathrm{Ca}_{0.585} \mathrm{~K}_{0.132} \mathrm{Na}_{0.383} \mathrm{Al}_{2.165} \mathrm{Si}_{6.835} \mathrm{O}_{18}: 6 \mathrm{H}_{2} \mathrm{O}$ \\
\hline Huntite & $\mathrm{CaMg}_{3}\left(\mathrm{CO}_{3}\right)_{4}$ \\
\hline Hydroxylapatite & $\mathrm{Ca}_{5}(\mathrm{OH})\left(\mathrm{PO}_{4}\right)_{3}$ \\
\hline Hydromagnesite & $\mathrm{Mg}_{5}\left(\mathrm{CO}_{3}\right)_{4}(\mathrm{OH})_{2}: 4 \mathrm{H}_{2} \mathrm{O}$ \\
\hline Illite & $\mathrm{K}_{0.6} \mathrm{Mg}_{0.25} \mathrm{Al}_{1.8} \mathrm{Al}_{0.5} \mathrm{Si}_{3.5} \mathrm{O}_{10}(\mathrm{OH})_{2}$ \\
\hline Jarosite & $\mathrm{KFe}_{3}\left(\mathrm{SO}_{4}\right)_{2}(\mathrm{OH})_{6}$ \\
\hline Jarosite-Na & $\mathrm{NaFe}_{3}\left(\mathrm{SO}_{4}\right)_{2}(\mathrm{OH})_{6}$ \\
\hline K-Feldspar & $\mathrm{KalSi}_{3} \mathrm{O}_{8}$ \\
\hline $\mathrm{K} 2 \mathrm{CO} 3: 1.5 \mathrm{H} 2 \mathrm{O}$ & $\mathrm{K}_{2} \mathrm{CO}_{3}: 1.5 \mathrm{H}_{2} \mathrm{O}$ \\
\hline Kaolinite & $\mathrm{Al}_{2} \mathrm{Si}_{2} \mathrm{O}_{5}(\mathrm{OH})_{4}$ \\
\hline $\mathrm{KMgCl} 3: 2 \mathrm{H} 2 \mathrm{O}$ & $\mathrm{KMgCl}_{3}: 2 \mathrm{H}_{2} \mathrm{O}$ \\
\hline Lansfordite & $\mathrm{MgCO}_{3}: 5 \mathrm{H}_{2} \mathrm{O}$ \\
\hline Laumontite & $\mathrm{K}_{0.2} \mathrm{Na}_{0.2} \mathrm{Ca}_{1.8} \mathrm{Al}_{4} \mathrm{Si}_{8.0} \mathrm{O}_{24}: 8 \mathrm{H}_{2} \mathrm{O}$ \\
\hline Lime & $\mathrm{CaO}$ \\
\hline Magnesite & $\mathrm{MgCO}_{3}$ \\
\hline Maximum_Microcline & $\mathrm{KAISi}_{3} \mathrm{O}_{8}$ \\
\hline Mesolite & $\mathrm{Na}_{0.676} \mathrm{Ca}_{0.657} \mathrm{Al}_{1.99} \mathrm{Si}_{3.01} \mathrm{O}_{10}: 2.647 \mathrm{H}_{2} \mathrm{O}$ \\
\hline Minnesotaite & $\mathrm{Fe}_{3} \mathrm{Si}_{4} \mathrm{O}_{10}(\mathrm{OH})_{2}$ \\
\hline $\mathrm{MoO} 2 \mathrm{Cl} 2$ & $\mathrm{MoO}_{2} \mathrm{Cl}_{2}$ \\
\hline Molysite & $\mathrm{FeCl}_{3}$ \\
\hline Montmorillonite-H & $\mathrm{H}_{0.33} \mathrm{Mg}_{0.33} \mathrm{Al}_{1.67} \mathrm{Si}_{4} \mathrm{O}_{10}(\mathrm{OH})_{2}$ \\
\hline Montmorillonite-Na & $\mathrm{Na}_{0.33} \mathrm{Mg}_{0.33} \mathrm{Al}_{1.67} \mathrm{Si}_{4} \mathrm{O}_{10}(\mathrm{OH})_{2}$ \\
\hline Montmorillonite-K & $\mathrm{K}_{0.33} \mathrm{Mg}_{0.33} \mathrm{Al}_{1.67} \mathrm{Si}_{4} \mathrm{O}_{10}(\mathrm{OH})_{2}$ \\
\hline Montmorillonite-Ca & $\mathrm{K}_{0.165} \mathrm{Mg}_{0.33} \mathrm{Al}_{1.67} \mathrm{Si}_{4} \mathrm{O}_{10}(\mathrm{OH})_{2}$ \\
\hline Montmorillonite-Mg & $\mathrm{Mg}_{0.495} \mathrm{Al}_{1.67} \mathrm{Si}_{4} \mathrm{O}_{10}(\mathrm{OH})_{2}$ \\
\hline Mordenite & $\mathrm{Ca}_{0.2895} \mathrm{Na}_{0.361} \mathrm{Al}_{0.94} \mathrm{Si}_{5.06} \mathrm{O}_{12}: 3.468 \mathrm{H}_{2} \mathrm{O}$ \\
\hline Natrolite & $\mathrm{Na}_{2} \mathrm{Al}_{2} \mathrm{Si}_{3} \mathrm{O}_{10}: 2 \mathrm{H}_{2} \mathrm{O}$ \\
\hline Nesquehonite & $\mathrm{MgCO}_{3}: 3 \mathrm{H}_{2} \mathrm{O}$ \\
\hline Nontronite-Mg & $\mathrm{Mg}_{0.165} \mathrm{Fe}_{2} \mathrm{Al}_{0.33} \mathrm{Si}_{3.67} \mathrm{H}_{2} \mathrm{O}_{12}$ \\
\hline Nontronite-Ca & $\mathrm{Ca}_{0.165} \mathrm{Fe}_{2} \mathrm{Al}_{0.33} \mathrm{Si}_{3.67} \mathrm{H}_{2} \mathrm{O}_{12}$ \\
\hline Nontronite-K & $\mathrm{K}_{0.33} \mathrm{Fe}_{2} \mathrm{Al}_{0.33} \mathrm{Si}_{3.67} \mathrm{H}_{2} \mathrm{O}_{12}$ \\
\hline Nontronite-Na & $\mathrm{Na}_{0.33} \mathrm{Fe}_{2} \mathrm{Al}_{0.33} \mathrm{Si}_{3.67} \mathrm{H}_{2} \mathrm{O}_{12}$ \\
\hline Nontronite-H & $\mathrm{H}_{0.33} \mathrm{Fe}_{2} \mathrm{Al}_{0.33} \mathrm{Si}_{3.67} \mathrm{H}_{2} \mathrm{O}_{12}$ \\
\hline Phillipsite & 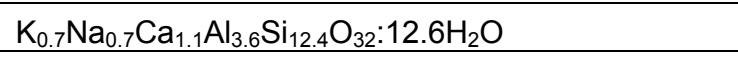 \\
\hline Portlandite & $\mathrm{Ca}(\mathrm{OH})_{2}$ \\
\hline Pyrolusite & $\mathrm{MnO}_{2}$ \\
\hline
\end{tabular}


Table I-27. Solid Minerals Sourced from the Data0.ymp.R2 Database (Continued)

\begin{tabular}{|l|l|}
\hline \multicolumn{1}{|c|}{ Solid Mineral } & \multicolumn{1}{c|}{ Molecular Formula } \\
\hline Pyrophyllite & $\mathrm{Al}_{2} \mathrm{Si}_{4} \mathrm{O}_{10}(\mathrm{OH})_{2}$ \\
\hline Quartz & $\mathrm{SiO}_{2}$ \\
\hline Ripidolite-7A & $\mathrm{Mg}_{3} \mathrm{Fe}_{2} \mathrm{Al}_{2} \mathrm{Si}_{3} \mathrm{O}_{10}(\mathrm{OH})_{8}$ \\
\hline Ripidolite-14A & $\mathrm{Mg}_{3} \mathrm{Fe}_{2} \mathrm{Al}_{2} \mathrm{Si}_{3} \mathrm{O}_{10}(\mathrm{OH})_{8}$ \\
\hline Saponite-H & $\mathrm{H}_{0.33} \mathrm{Mg}_{3} \mathrm{Al}_{0.33} \mathrm{Si}_{3.67} \mathrm{O}_{10}(\mathrm{OH})_{2}$ \\
\hline Saponite-Na & $\mathrm{Na}_{0.33} \mathrm{Mg}_{3} \mathrm{Al}_{0.33} \mathrm{Si}_{3.67} \mathrm{O}_{10}(\mathrm{OH})_{2}$ \\
\hline Saponite-K & $\mathrm{K}_{0.33} \mathrm{Mg}_{3} \mathrm{Al}_{0.33} \mathrm{Si}_{3.67} \mathrm{O}_{10}(\mathrm{OH})_{2}$ \\
\hline Saponite-Ca & $\mathrm{Ca}_{0.165} \mathrm{Mg}_{3} \mathrm{Al}_{0.33} \mathrm{Si}_{3.67} \mathrm{O}_{10}(\mathrm{OH})_{2}$ \\
\hline Saponite-Mg & $\mathrm{Mg}_{0.165} \mathrm{Mg}_{3} \mathrm{Al}_{0.33} \mathrm{Si}_{3.67} \mathrm{O}_{10}(\mathrm{OH})_{2}$ \\
\hline Scolecite & $\mathrm{CaAl}_{2} \mathrm{Si}_{3} \mathrm{O}_{10}: 3 \mathrm{H}_{2} \mathrm{O}$ \\
\hline Sepiolite & $\mathrm{Mg}_{4} \mathrm{Si}_{6} \mathrm{O}_{15}\left(\mathrm{OH}_{2}: 6 \mathrm{H}_{2} \mathrm{O}\right.$ \\
\hline SiO2$($ am) & $\mathrm{SiO}_{2}$ \\
\hline Smectite-high-Fe-Mg & $\mathrm{Ca}_{0.025} \mathrm{Na}_{0.1} \mathrm{~K}_{0.2} \mathrm{Fe}_{0.5}^{++} \mathrm{Fe}^{+++}{ }_{0.2} \mathrm{Mg}_{1.15} \mathrm{Al}_{1.25} \mathrm{Si}_{3.5} \mathrm{H}_{2} \mathrm{O}_{12}$ \\
\hline Smectite-high-Fe-Mg & $\mathrm{Ca}_{0.02} \mathrm{Na}_{0.15} \mathrm{~K}_{0.2} \mathrm{Fe}^{++}{ }_{0.29} \mathrm{Fe}^{+++}{ }_{0.16} \mathrm{Mg}_{0.9} \mathrm{Al}_{1.25} \mathrm{Si}_{3.75} \mathrm{H}_{2} \mathrm{O}_{12}$ \\
\hline Stellerite & $\mathrm{Ca}_{2} \mathrm{Al}_{4} \mathrm{Si}_{14} \mathrm{O}_{36}: 14 \mathrm{H}_{2} \mathrm{O}$ \\
\hline Stilbite & $\mathrm{Ca}_{1.019} \mathrm{Na}_{0.136} \mathrm{~K}_{0.006} \mathrm{Al}_{2.18} \mathrm{Si}_{6.82} \mathrm{O}_{18}: 7.33 \mathrm{H}_{2} \mathrm{O}$ \\
\hline Strontianite & $\mathrm{SrCO}_{3}$ \\
\hline Talc & $\mathrm{Mg}_{3} \mathrm{Si}_{4} \mathrm{O}_{10}\left(\mathrm{OH}_{2}\right.$ \\
\hline Whitlockite & $\mathrm{Ca}_{3}\left(\mathrm{PO}_{4}\right)_{2}$ \\
\hline
\end{tabular}

Source: DTN: MO0302SPATHDYN.000 [DIRS 161756].

Table I-28. Cement Phases Sourced from the Data0.ymp.R2 Database

\begin{tabular}{|l|l|}
\hline \multicolumn{1}{|c|}{ Cement Phase } & \multicolumn{1}{c|}{ Molecular Formula } \\
\hline Afwillite & $\mathrm{Ca}_{3} \mathrm{Si}_{2} \mathrm{O}_{4}(\mathrm{OH})_{6}$ \\
\hline Allite_(C3S) & $3 \mathrm{CaO}: \mathrm{SiO}_{2}$ \\
\hline Bellite_(C2S) & $2 \mathrm{CaO}: \mathrm{SiO}_{2}$ \\
\hline (C12A7) & $12 \mathrm{CaO}: 7 \mathrm{Al}_{2} \mathrm{O}_{3}$ \\
\hline (C2AH8) & $2 \mathrm{CaO}: \mathrm{Al}_{2} \mathrm{O}_{3}: 8 \mathrm{H}_{2} \mathrm{O}$ \\
\hline (C3A) & $3 \mathrm{CaO}: \mathrm{Al}_{2} \mathrm{O}_{3}$ \\
\hline (C4AF) & $4 \mathrm{CaO}: \mathrm{Al}_{2} \mathrm{O}_{3}: \mathrm{Fe}_{2} \mathrm{O}_{3}$ \\
\hline (C4AH13) & $4 \mathrm{CaO}: \mathrm{Al}_{2} \mathrm{O}_{3}: 13 \mathrm{H}_{2} \mathrm{O}$ \\
\hline (C4AH19) & $4 \mathrm{CaO}: \mathrm{Al}_{2} \mathrm{O}_{3}: 19 \mathrm{H}_{2} \mathrm{O}$ \\
\hline (CA) & $\mathrm{CaO}: \mathrm{Al}_{2} \mathrm{O}_{3}$ \\
\hline (CA2) & $\mathrm{CaO}: 2 \mathrm{Al}_{2} \mathrm{O}_{3}$ \\
\hline (CAH10) & $\mathrm{CaO}: \mathrm{Al}_{2} \mathrm{O}_{3}: 10 \mathrm{H}_{2} \mathrm{O}$ \\
\hline CSH:1.7 & $1.7 \mathrm{Ca}\left(\mathrm{OH}_{2} \mathrm{SiO}_{2}: 0.917 \mathrm{H}_{2} \mathrm{O}\right.$ \\
\hline Ettringite & $3 \mathrm{CaO}: \mathrm{Al}_{2} \mathrm{O}_{3}: 3 \mathrm{CaSO}_{4}: 32 \mathrm{H}_{2} \mathrm{O}$ \\
\hline Ferrite-Ca & $\mathrm{CaFe}_{2} \mathrm{O}_{4}$ \\
\hline Ferrite-Dicalcium & $\mathrm{Ca}_{2} \mathrm{Fe}_{2} \mathrm{O}_{5}$ \\
\hline Ferrite-Mg & $\mathrm{MgFe}_{2} \mathrm{O}_{4}$ \\
\hline Foshagite & $\mathrm{Ca}_{4} \mathrm{Si}_{3} \mathrm{O}_{9}(\mathrm{OH})_{2}: 0.5 \mathrm{H}_{2} \mathrm{O}$ \\
\hline Friedl_salt & $\mathrm{CaCl}_{2}\left(\mathrm{CaO}_{3}: 16 \mathrm{H}_{2} \mathrm{O}\right.$ \\
\hline Gehlenate_Hydrate & $\mathrm{Ca}_{2} \mathrm{Al}_{2} \mathrm{SiO}_{7}: 8 \mathrm{H}_{2} \mathrm{O}$ \\
\hline Gismondine-Na & $\mathrm{Na}_{2} \mathrm{Al}_{2} \mathrm{Si}_{2} \mathrm{O}_{8}: 4 \mathrm{H}_{2} \mathrm{O}$ \\
\hline & \\
\hline
\end{tabular}


Table I-28. Cement Phases Sourced from the Data0.ymp.R2 Database (Continued)

\begin{tabular}{|l|l|}
\hline \multicolumn{1}{|c|}{ Cement Phase } & \multicolumn{1}{c|}{ Molecular Formula } \\
\hline Gismondine-Ca & $\mathrm{CaAl}_{2} \mathrm{Si}_{2} \mathrm{O}_{8}: 4 \mathrm{H}_{2} \mathrm{O}$ \\
\hline Gyrolite & $\mathrm{Ca}_{2} \mathrm{Si}_{3} \mathrm{O}_{7}(\mathrm{OH})_{2}: 1.5 \mathrm{H}_{2} \mathrm{O}$ \\
\hline Hemicarboaluminate & $3 \mathrm{CaOAl}_{2} \mathrm{O}_{3}: 0.5 \mathrm{CaCO}_{3}: 0.5 \mathrm{Ca}(\mathrm{OH})_{2}: 10.5 \mathrm{H}_{2} \mathrm{O}$ \\
\hline Hillebrandite & $\mathrm{Ca}_{2} \mathrm{SiO}_{3}\left(\mathrm{OH}_{2}: 0.17 \mathrm{H}_{2} \mathrm{O}\right.$ \\
\hline Hydrogarnet & $3 \mathrm{CaO}: \mathrm{Al}_{2} \mathrm{O}_{3}: 6 \mathrm{H}_{2} \mathrm{O}$ \\
\hline Hydrotalcite & $4 \mathrm{MgO}: \mathrm{Al}_{2} \mathrm{O}_{3}: 10 \mathrm{H}_{2} \mathrm{O}$ \\
\hline Monocarboaluminate & $3 \mathrm{CaOAl} \mathrm{O}_{3} \mathrm{CaCO}_{3}: 10 \mathrm{H}_{2} \mathrm{O}$ \\
\hline Monosulphate & $3 \mathrm{CaO}: \mathrm{Al}_{2} \mathrm{O}_{3}: \mathrm{CaSO}_{4}: 12 \mathrm{H}_{2} \mathrm{O}$ \\
\hline Okenite & $\mathrm{CaSi}_{2} \mathrm{O}_{4}(\mathrm{OH})_{2}: \mathrm{H}_{2} \mathrm{O}$ \\
\hline Plombierite & $\mathrm{Ca}_{5} \mathrm{Si}_{6} \mathrm{H}_{11} \mathrm{O}_{22.5}$ \\
\hline Riversideite & $\mathrm{Ca}_{5} \mathrm{H}_{2}\left(\mathrm{SiO}_{3}\right)_{6}: 2 \mathrm{H}_{2} \mathrm{O}$ \\
\hline Tobermorite & $5 \mathrm{CaO}_{6} 6 \mathrm{SiO}_{2}: 5.5 \mathrm{H}_{2} \mathrm{O}$ \\
\hline Xonotlite & $\mathrm{Ca}_{6} \mathrm{Si}_{6} \mathrm{O}_{17}(\mathrm{OH})_{2}$ \\
\hline
\end{tabular}

Source: DTN: MO0302SPATHDYN.000 [DIRS 161756].

Table I-29. Salt Solids Sourced from Various Spreadsheets

\begin{tabular}{|c|c|c|}
\hline Solid Mineral & Molecular Formula & DTN or Spreadsheet File (.xIs) \\
\hline Anhydrite & $\mathrm{CaSO}_{4}$ & Minerals_gmo \\
\hline Antarcticite & $\mathrm{CaCl}_{2}: 6 \mathrm{H}_{2} \mathrm{O}$ & cacl2_hydrates_min_cal_CFJC \\
\hline Arcanite & $\mathrm{K}_{2} \mathrm{SO}_{4}$ & Minerals_gmo \\
\hline Bischofite & $\mathrm{MgCl}_{2}: 6 \mathrm{H}_{2} \mathrm{O}$ & Solids_j_Pabalan_TJW_1 \\
\hline Bloedite & $\mathrm{Na}_{2} \mathrm{Mg}\left(\mathrm{SO}_{4}\right)_{2}: 4 \mathrm{H}_{2} \mathrm{O}$ & Minerals_hmw \\
\hline Brushite & $\mathrm{CaHPO}_{4}: 2 \mathrm{H}_{2} \mathrm{O}$ & Solids_j_Ca_TJW_1 \\
\hline Burkeite & $\mathrm{Na}_{6} \mathrm{CO}_{3}\left(\mathrm{SO}_{4}\right)_{2}$ & Minerals_hmw \\
\hline $\mathrm{CaBr} 2$ & $\mathrm{CaBr}_{2}$ & Solids_j_Ca_TJW_1 \\
\hline $\mathrm{Ca} 2 \mathrm{Cl} 2(\mathrm{OH}) 2: \mathrm{H} 2 \mathrm{O}$ & $\mathrm{Ca}_{2} \mathrm{Cl}_{2}(\mathrm{OH})_{2}: \mathrm{H}_{2} \mathrm{O}$ & Minerals_hmw \\
\hline $\mathrm{Ca} 4 \mathrm{Cl} 2(\mathrm{OH}) 6: 13 \mathrm{H} 2 \mathrm{O}$ & $\mathrm{Ca}_{4} \mathrm{Cl}_{2}(\mathrm{OH})_{6}: 13 \mathrm{H}_{2} \mathrm{O}$ & Minerals_hmw \\
\hline $\mathrm{CaCl} 2$ & $\mathrm{CaCl}_{2}$ & $\begin{array}{l}\text { cacl2_solub_tab. DTN: } \\
\text { SN0306T0510102.007 }\end{array}$ \\
\hline $\mathrm{CaCl} 2: 2 \mathrm{H} 2 \mathrm{O}$ & $\mathrm{CaCl}_{2}: 2 \mathrm{H}_{2} \mathrm{O}$ & cacl2_hydrates_min_cal_CFJC \\
\hline $\mathrm{CaCl} 2: 4 \mathrm{H} 2 \mathrm{O}$ & $\mathrm{CaCl}_{2}: 4 \mathrm{H}_{2} \mathrm{O}$ & cacl2_hydrates_min_cal_CFJC \\
\hline Cal2 & $\mathrm{Cal}_{2}$ & Solids_j_Ca_TJW_1 \\
\hline $\mathrm{Ca}(\mathrm{NO} 3) 2$ & $\mathrm{Ca}\left(\mathrm{NO}_{3}\right)_{2}$ & Solids_j_Ca_TJW_1 \\
\hline $\mathrm{Ca}(\mathrm{NO} 3) 2: 2 \mathrm{H} 2 \mathrm{O}$ & $\mathrm{Ca}\left(\mathrm{NO}_{3}\right)_{2}: 2 \mathrm{H}_{2} \mathrm{O}$ & Solids_j_Ca_TJW_1 \\
\hline $\mathrm{Ca}(\mathrm{NO} 3) 2: 3 \mathrm{H} 2 \mathrm{O}$ & $\mathrm{Ca}\left(\mathrm{NO}_{3}\right)_{2}: 3 \mathrm{H}_{2} \mathrm{O}$ & Solids_j_Ca_TJW_1 \\
\hline $\mathrm{Ca}(\mathrm{NO} 3) 2: 4 \mathrm{H} 2 \mathrm{O}$ & $\mathrm{Ca}\left(\mathrm{NO}_{3}\right)_{2}: 4 \mathrm{H}_{2} \mathrm{O}$ & Solids_j_Ca_TJW_1 \\
\hline $\mathrm{CaOHCl}$ & $\mathrm{CaOHCl}$ & Solids_j_Misc_1_TJW_11 \\
\hline Carnallite & $\mathrm{KMgCl}_{3}: 6 \mathrm{H}_{2} \mathrm{O}$ & Solids_j_Pabalan_TJW_1 \\
\hline Carobbite & $\mathrm{KF}$ & Cp_Solids___K_TJW_1 \\
\hline CaWO4 & $\mathrm{CaWO}_{4}$ & Solids___Ca_TJW_1 \\
\hline Chloromagnesite & $\mathrm{MgCl}_{2}$ & Solids_j_Pabalan_TJW_1 \\
\hline Cryolite & $\mathrm{Na}_{3} \mathrm{AlF}_{6}$ & Solids___Na_TJW_1 \\
\hline Darapskite & $\mathrm{Na}_{3} \mathrm{SO}_{4} \mathrm{NO}_{3}: \mathrm{H} 2 \mathrm{O}$ & Solids___Misc_1_TJW_11 \\
\hline
\end{tabular}


Table I-29. Salt Solids Sourced from Various Spreadsheets (Continued)

\begin{tabular}{|c|c|c|}
\hline Solid Mineral & Molecular Formula & DTN or Spreadsheet File (.xIs) \\
\hline Epsomite & $\mathrm{MgSO}_{4}: 7 \mathrm{H}_{2} \mathrm{O}$ & Minerals_hmw \\
\hline Gaylussite & $\mathrm{CaNa}_{2}\left(\mathrm{CO}_{3}\right)_{2}: 5 \mathrm{H}_{2} \mathrm{O}$ & Minerals_hmw \\
\hline Glaserite & $\mathrm{NaK}_{3}\left(\mathrm{SO}_{4}\right)_{2}$ & Minerals_hmw \\
\hline Glauberite & $\mathrm{Na}_{2} \mathrm{Ca}\left(\mathrm{SO}_{4}\right)_{2}$ & Minerals_gmo \\
\hline Gypsum & $\mathrm{CaSO}_{4}: 2 \mathrm{H}_{2} \mathrm{O}$ & Minerals_gmo \\
\hline Halite & $\mathrm{NaCl}$ & Minerals_gmo \\
\hline Hemihydrate & $\mathrm{CaSO}_{4}: 0.5 \mathrm{H}_{2} \mathrm{O}$ & Minerals_gmo \\
\hline Hexahydrite & $\mathrm{MgSO}_{4}: 6 \mathrm{H}_{2} \mathrm{O}$ & Solids_j_Pabalan_TJW_1 \\
\hline $\mathrm{K} 2 \mathrm{CO} 3$ & $\mathrm{~K}_{2} \mathrm{CO}_{3}$ & Cp_Solids_j_K_TJW_1 \\
\hline $\mathrm{K} 2 \mathrm{O}$ & $\mathrm{K}_{2} \mathrm{O}$ & Cp_Solids__K_TJW_1 \\
\hline K2Si4O9 & $\mathrm{K}_{2} \mathrm{Si}_{4} \mathrm{O}_{9}$ & Cp_Solids__K_TJW_1 \\
\hline $\mathrm{K} 3 \mathrm{H}(\mathrm{SO} 4) 2$ & $\mathrm{~K}_{3} \mathrm{H}\left(\mathrm{SO}_{4}\right)_{2}$ & Minerals_hmw \\
\hline $\mathrm{K} 8 \mathrm{H} 4(\mathrm{CO} 3) 6: 3 \mathrm{H} 2 \mathrm{O}$ & $\mathrm{K}_{8} \mathrm{H}_{4}\left(\mathrm{CO}_{3}\right)_{6}: 3 \mathrm{H}_{2} \mathrm{O}$ & Minerals_hmw \\
\hline Kainite & $\mathrm{KmgClSO}_{4}: 3 \mathrm{H}_{2} \mathrm{O}$ & Minerals_hmw \\
\hline $\mathrm{KAICl} 4$ & $\mathrm{KAICl}_{4}$ & Cp_Solids__K_TJW_1 \\
\hline $\mathrm{K} 2 \mathrm{HPO} 4$ & $\mathrm{~K}_{2} \mathrm{HPO}_{4}$ & Cp_Solids__K_TJW_1 \\
\hline $\mathrm{K} 3 \mathrm{AICl} 6$ & $\mathrm{~K}_{3} \mathrm{AlCl}_{6}$ & Cp_Solids__K_TJW_1 \\
\hline K3AIF6 & $\mathrm{K}_{3} \mathrm{AlF}_{6}$ & Cp_Solids_j_K_TJW_1 \\
\hline K3PO4 & $\mathrm{K}_{3} \mathrm{PO}_{4}$ & Cp_Solids__K_TJW_1 \\
\hline Kalicinite & $\mathrm{KHCO}_{3}$ & Minerals_hmw \\
\hline $\mathrm{KAl}(\mathrm{SO} 4) 2$ & $\mathrm{KAl}\left(\mathrm{SO}_{4}\right)_{2}$ & Cp_Solids__K_TJW_1 \\
\hline $\mathrm{KAl}(\mathrm{SO} 4) 2: 3 \mathrm{H} 2 \mathrm{O}$ & $\mathrm{KAI}\left(\mathrm{SO}_{4}\right)_{2}: 3 \mathrm{H}_{2} \mathrm{O}$ & Cp_Solids__K_TJW_1 \\
\hline $\mathrm{KAl}(\mathrm{SO} 4) 2: 12 \mathrm{H} 2 \mathrm{O}$ & $\mathrm{KAI}\left(\mathrm{SO}_{4}\right)_{2}: 12 \mathrm{H}_{2} \mathrm{O}$ & Cp_Solids__K_TJW_1 \\
\hline $\mathrm{KBr}$ & $\mathrm{KBr}$ & Cp_Solids_j_K_TJW_1 \\
\hline $\mathrm{KClO} 4$ & $\mathrm{KclO}_{4}$ & Cp_Solids__K_TJW_1 \\
\hline $\mathrm{KH} 2 \mathrm{PO} 4$ & $\mathrm{KH}_{2} \mathrm{PO}_{4}$ & Cp_Solids__K_TJW_1 \\
\hline $\mathrm{KI}$ & $\mathrm{KI}$ & Cp_Solids__K_TJW_1 \\
\hline Kieserite & $\mathrm{MgSO}_{4}: \mathrm{H}_{2} \mathrm{O}$ & Cp_Solids__Pabalan_TJW_1 \\
\hline KnaCO3:6H2O & $\mathrm{KnaCO}_{3}: 6 \mathrm{H}_{2} \mathrm{O}$ & Minerals_hmw \\
\hline $\mathrm{KOH}$ & $\mathrm{KOH}$ & Cp_Solids__K_TJW_1 \\
\hline Labile_Salt & $\mathrm{Na}_{2} \mathrm{Ca}_{5}\left(\mathrm{SO}_{4}\right)_{6}: 3 \mathrm{H}_{2} \mathrm{O}$ & Minerals_gmo \\
\hline Leonhardtite & $\mathrm{MgSO}_{4}: 4 \mathrm{H}_{2} \mathrm{O}$ & Solids_j_Pabalan_TJW_1 \\
\hline Leonite & $\mathrm{K}_{2} \mathrm{Mg}\left(\mathrm{SO}_{4}\right)_{2}: 4 \mathrm{H}_{2} \mathrm{O}$ & Minerals_hmw \\
\hline Mercallite & $\mathrm{KHSO}_{4}$ & Minerals_hmw \\
\hline $\mathrm{MgBr} 2$ & $\mathrm{MgBr}_{2}$ & Solids_j_Mg_TJW_1 \\
\hline $\mathrm{MgCl} 2: \mathrm{H} 2 \mathrm{O}$ & $\mathrm{MgCl}_{2}: \mathrm{H}_{2} \mathrm{O}$ & Solids_j_Pabalan_TJW_1 \\
\hline $\mathrm{MgCl} 2: 2 \mathrm{H} 2 \mathrm{O}$ & $\mathrm{MgCl}_{2}: 2 \mathrm{H}_{2} \mathrm{O}$ & Solids_j_Pabalan_TJW_1 \\
\hline $\mathrm{MgCl} 2: 4 \mathrm{H} 2 \mathrm{O}$ & $\mathrm{MgCl}_{2}: 4 \mathrm{H}_{2} \mathrm{O}$ & Solids_j_Pabalan_TJW_1 \\
\hline Mgl2 & $\mathrm{Mgl}_{2}$ & Solids_j_Mg_TJW_1 \\
\hline MgMoO4 & $\mathrm{MgMoO}_{4}$ & Solids_j_Mg_TJW_1 \\
\hline $\mathrm{Mg}(\mathrm{NO} 3) 2$ & $\mathrm{Mg}\left(\mathrm{NO}_{3}\right)_{2}$ & Solids_j_Mg_TJW_1 \\
\hline $\mathrm{MgOHCl}$ & $\mathrm{MgOHCl}$ & Solids_j_Mg_TJW_1 \\
\hline
\end{tabular}


Table I-29. Salt Solids Sourced from Various Spreadsheets (Continued)

\begin{tabular}{|c|c|c|}
\hline Solid Mineral & Molecular Formula & DTN or Spreadsheet File (.xIs) \\
\hline MgSO4 & $\mathrm{MgSO}_{4}$ & Solids_j_Pabalan_TJW_1 \\
\hline MgWO4 & $\mathrm{MgWO}_{4}$ & Solids_j_Mg_TJW_1 \\
\hline Mirabilite & $\mathrm{Na}_{2} \mathrm{SO}_{4}: 10 \mathrm{H}_{2} \mathrm{O}$ & Minerals_gmo \\
\hline Misenite & $\mathrm{K}_{8} \mathrm{H}_{6}\left(\mathrm{SO}_{4}\right)_{7}$ & Minerals_hmw \\
\hline $\mathrm{NaBr}$ & $\mathrm{NaBr}$ & Solids_j_Na_TJW_1 \\
\hline $\mathrm{NaClO} 4$ & $\mathrm{NaClO}_{4}$ & Solids_j_Na_TJW_1 \\
\hline $\mathrm{Nal}$ & $\mathrm{Nal}$ & Solids_j_Na_TJW_1 \\
\hline $\mathrm{NaNO} 2$ & $\mathrm{NaNO}_{2}$ & Solids_j_Na_TJW_1 \\
\hline $\mathrm{NaOH}$ & $\mathrm{NaOH}$ & Solids_j_Na_TJW_1 \\
\hline $\mathrm{Na} 2 \mathrm{CO} 3: 7 \mathrm{H} 2 \mathrm{O}$ & $\mathrm{Na}_{2} \mathrm{CO}_{3}: 7 \mathrm{H}_{2} \mathrm{O}$ & Minerals_hmw \\
\hline $\mathrm{Na} 2 \mathrm{CrO} 4$ & $\mathrm{Na}_{2} \mathrm{CrO}_{4}$ & Solids_j_Na_TJW_1 \\
\hline $\mathrm{Na} 2 \mathrm{MoO} 4$ & $\mathrm{Na}_{2} \mathrm{MoO}_{4}$ & Solids_j_Na_TJW_1 \\
\hline $\mathrm{Na} 2 \mathrm{WO} 4$ & $\mathrm{Na}_{2} \mathrm{WO}_{4}$ & Solids_j_Na_TJW_1 \\
\hline $\mathrm{Na} 2 \mathrm{O}$ & $\mathrm{Na}_{2} \mathrm{O}$ & Solids_j_Na_TJW_1 \\
\hline $\mathrm{Na} 2 \mathrm{SO} 4(\mathrm{Sol}-3)$ & $\mathrm{Na}_{2} \mathrm{SO}_{4}$ & Solids_j_Na_TJW_1 \\
\hline $\mathrm{Na} 3 \mathrm{H}(\mathrm{SO} 4) 2$ & $\mathrm{Na}_{3} \mathrm{H}\left(\mathrm{SO}_{4}\right)_{2}$ & Minerals_hmw \\
\hline $\mathrm{Na} 4 \mathrm{Ca}(\mathrm{SO} 4) 3: 2 \mathrm{H} 2 \mathrm{O}$ & $\mathrm{Na}_{4} \mathrm{Ca}\left(\mathrm{SO}_{4}\right)_{3}: 2 \mathrm{H}_{2} \mathrm{O}$ & Minerals_hmw \\
\hline Nahcolite & $\mathrm{NaHCO}_{3}$ & Solids_j_Na_TJW_1 \\
\hline Natrite & $\mathrm{Na}_{2} \mathrm{CO}_{3}$ & Solids_j_Na_TJW_1 \\
\hline Natron & $\mathrm{Na}_{2} \mathrm{CO}_{3}$ & Minerals_hmw \\
\hline $\mathrm{NH} 4 \mathrm{Cl}$ & $\mathrm{NH}_{4} \mathrm{Cl}$ & Solids__NH4_TJW_1 \\
\hline $\mathrm{NH} 4 \mathrm{ClO} 4$ & $\mathrm{NH}_{4} \mathrm{ClO}_{4}$ & Solids__NH4_TJW_1 \\
\hline $\mathrm{NH} 4 \mathrm{I}$ & $\mathrm{NH}_{4} \mathrm{I}$ & Solids__NH4_TJW_1 \\
\hline$(\mathrm{NH} 4) 2 \mathrm{SO} 4$ & $\left(\mathrm{NH}_{4}\right)_{2} \mathrm{SO}_{4}$ & Solids__NH4_TJW_1 \\
\hline Niter & $\mathrm{KNO}_{3}$ & Cp_Solids__K_TJW_1 \\
\hline Oxychloride-Mg & $\mathrm{Mg}_{2} \mathrm{Cl}(\mathrm{OH})_{3}: 4 \mathrm{H}_{2} \mathrm{O}$ & Minerals_hmw \\
\hline Pentahydrite & $\mathrm{MgSO}_{4}: 5 \mathrm{H}_{2} \mathrm{O}$ & Solids__Pabalan_TJW_1 \\
\hline Pentasalt & $\mathrm{K}_{2} \mathrm{Ca}_{5}\left(\mathrm{SO}_{4}\right)_{6}: \mathrm{H}_{2} \mathrm{O}$ & Minerals_gmo \\
\hline Periclase & $\mathrm{MgO}$ & Solids_j_Mg_TJW_1 \\
\hline Picromerite & $\mathrm{K}_{2} \mathrm{Mg}\left(\mathrm{SO}_{4}\right)_{2}: 6 \mathrm{H}_{2} \mathrm{O}$ & Minerals_hmw \\
\hline Pirssonite & $\mathrm{Na}_{2} \mathrm{Ca}\left(\mathrm{CO}_{3}\right)_{2}: 2 \mathrm{H}_{2} \mathrm{O}$ & Minerals_hmw \\
\hline Polyhalite & $\mathrm{K}_{2} \mathrm{MgCa}_{2}\left(\mathrm{SO}_{4}\right)_{4}: 2 \mathrm{H}_{2} \mathrm{O}$ & Minerals_hmw \\
\hline Powellite & $\mathrm{CaMoO}_{4}$ & Solids_j_Ca_TJW_1 \\
\hline Sellaite & $\mathrm{MgF}_{2}$ & Solids_j_Mg_TJW_1 \\
\hline Soda Niter & $\mathrm{NaNO}_{3}$ & NaNO3_min_cal_CFJC \\
\hline SrBr2 & $\mathrm{SrBr}_{2}$ & Solids_j_Sr_TJW_1 \\
\hline $\mathrm{SrCl} 2$ & $\mathrm{SrCl}_{2}$ & Solids_j_Sr_TJW_1 \\
\hline SrF2 & $\mathrm{SrF}_{2}$ & Solids_j_Sr_TJW_1 \\
\hline Srl2 & $\mathrm{Srl}_{2}$ & Solids_j_Sr_TJW_1 \\
\hline $\mathrm{SrMoO} 4$ & $\mathrm{SrMoO}_{4}$ & Solids_j_Sr_TJW_1 \\
\hline $\mathrm{SrO}$ & $\mathrm{SrO}$ & Solids_j_Sr_TJW_1 \\
\hline $\mathrm{Sr}(\mathrm{OH}) 2$ & $\mathrm{Sr}(\mathrm{OH})_{2}$ & Solids_j_Sr_TJW_1 \\
\hline SrWO4 & $\mathrm{SrWO}_{4}$ & Solids___Sr_TJW_1 \\
\hline
\end{tabular}


Table I-29. Salt Solids Sourced from Various Spreadsheets (Continued)

\begin{tabular}{|l|l|l|}
\hline \multicolumn{1}{|c|}{ Solid Mineral } & \multicolumn{1}{|c|}{ Molecular Formula } & \multicolumn{1}{c|}{ DTN or Spreadsheet File (.xIs) } \\
\hline Sylvite & $\mathrm{KCl}$ & Minerals_gmo \\
\hline Syngenite & $\mathrm{K}_{2} \mathrm{Ca}\left(\mathrm{SO}_{4}\right)_{2}: \mathrm{H}_{2} \mathrm{O}$ & Minerals_gmo \\
\hline Tachyhydrite & $\mathrm{Mg}_{2} \mathrm{CaCl}_{6}: 12 \mathrm{H}_{2} \mathrm{O}$ & Minerals_hmw \\
\hline Tarapacaite & $\mathrm{K}_{2} \mathrm{CrO}_{4}$ & Cp_Solids__K_TJW_1 \\
\hline Thenardite & $\mathrm{Na}_{2} \mathrm{SO}_{4}$ & Minerals_gmo \\
\hline Thermonatrite & $\mathrm{Na}_{2} \mathrm{CO}_{3}: \mathrm{H}_{2} \mathrm{O}$ & thermonatrite_min_cal_CFJC \\
\hline Trona & $\mathrm{Na}_{3} \mathrm{H}_{\left(\mathrm{CO}_{3}\right)_{2}: 2 \mathrm{H}_{2} \mathrm{O}}$ & Minerals_hmw \\
\hline Trona-K & $\mathrm{K}_{2} \mathrm{NaH}\left(\mathrm{CO}_{3}\right)_{2}: 2 \mathrm{H}_{2} \mathrm{O}$ & Minerals_hmw \\
\hline Villiaumite & $\mathrm{NaF}$ & Solids_j_Na_TJW_1 \\
\hline
\end{tabular}

Output DTN: SN0306T0510102.007.

Table I-30. Auxiliary Basis Aqueous Species Data Sources

\begin{tabular}{|l|l|l|}
\hline \multicolumn{1}{|c|}{$\begin{array}{c}\text { Aqueous } \\
\text { Species }\end{array}$} & $\begin{array}{c}\text { Molecular } \\
\text { Formula }\end{array}$ & \multicolumn{1}{c|}{ DTN or Spreadsheet } \\
\hline $\mathrm{ClO} 4-$ & $\mathrm{ClO}_{4}^{-}$ & MO0302SPATHDYN.000 [DIRS 161756] \\
\hline $\mathrm{Fe}+++$ & $\mathrm{Fe}^{3+}$ & MO0302SPATHDYN.000 [DIRS 161756] \\
\hline $\mathrm{H} 2(\mathrm{aq})$ & $\mathrm{H}_{2}(\mathrm{aq})$ & MO0302SPATHDYN.000 [DIRS 161756] \\
\hline $\mathrm{NH} 4+$ & $\mathrm{NH}_{4}{ }^{+}$ & AuxBasisSpecies.xls \\
\hline $\mathrm{NO} 2-$ & $\mathrm{NO}_{2}^{-}$ & AuxBasisSpecies.xls \\
\hline $\mathrm{O} 2(\mathrm{aq})$ & $\mathrm{O}_{2}(\mathrm{aq})$ & MO0302SPATHDYN.000 [DIRS 161756] \\
\hline
\end{tabular}


Table I-31. Aqueous Species Data Sources

\begin{tabular}{|c|c|c|}
\hline $\begin{array}{l}\text { Aqueous } \\
\text { Species }\end{array}$ & $\begin{array}{c}\text { Molecular } \\
\text { Formula }\end{array}$ & DTN or Spreadsheet \\
\hline $\mathrm{AlO} 2-$ & $\mathrm{AlO}_{2}^{-}$ & MO0302SPATHDYN.000 [DIRS 161756] \\
\hline $\mathrm{AlOH}++$ & $\mathrm{AlOH}^{2+}$ & MO0302SPATHDYN.000 [DIRS 161756] \\
\hline $\mathrm{AlO}+$ & $\mathrm{AlO}^{+}$ & MO0302SPATHDYN.000 [DIRS 161756] \\
\hline $\mathrm{CaCO} 3(\mathrm{aq})$ & $\mathrm{CaCO}_{3}(\mathrm{aq})$ & MO0302SPATHDYN.000 [DIRS 161756] \\
\hline $\mathrm{CaHCO} 3+$ & $\mathrm{CaHCO}_{3}^{+}$ & MO0302SPATHDYN.000 [DIRS 161756] \\
\hline $\mathrm{CaOH}+$ & $\mathrm{CaOH}^{+}$ & MO0302SPATHDYN.000 [DIRS 161756] \\
\hline $\mathrm{CaSO} 4(\mathrm{aq})$ & $\mathrm{CaSO}_{4}(\mathrm{aq})$ & Minerals_gmo.xls \\
\hline $\mathrm{CO} 2(\mathrm{aq})$ & $\mathrm{CO}_{2}(\mathrm{aq})$ & MO0302SPATHDYN.000 [DIRS 161756] \\
\hline CO3-- & $\mathrm{CO}_{3}{ }^{2-}$ & MO0302SPATHDYN.000 [DIRS 161756] \\
\hline HSO4- & $\mathrm{HSO}_{4}^{-}$ & MO0302SPATHDYN.000 [DIRS 161756] \\
\hline HSiO3- & $\mathrm{HSiO}_{3}^{-}$ & MO0302SPATHDYN.000 [DIRS 161756] \\
\hline $\mathrm{H} 2 \mathrm{PO} 4-$ & $\mathrm{H}_{2} \mathrm{PO}_{4}^{-}$ & MO0302SPATHDYN.000 [DIRS 161756] \\
\hline $\mathrm{H} 3 \mathrm{PO} 4(\mathrm{aq})$ & $\mathrm{H}_{3} \mathrm{PO}_{4}(\mathrm{aq})$ & MO0302SPATHDYN.000 [DIRS 161756] \\
\hline $\mathrm{MgCO} 3(\mathrm{aq})$ & $\mathrm{MgCO}_{3}(\mathrm{aq})$ & MO0302SPATHDYN.000 [DIRS 161756] \\
\hline $\mathrm{MgHCO} 3+$ & $\mathrm{MgHCO}_{3}{ }^{+}$ & MO0302SPATHDYN.000 [DIRS 161756] \\
\hline $\mathrm{MgOH}+$ & $\mathrm{MgOH}^{+}$ & MO0302SPATHDYN.000 [DIRS 161756] \\
\hline $\mathrm{NH} 3(\mathrm{aq})$ & $\mathrm{NH}_{3}(\mathrm{aq})$ & MO0302SPATHDYN.000 [DIRS 161756] \\
\hline $\mathrm{NaF}(\mathrm{aq})$ & $\mathrm{NaF}(\mathrm{aq})$ & MO0302SPATHDYN.000 [DIRS 161756] \\
\hline $\mathrm{OH}-$ & $\mathrm{OH}^{-}$ & MO0302SPATHDYN.000 [DIRS 161756] \\
\hline PO4--- & $\mathrm{PO}_{4}{ }^{3-}$ & MO0302SPATHDYN.000 [DIRS 161756] \\
\hline
\end{tabular}

Table I-32. Gas Data Sources

\begin{tabular}{|l|l|l|}
\hline \multicolumn{1}{|c|}{ Gases } & \multicolumn{1}{c|}{$\begin{array}{c}\text { Molecular } \\
\text { Formula }\end{array}$} & \multicolumn{1}{c|}{ DTN or Spreadsheet } \\
\hline $\mathrm{CO} 2(\mathrm{~g})$ & $\mathrm{CO}_{2}$ & MO0302SPATHDYN.000 [DIRS 161756] \\
\hline $\mathrm{H} 2(\mathrm{~g})$ & $\mathrm{H}_{2}$ & MO0302SPATHDYN.000 [DIRS 161756] \\
\hline $\mathrm{H} 2 \mathrm{O}(\mathrm{g})$ & $\mathrm{H}_{2} \mathrm{O}$ & MO0302SPATHDYN.000 [DIRS 161756] \\
\hline $\mathrm{HBr}(\mathrm{g})$ & $\mathrm{HBr}$ & MO0302SPATHDYN.000 [DIRS 161756] \\
\hline $\mathrm{HCl}(\mathrm{g})$ & $\mathrm{HCl}$ & MO0302SPATHDYN.000 [DIRS 161756] \\
\hline $\mathrm{HF}(\mathrm{g})$ & $\mathrm{HF}$ & MO0302SPATHDYN.000 [DIRS 161756] \\
\hline $\mathrm{HNO}(\mathrm{g})$ & $\mathrm{HNO}$ & MO0302SPATHDYN.000 [DIRS 161756] \\
\hline $\mathrm{N} 2 \mathrm{O} 5(\mathrm{~g})$ & $\mathrm{N}_{2} \mathrm{O}_{5}$ & MO0302SPATHDYN.000 [DIRS 161756] \\
\hline $\mathrm{NO} 3(\mathrm{~g})$ & $\mathrm{NO}_{3}$ & MO0302SPATHDYN.000 [DIRS 161756] \\
\hline $\mathrm{O} 2(\mathrm{~g})$ & $\mathrm{O}_{2}$ & Gases__TJW_2.xls \\
\hline
\end{tabular}




\section{I.5.1 $\mathrm{CaCl}_{2} \mathrm{HYDRATES}\left(\mathrm{CaCl}_{2} \bullet \mathrm{NH}_{2} \mathrm{O}\right.$ WHERE N EQUALS 2, 4, AND 6)}

Associated Spreadsheets: cac12_hydrates_min_cal_CFJC.xls; Solids_j_CaCl2hydrates_TJW_1.xls; Cp_Solids_j_CaCl2hydrates_TJW_1.xls

Source: Meisingset and Grønvold 1986 [DIRS 162094]; Pitzer and Shi 1993 [DIRS 163582]; Pitzer and Oakes 1994 [DIRS 163583]; Robie and Hemingway 1995 [DIRS 153683], pp. 23 and 53.

Description: Solubilities of $\mathrm{CaCl}_{2}$ hydrates $\left(\mathrm{CaCl}_{2} \bullet \mathrm{nH}_{2} \mathrm{O}\right.$ where $\mathrm{n}$ equals 2 , 4, and 6) were estimated for a temperature range of 25 to $95^{\circ} \mathrm{C}$ within the valid range of the activity model to generate bounding saturation molalities for the stable phases. Standard state thermodynamic properties were obtained from Pitzer and Shi (1993 [DIRS 163582]) and Pitzer and Oakes (1994 [DIRS 163583]) along with their reported saturation molality values of the corresponding $\mathrm{CaCl}_{2}$ hydrate phases. Calculations of initial $\log \mathrm{K}$ 's were conducted in the 'Solids_j_CaCl2hydrates_TJW_1.xls' spreadsheet using heat capacity data from Meisingset and Grønvold (1986 [DIRS 162094$]$ ). Log K values for dehydrated $\mathrm{CaCl}_{2}$ were obtained from thermodynamic data reported by Robie and Hemingway (1995 [DIRS 153683], pp. 23 and 53 ) and using SUPCRT92 Version 1.0 (See output file cacl2_solub_tab (DTN: SN0306T0510102.007)). Because the stability range of dehydrated $\mathrm{CaCl}_{2}$ with respect to temperature exceeds the validity range of the activity model to predict $\mathrm{CaCl}_{2} \cdot 2 \mathrm{H}_{2} \mathrm{O}$ solubility, it was not considered in the fitting but was added to the database for the sake of completeness. Initial $\log \mathrm{K}$ values for the dissolution of the hydrated phases were obtained using the 'Solids_j_CaCl2hydrates_TJW_1.xls' spreadsheet and tested for prediction of solid solubility using the Pitzer parameters from Sterner et al. (1998 [DIRS 162116]). The log K values were then modified to fit saturation molalities of the $\mathrm{CaCl}_{2}$ hydrates given by Pitzer and Shi (1993 [DIRS 163582]) and Pitzer and Oakes (1994 [DIRS 163583]) within their estimated temperature range of stability. The resulting $\log \mathrm{K}$ values plus their relative differences from the initial values determined using the 'Solids_j_CaCl2hydrates_TJW_1.xls' spreadsheet are given in Table I-33 below.

Table I-33. Comparison of Initial and Fitted log $\mathrm{K}$ Values for $\mathrm{CaCl}_{2}$ Hydrates Used in the data0.ypf

\begin{tabular}{|ccccc|}
\hline $\mathbf{T}\left({ }^{\circ} \mathbf{C}\right)$ & $\mathbf{C a C l}_{2} \bullet \mathbf{n H}_{2} \mathbf{O}$ & $\begin{array}{c}\text { log K for } \mathbf{C a C l}_{\mathbf{2}} \\
\text { Hydrate from } \\
\text { Pitzer \& Shi (1993) } \\
\text { and Pitzer \& } \\
\text { Oakes (1994) data }\end{array}$ & $\begin{array}{c}\text { Fitted Log K to } \\
\text { Fit Saturation } \\
\text { Molality }\end{array}$ & $\begin{array}{c}\text { \% Difference in } \\
\text { log K }\end{array}$ \\
\hline 25 & $\mathrm{CaCl}_{2}: 6 \mathrm{H}_{2} \mathrm{O}$ & 3.8293 & 3.5993 & 6.39 \\
60 & $\mathrm{CaCl}_{2}: 6 \mathrm{H}_{2} \mathrm{O}$ & 4.1076 & 3.9976 & 2.75 \\
25 & $\mathrm{CaCl}_{2}: 4 \mathrm{H}_{2} \mathrm{O}$ & 5.3425 & 4.9488 & 7.96 \\
60 & $\mathrm{CaCl}_{2}: 4 \mathrm{H}_{2} \mathrm{O}$ & 5.0728 & 4.9458 & 2.57 \\
25 & $\mathrm{CaCl}_{2}: 2 \mathrm{H}_{2} \mathrm{O}$ & 7.4163 & 6.9891 & 6.11 \\
60 & $\mathrm{CaCl}_{2}: 2 \mathrm{H}_{2} \mathrm{O}$ & 6.5028 & 6.2038 & 4.82 \\
100 & $\mathrm{CaCl}_{2}: 2 \mathrm{H}_{2} \mathrm{O}$ & 5.4969 & 5.5015 & -0.08 \\
150 & $\mathrm{CaCl}_{2}: \mathrm{H}_{2} \mathrm{O}$ & 4.2688 & 4.3320 & -1.46 \\
200 & $\mathrm{CaCl}_{2}: \mathrm{H}_{2} \mathrm{O}$ & 3.0166 & 3.0196 & -0.10 \\
250 & $\mathrm{CaCl}_{2}: \mathrm{H}_{2} \mathrm{O}$ & 1.6525 & 1.8200 & -9.20 \\
\hline
\end{tabular}


As shown in the above table, the relative differences in $\log \mathrm{K}$ computed from tabulated thermodynamic data and the fitted saturation molalities at 25,60 , and $100^{\circ} \mathrm{C}$ are on the order of less than a percent up to $\sim 9.2 \%$ depending on the temperature range. Fitting solubility data for $\mathrm{CaCl}_{2} \cdot 2 \mathrm{H}_{2} \mathrm{O}$ above $\sim 45^{\circ} \mathrm{C}$ was satisfactory up to a temperature of $95^{\circ} \mathrm{C}$. Above this temperature, the model begins to under-predict the solubility of this phase and $\log \mathrm{K}$ values above $100^{\circ} \mathrm{C}$ should be used with caution (see explanation later in this section and EQ6 output files cacl2_h2o_CFJC-*.6o, where * stands for identifiers for different runs). Overall, the differences between model predictions and reported saturation molalities for all $\mathrm{CaCl}_{2}$ hydrates are satisfactory given the fitting approach used and combined uncertainties. It must be emphasized that these $\mathrm{CaCl}_{2}$ hydrates undergo phase transitions to less hydrated forms with increasing temperature.

Log Ks are entered in the data0.ypf database only at specific temperatures, namely, 0, 25, 60, $100,150,200,250$, and $300{ }^{\circ} \mathrm{C}$. For other temperatures $E Q 3 / 6$ uses a polynomial fit, either to the $\log$ K's at the four lower temperatures, or to the five upper ones. (Thus, the fits match at 100 ${ }^{\circ} \mathrm{C}$.) This means that, if a phase transition occurs between 25 and $60{ }^{\circ} \mathrm{C}$, there will be only two points, those at 0 and $25^{\circ} \mathrm{C}$, available for fitting log $\mathrm{K}$ 's to the phase stable below the transition temperature. In other words the fit of $\log \mathrm{K}$ against temperature will be linear. The same situation applies to the phase stable above the transition; namely, only the points for 60 and 100 ${ }^{\circ} \mathrm{C}$ are available. If data for metastable equilibria, or heat capacity data, were available for these phases outside their stability ranges better fits could, of course, be obtained. Specifically, $\mathrm{CaCl}_{2} \cdot 6 \mathrm{H}_{2} \mathrm{O}$ appears to be the stable phase from temperatures below $25^{\circ} \mathrm{C}$ up to $\sim 30^{\circ} \mathrm{C}$ based on the reported solubility and thermodynamic data; above $30^{\circ} \mathrm{C} \mathrm{CaCl}_{2} \cdot 4 \mathrm{H}_{2} \mathrm{O}$ becomes stable. Above $\sim 45^{\circ} \mathrm{C} \mathrm{CaCl}_{2} \cdot 2 \mathrm{H}_{2} \mathrm{O}$ is the dominant phase. On the basis of these considerations and the available heat capacity data, log $\mathrm{K}$ 's calculated in spreadsheet Solids_j_CaCl2hydrates_TJW1.xls were entered into data0.ypf at 0, 25, and $60^{\circ} \mathrm{C}$ for $\mathrm{CaCl}_{2} \cdot 6 \mathrm{H}_{2} \mathrm{O}$, at 25 and $60^{\circ} \mathrm{C}$ for $\mathrm{CaCl}_{2} \cdot 4 \mathrm{H}_{2} \mathrm{O}$, and at all temperatures up to $250^{\circ} \mathrm{C}$ for $\mathrm{CaCl}_{2} \cdot 2 \mathrm{H}_{2} \mathrm{O}$. By suppressing selected solids $E Q 3 / 6$ was run at several temperatures in the range 25 to $95{ }^{\circ} \mathrm{C}$ to obtain the curves shown in Figure I-3 for these three solids. (The outputs of these runs, are documented in file names cacl2_h2o_CFJC_*.6o.) These plots identify approximately the intersection temperatures of the calculated solubility curves. In general, $\mathrm{m}_{\text {sat }}$ predictions in the lower temperature range seem to fit the data acceptably, but slight deviations are apparent at temperatures above $\sim 50^{\circ} \mathrm{C}$. Nevertheless, considering the inherent uncertainties of the $\mathrm{CaCl}_{2}$ activity model, those associated with the parameter conversion to a standard Pitzer form, and the collective uncertainties from utilizing multiple data sources, the use of the fitted values for $\log \mathrm{K}$ results in a fairly good level of confidence in predictions of the solubility of these highly soluble salts. 


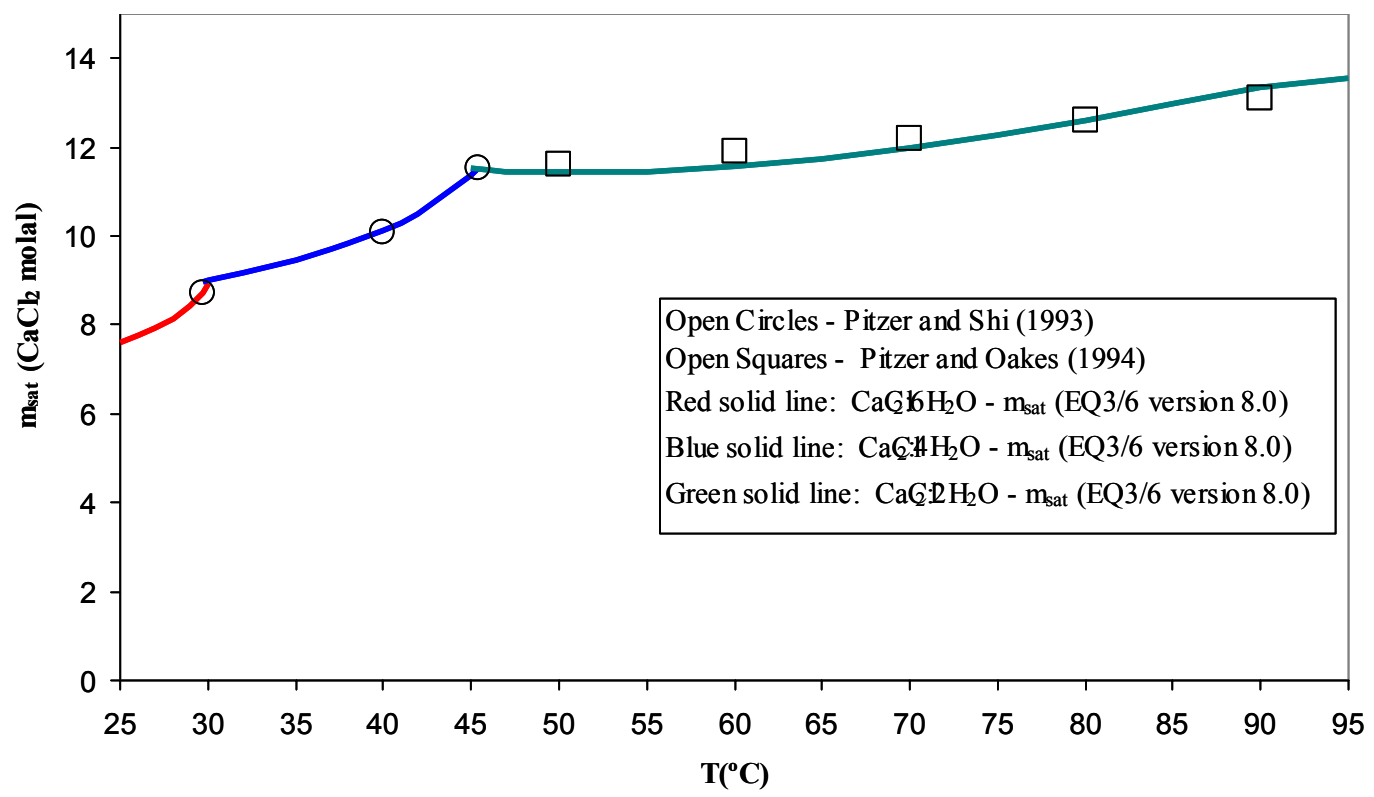

Output DTN: SN0306T0510102.007.

NOTE: Predicted msat values were computed using data0.ypf and EQ3/6 Version 8.0.

Figure I-3. Comparison of Predicted and Compiled Saturation Molalities (msat) for $\mathrm{CaCl}_{2} \mathrm{Hydrates}$

\section{I.5.2 THERMONATRITE $\left(\mathrm{Na}_{2} \mathrm{CO}_{3}: \mathrm{H}_{2} \mathrm{O}\right)$}

Associated Spreadsheet: thermonatrite_min_CFJC.xls

Source: Grønvold and Mesingset 1983 [DIRS 162069]; Robie and Hemingway 1995 [DIRS 153683], pp. 26 and 55; Linke 1965 [DIRS 166191], p. 915.

Description: Solubility of thermonatrite $\left(\mathrm{Na}_{2} \mathrm{CO}_{3} \cdot \mathrm{H}_{2} \mathrm{O}\right)$ as predicted using the activity model of He and Morse (1993 [DIRS 162090]) for the carbonate system and bounded by saturation molalities reported by Linke (1965 [DIRS 166191], p. 915) was estimated for a temperature of 25 to $109^{\circ} \mathrm{C}$ (See $E Q 3 / 6$ output files input_na_cos_thermonatrite_equil *.3o). Initial $\log \mathrm{K}$ 's were determined by SUPCRT92 Version $1 . \overline{0}$ (DTN: SN0306T0510102.007) using thermodynamic data from Grønvold and Mesingset (1983 [DIRS 162069]), and Robie and Hemingway (1995 [DIRS 153683], pp. 26 and 55). Heat capacities reported by Grønvold and Mesingset (1983 [DIRS 162069]) are those listed by Robie and Hemingway (1995 [DIRS 153683]). It should be emphasized that the log K's generated by SUPCRT92 are only use either as initial reference values or for comparison purposes only. That is, these are not used as direct data inputs. The resulting fit of these initial log K's to fit Linke (1965 [DIRS 166191]) saturation molalities shows that the difference between initial and fitted log K's is on the order of less than a percent to $\sim 1.9 \%$. Figure I-3 below shows a comparison of initial and modified log $\mathrm{K}$ 's for the $E Q 3 / 6$ temperature grid up to a temperature of $150^{\circ} \mathrm{C}$. The log $\mathrm{K}$ value at this latter temperature should be considered as fictive since the upper stability temperature for this phase is around $109^{\circ} \mathrm{C}$. That is, this $150^{\circ} \mathrm{C}$ value was modified to fit the saturation molality at $109^{\circ} \mathrm{C}$. As shown in the figure, the fitted $\log \mathrm{K}$ values are in good agreement with those obtained with SUPCRT92 up to a temperature of $100^{\circ} \mathrm{C}$. 


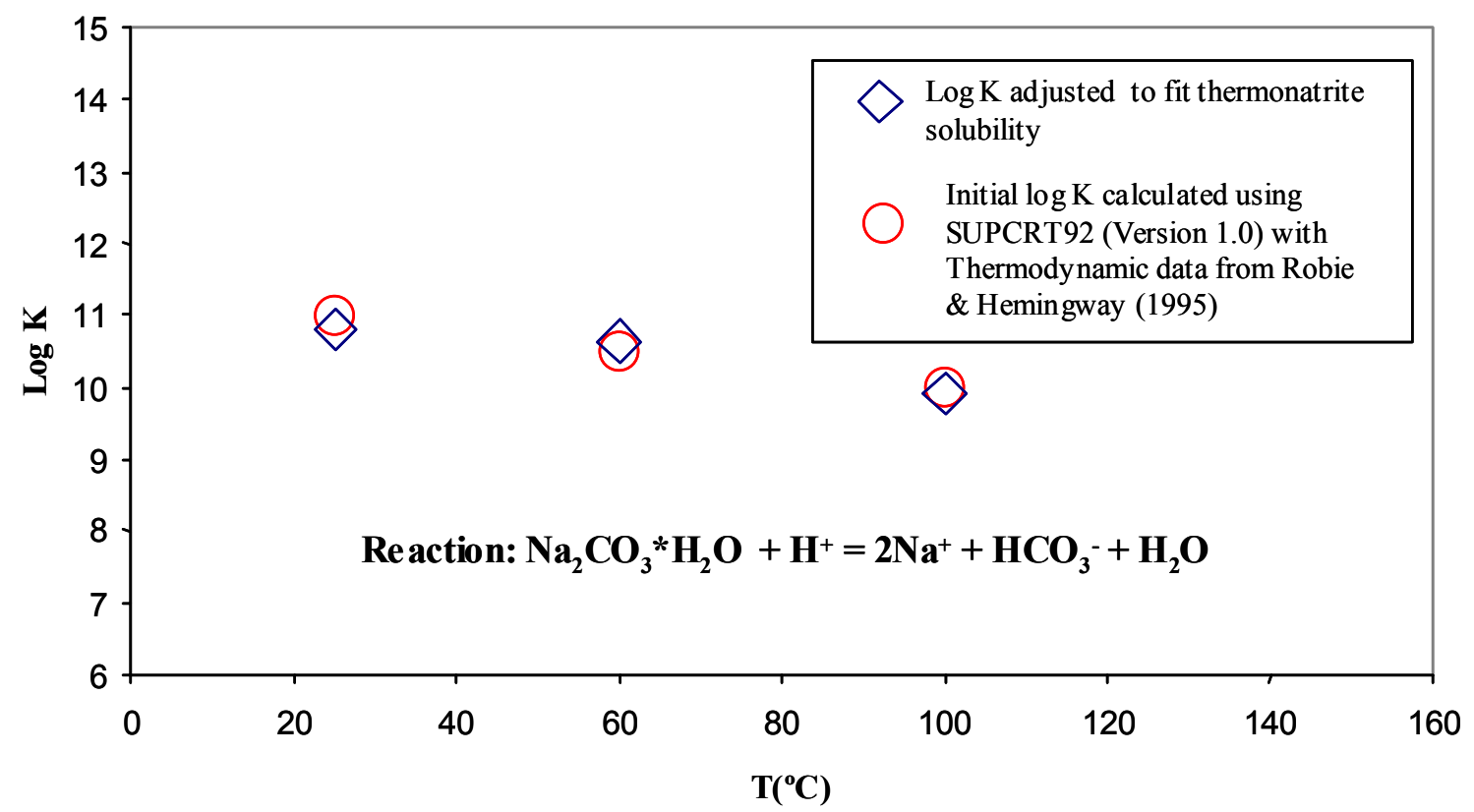

Output DTN: SN0306T0510102.007.

NOTE: Initial values were obtained from thermodynamic data reported by Robie and Hemingway (1995 [DIRS 153683]) and the code SUPCRT92 (Version 1.0). Notice the relatively small difference between initial and fitted values modified in conjunction with He and Morse (1993 [DIRS 162090]) Pitzer parameters to fit saturation molalities for thermonatrite reported by Linke (1965 [DIRS 166191]).

Figure I-4. Comparison of Initial and Fitted log $\mathrm{K}$ Values for the Reaction Describing Thermonatrite Solubility as Implemented in the data0.ypf Database.

Figure I-4 depicts the saturation molalities obtained with the use of modified log K values to fit the thermonatrite solubility in Linke (1965 [DIRS 166191]). Notice that the resulting saturation molalities strongly conform to the reported solubility values up to the upper stability temperature limit of $109^{\circ} \mathrm{C}$. The strong agreement in predicted saturation molalities and the relatively minimal change in $\log \mathrm{K}$ values is viewed as a robust validation of the Pitzer activity model given the different data sources used to constrain the model. The thermodynamic data obtained by the fitting to the Linke (1965, p. 915) solubility data were those actually adopted for the IDPS model. The cited data based on Grønvold and Meisingset (1983 [DIRS 162069]) and Robie and Hemingway (1995 [DIRS 153683]) constitutes the validation. 


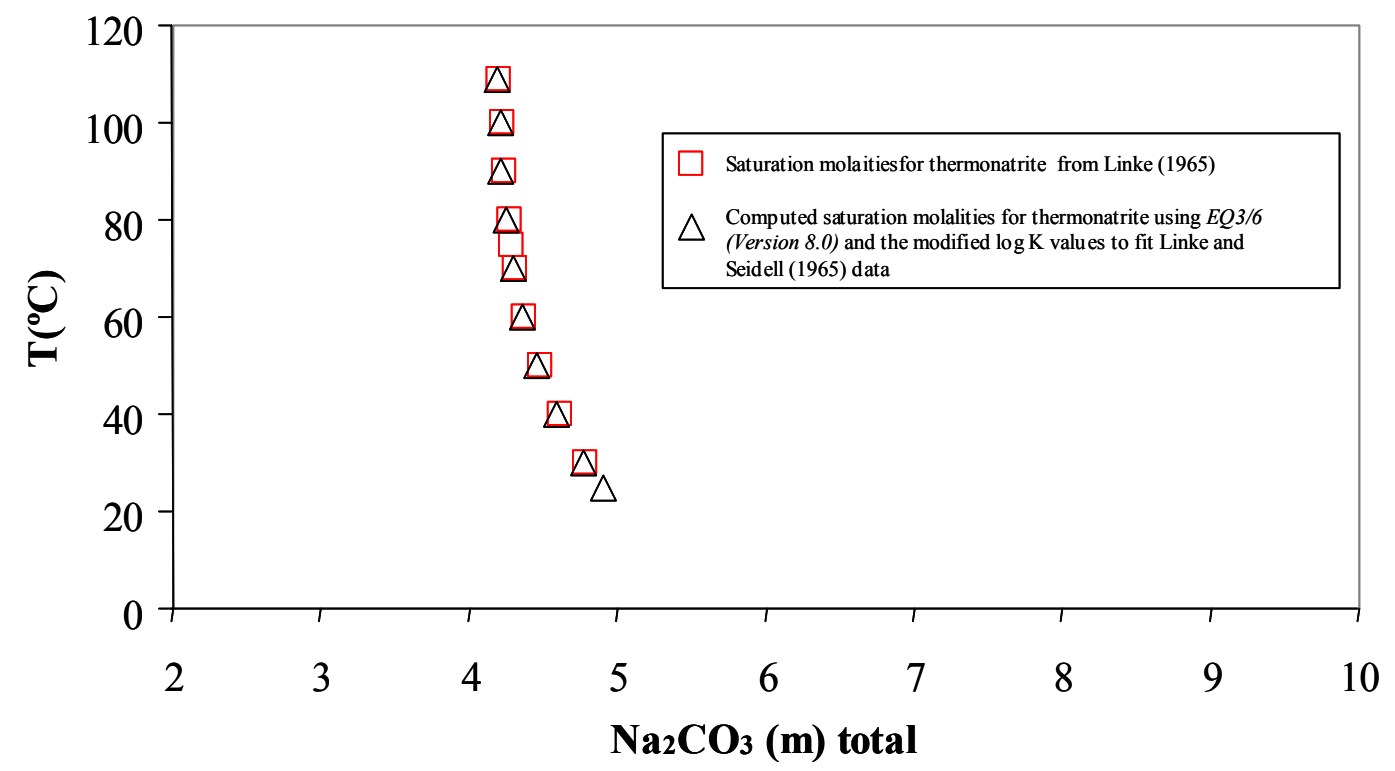

Output DTN: SN0306T0510102.007.

NOTE: $\quad$ The fitted log K values used in data0.ypf are those modified to fit Linke (1965 [DIRS 166191]) thermonatrite solubility data using He and Morse (1993 [DIRS 162090]) Pitzer parameters.

Figure 1-5. Comparison of Predicted Saturation Molalities for Thermonatrite Using EQ3/6 (Version 8.0) and data0.ypf to Those Reported by Linke

\section{I.5.3 SODA NITER $\left(\mathrm{NaNO}_{3}\right)$}

Associated Spreadsheet: NaNO3_min_cal_CFJC

Source: Robie and Hemingway 1995 [DIRS 153683], pp. 27 and 55; Barin and Platzki 1995 [DIRS 157865]; Archer 2000 [DIRS 162065].

Description: The solubility of soda niter $\left(\mathrm{NaNO}_{3}\right)$ was modeled using the recent thermodynamic model and Pitzer parameters of Archer (2000 [DIRS 162065]) up to a temperature of $119^{\circ} \mathrm{C}$. The temperature of $119^{\circ} \mathrm{C}$ represents the approximate maximum temperature for which solubility data are reported in Figure 10 of Archer (2000 [DIRS 162065], p. 1153). Accurate $\log \mathrm{K}$ fits were only obtained from 0 to $100^{\circ} \mathrm{C}$ since saturation molality values compiled by Archer (2000 [DIRS 162065]) are only tabulated in this temperature range. The $\log \mathrm{K}$ value at $150^{\circ} \mathrm{C}$ in the data0.ypf data block for this phase is suspect since it was fitted to obtain an approximate bounding saturation molality value of $\sim 24.1$ at $119^{\circ} \mathrm{C}$. Figure $\mathrm{I}-6$ shows a comparison between $\log \mathrm{K}$ values obtained from 1) combined data from Robie and Hemingway (1995 [DIRS 153683], pp. 27 and 55) and Archer (2000 [DIRS 162065]) incorporated into the modified database for SUPCRT92 Version 1.0 (DTN: SN0306T0510102.007), 2) data from Barin and Platzki (1995 [DIRS 157865]) (see spreadsheet 'Solids_j_Na_TJW_1.xls'), and 3) $\log$ $\mathrm{K}$ values fitted to saturation molalities reported in Archer (2000 [DIRS 162065]). It should be emphasized that the log K's generated by SUPCRT92 or the Excel spreadsheet using data from Barin and Platzki (1995 [DIRS 157865]) are only used either as initial reference values or for comparison purposes. That is, these are not used as direct data inputs. As shown in the figure, the differences in $\log \mathrm{K}$ values between different data sets are relatively minor. Figure I-7 shows the predicted saturation molalities for soda niter from 0 to $100^{\circ} \mathrm{C}$ indicating nearly 
identical values to those reported by Archer (2000 [DIRS 162065]). The close agreement of log $\mathrm{K}$ values from multiple sources and those obtained in the fitting, together with the prediction of saturation molalities in Archer (2000 [DIRS 162065]) validates the Pitzer activity model for $\mathrm{NaNO}_{3}$.

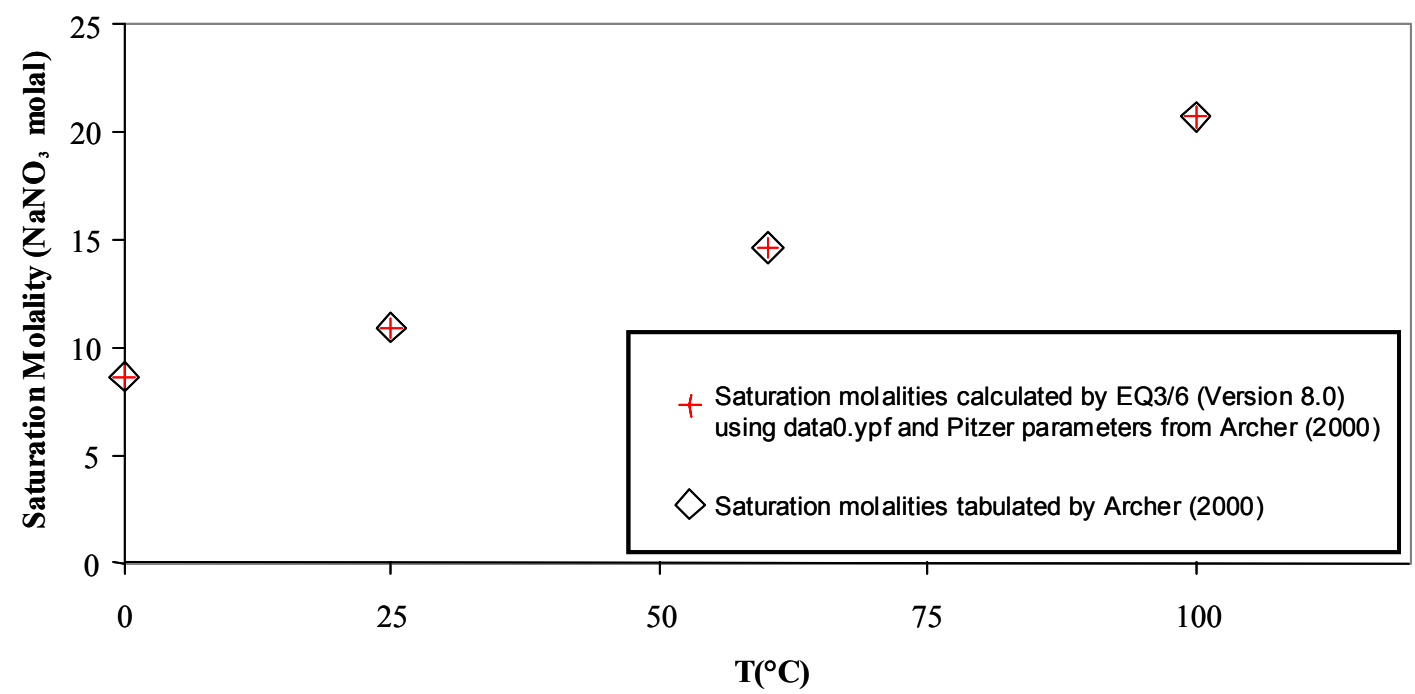

Output DTN: SN0306T0510102.007.

Source: Archer 2000 [DIRS 162065].

Figure I-6. Comparison of log $\mathrm{K}$ Values for Soda Niter $\left(\mathrm{NaNO}_{3}(\mathrm{~s})\right)$ Dissolution from Various Sources and Those Obtained by Fitting Saturation Molalities Reported by Archer

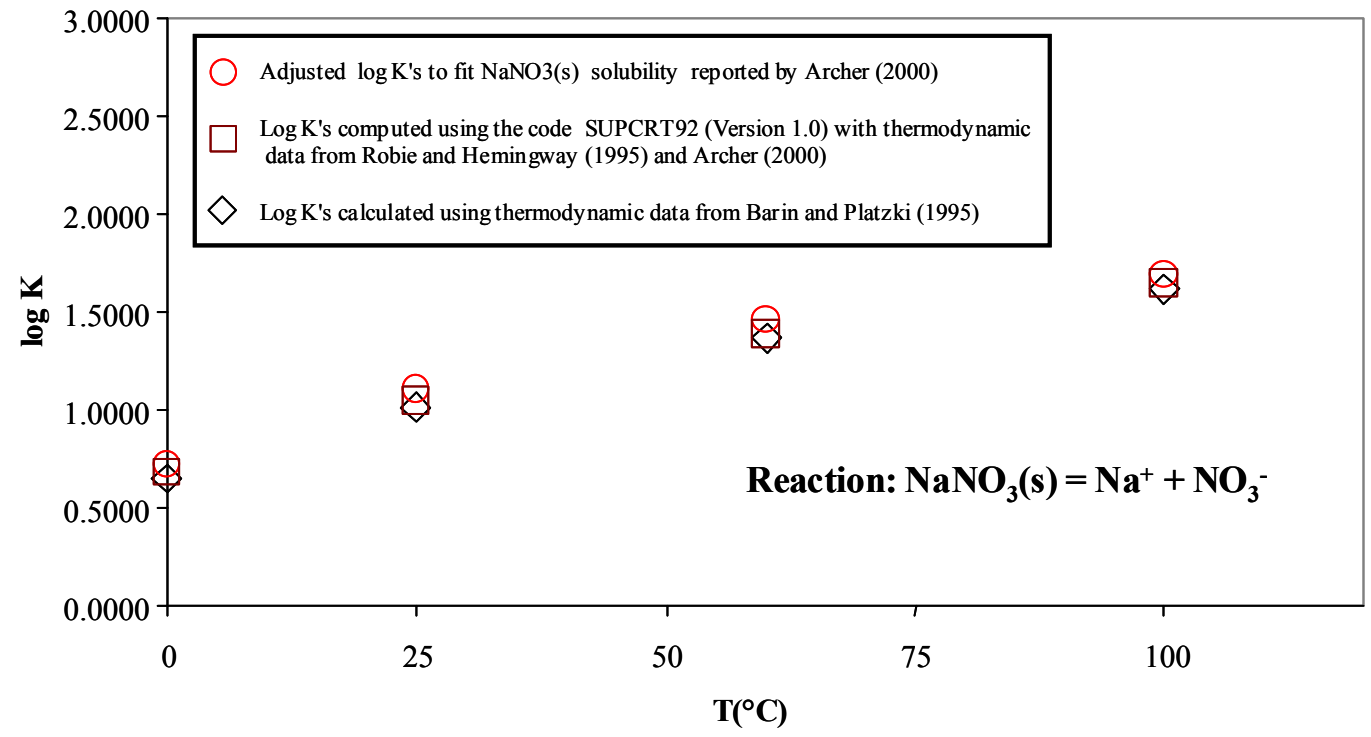

Output DTN: SN0306T0510102.007.

Source: Archer 2000 [DIRS 162065].

Figure 1-7. Comparison of Saturation Molalities for Soda Niter $\left(\mathrm{NaNO}_{3}(\mathrm{~s})\right)$ Predicted by $\mathrm{EQ} 3 / 6$ Version 8.0 Using data0.ypf and Fitted log $\mathrm{K}$ to Those in Archer up to a Temperature of $100^{\circ} \mathrm{C}$. 


\section{INTENTIONALLY LEFT BLANK}




\section{APPENDIX II}

\section{EXAMPLE IDPS EVAPORATION LOOKUP TABLE}


Table II-1 is an example IDPS model lookup table for the example evaporation of average in situ $\mathrm{J}-13$ well water. For this example, the rows below $R H 56$ percent have been truncated. The full lookup table is documented in DTN: MO0304SPAJ13IS.001, file j13c3t7e.xls.

Table II-1. Example IDPS Model Evaporation Lookup Table for Average In Situ J-13 Well Water

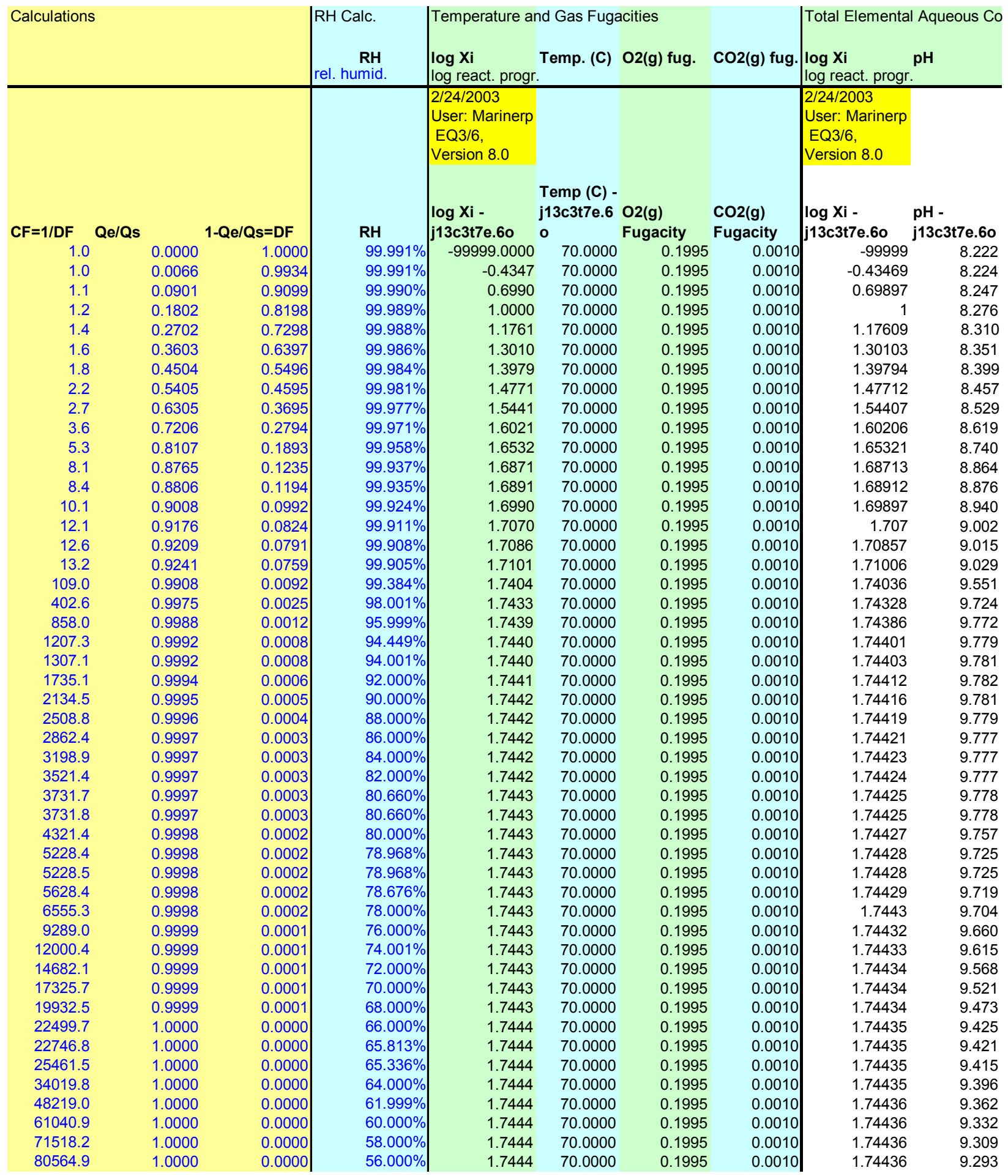


Table II-1. Example IDPS Model Evaporation Lookup Table for Average In Situ J-13 Well Water (Continued)

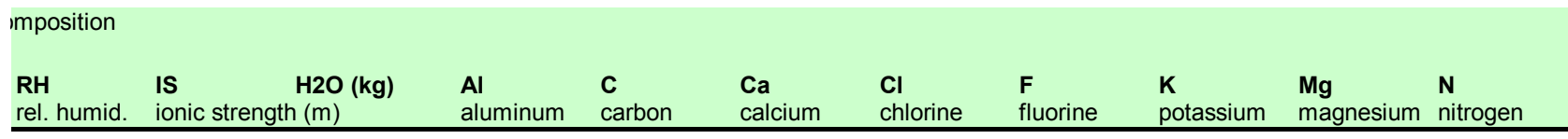

\begin{tabular}{|c|c|c|c|c|c|c|c|c|c|c|}
\hline $\begin{array}{l}a(w)- \\
\text { j13c3t7e.6o }\end{array}$ & $\begin{array}{l}\text { (I) - } \\
\text { j13c3t7e.6o }\end{array}$ & $\begin{array}{l}\text { Mass Solvent } \\
\text { (kg) - } \\
\text { j13c3t7e.6o }\end{array}$ & $\begin{array}{l}\text { Al } \\
\text { Moles/kg. } \\
\text { H2O }\end{array}$ & $\begin{array}{l}\text { C } \\
\text { Moles/kg. } \\
\text { H2O }\end{array}$ & $\begin{array}{l}\mathrm{Ca} \\
\text { Moles/kg. } \\
\mathrm{H} 2 \mathrm{O}\end{array}$ & $\begin{array}{l}\mathrm{Cl} \\
\text { Moles/kg. } \\
\mathrm{H} 2 \mathrm{O}\end{array}$ & $\begin{array}{l}\text { F Moles/kg. } \\
\text { H2O }\end{array}$ & $\begin{array}{l}\mathrm{K} \\
\text { Moles/kg. } \\
\mathrm{H} 2 \mathrm{O}\end{array}$ & $\begin{array}{l}\text { Mg } \\
\text { Moles/kg. } \\
\text { H2O }\end{array}$ & $\begin{array}{l}\mathrm{N} \\
\text { Moles/kg. } \\
\mathrm{H} 2 \mathrm{O}\end{array}$ \\
\hline 1.000 & $2.644 \mathrm{E}-03$ & $1.000 \mathrm{E}+00$ & $1.096 \mathrm{E}-09$ & $1.368 \mathrm{E}-03$ & $3 \quad 1.070 \mathrm{E}-04$ & $2.014 \mathrm{E}-04$ & 1.147E-04 & $1.289 \mathrm{E}-04$ & $4 \quad 7.979 \mathrm{E}-06$ & $1.416 \mathrm{E}-04$ \\
\hline 1.000 & $2.657 \mathrm{E}-03$ & 9.934E-01 & 1.078E-09 & $1.374 \mathrm{E}-03$ & 1.063E-04 & 2.027E-04 & 1.155E-04 & $1.298 \mathrm{E}-04$ & 7.854E-06 & $1.425 \mathrm{E}-04$ \\
\hline 1.000 & 2.842E-03 & $9.099 \mathrm{E}-01$ & $8.676 \mathrm{E}-10$ & 1.452E-03 & $9.725 \mathrm{E}-05$ & 2.213E-04 & 1.261E-04 & 1.417E-04 & $6.360 \mathrm{E}-06$ & $1.556 \mathrm{E}-04$ \\
\hline 1.000 & 3.091E-03 & 8.199E-01 & $6.721 \mathrm{E}-10$ & $1.558 \mathrm{E}-03$ & 8.705E-05 & $2.456 \mathrm{E}-04$ & 1.400E-04 & 1.572E-04 & $4.922 \mathrm{E}-06$ & $1.727 \mathrm{E}-04$ \\
\hline 1.000 & 3.409E-03 & 7.298E-01 & $5.079 \mathrm{E}-10$ & $1.691 \mathrm{E}-03$ & 7.657E-05 & $2.760 \mathrm{E}-04$ & 1.572E-04 & 1.766E-04 & 3.676E-06 & \\
\hline 1.000 & 3.829E-03 & 6.397E-01 & 3.723E-10 & $1.866 \mathrm{E}-03$ & $6.599 \mathrm{E}-05$ & $3.148 \mathrm{E}-04$ & 1.794E-04 & $2.015 \mathrm{E}-04$ & $2.632 \mathrm{E}-06$ & $2.214 \mathrm{E}-04$ \\
\hline 1.000 & 4.399E-03 & 5.496E-01 & 2.627E-10 & $2.098 \mathrm{E}-03$ & 5.554E-05 & $3.664 \mathrm{E}-04$ & 2.088E-04 & 2.345E-04 & $1.788 \mathrm{E}-06$ & \\
\hline 1.000 & $5.210 \mathrm{E}-03$ & 4.596E-01 & $1.761 \mathrm{E}-10$ & $2.421 \mathrm{E}-03$ & 4.548E-05 & 4.382E-04 & 2.497E-04 & 2.805E-04 & 1.137E-06 & $3.081 \mathrm{E}-04$ \\
\hline 1.000 & $6.438 \mathrm{E}-03$ & 3.695E-01 & 1.100E-10 & $2.891 \mathrm{E}-03$ & 3.607E-05 & $5.451 \mathrm{E}-04$ & 3.106E-04 & 3.489E-04 & $6.627 \mathrm{E}-07$ & 3.833E-04 \\
\hline 1.000 & 8.489E-03 & 2.794E-01 & $6.153 \mathrm{E}-11$ & $3.635 \mathrm{E}-03$ & 2.757E-05 & 7.208E-04 & 4.107E-04 & 4.614E-04 & $3.419 \mathrm{E}-07$ & $5.068 \mathrm{E}-04$ \\
\hline 1.000 & 1.254E-02 & 1.893E-01 & $2.843 \mathrm{E}-11$ & $4.983 \mathrm{E}-03$ & $2.020 \mathrm{E}-05$ & 1.064E-03 & 6.061E-04 & $6.809 \mathrm{E}-04$ & 1.458E-07 & 80E-04 \\
\hline 0.999 & $\mathrm{E}-02$ & & $3 \mathrm{E}-11$ & $0 \mathrm{E}-03$ & EE-05 & $1 \mathrm{E}-03$ & $E-04$ & 1.044E-03 & $37 \mathrm{E}-08$ & \\
\hline 0.999 & E-02 & & $E-11$ & BE-03 & E-05 & E-03 & -04 & E-03 & $\mathrm{E}-08$ & \\
\hline 0.999 & E-02 & -02 & $\mathrm{E}-11$ & $\mathrm{E}-03$ & $E-05$ & E-03 & & E-03 & $\mathrm{E}-08$ & \\
\hline 0.999 & $\mathrm{E}-02$ & & $\mathrm{E}-11$ & $\mathrm{E}-02$ & & $\mathrm{E}-03$ & & E-03 & BE-08 & \\
\hline 0.999 & 3.056E-02 & 7.910E-02 & $1.751 \mathrm{E}-11$ & 1.071E-02 & $1.220 \mathrm{E}-05$ & $6 \mathrm{E}-03$ & & 7E-03 & $4.315 \mathrm{E}-08$ & \\
\hline 0.999 & 3.187E-02 & & 1.692E-11 & 1.114E-02 & 1.199E-05 & $2.652 \mathrm{E}-03$ & & $1.684 \mathrm{E}-03$ & $4.188 \mathrm{E}-08$ & \\
\hline 0.994 & $=-01$ & & $\mathrm{E}-12$ & $\mathrm{E}-02$ & -06 & $E-02$ & & E-02 & E-08 & \\
\hline 0.980 & +00 & & $E-12$ & E-01 & & $E-02$ & & $\mathrm{E}-02$ & $E-08$ & \\
\hline 0.960 & +00 & & $E-13$ & $E-01$ & & $E-01$ & & E-01 & E-08 & \\
\hline 0.944 & $3.456 \mathrm{E}+00$ & 8.283E-04 & $5.595 \mathrm{E}-13$ & 8.016E-01 & 1.068E-05 & E-01 & & $4 \mathrm{E}-01$ & $43 E-08$ & $0 \mathrm{E}-01$ \\
\hline 0.940 & $3.749 \mathrm{E}+00$ & & $5.226 \mathrm{E}-13$ & $8.688 \mathrm{E}-01$ & 1.083E-05 & EE-01 & & $1 \mathrm{E}-01$ & 3.836E-08 & \\
\hline 0.920 & $E+00$ & & -13 & $E+00$ & -05 & $E-01$ & & $E-01$ & E-08 & \\
\hline 0.900 & +00 & & -13 & +00 & & $E-01$ & & $E-01$ & $E-08$ & \\
\hline 0.880 & $E+00$ & & $E-13$ & $E+00$ & & $E-01$ & & $E-01$ & $E-08$ & \\
\hline 0.860 & $8.319 \mathrm{E}+00$ & & $2.233 \mathrm{E}-13$ & $1.909 \mathrm{E}+00$ & 1.115E-05 & 5.765E-01 & & $60 \mathrm{E}-01$ & $4 \mathrm{E}-08$ & \\
\hline 0.840 & $9.305 E+00$ & & $1.904 \mathrm{E}-13$ & $2.131 \mathrm{E}+00$ & 1.091E-05 & 6.442E-01 & & 90E-01 & $2 \mathrm{E}-08$ & \\
\hline 0.820 & +01 & & & +00 & & -01 & & E-01 & $=-08$ & \\
\hline 0.807 & +01 & & -13 & +00 & & -01 & & $E-01$ & $E-08$ & \\
\hline 0.807 & 1.0 & & & +00 & & & & $E-01$ & & \\
\hline 0.800 & $1.105 E+01$ & 2.314E-04 & 1.301E-13 & $2.362 \mathrm{E}+00$ & 1.009E-05 & $3 \mathrm{E}-01$ & $E-01$ & 5.526E-01 & 3.576E-08 & $9 \mathrm{E}-01$ \\
\hline 0.790 & $1.137 \mathrm{E}+01$ & & $1.088 \mathrm{E}-13$ & $2.188 \mathrm{E}+00$ & & $E+00$ & & $35 \mathrm{E}-01$ & 3.294E-08 & $4 \mathrm{E}-01$ \\
\hline 0.790 & & & & & & +00 & & $E-01$ & $=-08$ & \\
\hline 0.787 & & & & & & & & -01 & $E-08$ & \\
\hline 0.780 & & & -14 & +00 & & +00 & & $\mathrm{E}-01$ & $E-08$ & \\
\hline 0.760 & $1.155 E+01$ & 1.077E-04 & $6.276 \mathrm{E}-14$ & $1.901 \mathrm{E}+00$ & 8.643E-06 & $1.871 \mathrm{E}+00$ & 2.282E-01 & $1.188 \mathrm{E}+00$ & 2.941E-08 & $E+00$ \\
\hline 0.740 & $1.172 \mathrm{E}+01$ & & $4.912 \mathrm{E}-14$ & $1.717 \mathrm{E}+00$ & 8.290E-06 & $2.417 \mathrm{E}+00$ & 2.061E-01 & $1.534 \mathrm{E}+00$ & $2.878 \mathrm{E}-08$ & $E+00$ \\
\hline 0.720 & $E+01$ & & -14 & $E+00$ & & $E+00$ & & $E+00$ & $\mathrm{E}-08$ & $E+00$ \\
\hline & & & & & & & & & & \\
\hline & & & & & & & & & E-08 & \\
\hline 0.660 & $1.286 \mathrm{E}+01$ & 4.445E-05 & $2.618 \mathrm{E}-14$ & $1.084 \mathrm{E}+00$ & 7.814E-06 & $4.531 \mathrm{E}+00$ & 1.422E-01 & $2.877 \mathrm{E}+00$ & $3.251 \mathrm{E}-08$ & $3.186 \mathrm{E}+00$ \\
\hline 0.658 & $1.289 \mathrm{E}+01$ & 4.396E-05 & $2.588 \mathrm{E}-14$ & $1.072 \mathrm{E}+00$ & 7.811E-06 & $4.578 \mathrm{E}+00$ & $1.411 \mathrm{E}-01$ & $2.909 \mathrm{E}+00$ & 3.267E-08 & $3.221 \mathrm{E}+00$ \\
\hline 0.653 & $1.327 \mathrm{E}+01$ & & $2.390 \mathrm{E}-14$ & $1.057 \mathrm{E}+00$ & & & & $E+00$ & 3.291E-08 & $E+00$ \\
\hline 0.640 & 1.447E+01 & & $1.944 \mathrm{E}-14$ & $90 \mathrm{E}-01$ & & $E+00$ & $E-01$ & $E+00$ & 3.372E-08 & \\
\hline & & & & & & & & & 3.525E-08 & \\
\hline 0.600 & $1.873 \mathrm{E}+01$ & 1.638E-05 & 1.140E-14 & 7.166E-01 & 7.630E-06 & $3.636 \mathrm{E}+00$ & $1.018 \mathrm{E}-01$ & $7.805 E+00$ & $3.716 \mathrm{E}-08$ & $8.643 \mathrm{E}+00$ \\
\hline 0.580 & $2.090 \mathrm{E}+01$ & 1.398E-05 & $9.097 \mathrm{E}-15$ & $5.658 \mathrm{E}-01$ & 7.622E-06 & $3.405 E+00$ & $9.250 \mathrm{E}-02$ & $9.145 E+00$ & $3.943 \mathrm{E}-08$ & $1.013 \mathrm{E}+01$ \\
\hline 0.560 & $2.377 \mathrm{E}+01$ & $1.241 \mathrm{E}-05$ & 7.356E-15 & $3.962 \mathrm{E}-01$ & $7.628 \mathrm{E}-06$ & $3.250 \mathrm{E}+00$ & 8.424E-02 & $1.030 \mathrm{E}+01$ & $4.221 \mathrm{E}-08$ & $1.141 \mathrm{E}+01$ \\
\hline
\end{tabular}


Table II-1. Example IDPS Model Evaporation Lookup Table for Average In Situ J-13 Well Water (Continued)

\begin{tabular}{|c|c|c|c|c|c|c|c|c|c|c|}
\hline \multirow[t]{2}{*}{$\begin{array}{l}\mathrm{Na} \\
\text { sodium } \\
\end{array}$} & $\begin{array}{l}\text { S } \\
\text { sulfur }\end{array}$ & $\begin{array}{l}\text { Si } \\
\text { silicon }\end{array}$ & $\begin{array}{l}\log \mathbf{X i} \\
\log \text { react. progr. }\end{array}$ & $\mathrm{H} 2 \mathrm{O}(\mathbf{k g})$ & $\mathrm{HCO}-$ & CO3-- & HSiO3- & CaHCO3+ & $\mathrm{OH}-$ & MgHCO3+ \\
\hline & & & $\begin{array}{l}\text { 2/24/2003 } \\
\text { User: Marinerp } \\
\text { EQ3/6, } \\
\text { Version } 8.0\end{array}$ & & & & & & & \\
\hline $\begin{array}{l}\mathrm{Na} \\
\text { Moles/kg. } \\
\mathrm{H} 2 \mathrm{O}\end{array}$ & $\begin{array}{l}\text { S Moles/kg. } \\
\mathrm{H} 2 \mathrm{O}\end{array}$ & $\begin{array}{l}\mathrm{Si} \\
\text { Moles/kg. } \\
\mathrm{H} 2 \mathrm{O}\end{array}$ & $\begin{array}{l}\log X i- \\
j 13 c 3 t 7 e .60\end{array}$ & $\begin{array}{l}\text { Mass Solvent } \\
\text { (kg) - } \\
\text { j13c3t7e.6o }\end{array}$ & $\begin{array}{l}\text { HCO3- } \\
\text { Molality }\end{array}$ & $\begin{array}{l}\text { CO3-- } \\
\text { Molality }\end{array}$ & $\begin{array}{l}\text { HSiO3- } \\
\text { Molality }\end{array}$ & $\begin{array}{l}\text { CaHCO3+ } \\
\text { Molality }\end{array}$ & $\begin{array}{l}\mathrm{OH}- \\
\text { Molality }\end{array}$ & $\begin{array}{l}\text { MgHCO3+ } \\
\text { Molality }\end{array}$ \\
\hline $1.992 \mathrm{E}-03$ & 1.915E-04 & 8.995E-04 & $-1.000 E+05$ & $5 \quad 1.000 E+00$ & $1.324 \mathrm{E}-03$ & 2.092E-05 & 1.001E-04 & $1.622 \mathrm{E}-06$ & $2.757 \mathrm{E}-05$ & $5 \quad 1.280 \mathrm{E}-07$ \\
\hline 2.005E-03 & 1.928E-04 & 9.053E-04 & $-4.347 \mathrm{E}-01$ & 9.934E-01 & 1.329E-03 & 2.110E-05 & 1.011E-04 & $1.616 \mathrm{E}-06$ & 2.768E-05 & 1.264E-07 \\
\hline 2.189E-03 & 2.105E-04 & 9.850 E-04 & $6.990 \mathrm{E}-01$ & $9.099 \mathrm{E}-01$ & $1.405 \mathrm{E}-03$ & 2.367E-05 & $1.155 \mathrm{E}-04$ & $1.535 \mathrm{E}-06$ & 2.926E-05 & $1.068 \mathrm{E}-07$ \\
\hline $2.430 \mathrm{E}-03$ & $2.336 \mathrm{E}-04$ & $1.090 \mathrm{E}-03$ & $1.000 \mathrm{E}+00$ & 8.199E-01 & 1.507E-03 & $2.735 \mathrm{E}-05$ & 1.359E-04 & $1.439 \mathrm{E}-06$ & 3.136E-05 & $8.712 \mathrm{E}-08$ \\
\hline $2.730 \mathrm{E}-03$ & $2.625 \mathrm{E}-04$ & $1.222 \mathrm{E}-03$ & $1.176 \mathrm{E}+00$ & $7.298 \mathrm{E}-01$ & 1.636E-03 & $3.243 \mathrm{E}-05$ & 1.636E-04 & $1.335 \mathrm{E}-06$ & 3.404E-05 & $6.918 \mathrm{E}-08$ \\
\hline 3.114E-03 & 2.994E-04 & 1.391E-03 & $1.301 \mathrm{E}+00$ & 6.397E-01 & 1.803E-03 & 3.969E-05 & $2.026 \mathrm{E}-04$ & $1.221 \mathrm{E}-06$ & 3.750E-05 & $5.314 \mathrm{E}-08$ \\
\hline 3.625E-03 & $3.485 \mathrm{E}-04$ & 1.618E-03 & $1.398 \mathrm{E}+00$ & 5.496E-01 & $2.025 \mathrm{E}-03$ & 5.055E-05 & 2.599E-04 & 1.099E-06 & 4.210E-05 & $3.918 \mathrm{E}-08$ \\
\hline 4.335E-03 & 4.168E-04 & 1.933E-03 & $1.477 \mathrm{E}+00$ & $4.596 \mathrm{E}-01$ & $2.330 \mathrm{E}-03$ & 6.780E-05 & $3.490 \mathrm{E}-04$ & $9.675 \mathrm{E}-07$ & 13E-05 & $2.738 \mathrm{E}-08$ \\
\hline 5.392E-03 & 5.184E-04 & 2.403E-03 & $1.544 \mathrm{E}+00$ & 3.695E-01 & $2.771 \mathrm{E}-03$ & 9.753E-05 & 4.989E-04 & 8.287E-07 & 5.755E-05 & $1.780 \mathrm{E}-08$ \\
\hline 7.130E-03 & $6.856 \mathrm{E}-04$ & $3.177 \mathrm{E}-03$ & $1.602 \mathrm{E}+00$ & $2.794 \mathrm{E}-01$ & 3.457E-03 & 1.555E-04 & 7.827E-04 & $6.824 \mathrm{E}-07$ & 7.172E-05 & $1.040 \mathrm{E}-08$ \\
\hline 1.052E-02 & $1.012 \mathrm{E}-03$ & 4.688E-03 & $1.653 E+00$ & 1.893E-01 & 4.667E-03 & 2.946E-04 & $1.436 \mathrm{E}-03$ & 5.282E-07 & $9.660 \mathrm{E}-05$ & 5.087E-09 \\
\hline 1.614E-02 & 1.551E-03 & $7.182 \mathrm{E}-03$ & $1.687 \mathrm{E}+00$ & 1.235E-01 & $6.388 \mathrm{E}-03$ & $5.802 \mathrm{E}-04$ & $2.706 \mathrm{E}-03$ & $4.087 \mathrm{E}-07$ & 1.318E-04 & $2.441 \mathrm{E}-09$ \\
\hline $1.668 \mathrm{E}-02$ & 1.604E-03 & 7.263E-03 & $1.689 \mathrm{E}+00$ & 1.194E-01 & $6.578 \mathrm{E}-03$ & 6.177E-04 & $2.786 \mathrm{E}-03$ & $3.989 \mathrm{E}-07$ & $1.357 \mathrm{E}-04$ & $2.383 \mathrm{E}-09$ \\
\hline 2.007E-02 & 1.930E-03 & 7.754E-03 & $1.699 \mathrm{E}+00$ & $9.924 \mathrm{E}-02$ & 7.730E-03 & 8.736E-04 & $3.276 \mathrm{E}-03$ & 3.495E-07 & $1.591 \mathrm{E}-04$ & $2.088 \mathrm{E}-09$ \\
\hline 2.417E-02 & 2.324E-03 & 8.320E-03 & $1.707 \mathrm{E}+00$ & 8.243E-02 & $9.055 \mathrm{E}-03$ & 1.229E-03 & 3.840E-03 & 3.080E-07 & $1.860 \mathrm{E}-04$ & $1.841 \mathrm{E}-09$ \\
\hline $2.519 \mathrm{E}-02$ & $2.421 \mathrm{E}-03$ & $8.454 \mathrm{E}-03$ & $1.709 E+00$ & 7.910E-02 & 9.369E-03 & $1.323 \mathrm{E}-03$ & 3.974E-03 & $2.999 \mathrm{E}-07$ & 1.923E-04 & $1.792 \mathrm{E}-09$ \\
\hline 2.623E-02 & $2.522 \mathrm{E}-03$ & $3 \mathrm{E}-03$ & $1.710 \mathrm{E}+00$ & $E-02$ & E-03 & $E-03$ & E-03 & -07 & E-04 & $1.745 \mathrm{E}-09$ \\
\hline 2.172E-01 & 2.089E-02 & 2.298E-02 & $1.740 \mathrm{E}+00$ & E-03 & $4.234 \mathrm{E}-02$ & $E-02$ & $\mathrm{E}-02$ & & E-04 & 7.399E-10 \\
\hline 8.021E-01 & $7.712 \mathrm{E}-02$ & $4.269 \mathrm{E}-02$ & $1.743 E+00$ & $2.484 \mathrm{E}-03$ & 8.216E-02 & $1.969 \mathrm{E}-01$ & 3.790E-02 & 1.185E-07 & 1.320E-03 & $7.323 \mathrm{E}-10$ \\
\hline $1.709 E+00$ & 1.643E-01 & $6.092 \mathrm{E}-02$ & $1.744 \mathrm{E}+00$ & 1.166E-03 & 1.120E-01 & 4.642E-01 & $5.573 \mathrm{E}-02$ & $1.328 \mathrm{E}-07$ & 1.487E-03 & 8.507E-10 \\
\hline $2.405 E+00$ & 2.313E-01 & 7.218E-02 & $1.744 E+00$ & 8.283E-04 & $1.268 \mathrm{E}-01$ & $6.748 \mathrm{E}-01$ & 6.666E-02 & $1.409 \mathrm{E}-07$ & $1.478 \mathrm{E}-03$ & $9.287 E-10$ \\
\hline $2.604 \mathrm{E}+00$ & $2.504 \mathrm{E}-01$ & $7.539 \mathrm{E}-02$ & $1.744 \mathrm{E}+00$ & 7.651E-04 & 1.307E-01 & 7.381E-01 & 6.977E-02 & $1.424 \mathrm{E}-07$ & 1.469E-03 & $9.469 \mathrm{E}-10$ \\
\hline $3.457 \mathrm{E}+00$ & 3.323E-01 & $8.883 \mathrm{E}-02$ & $44 \mathrm{E}+00$ & & & & & & & $1.012 \mathrm{E}-09$ \\
\hline $4.252 \mathrm{E}+00$ & 4.088E-01 & $1.015 \mathrm{E}-01$ & $1.744 E+00$ & $35 \mathrm{E}-04$ & $1.571 \mathrm{E}-01$ & $1.267 \mathrm{E}+00$ & $9.492 \mathrm{E}-02$ & 1.473E-07 & I3E-03 & 1.057E-09 \\
\hline $4.998 \mathrm{E}+00$ & 4.805E-01 & 1.137E-01 & $1.744 \mathrm{E}+00$ & & $E-01$ & $1.507 \mathrm{E}+00$ & $1.067 \mathrm{E}-01$ & & E-03 & 1.087E-09 \\
\hline $5.702 E+00$ & $5.483 \mathrm{E}-01$ & $1.260 \mathrm{E}-01$ & $1.744 \mathrm{E}+00$ & 3.494E-04 & 1.760E-01 & $1.733 \mathrm{E}+00$ & 1.185E-01 & 1.424E-07 & 1.143E-03 & 1.106E-09 \\
\hline $6.373 E+00$ & 6.127E-01 & 1.383E-01 & $1.744 \mathrm{E}+00$ & $3.126 \mathrm{E}-04$ & 1.842E-01 & $1.947 \mathrm{E}+00$ & 1.303E-01 & 1.382E-07 & 1.066E-03 & 1.119E-09 \\
\hline $7.015 \mathrm{E}+00$ & $6.745 \mathrm{E}-01$ & $1.508 \mathrm{E}-01$ & $1.744 \mathrm{E}+00$ & $2.840 \mathrm{E}-04$ & 1.919E-01 & $2.151 \mathrm{E}+00$ & $1.423 \mathrm{E}-01$ & 1.334E-07 & $9.955 \mathrm{E}-04$ & 1.126E-09 \\
\hline $7.432 \mathrm{E}+00$ & $7.148 \mathrm{E}-01$ & $1.594 \mathrm{E}-01$ & $1.744 \mathrm{E}+00$ & $2.680 \mathrm{E}-04$ & $1.968 \mathrm{E}-01$ & $2.282 \mathrm{E}+00$ & $1.505 \mathrm{E}-01$ & $1.299 \mathrm{E}-07$ & 9.514E-04 & 1.129E-09 \\
\hline $7.432 \mathrm{E}+00$ & 7.148E-01 & $1.594 \mathrm{E}-01$ & $1.744 \mathrm{E}+00$ & $80 \mathrm{E}-04$ & $1.968 \mathrm{E}-01$ & $E+00$ & E-01 & & $4 \mathrm{E}-04$ & 1.129E-09 \\
\hline $7.548 \mathrm{E}+00$ & 8.277E-01 & 1.557E-01 & $1.744 \mathrm{E}+00$ & 2.314E-04 & $1.872 \mathrm{E}-01$ & $E+00$ & $1.472 \mathrm{E}-01$ & E-07 & 2E-04 & 1.172E-09 \\
\hline $7.739 E+00$ & $1.001 \mathrm{E}+00$ & $1.502 \mathrm{E}-01$ & $1.744 \mathrm{E}+00$ & 1.913E-04 & 1.734E-01 & $2.015 \mathrm{E}+00$ & 1.423E-01 & $1.378 \mathrm{E}-07$ & 8.986E-04 & 1.243E-09 \\
\hline $7.739 E+00$ & $1.001 \mathrm{E}+00$ & $1.502 \mathrm{E}-01$ & $1.744 \mathrm{E}+00$ & 1.913E-04 & 1.734E-01 & $2.015 E+00$ & 1.423E-01 & $1.378 \mathrm{E}-07$ & 8.986E-04 & 1.243E-09 \\
\hline $7.739 E+00$ & $9.878 \mathrm{E}-01$ & $1.484 \mathrm{E}-01$ & $1.744 E+00$ & $1.777 \mathrm{E}-04$ & 1.704E-01 & $1.989 \mathrm{E}+00$ & $1.407 \mathrm{E}-01$ & $1.384 \mathrm{E}-07$ & 8.873E-04 & 1.256E-09 \\
\hline $7.742 \mathrm{E}+00$ & $9.591 \mathrm{E}-01$ & 1.442E-01 & $1.744 \mathrm{E}+00$ & 1.526E-04 & $1.636 \mathrm{E}-01$ & $1.930 \mathrm{E}+00$ & 1.369E-01 & $1.400 \mathrm{E}-07$ & 8.613E-04 & 1.290E-09 \\
\hline $7.773 E+00$ & $8.810 \mathrm{E}-01$ & 1.325E-01 & $1.744 \mathrm{E}+00$ & 1.077E-04 & 1.447E-01 & $1.756 \mathrm{E}+00$ & 1.263E-01 & $1.451 \mathrm{E}-07$ & 7.851E-04 & 1.400E-09 \\
\hline $7.836 \mathrm{E}+00$ & 8.127E-01 & 1.217E-01 & $1.744 \mathrm{E}+00$ & 8.333E-05 & 1.277E-01 & $1.589 \mathrm{E}+00$ & 1.165E-01 & E-07 & 7.109E-04 & 1.527E-09 \\
\hline $7.931 \mathrm{E}+00$ & 7.531E-01 & 1.119E-01 & $1.744 \mathrm{E}+00$ & 6.811E-05 & 1.124E-01 & $1.429 \mathrm{E}+00$ & $1.074 \mathrm{E}-01$ & 1.579E-07 & 6.397E-04 & $1.674 \mathrm{E}-09$ \\
\hline $8.057 \mathrm{E}+00$ & 7.017E-01 & $1.030 \mathrm{E}-01$ & $1.744 \mathrm{E}+00$ & 5.772E-05 & $9.878 \mathrm{E}-02$ & $1.279 \mathrm{E}+00$ & $9.910 \mathrm{E}-02$ & $1.655 \mathrm{E}-07$ & 5.724E-04 & $1.844 \mathrm{E}-09$ \\
\hline $8.214 \mathrm{E}+00$ & $6.576 \mathrm{E}-01$ & $9.489 \mathrm{E}-02$ & $1.744 \mathrm{E}+00$ & 5.017E-05 & 8.672E-02 & $1.138 \mathrm{E}+00$ & $9.149 \mathrm{E}-02$ & $1.740 \mathrm{E}-07$ & 5.093E-04 & $2.038 \mathrm{E}-09$ \\
\hline $8.400 E+00$ & $6.200 \mathrm{E}-01$ & 8.753E-02 & $1.744 E+00$ & 4.445E-05 & 7.607E-02 & $1.008 \mathrm{E}+00$ & $8.454 \mathrm{E}-02$ & $1.832 \mathrm{E}-07$ & $4.508 \mathrm{E}-04$ & $2.262 E-09$ \\
\hline $8.418 \mathrm{E}+00$ & $6.170 \mathrm{E}-01$ & $8.689 \mathrm{E}-02$ & $1.744 \mathrm{E}+00$ & 4.396E-05 & 7.516E-02 & $9.964 \mathrm{E}-01$ & 8.393E-02 & $1.841 \mathrm{E}-07$ & 4.455E-04 & 2.284E-09 \\
\hline $8.428 \mathrm{E}+00$ & $6.549 \mathrm{E}-01$ & $8.840 \mathrm{E}-02$ & $1.744 \mathrm{E}+00$ & $3.928 \mathrm{E}-05$ & 7.735E-02 & $9.795 \mathrm{E}-01$ & 8.564E-02 & $1.822 \mathrm{E}-07$ & 4.119E-04 & 2.290E-09 \\
\hline $8.467 \mathrm{E}+00$ & 7.882E-01 & $9.325 \mathrm{E}-02$ & $1.744 \mathrm{E}+00$ & 2.939E-05 & 8.427E-02 & $9.147 \mathrm{E}-01$ & $9.101 \mathrm{E}-02$ & $1.766 \mathrm{E}-07$ & $3.204 \mathrm{E}-04$ & $2.300 \mathrm{E}-09$ \\
\hline $8.606 \mathrm{E}+00$ & $1.074 \mathrm{E}+00$ & $1.012 \mathrm{E}-01$ & $1.744 \mathrm{E}+00$ & 2.074E-05 & 9.502E-02 & 7.737E-01 & 9.963E-02 & 1.686E-07 & 2.069E-04 & $2.322 \mathrm{E}-09$ \\
\hline $8.908 \mathrm{E}+00$ & $1.447 \mathrm{E}+00$ & $1.075 \mathrm{E}-01$ & $1.744 \mathrm{E}+00$ & $1.638 \mathrm{E}-05$ & $1.020 \mathrm{E}-01$ & 6.147E-01 & $1.064 \mathrm{E}-01$ & 1.643E-07 & 1.339E-04 & 2.397E-09 \\
\hline $9.435 E+00$ & $1.908 \mathrm{E}+00$ & 1.113E-01 & $1.744 \mathrm{E}+00$ & 1.398E-05 & 1.029E-01 & 4.629E-01 & 1.104E-01 & $1.648 \mathrm{E}-07$ & 8.904E-05 & $2.550 \mathrm{E}-09$ \\
\hline $1.056 \mathrm{E}+01$ & $2.655 \mathrm{E}+00$ & $1.128 \mathrm{E}-01$ & $1.744 \mathrm{E}+00$ & $1.241 \mathrm{E}-05$ & 9.453E-02 & 3.017E-01 & $1.120 \mathrm{E}-01$ & 1.739E-07 & $5.710 \mathrm{E}-05$ & $2.861 \mathrm{E}-09$ \\
\hline
\end{tabular}


Table II-1. Example IDPS Model Evaporation Lookup Table for Average In Situ J-13 Well Water (Continued)

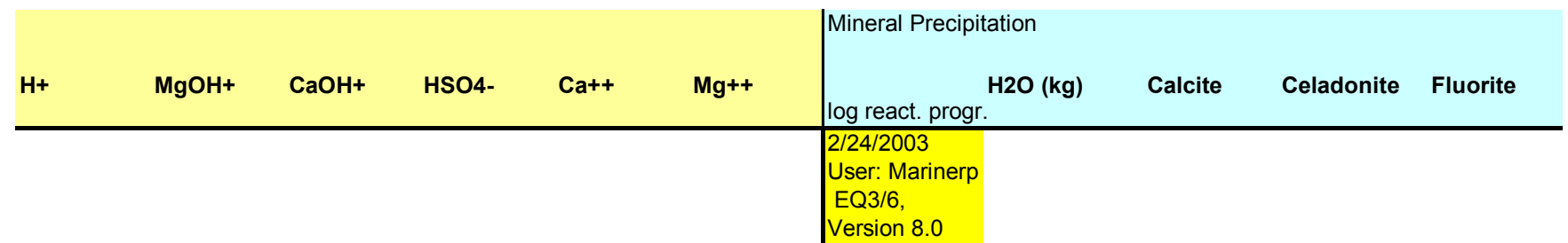

\begin{tabular}{|c|c|c|c|c|c|c|c|c|c|c|}
\hline H+ Molality & $\begin{array}{l}\text { MgOH+ } \\
\text { Molality }\end{array}$ & $\begin{array}{l}\text { CaOH+ } \\
\text { Molality }\end{array}$ & $\begin{array}{l}\text { HSO4- } \\
\text { Molality }\end{array}$ & $\begin{array}{l}\text { Ca++ } \\
\text { Molality }\end{array}$ & $\begin{array}{l}\text { Mg++ } \\
\text { Molality }\end{array}$ & $\begin{array}{l}\log X i- \\
j 13 c 3 t 7 e .6 o\end{array}$ & $\begin{array}{l}(\mathrm{kg})- \\
\text { j13c3t7e.6o }\end{array}$ & $\begin{array}{l}\text { Calcite } \\
\text { Moles }\end{array}$ & $\begin{array}{l}\text { Celadonite } \\
\text { Moles }\end{array}$ & $\begin{array}{l}\text { Fluorite } \\
\text { Moles }\end{array}$ \\
\hline 6.392E-09 & 6.462E-08 & 1.131E-07 & $3.551 \mathrm{E}-10$ & 9.591E-05 & 7.609E-06 & -99999 & 1 & 0.0002168 & & \\
\hline 6.368E-09 & 6.381E-08 & 1.127E-07 & $3.559 \mathrm{E}-10$ & $9.521 \mathrm{E}-05$ & $7.488 \mathrm{E}-06$ & -0.43469 & 0.99338 & 0.00021821 & & \\
\hline 6.049E-09 & 5.392E-08 & $1.071 \mathrm{E}-07$ & 3.665E-10 & 8.626E-05 & 6.043E-06 & 0.69897 & 0.90993 & 0.00023536 & & \\
\hline 5.671E-09 & 4.398E-08 & 1.004E-07 & $3.779 \mathrm{E}-10$ & 7.624E-05 & 4.654E-06 & 1 & 0.81985 & 0.00025248 & & \\
\hline 5.258E-09 & 3.492E-08 & $9.308 \mathrm{E}-08$ & $3.891 \mathrm{E}-10$ & 6.597E-05 & $3.455 \mathrm{E}-06$ & 1.17609 & 0.72977 & 0.00026797 & & \\
\hline 4.810E-09 & $2.682 \mathrm{E}-08$ & 8.516E-08 & $4.002 \mathrm{E}-10$ & 5.563E-05 & 2.454E-06 & 1.30103 & 0.6397 & 0.00028163 & & \\
\hline 4.327E-09 & 1.977E-08 & 7.661E-08 & 4.111E-10 & 4.546E-05 & $1.648 \mathrm{E}-06$ & 1.39794 & 0.54962 & 0.00029332 & & \\
\hline 3.811E-09 & $1.382 \mathrm{E}-08$ & $6.748 \mathrm{E}-08$ & $4.222 \mathrm{E}-10$ & 3.571E-05 & $1.032 \mathrm{E}-06$ & 1.47712 & 0.45955 & 0.00030295 & & \\
\hline 3.263E-09 & 8.978E-09 & 5.780E-08 & 4.343E-10 & 2.663E-05 & 5.875E-07 & 1.54407 & 0.36947 & 0.00031052 & & \\
\hline 2.686E-09 & 5.242E-09 & 4.759E-08 & 4.492E-10 & 1.849E-05 & 2.919E-07 & 1.60206 & 0.27939 & 0.00031615 & & \\
\hline 2.077E-09 & 2.562E-09 & 3.684E-08 & 4.719E-10 & 1.151E-05 & 1.164E-07 & 1.65321 & 0.18932 & 0.00032003 & & \\
\hline 1.605E-09 & $1.228 \mathrm{E}-09$ & $2.850 \mathrm{E}-08$ & $5.018 \mathrm{E}-10$ & 7.234E-06 & 4.622E-08 & 1.68713 & 0.12346 & 0.00032192 & & \\
\hline 1.567E-09 & 1.198E-09 & 2.782E-08 & $5.016 \mathrm{E}-10$ & 6.919E-06 & 4.428E-08 & 1.68912 & 0.11943 & 0.00032202 & & \\
\hline 1.372E-09 & 1.049E-09 & $2.438 \mathrm{E}-08$ & 5.007E-10 & 5.434E-06 & $3.512 \mathrm{E}-08$ & 1.69897 & 0.099242 & 0.00032249 & & \\
\hline 1.208E-09 & $9.242 \mathrm{E}-10$ & 2.148E-08 & $5.008 \mathrm{E}-10$ & 4.325E-06 & 2.823E-08 & 1.707 & 0.082431 & 0.0003229 & 1.5085E-07 & \\
\hline 1.176E-09 & 8.997E-10 & 2.092E-08 & $5.013 \mathrm{E}-10$ & 4.123E-06 & 2.697E-08 & 1.70857 & 0.0791 & 0.0003234 & 1.0377E-06 & \\
\hline 1.145E-09 & 8.759E-10 & $2.037 \mathrm{E}-08$ & $5.016 \mathrm{E}-10$ & 3.931E-06 & $2.578 \mathrm{E}-08$ & 1.71006 & 0.075938 & 0.00032346 & 1.0377E-06 & \\
\hline 4.641E-10 & 3.619E-10 & 8.556E-09 & $6.222 \mathrm{E}-10$ & 1.057E-06 & 7.683E-09 & 1.74036 & 0.0091707 & 0.00032429 & 1.0377E-06 & \\
\hline 4.094E-10 & $3.489 \mathrm{E}-10$ & 8.263E-09 & 8.064E-10 & 1.501E-06 & 1.096E-08 & 1.74328 & 0.0024836 & 0.00032434 & 1.0377E-06 & \\
\hline 4.036E-10 & $4.041 \mathrm{E}-10$ & $9.259 \mathrm{E}-09$ & $9.256 \mathrm{E}-10$ & 2.480E-06 & 1.742E-08 & 1.74386 & 0.0011655 & 0.00032436 & 1.0377E-06 & \\
\hline 3.893E-10 & 4.442E-10 & 9.824E-09 & $9.715 \mathrm{E}-10$ & 3.108E-06 & $2.118 \mathrm{E}-08$ & 1.74401 & 0.00082827 & 0.00032433 & 1.0377E-06 & \\
\hline 3.832E-10 & 4.541E-10 & 9.933E-09 & $9.791 \mathrm{E}-10$ & $3.248 \mathrm{E}-06$ & 2.196E-08 & 1.74403 & 0.00076505 & 0.00032209 & & \\
\hline $3.515 \mathrm{E}-10$ & $4.920 \mathrm{E}-10$ & 1.023E-08 & $9.974 \mathrm{E}-10$ & 3.669E-06 & $2.400 \mathrm{E}-08$ & 1.74412 & 0.00057634 & 0.0003151 & 1.0377E-06 & 9.2572E-06 \\
\hline 3.171E-10 & $5.209 \mathrm{E}-10$ & 1.027E-08 & $9.974 \mathrm{E}-10$ & 3.808E-06 & 2.423E-08 & 1.74416 & 0.0004685 & 0031106 & 377E-06 & \\
\hline 2.835E-10 & $5.431 \mathrm{E}-10$ & $1.016 \mathrm{E}-08$ & $9.848 \mathrm{E}-10$ & 3.756E-06 & 2.334E-08 & 1.74419 & 0.0003986 & 0.00030859 & 1.0377E-06 & 1.5775E-05 \\
\hline 2.521E-10 & $5.605 \mathrm{E}-10$ & 9.933E-09 & 9.633E-10 & 3.588E-06 & $2.184 \mathrm{E}-08$ & 1.74421 & 0.00034936 & 0.00030705 & 377E-06 & 1.7316E-05 \\
\hline 2.234E-10 & $5.743 \mathrm{E}-10$ & 9.640E-09 & $9.353 \mathrm{E}-10$ & 3.353E-06 & 2.006E-08 & 1.74423 & 0.00031261 & 0.00030613 & 1.0377E-06 & 1.8239E-05 \\
\hline 1.976E-10 & $5.854 \mathrm{E}-10$ & 9.303E-09 & 9.027E-10 & 3.087E-06 & 1.819E-08 & 1.74424 & 0.00028398 & 0.00030564 & 1.0377E-06 & 1.8723E-05 \\
\hline 1.819E-10 & 5.917E-10 & 9.061E-09 & 8.792E-10 & 2.902E-06 & $1.695 \mathrm{E}-08$ & 1.74425 & 0.00026797 & 0.0003055 & 1.0377E-06 & 1.8868E-05 \\
\hline 1.819E-10 & 5.917E-10 & $9.061 \mathrm{E}-09$ & 8.792E-10 & 2.902E-06 & 1.695E-08 & 1.74425 & 0.00026797 & 0.0003055 & 377E-06 & 1.8869E-05 \\
\hline $1.701 \mathrm{E}-10$ & $6.192 \mathrm{E}-10$ & $9.272 \mathrm{E}-09$ & 1.013E-09 & 2.530E-06 & $1.408 \mathrm{E}-08$ & 1.74427 & 0.00023141 & 0.00029926 & 1.0377E-06 & 2.5104E-05 \\
\hline $1.533 \mathrm{E}-10$ & $6.655 \mathrm{E}-10$ & $9.608 \mathrm{E}-09$ & 1.212E-09 & 2.074E-06 & $1.068 \mathrm{E}-08$ & 1.74428 & 0.00019126 & 0.00029247 & 377E-06 & 3.1895E-05 \\
\hline $1.533 \mathrm{E}-10$ & $6.655 \mathrm{E}-10$ & $9.608 \mathrm{E}-09$ & 1.212E-09 & 2.074E-06 & $1.068 \mathrm{E}-08$ & 1.74428 & 0.00019126 & 0.00029247 & 1.0377E-06 & 1895E-05 \\
\hline 1.477E-10 & $6.761 \mathrm{E}-10$ & 9.653E-09 & 1.198E-09 & 1.935E-06 & 9.987E-09 & 1.74429 & 0.00017767 & 0.0002903 & 377E-06 & 3.4066 E-05 \\
\hline 1.356E-10 & 7.017E-10 & 9.762E-09 & 1.165E-09 & 1.652E-06 & 8.552E-09 & 1.7443 & 0.00015255 & 0.00028631 & 377E-06 & 003806 \\
\hline $1.055 \mathrm{E}-10$ & 7.876E-10 & $1.012 \mathrm{E}-08$ & 1.069E-09 & 1.055E-06 & 5.463E-09 & 1.74432 & 0.00010765 & 0.00027928 & 1.0377E-06 & 4.5091E-05 \\
\hline 8.243E-11 & 8.911E-10 & $1.054 \mathrm{E}-08$ & $9.785 \mathrm{E}-10$ & 6.957E-07 & 3.559E-09 & 1.74433 & 8.33308E-05 & 0.00027558 & 1.0377E-06 & 4.8786E-05 \\
\hline 6.476E-11 & 1.017E-09 & $1.101 \mathrm{E}-08$ & 8.928E-10 & 4.744E-07 & 2.372E-09 & 1.74434 & 6.81103E-05 & 0.00027335 & 1.0377E-06 & 5.1015E-05 \\
\hline 5.119E-11 & 1.169E-09 & 1.155E-08 & 8.127E-10 & 3.352E-07 & 1.620E-09 & 1.74434 & 5.77179E-05 & 0.00027189 & 1.0377E-06 & 5.2473E-05 \\
\hline 4.069E-11 & 1.355E-09 & $1.213 \mathrm{E}-08$ & 7.382E-10 & 2.453E-07 & 1.134E-09 & 1.74434 & 5.01695E-05 & 0.00027088 & 1.0377E-06 & 5.3485E-05 \\
\hline 3.253E-11 & 1.582E-09 & $1.278 \mathrm{E}-08$ & 6.694E-10 & 1.859E-07 & $8.141 \mathrm{E}-10$ & 1.74435 & 4.44452E-05 & 0.00027015 & 1.0377E-06 & 5.4214E-05 \\
\hline 3.186E-11 & 1.606E-09 & $1.284 \mathrm{E}-08$ & 6.634E-10 & 1.814E-07 & $7.898 \mathrm{E}-10$ & 1.74435 & 4.39623E-05 & 0.00027009 & 1.0377E-06 & 5.4273E-05 \\
\hline $2.921 \mathrm{E}-11$ & $1.628 \mathrm{E}-09$ & $1.271 \mathrm{E}-08$ & 6.787E-10 & 1.553E-07 & $6.487 \mathrm{E}-10$ & 1.74435 & 3.92752E-05 & 0.0002697 & 1.0377E-06 & 5.4664E-05 \\
\hline 2.229E-11 & $1.680 \mathrm{E}-09$ & $1.232 \mathrm{E}-08$ & 7.268E-10 & 9.529E-08 & $3.445 \mathrm{E}-10$ & 1.74435 & 2.93947E-05 & 0.00026888 & 1.0377E-06 & 5.5484E-05 \\
\hline 1.432E-11 & 1.741E-09 & 1.176E-08 & $8.008 \mathrm{E}-10$ & 4.293E-08 & $1.179 \mathrm{E}-10$ & 1.74436 & 2.07388E-05 & 0.00026818 & 1.0377E-06 & 5.6192E-05 \\
\hline $9.586 \mathrm{E}-12$ & 1.817E-09 & 1.146E-08 & 8.483E-10 & 2.172E-08 & $4.444 \mathrm{E}-11$ & 1.74436 & 1.63825E-05 & 0.00026783 & 1.0377E-06 & 5.6539E-05 \\
\hline $6.755 \mathrm{E}-12$ & 1.943E-09 & 1.149E-08 & 8.559E-10 & 1.327E-08 & $1.973 \mathrm{E}-11$ & 1.74436 & 1.39825E-05 & 0.00026764 & 1.0377E-06 & 5.6727E-05 \\
\hline 4.557E-12 & 2.207E-09 & $1.213 \mathrm{E}-08$ & 8.069E-10 & 1.003E-08 & 8.885E-12 & 1.74436 & 1.24124E-05 & 0.00026752 & 1.0377E-06 & 0.00005685 \\
\hline
\end{tabular}


Table II-1. Example IDPS Model Evaporation Lookup Table for Average In Situ J-13 Well Water (Continued)

Halite Natrite Sepiolite SiO2(am) Stellerite Thenardite \#VALUE! \#VALUE! \#VALUE! \#VALUE! \#VALUE!

\begin{tabular}{|c|c|c|c|c|c|}
\hline \multirow[t]{42}{*}{$\begin{array}{l}\text { Halite } \\
\text { Moles }\end{array}$} & $\begin{array}{l}\text { Natrite } \\
\text { Moles }\end{array}$ & $\begin{array}{l}\text { Sepiolite } \\
\text { Moles }\end{array}$ & $\begin{array}{l}\text { SiO2(am) } \\
\text { Moles }\end{array}$ & $\begin{array}{l}\text { Stellerite } \\
\text { Moles }\end{array}$ & $\begin{array}{l}\text { Thenardite } \\
\text { Moles }\end{array}$ \\
\hline & & 0.00001868 & & $2.5916 \mathrm{E}-07$ & \\
\hline & & $1.8724 \mathrm{E}-05$ & & $2.5917 \mathrm{E}-07$ & \\
\hline & & $1.9228 \mathrm{E}-05$ & & $2.5924 \mathrm{E}-07$ & \\
\hline & & 1.9666E-05 & & 2.593E-07 & \\
\hline & & $2.0004 \mathrm{E}-05$ & & $2.5934 \mathrm{E}-07$ & \\
\hline & & 2.0254E-05 & & $2.5938 \mathrm{E}-07$ & \\
\hline & & 2.0429E-05 & & 2.594E-07 & \\
\hline & & 2.0544E-05 & & 2.5942E-07 & \\
\hline & & $2.0614 \mathrm{E}-05$ & & $2.5943 \mathrm{E}-07$ & \\
\hline & & 2.0651E-05 & & 2.5943E-07 & \\
\hline & & 2.0668E-05 & & $2.5944 \mathrm{E}-07$ & \\
\hline & & 2.0673E-05 & 8.8945E-07 & $2.5944 \mathrm{E}-07$ & \\
\hline & & $2.0673 \mathrm{E}-05$ & $2.0169 \mathrm{E}-05$ & $2.5944 \mathrm{E}-07$ & \\
\hline & & 2.0673E-05 & 0.00011804 & $2.5944 \mathrm{E}-07$ & \\
\hline & & $2.0636 \mathrm{E}-05$ & 0.00020192 & $2.2172 \mathrm{E}-07$ & \\
\hline & & $2.0414 \mathrm{E}-05$ & 0.0002199 & & \\
\hline & & $2.0415 \mathrm{E}-05$ & 0.00023608 & & \\
\hline & & $2.0415 \mathrm{E}-05$ & 0.00067782 & & \\
\hline & & $2.0415 \mathrm{E}-05$ & 0.00078257 & & \\
\hline & & $2.0415 \mathrm{E}-05$ & 0.00081759 & & \\
\hline & & $2.0415 \mathrm{E}-05$ & 0.00082881 & & \\
\hline & & $2.0415 \mathrm{E}-05$ & 0.00083092 & & \\
\hline & & $2.0415 \mathrm{E}-05$ & 0.0008374 & & \\
\hline & & $2.0415 \mathrm{E}-05$ & 0.00084106 & & \\
\hline & & $2.0415 \mathrm{E}-05$ & 0.00084326 & & \\
\hline & & $2.0415 \mathrm{E}-05$ & 0.00084459 & & \\
\hline & & $2.0415 \mathrm{E}-05$ & 0.00084537 & & \\
\hline & & $2.0415 \mathrm{E}-05$ & 0.00084577 & & \\
\hline & $2.5601 \mathrm{E}-07$ & $2.0415 \mathrm{E}-05$ & 0.00084589 & & \\
\hline & 2.7273E-07 & $2.0415 \mathrm{E}-05$ & 0.00084589 & & \\
\hline & 0.00012272 & $2.0415 \mathrm{E}-05$ & 0.00085257 & & \\
\hline & 0.00025585 & $2.0415 \mathrm{E}-05$ & 0.00085986 & & 1.6162E-07 \\
\hline & 0.00025586 & $2.0415 \mathrm{E}-05$ & 0.00085986 & & $1.6668 \mathrm{E}-07$ \\
\hline & 0.00029255 & $2.0415 \mathrm{E}-05$ & 0.00086223 & & $1.6028 \mathrm{E}-05$ \\
\hline & 0.00036034 & 2.0415E-05 & 0.0008666 & & $4.5228 \mathrm{E}-05$ \\
\hline & 0.00048102 & $2.0415 \mathrm{E}-05$ & 0.00087434 & & $9.6694 \mathrm{E}-05$ \\
\hline & 0.0005458 & $2.0415 \mathrm{E}-05$ & 0.00087845 & & 0.00012382 \\
\hline & 0.00058577 & $2.0415 \mathrm{E}-05$ & 0.00088097 & & 0.00014024 \\
\hline & 0.00061254 & $2.0415 \mathrm{E}-05$ & 0.00088265 & & 0.00015104 \\
\hline & 0.00063151 & $2.0415 \mathrm{E}-05$ & 0.00088384 & & 0.00015855 \\
\hline & 0.00064545 & $2.0415 \mathrm{E}-05$ & 0.00088471 & & 0.00016398 \\
\hline 1.1477E-07 & 0.00064658 & $2.0415 \mathrm{E}-05$ & 0.00088478 & & 0.00016441 \\
\hline $2.4346 \mathrm{E}-05$ & 0.0006526 & $2.0415 \mathrm{E}-05$ & 0.00088513 & & 0.00016582 \\
\hline 7.5306E-05 & 0.00066563 & $2.0415 \mathrm{E}-05$ & 0.00088586 & & 0.00016837 \\
\hline 0.0001197 & 0.00067774 & $2.0415 \mathrm{E}-05$ & 0.0008865 & & 0.00016926 \\
\hline 0.00014183 & 0.00068438 & $2.0415 \mathrm{E}-05$ & 0.00088684 & & 0.00016783 \\
\hline 0.00015379 & 0.00068838 & $2.0415 \mathrm{E}-05$ & 0.00088704 & & 0.00016486 \\
\hline 0.00016105 & 0.00069144 & $2.0415 \mathrm{E}-05$ & 0.0008872 & & 0.00015859 \\
\hline
\end{tabular}




\section{INTENTIONALLY LEFT BLANK}




\section{APPENDIX III}

\section{EXAMPLE IDPS CONDENSATION LOOKUP TABLE}


Table III-1 is an example IDPS model lookup table for the example dilution of average in situ J-13 well water by condensation of water vapor. This lookup table is documented in DTN: MO0304SPAJ13IS.001, file j13c3t7c.xls.

Table III-1. Example IDPS Model Condensation Lookup Table for Average In Situ J-13 Well Water

\begin{tabular}{|c|c|c|c|c|c|c|c|c|c|}
\hline Calculations & & & RH Calc. & $\begin{array}{l}\log \mathbf{X i} \\
\log \text { react. progr. }\end{array}$ & Temp. (C) & O2(g) fug. & CO2(g) fug. & \multicolumn{2}{|c|}{ |Total Elemental Aqueous Co } \\
\hline$C F=1 / D F$ & Qe/Qs & $1-Q e / Q s=D F$ & RH & $\begin{array}{l}\text { 2/24/2003 } \\
\text { User: Marinerp } \\
\text { EQ3/6, } \\
\text { Version } 8.0 \\
\text { Iog Xi - } \\
\text { j13c3t7c.6o }\end{array}$ & $\begin{array}{l}\text { Temp (C) - } \\
\text { j13c3t7c.6 } \\
\text { o }\end{array}$ & $\begin{array}{l}\text { O2(g) } \\
\text { Fugacity }\end{array}$ & $\begin{array}{l}\text { CO2(g) } \\
\text { Fugacity }\end{array}$ & $\begin{array}{l}\text { 2/24/2003 } \\
\text { User: Marinerp } \\
\text { EQ3/6, } \\
\text { Version } 8.0 \\
\text { log Xi - } \\
\text { j13c3t7c.6o }\end{array}$ & $\begin{array}{l}\mathrm{pH}- \\
\mathrm{j} 13 \mathrm{c} 3 \mathrm{t} 7 \mathrm{c.6o}\end{array}$ \\
\hline 1.000 & 0.0000 & 1.0000 & $99.9906 \%$ & 0.0000 & 70.0000 & 0.1995 & $\quad 0.0010$ & 0 & 8.222 \\
\hline 0.631 & -0.5853 & 1.5853 & $99.9933 \%$ & 0.2000 & 70.0000 & 0.1995 & 0.0010 & 0.2 & 8.124 \\
\hline 0.537 & -0.8632 & 1.8632 & $99.9940 \%$ & 0.2701 & 70.0000 & 0.1995 & 0.0010 & 0.27012 & 8.099 \\
\hline 0.469 & -1.1300 & 2.1300 & $99.9946 \%$ & 0.3282 & 70.0000 & 0.1995 & 0.0010 & 0.32821 & 8.057 \\
\hline 0.398 & -1.5130 & 2.5130 & $99.9953 \%$ & 0.4000 & 70.0000 & 0.1995 & 0.0010 & 0.4 & 7.992 \\
\hline 0.365 & -1.7406 & 2.7406 & $99.9957 \%$ & 0.4376 & 70.0000 & 0.1995 & 0.0010 & 0.43764 & 7.958 \\
\hline 0.364 & -1.7444 & 2.7444 & $99.9957 \%$ & 0.4382 & 70.0000 & 0.1995 & 0.0010 & 0.43824 & 7.957 \\
\hline 0.251 & -2.9833 & 3.9833 & $99.9969 \%$ & 0.6000 & 70.0000 & 0.1995 & 0.0010 & 0.6 & 7.806 \\
\hline 0.158 & -5.3135 & 6.3135 & $99.9979 \%$ & 0.8000 & 70.0000 & 0.1995 & 0.0010 & 0.8 & 7.616 \\
\hline 0.148 & -5.7359 & 6.7359 & $99.9980 \%$ & 0.8281 & 70.0000 & 0.1995 & 0.0010 & 0.82812 & 7.589 \\
\hline 0.100 & -9.0067 & 10.0067 & $99.9986 \%$ & 1.0000 & 70.0000 & 0.1995 & 0.0010 & 1 & 7.422 \\
\hline 0.063 & -14.8600 & 15.8600 & $99.9990 \%$ & 1.2000 & 70.0000 & 0.1995 & 0.0010 & 1.2 & 7.227 \\
\hline 0.040 & -24.1368 & 25.1368 & $99.9992 \%$ & 1.4000 & 70.0000 & 0.1995 & 0.0010 & 1.4 & 7.030 \\
\hline 0.025 & -38.8396 & 39.8396 & $99.9994 \%$ & 1.6000 & 70.0000 & 0.1995 & 0.0010 & 1.6 & 6.833 \\
\hline 0.016 & -62.1420 & 63.1420 & $99.9995 \%$ & 1.8000 & 70.0000 & 0.1995 & 0.0010 & 1.8 & 6.637 \\
\hline 0.010 & -99.0738 & 100.0738 & $99.9996 \%$ & 2.0000 & 70.0000 & 0.1995 & 0.0010 & 2 & 6.443 \\
\hline 0.010 & -99.0738 & 100.0738 & $99.9996 \%$ & 2.0000 & 70.0000 & 0.1995 & 0.0010 & 2 & 6.443 \\
\hline
\end{tabular}


In-Drift Precipitates/Salts Model

Table III-1. Example IDPS Model Condensation Lookup Table for Average In Situ J-13 Well Water (Continued)

\begin{tabular}{|c|c|c|c|c|c|c|c|c|c|c|}
\hline $\begin{array}{l}\text { RH } \\
\text { rel. humid. }\end{array}$ & $\begin{array}{l}\text { IS } \\
\text { ionic strength }\end{array}$ & $\begin{array}{l}\mathbf{H 2 O}(\mathbf{k g}) \\
h(\mathrm{~m})\end{array}$ & $\begin{array}{l}\text { Al } \\
\text { aluminum }\end{array}$ & $\begin{array}{l}\text { C } \\
\text { carbon }\end{array}$ & $\begin{array}{l}\text { Ca } \\
\text { calcium }\end{array}$ & $\begin{array}{l}\text { CI } \\
\text { chlorine }\end{array}$ & $\begin{array}{l}F \\
\text { fluorine }\end{array}$ & $\begin{array}{l}\mathbf{K} \\
\text { potassium }\end{array}$ & $\begin{array}{l}\text { Mg } \\
\text { magnesium }\end{array}$ & $\begin{array}{l}\mathbf{N} \\
\text { nitrogen }\end{array}$ \\
\hline $\begin{array}{l}a(w)- \\
\text { j13c3t7c.6o }\end{array}$ & $\begin{array}{l}\text { (I) - } \\
\text { j13c3t7c.6o }\end{array}$ & $\begin{array}{l}\text { Mass Solvent } \\
\text { (kg) - } \\
\text { j13c3t7c.6o }\end{array}$ & $\begin{array}{l}\text { Al } \\
\text { Moles/kg. } \\
\text { H2O }\end{array}$ & $\begin{array}{l}\text { C } \\
\text { Moles/kg. } \\
\text { H2O }\end{array}$ & $\begin{array}{l}\mathrm{Ca} \\
\text { Moles/kg. } \\
\mathrm{H} 2 \mathrm{O}\end{array}$ & $\begin{array}{l}\mathrm{Cl} \\
\text { Moles/kg. } \\
\mathrm{H} 2 \mathrm{O}\end{array}$ & $\begin{array}{l}\text { F Moles } / \mathrm{kg} . \\
\mathrm{H} 2 \mathrm{O}\end{array}$ & $\begin{array}{l}\mathrm{K} \\
\text { Moles/kg. } \\
\mathrm{H} 2 \mathrm{O}\end{array}$ & $\begin{array}{l}\text { Mg } \\
\text { Moles/kg. } \\
\text { H2O }\end{array}$ & $\begin{array}{l}\text { N } \\
\text { Moles/kg. } \\
\text { H2O }\end{array}$ \\
\hline 1.000 & $2.644 \mathrm{E}-03$ & $1.000 \mathrm{E}+00$ & 1.096E-09 & $1.368 \mathrm{E}-03$ & $3 \quad 1.070 \mathrm{E}-04$ & 2.014E-04 & 1.147E-04 & $4 \quad 1.289 \mathrm{E}-04$ & $7.979 \mathrm{E}-06$ & $1.416 \mathrm{E}-04$ \\
\hline 1.000 & $1.972 \mathrm{E}-03$ & $1.585 \mathrm{E}+00$ & 3.450E-09 & 1.084E-03 & $1.574 \mathrm{E}-04$ & 1.270E-04 & 7.238E-05 & $8.131 \mathrm{E}-05$ & 2.155E-05 & 8.932E-05 \\
\hline 1.000 & $1.824 \mathrm{E}-03$ & $1.863 \mathrm{E}+00$ & $5.046 \mathrm{E}-09$ & $1.022 \mathrm{E}-03$ & $1.738 \mathrm{E}-04$ & $1.081 \mathrm{E}-04$ & $6.158 \mathrm{E}-05$ & $6.918 \mathrm{E}-05$ & $2.881 \mathrm{E}-05$ & 7.600E-05 \\
\hline 1.000 & 1.639E-03 & $2.130 \mathrm{E}+00$ & 7.095E-09 & $9.260 \mathrm{E}-04$ & $1.520 \mathrm{E}-04$ & 9.455E-05 & 5.387E-05 & 6.052E-05 & 3.883E-05 & 6.648E-05 \\
\hline 1.000 & 1.393E-03 & $2.513 \mathrm{E}+00$ & 1.299E-08 & 7.934E-04 & 1.289E-04 & 8.014E-05 & 4.566E-05 & 5.130E-05 & 3.291E-05 & 5.635E-05 \\
\hline 1.000 & $1.278 \mathrm{E}-03$ & $2.741 \mathrm{E}+00$ & 1.787E-08 & 7.314E-04 & 1.182E-04 & 7.349E-05 & 4.187E-05 & 4.703E-05 & 3.018E-05 & 5.167E-05 \\
\hline 1.000 & 1.277E-03 & $2.744 \mathrm{E}+00$ & 1.789E-08 & 7.304E-04 & 1.180E-04 & 7.338E-05 & 4.181E-05 & 4.695E-05 & 3.013E-05 & 5.160E-05 \\
\hline 1.000 & 8.827E-04 & $3.983 \mathrm{E}+00$ & 4.327E-08 & 5.142E-04 & 8.133E-05 & 5.056E-05 & 2.881E-05 & $3.235 \mathrm{E}-05$ & 2.076E-05 & 3.555E-05 \\
\hline 1.000 & 5.584E-04 & $6.314 \mathrm{E}+00$ & 1.316E-07 & 3.332E-04 & $5.136 \mathrm{E}-05$ & 3.190E-05 & 1.817E-05 & 2.042E-05 & 1.310E-05 & 2.243E-05 \\
\hline 1.000 & $5.235 \mathrm{E}-04$ & $6.736 \mathrm{E}+00$ & $1.541 \mathrm{E}-07$ & 3.136E-04 & 4.816E-05 & 2.990E-05 & 1.704E-05 & 1.914E-05 & $1.228 \mathrm{E}-05$ & 2.102E-05 \\
\hline 1.000 & 3.527E-04 & $1.001 \mathrm{E}+01$ & 1.037E-07 & 2.169E-04 & $3.241 \mathrm{E}-05$ & 2.013E-05 & 1.147E-05 & $1.288 \mathrm{E}-05$ & 8.264E-06 & 1.415E-05 \\
\hline 1.000 & 2.227E-04 & $1.586 \mathrm{E}+01$ & $6.543 \mathrm{E}-08$ & $1.428 \mathrm{E}-04$ & 2.045E-05 & 1.270E-05 & 7.235E-06 & $8.128 \mathrm{E}-06$ & 5.214E-06 & 8.928E-06 \\
\hline 1.000 & 1.406E-04 & $2.514 \mathrm{E}+01$ & $4.128 \mathrm{E}-08$ & $9.566 \mathrm{E}-05$ & 1.290E-05 & 8.012E-06 & 4.565E-06 & $5.128 \mathrm{E}-06$ & 3.290E-06 & 5.633E-06 \\
\hline 1.000 & 8.883E-05 & $3.984 \mathrm{E}+01$ & 2.605E-08 & $6.583 \mathrm{E}-05$ & 8.142E-06 & 5.055E-06 & $2.880 \mathrm{E}-06$ & 3.236E-06 & 2.076E-06 & 3.554E-06 \\
\hline 1.000 & $5.619 \mathrm{E}-05$ & $6.314 \mathrm{E}+01$ & 1.644E-08 & 4.701E-05 & $5.137 \mathrm{E}-06$ & 3.190E-06 & 1.817E-06 & 2.042E-06 & 1.310E-06 & 2.243E-06 \\
\hline 1.000 & 3.567E-05 & $1.001 \mathrm{E}+02$ & 1.037E-08 & 3.519E-05 & $3.241 \mathrm{E}-06$ & 2.012E-06 & 1.147E-06 & $1.288 \mathrm{E}-06$ & 8.264E-07 & $1.415 \mathrm{E}-06$ \\
\hline 1.000 & 3.567E-05 & $1.001 \mathrm{E}+02$ & 1.037E-08 & 3.519E-05 & $3.241 \mathrm{E}-06$ & 2.012E-06 & 1.147E-06 & $1.288 \mathrm{E}-06$ & 8.264E-07 & 1.415E-06 \\
\hline
\end{tabular}


Table III-1. Example IDPS Model Condensation Lookup Table for Average In Situ J-13 Well Water (Continued)

\begin{tabular}{|c|c|c|c|c|c|c|c|c|c|c|}
\hline \multirow[b]{2}{*}{$\begin{array}{l}\mathrm{Na} \\
\text { sodium }\end{array}$} & \multirow[b]{2}{*}{$\begin{array}{l}\text { S } \\
\text { sulfur }\end{array}$} & \multirow[b]{2}{*}{$\begin{array}{l}\text { Si } \\
\text { silicon }\end{array}$} & \multicolumn{8}{|c|}{ ANC species concentrations } \\
\hline & & & $\begin{array}{l}\log \mathbf{X i} \\
\log \text { react. progr. }\end{array}$ & $\mathrm{H} 2 \mathrm{O}$ (kg) & HCO3- & co3-- & HSiO3- & $\mathrm{CaHCO}+$ & $\mathrm{OH}-$ & MgHCO3+ \\
\hline & & & $\begin{array}{l}\text { 2/24/2003 } \\
\text { User: Marinerp } \\
\text { EQ3/6, } \\
\text { Version } 8.0\end{array}$ & & & & & & & \\
\hline $\begin{array}{l}\mathrm{Na} \\
\text { Moles/kg. } \\
\mathrm{H} 2 \mathrm{O}\end{array}$ & $\begin{array}{l}\text { S Moles/kg. } \\
\text { H2O }\end{array}$ & $\begin{array}{l}\mathrm{Si} \\
\text { Moles/kg. } \\
\mathrm{H} 2 \mathrm{O}\end{array}$ & $\begin{array}{l}\log X i- \\
j 13 c 3 t 7 c .60\end{array}$ & $\begin{array}{l}\text { Mass Solvent } \\
\text { (kg) - } \\
\text { j13c3t7c.6o }\end{array}$ & $\begin{array}{l}\text { HCO3- } \\
\text { Molality }\end{array}$ & $\begin{array}{l}\text { CO3-- } \\
\text { Molality }\end{array}$ & $\begin{array}{l}\text { HSiO3- } \\
\text { Molality }\end{array}$ & $\begin{array}{l}\text { CaHCO3+ } \\
\text { Molality }\end{array}$ & $\begin{array}{l}\mathrm{OH}- \\
\text { Molality }\end{array}$ & $\begin{array}{l}\text { MgHCO3+ } \\
\text { Molality }\end{array}$ \\
\hline 1.992E-03 & $1.915 \mathrm{E}-04$ & $8.995 \mathrm{E}-04$ & $0.000 \mathrm{E}+00$ & $1.000 \mathrm{E}+00$ & 1.324E-03 & $2.092 \mathrm{E}-05$ & $1.001 \mathrm{E}-04$ & 1.622E-06 & 2.757E-05 & $1.280 \mathrm{E}-07$ \\
\hline 1.257E-03 & $1.208 \mathrm{E}-04$ & 5.922E-04 & $2.000 \mathrm{E}-01$ & $1.585 \mathrm{E}+00$ & 1.047E-03 & $1.288 \mathrm{E}-05$ & 5.334E-05 & 2.017E-06 & $2.181 \mathrm{E}-05$ & 2.876E-07 \\
\hline $1.069 \mathrm{E}-03$ & $1.028 \mathrm{E}-04$ & $5.196 \mathrm{E}-04$ & $2.701 \mathrm{E}-01$ & $1.863 \mathrm{E}+00$ & $9.864 \mathrm{E}-04$ & $1.140 \mathrm{E}-05$ & 4.434E-05 & $2.132 \mathrm{E}-06$ & 2.056E-05 & 3.670E-07 \\
\hline $9.353 E-04$ & 8.992E-05 & 4.750E-04 & 3.282E-01 & $2.130 E+00$ & 8.943E-04 & $9.315 \mathrm{E}-06$ & 3.704E-05 & $1.724 \mathrm{E}-06$ & 1.864E-05 & $4.552 \mathrm{E}-07$ \\
\hline 7.927E-04 & $7.622 \mathrm{E}-05$ & 4.026E-04 & $4.000 \mathrm{E}-01$ & $2.513 \mathrm{E}+00$ & $7.668 \mathrm{E}-04$ & 6.795E-06 & $2.722 \mathrm{E}-05$ & $1.287 \mathrm{E}-06$ & $1.598 \mathrm{E}-05$ & 3.379E-07 \\
\hline 7.269E-04 & 6.989E-05 & 3.693E-04 & 4.376E-01 & $2.741 \mathrm{E}+00$ & 7.069E-04 & 5.752E-06 & 2.313E-05 & 1.101E-06 & 1.473E-05 & 2.885E-07 \\
\hline 7.259E-04 & $6.979 \mathrm{E}-05$ & 3.692E-04 & 4.382E-01 & $2.744 \mathrm{E}+00$ & 7.059E-04 & $5.736 \mathrm{E}-06$ & $2.310 \mathrm{E}-05$ & 1.099E-06 & 1.471E-05 & 2.878E-07 \\
\hline $5.001 \mathrm{E}-04$ & 4.809E-05 & 2.544E-04 & $6.000 \mathrm{E}-01$ & $3.983 E+00$ & 4.953E-04 & $2.781 \mathrm{E}-06$ & $1.138 \mathrm{E}-05$ & 5.554E-07 & 1.032E-05 & 1.445E-07 \\
\hline 3.155E-04 & 3.034E-05 & $1.607 \mathrm{E}-04$ & 8.000E-01 & $6.314 \mathrm{E}+00$ & $3.171 \mathrm{E}-04$ & 1.122E-06 & 4.677E-06 & $2.339 \mathrm{E}-07$ & 6.609E-06 & 6.056E-08 \\
\hline $2.958 \mathrm{E}-04$ & 2.844E-05 & $1.507 \mathrm{E}-04$ & $8.281 \mathrm{E}-01$ & $6.736 E+00$ & $2.977 \mathrm{E}-04$ & $9.871 \mathrm{E}-07$ & $4.124 \mathrm{E}-06$ & $2.068 \mathrm{E}-07$ & $6.204 \mathrm{E}-06$ & 5.353E-08 \\
\hline $1.991 \mathrm{E}-04$ & 1.914E-05 & $1.015 \mathrm{E}-04$ & $1.000 \mathrm{E}+00$ & $1.001 E+01$ & 2.019E-04 & 4.493E-07 & 1.900E-06 & $9.682 \mathrm{E}-08$ & 4.208E-06 & $2.503 E-08$ \\
\hline $1.256 \mathrm{E}-04$ & $1.208 \mathrm{E}-05$ & $6.401 \mathrm{E}-05$ & $1.200 \mathrm{E}+00$ & $1.586 \mathrm{E}+01$ & $1.282 \mathrm{E}-04$ & $1.792 \mathrm{E}-07$ & 7.658E-07 & 3.965E-08 & 2.671E-06 & $1.024 \mathrm{E}-08$ \\
\hline 7.925E-05 & $7.620 \mathrm{E}-06$ & 4.039E-05 & $1.400 E+00$ & $2.514 \mathrm{E}+01$ & $8.120 \mathrm{E}-05$ & $7.135 \mathrm{E}-08$ & $3.075 \mathrm{E}-07$ & $1.612 \mathrm{E}-08$ & $1.692 \mathrm{E}-06$ & 4.165E-09 \\
\hline 5.001E-05 & 4.808E-06 & $2.548 \mathrm{E}-05$ & $1.600 \mathrm{E}+00$ & $3.984 \mathrm{E}+01$ & 5.143E-05 & $2.844 \mathrm{E}-08$ & 1.232E-07 & $6.530 \mathrm{E}-09$ & $1.072 \mathrm{E}-06$ & 1.687E-09 \\
\hline $3.155 \mathrm{E}-05$ & 3.033E-06 & $1.608 \mathrm{E}-05$ & $1.800 \mathrm{E}+00$ & $6.314 \mathrm{E}+01$ & 3.263E-05 & $1.139 \mathrm{E}-08$ & $4.941 \mathrm{E}-08$ & $2.641 \mathrm{E}-09$ & 6.799E-07 & $6.824 \mathrm{E}-10$ \\
\hline $1.991 \mathrm{E}-05$ & 1.914E-06 & $1.014 \mathrm{E}-05$ & $2.000 \mathrm{E}+00$ & $1.001 \mathrm{E}+02$ & $2.082 \mathrm{E}-05$ & 4.619E-09 & $1.991 \mathrm{E}-08$ & 1.072E-09 & 4.338E-07 & $2.769 \mathrm{E}-10$ \\
\hline 1.991E-05 & 1.914E-06 & 1.014E-05 & $2.000 \mathrm{E}+00$ & $1.001 \mathrm{E}+02$ & $2.082 \mathrm{E}-05$ & 4.619E-09 & $1.991 \mathrm{E}-08$ & 1.072E-09 & 4.338E-07 & $2.769 \mathrm{E}-10$ \\
\hline
\end{tabular}


In-Drift Precipitates/Salts Model

Table III-1. Example IDPS Model Condensation Lookup Table for Average In Situ J-13 Well Water (Continued)

\begin{tabular}{|c|c|c|c|c|c|c|}
\hline $\mathrm{H}+$ & $\mathrm{MgOH}+$ & $\mathrm{CaOH}+$ & HSO4- & $\mathrm{Ca}++$ & Mg++ & \\
\hline $\mathrm{H}+$ Molality & $\begin{array}{l}\text { MgOH+ } \\
\text { Molality }\end{array}$ & $\begin{array}{l}\mathrm{CaOH}+ \\
\text { Molality }\end{array}$ & $\begin{array}{l}\text { HSO4- } \\
\text { Molality }\end{array}$ & $\begin{array}{l}\text { Ca++ } \\
\text { Molality }\end{array}$ & $\begin{array}{l}\text { Mg++ } \\
\text { Molality }\end{array}$ & \\
\hline 6.392E-09 & $6.462 \mathrm{E}-08$ & 1.131E-07 & $3.551 \mathrm{E}-10$ & 9.591E-05 & $7.609 \mathrm{E}-06$ & \\
\hline 7.951E-09 & 1.452E-07 & 1.407E-07 & $2.857 \mathrm{E}-10$ & 1.458E-04 & $2.079 \mathrm{E}-05$ & \\
\hline 8.403E-09 & 1.853E-07 & 1.487E-07 & $2.582 \mathrm{E}-10$ & 1.622E-04 & $2.787 \mathrm{E}-05$ & \\
\hline $9.220 \mathrm{E}-09$ & 2.299E-07 & 1.203E-07 & $2.508 \mathrm{E}-10$ & 1.432E-04 & 3.770E-05 & \\
\hline 1.067E-08 & $1.706 \mathrm{E}-07$ & 8.973E-08 & $2.505 \mathrm{E}-10$ & $1.228 \mathrm{E}-04$ & $3.212 \mathrm{E}-05$ & \\
\hline 1.153E-08 & 1.457E-07 & $7.680 \mathrm{E}-08$ & $2.504 \mathrm{E}-10$ & 1.132E-04 & $2.952 \mathrm{E}-05$ & \\
\hline $1.155 \mathrm{E}-08$ & 1.453E-07 & $7.662 \mathrm{E}-08$ & $2.504 \mathrm{E}-10$ & $1.131 \mathrm{E}-04$ & $2.948 \mathrm{E}-05$ & \\
\hline 1.622E-08 & 7.299E-08 & 3.874E-08 & $2.508 \mathrm{E}-10$ & 7.922E-05 & 2.047E-05 & \\
\hline 2.496E-08 & 3.059E-08 & 1.631E-08 & $2.520 \mathrm{E}-10$ & 5.062E-05 & $1.299 \mathrm{E}-05$ & \\
\hline $2.654 \mathrm{E}-08$ & $2.704 \mathrm{E}-08$ & 1.442E-08 & 2.522E-10 & 4.751E-05 & $1.218 \mathrm{E}-05$ & \\
\hline 3.873E-08 & $1.264 \mathrm{E}-08$ & 6.752E-09 & $2.535 \mathrm{E}-10$ & 3.214E-05 & $8.221 \mathrm{E}-06$ & \\
\hline $6.045 \mathrm{E}-08$ & 5.174E-09 & 2.765E-09 & $2.551 \mathrm{E}-10$ & 2.035E-05 & $5.197 \mathrm{E}-06$ & \\
\hline 9.467E-08 & 2.104E-09 & 1.125E-09 & $2.564 \mathrm{E}-10$ & 1.287E-05 & $3.283 \mathrm{E}-06$ & \\
\hline 1.486E-07 & $8.522 \mathrm{E}-10$ & $4.554 \mathrm{E}-10$ & $2.572 \mathrm{E}-10$ & 8.127E-06 & $2.073 \mathrm{E}-06$ & \\
\hline 2.330E-07 & $3.447 \mathrm{E}-10$ & 1.842E-10 & $2.572 \mathrm{E}-10$ & $5.131 \mathrm{E}-06$ & 1.309E-06 & \\
\hline 3.638E-07 & $1.399 \mathrm{E}-10$ & 7.476E-11 & $2.555 \mathrm{E}-10$ & 3.239E-06 & $8.260 \mathrm{E}-07$ & \\
\hline $3.638 \mathrm{E}-07$ & $1.399 \mathrm{E}-10$ & $7.476 \mathrm{E}-11$ & $2.555 \mathrm{E}-10$ & $3.239 \mathrm{E}-06$ & $8.260 \mathrm{E}-07$ & \\
\hline
\end{tabular}

